


\section{EX LIBRIS}

The Cooper Union Afu seum Library THE GIFT OF

Lөo Wallerstein 


. 

LA

Verrerie en Gaule SOUS I'EMPIRE ROMAIN 


\section{BIBLIOTHEQQUE D'ERUDITION ARTISTIQUE}

Le Dessin des Animaux en Grèce d'après les Vases peints, par MORIN-JEAN, i vol. La Peinture d'Histoire en France de 1747 à 1785 , par Jean LocQuin.

Gouthière. Sa vie, son œuvre, par Jacques Robiquet.

Piranesi. Sa vie, son œuvre, par Henri Focillon.

JAN 211952

313633

CORBEIL. - Imprimerie CrÉté. 


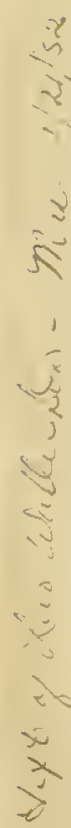



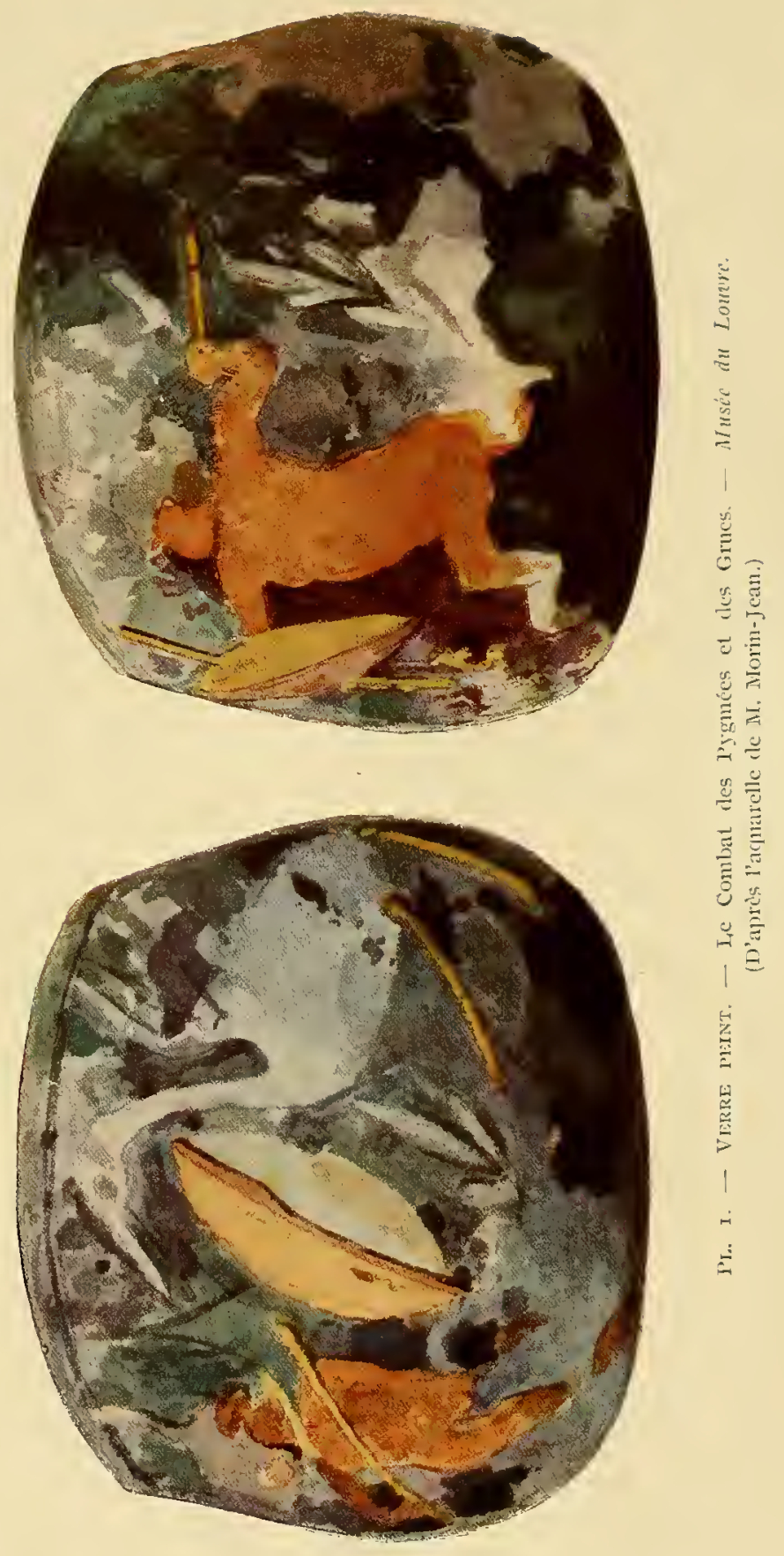
LA

\title{
Verrerie en Gaule SOUS L'EMPIRE ROMAIN
}

ESSAI DE MORPHOLOGIE ET DE CHRONOLOGIE

\author{
PAR \\ $M \bigcirc R I N-J E A N$
}

ARCHÉLOGUE DIPLOMÉ DE L'ÉCOLE DU LOUVRE

LAUREAT DE L'ACADÉMIE DES INSCRIPTIONS ET BELLES-LETTRES

MEMBRE CORRESPONDANT DE LA SOCIEtT DES ANTIQUAIRES DE FRANCE

OUVRAGE ILLUSTRÉ DE 353 GRAVURES, DE IO PLANCHES HORS TEXTE DONT 4 EN COULEURS, D'APRÈS LES DESSINS ET AQUARELLES DE L'AUTEUR

\section{Préface de $M$. ERNEST BABELON \\ MEMBRE DE L'INSTITUT}

\section{PARIS}

Librairie REyOUARD. - HENRI LAURENS, Éditeur

$$
\begin{gathered}
\text { 6, RUE DE TOURNON, } 6 \\
- \\
\text { I } 9 \text { I } 3
\end{gathered}
$$

Tous droits de traduction et de reproduction réservés pour tous pays 


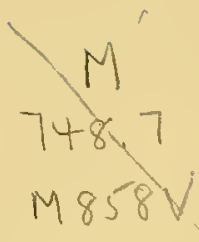

NK

5107

M6x

CHM

$313 \in 3.0$ 


\section{Ernest Babelon}

MEMBRE DE L'INSTITUT

Hommage de ma reconnaissance

pour l'accueil sympathique qu'il a bien voulu faire

à cet ouvrage.

MORIN-JEAN. 



\section{LETT RE - P R ÉFACE}

Cher Monsieur Morin,

Je viens de lire, sur épreuves, l'histoire de la Verrerie en Gaule sous l'Empire romain, que vous allez livrer au public. J'ai eu tout à apprendre dans ce bel ouvrage qui traite d'un domaine auquel je suis à peu près étranger. Aussi, au moment d'écrire cette Lettre-préface que vous m'avez demandée avec une si flatteuse insistance, je me sens partagé entre le sentiment de mon incompétence qui m'invite au silence et le désir que j'éprouve de dire publiquement la grande satisfaction intellectuelle dont vous m'avez fait jouir en m'instruisant si bien de l'histoire d'une industrie d'art qui fut si florissante dans notre Gaule.

Si un écrivain observateur faisait la psychologie des amateurs et des collectionneurs d'antiquités, de notre temps, il trouverait, dans ce milieu de la Curiosité, bien des variétés originales, mais il placerait à coup sûr au premier rang l'espèce dont vous êtes l'un des représentants les plus distingués. Votre éducation artistique vous permet de manier le crayon et le pincean, si bien que vous ne voyagez point sans rapporter de vos excursions des albums remplis de croquis, et vous affectionnez particulièrement sous ce rapport les galeries et les vitrines des musées. Vos connaissances en érudition vous mettent à même, non seulement de recourir aux sources classiques, mais de lire et de consulter avec une parfaite aisance les ouvrages que produit l'érudition allemande. Enfun, libre de votre temps, vous suivez les ventes, vous choisissez, parmi tout ce 
qui passe sous le feu des enchères, des pièces typiques, utiles à une démonstration et qui répondent à votre expérience d'archéologue et à votre goît d'artiste. C'est ainsi qu'on apprend beaucoup, presque sans y penser, en contemplant dáns votre galerie si bien classée, des échantillons de l'époque préhistorique, de l'âge du bronze, de la céramique grecque et romaine et surtout, - ce qui est, malgré votre éclectisme, l'objet de votre passion préférée, - ces beaux verres irisés, de toutes formes, dont le merveilleux chatoiement d'arc-en-ciel ou d'ailes de papillons est une volupté pour nos yeux.

Ce n'est pas tout encore; à cette passion du collectionneur artiste et savant, vous ajoutez la qualité plus rare de l'écrivain érudit. Vous savez communiquer au public, pour son plus grand profit, le fruit de vos observations et de vos recherches, vous synthétisez et dressez en tableaux les transformations graduelles des industries d'autrefois, dont vous avez collectionné et étudié avec tant de conscience les produits partout disséminés. L'artiste et l'amateur se doublent en vous de l'historien qui expose les faits "sans fioritures littéraires", comme vous dites quelque part, mais avec clarté, méthode, compétence. Ceux qui vous connaissent et ceux qui vous liront seront d'accord pour reconnaître qu'il est bien rare que toutes ces qualités qui se complètent l'une l'autre et s'entr'aident, se trouvent réunies dans les productions de l'érudition archéologique.

Vous avez déjà fait fait vos prenves en ce genre par la publication d'un beau livre sur la Céramique grecque: Le dessin des animaux en Grèce d'après les vases peints. Cette étude approfondie sur les procédés des dessinateurs industriels dans l'antiquité, écrite par vous, illustrée par vous de plus de trois cents dessins exécutés directement sur les originaux, nous a montré qu'un animalier ionien ne dessinait pas conme un animalier corinthien, ni un attique comme un béotien. Ces décorateurs de vases, tous idéalistes et conventionnels, n'interprétaient pas la nature de la même façon : voilà surtout ce que vous avez 
voulu démontrer dans ce travail que l'un de nos maîtres les plus antorisés cn céramique grecque a jugé "un bon livre».

Aujourd'hui, vous nous présentez donc votre ouvrage sur la Verrerie en Gaulc avec la garantie de titres déjà consacrés par le succès scientifique. Mais ce nouveau livve est d'un caractère bien différent du précédent. Vous ne vous contentez pas d'étudier un point spécial de l'art du verrier, comme vous avez concentré vos recherches sur une des particularités du décor des vases peints : c'est un traité complet de l'Industrie du verre souffé on des récipients vitreux dans la Gaule romaine, que vous nous offrcz. Désireux avant tout d'être scientifique et de formuler les principes de l'art et de la technique, il vous a fallu de longues années pour rassembler les matériaux de cette étude; vous vous êtes montré surtout scrupuleusement attentif à ne faire entrer dans votre démonstration que des verres trouvés sur le sol de la Gaule, depuis les Alpes jusqu'à l'embouchure du Rhin, depuis l'Océan jusqu'aux Pyrénées. Vous avez banni impitoyablement, - et cette chasse était semée de difficultés, - tous les verres qui foisonnent dans nos musées avec de fausses indications de provenance, ou dont l'origine n'est pas sîre, verres qu'on croit trouvés dans la nécropole voisine, alors qu'ils ont été apportés récemment en France par des marchands de la Syrie ou de l'Egypte.

Cest sur cette base solide que vous avez ćtabli les deux parties principales de votre étude: la morphologie des récipients de verre et leur classement chronologique. Dans le tableau des formes, ou vous analysez jusqu'à I39 variétés typiques, vous démontrez que l'industrie du verre est un art subordonné qui s'applique généralement à imiter ou à copier les formes déjà courantes dans l'orfèvrerie et la céramique. Dans l'établissement si délicat de la chronologie des produits, oì vous avez donné à chaque page des preuves de votre perspicacité critique, vous faites ressortir l'infuence des écoles d'Orient, en dépit de la distance, sur les écoles de nos verriers des bords de la Moselle ou du Rhin. 
Vous distinguez, avec les savants allemands, au point de vue de l'art et de l'habileté technique, une première époque romaine qui funit avec le siècle des Antonins, puis une seconde époque qui commence avec les Sévères pour se poursuivre jusqu'aux invasions barbares. Dans ces deux périodes, vous faites ressortir l'enchainement et la lente évolution des formes; vous précisez d'une manière scientifique le moment oì apparaissent dans l'art du verrier des éléments nouveaux de décoration ou d'ornementation, la peinture, l'émaillage, la dorure, le décor par cabochons, par ciselure en relief, par dépression, par appliques de fils en festons serpentiformes, par étirage, par bosselures, par pâtes superposées qui imitent les camées, par résille distante du récipient, comme dans ces diatreta si curieux qui sont bien le tour de force de l'art industriel.

Que dirai-je des chapitres où vous analysez les procédés du moulage et décrivez les sujets moulés, tels que courses de chars, combats de gladiateurs, scènes mythologiques et autres, qui se retrouvent si abondamment dans les reliefs d'applique de la céramique gallo-romaine? Et aussi, des chapitres oì vous passez en revue la gravure en creux sur verre, imitation de la gravure sur cristal de roche, qui s'est exercée à interpréter des scènes païennes et chrétiennes d'un si puissant intérêt?

Si les musées de Trèves, de Mayence, de Bonn, de Cologne, de Belgique, aussi bien que ceux de France, vous ont fourniles éléments de ce traité général, je remarque que c'est de Venise qu'est datée votre Préface. Vous avez voulu, avant de mettre sous presse, vous rendre compte de visu des procédés actuels des verriers de Murano qui travaillent encore, au moins dans certaines officines, avec des méthodes qui passent pour arriérées et perpétuent au milieu de nous des traditions de technique plusieurs fois séculaires.

Ces déplacements, ces vérifications sur place, ces notes abondantes, ces dessins si exacts, ces recherches érudites, cette manipulation délicate 
de ces précieux monuments, les phus fragiles qui soient au monde, voila le secret de ce livre original qui non seulement est, comme on dit ordinairement, au conrant de la science et des découvertes, mais qui, par sa concision et la précision de ses défunitions, scra le Standard Work indispensable aux conservatcurs de musées, aux collectionneurs, aux historiens de l'art. Il est un des meilleurs guides qui aient été composés sur les diverses branches de notre archéologie nationale.

Veuillez agréer, etc...

E. BABELON.

Paris, ce I4 octobre I9I3. 



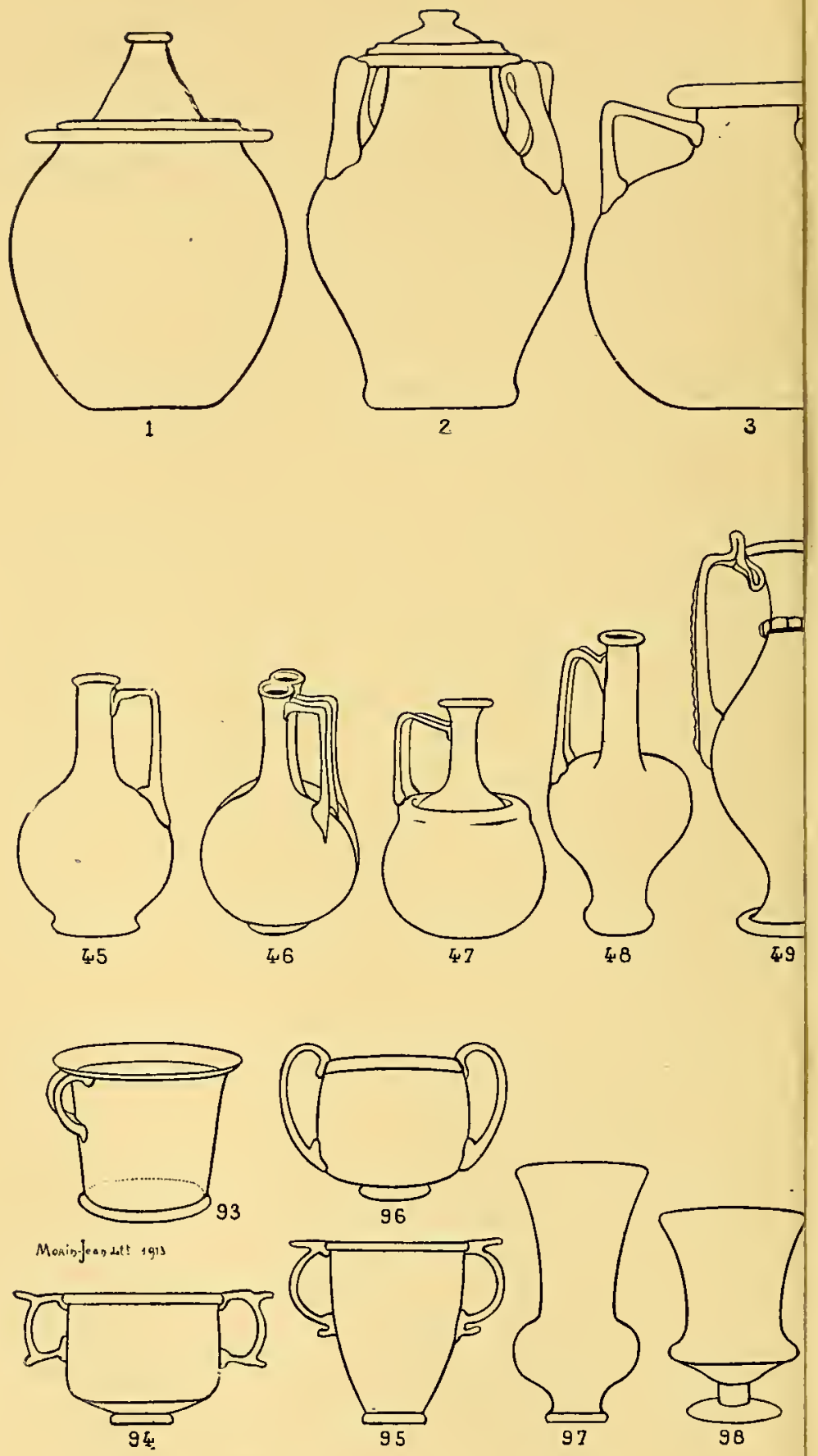


\section{INTRODUCTION (I)}

I. DÉLIMITATION DU SUJET. - 2. DIFFICULTÉ A DÉFINIR IES FORMES. - 3. DIFFICULTÉ A ÉTABLIR UNE CHRONOLOGIE. - 4. MÉTHODE EMIPLOYÉE : L'ÉTUDE D'APRÉS LES LIVRES ET L'ÉTUDE DIRECTE: DES MLATÉRIAUX; I'IMPORTANCE DU DESSIN. - 5. CLASSEMENT TYPOLOGIQUE DES VERRERIES. - 6. INTÉRÂT DE IA QUESTION.

I. Mon travail n'est pas une histoire générale du verre dans l'antiquité. Le champ de mes recherches est loin d'être aussi vaste. Je me suis borné, d'une part, à examiner les récipients vitreux. J'ai laissé de côté tous les autres monuments de verre tels que : perles, pendeloques, bracelets, baguettes à fard, vitres, miroirs, émaux et mosaïques.

Parmi les récipients vitreux de l'antiquité, on ne trouvera ici décrits que ceux qui remontent à la période comprise entre le début de l'Empire et les grandes invasions germaniques. Les verroteries pré- et protohistoriques ainsi que les verres du haut Moyen-âge sont par conséquent exclus de cette étude.

D'autre part, je me suis astreinlt à ne décrire que les spécimens trouvés en Gaule. Là, je me suis heurté à une difficulté : elle consistait à définir le champ topographique de mes recherches. Devais-je m'en tenir au territoire français actuel? Évidemment non. Le mot Gaule doit être entendu dans un sens moins restreint.

La Gaule que je me suis proposé d'explorer est celle que 1'on trouve délimitée dans la Notitia provinciarum et civitatum Gallice, rédigée après 395, probablement vers le début du ve siècle. Elle

(I) Rédigée à Paris, en juillet IgI2, cette introduction a été entièrement refondue à Venise, à la suite d'un voyage dans les vallées du Rhin et de la Moselle. 


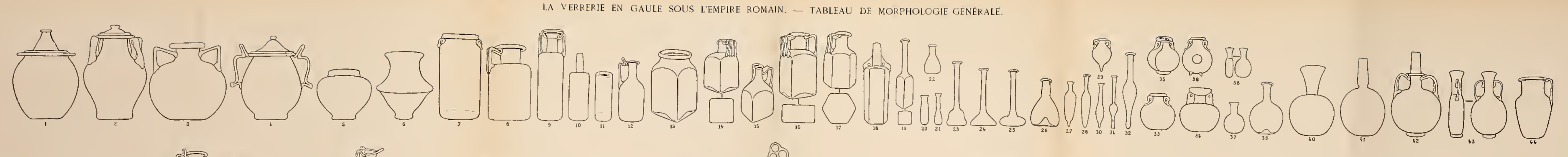

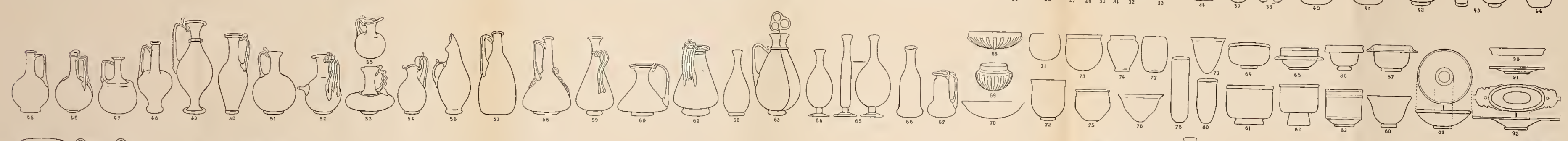

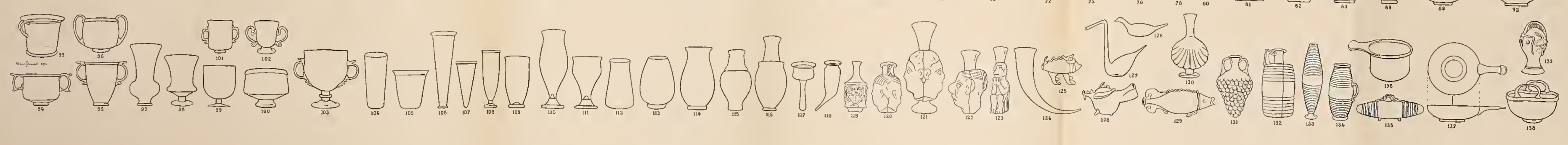



laisse la Cisalpine en dehors de son aire géographique, mais elle embrasse les territoires nordiques qui s'étendent jusqu'au Rhin. Des centres très importants d'industrie verrière existaient dans le Rheinland aux $\mathrm{III}^{\mathrm{e}}$, IV ${ }^{\mathrm{e}}$ siècles. Les officines établies plus à 1'Ouest, dans le Boulonnais, la Picardie, la Champagne, appartiennent au même groupe que celle du pays rhénan; il est impossible de les en séparer.

Mon champ d'étude étant ainsi délimité dans le temps et dans l'espace, il me restait à savoir comment j'allais procéder pour examiner les produits industriels soumis à mon observation. Un verre peut être étudié à différents points de vue. On peut considérer particulièrement sa forme, sa fabrication technique, sa couleur, son décor, les marques qu'il porte (I), l'usage qu'on en a pu faire, l'époque à laquelle on s'en est servi.

Deux d'entre ces points de vue, celui concernant la forme et celui ayant trait à la datation, ont, semble-t-il, été jusqu'ici quelque peu négligés par les archéologues. J'ai tenu à m'attacher à eux plus spécialement. J'ai visé surtout à établir une morphologie et une chronologie. Je n'abandonnerai pas pour cela l'étude des problèmes relatifs à la technique et à l'ornementation; je traiterai dans son ensemble la verrerie en Gaule sous l'Empire romain, mais avec la préoccupation constante de donner à la morphologie et à la chronologie. la place la plus importante.

2. I a morphologie, considérée en dehors de toute préoccupation de classement chronologique, me mit en présence d'un certain nombre de problèmes difficiles à résoudre.

A) Les formes des verreries romaines sont-elles particulières à 1'industrie verrière?

B) Les formes des verreries découvertes en Gaule se retrouventelles ailleurs?

(r) Je n'ai pas jugé utile de rédiger uu chapitre spécial sur les marques et estampilles de verriers. Ces marques ont fait l'objet d'études très complètes auxquelles je ne pourrais ajouter que quelques observations de peu d'importance. Je me contente de renvoyer le lecteur an bon répertoire dressé, d'après le orpus inscriptionum latinarwm, par Anton Kisa, dans son livre: Das Glas im Altertume, p. 936 et stiv. 
C) Comment désigner les formes?

A) Dans l'antiquité, comme aujourd'hui, quand il s'est agi de procéder à la confection d'un objet quelconque en verre souffé, on a pris, parmi les choses plus ou moins usuelles, un modèle et on l'a copié. Le modèle n'est ou n'a pas toujours été en verre. Il peut ou a pu être en métal, en pierre, en bois, en argile.

Comparativement à la céramique, la verrerie n'arriva à son complet développement et ne fut capable de produire des récipients vastes et bien compris, qu'à une époque assez tardive. Il est donc naturel qu'elle ait, en partie, emprunté le répertoire de ses formes à celui de la poterie (I).

D'autre part, l'orfèvrerie, industrie aristocratique, a fourni des modèles aux verriers, comme elle en fournissait aux céramistes. Tous les récipients, qu'ils soient sortis de l'officine d'un verrier, de la boutique d'un orfèvre ou de l'atelier d'un céramiste, forment une filiation continue et bien mieux établie qu'on ne saurait, au premier abord, se l'imaginer.

La morphologie des verres est intimement liée à celle des pots d'argile, des vases en pierre ou en métal. La toreutique et surtout la céramique mettent à même de connaître ses sources et de saisir sur le vif les transformations qui la constituent. Il n'existe pour ainsi dire pas un récipient de verre qui n'ait un similaire en argile ou en métal.

Les verriers eurent surtout pour modèles les vases hellénistiques dont les formes s'établirent nettement à l'époque des successeurs d'Alexandre, après avoir eu des origines complexes à la fois grecques ef orientales.

Alexandrie, chacun le sait, est le grand centre où l'hellénisme et l'Orient se sont amalgamés.

B) Sous 1'Empire romain, la civilisation que nous pourrions appeler gréco-syrienne et alexandrine s'infiltre et s'impose partout. Le bassin

(r) Par suite de chocs en retour, qui sont si fréqueuts dans l'antiquité, la verrerie a elle-même, à certains égards, exercé une influence sur l'industrie céramique (Voy. DragendorfF, Terra sigillata dans les Bonner Jahrbiicher de 1895 , fasc. $96-97$, p. 122). 
oriental de la Méditerranée reste, comme auparavant, le centre le plus important de l'industrie verrière. Les fabriques d'Alexandrie et de la côte de Syrie envoient leurs produits sur tous les marchés européens. Ia Gaule n'échappe pas à cet envahissement. Sans doute, i1 y a eu en Gaule, de très bonne heure, des officines de verriers (I). Mais elles furent pour ainsi dire des succursales des grandes fabriques d'Orient et répandirent en deçà des Alpes des produits analogues à ceux de ces lointains centres de production. C'est seulement à une époque assez tardive, aux $\mathrm{II}^{\mathrm{e}}, \mathrm{IV}^{\mathrm{e}}$ siècles, qu'ayant pris dans le Nord une grande importance, elles acquirent, tout en continuant à subir la même influence, une personnalité dans la technique de la fabrication et créèrent quelques formes qu'on ne rencontre pas en Orient.

C) Sur quoi se baser pour donner des noms précis et caractéristiques aux objets dont nous faisons ici une étude spéciale? L'onomastique de la céramique nous est d'un faible secours. Elle est elle-même loin d'être bien établie. Pour éviter des confusions inévitables, je désignerai les formes typiques par un numéro. Cette méthođe pratique, que je ne suis pas le premier à employer, a fait ses preuves. Elle permet de rester clair malgré l'abondance et la variété des matériaux.

3. Etablir une chronologie des verres romains n'est pas chose aisée. Il est très difficile de les dater en se basant seulement sur leurs formes. Les formes ont évolué lentement. Il en est qui se sont maintenues sans changement important, pendant toute la période romaine.

Certains archéologues ont daté les verreries d'après les monnaies qui les accompagnaient dans les tombes. Cette méthode a souvent conduit ceux qui l'ont employée, à dés conclusions erronées (2).

I a monnaie donne un terminus post quem.

Il est certain qu'une tombe renfermant une monnaie d'Hadrien ne peut être d'une époque antérieure à celle où régnait cet empereur, mais elle peut incontestablement être beaucoup plus récente.

(r) PLIvE parle de l'établissement des premières verreries en Gaule (Hist. nat., Livre XXXVI, c. 66).

(2) L,es mounaies datent plus sûrement les nécropoles prises en bloc que telle ou telle tombe prise isolément. 
Dans une sépulture du cimetière de la rue de I,uxembourg à Cologne, on a trouvé une monnaie de Julia Domna (morte e11 2I7) et un grand bronze de Trajan ( $9 S$ à II 7 ). De deux choses l'une : ou ce tombeau est du temps de Julia Domna, ou il est postérieur à la mort de cette princesse.

Or, si, pour une raison ou pour une autre, la monnaie de Julia Domna ell avait disparu et s'il n'y était resté que celle de Trajan, on se serait trompé d'une centaine d'années au moins en le déclarant contemporain de cet empereur.

Certaines verreries que des archéologues allemands, trop pressés de conclure, datent du $\mathrm{II}^{\mathrm{e}}$ siècle, parce qu'elles ont été recueillies avec des monnaies des Antonins, sont en réalité de la première moitié du IIr siècle; leur technique, leur forme, leur décor, tout empêche de les faire remonter plus haut.

Une chronologie qui reposerait uniquement sur la qualité et la coloration du verre serait sujette à caution. En effet, s'il est vrai, en principe, que le verre est bleu-verdâtre, comme le sont les produits alexandrins, aux $\mathrm{I}^{\mathrm{er}}$, $\mathrm{II}^{\mathrm{e}}$ siècles, incolore au $\mathrm{III}^{\mathrm{e}}$, chargé de bulles d'air et de filandres aux $\mathrm{IV}^{\mathrm{e}}, \mathrm{V}^{\mathrm{e}}$, il peut quelquefois en être autrement.

Les bulles d'air et les filandres sont des défauts de fabrication qu'on rencontre dans les produits de qualité inférieure, même aux époques où l'on savait très bien souffler le verre.

Par ailleurs, le verre bleu-verdâtre existe aux III ${ }^{\mathrm{e}}$, IV siècles à côté du verre incolore; on le trouve même à l'époque mérovingienne.

Le classement de la verrerie romaine en verres des tombes à incinération et verres des tombes à inhumation, ne permet pas d'établir des distinctions chronologiques précises. La verrerie typique des sépultures à inhumation se rencontre dans les tombes à ustion de la dernière période.

En s'appuyant sur le décor des verreries pour établir une classification chronologique, on aura chance d’obtenir un résultat plus 
probant (I). Enn effet, la gravure en creux, le décor en cabochons, l'ornementation en fil serpentant, la peinture, l'émaillage et la dorure n'apparaissent dans le travail du verre en Gaule, qu'à des époques que l'on est parvenu à fixer d'une façon assez précise.

Pour dater la verrerie, il ne suffit pas de la bien examiner. Il faut encore considérer avec soin les objets d'usage plus ou moins courant qui ont été placés avec elle dans les sépultures. Ces objets donnent de plus sûres indications que les monnaies. Les monnaies de naulage, les oboles à Caron, étaient mises dans la main ou dans la bouche des défunts à une époque souvent très postérieure à celle de leur frappe ; les héritiers, sous 1'Empire romain, n'éprouvaient pas de scrupule à payer le passage du Styx de leurs parents morts avec des pièces n'ayant plus cours et ne soupçonnaient pas Caron d'avoir l'idée d'y regarder de très près. Ayant à placer à côté des membres de leur famille descendus dans la tombe des vases d'argile remplis d'aliments, ils prenaient, cela va de soi, des récipients faciles à se procurer, des spécimens de la céramique que l'on fabriquait alors communément. De même, pour donner au mort un objet de parure, ils se contentaient, sans nul doute, de disposer, en sa faveur, de la fibule dont il s'était servi quotidiennement pour attacher son vêtement.

Les poteries et les récipients de métal que les verriers romains ont copiés peuvent fournir aussi quelques renseignements sur la chronologie des verres. Ils permettent, comme les monnaies, d'établir un terminus post quem, mais il ne faut pas leur en demander davantage. La copie, en verre, d'un vase d'argile peut être très postérieure au modèle dont elle est issue : des canthares de verre du IVe siècle reproduisent, dans leurs moindres détails, les pièces d'argenterie du trésor de Boscoréale qui appartiennent, on le sait, à la toreutique du rer siècle.

De nombreux écueils sont à éviter pour arriver à procéder à la

(I) Nons avons cherché à savoir si les inscriptions, les sigles, les marques de fabrique n'aideraient pas à dater les verreries qui en sont pourvues. Nos irecherches nous ont amené à constater que ces inscriptions ne renseignent guère à cet égard et qu'on n'en peut tirer que de trés vagues indications chronologiques. 
datation des verreries; ces observations en font foi. Le domaine de l'hypothèse est vaste et rempli de traquenards ; mieux vaut ne pas s'y engager.

Il est difficile d'établir, pendant la période romaine, des subdivisions nombreuses dans la chronologie de la verrerie. Toutefois, rien ne s'oppose à ce qu'on répartisse la verrerie romaine en deux grands groupes correspondant aux deux grandes divisions qui, aux. yeux des historiens, scindent assez nettement l'époque impériale.

Nous appellerons Romain I la période qui va d'Auguste à la fin de la dynastie des Antonins (+ I92) et Romain II celle qui va de Septime-Sévère (I93 à 2II) aux grandes invasions.

Par verres du Romain $I$, on devra entendre ceux dont les anciens se servirent couramment au $\mathrm{I}^{\mathrm{er}}$ et au $\mathrm{II}^{\mathrm{e}}$ siècles, et par verres du Romain $I I$, ceux dont ils firent usage au III e et au IV siècles, à l'époque où des invasions redoutables et de nombreuses guerres de compétition au trône amenèrent la décadence de 1'Empire.

Entre la verrerie du Romain I et la verrerie du Romain II, il y a de notables différences qui s'accusent dans la fabrication et la décoration du verre, dans la forme des anses et des pieds des récipients.

4. Pour composer un ouvrage d'archéologie du genre de celui-ci, il est indispensable de recourir à deux sources distinctes :

A) L'une d'elles est constituée par les livres ;

B) L'autre, par les matériaux conservés dans les collections publiques et privées.

A) Les objets en verre ont depuis longtemps exercé la sagacité des archéologues. On a entrepris, ici et là, de les décrire et de les cataloguer. Ces descriptions et ces classifications sont, pour la plupart, assez anciennes, et par cela même peu faciles à utiliser.

Les travaux allemands sont en avance sur les travaux français. Le meilleur manuel sur le verre dans l'antiquité est celui d'Anton Kisa (I). Il est indispensable pour toute étude sérieuse. Mais il faut

(I) Das Glas im Altcriume, 3 volumes, I,eipzig, Igo8. 
le lire avec discernement et esprit critique, car, s'il est bourré de documents intéressants, il est par contre mal ordonné (I) et contient des erreurs (2).

Une des sources d'information les plus riches est la publication périodique des antiquaires du Rhin (3) (Bonner Jahrbücher), qui paraît à Bonn.

Des otuvrages généraux comme ceux de Deville (I873) et de Froehner (4) ont beaucoup vieilli. L'archéologue qui s'intéresse à la chronologie n'y trouve pas son compte.

Il est impossible d'être au courant sans lire les notes prises par les fouilleurs au cours de leurs recherches. Les journaux de fouilles des cimetières romains découverts en Gaule forment un ensemble de documents considérable. Beaucoup d'entre eux étant dépourvus de dessins sont malheuretusement inttilisables.

Ces comptes rendus ne sont pas tous d'égale valeur. On sait que les renseignements fournis par certains fouilleurs, Lelaurain est du nombre, ne valent guèré mieux que ceux des marchands. Il n'en faut faire usage qu'avec tine extrême prudence.

Les conclusions formulées par l'abbé Cochet, dont personne ne suspecte la bonne foi, ne doivent pas être non plus acceptées sans contrôle. L'abbé Cochet fouillait les tombes de la Normandie entre I845 et I866 ; c'est assez dire que ses recherches n'ont pu être faites stuivant les méthodes modernes.

MM. Pilloy, Th. Eck, Sauvage et Frédéric Moreau ont exploré les nécropoles du nord de la France avec le scrupule constant de faire du travail scientifique; leurs publications sont des œuvres définitives, indispensables à consulter.

B) Mon travail n'aurait pas été complet et ne m'aurait pas

(r) L'imperfection de cette œuvre tient beaucoup, sans doute, à ce que son auteur est mort avant d'avoir eu le temps d'utiliser, comme il convenait, les matẻriaux accumulés pour la constituer.

(2) C'est ainsi que, p. 899, fig. 373, la tombe du chef de Monceau-le-Neuf, découverte par L,ELAURAIx, est dẻsignẻe comme étant une sẻpulture de Vermand, et que, fig. I30, une bouteille à applications rermiculaires est attribuée au musée de Boulogne alors qu'elle n’a jamais fait partie des collections de ce inusée.

(3) Jahrbuch des Vereins von Altertums freunden im Rheinlande.

) La Verrerie antique (1879); Collection J. Grëan (I903). 
permis d'obtenir des résultats probants si je m'étais borné à consulter des ouvrages plus ou moins importants. J'étais aussi tenu de recourir à l'observation directe, d'examiner les matériaux eux-mêmes, d'étudier la verrerie romaine, non plus d'après des reproductions plus ou moins fidèles, mais d'après les originaux, conservés dans les musées.

La méthode d'observation directe empêche de commettre bien des erreurs; elle permet d'étayer ou de détruire une argumentation scientifique, de découvrir des documents différents de ceux auxquels ou a eu recours précédemment.

Après avoir travaillé à Saint-Germain, au Louvre, au Cabinet des Médailles et à Carnavalet, j'ai visité, le crayon en main, tous nos musées de provinces qui contiennent une série de verres romains assez importante.

Qu'il me soit permis d'adresser ici aux conservateurs de ces musées, particulièrement à MM. Salomon Reinach, Michon, Babelon, de la Tour, de Villenoisy, Georges Cain, Sauvage, de Vesly, Th. Eck, Michel Clerc, Mazauric, Papillon, H. Michel, Dangibaud, et à toutes les personnes qui, comme MM. Déchelette et Champion, ont facilité ma tâche par leur gracieuse obligeance, l'expression de ma plus vive reconnaissance.

Je ne me suis pas limité à l'étude des musées français. J'ai examiné sur place la verrerie des musées de Trèves, de Bonn, de Cologne, de Mayence, de Bruxelles, de Liège, de Namur (I).

J'ai jugé utile d'élargir le champ de mes investigations en me livrant à quelques comparaisons sur les formes des verres du Moyenâge, de la Renaissance et des Temps modernes. De plus, j'ai fait faire, sous mes yeux, par les verriers de Murano, des reproductions de verreries antiques, afin de me familiariser avec la technique du verre soufflé.

Développer l'illustration, multiplier les graphiques, les planches, les tableaux d'ensemble et réduire au minimum le texte explicatif,

(I) Les verres de ma modeste collection m'ont servi à compléter ma documentation. J'en publie des dessins dans cet ouvrage. 
telle a été ma constante préoccupation (I). Le texte des ouvrages d'archéologie vieillit, en général, très vite. L'illustration, au contraire, conserve toujours sa valeur.

J'ai eu le plus grand scrupule de ne dessiner que des monuments dont la provenance est sûre. Dans ces dernières années, on a miś en vente des quantités de verres d'Orient qui ont été mêlés à ceux de la Gaule. Il en est résulté des confusions fâcheuses, et il est même arrivé que des marchands mettaient une provenance française sur des verres syriens afin de faire de plus gros bénéfices. Aussi, j'ai écarté les pièces dont l'origine m'a paru équivoque et j'ai reproduit de préférence celles qui proviennent de fouilles faites par des archéologues dont l'honnêteté scientifique est hors de doute (2).

Les reproductions photographiques ont été, de parti pris, et après mûre réflexion, exclues de cet ouvrage, parce qu'elles n'auraient pas permis de faire suffisamment ressortir le caractère des objets.

J'appelle tout spécialement l'attention sur les index qui terminent ce mémoire :

Index muséographique, dressé par ordre alphabétique de noms de villes ;

Index bibliographique, dressé par ordre alphabétique de noms d'auteurs ;

Index général alphabétique.

Tous trois sont indispensables pour faciliter les recherches.

5. J'ai cherché à classer des verres antiques comme 1'on classe les fossiles d'un terrain déterminé.

J'ai procédé du connu à l'inconnu. Si, bien souvent, il m'est arrivé d'aboutir à un nous ne savons pas, je n'ai pas craint de le laisser voir. La science ne doit pas adopter des solutions prématurées qui, loin d'accélérer sa marche, contribuent à l'entraver.

(I) Je n'ai pas voulu donner à mon texte un aspect littéraire. I,es fioritures, très en vogue au temps de Buffon, ne sont plus de mise aujourd'hui dans la rédaction des travaux scientifiques.

(2) Je me suis efforcé, en dessinant ces pièces, d'observer les règles de la perspective. Il est regrettable qu'à ce point de vue, un grand nombre de dessins, ornant de récentes et surtout d'anciennes publications, aient été incorrectement exécutés. 
Il est difficile d'établir un classenent méthodique des différentes formes de verres ; il u'est guère possible, pour y parvenir, de s'appuyer sur la chronologie. On ne trouve pas de cloisons étanches entre les étapes successives du développeunent industriel. En étudiant de très près les choses, on en arrive à affirmer qu'il y a un enchaînement des types, et non une succession de types.

L'examen des origines typologiques des formes permet de grouper les verreries romaines suivant leurs affinités ancestrales. En prenant . ce groupement pour point de départ, et en y mêlant d'autres groupements fondés sur l'analogie de certaines formes, j'ai pu dresser le tableau de morphologie générale, placé en tête de ce volume.

Ce tableau, qui réduit à I39 types les formes des verres d'époque romaine découverts en Gaule, est en quelque sorte la pierre angulaire de mon travail (I). Il montre que la fantaisie individuelle joue un rôle minime dans l'industrie des anciens et qu'on peut ramener les productions de ceux-ci à des formes générales synthétiques autour desquelles oscillent des variantes (2).

6. Il est superflu, ce me semble, d'insister sur l'intérêt à la fois scientifique et artistique des travaux consacrés à l'étude des menus objets fabriqués par les industriels de l'antiquité. Rien n'est négligeable en archéologie. Les verreries de peu de valeur, celles que les anciens achetaient quelques sesterces, doivent nous intéresser au même titre que les pièces de luxe à la description desquelles quelques archéologues se sont à tort limités.

(I) J'ai adopté dans la prèsentation de ce tableau un dispositif analogue à celui des planches I et II de : Die Vasensammlungen des Museo Nazionale zu Neapel, par H. Heydencans, ouvrage paru à Berlin en 1872 . Heydemann ramène à 185 types les formes des vases du musée de Naples. Mais ses planches sont reliées à l'intérieur du livre. Mon tableau de morphologie générale a été monté sur un onglet à grand talon, de façou à ce que, le volume étant ouvert d̀ n'importe quel endroit, il puisse rester déployé sous les yeur du lecteur.

(2) I,es verreries dont la forme est tout à fait exceptionnelle n'y figurent pas, attendn qu'elles échappent à tout classement typologique. Je n'ai d'ailleurs pas songé à reproduire dans ce tableau toutes les formes de verres trouvés en Gaule. J'ai tenu à n'y mettreque les types les plus répandus et les plus caractéristiques. On ne devra pas oublier que chacun de ces types comporte des variantes souvent nombreuses et qu'il existe des formes hybrides participant de plusieurs types. 
J'ai tenu à ne pas sacrifier celles-là au profit de celles-ci. J'ai visé à réunir en volume, pour en rendre la consultation facile, des documents nombreux, disséminés dans des musées plus ou moins éloignés les uns des autres, à donner aux travailleurs un fil conducteur dans leurs recherches, à mettre les industriels, déterminés à ne pas se servir toujours des mêmes formules, en mesure de modifier heureusement les formes de leurs produits, de rompre avec de fâcheuses routines, de trouver des silhouettes, des combinaisons propres à satisfaire leur clientèle et à l'augmenter.

J'ai cherché également à être utile aux conservateurs de musées désireux de mettre de l'ordre dans les séries d'objets dont ils ont la garde et soucieux de les rendre aussi intéressantes que possible pour le public.

La difficulté du travail que j'ai entrepris en excusera, je l'espère, les imperfections. Des inexactitudes, des oublis seront certainement relevés dans cet ouvrage (I). Si toutefois des industriels, si des archéologues trouvent quelque profit à consulter mon livre et parviennent à y glaner des indications qu'il leur serait difficile de récolter ailleurs, je me considérerai comme suffisamment récompensé des efforts que j'ai faits pour remplir une tâche ardue et compliquée.

$$
\text { Venise, le } 8 \text { octobre I9I2. }
$$

(I) Ies verreries romaines découvertes en Gaule sol1t trop nombreuses pour qu'il soit possible d'en connaître la totalité. En dehors des musées publics, où il est facile de pénétrer, il y a des collections privées, plus ou moins riches, parmi lesquelles les unes sont peu connues, les autres difficilement accessibles. Je n'ai visité que peu d'entre elles. C'est d'abord celle de M. CH. MAGNE, inspecteur des fouilles archéologiques de Paris au musée Carnavalet. I,es verreries recueillies par $\mathrm{M}$. MIagne nous sont précieuses, car toutes ont été trouvées à Paris même, quelquefois dans des déblais, mais souvent aussi dans des tombes datées.

C'est ensuite la jolie série de verres appartenant à M. TH. ECK, de Saint-Quentin. Ces verres ont tous été recueillis par $\lambda$. İck lui-même dans la célèbre nécropole de Vermand et dans celle de Saint-Quentin.

C'est encore la collection de M. Cl. Boulanger, de Péronne, dont les spécimens out été publiés par M. Boulanger, dans son luxueux ourrage : Le mobitier funeraire.

Ces diverses collections particulières ont été très aimablememt mises à mon entière disposition. Je suis heureux d'en exprimer ici à leurs possesseurs ma bien vive gratitude. 


\section{Notions historiques.}

Après la découverte du soufflage du verre que les archéologues sont d'accord à placer au temps de Jules César ( - Ior à - 44), l'industrie verrière prit une grande extension.

Au témoignage des auteurs anciens, les officines d'Alexandrie, de Tyr et de Sidon étaient alors particulièrement célèbres.

Les produits qui sortaient en masse de ces trois grands centres étaient écoulés par les Alexandrins vers l'Ouest méditerranéen, en Italie (Pompéi est une colonie alexandrine), en Espagne, dans le nord de 1'Afrique, à Carthage, qui était une très ancienne colonie phénicienne, en Gaule où, depuis longtemps, Marseille était en relation avec les Iles Ioniennes.

De très bonne heure, des verriers s'établirent en Italie entre Cumes et Liternum (I). De là, l'art du verre soufflé se répandit dans tout 1'Empire.

Il semble établi que les récipients vitreux en usage en Gaule pendant le $I^{\text {er }}$ siècle étaient importés, les uns d'Italie, les autres du bassin oriental de la Méditerranée. Ce n'est qu'au cours de la seconde moitié $d u I^{\text {er }}$ siècle et pendant le $\mathrm{II}^{\mathrm{e}}$, que des officines locales furent fondées. Ces fabriques, établies surtout dans la basse vallée du Rhône, étaient entre les mains d'artisans originaires pour la plupart des grands centres syriens. On y façonnait des verreries qui constituent des imitations presque serviles des produits orientaux.

Une stèle funéraire, découverte en I757, nous apprend qu'un

(1) Yos Bissrivg, Dans la Revue archeotogique, Ig08, t. I, p. 2Ig. - PlINE, Hist. nat., xxxvi, 66. 
industriel de Carthage (I), nommé Julius Alexander, opifex artis vitria, fonda, à Lyon, une dynastie de verriers (2).

L'Occident latin fut pénétré des éléments de l'art grec apparaissant sous sa forme orientale. Dès le second siècle de notre ère, des

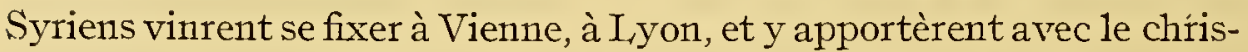
tianisme diverses industries, notamment celles du verre et de la soie.

Au début du III $^{\mathrm{e}}$ siècle, $1^{\prime}$ Empire devint de plus en plus orientalisant. I,es allures, les mœurs de la cour étaient alors celles de l'Orient. Julia Domna ( 158 à 2I8), Héliogabale (2I 8 à 222) favorisèrent à Rome et dans tous les pays soumis à la domination romaine l'extension du luxe et du despotisme syriens.

Un tombeau d'Alexandrin, découvert à Clermont (Oise), prouve que les artisans de l'Égypte ne se sont pas contentés d'occuper, en Gaule, le littoral méditerranéen.

L'immigration, dans les pays situés au nord de la Seine et de la Somme, de commerçants et d'industriels venus du Sud-Est hellénistique commença de très bonne heure; mais elle fut arrêtée, dans la seconde moitié du' $\mathrm{I}^{\mathrm{er}}$ siècle, par l'insurrection des Bataves. A partir du règne d'Hadrien, lorsque l'ordre fut rétabli, un nouveau courant d'immigránts se répandit jusque dans les provinces du Rhin. Les Asiatiques arrivèrent dans ces régions, soit par les vallées du Rhône et de la Moselle, soit par la voie maritime, en suivant les côtes de l'Océan et de la Manche.

Aussi le $\mathrm{III}^{\mathrm{e}}$ siècle amena-t-il en Gaule une nouvelle invasion de la technique et des formes en usage dans les verreries du littoral de l'Égypte et de la Syrie. Alors se développa la verrerie plastique, alors se multiplièrent les verres en forme de têtes grotesques. Ce sont les Alexandrins, on le sait, qui ont particulièrement développé l'art de la caricature.

En même temps, l'industrie du verre se déplaçait. Elle tombait en. décadence dans la vallée du Rhône et devenait particulièrement florissante à Boulogne, à Amiens, à Vermand, à Reims, à Strasbourg, à Trèves et à Cologne.

(I) Carthage, au point de vue de l'industrie du verre, peut être considérée comme une succursale de Tyrr. (2) GERSPACH, L'art de la verrerie, p. Ig. 
Il y a eu à Cologne, aux III $^{\mathrm{e}}$, IV ${ }^{\mathrm{e}}$ siècles, une véritable école de verriers. Elle fit concurrence à Rome et même à l'Orient. On rencontre ses produits jusqu'en Rhétie, en Pannonie et en Scandinavie.

A partir de la fin du III $^{\mathrm{e}}$ siècle, les commerçants de la côte d'Asie affluèrent dans les vallées de la Moselle et du Rhin. Ils y firent d'excellentes affaires, surtout à Trèves, où la Cour Impériale vint résider à maintes reprises dans le courant du $\mathrm{IV}^{\mathrm{e}}$ siècle.

Saint Jérôme, qui visita la Gaule en 369 et s'initia à l'étude de la théologie pendant un séjour à Trèves, cette cité, qu'on appelait la seconde Rome, dit, dans ses commentaires sur Ézéchiel (I), que les Syriens étaient alors partout et faisaient avec l'Occident le commerce de l'ivoire, des étoffes, des encens, des pierres fines, du verre, des peaux, du papyrus, des fruits et de l'huile (2).

L'école des verriers de Cologne est une branche rhénane de l'industrie orientale.

On lit sur des stèles funéraires conservées au musée WallrafRichartz, qu'une famille de Syrie (3), d'abord établie à Viromandum (Vermand) en Belgique, vint se fixer ensuite à Cologne quand cette ville devint la plus prospère du Bas-Rhin (4).

Jusqu'à une époque très tardive (peut-être la fin du Ive siècle), les Syriens de Cologne restèrent en relation :

Io Avec les industriels de la Gaule Belgique, ce qui est confirmé par la ressemblance qui existe entre les verreries de la vallée du Rhin et celles de la Picardie et du Boulonnais;

$2^{\circ}$ Avec les industriels d'Alexandrie et d'Asie.

Il est donc naturel qu'au Ive siècle les formes données aux verreries par les ouvriers de Cologne soient à peu près semblables à celles des verres syriens.

Après la mort de Constantin (337), 1'industrie verrière gallorhénane tomba en décadence.

Mais les officines ne disparurent pas pendant les grandes inva-

(1) Ézéchiel, XXVII, I6, lettre cxxx, 7 .

(2) Voy. Courajod, Les origines de l'art roman et gothique. - Leçons professées à l'Ecole du Louruc (1887-I896), publiées par LevoNiter et A. AIICHeL, p. 325.

(3) Les noms de Cabirus et d'Atrusus gravés sur ces pierres sont, d'après Kisa, d'origine syrienne.

(4) Avtox Kis., Das Glas in Alterlume, t. I, p. 239. 
sions. Beaucoup d'entre elles continuèrent à fonctionner malgré les troubles causés par les incursions fréquentes des Francs. Elles devaient être encore en partie administrées par des Orientaux, car, jusqu'au temps de Grégoire de Tours et même après lui, les colonies syriennes de la Gaule furent très florissantes.

On a tort d'établir une profonde lacune, un hiatus entre l'industrie romaine et celle des périodes postérieures à la chute de l'Empire. Dans leur forme, dans leur décor, dans la manière dont ils ont été fabriqués, les verres anciens, qu'ils soient romains, mérovingiens, du Moyen-âge, de la Renaissance ou du $\mathrm{xvmr}^{\mathrm{e}}$ siècle, montrent une tradition ininterrompue. 


\section{Condition sociale des verriers en Gaule.}

Sur la condition sociale des verriers en Gaule, nous n'avons guère de renseignements.

Au début de 1'Empire, l'industrie du verre, encore peu développée, semble tout entière confinée entre les mains de petits artisans orientaux, établis dans les villes de la basse vallée du Rhône, où la population était très dense et très variée.

La condition sociale de ces artisans devait, mutatis mutandis, ressembler à celle de ces métèques qui, au ve siècle avant Jésus-Christ, façonnaient des poteries au Céramique d'Athènes.

Le besoin d'action, l'amour du travail, qui, de tous temps, caractérisèrent les peuplades gauloises, poussèrent nos ancêtres à se joindre à ces artisans étrangers.

Aussi, dès le $\mathrm{II}^{\mathrm{e}}$ siècle, la corporation des verriers de Gaule, composée de nombreux ouvriers, tant orientaux qu'indigènes, avait une réelle importance et jouissait de certains privilèges. Jusqu'à la fin de 1'Empire, les Syriens y tinrent une très grande place. C'étaient des gens vifs, intelligents, qui avaient le flair du négoce. Ils y jouaient le même rôle que les Juifs à l'époque médiévale. Ils jouissaient du droit de citoyen. Plusieurs d'entre eux se sont alliés à des familles locales : les pierres tumulaires découvertes à Cologne en font foi.

Il est possible que, de père en fils, les membres de la même famille aient exercé en Gaule le métier de verrier. N'est-ce pas ce qui s'est passé à Murano aux $\mathrm{xV}^{\mathrm{e}}-\mathrm{xvI}^{\mathrm{e}}$ siècles et ce qui s'y passe de nos jours encore? 
La fabrication des verreries, sous l'empire romain, comportait une assez grande division du travail. Certains ouvriers ne faisaient qu'entretenir le feu. D'autres soufflaient le verre et le travaillaient à chaud (vitrearii) (I) ; d'autres le travaillaient à froid, le taillaient et le gravaient (diatretarii). Ceux qui façonnaient la pâte vitreuse à la manière des gemmes se livraient à une besogne que les auteurs anciens appellent Toreuma vitri.

Des signatures d'industriels comme Frontinus, Patrimonius, Dæcius, Imperator, Amaranthus, Lupio, Felix, Q.-C. Nocturnus, etc., nous portent à penser que les verriers de la Gaule avaient conscience de leur importance (2). Ces estampilles avaient pour but de garantir l'origine des objets aux yeux de la clientèle.

Alexandre Sévère mit la verrerie romaine au rang des arts somptuaires. Le 2 août 337, un édit de Constantin exempta les verriers des charges publiques.

Nous sommes certains, grâce à ces renseignements, que la corporation des verriers était loin d'être une des plus humbles et des plus insignifiantes.

Toutefois, le niveau intellectuel des ouvriers qui en faisaient partie devait être assez médiocre. Les verriers n'ont pas été, à proprement parler, des créateurs. Ils ont copié les céramistes, les orfèvres, les graveurs de gemmes, les modeleurs de figurines. Ils n'ont pas cherché à tirer de la matière dont ils disposaient des œuvres franchement originales.

Nous ne savons pas quel était le taux de leur salaire, mais nous connaissons approximativement le prix qu'ils obtenaient de leurs produits.

Les verres courants se vendaient trois sesterces, c'est-à-dire bon marché puisqu'un sesterce impérial valait quatre as (3), autrement dit vingt centimes environ de notre monnaie. On pouvait même,

(I) SÉNÈQUE, Epistol. go.

(2) L'estampille d'un atelier déterminé ne se trouve générajement que sur des verres de la même forme. Faut-il en déduire que chaque officine ne produisait qu'un seul type de verrerie?

(3) Voir l'article de Mr. Babelox dans le Dictiomaire des Antiquties grecques et romaines, de SAgLIo, t. IV, seconde partie, p. I285. 
paraît-il, acheter un petit verre à boire avec sa soucoupe pour u11 as (I).

La verrerie de luxe atteignait quelquefois des prix élevés. Pline raconte que, du temps de Néron, on a trouvé un procédé de vitrification qui permit de vendre 6.000 sesterces deux coupes assez petites qu'on nommait ptérotes (2).
(I) Strabox, Xit, p. 645.
(2) PLINE, Hist. nat, livre XXXivi, I95. 


\section{Découverte du verre soufflé. Qualité et coloration du verre antique.}

Longtemps, les archéologues sont restés dans la plus grande incertitude au sujet de l'époque de la découverte du verre soufflé. On a cru, jusqu'à ces dernières années, que l'invention de la canne de verrier remontait à la plus haute antiquité. On pensait voir des souffleurs de verre dans les peintures de Beni-Hassan (XII ${ }^{\mathrm{e}}$ dynastie) (I). Les fouilleurs cependant ne découvraient aucune trace de verrerie soufflée dans le mobilier funéraire des nécropoles antérieures à la fin de la République romaine (2). Tous les vases en verres recueillis dans ces tombes étaient de petites dimensions; c'étaient de minuscules œnochoés, des réductions d'alabastres qui avaient été façonnées sur un noyau d'argile.

Un désaccord inexplicable semblait exister entre ce que nous apprenaient les peintures, de l'époque du pharaon Ousirtasen I $^{\text {er }}$ et ce que révélaient les fouilles, quand on s'aperçut enfin que les soidisant verriers de Beni-Hassan étaient des métallurgistes.

Griffith a montré que la scène reproduite dans les hypogées de 1'Ëgypte pharaonique appartenait à une série de tableaux représentant les différentes étapes du travail des métaux (3).

(I) SAUzaY, La verrerie (Bibliothèque des Merveilles), Paris, Hachette, I876, p. 8, fig. r, 2, 3. - GersPACH, L'art de la verrerie, Paris, 1885 , p. 9, fig. 2. - ÉDOUARD GARNIER, Histoire de la Verrerie et de l'Émaillerie, Tours, 1886, p. 4 et 5 , fig. I.

(2) A Ornavasso, les tombes de Persona, qui vont de - jo à la fin du principat de Tibère, ont livré des balsamaires de verre, alors que la nécropole immédiatement antérieure de San Bernardo (- I50 à - 5o) n'en contenaitaucun (Voy. BIAnchetri, Omavasso) (dans Atti della Soc. di A rch.e B. A. di Torino, VI).

(3) GrIfFith, Beni-Hassan, Londres, Igoo, part. IV, p. 6 et pl. XX. 
Les deux hommes, placés auprès du foyer, soufflent sur la flanme à l'aide de longs tubes métalliques, dont l'extrémité est pourvue d'une chape protectrice en argile réfractaire (I). Des scènes semblables ont été figurées daus les tombes de la XVIII dynastie (2).

Le verre a été découvert en Égypte, peut-être quatre mille ans avant J.-C., et non en Phénicie comme le racontent les auteurs anciens. Mais le verre souffé, lui, est une invention syrienne, de la fin de la République romaine (3).

Les plus anciennes verreries soufflées sont transparentes, mais elles ne sont pas incolores. Toutes sont plus ou moins teintées en bleu-verdâtre. Ce ton caractéristique (pl. 5) est donné par les oxydes métalliques (surtout les oxydes de fer) contenus dans les sables.

Le verre incolore, que les anciens ont trouvé en ajoutant à la masse vitreuse une petite quantité de bioxyde de manganèse (savon des verriers), est d'invention plus récente que la canne (4).

De quelle époque date-t-il? Il est difficile de le savoir. En Gaule, on ne trouve pas de verres décolorés au manganèse dans les nécropoles du I ${ }^{e r}$ siècle. Par contre, les tombes de l'époque des empereurs syriens (5) et de leurs successeurs en contiennent beaucoup. Après Constantin, le verre incolore perd sa pureté ; il devient d'un jaune sale caractéristique ; les ouvriers qui le travaillent ne savent plus en éliminer les oxydes colorants.

Le verre antique n'est pas toujours très pur; il est souvent rempli de bulles d'air, de nuages et de filaments que les techniciens nomment filandres.

Au début de l'Empire et jusque vers le milieu du III siècle, les bulles d'air et les filandres sont relativement rares; ils n'existent que dans les produits de fabrication négligée, dans les verres soufflés

(I) Avton Kisa, Das Glas im Allertume, p. 35.

(2) Tombe de Rechmara, à Thèbes.

(3) Anton Kiss, loc. cii.., p. 299. - Vox BIssixg, L'histoire du verre en Égyple, daus la Revue archiologique: Ig08, t. I: p. $21 \mathrm{I}-22 \mathrm{I}$.

(4) On lit dans Rosert Scmunt, Das Glas, Berlin, Ig I 2, p. I, que le verre incolore au plomb était inconnu des anciens. Il aurait été découvert en Angleterre, au sime sidccle seulement.

(5) On entend par époque des empereurs syriens la période comprise entre I93 et 235 (eutre Septime Sévère et Alexandre Sévère). 
à une température trop basse (I). Au IV siècle, on en trouve partout. Si les verriers de cette époque savent mieux que leurs prédécesseurs donner aux récipients vitreux des formes élégantes, ils sont, parcontre, en pleine décadence au point de vue technique et sont incapables de faire une pâte vitreuse pure et homogène.

Les verres romains qui sont parvenus jusqu'à nous sont loin, pour la plupart, d'avoir l'aspect qu'ils présentaient dans l'antiquité. Beaucoup d'entre eux sont décomposés dans leur masse; ils ont perdu, à des degrés différents, leur qualité essentielle, la transparence; ils sont parfois fortement irisés. Les reflets métalliques, les tons bleus, rouges, jaunes, violets et verts, qui se fondent les uns dans les autres, ajoutent aux verreries les plus ordinaires un attrait, un charme, une beauté qui les font rechercher des collectionneurs. C'est une polyphonie tour à tour délicate et subtile, brutale et heurtée, où abondent les effets imprévus.

L'irisation est, en général, beaucoup plus belle sur les verres d'Orient que sur ceux de la Gaule. Les terrains, selon leur nature, favorisent plus ou moins la décomposition des verreries qui y sont enfouies. M. Th. Eck a constaté, en fouillant le cimetière de Vermand, que les pièces recueillies dans 1'argile n'étaient pas irisées, tandis que celles des tombes creusées dans la craie étaient toutes pourvues d'une belle irisation argentée ou opaline.

Le verre à l'oxyde de fer ou de cuivre se décompose moins facilement que le verre décoloré par le manganèse.

Les flacons prismatiques, en verre épais bleu-verdâtre, de fabrication alexandrine, ont souvent conservé toute leur transparence. Les verres incolores, au contraire, ont très rarement gardé leur pureté primitive. Presque tous sont décomposés ; ils paraissent plongés dans une buée; ils ressemblent à notre verre dépoli; ils ont pris l'aspect du papier à calquer que nous appelons dioptrique.

Depuis la plus haute antiquité, les verriers égyptiens savaient colorer les matières vitreuses à l'aide de différents oxydes métalliques.

(r) Aux filandres se joignent des nodules blancs et opaques, constitús par les sulfates et les chlorures qui fondent en partie sans se mêler au verre. 
Après l'invention de la canne, bien qu'on cherchât à donner au verre sa qualité maîtresse, la transparence, on continua, longtemps encore, à l'enrichir de tons vifs, violents, criards même.

Le bleu était donné par l'oxyde de cobalt ; le rouge et le vert, par les oxydes de cuivre.

Au commencement du $\mathrm{um}^{\mathrm{e}}$ siècle, la verrerie romaine est à son apogée. I e grand éclat de sa fabrication date de l'époque des empereurs syriens. On sait alors façonner des vases de verre si transparents, si purs, qu'ils rivalisent avec les récipients de quartz taillé. Ces vases, souvent gravés à la meule, sont préférés aux verres de couleur.

Cependant, sous le principat d'Aurélien, à l'époque de l'expédition de Palmyre qui établit un nouveau courant artistique entre l'Asie et l'occident de l'Europe, de nouvelles modes orientales

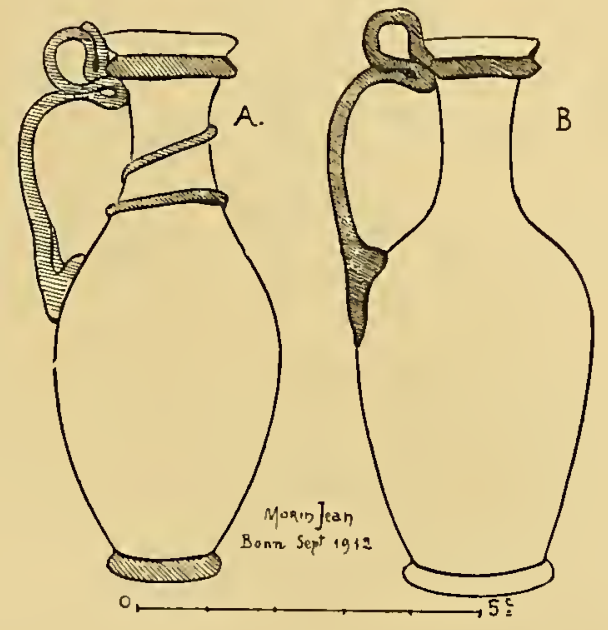

FIG. I. - A. Flacox en verRe bleU (anse, bourrelet iuférieur de l'embouchure, filetage et pied en verre jaune opaque). Fin III ou IVe s. Musée provincial de Bonn. Salle V, I684.-B. FLACON EN VERRE VIOLIT (anse et bourrelet infẻrieur de l'embouchure en verre bleu). Fïn In' ou IVe s. Même musée. Salle VII, 4275.

viennent s'implanter en Gaule. Comme au $\mathrm{I}^{\mathrm{er}}$ siècle, le public accorde ses faveurs aux verreries colorées ; mais il recherche moins les couleurs franches et violentes que les tons distribués suivant une chromatique délicate. Il aime les tons mats et brisés, les verts-jaunâtres, les 
jaunes-verdâtres, les violets foncés, les bleus froids, les bruns, les rouges-violacés, le noir, le blanc laiteux.

A l'époque constantinienne, d'élégantes combinaisons, de savants contrastes sont obtenus par l'association, dans un même récipient,

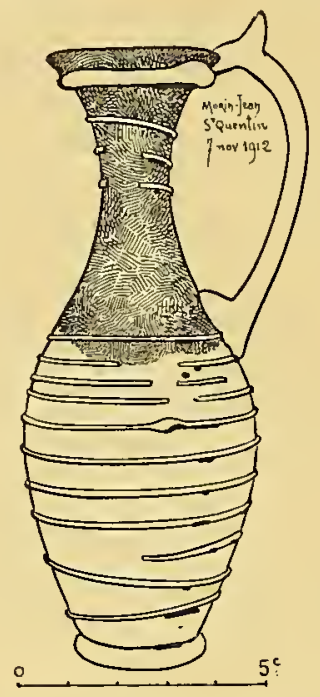

FIG. 2. - FLACON POLYCHROME (panse en verre incolore; col en verre rouge-violacé; anse, bourrelet inférieur de l'embouchure, pied et filetage en verre blanc opaque). Cimetière de Vermand. Musée de Saint-Quentin, $\mathrm{n}^{\circ} 2667$.

du verre transparent et du verre opaque (fig. I et 2). Le violet accompagne le bleu, le bleu soutient le jaune ou s'oppose au blanc dans une gamme tantôt sombre et soutenue, tantôt claire et fluide.

Techniquement, cela est très remarquable. Les artistes qui ont façonné ces flacons délicats connaissaient à fond toutes les ressources de leur métier, sans que toutefois leur habileté dégénérât en cette virtuosité un peu agaçante dont ont fait trop souvent parade les verriers de Venise. 


\section{Morphologie analytique.}

Un simple coup d'œil jeté sur les figures qui illustrent ce volume permet de s'apercevoir : $I^{0}$ que des types de verreries différents peuvent avoir la même embouchure, la même anse, le même pied ; $2^{\circ}$ que le même type peut recevoir successivement des embouchures, des anses, des pieds de différentes sortes.

Avant d'entrer dans la description générale des types, j'ai cru utile de faire cuvre d'analyse et d'envisager isolément les diverses parties d'un récipient de verre antique.

\section{I. - Panse. (Les profils. Le galbe.)}

La beauté ou la laideur d'un vase résident dans le jeu des lignes qui en constituent les divers profils.

Les verriers romains firent peu de recherches personnelles pour établir leurs profils ; ils adoptèrent ceux qu'avaient créés les industriels dont ils copiaient les produits.

Lorsqu'ils s'inspirèrent des formes grecques, ils obtinrent un galbe à la fois plus simple et plus élégant que lorsqu'ils prirent pour modèles les formes créés en Orient.

A l'époque romaine, surtout au $\mathrm{r}^{\mathrm{er}}$ et au $\mathrm{II}^{\mathrm{e}}$ siècles, les flacons à panse prismatique, cylindrique, tronconique, étaient très répandus. Leurs profils étaient raides et peu esthétiques. Aussi les verriers de l'antiquité ont-ils cherché, par tous les moyens possibles, à remédier à cet inconvénient, en arrondissant les angles, en créant, entre la 
panse et le col des bouteilles carrées, une sorte de coupole, de calotte qui n'a pas une forme géométrique bien déterminée et dont le galbe mou contraste heureusement avec les parties rigides du récipient.

Les verriers $d u I I I^{\mathrm{e}}$ et $d u \mathrm{IV}^{\mathrm{e}}$ siècles, plus raffinés dans leur goût que leurs prédécesseurs, abandonnèrent presque complètement la fabrication des flacons à panse prismatique. Ils firent surtout des verreries globulaires, tournées à l'air libre, plus conformes à la technique du verre soufflé.

Dans le tournassage du verre, la main de l'artiste est seule capable, et suivant l'occasion, d'imprimer au profil la grâce ou le caractère.

Le profil est un élément de forme aussi délicat qu'une fleur ou

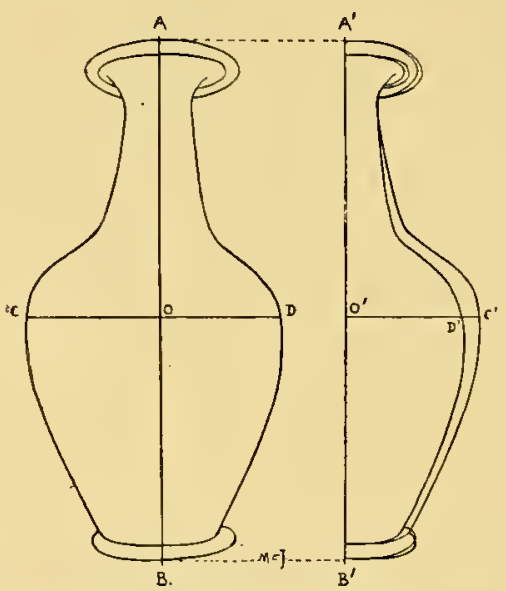

FIG. 3. - DisstMtÉtrIE DES PROFILS DANS LA VERRERIE ROMAARE.

qu'une figure. Aussi la recherche de ses contours est-elle incompatible avec les procédés mécaniques, si ingénieux qu'ils soient.

Tout en cherchant à tourner un vase le plus régulièrement possible, l'ouvrier ne peut pas obtenir la symétrie absolue des profils, car la matière qu'il emploie n'attend pas; elle le force à prendre ses mesures à vue de nez.

La dissymétrie des profils existe aussi bien dans les verreries romaines faites à la hâte, dans ce qu'on pourrait appeler la pacotille, que dans les produits soignés, sortis des meilleures officines.

Elle est souvent très accusée. Une bouteille du III siècle (fig. 3) 
va nous le prouver. Il suffit de faire tourner cette verrerie autour de son grand axe vertical $A B$ et de projeter sur un écran les silhouettes qui se présentent successivement au cours de la rotation pour constater que les profils, donnés par ces silhouettes, ne sont pas superposables.

I,e profil de gauche $\mathrm{ABC}$, rabattu en $\mathrm{A}^{\prime} \mathrm{B}^{\prime} \mathrm{C}^{\prime}$, est très différent du profil de droite $A B D$, rabattu en $A^{\prime} B^{\prime} D^{\prime}$.

La même opération, faite sur un grand nombre des figures qui illustrent le présent ouvrage, fournirait des résultats analogues.

Cette absence de régularité dans les profils de la panse donne aux verreries antiques une vie qui manque à beaucoup de nos verres modernes dans la fabrication desquels la règle, le compas, les machines, remplacent, sans la valoir, la main guidée par le sentiment.

\section{2. - Gouxo's.}

Le goulot des verreries romaines est tantôt court (voy. formes 3 , 8, I3, 33 du tableau de morphologie générale), tantôt long (formes 23 , $24,25)$.

Il est large ou étroit, suivant l'usage auquel est destiné le récipient. Les vases devant contenir des cendres, des pommades, des aliments solides, ont un large goulot ( I à 8 , I3, I6). Les flacons à huiles parfumées, à liquide précieux, ont un goulot étroit (I0, I9, 23, 3I, 34, 4I).

Dans sa conformation, le goulot peut présenter divers facies:

$A$. Il a environ le même diamètre en haut et en bas. Son profil est rectiligne $(\mathrm{I} S, 24)$, incurvé en dedans $(9,33,34,53,66)$, ou incurvé en dehors $(8,16,22)$;

$B$. Il s'élargit vers le haut (40, I2I, I23) ;

$C$. Il se rétrécit vers l'embouchure (10, 42, 58).

Le goulot des verreries romaines n'est pas toujours rattaché de la même façon à la panse.

$A$. Il peut y être fixé directement, sans que l'on ait songé à établir une transition à 1 'aide de courbes intermédiaires $(\delta, 9, I 4, I 6, I S, 40)$;

$B$. Il est relié à la panse par des courbes transitionnelles plus ou moins compliquées (I2, 33, 44, 49, 50, 54, 56, 59, 61, 62, 66); 
C. Un étranglement est ménagé entre le goulot et la panse (ro, 4x). Cet étranglement sert à empêcher l'écoulement trop rapide du liquide.

\section{3. - ORIFICESS (I).}

Les procédés employés dans la fabrication des orifices des verreries romaines étaient très variés.

On peut distinguer trois séries d'orifices (2):

Io Orifices non ourlés (fig. 4). - Les orifices non ourlés com-

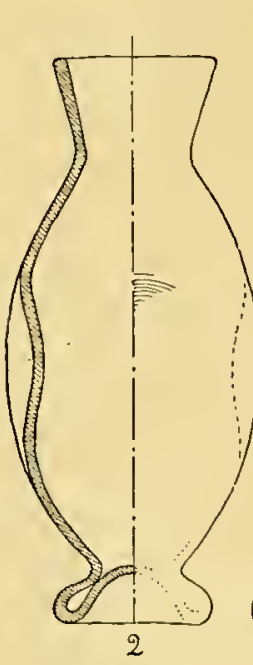

"THOPAISE:"
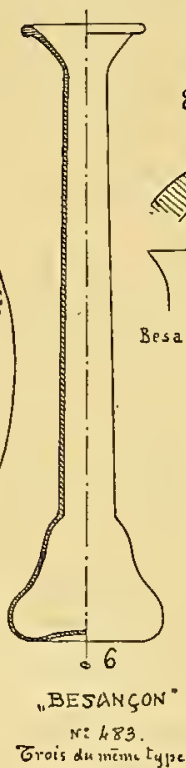

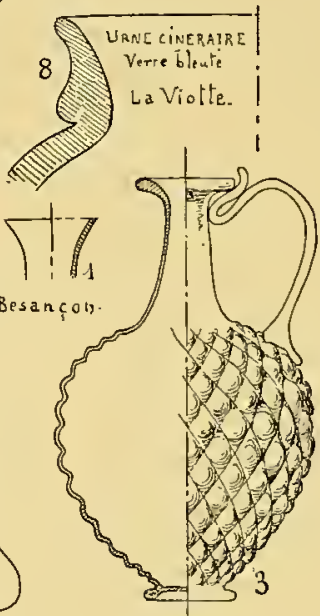

"THORALSE":

Musée de Besançoiz

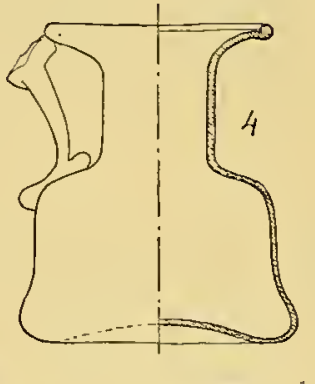

KO: 480. . BESAHÇON."
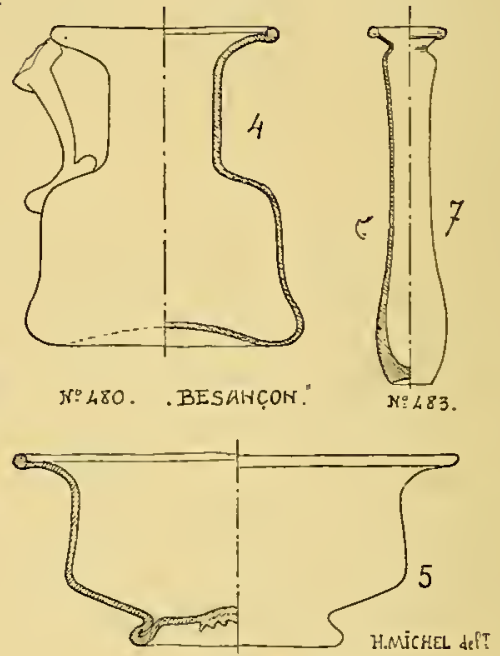

N: 173 BESANCON

FIG. 4. - VERRERIES A ORIFICE NON OURLE (Musee de Besançon).

prennent plusieurs types correspondant à des procédés différents : A. L'ouvrier donne à la paraison la forme désirée, puis la coupe

(I) I $I_{4}$ matériaux de ce paragraphe et du paragraphe suivant, m'ont été fournis en grande partie par M. H. MrcheL, conservateur du musée de Besançon, à qui j'adresse ici mes bien vifs remerciements. C'est à l'habile crayon de M. Michel que sont dues les figures 4, 5, 6 et 7 du présent ouvrage.

(2) Dans bien des cas, ces procédés sont difficiles à distinguer les uns des autres. On ne peut pas toujours se rendre compte de la façon exacte dont les embouchures sont constituées. C'est pourquoi, en dehors des figures 4,5 , 6 et 7 , qui reproduisent des types dont ou a pu connaître la structure complete, nous avons préféré, toutes les fois que nous avons eu à reproduire une embouchure en coupe, n' indiquer que les contours extérieurs (voy. notamment les fig. $1_{3}, 20,48,57,61,62$, etc.). 
avec des forces et laisse l'orifice à l'état brut avec ses arêtes vives (fig. $4,1^{\text {os } I}$ et 2 ). Ce procédé a été appliqué depuis le début jusqu'à la fill de la période impériale romaine.

$B$. Après avoir coupé la paraison, le verrier arrondit les bords de l'orifice (fig. $4, n^{\circ}$ 3). Il obtient ainsi, par refoulement de la matière, un bourrelet plein, plus ou moins gros, qui forme saillie, tantôt en

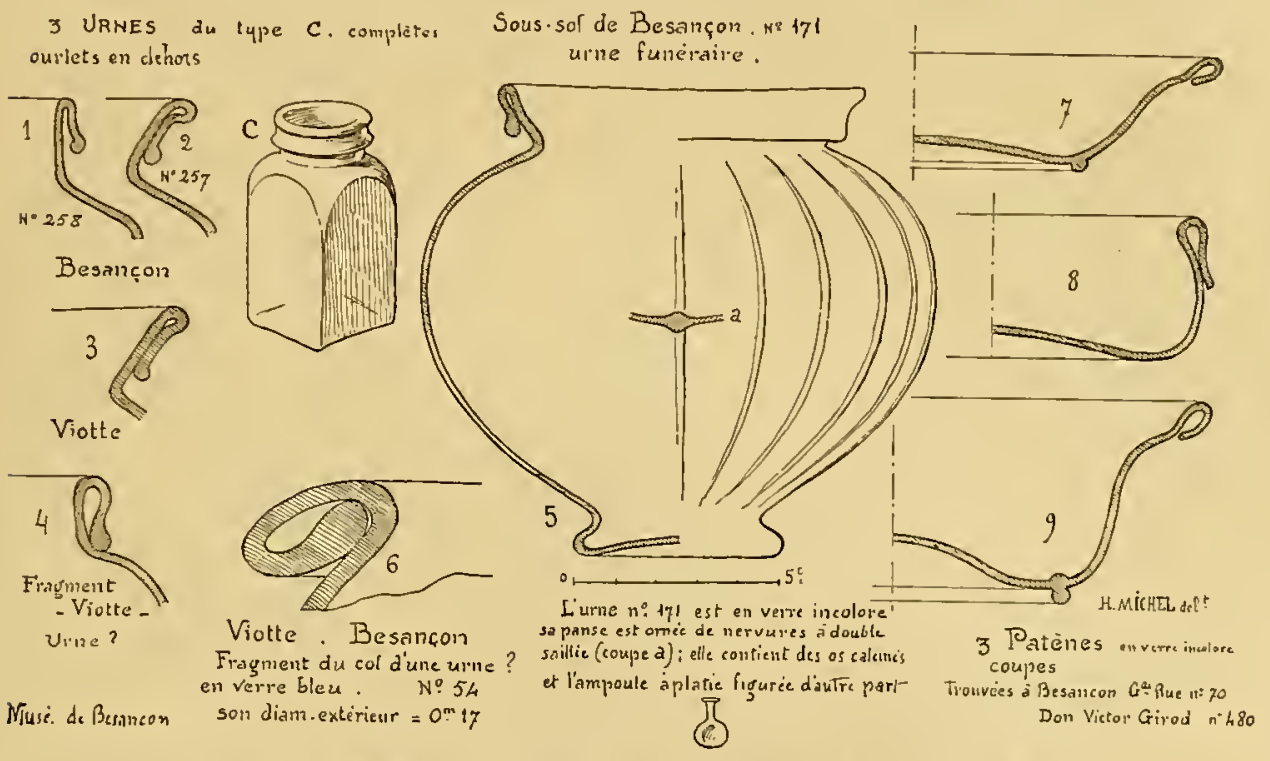

Fig. 5. - Verreries A ORIFICE OURLĖ Ex́ DeHors (Musće de Besaņon).

dedans (fig. 4 , nos 4 et 5), tantôt en dehors (fig. 4 , ño 6 ), tantôt des deux côtés (fig. 4, n⿳0 7).

$C$. Lorsque la paraison est en verre très épais, on peut moulurer, en pleine masse vitreuse, une embouchure (fig. $4, n^{\circ} 8$ ) qui ressemble aux embouchures ourlées 4 et 5 (fig. 5), mais qu'il importe de ne pas confondre avec ces dernières.

$D$. L'ouvrier fixe un fil de verre directement au-dessous du bourrelet que forme l'orifice type 3 , fig. 4 . Par cette opération, il obtient une embouchure à double bourrelet, qui, dans son aspect extérieur, ressemble beaucoup à certains modèles d'embouchures ourlées.

Le fil de verre rapporté n'est pas toujours de la même couleur que le récipient sur lequel il est appliqué (fig. I et 2). 
I.es bouteilles 5o du tableau de morphologie générale ont tantôt un orifice de ce genre, tantôt une embouchure ourlée du modèle 6 (fig. 6).

$2^{0}$ Orifices ourlés (fig. 5, 6 et 7). - Les orifices ourlés sont de plusieurs sortes.

A. Types ourlés en dehors. - Les orifices ourlés en dehors sont très variés dans leur forme (fig. 5 et 6 ).

Les urnes cinéraires du type I du tableau de morphologie générale

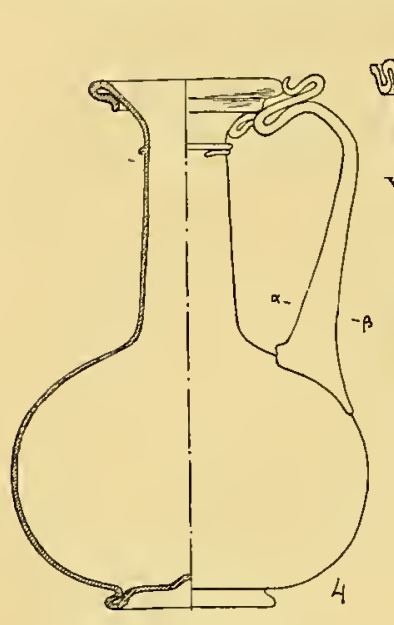

Sous - sol de Besançon

Coups de lianse

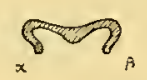

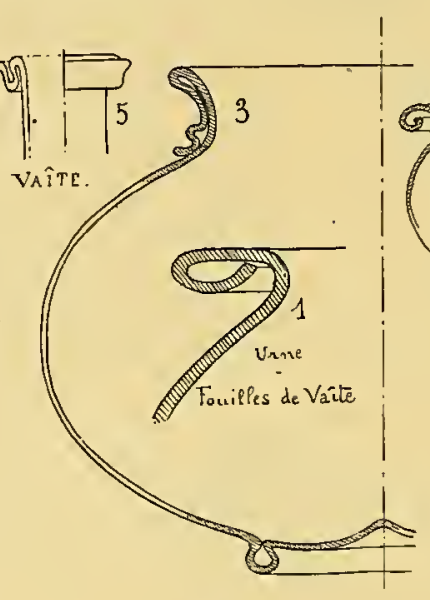

Urne en verre mince

"La Viotte" Besançon

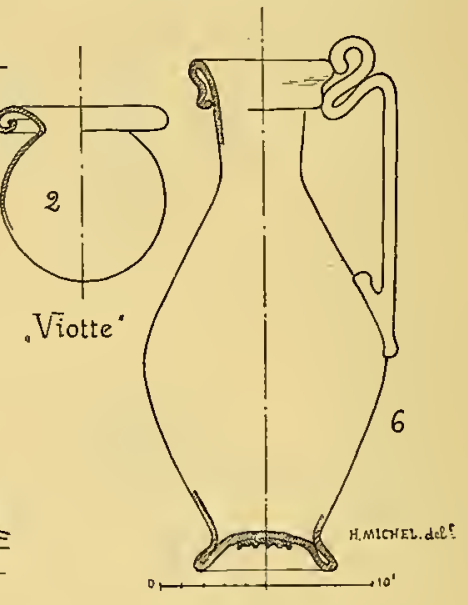

OEnochoe de. Ponziëres

Jusée de Besançur

Fig. 6. - Verrerues A ORIFICE OURLE EN DEHORS (Musée de Besançon).

ontleur embouchure, tantôt ourlée en dehors (nº I, fig. 6), tantôt ourlée en dedans ( $n^{0}$ I, fig. 7). Les urnes et les urnioles du type 5 ont l'orifice ourlé en dehors ( $\mathrm{n}^{\mathrm{OS}} \mathrm{I}, 4$ et 5 , fig. 5 , et $\mathrm{n}^{0} 3$, fig. 6).

L'ourlet 5, fig. 6, est un type intermédiaire peu répandu.

B. Types ourlés en dedans (fig. 7). - Ces types comportent de nombreuses variétés. L'embouchure des bouteilles $n^{0}$ I6 du tableau de morphologie générale est toujours ourlée en dedans. Il en est de même des orifices des flacons I9, 23, 24 et 25 et des embouchures de la plupart des barillets frontiniens, I32.

In étirant les bords de la paraison vers le milieu de l'orifice, on 
obtient les embouchures discoïdes à étroite ouverture spécialement affectées à certains vases à parfuin (fig. 9I, 92).

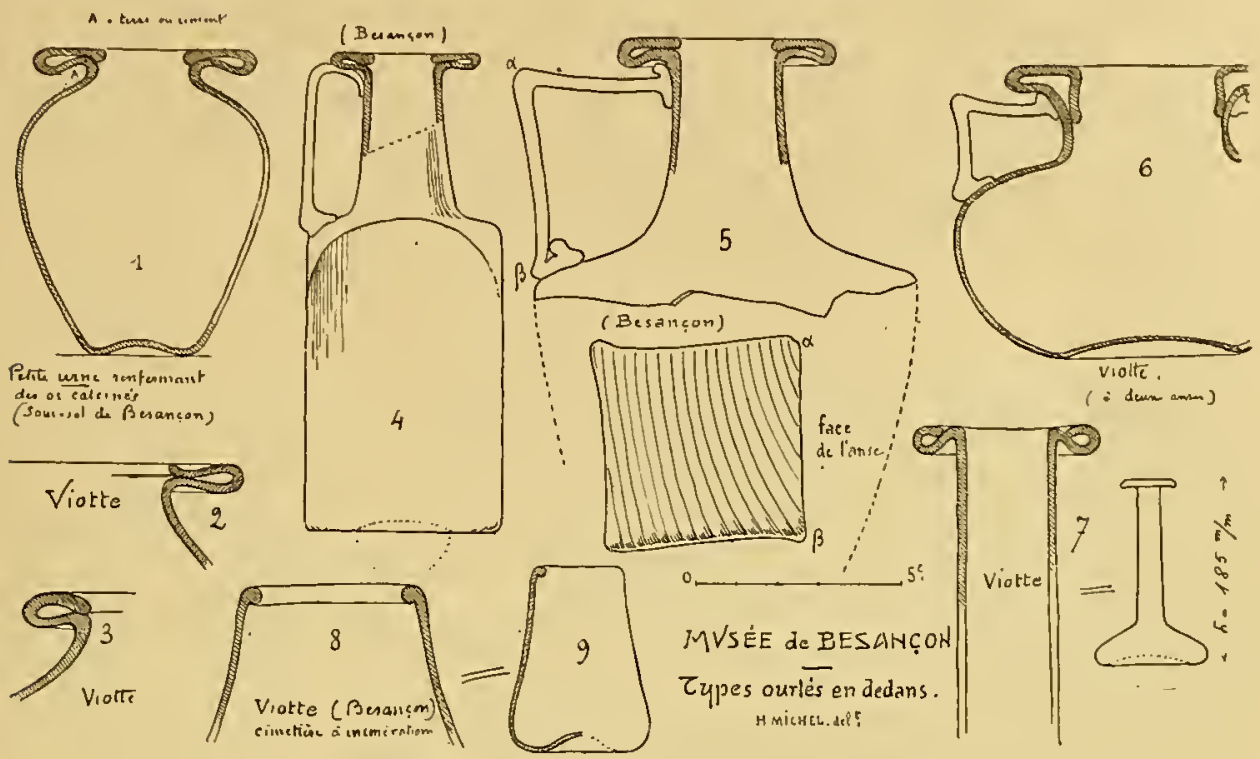

Fig. 7. - VerReries a ORIFICE OURLÉ en Dedans (MIusée de Besancon).

$3^{\circ}$ Orifices imitant des embouchures de vases grecs (fig. 8). - A. Type
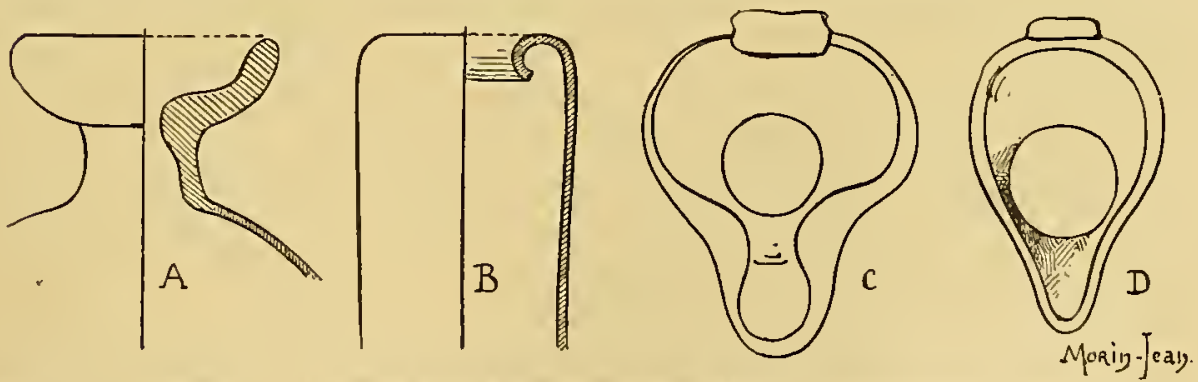

Fig. 8. - Ortfices nittant Les esmouchures des vases Grecs (A, Lécythe; B, Cothon; C et D, Ennochoés).

émanant de l'embouchure du lécythe classique (I) (orifice des aryballes forme 34 du tableau de morphologie générale).

B. Type émanant de l'embouchure du Cothon (2) (orifice des

(I) Toy. Dictionnaire des Antiquites de Saglio, t. III, deuxième partie, p. I.023, fig. 4.402.

(2) Dietionnaire cité, t. I, deuxième partie, p. I.543, fig. 2.024. 
flacons forme II du tableau). Le bord de la paraison fait une inflexion brusque au dedans du vase.

C. Type émanant del'embouchuretrilobée de l'cenochoé classique (I) (orifice des bouteilles 54 et 67 ).

$D$. Type à bec (variante du type $\mathrm{C}$ ) (orifice appliqué aux bóuteilles $53,55,60)$.

Ces quatre types d'orifices sont du Romain II.

$$
\text { 4. - Pieds. }
$$

Beaucoup de verreries romaines, surtout au Romain I, sont apodes et ne peuvent tenir debout (fig. 84, 88).

D'autres ont une dépression plus ou moins profonde qui s'accuse à la partie inférieure de la panse (fig. 9, $\mathrm{n}^{0} \mathrm{I}$ et fig. I3, 20).

C'est un moyen aussi simple qu'ingénieux de donner de l'assiette au récipient.

Au Romain I, cette dépression est légère.

Aux $\mathrm{III}^{\mathrm{e}}$ et $\mathrm{IV}^{\mathrm{e}}$ siècles, elle est plus profonde et forme souvent une saillie conique à l'intérieur de la bouteille (fig. $9, \mathrm{n}^{0} 2$ ).

Un grand nombre de verres romains ont un pied. Ce pied peut être exécuté suivant des procédés très différents. Nous envisagerons trois groupes:

Io Le groupe des pieds non rapportés, formés aux dépens de la paraison qui a servi à faire la panse;

$2^{0}$ Le groupe des pieds rapportés, constitués à l'aide d'un anneau de verre ou d'une paraison spéciale;

$3^{0}$ Le groupe des bases polypodes.

Io Pieds non rapportés. - A l'aide d'une seule paraison, les verriers romains savaient façonner un vase entier comportant une embouchure parfois compliquée et un pied souvent très délicat. Pour. faire ce pied, ils employaient diverses techniques. Les plus usitées de ces techniques sont les suivantes :

$A$. Un premier procédé consiste à refouler l'extrémité de la parai-

(I) Voy. Dictionnaire des Autiquités de Saglio, t. IV, première partie, p. I6I, fig. 5.382 et $5.3^{8} 3$. 
son (fig. 9, $n^{\text {os }} 3$ à Io). Le refoulement à cône élevé $n^{0}$ Io n'apparaît pas en Gaule avant le IIre. Il est très commun au IVe siècle.

$B$. Un second procédé consiste à façonner le pied tout entier dans la masse de verre qui forme, dans la paraison, l'extrémité opposée à celle où se trouve fixée la canne du souffleur. On sait qu'en cet endroit, la paraison est beaucoup plus épaisse que sur les côtés.

Les pieds pris aux dépens de la paraison, et dans son épaisseur même, sont assez variés dans leur forme (fig. 9, nos II à I4).

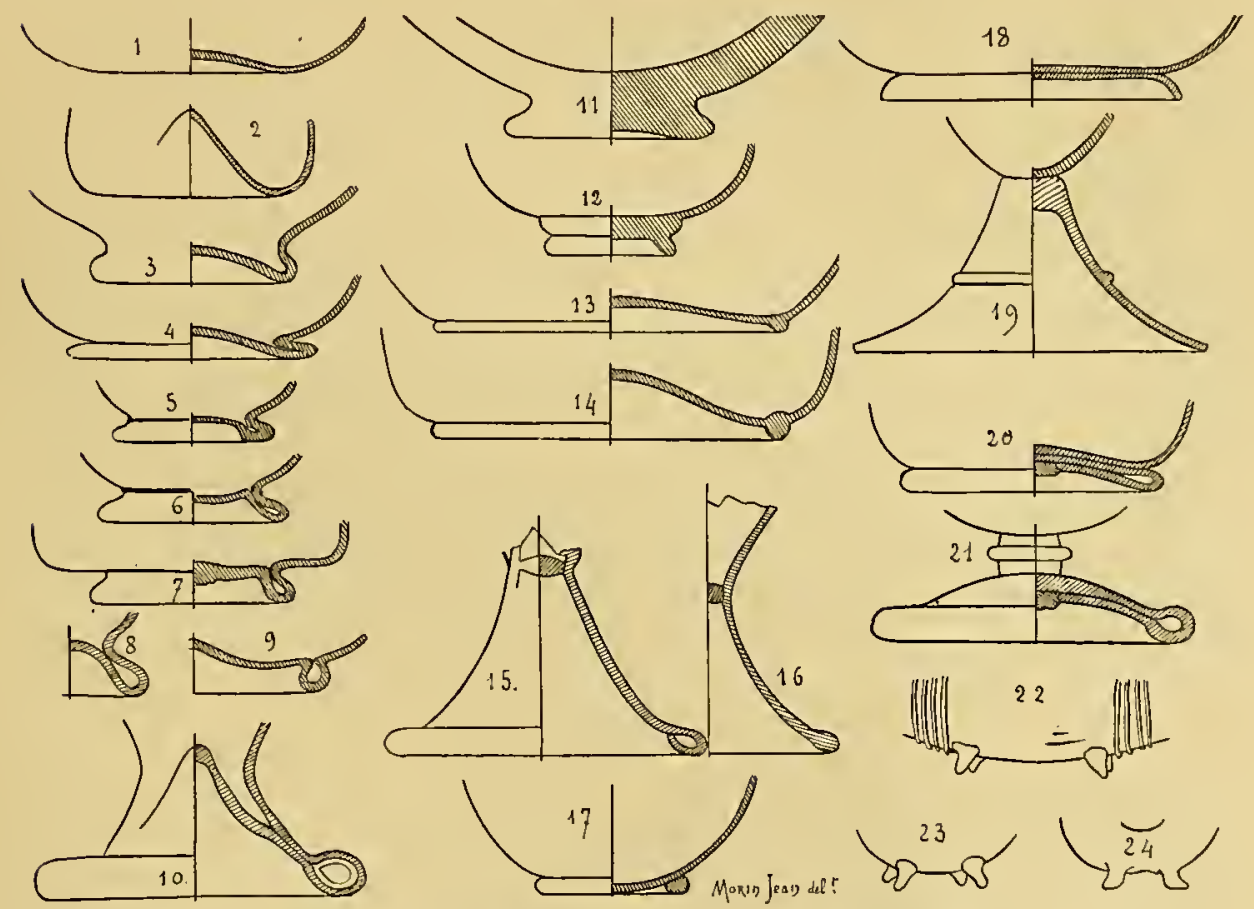

FiG. 9. - Pieds de verrertes découvertes en Gaule.

$C$. Dans un troisième, que nous appellerons «procédé à opercule rapporté », on étrangle la paraison à l'endroit où l'on veut placer le fond de la panse et on obture, à l'aide d'un bouchon de verre, l'espace resté vide entre la panse et le pied (fig. $9, n^{\text {os }}$ I $_{5}$ et 16 ).

Cette façon d'opérer est difficile à distinguer du procédé à refoulement $n^{\circ}$ IO. Nous ne sommes pas sûrs queles Romains l'aient employée, 
car nous n'avons pu l'étudier que sur des pieds détachés et fragmentés qui peuvent avoir appartenu à des verreries d'époque postérieure aux invasions.

$2^{\circ}$ Pieds rapportés. - Les pieds rapportés consistent, soit en un gros fil de verre formant anneau (fig. $9, \mathrm{n}^{\circ} \mathrm{I} 7$ ), soit en une paraison à laquelle on donne une forme très variable (fig. 9, n $n^{\text {os }}$ I8 à $2 \mathrm{I}$ ).

Cette paraison est tantôt non ourlée (fig. 9, $\mathrm{n}^{\text {os }} \mathrm{I} 8$, I9), tantôt ourlée (fig. $9, n^{\text {os }} 20,2 \mathrm{I}$ ).

Elle est directement soudée sous la panse du vase (fig. 9, $\mathrm{n}^{\text {os }} \mathrm{I} 8$, I9, 20), ou réunie à cette dernière par une masse vitreuse intermédiaire en forme de sphéroïde ou de balustre bas (fig. 9, $\mathrm{n}^{\mathbf{0}} 2 \mathrm{I}$ ).

L,es pieds à balustre $\left(\mathrm{n}^{\circ} 2 \mathrm{I}\right)$ sont très répandus dans la Gaule nordique au Romain II, surtout au $\mathrm{III}^{\mathrm{e}}$ siècle.

$3^{\circ}$ Bases polypodes. - Les verres à plusieurs pieds sont des fantaisies, généralement assez peu esthétiques. Ils sont rares à l'époque romaine. Ceux qui sont parvenus jusqu'à nous se classent tous au Romain II (voy. Tableau de morphologie générale, nos 36 , I28 et I35).

Les verreries polypodes ont trois ou quatre pieds. Ces pieds sont tantôt rapportés (fig. 9, $\mathrm{n}^{\mathrm{os}} 22$ et 23 ), tantôt extraits de la masse vitreuse du récipient et étirés à la pince (fig. 9, ñ 24).

$$
\text { 5. - ANSEs. }
$$

En divisant en deux groupes (p1. 2 et 3 ) les anses des verreries romaines, nous espérons faire comprendre à la fois les liens morphologiques qui unissent la série du Romain II à celle du Romain I, et les caractères spéciaux qui permettent de différencier ces deux séries.

Les anses du $\mathrm{I}^{\mathrm{er}}$ et $\mathrm{du} \mathrm{II}^{\mathrm{e}}$ siècles, sont peu variées. Elles ont de la simplicité, de la franchise, de la vigueur. Elles sont romaines et bien romaines.

Les anses $d u \mathrm{III}^{\mathrm{e}}$ et $\mathrm{du} \mathrm{IV}^{\mathrm{e}}$ siècles sont souples, élégantes. Eilles décrivent des courbes majestueuses, ou bien elles ondulent, frissonnent. Elles sont accompagnées de menus ornements qui amusent, 
qui lancent des notes joyeuses dans une symphonie de lumières et de reflets. Elles sont très orientales.

En étudiant lés principales variétés d'anses, nous essaierons de faire ressortir qu'une évolution a été suivie par chacune d'elles, au cours de la période impériale.

Io Anses des urnes cinéraires forme 2 du tableau de morphologie générale. - Gros boudins qui décrivent une simple courbe (type \%, p1. 2) ou se replient plusieurs fois sur eux-mêmes (type $\psi$ et $\omega$, pl. 2 . Anses dites en $\mathrm{M}$ ).

Les anses de cette première série ont peu évolué. Elles disparaissent en même temps que les récipients auxquels elles appartiennent, pendant la seconde moitié du $\mathrm{III}^{\mathrm{e}}$ siècle.

$2^{\circ}$ Rubans de verre à nerrures. - Les plus anciens exemplaires de ce modèle d'anse sont trapus, lisses sur leur face interne, et pourvus, sur leur face externe, de nervures plus ou moins nombreuses (types $\alpha$, $\beta, \gamma$, p1. 2). Ils sont coudés à angle droit ou aigu et forment un repli au point d'attache sur le col. Grâce à ce repli qui se fait pour ainsi dire de lui-même lorsqu' on appuie l'anse encore molle sur le goulot du vase, le joint est plus solide, la surface d'adhérence étant plus grande.

Les rubans de verre à nervures étaient affectés par les verriers du Romain I aux urnes 3, aux flacons cylindriques 8 , et aux bouteilles à panse prismatique $\mathrm{I}_{4}$ à $\mathrm{I} 7$. A partir du III ${ }^{\mathrm{e}}$ siècle, ils évoluent, ils se transforment (types $\alpha^{1}, \beta^{1}, \beta^{2}, \gamma^{1}, \nu, p 1.3$ ).

L,e type $\gamma^{1}$ reste seul coudé à angle droit (fig. Io) ; mais il est plus léger que les modèles du Romain I, et il paraît à peu près exclusivement réservé aux bouteilles 9 et 132 . Tous les autres types décrivent une courbe plus ou moins gracieuse. Le repli, formé au point de jonction avec le goulot du vase, se développe, devient une boucle dont l'importance décorative s'accentue dans le courant du Romain II.

Dans le type $\beta^{1}$, le repli est remplacé par un gros fil de verre qui forme une boucle au-dessus de l'orifice du vase et dont les bouts, ornés de saillies faites à la pince, sont ramenés en arc de cercle sur le rebord de l'embouchure ( $I$ ). Les anses de ce modèle ont quatre ou cinq ner-

(I) Cette disposition est cmpruntẻe à certains types d'anses métalliques. 


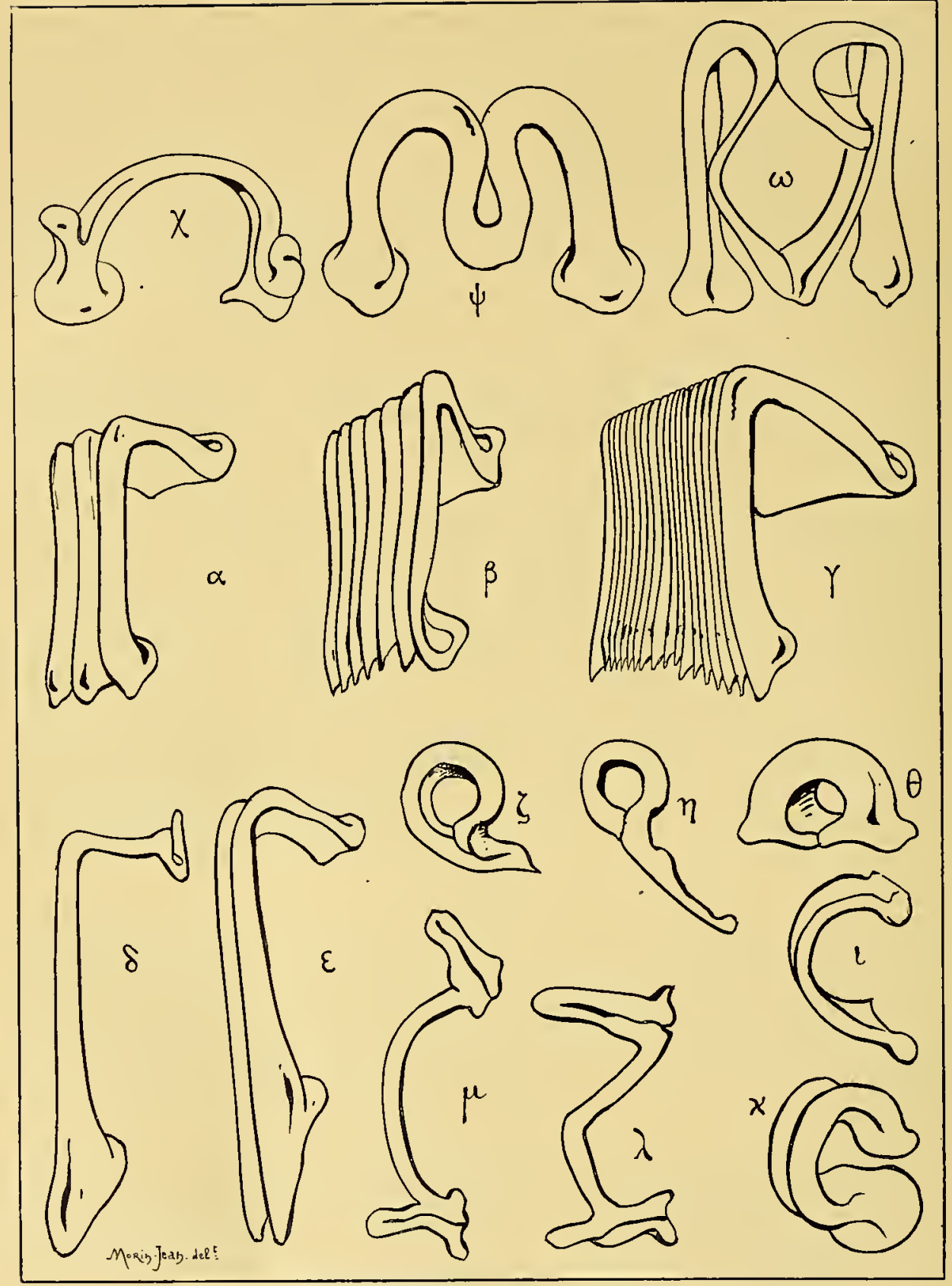

PL. 2. - ANSES DES verRerIES ROMANNES (types du Romain I). 


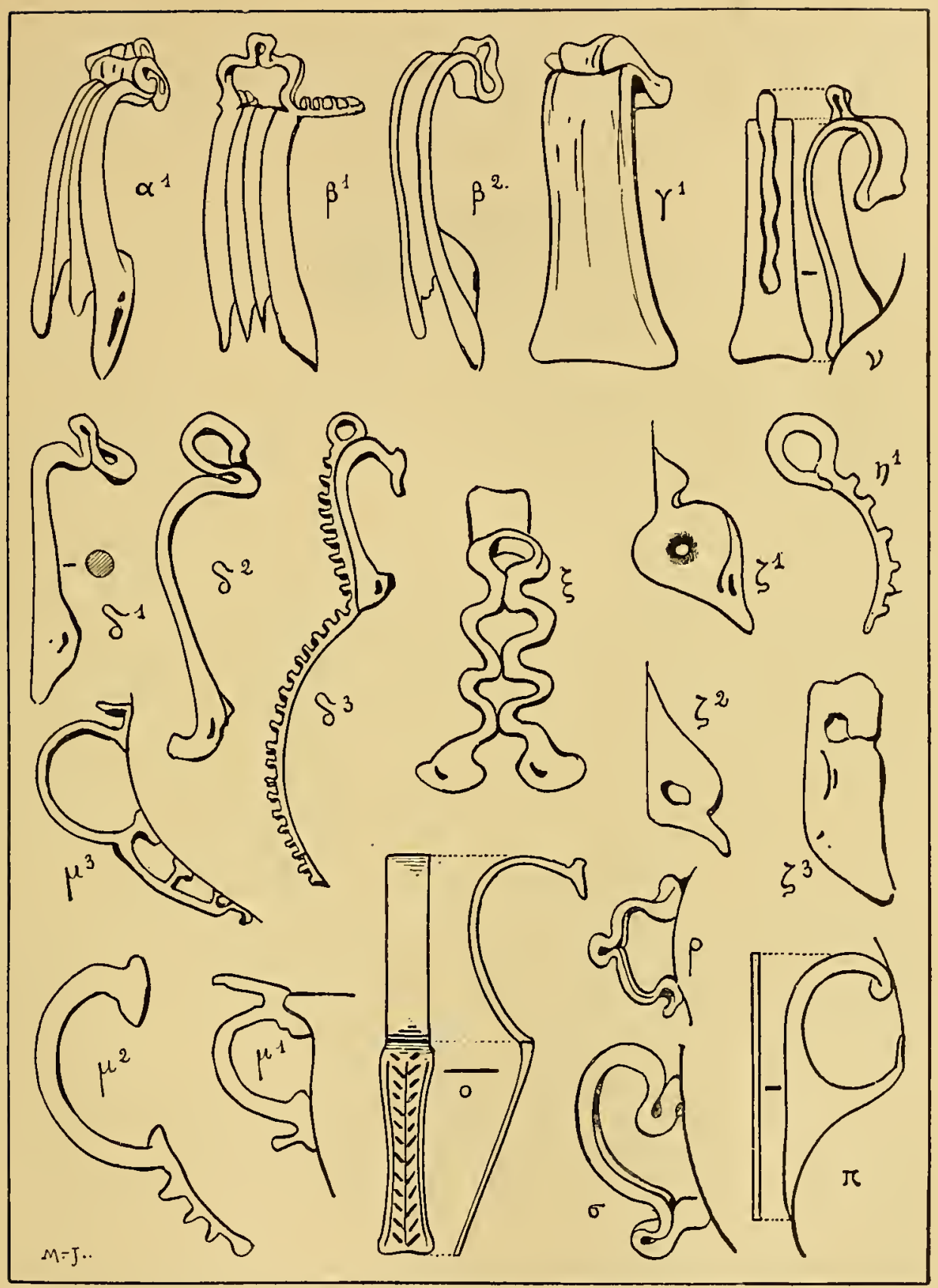

PL. 3. - ANSES Des verrerIeS romatnes (types du Romaiu II). 
vures très saillantes. Elles semblent réservées aux flacons forme $6 \mathrm{r}$. Elles sont du Irr $^{\mathrm{e}}$ et du rve siècles.

Le type $\vee$ a pour origine l'anse surélevée des œnochoés grecques de terre cuite. Il est orné d'un fil de verre souvent bleu qui forme

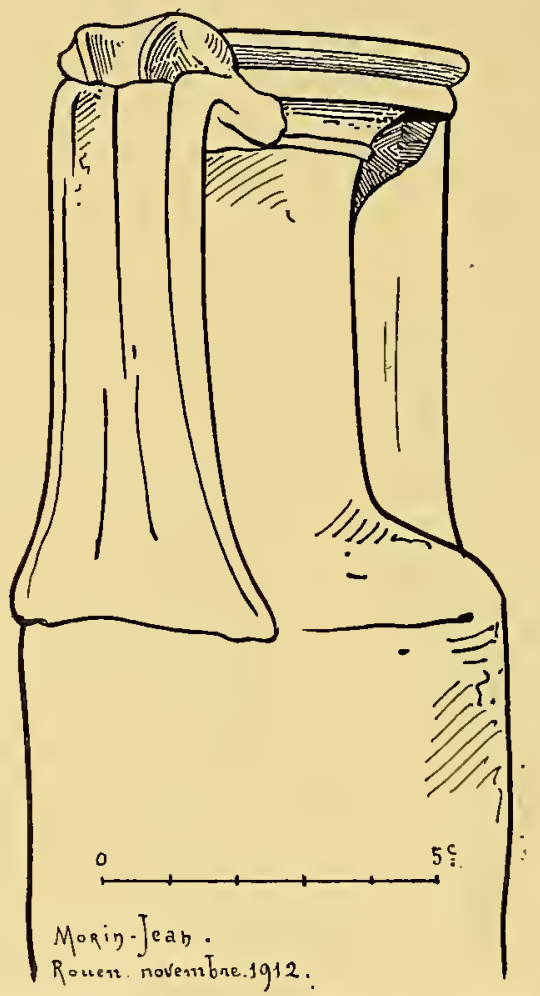

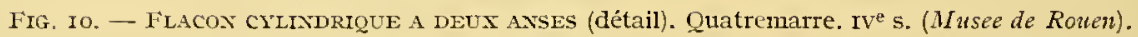

poucier à la partie supérieure. Les vases munis de cette sorte d'anse sont des œenochoés (forme 54) du mie siècle.

$3^{\circ}$ Anses en forme de baguette ronde. - Le bâton de verre artondi, terminé à sa partie inférieure par une large expansion qui embrasse une plus ou moins grande surface de la panse du vase, est une des formes d'anse les plus simples et dont sont pourvues maintes bouteilles du Romain I ( $\delta, \mathrm{pl}, 2)$.

Au Romain II, il forme, à la partie supérieure, un ample repli $(\$ 1$, pl. 3$)$ qui se développe et devient un anneau assez régulier ()$\left.^{2}, \mathrm{pl} .3\right)$. 
Il arrive aussi que cet anneau n'est pas issu du repli de l'anse, mais qu'il constitue l'extrémité supérieure d'un long ruban de verre qui contourne l'anse et descend le long de la panse ( $\left.\delta^{3}, \mathrm{pl} .3\right)$. Ces rubans décoratifs, dont nous ne connaissons pas d'exemple avant l'époque des empereurs syriens, sont garnis, d'un bout à l'autre, de petites saillies plates qui accrochent agréablement la lumière.

$4^{\circ}$ Anses delphiniformes. - Il est convenu d'appeler ainsi des anses d'un type spécial qui, suivant certains archéologues, représentent un dauphin.

L'origine de ce type est très ancienne. Les aryballes et les alabastres de pâte de verre opaque multicolore, recueillis en Orient et en Italie, dans les tombes du vire siècle av. J.-C., sont pourvus d'anses delphiniformes (fig. 65 et 86 ).

L,es verriers du Romain I ont réservé ces anses alix bouteilles de bain forme 33 .

Aux $\mathrm{III}^{\mathrm{e}}, \mathrm{IV}^{\mathrm{e}}$ siècles, les types \% et $\%$, p1. 2, subsistent sans modification, ou se terminent par un appendice décoré de saillies faites à la pince $\left(r_{1}^{1}\right.$, pl. 3 et fig. 90 B.), ou se transforment et deviennent par évolution les types $\zeta^{1}, \varkappa^{2}$ et $\zeta^{3}$ de la planche 3 . Ces nouveaux modèles, affectés aux flacons Io, 34, 35, et à quelques verreries plastiques en forme de tête humaine, sont tantôt lourds, épais (fig. 33), tantôt hauts et plats $(\% 2$ et $\% 3$, pl. 3$)$.

Tous sont conçus avec une savante entente de l'art décoratif.

$5^{\circ}$ Anses faites à l'imitation de types métalliques. - En créant les types $:, \%, \lambda, p$, p1. 2 , les verriers du I $^{\mathrm{er}}$ et du $\mathrm{II}^{\mathrm{e}}$ siècles se sont inspirés des anses des pièces d'orfèvrerie que nous connaissons par les magnifiques vases des trésors de Boscoreale et de Berthouville [voy. formes 93 à 95 du tableau de morphologie générale].

Au Romain II, ces types ne disparaissent pas ( $\left.\mu^{1}, \mathrm{p} 1.3\right)$.

Mais, à côté d'eux, on rencontre, à cette époque, des anses plus compliquées, dont quelques-unes sont d'une rare élégance $\left(\mu_{*}^{2}\right.$ et $\mu^{3}$, p1. 3).

On peut voir, il est vrai, dans ces complications, des signes de décadence, mais les nouveaux modèles sont néanmoins d'heureuses trouvailles dont sauront profiter plus tard les articans de Venise. 
Les verriers $d u \mathrm{III}^{\mathrm{e}}$ et $d u \mathrm{IV}^{\mathrm{e}}$ siècles sont maîtres dans leur art et aiment à le montrer.

I es anses $\mu^{2}$ et $\mu^{3}{ }^{3}$ sont souples et de style délicat. Elles siéent bien aux coupes profondes émanant du ciborium (fig. 303 et 304).

Le type $\sigma, \mathrm{pl} .3$, en forme d'oreille, complète harmonieusemént certains canthares auxquels il donne un facies un peulourd, mais qui a du rythme et de la solidité.

Le type $\pi$, dont on ne connaît que de très rares exemples, imite une anse découpée dans une feuille de métal.

Le type ^ est la reproduction d'une anse de métal battu, courbée en.arc et terminée par une plaque ornée au repoussé et rivée sur la panse. Les bouteilles 58 et 59 sont assez souvent pourvues de cette sorte d'anse.

C'est aussi aux métallurgistes que les verriers empruntèrent un modèle d'anse dont l'attache inférieure est recouverte d'un mascaron. Le musée de Bonn possède une très belle œnochoé, trouvée à Hausweiler, dont l'anse appartient à ce type $(x)$. Des mascarons isolés, représentant généralement une tête de méduse, ont été découverts en Gaule (2).

$6^{\circ}$ Anses à double ondulation ou anses en châne (type č, p1.3). - Création assez tardive qui fut très à la mode, dans la Gaule du nord, aux III'-IV siècles.

Un assez grand nombre de bouteilles à anse en chaîne (3), ou d'anses isolées, sont conservées aux musées de Mayence (fig. I28), de Bonn, de Spire, de Wiesbaden (trois exemplaires), d'Amiens (deux exemplaires), de Boulogne-sur-Mer (fig. I35), de Saint-Germain (4).

D'autres ont été trouvés à Paris (5), à Tourville-la-Rivière (6), à Neuville-le-Pollet (7) (fig. I34), à Strasbourg (8).

(1) Voy. Anton Kisa, Das Glas im Altertume, pl. XI et p. 4 ro.

(2) Musće de Saint-Germain, $n^{0} 23.482$ [Arbouville, commune de Rouvray-Saint-Denis (Eure-et-Loir)] et $11^{\circ} 29.869$.

(3) Ces bonteilles appartiennent surtout aux formes 50, 53, 60 et 6I du tableau de morphologie générale.

(4) Musée de Saint-Germain $n^{\circ}$ I 3.700 (MIont Chyprès, forêt de Compiègne). Fouilles de Roucy.

(5) Musée Carıavalet.

(6) COcuet, La Seine-Inféricure historique et archiologique, p. qo8.

(7) Соснет, La Normandie Souterraine, pl. III, no 18.

(8) Straub, Le Cimeticre gallo-romain de Strasbourg, p. 27. 


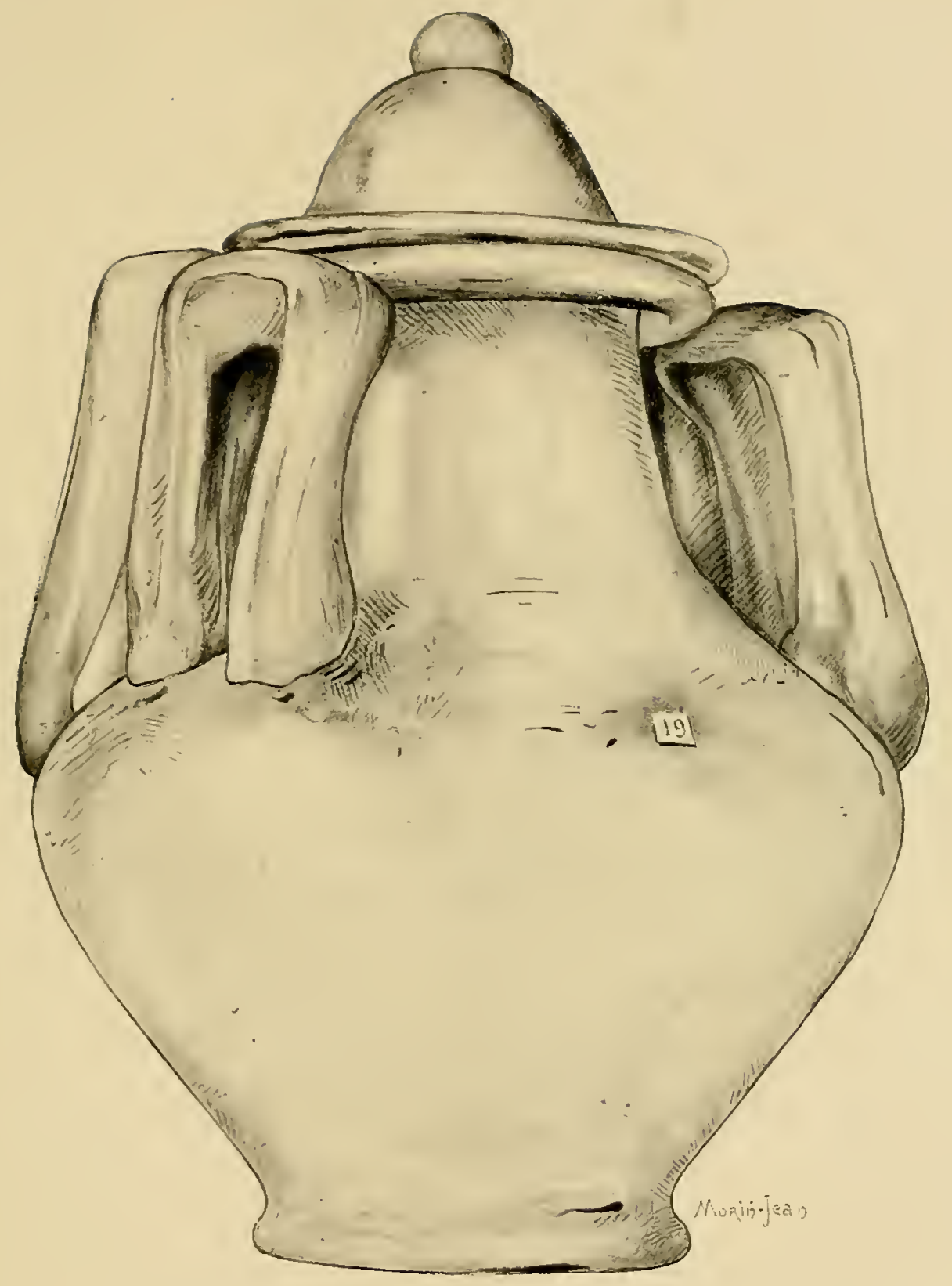

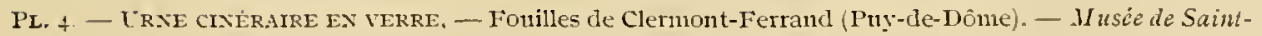
Germain, $1^{\circ} 29.506$. 


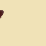


A Beauvais, deux cruches à anse en chaîne ont été déconvertes, l'une dans nne tombe de jenne fille inhumée au Ive siècle, l'autre dans un sarcophage de pierre qui contenait une monnaie de Postumus $(258$ à 267$)$ (I) .

M. Froehner a publié, dans le Catalogue de la Collection Gréau, une belle anse en chaîne dont la provenance n'est pas indiquée (2).

(I) W. Froeliner, La Verrerie antique. Frontispice du volume et p1. XIX, no 88.

(2) W. Frokhner, Collection Gréau, $\mathrm{nl}^{\circ}$ r.537, pl. 290, $\mathrm{n}^{\circ} 4$. 


\section{$\mathrm{V}$ \\ Description générale des types. \\ I. - URNES CINÉRAIRES. \\ (Formes I à 6 du tableau de morphologie générale.)}

Les auteurs anciens désignent par les termes de olla cinerarice, olla ossuaria, les vases d'argile ou de verre dans lesquels les Romains renfermaient les cendres de leurs parents défunts (I). Les coutumes funéraires n'obligeaient pas les survivants à adopter une forme spéciale de récipient rituellement consacrée. On découvre des incinérations dont l'urne est un vase quelconque ayant servi aux usages domestiques. Les urnes cinéraires en verre sont de formes très variées. Sporadiquement, les os calcinés du mort ont été déposés dans des récipients formes $7,8, \mathrm{I}_{3}$, dans des bouteilles à panse prismatique (2), dans des canthares, dans des vases plastiques (urne en forme de poisson, découverte à Coningsheim, signalée par Montfaucon); mais le plus souvent les olle cinerarice de verre appartiennent aux types I à 6 du tableau de morphologie générale. Ces types ont primitivement servi de vases à provisions (on en a la preuve par quelques exemplaires du musée de Naples qui contenaient, lorsqu'ils furent mis au jour, des restes de fruits, de vin

(I) L'Olla, chez les anciens, ćtait un récipient d'usage domestique d'assez grande dimension, destiné a contenir toute sorte de provisions solides et liquides. Le terme d'olla, appliqué à un pot, existe encore dans la langue espagnole moderne (Olla podrida) (voy. Dictionnaire des Antiquités de Saglio, t. IV, première partie, p. I I).

(2) Une grosse urne à panse hexagonale a été publiée par F. Moreau dans l'Album Caranda, pl. 2, nouvelle série. Elle a été đácouverte le i octobre r880, au cimetière đe Brény Aisne). Au milieu des cendres qu'elle contenait, on a recueilli un bronze de Domitien (5I à 96). 
et d'huile). Plus tard, principalement dans l'Ouest européen, ils furent exclusivement réservés aux usages funéraires. Ils constituaient,
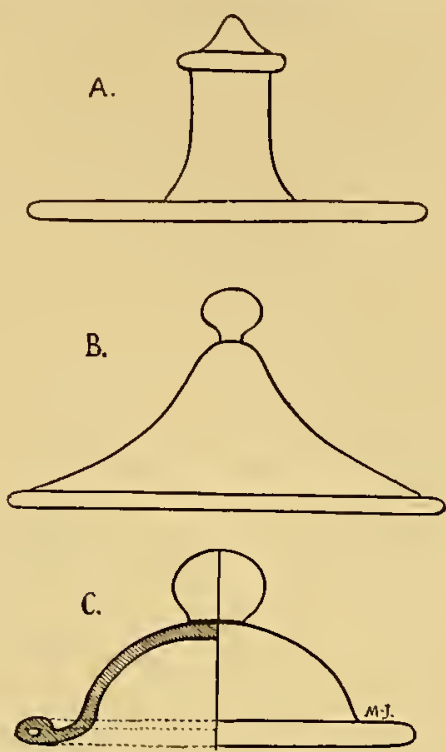

Fig. It. - Couvercles d'urves chérames: A. Ségutet (1838). Musée d'Avignon, no 8, - B. Vaison (I84z). Musée d'Avignon, n 9. - C. Poitiers. Musée de Saint-Germain, no 30304.

surtout au $\mathrm{II}^{\mathrm{e}}$ siècle, les récipients normaux des incinérations de la classe aisée de la société (I). Leur aire géographique est assez étendue; elle comprend la Gaule entière jusqu'aux bords du

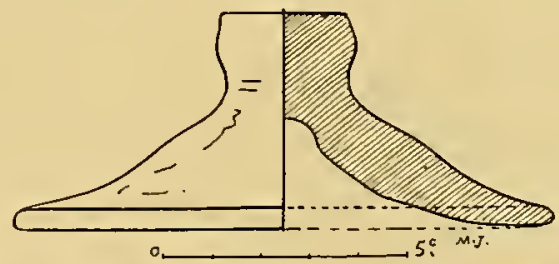

Fig. I 2. - OPERculua de TERRE cuite. - Couvercle d'une urne cinéraire trouvée à Reims, Collection Motin-Jean, à Paris.

Rhin (2), la Grande-Bretagne, l'Espagne, l'Italie et le nord de l'Afrique (3).

(I) Beaucoup d'entre enx sont parvenus jusqu'à nous en excellent état de conservation, parce que les Romains avaient l'habitude de les enfermer, soit dans une cuve de pierre à opercule (fig. 332), soit dans une amphore de terre cuite coupée par le milieu, soit dans une boîte formée par des tuiles.

(2) Beaux spécimens découverts à Cologne (Bonner. Jahrbïcher, I906, p. 392, pl. XXII) et à Strasbourg (STRAub, Le cimetiire gallo-romain de Strasbourg, tombe 87, p. 69, pl. II).

(3) Nombreux spécinens découverts à Carthage. 
Bien que la Grèce, la Syrie et l'Ëgypte n'aient livré aux fouilleurs que très peu de ces récipients, il n'en est pas moins vrai qu'un assez grand nombre de ceux découverts en Occident doivent être considérés plutôt comme des produits d'exportation alexandrine que comme des vases de fabrication indigène.

Les types I, 2 et 3 sont souvent bouchés à l'aide d'un couvercle (operculum) de verre surmonté d'un bouton pour faciliter la prise

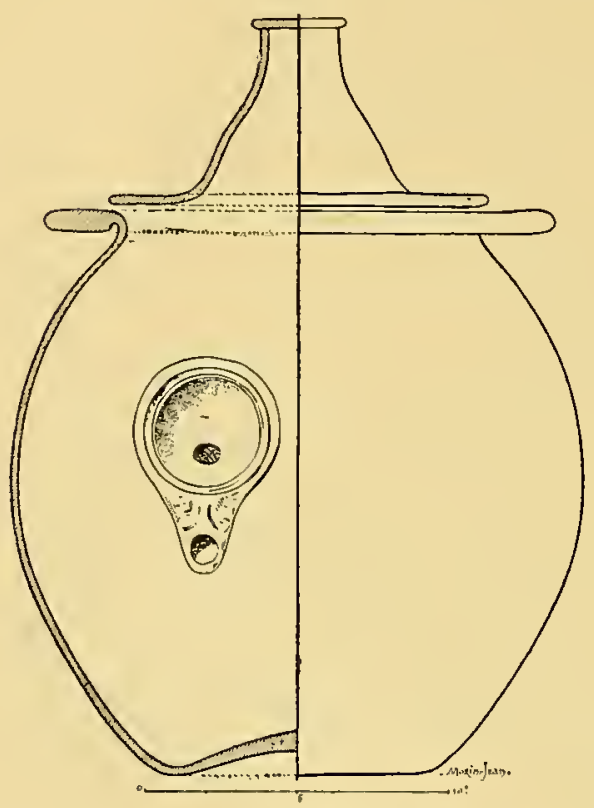

FIG. I3. - URNE DE VERRE SANS ANSE (à l'intérieur : ossements calcinés, lampe d'argile et fond de fiole de verre ayant subi l'action du feu). Environs d'Arles. Musée de Saint-Germain. Salle $\mathrm{XV}, \mathrm{n}^{\circ} 835$.

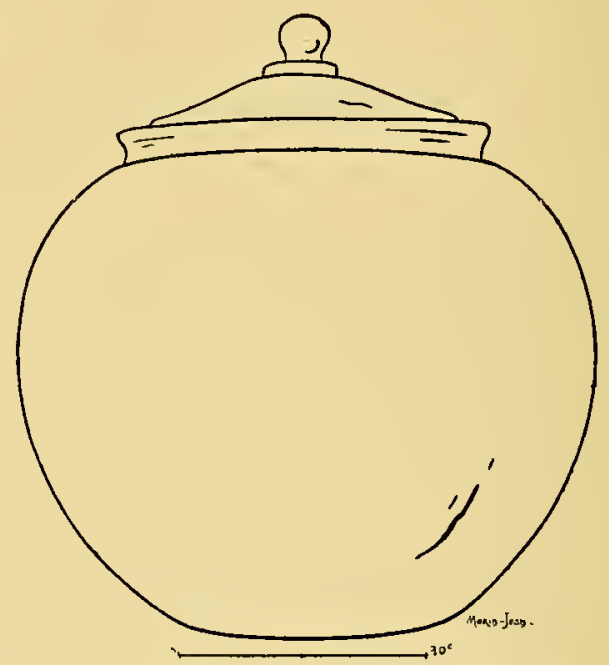

Fig. I4. - Olla civeraria des envitons d'Atles. Musée de Saint-Germain. Salle $\mathrm{XV}, \mathrm{n}^{\circ} 8350$.

(pl. 4 et fig. II). Ces opercula sont des copies, plus ou moins fidèles, des couvercles d'argile des poteries grecques: pyxides, amphores, loutrophores (fig. I6). Les olle de verre ne sont pas toujours pourvues d'un couvercle de même matière.

On en trouve dont l'opercule consiste soit en une tuile posée à plat sur l'embouchure, soit en un bol de terre cuite placé sens dessus dessous, soit en un couvercle destiné primitivenent à un récipient 
qui n'était pas en verre [couvercles de plomb (I), d'argile (2)].

FORne I. - Olla sans anses. - Panse globulaire dont le profil décrit une belle courbe ; embouchure ourlée type I, fig. 6 et 7 .

Pas de pied (base très simple constituée par une dépression ménagée sous la panse). Couvercle à bouton (fig. I3).

L'olla I est une copie, en verre, des urnes d'argile déjà en usage

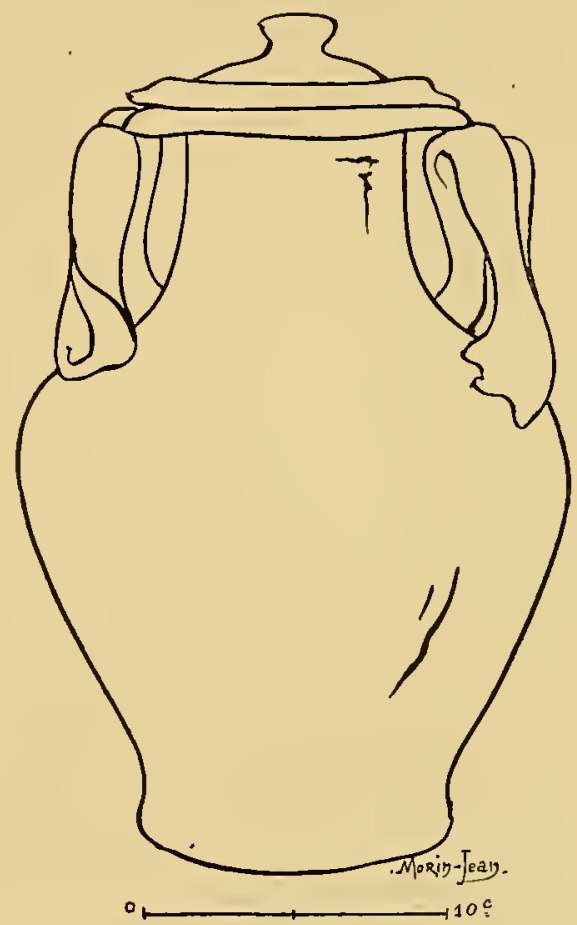

Fíg. 15. - Crve cinérare. - Poitiers (cimetière des Dunes). Musće de l'Hôtel de V'ille, à Poitiers.

à l'époque gauloise (période dite La Tène III). L,e verrier s'est inspiré du céramiste jusque dans la forme du couvercle (fig. I2).

Toutes les ollce se rattachant à la forme I présentent les mêmes caractères généraux, mais n'appartiennent pas à un modèle unique, figé, invariable.

(I) Une urne forme I, recouverte d’un opercule de plomb gravé, a été trouvée à Vitry-le-François [Fontaiue Sermaize] en I85 . (Collection Prerpont-MIorgan, ancienne collectiou J. GrÉt ; voy, FroEIIsER, Collection J. Gréau, nº I53 I, pl. 274). Line autre urne à couvercle de plonb ligure au Musée National bavarois à Munich $\left(\mathbf{n}^{\circ}\right.$ I 189$)$.

(2) T'ne urne forme 3 , recueillie à Vaicon, décrite plus loin (1).50, note i), avait un couvercle d'argile. 
Elles diffèrent en cela des récipients modernes qui sortent de fabriques où la main de l'ouvrier joue chaque jour un rôle moins grand, où la machine et le moule créent mécaniquement des milliers d'objets d'une monotonie désespérante.

Elles varient beaucoup dans les détails; quelques-unes s'éloignént très sensiblement du type primitif (fig. I4). Sous les Antonins, maints exemplaires sont munis d'un pied annulaire.

La pâte vitreuse des urnes forme $x$ n'est pas toujours de la même

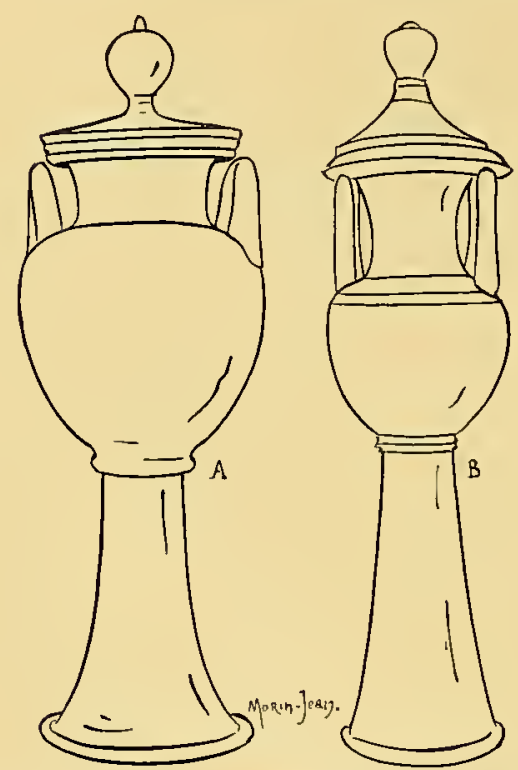

FIG. I6. - Loutrophores DE TERre CUite GRECQUEs. - Types à figures rouges: A. Du ves. av. J.-C. - B. Du Ives. av. J.-C.. - Musée d'Athines.

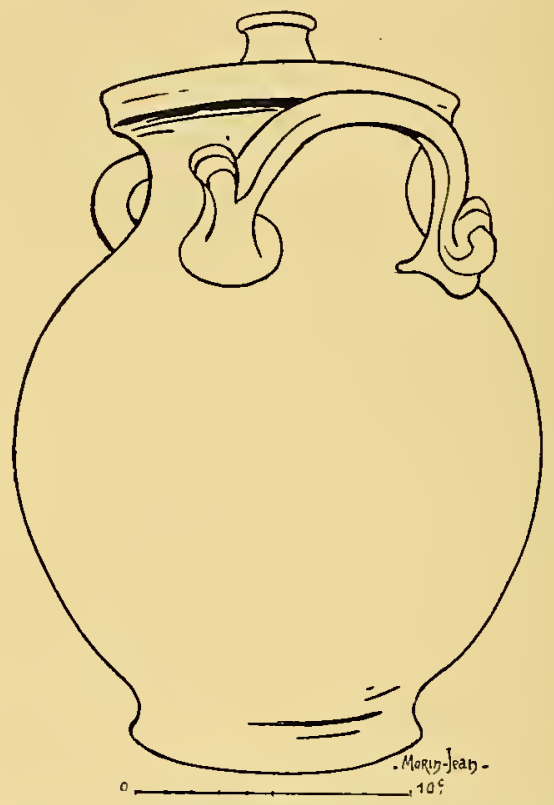

Fig. I7. - URNE cINÉratre. - Musie de SaintGermain. Salle IV, $11^{\circ} 26_{4} 89$.

qualité. Celle des pièces les plus anciennes, des ollce du Romain I, a été soufflée à haute température ; elle est assez épaisse et fortement colorée en bleu-verdâtre comme toutes les verreries alexandrines. Celle des urnes de la fin du II $^{\mathrm{e}}$ et du III $^{\mathrm{e}}$ siècles est ordinairement moins pure ; elle est quelquefois remplie de bulles d'air ; elle est jaunâtre, verdâtre, souvent même incolore.

Les olla forme I deviennent rares à partir de la seconde moitié 
du III $^{\mathrm{e}}$ siècle, mais ne disparaissent qu'à l'époque constantinienne, en même temps que la coutume de l'incinération.

FORve 2. - Olla ì anses établies dans deux plans parallìles. Panse globulaire; col large relié à la panse par des courbes plus ou moins moelleuses. Anses en M (Voy. p. 36, p1. 2,, ) partant de l'épaule du vase et montant verticalement jusqu'au-dessous du

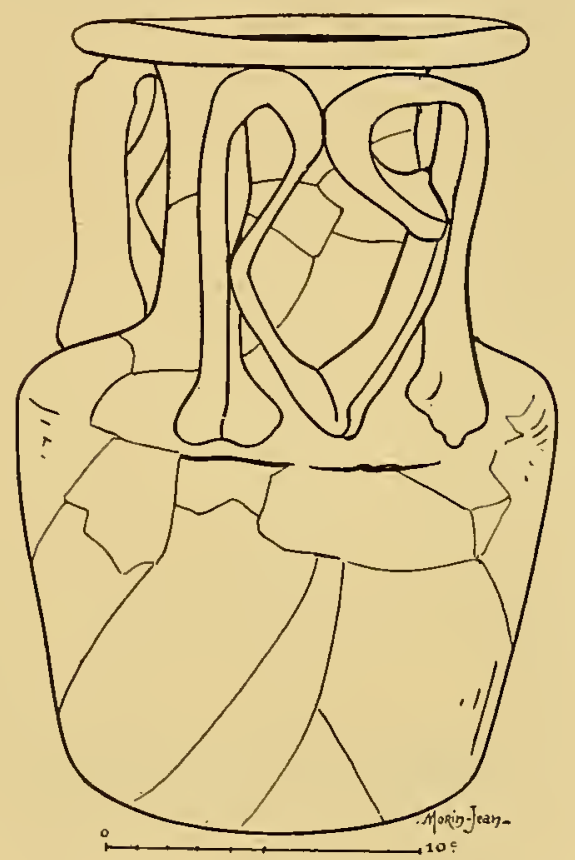

FIG. IS. - Ur.IE cNérarre. - Poitiers (eimetière des Dunes). - Musée de Saint-Germain. Salle XY, $n^{0} 30306$.

rebord de l'embouchure. Pied fondu dans la panse. Couvercle à bouton (fig. I5 et pl. 4).

Ce type d'urne emprunte sa forme à la loutrophore d'argile des Grecs (fig. I6).

La loutrophore grecque est un vase analogue à l'amphore, mais

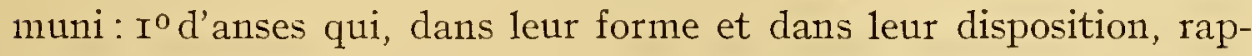
pellent celles des cratères: $2^{\circ}$ d'un pied aussi haut que le vase lui-même. L'olla forme 2 est la copie d'une loutrophore dont on a supprimé le grand pied. On peut la considérer comme le terminus d'un type 
de vase qui était déjà en voie de formation dans la céramique du vIII ${ }^{\mathrm{e}}$ siècle avant notre ère ( $\mathrm{I}$ ), qui a atteint sa plus grande perfection aux $V^{e}$, Ive siècles avant Jésus-Christ (fig. I6) et qui, à l'époque romaine, s'est transmis du répertoire des potiers à celui des souffleurs de verre.

Parmi les divers modèles d'urnes de verre se rattachant au type $n^{0} 2$, nous signalerons comme particulièrement remarquables: les

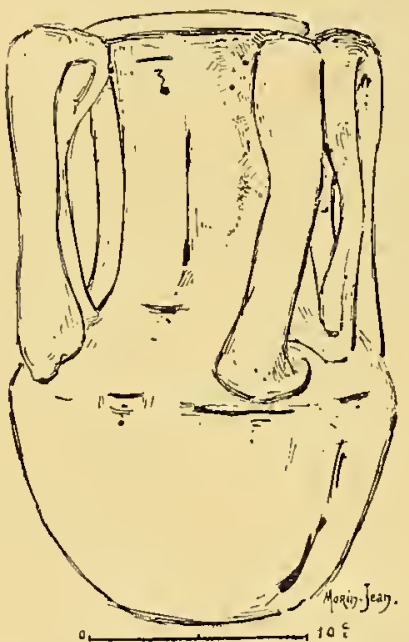

FIG. I9. - URNE CINÉRAIRE, découverte à Ruffieux, en I868. - Musée de Lyon.

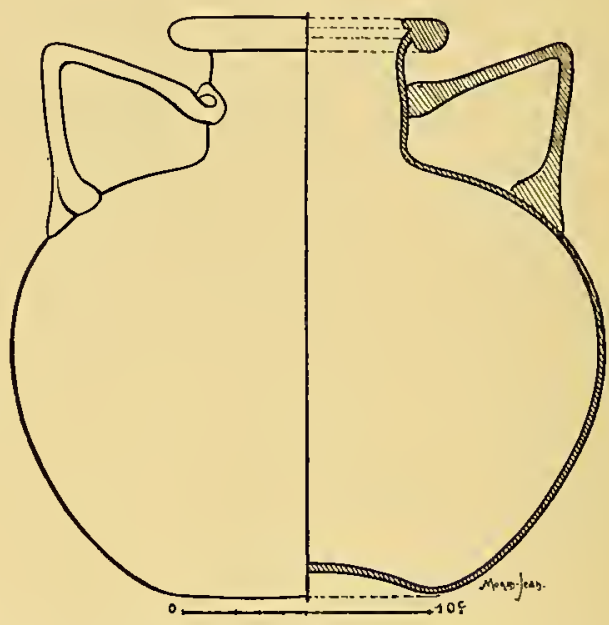

FIG. 20. - URNE cINÉraIre trouvée en Gaule. - Musée du Louvre. Ei. D., I527.

olla à anses (p.36, p1. 2, type $\gamma$ ) (fig. I7) et les urnes dont les anses en $M$ se développent au détriment de la panse (fig. I8 et I9) (2).

L'olla 2 et ses variantes sont très répandues en Occident dès le milieu du I $^{\text {er }}$ siècle de notre ère, comme le prouvent les nombreux exemplaires de Pompéi. Dans les premières années du $\amalg^{\mathrm{e}}$ siècle, leur col se détache moins nettement de la panse et se rétrécit vers la. partie supérieure.

(I) Vases de style géométrique dipylien. Voy. Collignon et Couve, Catalogue des Vases peints du musée national d'Athènes, p1. XVI, $1^{\circ} 34^{8}$.

(2) Il est intéressant de remarquer que les auses des loutrophores grecques se sont développées de la même façou • assez basses dans les spécimens du $\mathrm{V}^{\mathrm{e}}$ siècle (A, fig. I6), elles s'allongent dans les exemplaires du IV (B, fig.I6). 
Forme 3. - Olla à anses établies dans un même plan. - Panse

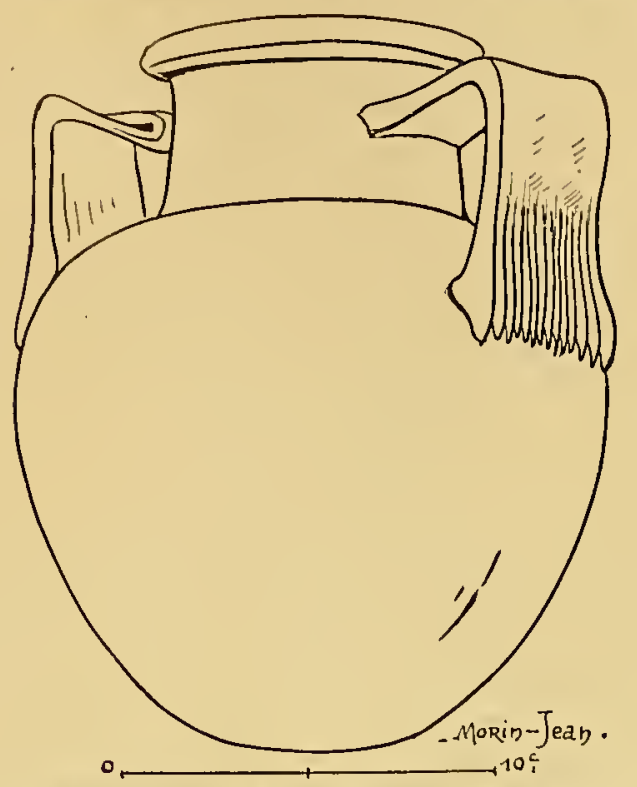

FIG. 2 I. - URNe civéraIre. - Musée de Saint-Germain. Salle XV, no 3 I 778.

globulaire dont le dessous est aplati pour assurer la stabilité du réci-

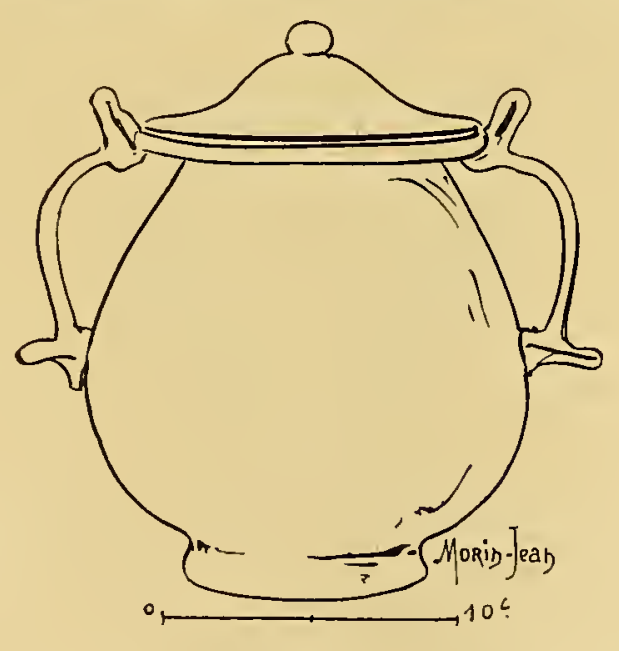

FIG. 22. - URTE CINERATRE. - Musée d'A vignon.

pient. Col court. Anses p. 36, p1. 2, type $\gamma$, d'un style vigoureux, posées l'une en face de l'autre, dans un même plan (fig. 20, 2 I et pl. 5). 
C'est la façon dont les anses sont placées dans les amphores grecques de terre cuite.

Les olla forme 3 sont contemporaines des urnes formes I et 2.

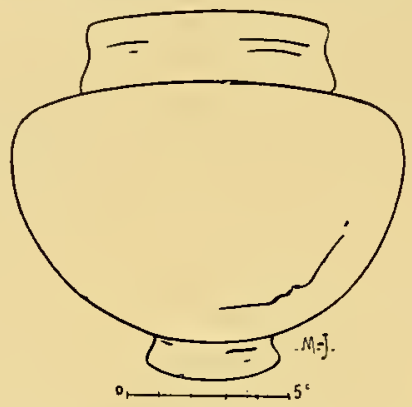

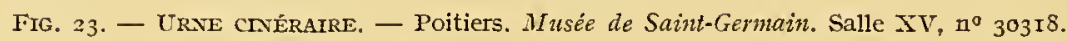

Ce que nous avons dit sur la qualité de la pâte vitreuse des urnes forme I s'applique aux formes 2 et 3 .

Une olla forme 3 , recueillie à Vaison (Vaucluse), dans la vigne de M. Guyon, doit être mentionnée à part, en raison des objets qu'elle contenait. C'est une urne de I6 à I 8 centimètres de hauteur, munie d'un grossier couvercle d'argile. A l'intérieur du vase étaient des ossements calcinés, une ampoule de verre sans intérêt et une figurine

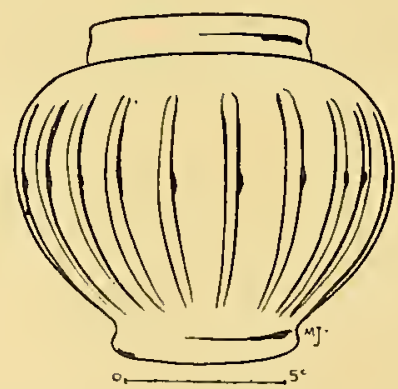

Fig. 24. - URNe cinéraire A Cotes en ReIIEF. - II ilsée de Coblence.

funéraire égyptienne, un oushabti de terre émaillée mesurant II centimètres et demi de longueur (I).

Forme 4. - Panse ovö̈de. Pied fondu dans la panse. Anses type ${ }^{\prime}$ 
(p1. 2, p.36). - Couvercle à bouton. I'application, à une olla cineraria, d'anses dont la forme est empruntée à la technique du métal, est un fait assez rare qui mérite d'être signalé. Iiolla, que nous reproduisons

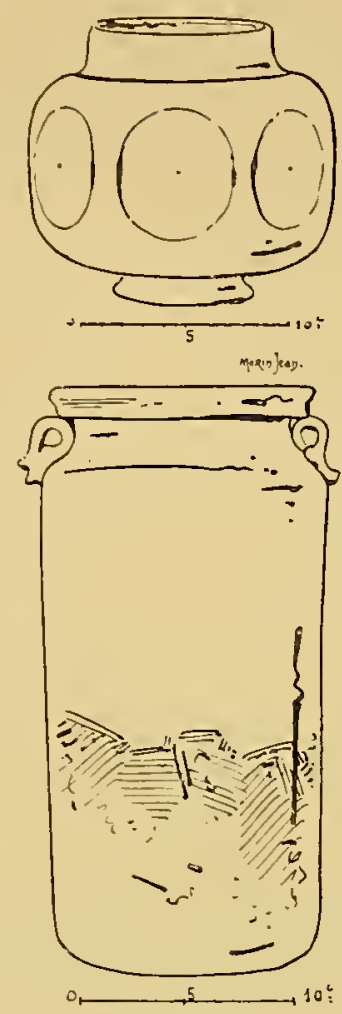

Fig. 25. - Trexes cixérures. - Musée provincial de Trèves. Salle XX.

fig. 22, semble avoir eu pour modèle les urnes d'albâtre de la haute époque impériale.

FORIE, 5. - Panse arrondie. Embouchure d̀ ourlet (type r, fig. 5).Les urnes de cette forme sont très répandues (fig. 23). Elles comprennent plusieurs types. Le type orné de côtes en relief se rencontre un peu dans toutes les régions de la Gaule (I) (fig. 5 [ $n^{\circ}$ 5] et 24). Le type dont la panse est ornée de dépressions est plus rare (2) (fig. 25).

(r) Une urne forme 5, portant le même décor que la bouteille reproduite plus loin fig. I28, est conserrée au musée de Vannes. Elle contient une monnaie de Postumus ( 258 à 267). La forme 5 a douc persisté jusqu'aux derniers temps de l'incinération.

(2) Une petite urne à 5 dépressions est conservée au Musće Provincial de Bonn (A. 693). 
La plupart des urnes forme 5 sont en verre bleu-verdâtre. On en connaît quelques spécimens en verre coloré (I).

Forme 6. - Ume carénée. - Cette forme existe en verre et en terre (2). Elle appartient au Romain I. L'exemplaire de verre reproduit fig. 26 est en pâte bleuâtre. Un spécimen du même type est

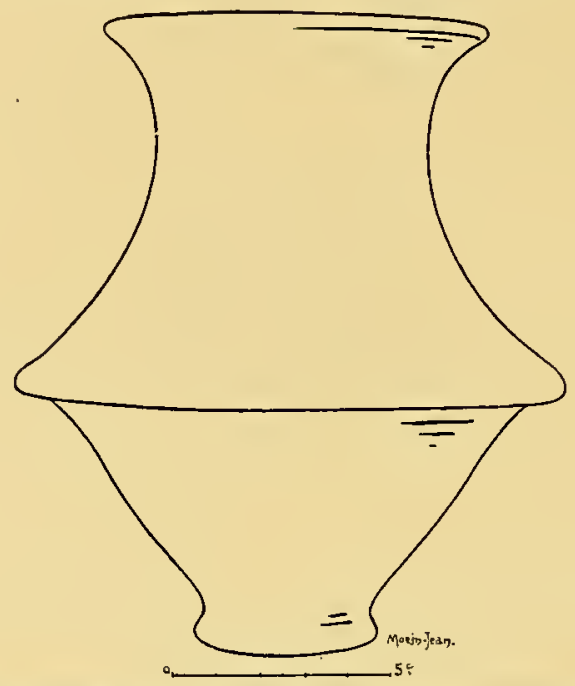

Fig. 26. - URNE cINÉRAIRE CARÉnÉE. - Cimetiète de Suèvres (Loit-et-Cher). Musée de Saint-Germain. Salle XV, no r95 I9.

exposé au Provinzialmuseum de Trèves (3). D'autres sont au musée de la Société des Antiquaires de 1'Ouest, à Poitiers.

2. - BOUTEILI, $I_{\text {ES }}(4)$ A PANSE, CYI,INDRIQUE A FOND PIAT. (Formes 7 à I2.)

Les bouteilles moulées à panse cylindrique et à fond plat sont d'origine égyptienne.

(r) Une Olla, forme 5 en verre jaune, trouvée à Trèves, a été reproduite par W. FroemnER, dans : Collection Julien Gréau. Verrerie antique appartenant à $M$. John Pierpont-Morgan, no 526 et pl. CCIXXI. Une urne à panse côtelée du musée de Trèves ( $\left.n^{\circ} 9957 a\right)$ est aussi en verre jaune.

(2) De belles urnes forme 6, en terre cuite à lustre noir, sont conservées au British Museum (Voy. Walters, Catalogue of the Roman Pottery in the British Museum, p. 42I, M. 2699, fig. 275) et dans les musées de la vallée du Rhin. Un spécimen a été recueilli à Cologne (cimetière romain de la rue de Luxembourg) avec des monnaies d'Auguste (Bomer Jahrbücher, I9o6, p. $3^{8} 5$, pl. XXI, tombe 9).

(3) Salle $\mathrm{XX}, \mathrm{n}^{0} 3.085$

(4) Nous désiguons par le terme général de bouteille tous les récipients de forme variable, ansés ou non, mais toujours pourvus d'un goulot plus ou moins étroil. 
Les moules dans lesquels elles ont été soufflées s'anincissent vers le bas pour que les flacons, une fois refroidis, puissent être facilement dégagés.

Des bouteilles à panse cylindrique ont servi d'urnes cinéraires. D'autres étaient destinées à divers usages domestiques. On en rencontre dans tous les milieux romains, depuis le début de l'Empire jusqu'au ve siècle.

FORME 7. - Bocal à large ouverture, muni de deux petites anses

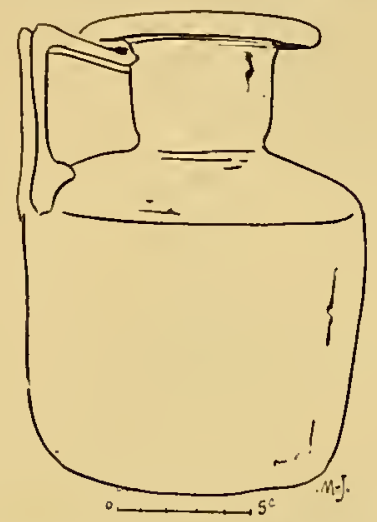

FIG. 27. - TRIE A P.ATSE CYZINDRIQUE. - Poitiers. Musie de Saint-Germain. Salle XY', $11^{\circ} 30325$.

type" (p1. 2, p. 36). - Cette forme n'est pas courante. Le spécimen que nous reproduisons est en verre bleu-verdâtre de bonne qualité. II a été trouvé à Trèves, rempli d'ossements calcinés. Il ne semble pas être postérieur au milieu du $\mathrm{II}^{\mathrm{e}}$ siècle (fig. 25 en bas).

FORME S. - Panse à épaulement plat. Goulot nettement détaché de la panse. Embouchure ourlée. Anse robuste type \& (p1. 2, p.36). - Les bouteilles forme $\delta$ ont été originairement importées d'Alexandrie et de 1'Italie du sud où elles étaient très abondantes dès le début de l'Empire. Elles sont en verre épais, bleu-verdâtre. Elles sont lourdes, trapues. Quelques-unes d'entre elles ont été utilisées comme urnes cinéraires (fig. 27). On n'en rencontre plus guère après le II siècle (I).

ForaIE 9. - Panse élancée. Epaulement plat. Goulot étroit. Embou-

(I) De très gros exemplaires de la forme 8 sont conservés au musée de Saint-Germain, au musée de la Société des Antiquaires de l'Ouest, à Poitiers (cimetière des Dunes), au musée de Boulogne-sur-Mer (n ${ }^{09} 4522$ et 25.124), au musée de Bourges (cimeticre dit du Fin Renard). 
chure ì double bourrelet. Anses type ${ }^{1}$ (p1.3, p. 37).- L L forme 9 dérive de la forme 8 . Elle se compose des mêmes éléments, mais elle a un tout autre caractère (fig. 28). Elle a gagné en élégance, en légèreté. En comparant l'une à l'autre, on voit que les verriers romains se sont livrés, comme les céramistes et les orfèvres, à des recherches aśsez

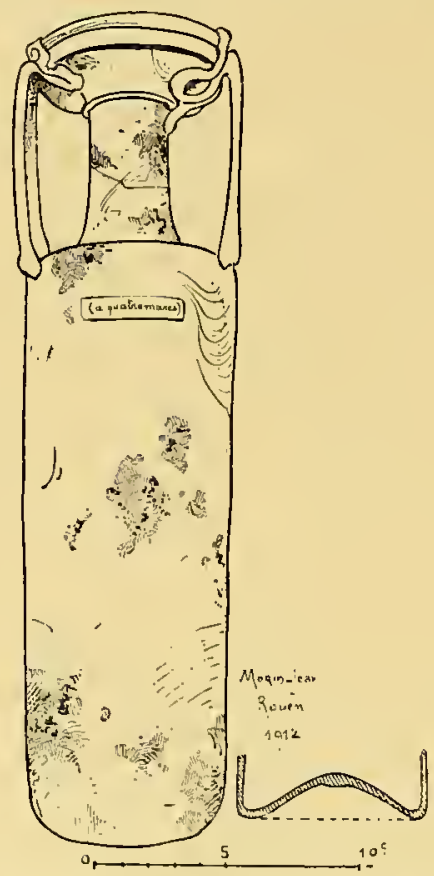

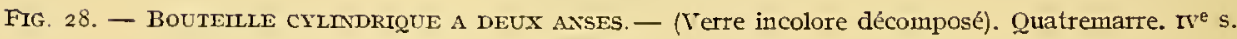
Musée de Rouen.

délicates dans les rapports de mesures entre les différentes parties des récipients. Les bouteilles forme 9 ne sont pas rares dans les cimetières à inhumations du Romain II. Des spécimens de très grande taille ont été trouvés à Monceau-le-Neuf (I), à Abbeville (Homblières) (2), à Vermand (3), à Spontin (Belgique) (4), à Cologne (5).

(I) Le spécimen de Monceau-le-Neuf (Aisne) publié par MI. CL. Boulanger (Le Mobilier funéraire, pl. II, $\mathrm{Il}^{\circ} 2$ et pl. 20), mesure $3^{8}$ centimètres de hauteur. Il était à gauche de la tête du chef gallo-romain inhumé vers l'époque de Constantin II (337 à 340).

(2) J. PILloy, Études sur d'anciens lieux de sépultures dans l'Aisne, t. II, p. I37.

(3) Tr. Еск, Les deux cimetières gallo-romains de Vermand et de Saint-Quentin, pl. VI, nº 9.

(4) A. Irmetette, Le cimetière de Spon'in, daus les Annales de la Société de Namur, t. VIII, troisième livraison, pl. III, fig. 5 .

(5) Bonner Jahrbiucher, Igo6, fasc. II $4^{-I I 5}, 13.430$, pl. SXVI. Tombe à inhumation no 67 (IV siècle). 
De beaux exemplaires à ornements gravés ont été recueillis à Boulogne-sur-Mer (I), au cimetière de Vermand (2), dans la vallée du Rhin (3).

On peut considérer comme une variante de la forme 9 le type fig. 29 sans anses, à goulot étroit et bas surmonté d'une volumineuse embouchure à double bourrelet. Les flacons appartenant à ce modèle sont en verre incolore, souvent rempli de filandres et de bulles d'air. Ils ont, en moyenne, 8 à I2 centimètres de

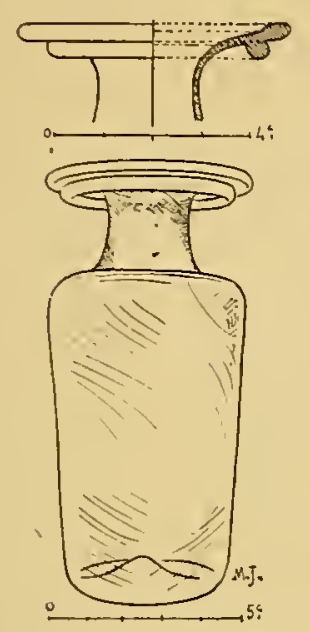

Fig. 20. - Flacon CYLINDRIQUE S.1.s MSE (Boulogne-sur-Mer, cimetière du Vieil-Atre). - Collection Worin-Jean, $\mathrm{n}^{\circ} 223 \mathrm{I}$ (ancicune Collection Bernay).

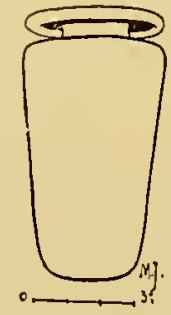

FIG. 30. - FLACON EN VERRE IMTPUR.- Ciuetière de Vermand. Collection $T h$. Eck, à Saint-Quentin.

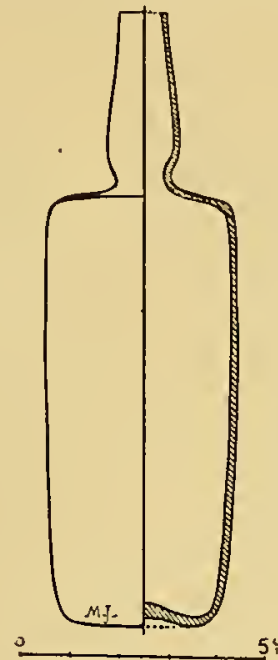

Fig. 3x. - Flacon DE TOLETTE EN VERRE FLANDREUX. - Cimetic̀rc de Vermand. - Collection $T$. $E c k$, à Saint-Quentin.

hauteur. On pense qu'ils servaient dans la toilette des femmes. Ils sont répandus dans toute la Gallia Belgica aux $\Pi \mathrm{I}^{\mathrm{e}}$-IVe siècles et ils se rencontrent jusqu'en Angleterre (4). Ils sont particulièrement

(I) Musée archéologique de Boulogne-sur-Mier, $11^{0} 2.5$ I 3 : 11auteur 33 centimètres, verre incolore, fin $\mathrm{II}^{\mathrm{c}}$ ou rvie siècle (Fouilles à l'Aqueduc de Bréquerecque).

(2) TH. Eck, loc. cit., pl. VIII, no 9 .

(3) AUS'x' WEerth, dans les Bonner Jahrbïcher, ISSI, fasc. 7r, pl. VI, no r.366. Signalons aussi le reıuarquable exemplaire de 40 centimètres de hauteur, orné de scènes gravées, conservé au musée de MIayence, et un spẻcimen à deux anses du musée de Trèves, couvert de gravures, figuraut des combinaisons gcométriques (vitrine VII, salle $20, \mathrm{G} .673$, Catalog. p. III) (hauteur 30 centimètres).

(4) Exemplairc du British Juseum (In a Barrow on Chartham Downs near Canlerbury Ficnl). 
nombreux à Reims (I), assez fréquents à Vermand (2) et à Boulogne. On en a découvert à Amiens (3), à Cologne (4), à Mayence (5), etc.

FORME Io. - Flacon cylindrique. Goulot se rétrécissant vers le haut etétranglé dans le bas. Embouchure non ourlée. - Les flacons forme Io sont tantôt sans anses, tantôt pourvus de deux petites ańses appartenant aux types $?^{\prime}, \% 2, \mathrm{pl} .3, \mathrm{p}$. 37. Ils ont Io à 20 centimètres de hauteur. Tous sont en verre incolore. Beaucoup ont été constitués à l'aide d'une pâte vitreuse chargée d'impuretés et de filandres
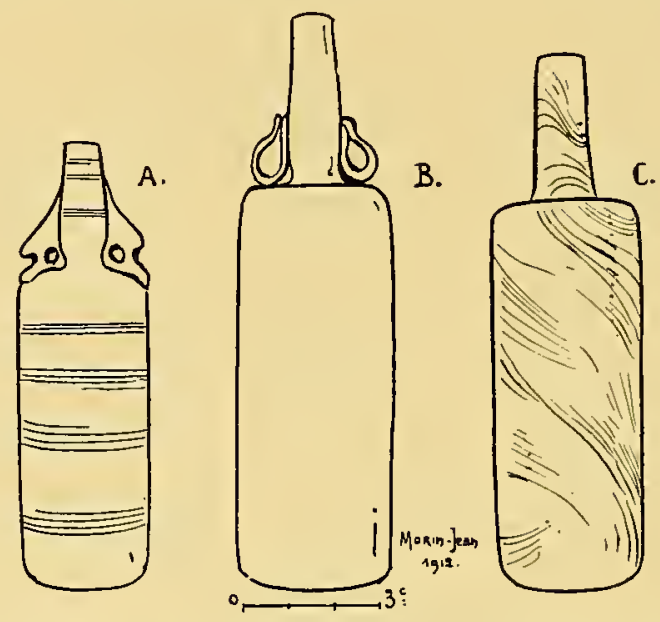

FIG. 32. - Bouteinles a PANSE Cylndprique. Romain II. - A. Cimetière d'Andernach. Tombe $n^{0} 37$. Musée provincial de Bonn. Salle VI. - B. et C. Cimetière de la rue de Iruxembourg, à Cologne. Musće de Cologne.

(fig. 32, C). Quelques-uns sont ornés de groupes de cercles gravés à la meule sur la panse et sur le goulot (fig. 32, A).

L,es collections de la Gaule du nord et de la Germanie occidentale renferment un très grand nombre de ces verreries. Des exem-

(I) Catalogue du Musée archéologique de Reims, nº 2.4 I 8 (recueilli dans un cercueil de plomb), 2.420, $2.42 \mathrm{I}, 4.643$ à $4.645,4.759$ à $4.764,4.930$ à 4.934 .

(2) Th. Eck, loc. cit., pl. VI, $\mathrm{n}^{0} 3$ et 4 ; et $\mathrm{CL}$. Boulanger, Le Mobilier funéraire, pl. I6, no 2 . Le spécimen de Vermand, que nous reproduisons (fig. 3o) est une variante à col court et à panse beaucoup plus étroite dans le bas que dans le haut.

(3) Spécimen en verre incolore légèrement décomposé. Goulot orné d'un fil de verre incolore faisant plusieurs tours : hauteur 9 centimétres. Amiens, Mrusée de Picardie, $n^{0} 9$ ro.

(4) AUs'Mr' WEERTH, dans les Bonner Jahrbilicher, I88I, fasc. 7I, pl. V, n ${ }^{0}$ I.697.

(5) Les exemplaires du musée de Mrayence appartiennent à des mobiliers funéraires d'époque tardive on ils sont souvent associés aux formes 4I, 50 [avec anse du 53], Iog ( $\mathrm{N}^{\mathrm{e}}$ siècle) (fig. 33\&). 
plaires bien conservés ont été recueillis à Vermand (I), à Reims (2), à Amiens, à Rouen (fig. 33), à Andernach (3), à Cologne (4), à Bonn, à Trèves, etc...

Les indications chronologiques que procurent les trouvailles confirment ici les observations morphologiques. Les flacons forme Io

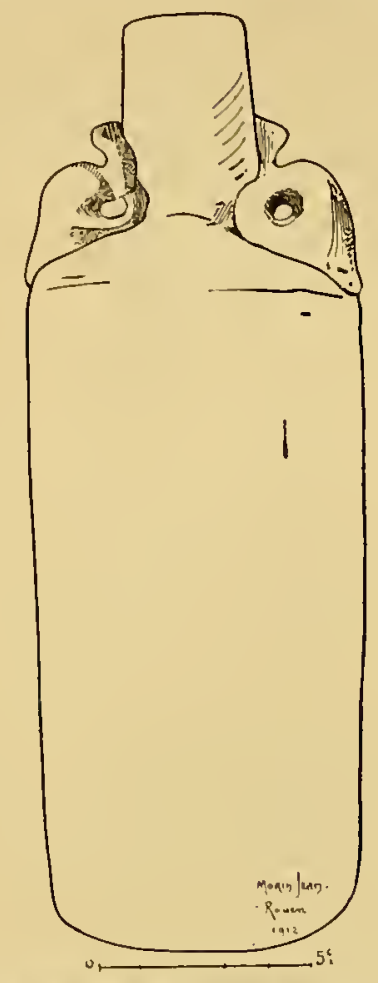

Fig. 33. - BOUTELLE EN VERRE verDatre. - IV s. Musée de Rouch.

n'apparaissent pas, en Gaule, avant le Romain II. Ils se classent

(I) Tr. Eck, loc. cit., pl. VII, n ${ }^{0}+$ [Spécimen à anses delphiniformes du rve siècle]. ar. Éck a découvert à Termand m flacon forme Io (sans anses) dans lequel se trouvaient des épingles de métal et d'os (Collect. particulière de II. Th. Eck).

(2) Catalogne du musée archéologique de Reims : 24I8 [Six flacons forme Io, trouvés à Reims, lieu dit La Maladrerie, en août I 896 , dans un cercueil de plomb ( $\mathrm{v}^{\mathrm{e}}$ siècle)]; 4.922 [Spécimen orné de cercles gravés sur la panse : hauteur 9 centimètres $\mathrm{r} / 2]$.

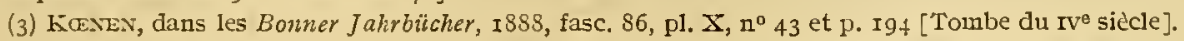

(4) A Cologne, la forme ro s'est rencontrée à la fois dans les incinérations tardives du IIr siècle (Bonner Jalirb, Ig06, fasc. II4-II5, pl. XXIV et p. 4I6, tombe 47) et daus les inhumations du IV siecle [Bomner. Jahr., même fascicule, pl. $\mathbf{X I V}$, et p. 425 : tombe 60 , qui contenait le gobelet orné de poissons décrit plus loin, p. I65, et une monuaie de Co:stance Chlore (305-306)].

Un flacon forme ro, à anses delphiniformes, trouvé à Cologne, a été publić par TV. FraeHver, Colleclion Gría $\pi^{0}$ r.2 r3 et pl. CCXXVII, $u^{0}$ I). 
même, pour la plupart, après le milieu du III siècle. A Gelsdorf, on en a trouvé en compagnie de monnaies de Dioclétien ( 284 à 305). Certains spécimens en verre filandreux sont d'une époque très basse.

FORME II. - Flacon cylindrique à embouchure de cothon grrec (type B, fig. 8). - Les récipients de cette forme ont Io à I5 centimètres de hauteur (fig. 34). On pense assez généralement que ce sont des vases de toilette. Un exemplaire découvert à Reims, lieu dit le Chemin Vert, en r894, a été employé comme porte-épingles pour

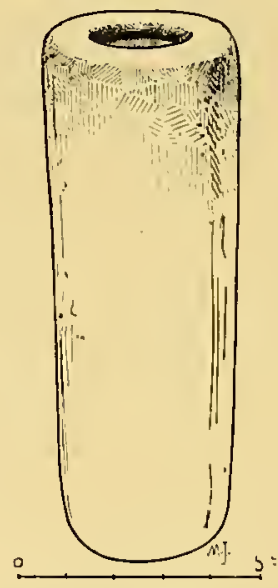

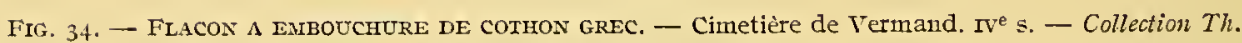
$E c k$, à Saint-Quentin.

la chevelure et renferme encore trois épingles: une en bronze, une en argent, une en os (I). Les flacons forme II ont la même qualité de pâte vitreuse, la même distribution géographique que les bouteilles forme ro; ils sont aussi de la même époque (III- $\mathrm{IV}^{\mathrm{e}}$ siècles). Au cimetière de Vermand, on a rencontré cinq ou six de ces fioles (2). On en a recueilli une près de Trèves (Musée de Trèves, $n^{0}$ 20.649). Un spécimen orné de cercles gravés à la meule a été trouvé à Mayence (3).

FORME I2. - Bouteille cylindrique à épaulement arrondi, à goulot

(I) Catalogue du musée archéologique de Reims, p. 7I, น. 2.257 à 2.260 . Un flacon forme II du musée de Reins a été trouvé avec son bouchon. Il contenait um liquide qui s'est solidifié.

(2) TH. E,ck, loc. cit., p. I62-I63 et pl. $\mathrm{YI}, \mathrm{n}^{\circ} 5$.

(3) Pâte vitreuse légèrement bleutée. Tombe à inhumatiou du rve siècle. Maỹence, musée Romanogermanique. 
fondu dans la panse. - Nous sommes ici en présence d'un type tardif qui est tantôt ansé (type $\delta^{1}$, pl. 3), tantôt sans anses (fig. 35). I1 est facile de se rendre compte que les flacons forme I2 appartiennent à une fabrication de très basse époque ( $I V^{e}$ et $V^{e}$ siècles), qu'ils

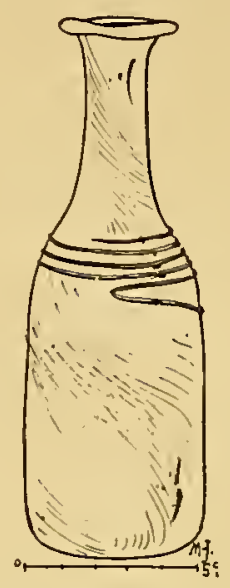

Fig. 35. - BouteIlle Saxs ANSE. IV s. - ILuse de Niort.

sont sortis d'officines en décadence. Leur pâte vitreuse est filandreuse et leur galbe est peu esthétique.

I1 est intéressant de noter que la forme I2 est le prototype de la bouteille à vin des temps modernes.

\section{3. - BOUTEILLES A PANSE PRISMATIQUE.}

(Formes I3 à I9.)

Les bouteilles à panse prismatique sont originaires d'Ëgypte. Elles étaient souffées et comprimées dans des moules probablement en bois ( $\mathrm{I}$ ).

Les bouteilles prismatiques sont le plus ordinairement à section

(I) A la Rochere (Haute-Saône), dans une verrerie on l'outillage employé était le même que trois ou quatre siecles auparavant, on soufllait encore, vers IS92, des pièces dans des moules en bois. Ces moules, qui coûtaient fort peu de fabrication, étaient en bois tendre (bouleau, aulne ou saule). On prenait soin de les mouiller avant chaque soufilage.

(Note communiouée par M. H. Michel, de Besançou.) 
quadrangulaire (n ${ }^{\text {os }} I_{3}, I_{4}, I_{5}$, I6, I9) ou à section hexagonale (n ${ }^{\text {os }} I_{7}$

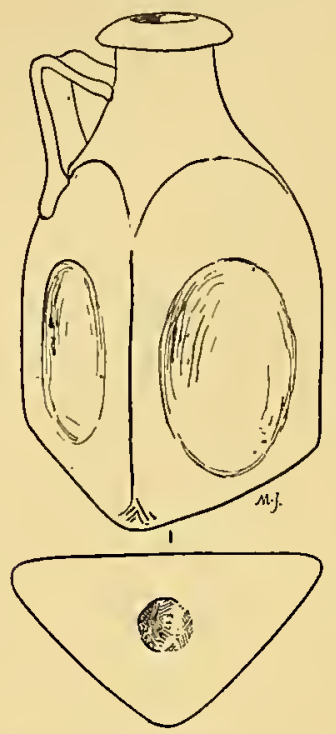

Fig. 36. - BOUTEILle PRISMATiQUe a SEction TRIANGUlaIre. - Musée national de Naples, no 13075 .

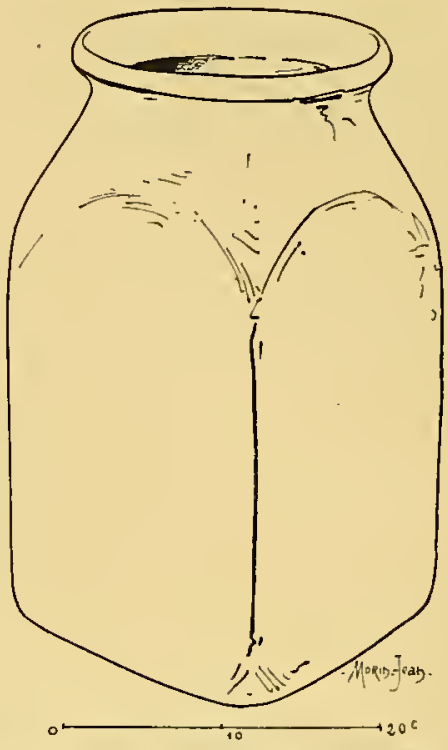

FIG. 37. - URNE CINÉRAIRE A PANSE PRISMATIQUE. Musée de Cannes (Alpes-Maritimes).

et I8). Le spécimen à section triangulaire de Pompéi (Naples, Musée National, $\mathrm{n}^{0}$ I3.075) est une rareté (fig. 36).

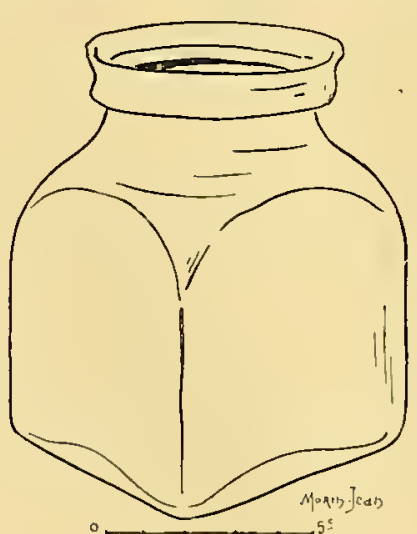

Fig. 38. - BOCAL PRISMatique a LARGE OUVERTURE, - Reims (lieu dit La Maladrerie). - Musée de Reims, $\mathrm{n}^{\circ} 4929$.

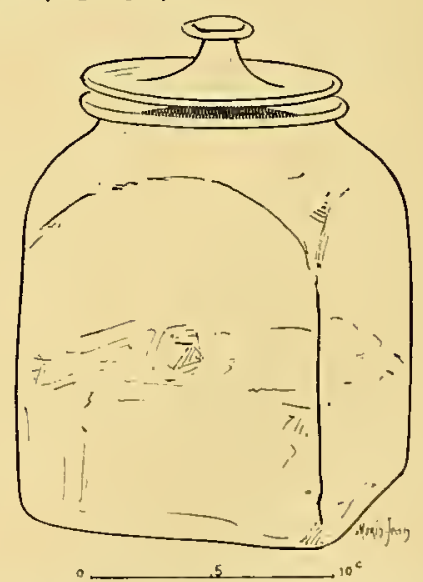

FiG. 39. - URNE A DENU-REMIPLIE D'OSSEMENTS CALcñ́s. - Cimetière de Vaison. Fouilles de I 83 S. - Musie d'Avignon, $\mathrm{n}^{\circ} 4 \mathrm{I}$.

FORME I3. - Panse prismatique à section carrée. Embouchure 
large, ì ourlet. - Ce type de bouteille comporte plusieurs variétés qui appartiennent pour la plupart à la liaute époque impériale (fig. 37à 40).

On l'a rencontré en maints endroits, notamment à Poitiers (cimetière des Dunes) (I), à Niort, à Lyon, à Bourges (cimetière du Fin Renard), en Champagne et dans la Gaule méridionale.

FORne If. - Panse prismatique à section carrée. Goulot étroit.

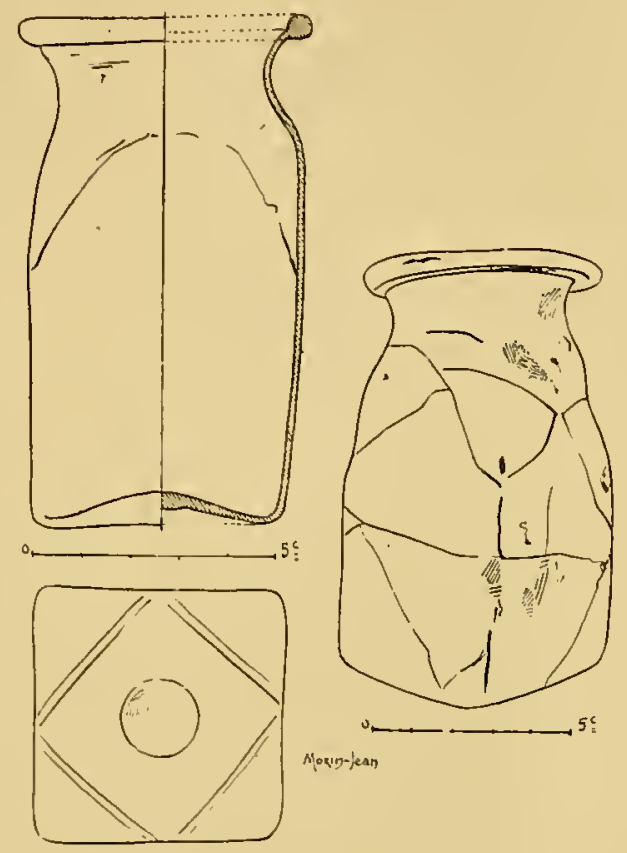

Fig. 40. - Bocal prisinatrque. - Cimetière de Vierville (Eure-et-Loir). Fouilles de 1895. - Collection Morin-Jean, $\mathrm{n}^{\circ} 22 \mathrm{r} 3$ (ancienne Collection Bernay).

Anse type? (p1. 2, p. 36). - On trouve des flacons forme I4 de toutes les grandeurs : il $\mathrm{y}$ en a depuis 5 centimètres jusqu'à près de 40 centimètres de hauteur (2). Ces boites carrées portent souvent sur le fond des marques de fabrique moulées en relief (fig. 45). Elles ont été rencontrées dans toute l'étendue de l'Empire romain, particulièrement dans les îles grecques et en Campanie (très nombreux

(1) Poitiers. Mrusée de la Société des Antiquaires de l'Ouest (Dunes U, XXII, n 67).

(2) Un des plus grauds spécimens connus est au musée de Bourges. Cette piece remarquable mesure 35 centimètres de hauteur : elle a servi d'urne ossuaire. Elle a été trouvée à la Maladrerie (commune đe cliâteaumeillant-sur-Cher) dans une cuve de pierre à operculum. 
exemplaires pompéiens an musée de Naples), dans la Gaule cisalpine et en Ligurie. En Gaule, elles sont répandues un peu dans toutes les régions. Elles peuvent se diviser en deux types:

A) Le premier a une panse se rapprochant plus ou moins de la forme cubique. I1 se rencontre au $\mathrm{I}^{\mathrm{er}}$ siècle $(\mathrm{I})$. Il est très abondant au $\mathrm{II}^{\mathrm{e}}$, plus rare au III ${ }^{\mathrm{e}}$ siècle (2). Au IV siècle, il disparaît des sépultures.

Les spécimens du début de l'Eimpire se distinguent assez facilement des exemplaires tardifs. Jusque vers le milieu du $\mathrm{II}^{\mathrm{e}}$ siècle, la bouteille carrée est en verre bleu-verdâtre de bonne qualité. Elle a

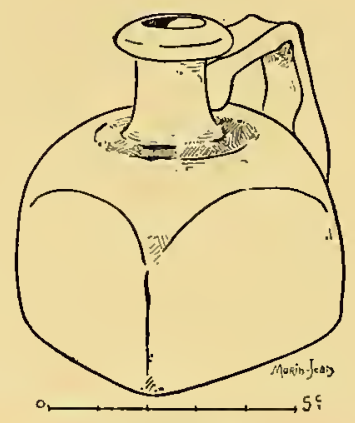

FiG. 4I. - Ftacon a panse Prismatique, trouvé à Saint-Cassien, en r88. - Musée de Caines (AlpesMaritimes).

des parois épaisses, solides ; elle est presque plate sur le dessus, à l'endroit où s'attache le goulot. Au $\mathrm{III}^{\mathrm{e}}$ siècle elle est en verre incolore ou jaune-verdâtre sale. Elle a des parois minces et fragiles. Le dessus de la panse est en forme de calotte plus ou moins bombée et d'un galbe mou.

B) Le second n'est qu'une variante du premier. Il en diffère par sa panse beaucoup plus haute que large (fig. 46). En Gaule, il est plus

(I) Au cimetière de Coblenz-Nenendorf, une bouteille carrée forme s 4 a été trouvée dans une tombe du début de l'Empire, avec une fibule de bronze dont le type, qui appartient au groupe de Ia Tène III, ne semble pas descendre plus bas que le second quart du Ier siècle (Musée de Coblence. Vitrine VI. Tombe à incinération, $\left.\mathbf{n}^{\circ} \mathrm{IV}\right]$.

(2) A Cologne, ou a trouvé des bouteilles forme I4 dans les tombes de l'époque des empereurs syriens, à côté des verreries ornées d'applications vermiculaires (voy. Bonner Jahrbücher, Igo6, fasc. I I4-II5, p. 406, pl. XXIII, tombe $\left.n^{\circ} 35\right]$. 
commun dans le Midi (I) que dans le Nord (2). Typologiquement et chronologiquement, il se place à côté du précédent. Comme 1ui, il devient très rare à la fin du $\mathrm{mI}^{\mathrm{e}}$ siècle; mais on ferait erreur en s'imaginant que les gens de la basse époque l'ignoraient complètement. A Cologne, en I905, une bouteille carrée, à panse élevée, a été recueillie, dans un sarcophage en pierre du Romain II tardif; cette bouteille était placée à côté d'une cruche de terre rouge, sur

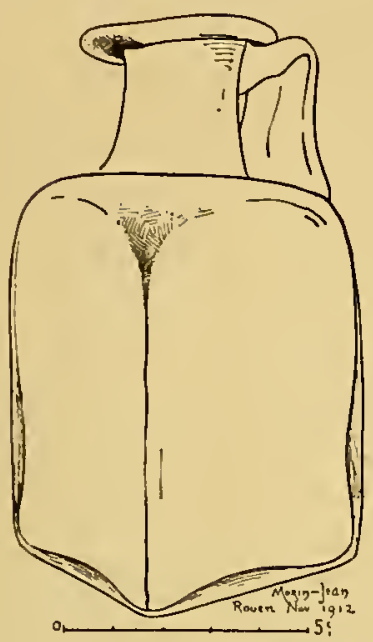

FIG. 42. - BOUTEILLE PRISML1TIQUE, VERRE BLEU-VERD.ATRE. P.IROIS tiPAISSES. - Tourvillela-Rivière (fouilles de I862). Musée de Routen (aneienne collection de Girancourt).

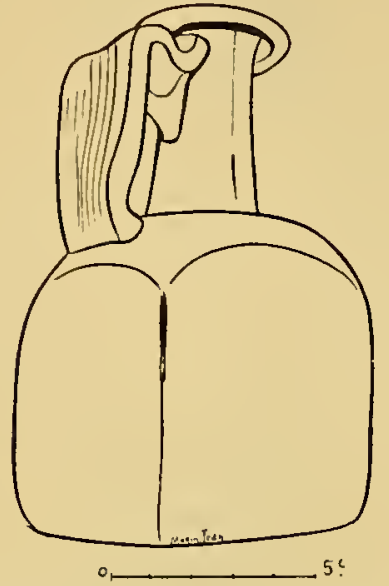

Fig. 43. - BOUTEIILE PRISMATIQUE EN VERRE VERT-BLEUATRE. - Paris, cimetière payen de la rue Nicole. - Collection Ch. Magne, à Paris.

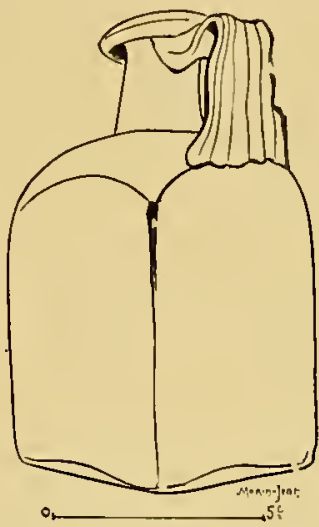

FIG. 44. - BOUTEILLE A pANSE PRISMATIQUE. - Paris, cimetière romain du faubourg Saint-Jacques. - Musée Carnavalet, à Paris.

laquelle l'inscription Reple Me est tracée à la barbotine blanche (3).

FORME I5. - Bouteille prismatique à denx compartiments. Cette forme, assez rare, est une variante de la forme $x_{4}$. La panse de la bouteille est divisée en deux compartiments, par une mince cloison de verre, placée verticalement. Le goulot est double; il se compose de deux tubes accolés (fig. $47, \mathrm{~B}$ ).

(I) Parmi les exemplaites de la basse vallée du Rhône, on peut signaler comme particulièrement intéressante la bouteille (fig. 46) qui porte une marque de fabrique (éléphant et nom grec ZH@OC) publiée par Flouest dans la Revue des Societés savantes de I 875 , t.I, p. I2+ et suiv.

(2) Un beau spécimen de $2+$ centimetres de hauteur, trouvé à Dannes (Pas-de-Caiais) en I823, est conservé au musée de Boulogne-sur-Mrer [120 2.5 I0].

(3) Bonner Jalirbïcher, , 906 , fasc. I If-I I5, P. 429 , tombe 64, pl. XXVT. 
Les flacons à deux compartiments constituent une catégorie de récipients dont les formes sont variées ( $\mathrm{n}^{\mathrm{OS}}$ I5, 35, 63 du tableau de morphologie générale). Ils sont désignés par les auteurs anciens sous le terme général de dilécythes. Il en existe des spécimens en terre cuite.

FORII I6. - Panse prismatique rectangulaire. Deux anses tri-

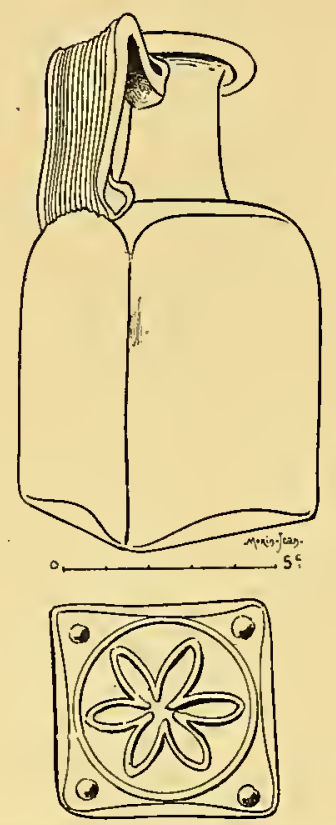

Iitg. 45. - Flacon a panse prismatigue en verre bleu-verdatre. - Fécamp. Fonilles de l'abbé Cochet, en I852. - Musée du Louvve.

fides type $\alpha\left(\mathrm{pl} .2, \mathrm{p} .3^{6}\right)$ (I). - Très répandues dans toute la Gaule, les bouteilles de ce modèle sont lourdes; elles ont des parois très épaisses et sont en verre bleu-verdâtre. Sur leur fond, on voit souvent une marque de fabrique (fig. 48 à 5o).

Les spécimens du musée de Saint-Germain (fig. 49), découverts. les uns dans la forêt de Compiègne, les autres dans la Vienne et dans l'Allier (2), les exemplaires d'Alesia (fig. 50), de Vendôme (3), de

(I) Ces anses n'appartiennent pas toujours au type $\alpha$. Le musée de Saint-Germain possèđe une bouteille forme I6 [Salle IV, $\mathrm{n}^{\circ} 29.489$, Néris (Allier)] dont les anses sont à uervures multiples du type $\gamma, \mathrm{pl} .2$.

(2) Musée de Saint-Germain. Salle IV, nos ${ }^{03} 3.689$, I4.042, I9.765, 29.100, 29.489, 30.328.

(3) Musée de Vendôme [Fouilles de Irussault (Iudre-et-L,oire)]. 
Paris (fig. 4S), de Poitiers (I), de Niort (2), d'Amiens (3), ceux de Normandie (4) et de la vallée du Rhin (5), appartiennent tous à la verrerie du Romain I.

FORIE I7. - Bouteille à panse prismatique hexagonale. - Les flacons de cette forme se placent typologiquement à côté des formes

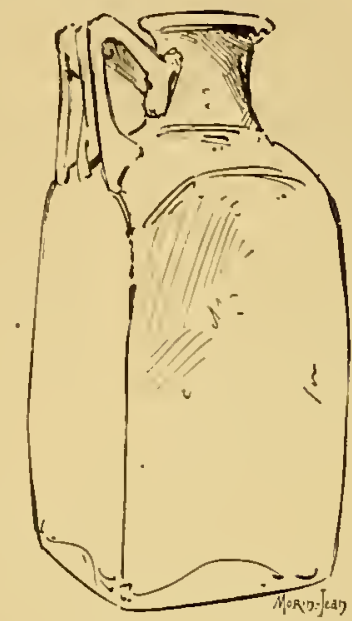

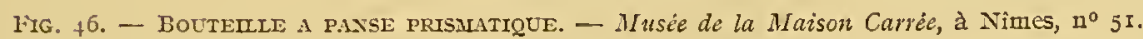

I3 à I6. On peut đy distinguer des variétés multiples que nous réunirons dans quatre groupes:

A. Bouteilles de grande taille, très lourdes, en verre épais, à goulot large et bas, à anse trapue du type $\gamma$ (p1. 2, pl. 36). - Elles ont été ordinairement employées comme urnes ossuaires (6).

B. Bouteilles de petite taille. Variantes à six pans de la forme I4 (fig. 5I, 52, 53).

C. Variantes à six pans de la forme Ig (fig. 54,55$)$.

(I) Musée de la Société des Antiquaires de l'Ouest. Spécimens provenant du cimetière des Dunes.

(2) Iusée archéologique de Niort, n० 89 .

(3) Musée de Picardie., nos $918,948,827,937$.

(4) Fouilles de l'Abbé Cochet.

(5) Trois beaux exemplaires, trouvés à Cologne, ont été publiés par Frenner [Collection Julien Gréan, pl. 292].

(6) L'urne à panse hexagonale de Bre̊ny (Aisne), signalèe plus haut, p. 42, a 25 centimètres de hauteur. Elle contenait une monnaie de Domitien. Deux urnes de même taille et de même forme ont été trouvées, l'une à Iilleboune (Seine-Inféricure) [MIusée de Saint-Germain, salle JV, nº 29.5I6. Fouilles Cochet], l'autre à Cherbourg [voy. W. Fraenser, Collection Julien Gréau, $11^{\circ}$ 1.525, pl. 270]. 
D. Variantes à panse prismatique de la forme 33 (fig. 56 et 57).

FORME I8. - Variante à six pans de la forme IO. - Les flacons forme $x 8$ sont de basse époque. Ils sont en verre incolore, quelquefois de bonne qualité, mais souvent chargés des impuretés, des bouillons et des filandres qui caractérisent la pâte du $\mathrm{IV}^{\mathrm{e}}$ siècle. Leurs parois

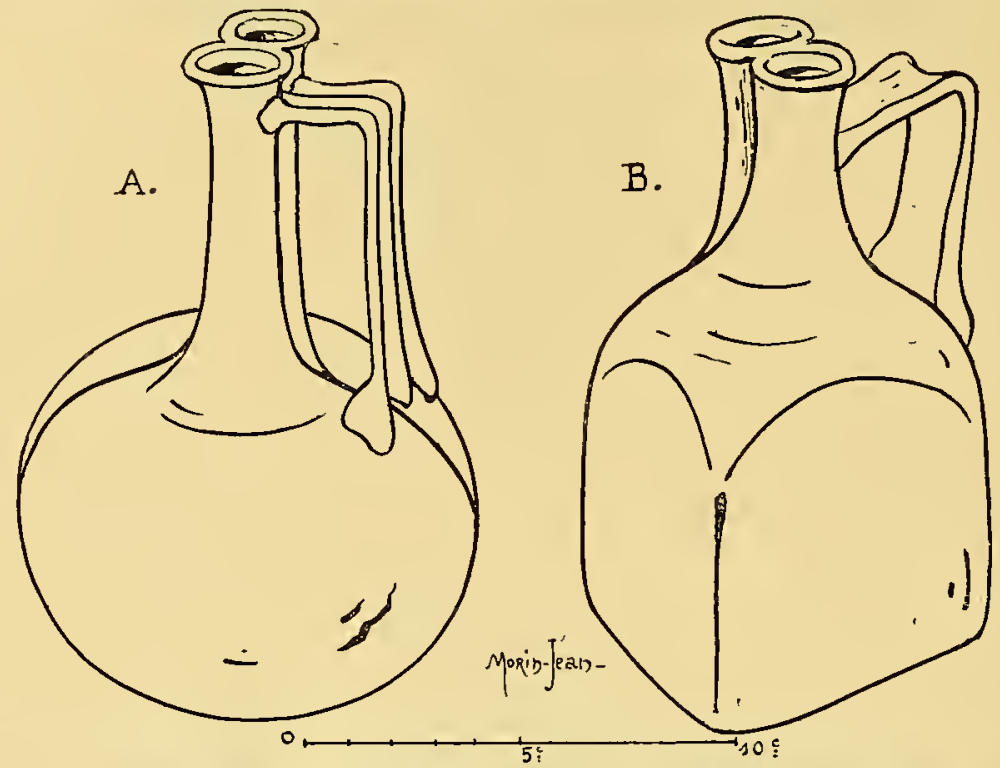

Fig. 47. - Bouteilles a Deux compartinevts : A. Type à panse sphèroïdale. Orange (I840). Muséc

Calvet à Avignon, $\mathrm{n}^{0}$ rr3. - B. Type à panse prismatique, Arles. Musée Bovély à Marseille, $\mathrm{n}^{0} 494$.

sont minces, lisses ou pourvues d'un décor très flou qui consiste en lignes parallèles disposées obliquement (I) (fig. 58).

Leur goulot, dont l'orifice est sans ourlet, est flanqué de deux anses du type $\zeta^{2}$ (pl. 3, p. 37).

Les flacons forme 18 sont assez répandus dans la Gaule du nord et sur les bords du Rhin (2).

FORME I9. - Flacons prismatiques sans anses, à goulot long et étroit. - Ces flacons portent, en Allemagne, le nom de Merkurflasche parce que, sur leur fond, on voit souvent une image en relief du dieu Mercure, cantonnée d'initiales de noms de fabricants (3).

(I) Ce type de décoration a été appliqué aussi à d'autres formes.

(2) Un bel exemplaire đu Ronnain II, orné de stries obliques, est conservé au IIusée Provincial de Bonn $\left[\mathrm{n}^{\circ} 3 \mathrm{I} 6\right]$.

(3) Sur les marques des flacons forme I9, consulter Axтox KISA, Das Glas im Altertume, p. 940 et suiv. 
I.es bouteilles forme I9 comprennent deux types :

Au premier, appartiennent les flacons dont les parois sont minces

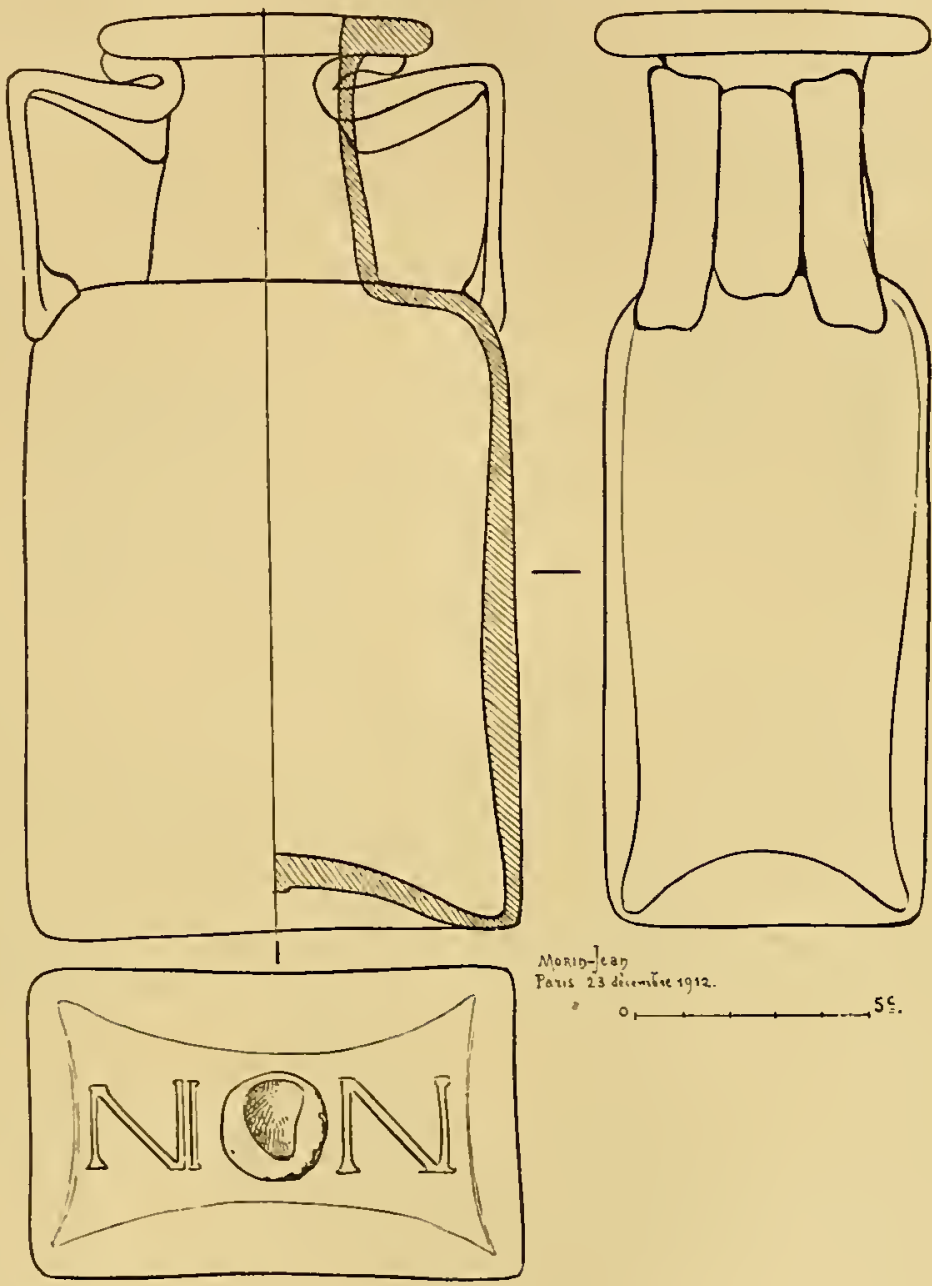

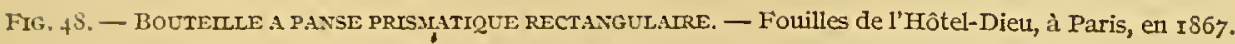
Musée Carnavalet, $\mathrm{n}^{\circ} \mathrm{I}+\mathrm{I}$.

(fig. 6o) et dont la pâte vitreuse est plus ou moins colorée naturellement par des oxydes métalliques.

Au second, il convient de rattacher les bouteilles dont les parois sont, comme celles de nos flacons modernes à odeur, très épaisses au 
milieu et vont en se rétrécissant vers les bords (I) (fig. 6I, 62). Les flacons du second type ont été soufflés dans une matière incolore formée de quartz en poudre. Leur embouchure est plate et très débordante, comme il convient pour verser des liquides épais (fig. 6I). Leur panse est souvent ornée, sur deux faces opposées, ou sur les quatre faces, de feuilles de palmier.

Les bouteilles forme $\mathrm{I} 9$ ont en moyenne I2 à $\mathrm{I} 5$ centimètres de

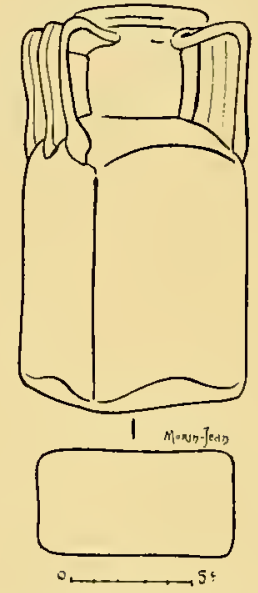

Fig. 49. - BoUterlle a PANSE PRISMatioue RECTANGulanRE. - Garente du Roi (forêt de Compiègne, Oise). - Musée de Saint-Germain. Salle XV, $\mathrm{n}^{\circ} \mathrm{I} 4042$.

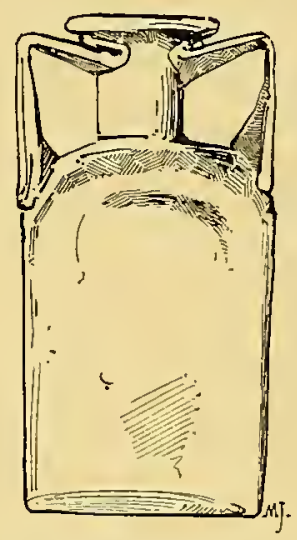

Fig. 50. - BoUteItle a paNse prismatiQUe rectangulaire. - Musée d'Alise-Sainte-Reine (Côte-d'Or).

hauteur; les plus petites ne dépassent pas 6 centimètres (2), les plus grandes atteignent jusqu'à 22 et 24 centimètres.

Un flacon forme I9, découvert à Clermarais près de Reims, porte une inscription que l'on a pensé pouvoir lire ainsi : Firmi Hilari ad tylosim aromaticum (3).

(I) Quelques-uns de ces flacons sout de véritables verres à tricherie, comme il sera facile de s'en con vaincre en examinant la fig. 62. L,es industriels et les commerçants de l'antiquité usajent déjà đe ces ruses dont se servent si fréquemment les négociants d'aujourd'hui pour faire croire à leur clieutèle qu'un flacon renferme plus de liquide qu'il n'en contient en réalité.

(2) Catalogue du Musée archéologique de Reims, n⿳ 5.339, trouvé à la Maladrerie en I899.

(3) Ch. Loruguet, Marque pharmacentique inscrite sur une fiole de verre. Dans la Revue archéologique, I 862 , t. I, p. 247 à 253 . 


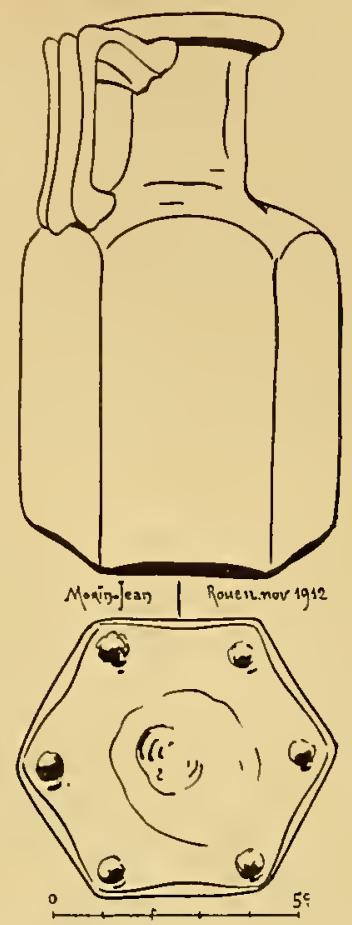

Fig. 5I. - Bouteille a paNSE PRISmatique hexagonale. - Fouilles d'Amiens, en i867. - Musée départemental d'Aniquités, à Rouen.

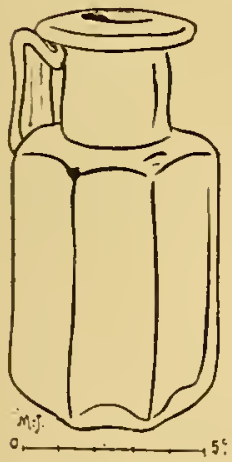

FIG. 52. - BOUTEILLE : PANSE PRISMITIRUE IIEXAGONALE. - Verre très épais. Cimetière de Conflans - sur - Seine (Marne). - Musie de Sain-Germain. Salle $\mathrm{XV}, \mathrm{n}^{\circ} \mathrm{I}_{9764}$.
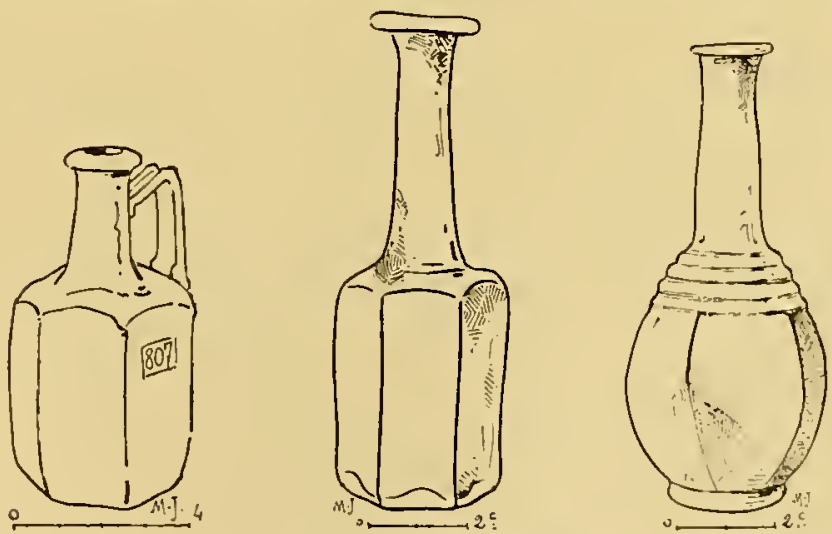

FIG. 53. - Fiacon a FIG. 54. - Flacon Fig. 55. - Fllacon déPATSE PRISALATIQUE TROUTÉ A REIMS. Hexigoxale. - Verte Musie de Saint-Gerverdâtre. - Musie de main. Salle XV, no Picardie, dे Amiens, 27233. $\mathrm{n}^{\circ} 807$. COUVERT A VAISON (Vaucluse). - Musée de Saint-Girmain. Salle $\mathrm{XV}, \mathrm{n}^{\circ} \mathrm{I}_{3408 .}$ 
Ia Tylosis serait une maladie consistant en callosités invétérées de l'intérieur des paupières. Le flacon aurait-il contenu un certain collyre destiné à guérir cette affection?

On a trouvé dans diverses régions des bouteilles r9 qui portent 1a même estampille que le flacon de Clermarais (Voy. Kisa, Das Glas, p. $\left.7 \delta_{3}\right)$.

Les flacons forme I9 sont très répandus en Gaule. Ils n'apparaissent pas avant $1 \mathrm{a}$ fin $\mathrm{du} \mathrm{II} \mathrm{I}^{\mathrm{e}}$ siècle. Ils sont très abondants pen-

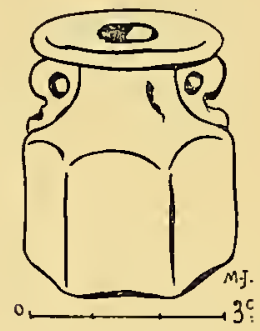

Fig. 56. - Flacon a panse hexagonale. Musée provincial de Bonn.

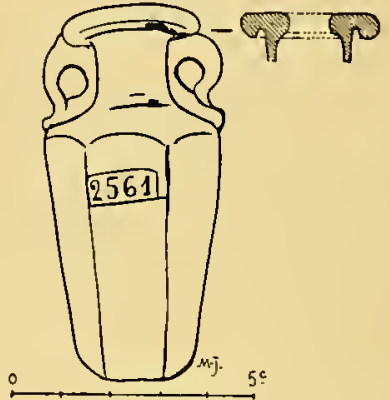

FIG. 57. - FLACON EN VERRE VERT. - Fouilles de Brequerecque. - Musée archéologique de Boulogne-sur-Mer, $\mathrm{n}^{\circ} 256 \mathrm{r}$.

dant la première moitié $d u \mathrm{II}^{\mathrm{e}}$ siècle (r) et figurent encore parmi les productions verrières de la fin $\mathrm{du}_{\mathrm{III}}^{\mathrm{e}}$ et $\mathrm{IV}^{\mathrm{e}} \mathrm{s}$. (2).

(I) Dans les tombes à incinération de la Normandie [Cocnet, La Normandie souterraine, pl. I, $\mathrm{n}^{\circ} 53$, Cimetière de Cany], les flacons forme ig sont associés aux barillets frontiniens. A Cologne, ils ontété trouvés dans les incinérations de l'époque des empereurs syriens avec des verres gravés et des verres à applications vermiculaires (formes 54, 62, 64) [voy. Bonner Jahrbiächer, I906, p. 409, pl. XXIV, tombe $\mathrm{n}^{0} 3^{8}$ ]. A Gelsdorf, près Meckenheim, ils ont été recueillis avec des monnaies de Julia Moesa, J ulia Domna et Septime Sévère (I93 à 2II) [Bonner Jahrbücher, t. XXXIII-IXIIV, I863, p. 227-228]. A Reims, un flacon forme I9, dont le fond porte une figure en relief de Mercure cantonnée des lettres II.-C.-H.-R., setrouvait dans unesépulture de la Maladrerie, avec nne monnaie de Commode frappée en 192 et une olla cineraria de terre cnite d'un type travaillé en relief d'applique caractéristique de la première unoitié du II $^{\mathrm{e}}$ siècle [voy. Catalogue du Musée archéologique de Reims, $n^{\circ} 2.549$, et $\mathrm{J}$. DÉcheLETte, Les vases céramiques ornés . de la Gaule Romaine, t. II, p. I7I].

(2) Spécimens en verre filandreux et verdâtre des musées de Rouen [fouilles de Quatremares], de Bonn et de Mayence. [Un exemplaire du musée de Mayence mesure i 8 ceutimètres de hauteur. I1 a un col court. Il a été trouvé dans une tombe du $\mathrm{IV}^{\mathrm{e}}$ sic̀cle avec une bouteille forme 40 ]. 


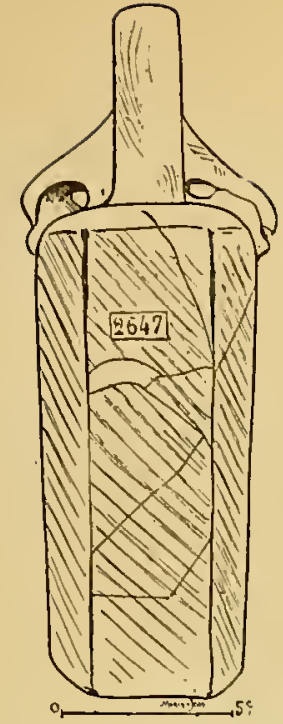

FIG. 58. - Bouterlle a P.ANSE PRISALATIOUE HEXIGONALI, IERRE IERDATRE CONTEXANT DES FRLANDRES ET DES BULLES D'ArR. - Foutlles du Boulonnais, en I870. - Wusie de Bonlogne-sur-1/er, no 2647 .

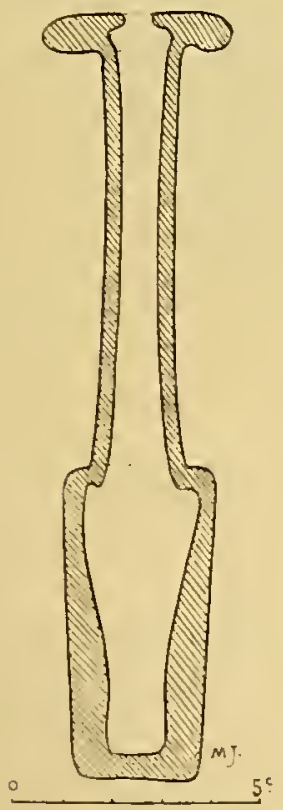

Fig. 6I. - FlatCON EN VERRE INCOLORE TRESS EPAIS. 'Trouvé à Rheindorf, le It mars 1839. - Muséc de Sivres, $\mathrm{n}^{\circ} 2665^{2}$.

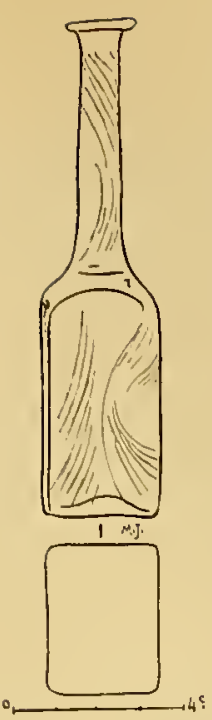

FIG. 59. - FLACON A LONG COL, VERRE FILANDreux. - Cimetière de Reins (Marne).-Muséede SaintGermain. Salle XV, $n^{0} 27232$.

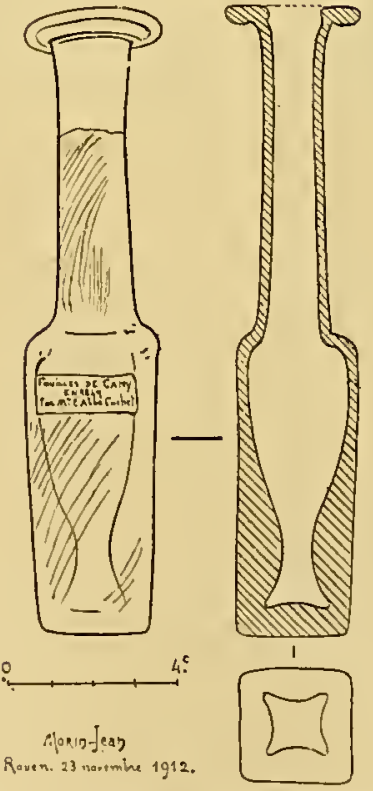

Fig. 62. - FilACON EN VERTE INCOLORE FIANDRECX. - Fouilles Cochet, à Cany, en IS49. - Music diparlemental d'antiquités, à Rouen.

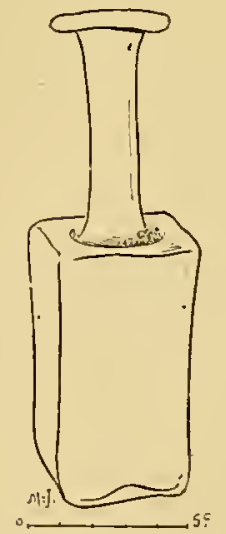

FIG. 63. - FLACON A PANSE PRISULATIQUE. IRISATION ARGENTÉE, - Trouvé à Arles (Trinquetaille). Musée Borély, a Marseille, $11^{\circ} 497$. 
4. - BOUTEILLES APPARENTÉES PAR LEUR FORME AU TYPE GRÉCOORIENTAL DE L'ALABASTRE ET DU BOMBYLIOS E'T LEURS DÉRTVÉS.

(Formes 20 à 26.)

Les ampoules et les flacons, dont la description va suivre, sont des vases destinés à renfermer des parfums, des essences, des baumes.

Ils sont apparentés plus ou moins directement aux balsamaires d'albâtre, de métal ou d'argile que les Égyptiens, les Grecs, les popu-

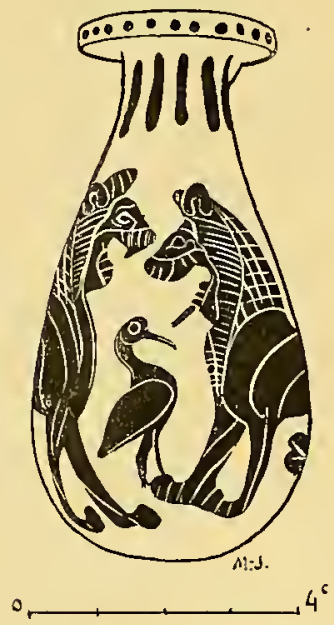

FIG. 64. - BOMIRYLIOS CORINTHIEN EN TERRE CUTTE. vi ${ }^{\mathrm{e}}$ s. av. J.-C. - Collection Morin-Jean, $n^{\circ} 474$.

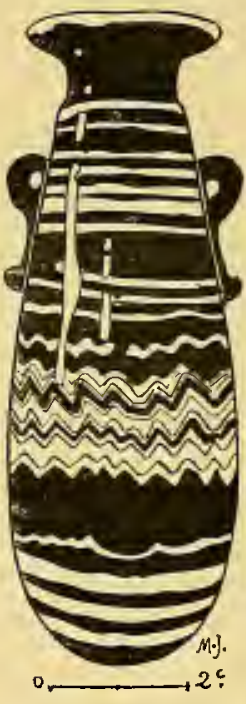

Fig. 65. - Alabastre en pate de VerRe MulTICOLORE. - Syrie. - Collection Morin-Jean, à Paris.

lations des îles et de la côte d'Asie employaient depuis fort longtemps au transport des parfums.

Ces balsamaires étaient désignés par les anciens sous les noms d'alabastre (I) et de bombylios (2). C'étaient des petits récipients en forme d'outre ou de poire, caractérisés par une panse renflée du bas (fig. 64). Ces vases étaient munis d'un goulot court surmonté d'une embouchure affectant la forme d'une rondelle plate, très débordante.

(I) Dictionnaire des Antiquités de Saglio, t. I, première partie, p. I75 et suiv.

(2) Dictionnaire des Antiquités de Saglio, t. I, première partie, p. 720. 
Les Corinthiens, au vir et au $\mathrm{vI}^{\mathrm{e}}$ siècles avant J.-C. ontinondé le monde méditerranéen de bombylios de terre cuite ornés d'animaux peints (fig. 64). Vers la même époque et pendant les siècles suivants,

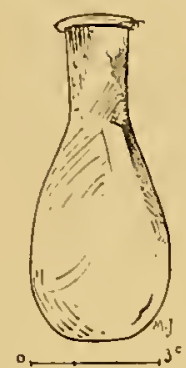

FIG. 66. - AMrPOULE DE VERRE BLEU. - Arles.

Cabinet des Médailles, à Paris, $\mathrm{n}^{0} 796$.

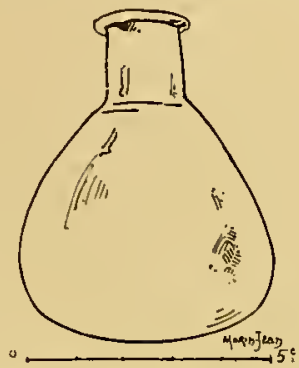

Fig. 67. - Ampoule a P.rRfum. - Provenance indéterminée. - Collection Morin-Jean, no 615 .

les Ëgyptiens ont fabriqué des alabastres en onyx oriental ou en pâte de verre opaque polychromée à l'aide de bâtonnets de couleurs variées (fig. 65).

Fornies 20-2I-22. - Petites ampoules piriformes. Goulot plus ou moins allongé. Embouchure tantôt sans ourlet (20-2I), tantôt ourléc

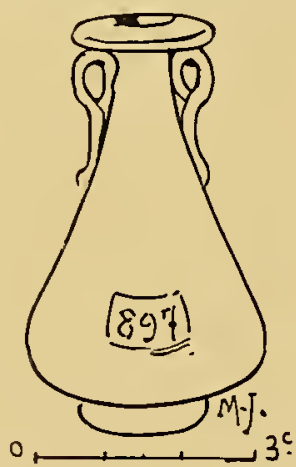

Fig. 6S, - Iilacon ex́ verre bleu-verdatre. - Musée de Picardie, à Amiens, nº 897.

(22). - Les spécimens munis d'anses (fig. 68 et 69) sont pen abondants dans cette série.

Des ampoules formes 20 à 22 ont été découvertes en masse dans les sépultures à ustion de la période romaine. Elles portent, dans le langage courant des fouilleurs, le nom de lacrymatoires, parce que, 
d'après la légende, les parents des défunts y rassemblaient les larmes qu'ils avaient versées pendant la cérémonie des funérailles.

On sait, aujourd'hui, que ces fioles n'ont jamais contenu de larmes,

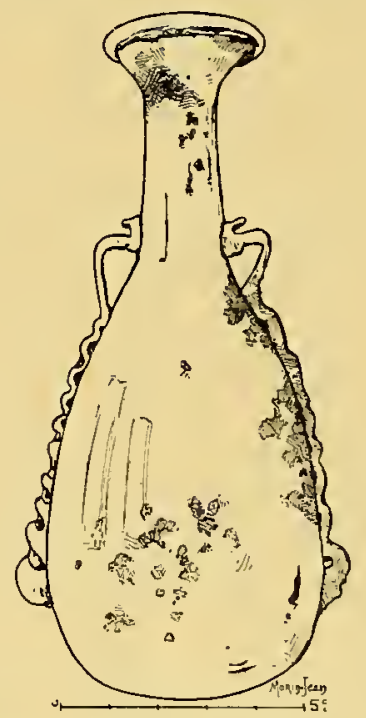

Fig. 69. - Fiole A ANSES APPENDiculées. - Syrie. $\mathrm{m}^{\mathrm{e}} \mathrm{s}$ - - Collection Morin-Jean, $\mathrm{n}^{\circ} 304 \mathrm{I}$.

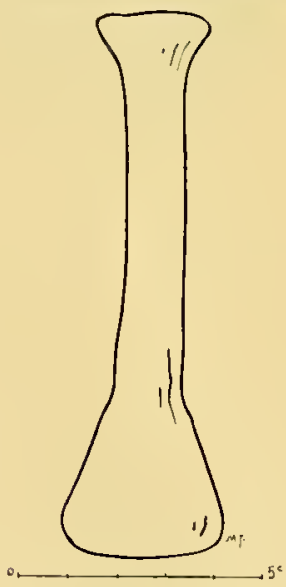

FIG. 7O. - FIOLE RECUEILLIE EN OCTOBRE I882, a Paris, $3^{8}$, avenue des Gobelins. - Collection Ch. Magne, à Paris.

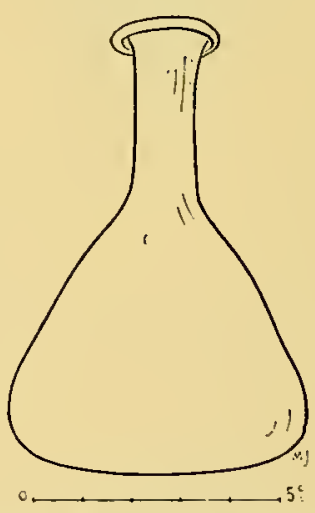

Fig. 7 I. - FIOLE DE VERRE VERDATRE, trouvée à Paris, 6, boulevard de Port-Royal, en août I881. Romain II. - Collection Ch. Magne, à Paris.

mais on continue à les désigner par le mot lacrymatoire qui est, en quelque sorte, consacré par l'usage. 
A la série des lacrymatoires, nous devons rattacher les nos 37 et 38 du tableau de morphologie générale qui ne diffèrent des types 20-22

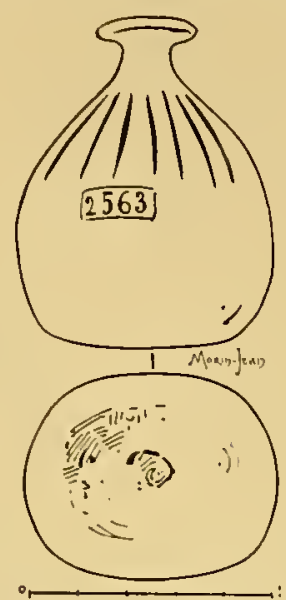

FIG. 72. - Frole sixs Anses. - Fouilles du Boulonnais. - Musée de Boulogne-sur-Mer, $\mathfrak{n}^{\circ} 25^{6} 3^{.}$

que par la forme de leur panse. Beaucoup de ces petites bouteilles nous sont parvenues désagrégées et tordues par le feu. Elles ont été recueillies au miliet des cendres du bûcher funèbre. M. Mazauric, l'actif conservateur du musée archéologique de Nîmes, pense qu'elles

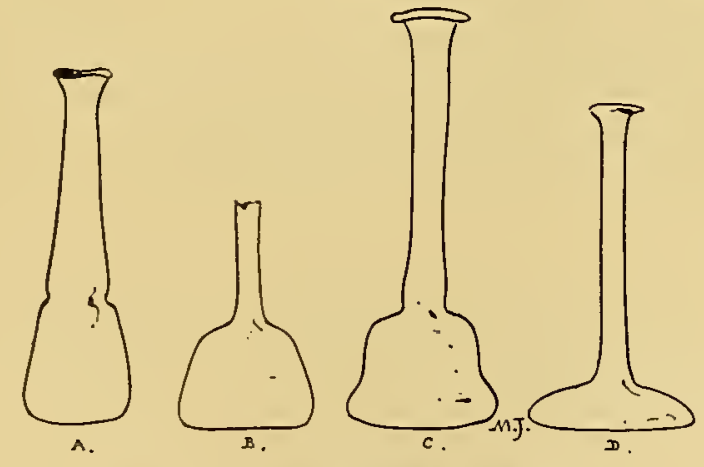

FIG. 73. - BALSAMATRES A LONG COL.

devaient renfermer des encens qui, en brûlant avec le défunt, servaient d'antidote contre les mauvaises odeurs.

Les fioles 20 à 22 sont en verre, tantôt teinté naturellement par les oxydes métalliques, tantôt coloré volontairement en jaune ou en 
bleu vif. Elles ont été utilisées du $\mathrm{I}^{\mathrm{er}}$ au $\mathrm{IV}^{\mathrm{e}} \mathrm{s}$. de notre ère, mais elles sont beaucoup plus abondantes au Romain I qu'au Romain Ir.

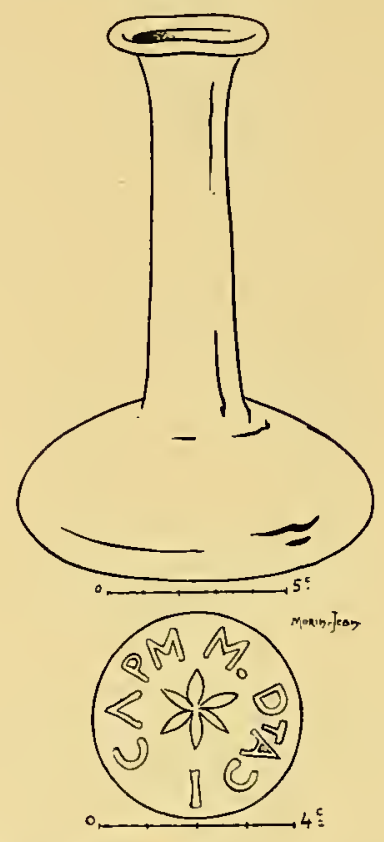

Fig. 74. - Balsamatre a Panse bulbeuse, trouvé à Arles. - Musée Borély, à Marseille.

A Cologne, elles ont été recueillies principalement dans les incinérations contenant des monnaies d'Auguste, de Tibère, de Néron (I). Il en est de même dans la Gaule méridionale.

Des ampoules forme 22 , en verre bleu intense, ont été trouvées
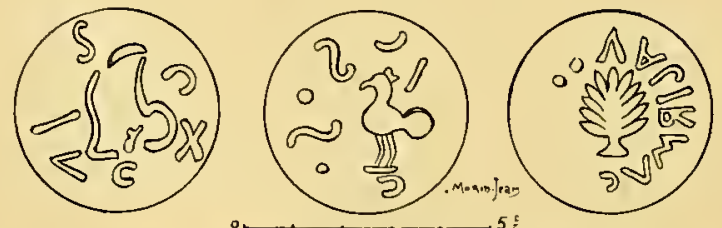

Fig. 75. - MLARQUes DE VERRIERS MOULEes SUR LE FOND DE TROIS BALSAMAIRES fotme 25. - Musée Borély, à Marseille (nos $533-534$ et 535).

en I882, à Boulogne-sur-Mer (Briqueterie de Saint-Martin) dans un cercueil de plomb qui paraît dater du III ${ }^{\mathrm{e}}$ ou du $\mathrm{IV}^{\mathrm{e}} \mathrm{s}$. (2).

(I) Voy. Bonner Jahrbïcher, I906, fasc. II4-II5, pl. XXI.

(2) Musẻe archéologique de Boulogne-sur-Mer, $11^{0} \mathbf{2 . 7 9 2 .}$ 
La fiole figure 79 est un spécimen très tardif (fin du IV e siècle) des bouteilles émanant du bombylios et de l'alabastre des Grecs.

FORMES 23-24-25. - Balsamaires à panse tronconique ou bulbeuse surmontée d'un goulot en forme de tuyau très long. Orifice à ourlet. - Les vases à parfums formes 23 à 25 dérivent de l'ampoule 22. La transformation s'est faite tout naturellement par allongement du col et aplatissement de la paraison. Ia panse de ces bouteilles varie beaucoup

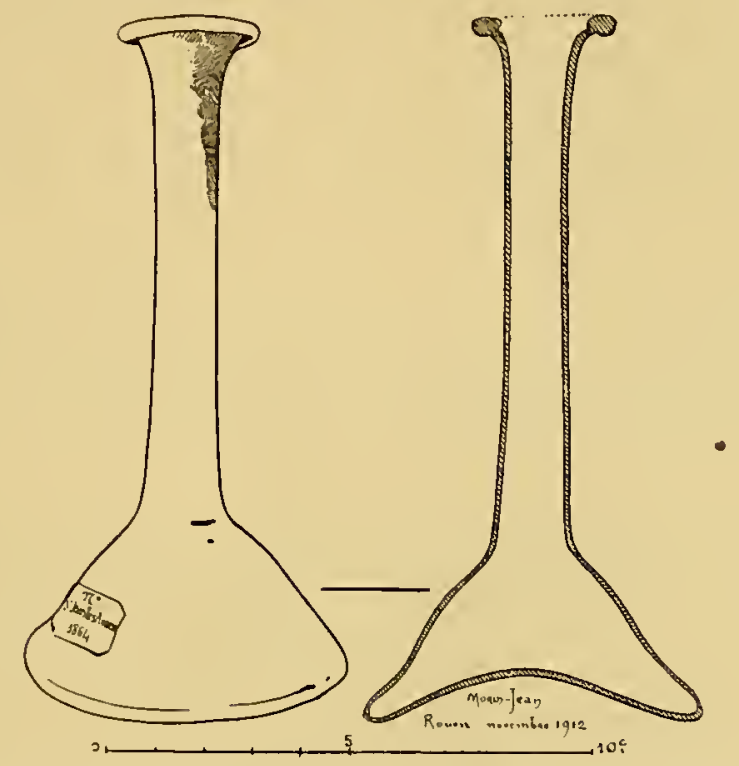

FIG. 76. - FIOLE DE VERRE BLEU-vERDATRE, trouvée à Saint-Jean-lès-Amiens en I864. - Musée départemental d'antiquités, à Rouen.

dans sa forme. Elle est tantôt tronconique ( $\mathrm{n}^{0} 24$ et fig. 76), ta ntôt bulbeuse ( $\mathrm{n}^{\circ} 25$ et fig. $73 \mathrm{D}$ et 74 ), tantôt très arrondie (fig. 77). Souvent, son profil affecte la forme d'une doucine ( ${ }^{0} 23$ et fig. 73 C.).

I,e type bulbeux $n^{0} 25$ avec marque de fabrique moulée sur le fond (fig. 74 et 75 ) est très abondant dans la vallée du Rhône (I) [il semble qu'il y ait eu à Iyon une fabrique de ces fioles]. Nous le retrouvons au musée de Trèves (2).

(1) Nombreux exemplaires aux musées de Lyon, d'Arles et de Marseille.

(2) Fuhrer durch das Provinzialmuseum in Trier, p. Ioz, tombe $n^{0} 1.727$. 
IAA VERRERIE EN GAULE SOUS I'EMPIRE ROMAIN.

Les fioles formes 23 à 25 sont quelquefois en verre bleu-verdâtre, plus souvent en verre incolore.

Elles sont très répandues dans le bassin oriental de la Méditer-

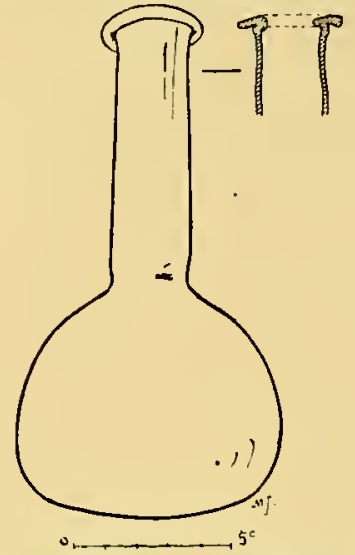

FIG. 77. - FTOLE EN VERRE verdatre, trouvée à Paris, 8 bis, rue Amyot, en septembre I 895 . Collection Ch. Magne, à Paris.

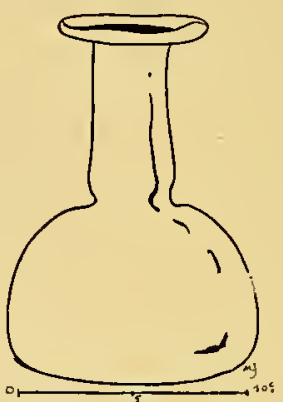

FIG. 78. - Flacon sans ANSE. - Musée d'Arles.

ranée dont elles sont originaires. On n'en voit guère à Pompéi. Par

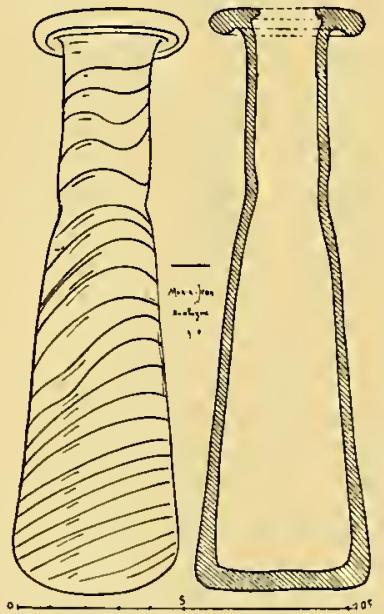

FIG. 79. - FIOLE DE VERRE VERDATRE tRÈs ÉPAS, ornée de stries blanchâtres. Fouilles du Vieil-Atre. Fin du IV s. - Musée archéologique de Bonlogne-sur-Mer.

contre, en Gaule, toutes les régions ou à peu près en ont fourni des spécimens qui, pour la plupart, faisaient partie du mobilier funé- 
raire des tombes qui vont de Commode à une date assez avancée du III ${ }^{\mathrm{e}}$ siècle (I).

FORME 26. - Bouteille piriforme dont le fond fait une très forte saillie à l'intéricur de la panse. - Les flacons formes 26 et 39 sont apparentés entre eux. Tous deux sont caractérisés par la disposition de leur fond qui ressemble à celui de nos bouteilles à kirsch. Ce modèle de cul de bouteille n'apparaît pas de bonne heure. La majorité des verreries qui en sont pourvues sont du $\mathrm{III}^{\mathrm{e}}$ et du $\mathrm{IV}^{\mathrm{e}}$ siècles.

Au cimetière romain de Cologne, elles ont été recueillies dans les incinérations tardives (2) et dans les inhumations des derniers temps de l'époque impériale (3).

5. - BOUTEILLES APPARENTÉES AU TYPE DE L'AMPHORE ROMAINE A BASE TERIINÉE EN POINTE ETT LEURS DÉRIVÉS.

(Fiormes 27 à 32.)

Les souffleurs de verre ont pris quelquefois pour modèle l'amphore romaine d'argile, à panse terminée en pointe, dont les anciens se servaient pour conserver le vin (4).

Forve 27. - Amphore à base pointue. Pas d'anses. - Les fioles forme 27 sont généralement de petite taille. Elles sont en verre mince et sont pourvues d'une embouchure sans ourlet, disposée en entonnoir (fig. 33I, n ${ }^{0}$ I).

Ce sont des flacous de la haute époque impériale, très abondants dans la verrerie pompéienne.

En Gaule, ils se rencontrent dans les incinérations du $\mathrm{I}^{\mathrm{er}}$ et du

(I) Bonner Jahrbücher, Igo6, fasc. II4-I 15, pl. XXIII, tombe $\mathrm{n1}^{\circ} 33$, et pl. XXIV, tombe $1^{\circ} 3^{8}$ (Groupe des incinératious de l'époque des empereurs syriens).

(2) Bonner Jahrbiucher, 1906. fascicule IIt-Ir5, p. I09, pl. XXIV, tombe no $3^{8}$ et pl. XXV [Tombe contenant un moxen bronze de l'empereur Postumus ( 258 à 267 )].

(3) Bonner Jahrbücher, Igo6, fasc. Ir4-II5, P. 430, et pl. xxVI, tombe no 68, ou une verreric forme 39 est accoumpagnce d'un barillet frontinien du rvo siècle.

(4) L'amphore romaine à vin ne pouvait tenir debout que si on la posait sur uu support (incilega) ou s on la plantait dans le sable (Voy. Dictionnaire des Anliquités grecques et romaines de Saglio, t. I, prenière partie, P. 248 , fig. 277 à 280 ). 
II $^{\mathrm{e}}$ siècles (fig. 33I). On en connaît des exemplaires en verre de couleur (I).

FORME 28. - Variante de la forme 27. - Les ampoules de ce type sont souvent ornées de profondes dépressions disposées verticalement tout autour de la panse (2) (fig. 257).

Forme 29. - Petit amphorisque à deux anses. - Une fiole de cette forme, appartenant au musée provincial de Bonn, est en verre incolore et filandreux du Romain II. Elle porte un texte gravé à la meule (fig. 8o).

FORME 30. - Amphorisque sans anses à goulot très allongé. -

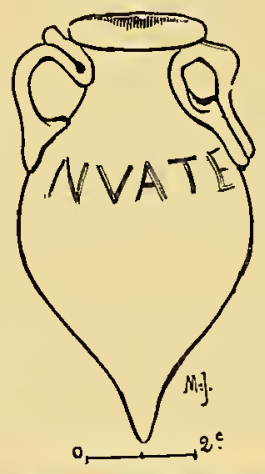

Fig. SO. - AyphorisQue EN VERRe fil.ANDREUT. Romain II. - Musée provincial de Bonn. Salle V, no A., 248).

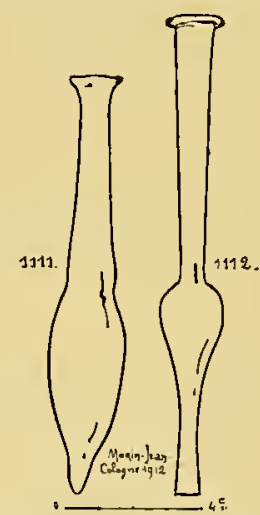

Fig. 8r. - Fioles de verRe incolore, trouvées dans une tombe du cimetière de la rue de I,uxembourg, à Cologne. Iv s. - Musée Wallraf-Richartz, à Cologne.

L'allongement du goulot, dans cette série d'ampoules, constitue une évolution morphologique qui semble s'être opérée an III $^{\mathrm{e}}$ siècle (3). Une fiole, forme 30 , se trouvait an cimetière de la rue de Luxembourg, à Cologne, dans une tombe datée par une monnaie de l'empereur Constans (337 à 350) (fig. 8I).

Forme 3I. - Amphorisque à long col, ouvert à ses deux extrémités.

(I) Tel est le joli amphorisque de 5 centimètres de long, en verre d'un beau bleu, exposé au musćc archéologique de Coblence. Vitrine XIII, n* I.I 49.

(2) Des exemplaires du type 28 orné đe dépressions longitudinales sont couservés aux musées d'Amiens, de Rouen et de Bourges [spécimen à quatre dépressions découvert à Bourges, au cimetière rowain du Fin Renard].

(3) I,es amphorisques à grand goulot, types 30,3 I et 32, appartiennent tous au Romain II. 


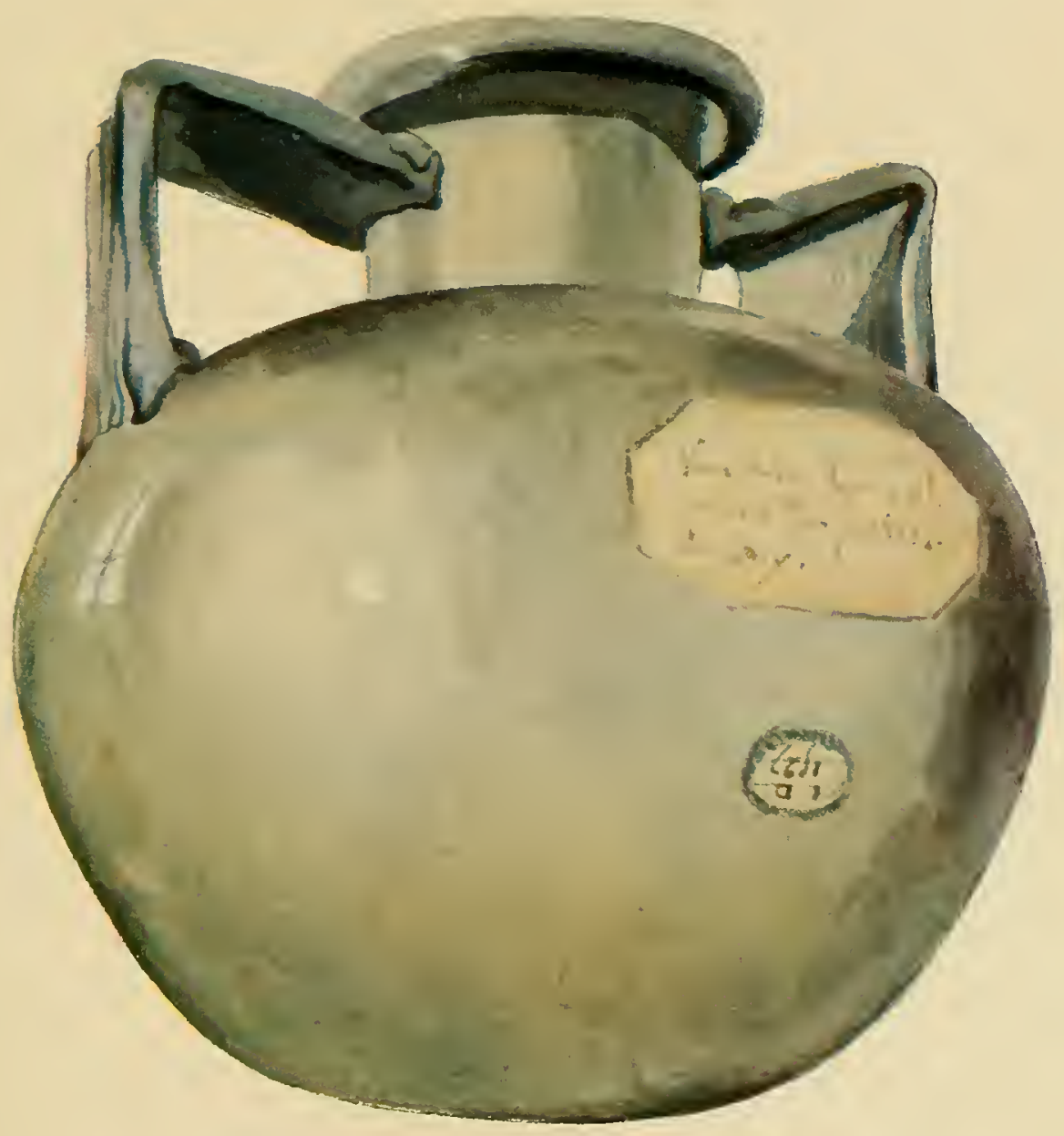

PL. 5. - Urse cinératre. - Musée du Louvre.

(D'après l'aquarelle de Mr. Moriı-Jean.) 

- La base présente la structure d'un tube cassé net par un procédé analogue à celui qu'emploient nos vitriers pour couper le verre. Ce curieux objet n'est pas sans analogie avec la pipette de nos laboratoires de chimie. Serait-ce une sorte de tube à décanter? On peut en voir

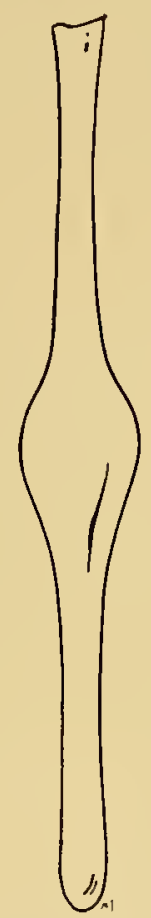

FIG. 82. - FIOLE FUSIFORME EY VERRE VERDATRE, découverte à Paris, $3 \mathrm{I}$, rue Descartes, en juillet I897. - Seconde moitié du $\mathrm{rv}^{\mathrm{e}} \mathrm{s}$. - Collection Ch. Magne, à Paris.

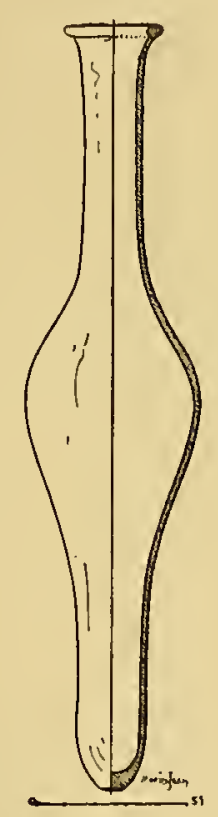

FIG. 83. - GRANDE FIOLE FUSIFORME A EMBOUCHURE OURLEE EA DEDANS. - Cimetière de Vermand (Aisne). IV ${ }^{\mathrm{e}}$ s. - Collection Morin Jean, n० 57 I.

au musée de Mayence plusieurs exemplaires qui faisaient partie de mobiliers funéraires du rve siècle (fig. $339, n^{0} 2$ ).

Le spécimen du musée de Cologne, que reproduit notre figure $8 \mathrm{I}$, se classe également à une très basse époque comme le prouve la monnaie de Constans, fils de Constantin le Grand, qui a été trouvée avec lui.

FORME 32. - Fiole fusiforme, d'origine orientale, atteignant jusqu'à 60 centimètres de longueur. - Orifice tantôt coupé net sans ourlet 
(fig. 82), tantôt ourlé (fig. 83). Pâte vitreuse incolore ou jauneverdâtre, souvent encombrée de nœuds et de filandres.

Le type 32 est très répandu en Gaule. Un grand nombre de trouvailles (I) démontrent qu'il appartient à l'époque de Constantin et de ses successeurs. Plusieurs archéologues pensent que les fioles 32 étaient déposées, pleines de vin, dans les tombes des prêtres chrétiens. Des traces de vin ont été trouvées dans une de ces verreries découverte à Bordeaux (2).

\section{6. - BOUTEILLES APPARENTÉES AU TYPE GREC DE L'ARYBALLE.}

(Formes 33 à 36. )

A l'époque impériale romaine, on fabriquait en verre soufflé des

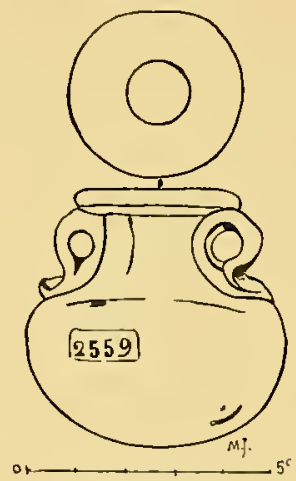

Fig. 84. - ARiballe a ANses delphiniforvies. Verre vert (AXises bleu pale). - Fouilles du VieilAtrc. - Musée archéologique de Boulogne-sur-Mer, $\mathrm{n}^{\circ} 2559$.

balsamaires à panse sphérique et à anses delphiniformes (fig. 84 ), qui

(I) Notamment celles de Nîmes (Saint-Beaudile) [Musée de la Maison Carrée, $\mathrm{n}^{0}$ 236, long. 40 centiurètres], d'Arles [Musée Borély à Marseille, $\mathrm{n}^{0} 459$, long. 48 centinètres environ, et musée d'Atles], de Bordeaux [Spécimen publié par M. Courteault dans la Revue des Études anciennes, IgII, t. XIII, $1^{\circ} 3$ ], de Louin (Deux-Sèvres) [Spécimen décuuvert par le R. P. CANTLLE DE IA CRor, dans un sarcophage de marbre doublé de plomb, entre les jambes d'un individu mortvers trente-cing ans], de Bourges [AIusce de Bourges, $n^{\circ}$ B. 567 , long. 30 centimetres], de Rcims [Musée de Reims; $11^{08} 4.703,4.704$, etc.], de Vermand [Musée I,écuyer et collection TH. Ėck, à Saint-Quentin], de Strasbourg [Spécimen recueilli par le chanoine Straub, avec une bouteille de verre forme 40 , dans un sarcophage de pierre (voy. StrauB, Le cimeticre gallo-romain de Strasbourg, P. 3I, pl. IX, $\mathbf{u}^{0} 7$, tombe 25)], d'Andernach [roy. Bonner Jahrbücher, I888, p. I 84 , fasc. $86, \mathrm{pl} . \mathrm{X}$ ], de Trèves [Musée Provincial de Trèves, salle $6, \mathrm{n}^{\circ} 59$, et salle $20, \mathrm{n}^{0} 5.000$ ], de Mayence [Musée de Mayence. Nombreux spécimens trouvés dans des sarcophages de pierre].

(2) P. Courteadlt, Fiole cn fuscau ayant conlcnu un vin antique, lrouvée à Bordeaux. Dans la Revue des études anciennes, t. XIII, année $\mathrm{I} 9 \mathrm{II}, \mathrm{n}^{\circ} 3$. 
sont des imitations directes des aryballes de terre cuite (fig. 85), et

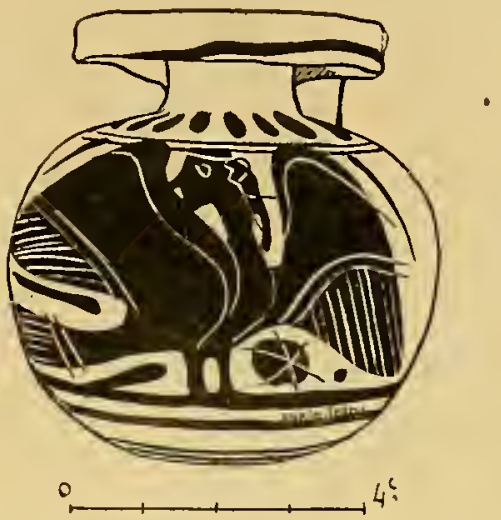

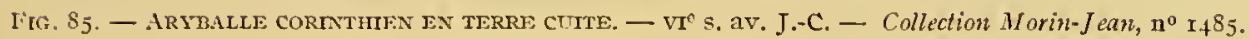

de pâte vitreuse opaque (fig. 86), connus dans toutes les régions méditerranéennes dès le viI ${ }^{\mathrm{e}}$ siècle avant J.-C. (I).

Pour être complet, l'aryballe de l'époque impériale devait avoir

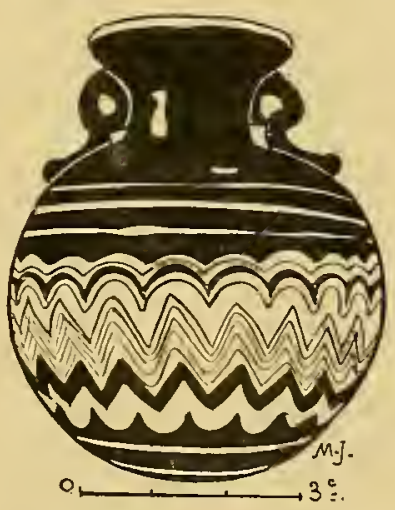

Fig. 86. - ARIBalle Ex PATE DE VERre MUlticolore (BLeU, JAUNE ET vert). - Sytie. - Collection Horin-Jean, no 995.

une anse de bronze (fig. 88,89 ) et un bouchon de même métal. L'anse était souvent remplacée par des chaînettes de bronze (2).

(I) Voy. Dictionnaire des Antiquités grecques et romaincs de SAGLro, t. I, premiere partie, 1). 453.

(2) Des aryballes avec tout on partic de leur monture de bronze et de leurs chainettes, ont été trouvés en Gaule, notamment au cimetière de Cany (Seinc-Inférieure) [voy. Abbé Cochet, La Normandie souterraine, pl. I, $n^{0} 56$. Fouilles de $\mathrm{r} 849$. Nusẻe de Rouen], et dans la vallée du Rhin [voy. AUs'M' WEERTI dans les Bonner Jahrbicher, 1881 , fasc. $\left.71,131 . \mathrm{V}, 11^{\circ} 1.603\right]$. 
Les aryballes de verre se suspendaient à la ceinture, avec des brosses et divers ustensiles, lorsqu'on allait au bain. Quelques archéo-

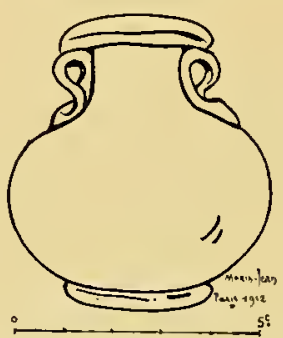

Frg. 87. - Aryballe a pied annUlatre. Verre bled-verdatre. — Fouilles à Paris, faubourg SaintJacques. - Musée Carnavalet.

logues ont pris l'habitude de les désigner sous le nom de bouteilles de bain.

FORME 33 (I). - La bouteille de bain, dans sa forme primitive,

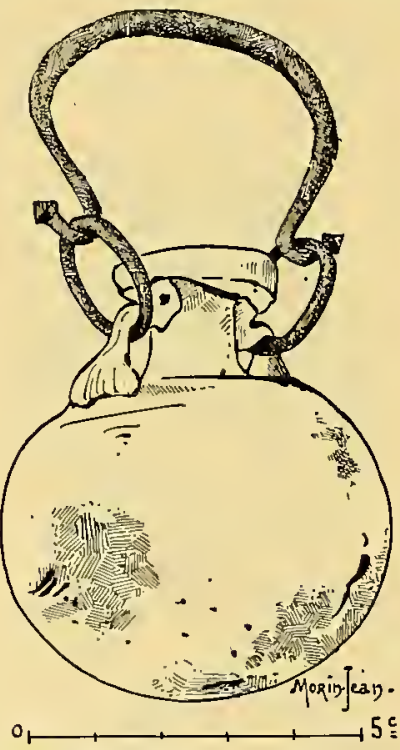

FIG. 88. - ARYBalle DE VERRE A ANSE DE BRONZE, trouvé en Italie. - Collection Morin-Jean, $\mathbf{n}^{\circ} 3040$ :

telle qu'on la voit à Pompéi dès la première moitié du I I $^{\text {er }}$ siècle de notre ère, est une ampoule sphérique dont le dessous est légèrement

(1) I,a forme 33 existe aussi parmi les récipients en métal de l'époque romaine. Des aryballes de bronze, en tous points semblables à ceux de verre, on tété trouvés à Cany [exemplaire du musẻede Rouen], à Reims [AIusće de Reims, no 5.136], à Bonn [Provinzialmuseum de Bonn, nos I4.140 et I6.377], à Cologne [voy. AnToN KISA, Das Glas, p. 322]. 
aplati. Flle a une embouchure à ourlet épais et deux petites anses types $\%, \%$, (p1. 2, p. 36). Elle est en verre naturellement teinté par des oxydes métalliques (verre bleu-verdâtre) ou colorée volontairement

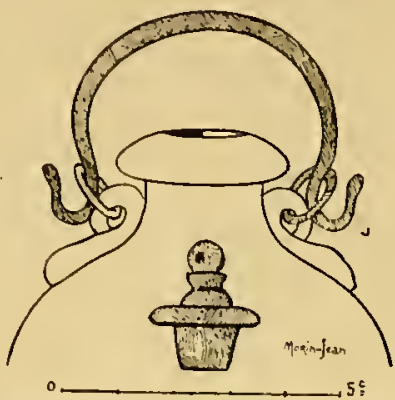

Fig. 89. - ANSE ET BOUChON DE BRONZE D'UN ARYBALIE DE vERRE, - Musée de Naples, nº I294I.

en vert-émeraude, en rouge, en brun-doré (I): Elle est ordinairement d'assez petite taille et ne dépasse guère 6 à 8 centimètres de hauteur (2).

En Gaule, les bouteilles 33 ont été connues de bonne heure. Sur

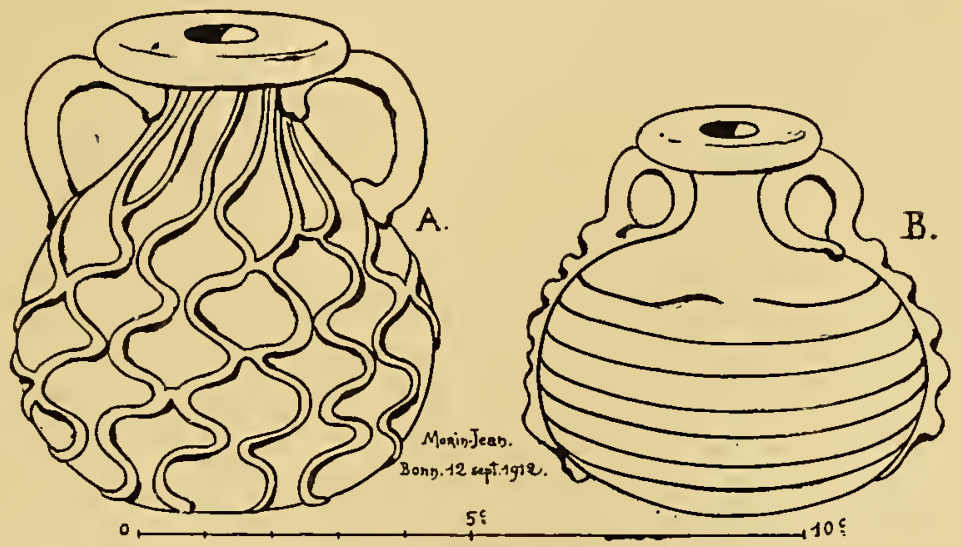

FIG. 90. - ARTBalles DU RosLan II : A. Musée provincial de Trèves. Salle XX. Vitrine IX, no I 7500. B. Musce provincial de Bonn. Salle $V, n^{\circ} 9886$.

les bords du Rhin, à Xanten, elles étaient accompagnées de monnaies de Néron.

(I) Sonvent il n'y a que les anses de la boutcille qui soient en verre de couleur.

(2) Un exemplaire minuscule, qui ne dépasse pas I centinètre $I / 2$ de hauteur totale, est conservé au musce de Saint-Germain [Salle IVT, no I4.060. Iituvirons de Compiène (Fouilles de Roncy)]. 
Dans les diverses nécropoles normandes de Neuville-le-Pollet (I), du Bois-des-Loges (2), du Mesnil-sous-Lillebonne (3), elles étaient associées aux barillets frontiniens de la première moitié du $\mathrm{III}^{\mathrm{e}}$ siècle.
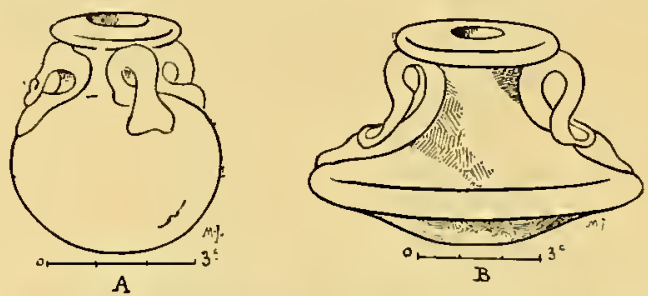

Frg. 9r. - ARYballes a ANSEs Delphiniformes. - Musée de Saint-Germain. Salle XY: A, no I9526.

Type à trois anses. Cimetière de Suèvres (Loir-et-Cher). - B, n ${ }^{\circ}$ r 342 . Type à panse aplatie. Vaison (Vaucluse).

A Cologne, elles ne sont pas rares dans les incinérations de l'époque des empereurs syriens et de leurs successeurs (4). On en trouve aussi, mais en moins grande quantité, dans les sépultures à inhumation de la fin du III et du IV ${ }^{\mathrm{e}} \mathrm{s}$. (5).

Les exemplaires tardifs de la forme 33 sont parfois ornés, suivant

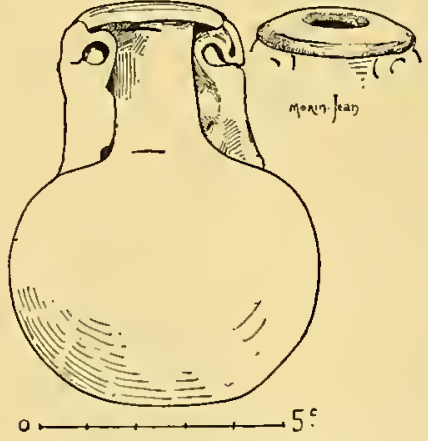

FIG. 92. - ARybatle DE VERRE bLev. - Cabinet des Médailles, à Paris.

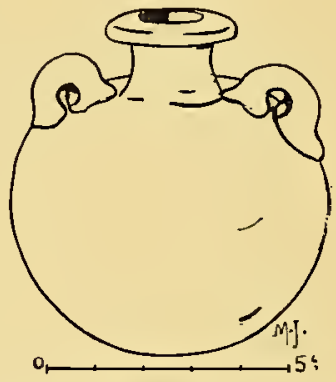

Fig. 93, - ARYBalde Découvert En PiCARdie, Musée d'A miens, no $95_{4}$.

la mode du temps, de fils de verre étirés à chaud (6) (fig. 90 A). Leurs

(I) Abbé Cochet, La Normandie souterraine, pl. II, nos 25 et 29.

(2) Abbé Cochet, loc. cit., pl. IV.

(3) Abbé Cocher, loc. cit., pl. VI, $\mathrm{n}^{0} \mathrm{I}$.

(4) Bonner Jahrbücher, I906, fasc. II4-II 5, p. 406, pl. XXIII, tombe nos 35 , et pl. XYT.

(5) THÉOPHLE Eck, Les deux cinetières gallo-romains de Iermand et de Saint-Quentin, pl. VI, $1^{\circ}$ II.

(6) Des bouteilles 33 , ornées d'un fil de verre qui s'enroule autour de la panse, sont conservées au musće de Trèves [Salle 20, $\mathrm{n}^{\circ} \mathrm{I} .209$ ] et dans la collection Pierpont-Morgan [roy. Fromner, Collection Gréan, $n^{0}$ I. 572$]$. 


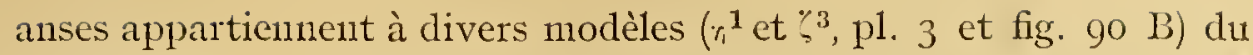
Romain II.

Les variantes du flacon 33 sont assez nombreuses (fig. 90 à 94). Kisa a reproduit, dans son ouvrage sur le verre, un typehybride participant de la forme 33 (panse et anses) et de la forme ro (goulot) (I).

Forme 34. - Boutcille de bain à parois épaisses gravées. -

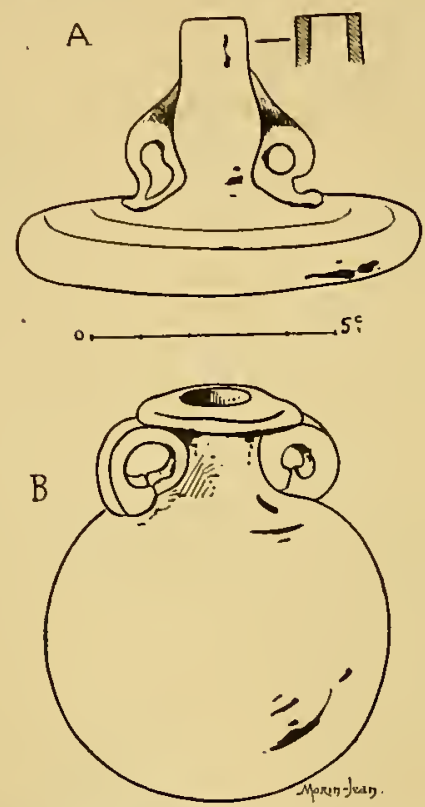

I'IG. 94. - B.iLswimares : A. Cimetière des Dunes. Toitiers, Musce de la Sociaté des Antiquaires de l'Ouest, I, IXI, n० 7 I (83). - B. Ruines romaines de Saint-Saloine, à Saintes. II usée archéologique de Saintes.

Embouchure type A, fig. 8, p. 3I. Anses type $\%$, p1. 3, p. 37. Pâte vitreuse incolore. Hauteur variant entre $\mathrm{I}_{2}$ et $\mathrm{I}_{5}$ centimètres. I.es plus beaux spécimens de bouteille 34 proviennent du Rheinland (2). (fig. 95) (3). Ils se rapportent à la verrerie du Romain II.

FORME 35. - Bouteille de bain à plusieurs compartiments. - I,es flacons 35 qui sont parvenus jusqu'à nous sont tous d'assez basse époque (fig. 96).

(I) Axtos Kisi, Das Glas im Allertume, fig. 61 (à droite).

(2) Beau spécineu au nusée de Cologne [voy. Kisa, loc, cit., fig. 6z].

(3) L'exemplaire que nous reproduisous a été publié par A. Deville : Histoirc de l'A rt de la verrerie, pl. I.XXIII A. 
Trois exemplaires de verre incolore et filandreux sont exposés au musée de Bonn (I) ; ils sont à deux compartiments.

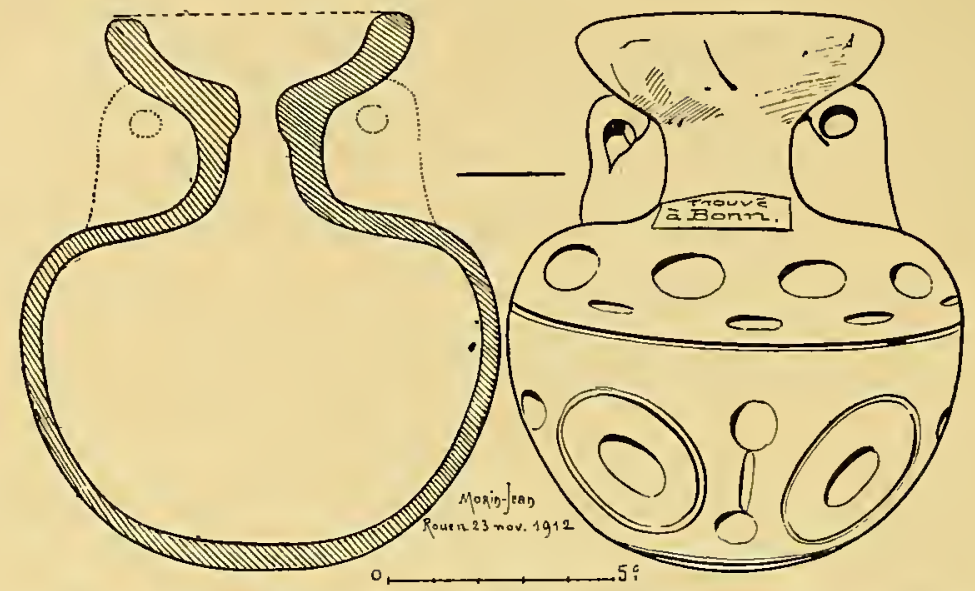

Fig. 95. - ARYBalle EN verre INCOLORE DÉcomposé. — Parois épaisses. Décor géométrique profondément entaillé. Vallée du Rhin. Époque tardive. - Musée départemental d'antiquités, à Rouen.

Un spécimen, signalé par Anton Kisa comme faisant partie de la collection Niessen à Cologne (2), est séparé, à l'intérieur, en trois com-

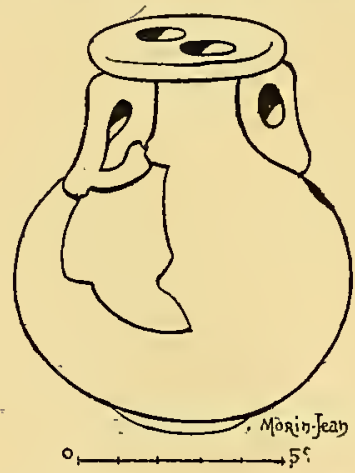

Fig. 96. - Boutertle de bain a deUX COMPARTMMENTS. - Romain II. - Nusée provincial de Bonn. Salle $\mathrm{V}, \mathrm{n}^{0} 8953$.

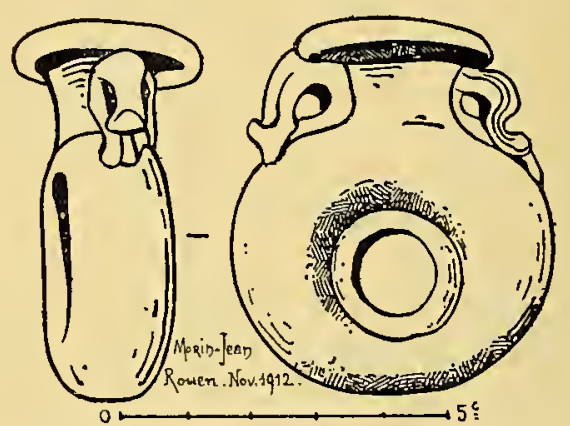

FIG. 97. - ARYballe a PANSE ANNUlaire. VERRE verDATRE. - Musée départemental d'antiquités, à Rouen.

partiments qui correspondent chacun à l'une des trois ouvertures pratiquées dans l'embouchure.

(I) BoNs, Provinzialmuseum, nos 8.953 [fig. 96], I 2.06o et $\mathrm{r}_{5.3} \mathrm{r}_{3}$.

(2) Anton Kisa, Das Glas, p. 323 et fig. 6r (à gauche). 
FORME 36. - Aryballe à panse ammlaire (I). - I es aryballes 36 , tous de petite taille, sont des vases dont la panse a la forme d'un tube circulaire, d'un coussinet rond percé d'une ouverture cen-

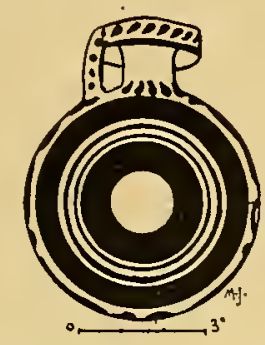

FIG. 98. - ARYBATLE CORNTHIEN DE TERRE CUTTE, A PANSE ANNULAIRE. - vi ${ }^{0}$ s. av. J.-C. - Colection Morin-Jean, n० 2992.

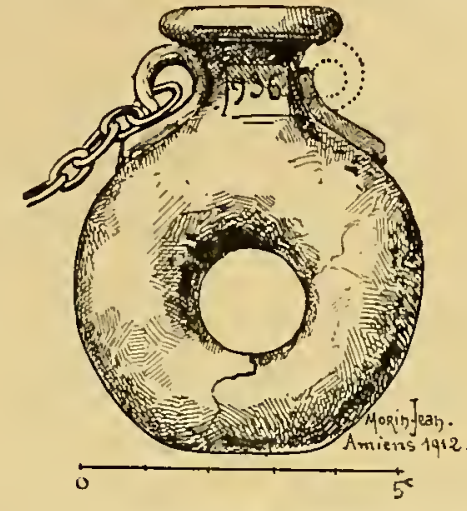

Fig. 99. - ARyballe de verre jaune. PANSE annulatre. - Amiens. Musée de Picardie, $\mathrm{n}^{\circ} 936$.

trale (fig. 97). Leur forme était déjà connue des céramistes corinthiens du vie siècle avant J.-C. (2) (fig. 98).

Les exemplaires en verre de la période impériale romaine sont

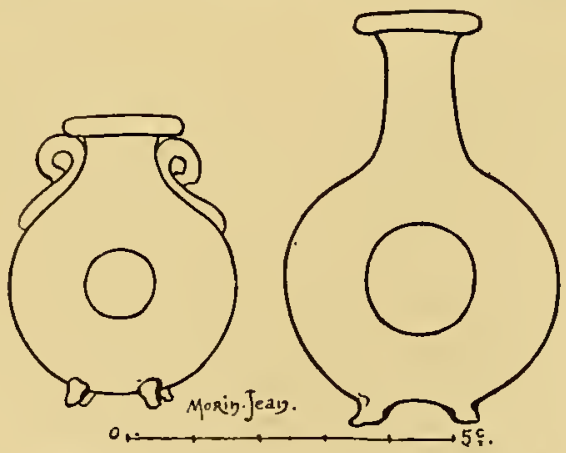

Fig. 100. - ARtballes a PaNse annulare. Types polypodes : A. Musác de Trives. Salle XX. B. Musée de Bonn. Salle V, a ${ }^{\circ} 5_{32}$.

tantôt apodes (fig. 99), tantôt pourvus de trois ou de quatre petites saillies qui permettent à la bouteille de se tenir debout.

(I) I,es Romains out aussi donué la forme annulaire à des vases d’argile comme la cẻlebre lagona du musce Carnavalet à Paris [roy. Revue archéologique, I868, p. 226]. I a lagona du innsée Carnavalet est un] vase qui par son gonlotet ses anses appartient à notre forme 42 , mais dont la panse consiste en un anneau très ctroit. Elle porte l'inscription : Hospita reple lagonam eervesia.

(2) Voy, En. Pottner, Tases antiques du Lourre, p. 17, pl. I 4, A. 428 et 429. 
Ces saillies sont constituées, soit par des guttules de verre rapportées à chaud (fig. Ioo, A.), soit par des protubérances que l'ouvrier obtenait en pinçant la pâte vitreuse pendant qu'elle était encore malléable (fig. Ioo, B.).

7. - I'AMPOULE A PANSE SPHÉRIQUE ET SES VARIANTES. DIOTAS ET GOURDES PLATES.

(Formes 37 à 43.)

FORME 37. - Les ampoules 37, dont l'embouchure, coupée aux oiseaux, est dépourvue d'ourlet, dont les minces parois sont en verre

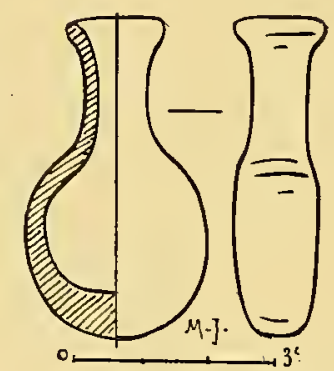

Fig. iot. - Ampodle a panse aplatie. Verre verdatre. - Vermand. - Musée Lícuyer, à Saint-Quentin, $\mathrm{n}^{\circ} 2713$.

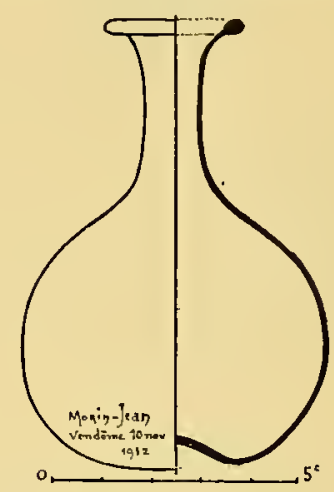

FIG. I02. - BoUTEILLE EN VERRE VERDATRE. Pezou (Loir-et-Cher). Romain II. - Musée de Vendôme.

bleu-verdâtre ou coloré en bleu-azur ou en jaune, appartiennent à la même série que les types 20-2I, et se classent aux mêmes époques (voy. plus haut, p. 75).

Une importante série de fioles 37 , les unes en verre bleu, les autres en verre jaune, est exposée au musée archéologique de I,yon.

FORne 38. - Variante à panse aplatie de la forme 37. - Parois épaisses. Verre verdâtre.

Les ampoules 38 se placent au Romain II. Elles ne sont pas rares dans les cimetières tardifs du nord de la France (I) (fig. IOI).

(I) Cimetière de Vermand. TH. Eck, Les deux cimetières gallo-romains de Vermand et de Saint-Quentin, pl. VI, n⿳亠口冋. 
FORME 39. - Variante à panse sphérique de la forme 26. - Elle

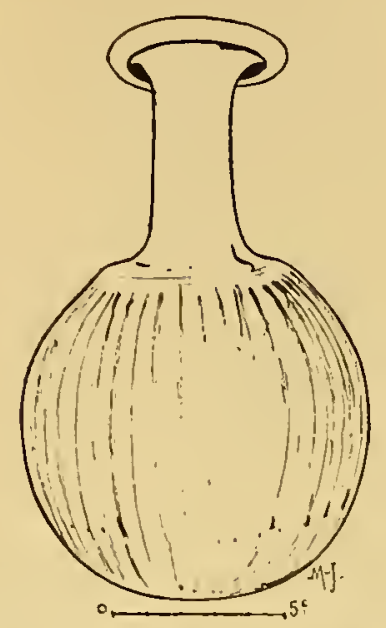

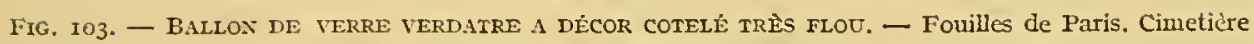
romain du faubourg Saint-Jacques, Ive s. - Musée Carnavalet, à Paris.

se classe, comme cette dernière, dans la verrerie d'époque tardive (fig. I02) (voy. plus haut, p. 79).

Forne 40. - Ballon de verre à goulot évasé. - Les bouteilles 40
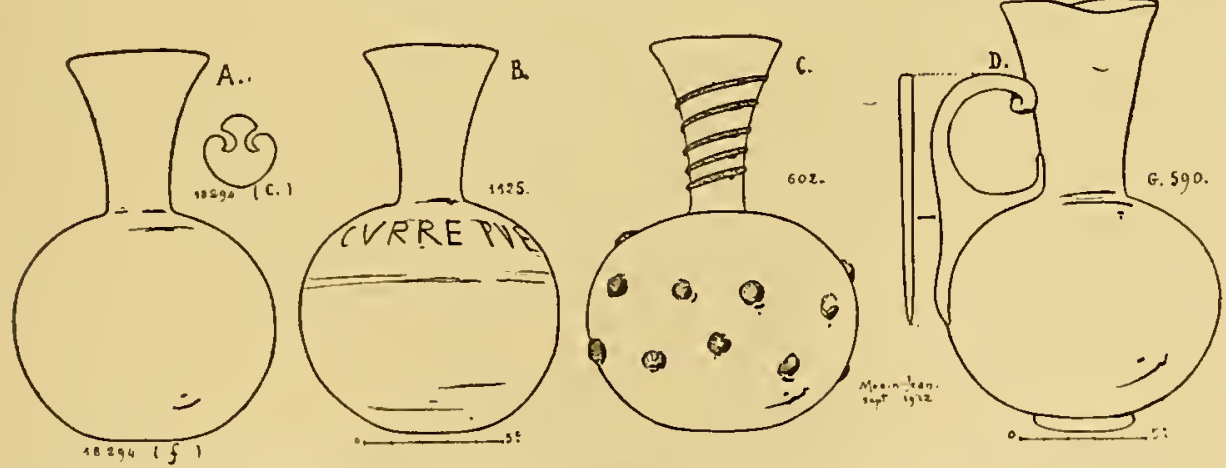

FIG. IO4. - BOUTEILLES SPHÉRIQUES A GOULOT ĖVASÉ. Romain II : A. Sépultures à inhumation d'Ehrang. Tombe n 6. Musée provincial de Trives. Salle XIX. - B. Inscription gtavée. cvrre. pverva. Muséc de. Vayenee, $n^{\circ}$ II $25 .-C$. Bouteille de verte incolore. Oruements en verre bleu. Fouilles de la rue d'Aixla-Chapelle, à Cologne. Musée Wallraf-Richariz, $\mathrm{n}^{\circ}$ 602. - D. Muséc provincial de Trives. Salle XX, $\mathrm{u}^{\circ} 590$.

sont tantôt apodes (fig. I04, A, B et C), tantôt pourvues d'un pied annulaire (fig. I05 à I07). Très rarement elles ont une anse (fig. I04, 
D.). I a plupart d'entre elles sont en verre uni. Quelques-unes sont

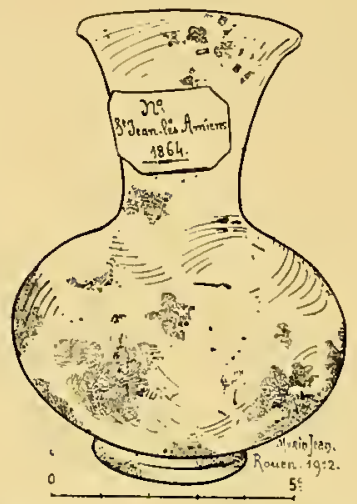

Fìg. I05. - BouteIlle a COL Évasé, trouvée à Saint-Jean-lès-Amiens, en I864. Romain II. - Musée départemental d'antiquités à Rouen (ancicnne Collection de Girancount).

décorées de dépressions (fig. 256), de fils de verre, de cabochons de couleur (fig. I04, C.). de gravures (fig. I04, B.).

Une variante assez répanđue comporte un goulot étranglé du bas

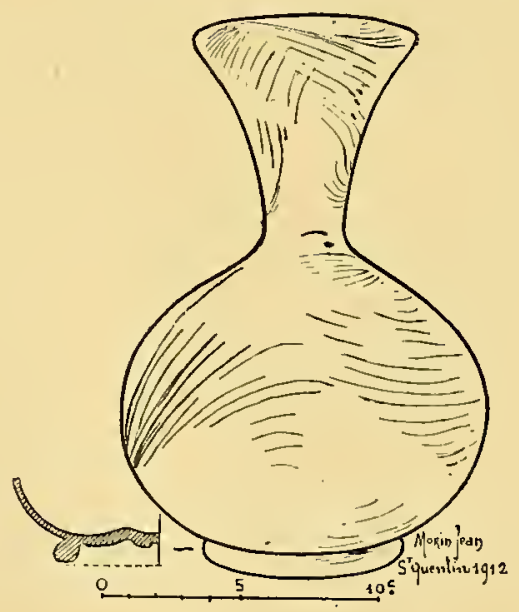

FIG. I06. - BOUTEILLE EN VERRE VERDATRE TRÈS FILANDREUX. - Vermand. Ive s. - Collection Théophile Eck, à Saint-Quentin.

et terminé à l'orifice par une embouchure brusquement évasée (fig. IOg).

Les bouteilles 40 sont d'origine orientale. En Gaule, elles sont très 
fréquentes dans les vallées de la Moselle et du Rhin ; elles deviennent

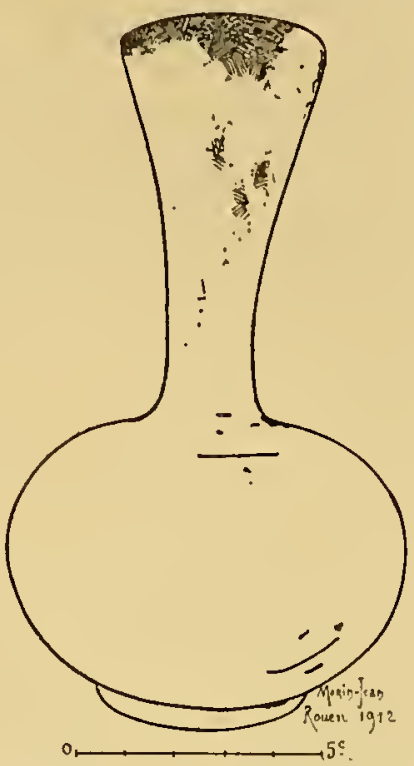

FiG. I0\% - BOUteIlle EN VERRE FILANDReux. - Environs d'Amiens (foulles de 1867). Romain II. Music dipartemental d'antiquités à Ronen. (aneienne Collection de Giraneourt).

plus rares à mesure que l'on s'éloigne de ces régions vers l'Ouest ou

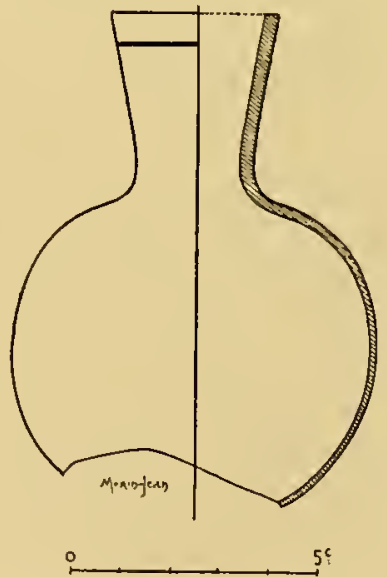

IitG. IO8. - BOUTEILle EN VERRE JAUNE-VERdatre, tronvéa à Ireims, en 1747. Romain IJ. Paris. Cabinet des Médailles, n 3722.

vers le Sud. Toutes sont en verre incolore ou légèrement verdâtre, 
souvent rempli de nœuds et de filandres. Elles apparaissent dans les sépultures du III siècle, mais c'est principalement dans les tombes à inhumation $d u \mathrm{IV}^{\mathrm{e}}$ siècle qu'elles ont été rencontrées. Elles abondent dans les mobiliers funéraires de la Germanie (I), et s'y trouvent mêlées à des plaques de ceintures de la seconde moitié du IV siècle, à des fibules cruciales caractéristiques des derniers temps de l'Empire (2), à des monnaies allant de Volusianus (25I à 254) à

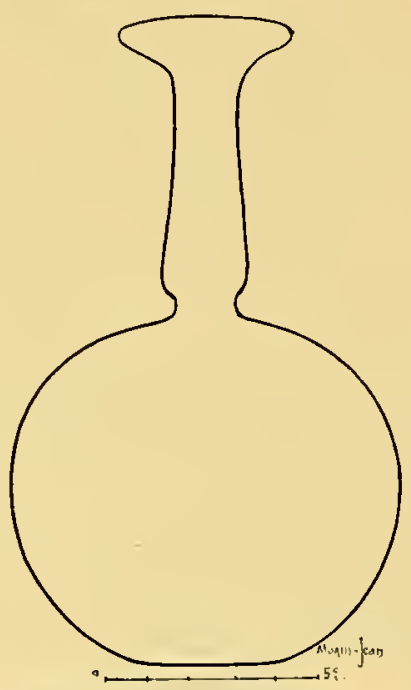

Fig. Iog. - BouteILle découverte PAR L'ABBÉ COCHET, à Lilleboune, en I867. - Romain II. - Misée départemental de Rouen.

Gratien (375 à 383), à d'autres verreries de formes tardives [types $9(3), 50(4), 6$ I (5), 76 (6), II6 (7), I24 (8), I32 (9)].

FORME $4 \mathrm{~T}$. - Ballon de verre dont le goulot, étranglé dans le bas, va en se rétrécissant vers l'orifice. - Tout ce qui vient d'être dit au

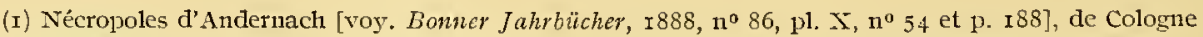
[Bonner Jahrb., I906, fasc. II4-II5, tombes 59, 60, 6I, 62, 66, 67, 68, 69, 71] de Trèves, de Strasbourg [STraub, Le cimetière gallo-romain de Strasbourg, p. 3 I, pl. VII, $\mathbf{n}^{\circ s}$ I et 2 ], de Mrayence, etc.

(2) Bonner Jahrbücher, I9o6, fasc. II4-II5, p. 427, pl. XXV, tombe 62 du cimetière de Cologne.

(3) Bonner Jahrbiicher, loc. cit.. Cimetiere de Cologne, tombe $n^{\circ} 67$.

(4) B. J., loc. cit., tombe 69 (avec moyen bronze de Dioclétien (284 à 305 ).

(5) B.J., loc. cit., tombe 68.

(6) B. J., loc. cit., tombes 66 et 68.

(7) Tombe du musée de Trèves.

(8) B. J., loc, cit., tombe 6i (avec monnaies de Cratde le Gotirgue et Carus).

(9) B. J., loc. cit., tombe 68. Barillet signé : Fron. 
sujet de la forme 40 peut être répété à propos de la forme 4I qui n’en diflère que par la structure de son goulot (fig. I Io).

On conserve aux musées de Trèves, de Strasbourg (I), de Bonn, de Cologne, de Mayence, d'Amiens (2) de belles bouteilles forme 4I dont quelques-unes sont gravées (fig. III) ou peintes (voy. plus loin, p. 249).

FORME 42. - Ballon de verre à anses arrondies fixées par leur

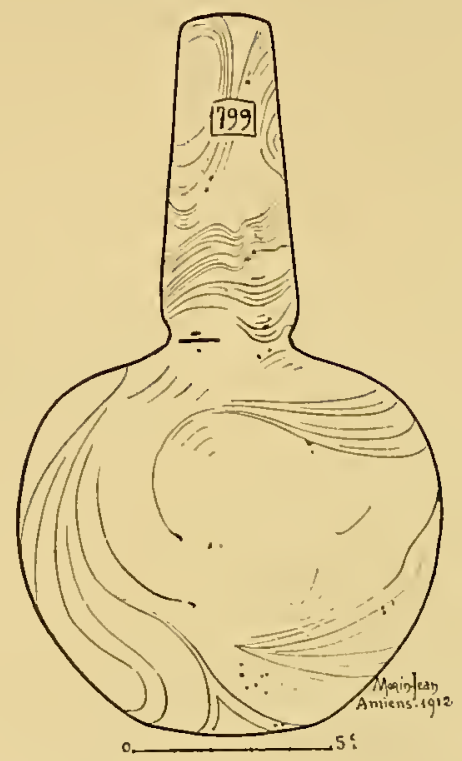

FIG, IYo. - BOCTEILLE DE VERRE VERDATRE CHARGÉ D'MMPURETÉs ET DE FILANDRES. TV ${ }^{\mathrm{e}}$ s. - Amiens. Musée de Picardie, $\mathbf{n}^{\circ} 799$.

extrémité supérieure, à une bague de verre placée vers le milicu du goulot (fig. II2, II3 et pl. 8). Les bouteilles 42, que les archéologues nomment quelquefois diota (de $\delta(\dot{c}) \cdot n$, mot grec signifiant $a$ deux oreilles), sont synchroniques avec les types 40 et $4 \mathrm{I}$; aussi sont-elles formées, comme eux, d'une pâte de verre incolore, souvent impure, chargée de bulles d'air et de filandres.

Elles ont presque toujours un pied annulaire, quelquefois un pied conique séparé de la panse par un sphéroïde. L.es spécimens à

(r) Straub, Le cimetive gallo-romain de Strasbourg, pl. VII, no 3 .

(2) Musée de Picardie, $n^{08} 799,844,961$. 
quatre anses (I) et ceux ornés de cabochons de verre (2), ou de serpents (3), ne sont pas communs.

La bague qui sert de point d'appui aux anses des diotas est formée, tantôt d'un gros fil de verre (fig. II2), tantôt d'une collerette festonnée ou ondulée au fer. Plus rarement, elle se compose de deux anneaux reliés entre eux par un fil de verre décrivant des zigzags (4).

Les diotas forme 42 sont très répandus dans le nord des Gaules. Ils y existent déjà au temps des empereurs syriens (5), mais de-

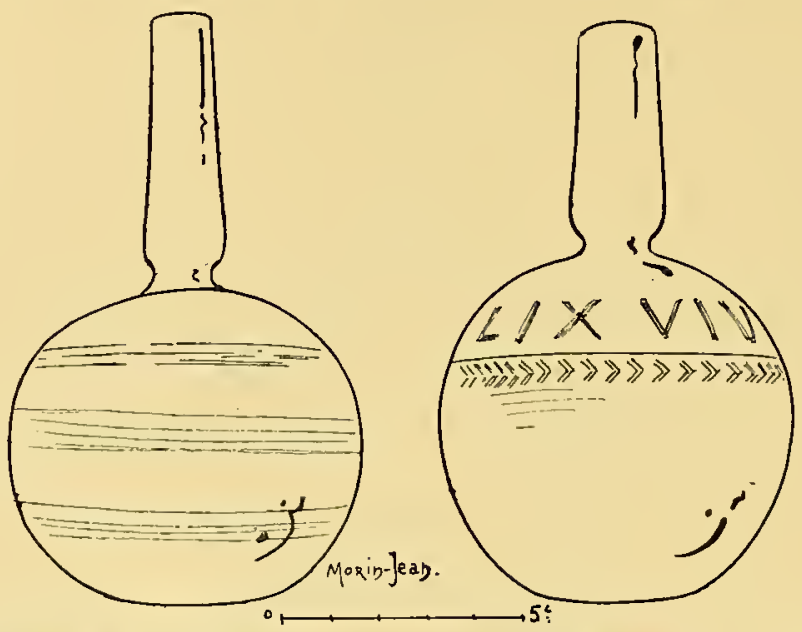

Fig. III. - BouteIlles DE LA vallée DU RHIN. - Décor gravé. Romain II : A. Musée provincial de Trèves, $\mathrm{n}^{0}{ }^{5268 \mathrm{~b}}$ - - B. Fouilles de Kastel. Musée de Mayence, $\mathrm{n}^{0} 44 \mathrm{II}$.

viennent plus nombreux à l'époque constantinienne. Ils sont surtout communs dans les inhumations postérieures au milieu du $\mathrm{III}^{\mathrm{e}}$ siècle (6).

(I) Exemplaire du cimetière de Vermand conservé au musée de Saint-Quentin et publié par Tr. ECK, loc. cit., p. I44 et pl. V, n०2.

(2) Spécimen du cimetière deCologne découvert daus une incinération du $\amalg^{\mathrm{e}}$ siècle [Bonner Jahrbücher, I906, fasc. I I4-II 5, p. 407, pl. XXIII, tombe no 36 ]. I,e diota à quatre anses de Vermand signale ci-dessus (note I) porte également des cabochons sur la panse (voy. plus loin, p. 223, $n^{\circ} 3$ ).

(3) Diota découvert à Vermand et publié par J. PILLoy, Études sur d'anciens lieux de sépultures dans l'Aisne, pl. VII bis, $\mathrm{n}^{\circ}$ I.

(4) I,e diota ci-dessus mentionné (note 3) est muni de ce type de collerette à jour.

(5) Diota trouvé en I 897, rue du I,uxembourg, à Cologne, dans une incinération, avec des bonteilles, formes 54,62 et 64 , ornées d'applications vermiculaires, et des monnaies d'Hadrien et de Crispina, femme de Commode [voy. Bonner Jahrbücher, I906, fasc. II 4-Ix 5, p. 409, pl. XXIV, tombe $n^{0} 3^{8}$ ].

(6) Nécropoles de Vermand, d'Amiens [MIusée de Picardie, no 803 et 936], de Strasbourg [STraub, Le cimetière gallo-romain de Strasbourg, p. 48 , pl. VI, $n^{\circ} 4$ ], de Trèves [Musée de Trèves, salle 20 , vitrine VIII, G. 747], de IIayence, de Cologne [Bonner Jahrbiicher, I906, fasc. II 4 -II5, p. +22 , tombe $n^{\circ} 59$, où le type de bouteille 42 est accompagné d'autres verreries tardives (formes 40,73 et $9^{8}$ ) et de monnaies des empereurs Volusianus, Postumus et Gallienus]. 


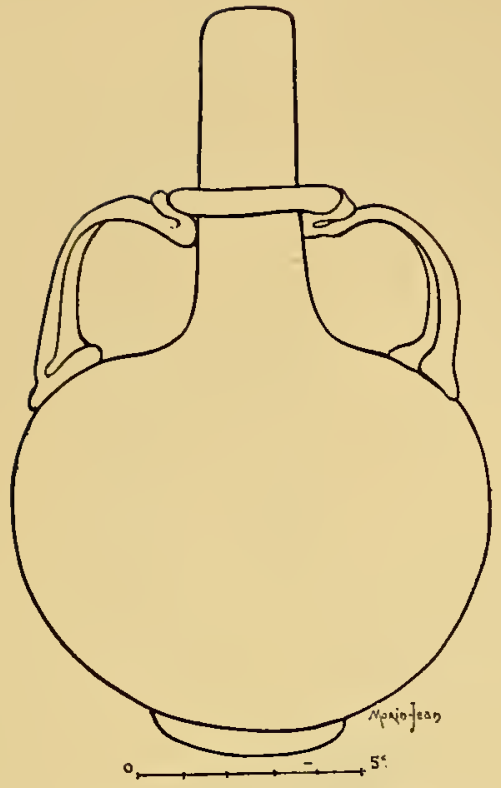

Fig. II2. - DrotA. - Verre incolore, IVe s. Mrusée de Rouen.

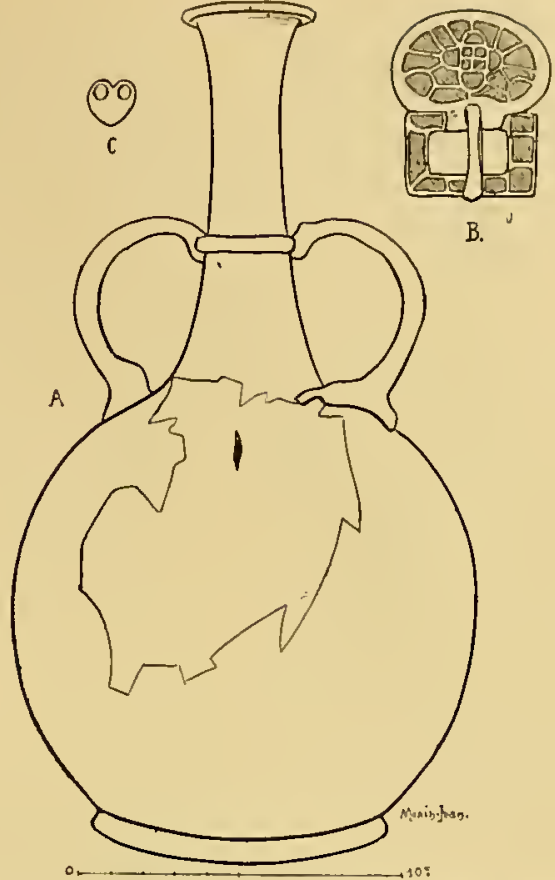

FIG. II3. - MOBIIIER FUNÉRATRE D'UNE TOMgBE A INHUMATION DU CIMETIÈRE D'ARCY-SANTE-REStrTuE (Aisne). - Epaque des invasions. - A. Drota de verre. - B. Boucle de ceinture, ornée de verroteries rouges. - $C$. Ornement de ceinturon. - Musée de Saint-Germain. Salle F. MIoreau. Vitrine 45 . Tombe I687.

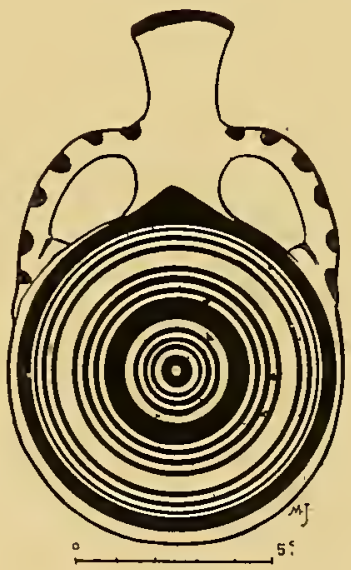

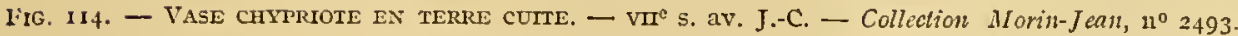


Quelques-uns, comme celui du mobilier funéraire du chef de Monceau-1e-Neuf (I), se distinguent de leurs congénères par leurs dimensions exceptionnelles.

La forme 42 était encore en usage à l'époque des invasions ; au
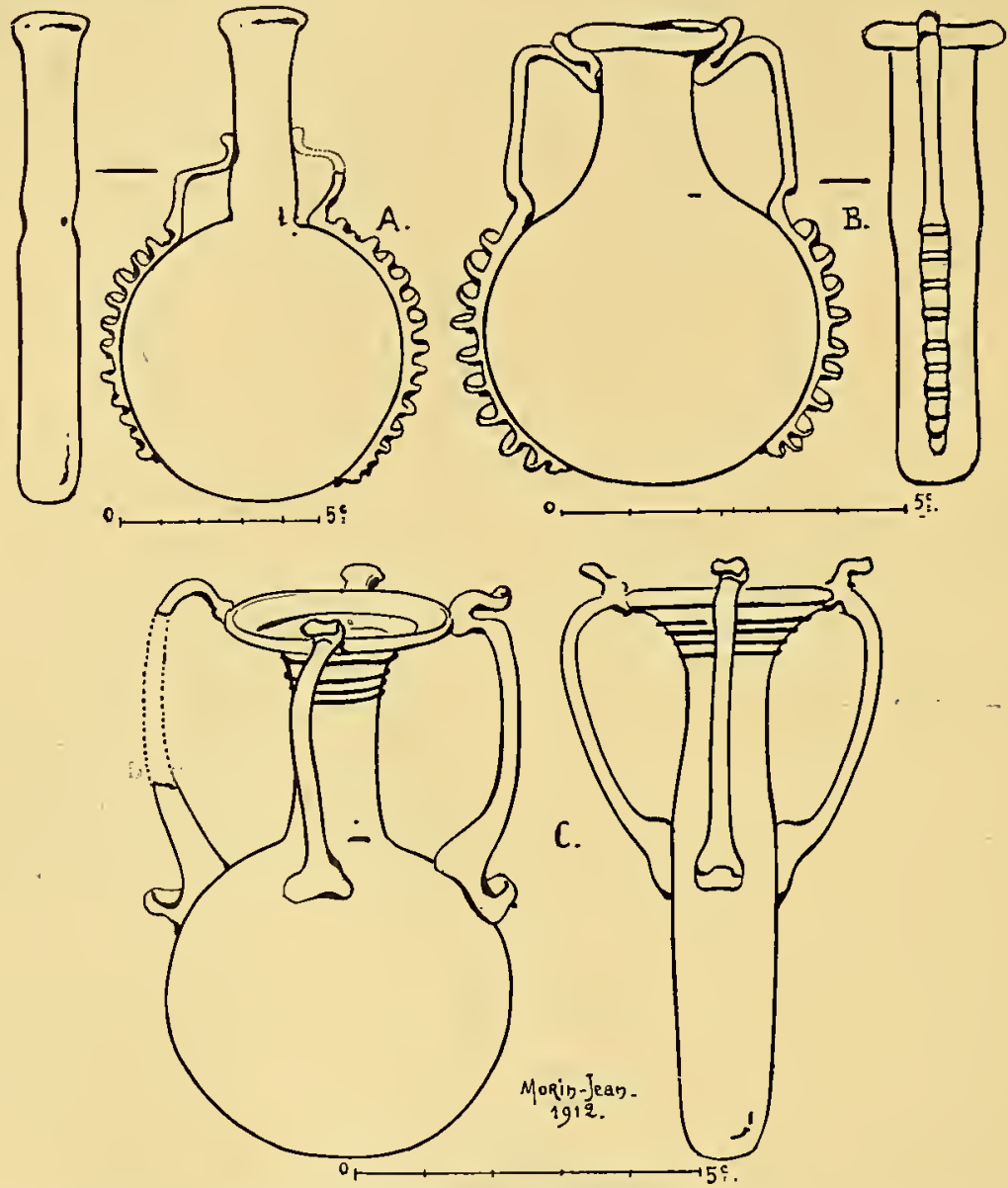

Fig. II5. - Flacons a panse aplatit: A. Fouilles de Palestine. Musée de Cologne, no 687. - B. Verte vert foncé. Musée de Bonn (Salle V, $n^{\circ}$ 206). - C. Mayence. Fouilles de I907. Musée de Mayence.

cimetière d'Arcy-Sainte-Restitue (Aisne), F. Moreau a ouvert une tombe contenant un diota et une boucle de ceinturon en bronze ornée de verroteries rouges cloisonnées, qui a déjà tous les caractères des bijoux francs (fig. II3).

r) Cl. Boulanger, Le Mobilier funeraire, pl. I5 et 20. 
FORnE 43. - Variante à panse plate du type 42. - I a gourde plate accostée de deux petites anses [ $\left[n^{0} 63\right.$ des types d'argile décrits par M. Dragendorff] (I), est d'origine gréco-égyptienne, comme nous l'apprennent les nombreux modèles de terre cuite découverts en Égypte (2), et à Chypre (fig. I I4). Les industriels de la Gaule l'ont connue par l'intermédiaire des fabriques établies dans l'Italie du Sud.

Au type 43 de terre, appartient le vase Sallier qui est du III $^{\mathrm{e}}$ siècle (3).

Au type 43 de verre, se rattachent plusieurs modèles de flacons

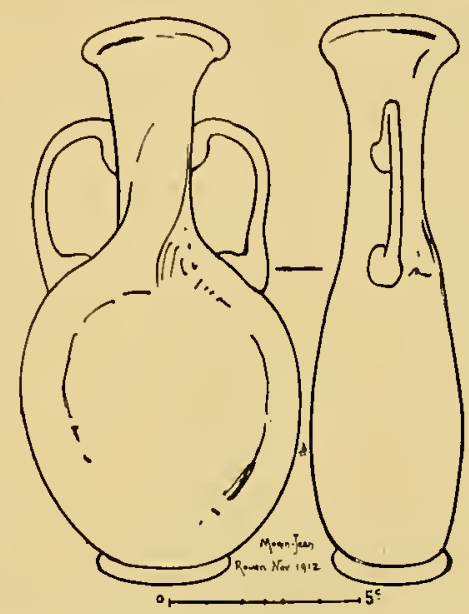

FIG. II6. - BOUTELle a PANSE APLATIE. VERRE VERDATre. Ive s. - Musée départemental d'antiquités, à Rouen.

qui ne se rencontrent guère en Gaule, avant l'époque des empereurs syriens (4), et dont quelques spécimens, comme la gourde du musée de Rouen (fig. II6) et celle du musée de Mayence, exceptionnellement pourvue de quatre anses (fig. II5, C.), sont de très basse époque.

(1) Terra Sigillala, dans les Bonner Jahrbiicher, fasc. 96-97, anuée I 895 .

(2) ED. PotтIER, Vases antiques $d u$ Louvre, Paris, Hachette, I 897 , p. I et pl. $3,11^{\circ} 2$.

(3) Sur le vase Sallier, couservé au musée de Saint-Germain, consulter J. Déchelette, Lés vascs círa* miques ornés de la Gaule romaine, t. II, p. 307 et pl. IV.

(4) Par exemple, la belle bouteille du musée de Cologne, publiće dans les Bonner Jahrbücher, fasc. 99, année I 896, pl. II, no 5 , et décrite plus loin, p. $2041^{\circ} 2$ et fig. 274. 
8. - BOUTEILLES A UNE ANSE. ENOCHOÉS ET VARIANTES.

(Formes 44 à 6I.).

FORME 44. - Copie des cnochoés de bronze de la haute époque impériale. - Une sépulture collective, découverte à Vaison, en I838 (fig. 334, 335), et reconstituée dans son état primitif au musée Calvet à Avignon, contient deux exemples de ce type de verrerie. Ce sont

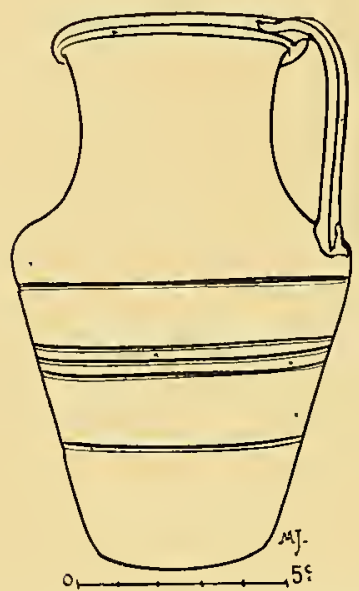

FiT. $117 .-$ EINOCHOÉ ORNÉE DE CERCLES GRAVÉS, VERRE INCOLORE. - $\mathrm{II}^{\mathrm{e}}$ s. - Paris, Cabinet des Médailles, $\mathrm{n}^{\circ} 5452$.

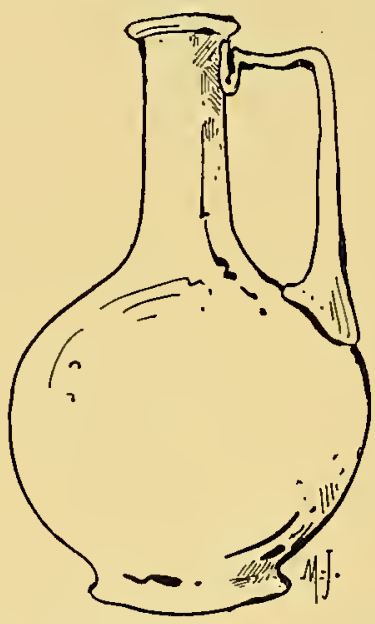

FIG. II8. - FLACON DE VERRE DU RoMAIN I. Muscée de la Maison Carrée, à Nîmes, nº ${ }_{13} 6$.

des récipients à encolure courte et largement ouverte, à anse plate (fig. 335, E). L'un d'eux est intact; 1'autre a la partie inférieure de la panse entièrement brisée. Que l'on compare ces verreries aux nombreuses onochoés de bronze découvertes à Pompéi, et l'on verra tout de suite que les verriers romains n'ont fait que copier, à peu près servilement, les produits qui sortaient des officines des bronziers d'Alexandrie et de 1'Italie méridionale.

L,es œnochoés de Vaison sont difficiles à dater. Une verrerie de même forme, conservée au Cabinet des Médailles à Paris, et dont la provenance ne nous est malheureusement pas connue, est incolore et ornée de cercles gravés à la meule (fig. II7). Si elle date 
du III siècle, ce qui nous semble à peu près certain, elle nous

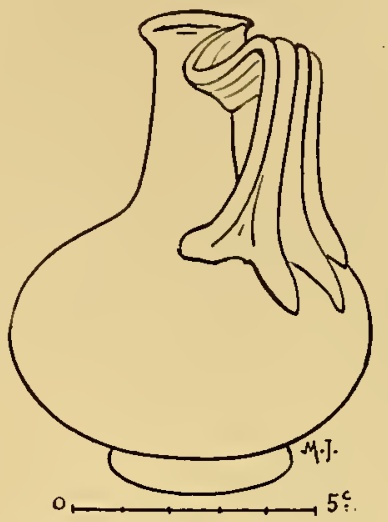

Fig. IIg. - BoUteIlle EN verRe BLEU•Vermatre, trouvée à Arles. - Cabinet des Médailles, à Paris, n० 5475 .

prouve que la forme 44 était connue des verriers du Romain II.

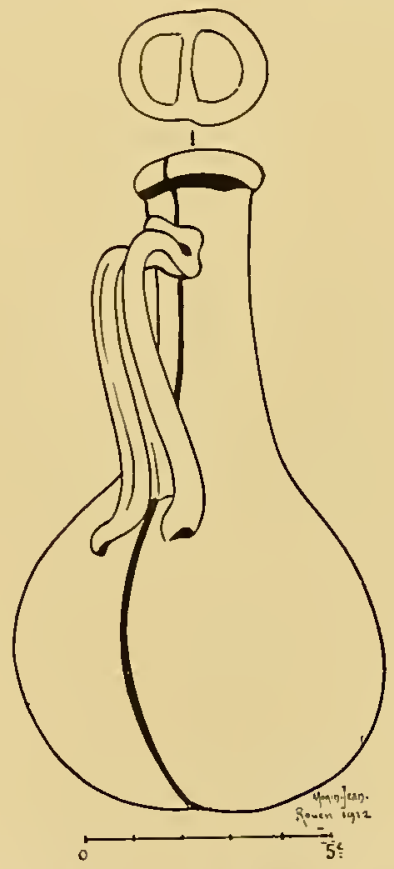

IIG. I20. -BOUteILle a Detx COMParTluents. - Cany (Seine-Inférienre). Fouillos Cochet en is $49 .-$ Muséc de Rouen.

FORME, 45. - Copie des cruches de terre blanche, rosée ou jannâtre, 
très communes au premier siècle de notre ère. - Les verieries de la forme 45, abondantes dans la basse vallée du Rhône, sont du I $\mathrm{I}^{\mathrm{er}}$ et du II $^{\mathrm{e}}$ siècles (fig. II8). La variante fig. II9 peut descendre jusqu'à la seconde moitié du III ${ }^{\mathrm{e}}$ siècle.

FORME 46 (I). - Variante à deux compartiments du type 45. Typologiquement et chronologiquement, les bouteilles 46 se rattachent au type I 5 dont elles ne diffèrent que par la forme de leur panse.

On trouve des modèles Romain I de la forme 46 au musée Calvet

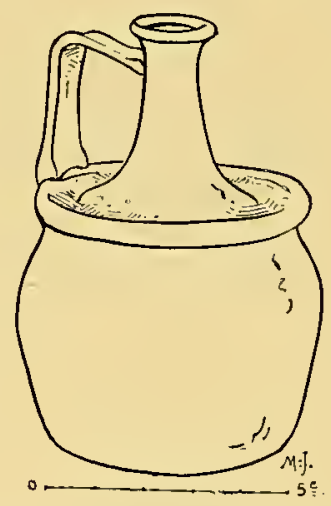

Fig. 12t. - Bouteile a goutrière. - Musée de la Maison Carrée, à Nîmes, no 84 .

à Avignon (2) et au musée archéologique de Reims (3). Au Romain II, la bouteille 46 évolue et aboutit à un type fig. I20 et forme 63, dont le galbe est plus mou, dont l'anse est plus arrondie, dont les embouchures sont moins distinctes, moins séparées les unes des autres.

FORME 47. - Bouteille pourvue d'un bourrelet formant gouttière à la partie supérieure de la panse. - Ce genre de bouteille a été rencontré à Saintes (4), à Nîmes (5), à Vaison (6). On en connaît des

[(1) L,es verriers orientaux sont peut-être les créateurs de cette forme. Des vases de verre à đeux compartiments ont été trouvés en Syrie [voy. Musée du I,ouvre. Département des antiquités orientales. Salle des petits monuments de Sarzec].

(2) MIusée d'Avignou, $n^{\circ}$ II3. Trouvẻ à Orange en I 840 . Hauteur : 17 centimètres.

(3) Musée archéologique de Reims, $\mathrm{n}^{\circ} 2.279$ [voy. Catalogue, p. 72].

(4) Musée de Saintes. Partie supéricure d'uue bouteille 47.

(5) Musée de la Maison Cartée, $n^{0} 84$ (fig. I2r).

(6) Deux spécimens de r $r$ centimètres de hauteur.t Musée Calve àAvignon, noo r 1 I et r 12. 
exemplaires provenant de l'île de Chypre (I). Le musée de SaintGermain en possède un spécimen fragmenté dont la provenance est inconnue (2).

Les vases de verre à gouttière se classent avant le IVe $s$. On n'en a pas trouvé, à notre connnaissance, dans les sépultures d'époque tardive.

FORME 48.- Panse fortement galbée, se rétrécissant à la partie inférieure. Même base qu'aux urnes 5 et 6 . Goulot long nettement dé-

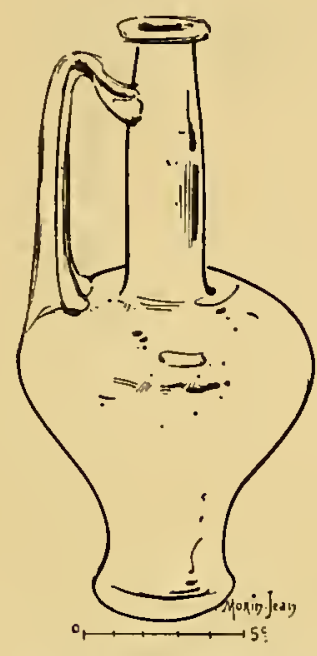

FIG. I22. - FLACON DE VERRE BLEU, trouvé à Valrẻas. - . Tusée Calvet, à Avignou, $\mathrm{n}^{0}$ ro3.

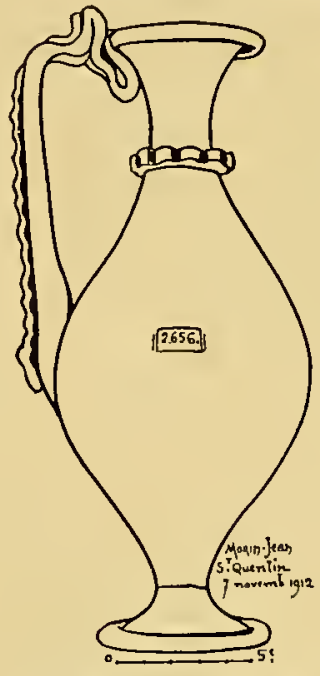

FIG. I23. - BOUTEILle A UNE ANSE, VERRE VERDATRE. - Cimetière de Vermand. $\mathrm{IV}^{\mathrm{e}} \mathbf{s}$. - Musée Licuyer, à Saint-Quentin, $\mathrm{n}^{\circ} 2656$.

taché de la panse. Anse bifide. - Les œnochoés forme 48 sont de la haute époque impériale. Elles sont synchroniques avec le type 57. Le spécimen que nous reproduisons fig. I22 est en verre d'un bleu magnifique.

FORME 49. - La panse, fuselée, s'amincit autant, et quelquefois plus, dans le bas que dans le haut. Le goulot, fondu dans la panse, est orné d'une bague de verre. Le pied tronconique à gros bourrelet se fond dans la panse. - Les bouteilles forme 49 appartiennent toutes à la verrerie

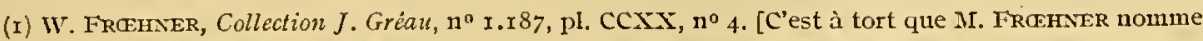
chytra ce genre de récipient. I,es chytres antiques sont des marnites qui n'out rien à voir avec nos fla. cons 47 (roy. Dictionnaire de Saglio, t. I, deuxieme partie, p. I I 40)).

(2) MIusée de Suint-Germain, no 29.525 (achat en 1885 ). 
tournée de la seconde moitié du mI et du IV $\mathrm{s}$. En Syrie, elles atteignent des dimensions colossales (superbes exemplaires orientaux au musée du Louvre). En Gaule, elles sont particulièrement abondantes dans le nord et sur les bords du Rhin. On en a recueilli plusieurs au cimetière de Vermand (I) (fig. I23). A Homblières (Abbeville), M. Pilloy en a trouvé une dans une tombe qui contenait une monnaie de l'empereur Valens (364 à 378) (2). Un spécimen dont la pâte vitreuse

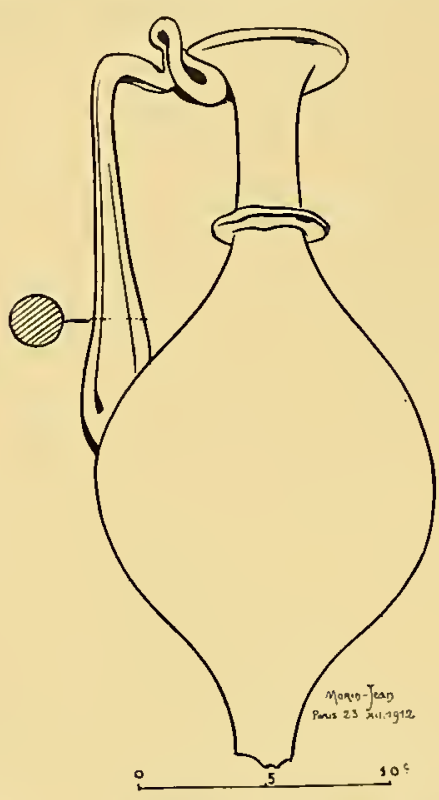

FIG. I24. - BOUTEILLE EN VERRE VERUATRE CHARGÉ DE FILANDRES. - Trouvée à Paris, près l'église Saint-Germain-des-Prés, dans une tombe à inhumation. - Musée Carnavalet.

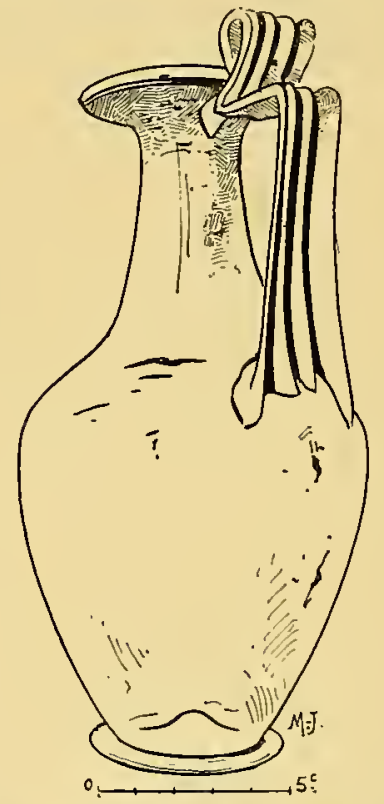

FIG. 125. - ENOCHOE DE VERRE INCOLORE (Marne). - Collection Morin-Jean, $\mathrm{n}^{0} 203^{8}$.

indique une époque très basse, peut-être le ve siècle, a été découvert à Paris (fig. I24). Un très bel exemplaire, rencontré avec une monnaie de Constantin le Jeune (337 à 340) au cimetière de Strasbourg (3), offre une particularité remarquable: la bague qui entoure le goulot est constituée par un gros fil de verre bleu disposé en zigzag.

FORne 50. - Panse ovale un peu rétrécie dans le bas. Goulot plus

(I) Voy. TH. Eck, Les deux cimetières gallo-romains de Vermand et de Saint-Quentin, pl. IV, $\mathrm{n}^{0 \mathrm{~s}}{ }_{4}$ et $\mathrm{IO}$.

(2) Voy. J. Pilloy, Etudes sur d'anciens lieux de sépultures dans l'Aisne, t. I, pl. III, no I3.

(3) Straur, Le_cimetière gallo-romain de Strasbourg, tombe à inhumation $\mathrm{n}^{0} 7_{2}, \mathrm{pl} . \mathrm{V}, \mathrm{n}^{\circ} \mathrm{I}$. 
ou moins fondu dans la panse. Pied annulaire. Embouchure à double bourrelet. - Les bouteilles 50 font partie du même groupe de verreries et se rencontrent dans les mêmes régions que les bouteilles 49 . Leur fabrication semble avoir débuté au $\mathrm{III}^{\mathrm{e}}$ siècle (I), mais appartient surtout au Ive.

Ces élégantes aiguières sont rangées par les archéologues, tantôt dans la catégorie des prochous (2), tantôt dans celle des lagènes (3)

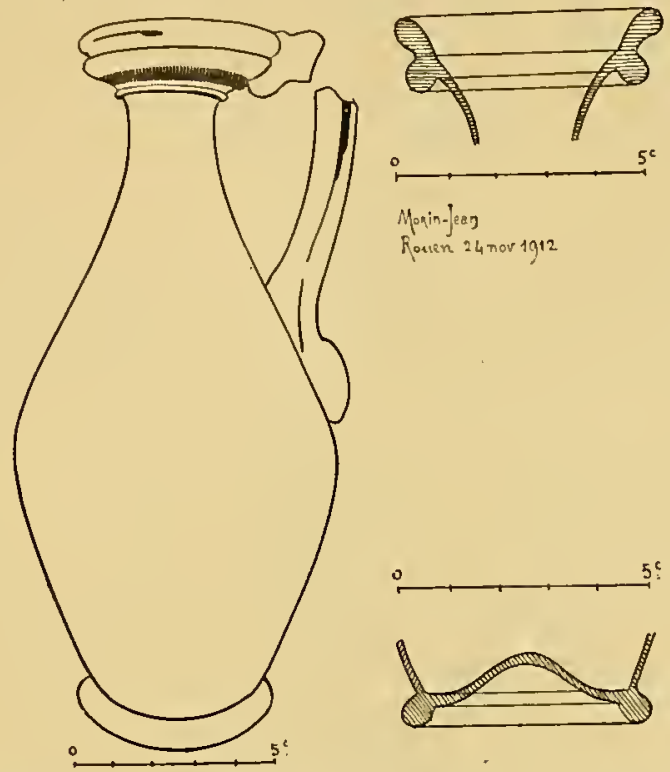

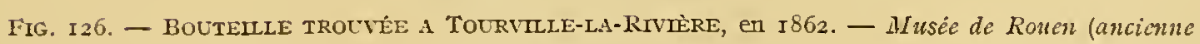
Collection de Giranconrt).

ou des conochoés (4). Mais ces noms ne correspondent à rien de précis, puisque les auteurs anciens employaient chacun d'eux pour désigner des récipients de formes diverses.

Quoi qu'il en soit, les bouteilles se rattachant à notre forme 50 sont si différentes les unes des autres dans les détails de leur structure que nous ne pouvons songer à en décrire ici toutes les variantes. On peut, du moins, distinguer deux séries assez nettement caractérisées.

(I) Spécimens des incinerations du cimetière de Cologne [Bonner Jahrbïcher, rgo6, fasc. I I 4-I I5, p. 4Io, pl. XXIV, tombes 39 et 47 ].

(2) Sur le Prochous, voy. Dictionnaire da Saglio, t. IT, première partie, p. 66I.

(3) Sur la Lagena, roy. Diclionnaire de Saglio, t. III, deuxième partie, p. 907.

(4) Sur l'Enochoé. voy. Dictionnaire de Saglio, t. IV, première partie, p. I59. 
I06 LA VERRERIE EN GAULE SOUS L'EMPIRE, ROMAIN.

$A$. Dans la première, on rangera les spécimens de verre incolore ou

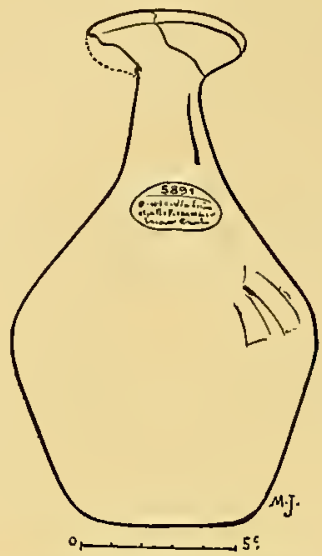

Fig. I27. - BouteIlle trouvéE a BREsles, près de Beauvais, en I86I. - Musée de Sèvres, n0 589 I.

verdâtre, pour la plupart d'assez grande taille, et comprenant des

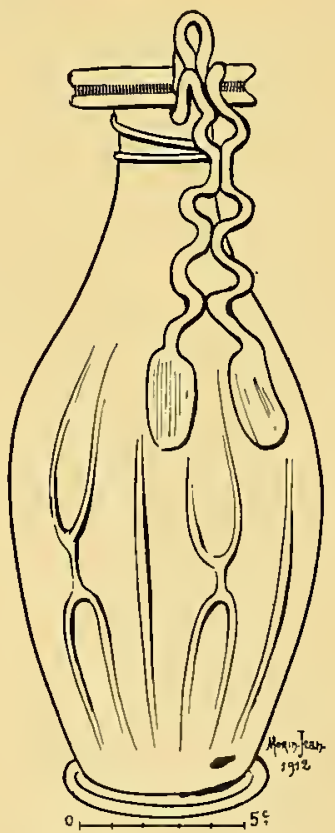

F'IG. I28. - Bouteille a ANSE EN ChaINE. - Fin $\mathrm{II}^{\mathrm{e}}$ ou $\mathrm{TV}^{\mathrm{e}}$ siècle - Musée de Mayence.

variétés nombreuses (fig. I25 à I28). Ici, la panse aura un profil pur et bien cadencé; 1'embouchure ne comportera exceptionnellement qu'un 
simple bourrelet; l'anse plate à quatre nervures décrira au sommet une boucle, hésitera à effleurer le goulot, puis remontera un peu pour descendre ensuite brusquement, à la fois légère et puissante, sur l'épaule du vase (fig. I25). Là, le galbe sera moins pur; le goulot mangé par la panse, le ventre anguleux de la bouteille, l'anse empâtée, tout dénotera le travail d'un artisan moins doué (fig. I26). Ailleurs, le même type de bouteille sera dépouillée de son anse et de son pied (fig. I27) ; ailleurs encore, l'anse à double ondulation type $\zeta$

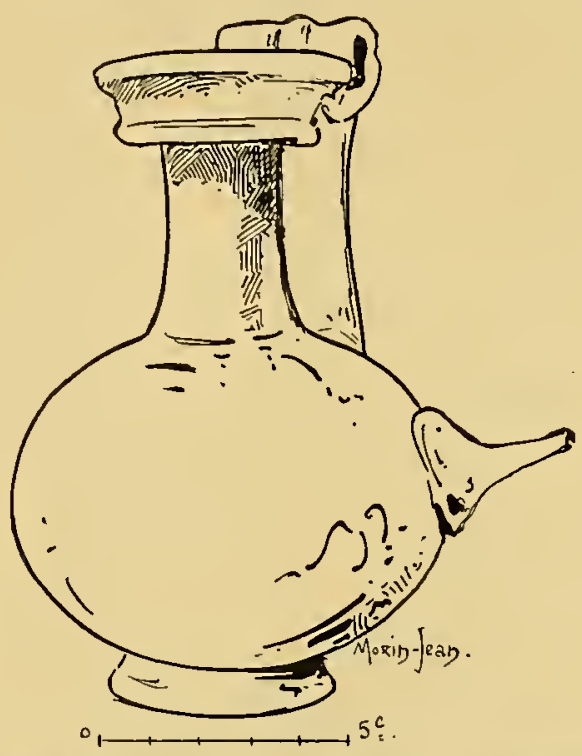

Fig. I29. - Bouterlle a tubulure Latérale, - Reims. Iiendit « Ia Maladretie». Fouilles J. Orblin, en I8gS. - Musée de Reims, $n^{\circ} 4944$.

(p1. 3, p. 37) viendra se substituer aux types plus simples (I) (fig. I28). Les bouteilles forme 50 sont très souvent ornées d'un fil de verre étiré à chaud qui les enveloppe entièrement (fig. 259) ou s'enroule seulement autour de leur goulot (fig. 26I). C'est le décor courant des Kännchen du Rheinland (2).

(I) L.es bouteilles 50 à anse du type ६̧, pl. 3, appartiennent à une série de récipients dont le centre de production doit, semble-t-il, être placé en Germanie occidentale. Elles sont de basse époque. On peut en voir aux nusées de Mayence [spécinens de 20 à 25 centimètres de hauteur, en verre trìs impur], de Stras-

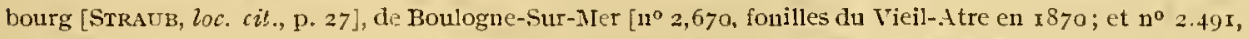
fonilles à Bréquerecque (le $n^{0} 2.49$ I a èlé publić par RoAch Smtr dans Collectanea Antiqua, I $843, \mathbf{u}^{\circ}$ I)], d'Amiens [deux spécimens]. Des exemplaires ont été découver ts an cimetière de Vermand [voy. TH. Fick. Les deux cimetières gallo-romains de Vermund et de Saint-Quentin, pl. IV, no $\mathrm{I}$ et à Paris [Muséc Carnavalet].

(2) Voy. Avtor Krsa, Das Glas, fig. 38, 39 et 40. 
Une autre ornementation consiste en filets appliqués à chaud et disposés en spirales qui partent du haut du goulot, couvrent la panse et se fondent dans la partie inférieure du récipient (I).

$B$. La seconde série comprend des flacons de petite taille (les plus grands ne dépassent pas I2 centimètres); caractérisés par leur polychromie et l'association du verre transparent et du verre opaque

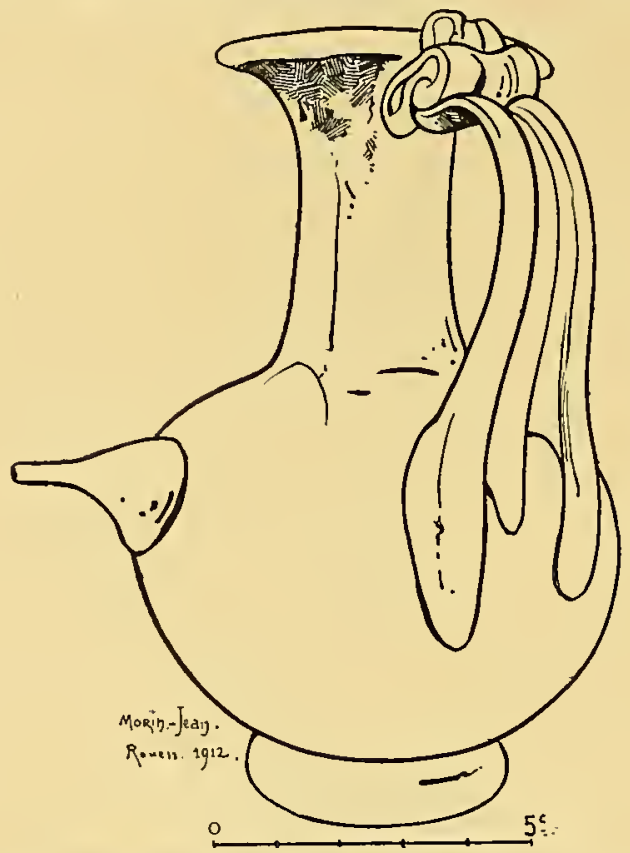

Fig. I30. - Bouteille a tubulure latérate, verre verdatre. - Ŕtaples, I864 Romain II. Musée de Rouen (ancienne Collection de Girancourt).

(fig. I et 2). Ces bouteilles sont ordinairement de deux tons. L'un est appliqué aux parties qui constituent la bouteille proprement dite : panse, goulot et bourrelet supérieur de l'embouchure. L'autre est réservé pour les parties accessoires : anse, pied, bourrelet inférieur de l'embouchure et filets qui entourent quelquefois le goulot.

(I) Des bouteilles de Ja fin du mi et du IV ${ }^{\mathrm{e}}$ s, ornées de filets en spirales, proviennent de Monceau-leNeuf [Forme 5o. Tombe du chef. Collect. Boulanger à Péronne. Voy. Cl. Boulañger, Le Mobilier funéraire, pl. I I et pl. 20], de Vermand [Forme 59. Voy. TH. Eck, Les deux cimetiches, pl. IV, $\mathrm{n}^{\circ}$ 9], de Beanvais [Forme $6 \mathbf{I}$ à anse du type $\xi$, pl. 3. Voy. W. Frohiner, La Verrerie antique. Collect. Charvet, $\mathbf{n}^{0} 88$, p1. XIX], de Steinfort, Grand-Duché de I,uxembourg [Publication de la Socièté pour la recherche et la conservation des monuments historiques dans le Grand-Duché de Luxembourg, I 849, p. 45, pl. 2, fig. 5 et 6]. 
Ces flacons forment un des groupes les plus charmants de toute la verrerie rhénane du Romain II (I).

Forme 5.1. - Panse spérique. Même goulot et même cmbouchure qu'aux types 62,64 et 65. Anse en forme de ruban plat avec repli supéricur formant poucier. Pied annulaire. Une bouteille de ce type est décrite plus loin, p. 207 et fig. 276 . Elle est en verre incolore et ornée d'applications vermiculaires ( $\mathrm{II}^{\mathrm{e}}$ siècle).

FORME 52. - Bouteilles à panse sphérique pourvue d'une tubulure

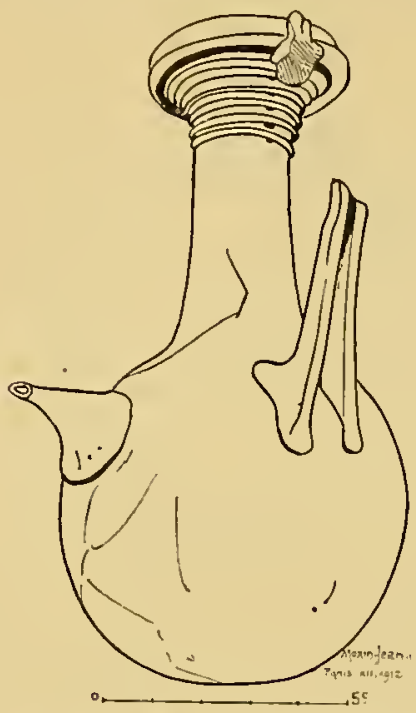

Fig. r3r. - Bouteille a tubuldre latfrale. - Paris. Fouilles du cimetière romain du faubourg SaintJacques. $\mathrm{rv}^{\mathrm{e}}$ s. - Muse Carnavalet, Paris.

à extrémité efflée (fig. I29 à I32). - Bien que de nombreux archéologues s'obstinent à voir dans ces flacons des biberons d'enfants (2), nous restons persuadés que jamais ces bouteilles n'ont été utilisées pour l'allaitement artificiel des nouveau-nés.

(I) Musée de Bonn (Bouteille en verre bleu transparent; parties accessoires en verre jaune opaque. Trouvée avec monnaies de Dioclétien [28.+ à 305], $\mathrm{n}^{0}$ r.684. Hauteur : 8 centimètres. - Bouteille forne 50 en verre violet transparent ; parties accessoires en verre bleu pâle (fig. r), hauteur : 8 centiincttres. Salle VII, tombe I9; iuveutaire 4.275). - Musée de Trives (Bonteille en verre bleu transparent; parties accessoires en verre blanc opaque, $n^{\circ}$ I3.603 [voy. Fühver durch das Provinzialmuseum in Trier, p. ro8]. Deux flacons différents des précédents en ce qu'ils sont entièrement formés de verre opaque : la bouteille est en émail blanc et les parties accessoires sout en émail bleu, 11 os 02.376 et 05.278). - Iusće de Breslau (Bouteille en verre bleu de Turquie; parties accessoires eu émail blanc. Trouvée à Cologne).

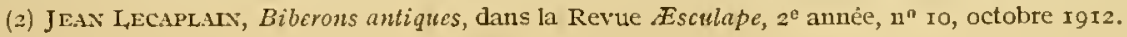


S'il en avait été ainsi, on aurait au moins pris soin d'user à la meule l'extrémité de la tétine. Cette extrémité est, au contraire, cassée net et coupante. Elle est, de plus, mince et fragile. Il serait très dangereux de l'introduire dans la bouche d'un enfant. D'autre part, l'anse, inutile et même incommode, si l'on se sert du

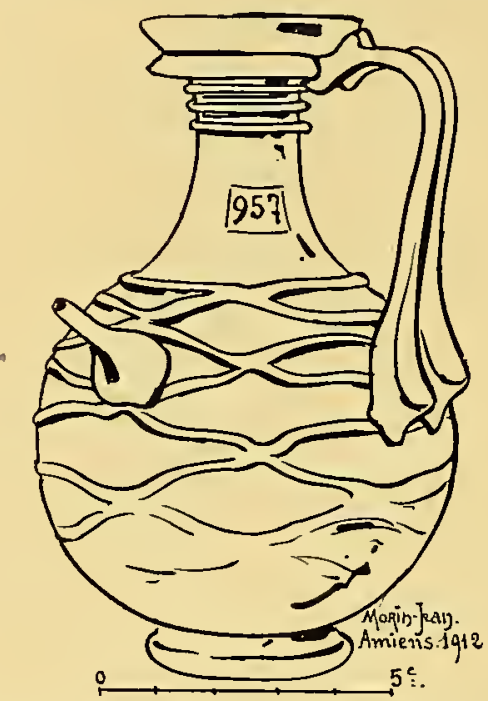

Fig. I32. - Bouteille a tUbUluRe Latérate, verre verdatre. - Romain II tardif. - Musée d' A micns.

flacon comme biberon, devient indispensable si on l'utilise comme verseuse.

Les Romains appliquaient une tubulure latérale à des récipients de formes et de matières diverses (I).

L,es bouteilles forme 52 paraissent inconnues au début de 1'époque impériale.

Quelques exemplaires, par la qualité de leur pâte vitreuse, peuvent peut-être se placer au $\mathrm{II}^{\mathrm{C}}$ siècle de notre ère; mais presque tous ceux que l'on voit dans les vitrines de nos musées sont du $\operatorname{III}^{\mathrm{e}}$ et du IV siècles.

(I) Askos en terre cuite de la nécropole de Rabs (Carthage) [Musée de Rouen]; vases d'argile à courerte blanche, rouge et noir, du musée de Reims [n ${ }^{0 s} 3.766,3.948,3.949,3.950,3.960,4.01$ I, 4.053, 5.304, etc. Voy. Catalogue du Musée archéologique de Reims]. Poterie noire à décor en barbotine blanche dn musée cle Coblence (fig. I33), etc. 
Ceux que le chanoine Straub a recueillis à Strasbourg étaient dans des tombes à inhumation du IVe siècle (I). Ceux que l'abbé

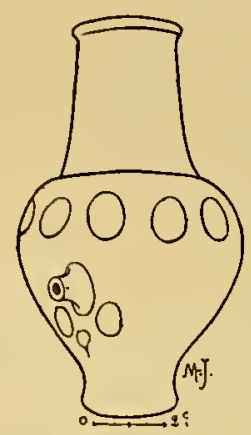

Fig. I33. - Poterie a tubulure latérale. - III -IVe s. - Musée de Coblence.

Hamard a trouvés au cimetière de Bury (Oise) datent aussi de l'époque constantinienne (2).

Il semble qu'il y ait eu deux types de flacons 52 , qui se suivent chronologiquement. L,es flacons du premier type sont en verre bleu-

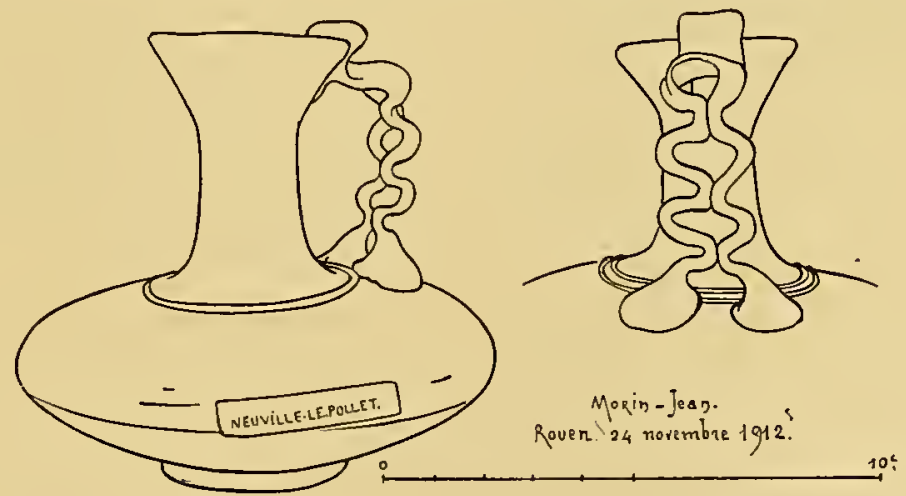

Fig. I34. - Boutemide a paxse bulbeuse et a ANSE en chande, verre incolore. - Neuville-le-Pollet (Seine-Inférieure). $\mathbf{m}^{\mathrm{e}} \mathrm{s} .-M$ Msée de Rouen.

verdâtre, un peu épais. Ils sont contemporains des premiers barillets frontiniens et existaient dès le début du mre siècle. Ceux du second sont en verre mince souvent rempli de filandres (3); leur anse,

(I) Straub, Le cimeticre gallo-romain de Strasbourg, p. 78 , et pl. IX, n⿳3 3 .

(2) Abbé Handard, Découverte d'une nićopole romaine à Bury (Oise). Dans le Bulletin archiologique, 19oo, p. 23 .

(3) Exxemplaires en verre filandreux aux musces de Trèves [Salle $20, n^{\circ} 3.500$ ], de Mayence, de Poitier Dunes I., XXXVII, $\mathfrak{n}^{\circ}$ III (16I)], etc. 
leur embouchure, leur décor sont caractéristiques de la basse époque (fig. I3 I et I32).

FORME 53. - Bouteille à panse en forme de bulbe aplati. - Le type 53 peut être rapproché du type 60 avec lequel il est synchronique. Tous les intermédiaires existent entre la panse dont la coupe

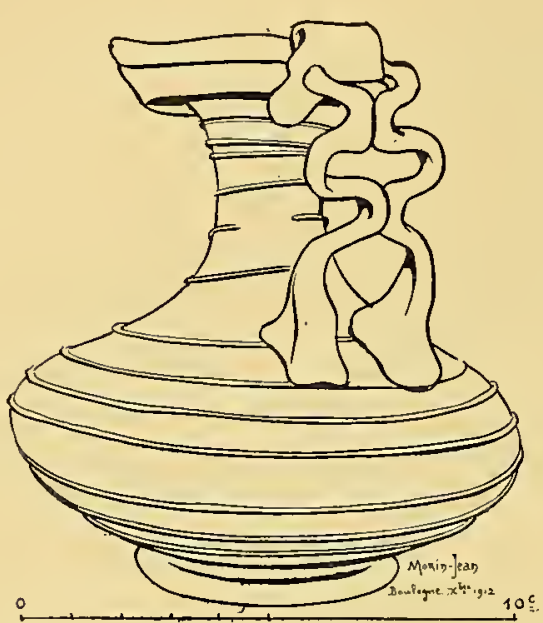

FIG. I35. - BoUteILLE A ANSE EN CHAINE, VERRE INCOLORE. - Vieil-Atre. Fouilles de I869. Fin III $^{\mathrm{e}}$ ou $\mathrm{IV}^{\mathrm{e}} \mathrm{s}$. - Musće de Boulogne-sur-Mer, $n^{\circ} 2673$.

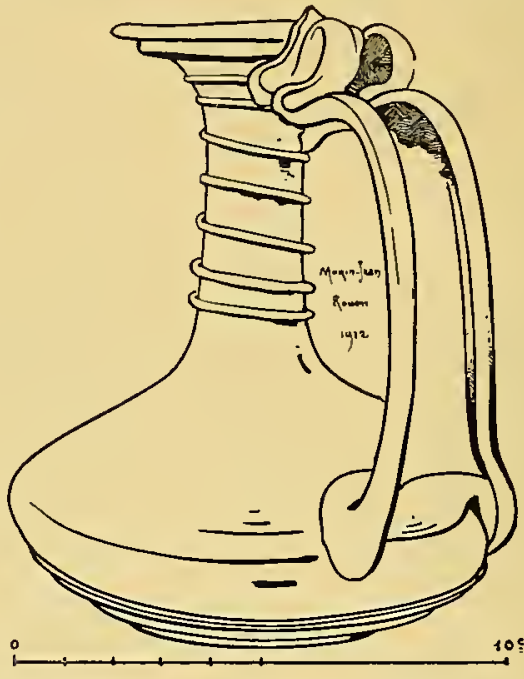

FIG. I $36 .-$ FLACON EN VERRE FILANDREUX, EMrBOUCHURE A BEC. - Tourville-la-Rivière (fouilles de 1862). Romain II. - Musée de Rouen (ancienne Collection de Girancourt).

verticale offre l'aspect d'une ellipse presque parfaite (fig. I34) et la panse tronconique (fig. I45).

Les flacons en forme de bulbe aplati sont souvent ornés de fils de verre qui s'enroulent autour de la panse et du goulot (fig. I35). Leur embouchure est tantôt circulaire, tantôt munie d'un bec (fig. I37). Leur anse est très varjable dans sa forme (types $\xi^{2}, \zeta$, etc., de la pl. 3, p. 37).

Les bouteilles forme 53 ont été trouvées dans les mêmes régions que les bouteilles formes 49 et 50 . Elles datent du Romain II.

FORME 54. - Enochoé à embonchure trilobée (type C, fig. 8) et à anse surélevée. Forme des anochoés grecques. - Telle qu'elle se présente dans notre tableau de morphologie générale, l'œnochoé romaine de verre est un type de la première moitié $d \mathrm{Im}^{\mathrm{e}} \mathrm{s}$. Elle est de petite 
taille, en verre incolore très pur et ornée d'applications vermiculaires (fig. 275). Elle ne se trouve guère en dehors de la vallée du Rhin (r).

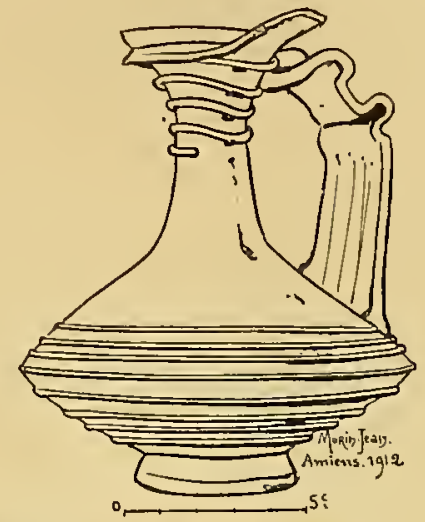

HIG. I37. - BoutemLle en verre verdatre. - Romain II. - Musée de Picardie, à Amiens.

Les œnochoés que l'on a exhumées des nécropoles du nord de la

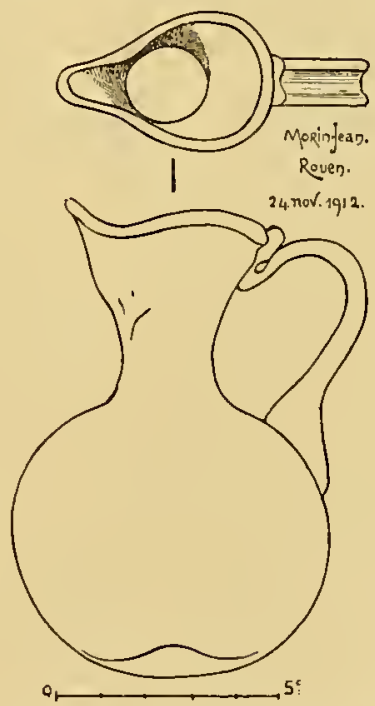

Fig. 138. - BOUteille DE VERRE BLEU-VERd.1TRe. — exrouchure a bec. - Fouilles de Neuville-lePollet. Muscie de Rouen.

France sont d'un galbe beaucoup plus lourd. Ce sont des imitations

(I) Les plus beaux exemplaires ont été tronvés à Cologne, dans les tombes à incinération de l'époque des empereurs syriens, avec des monnaies de Julia Domna et d'Alexandre Sévère. Ils étaient déposés dans une soucoupe forme 89 , ornée, comme eux, d'applications vermiculaires [voy. Bomner Jahrbiicher, Igo6, fasc. II 4II5, pl. XIIV, tombes 38,40 et 42$]$. 
de cruches d'argile très communes en Picardie au IVe siècle (I). FORME. 55. - Panse sphérique. Embouchure à bec (type D, fig. 8). - On connaît de cette forme des exemplaires apodes (2) (fig. I38) et des exemplaires pourvus d'un pied annulaire (3), des

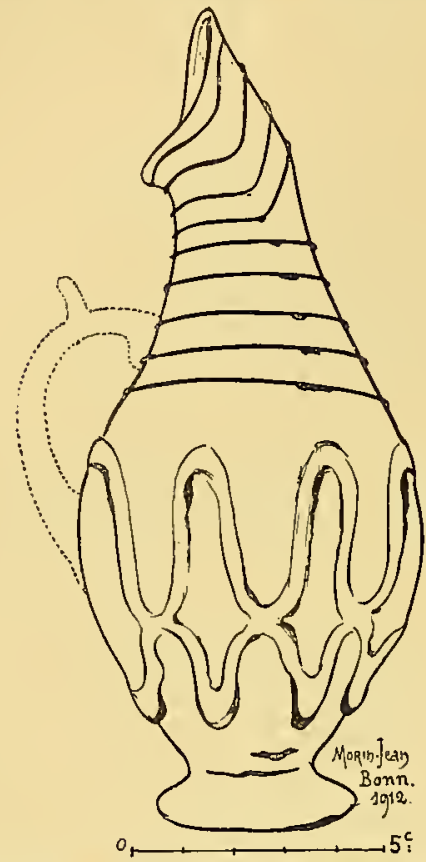

FIG. I39. - GNOCHOE A COI RENVERSÉ. - Verre incolore décomposé. Romain II. - Musée provincial de Bonn. Salle IV.

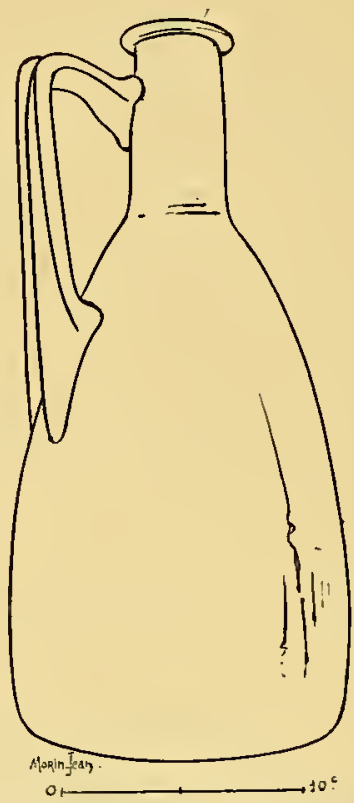

Fig. I40. - FLACON TROUVÉ AU CIMETIÈRE DE VAIson. - Musée Borély, à Marseille, nº 572.

spécimens sans ornements et des spécimens décorés de fils de verre entourant la panse et le goulot (4).

Un modèle hybride, représenté au musée de Mayence, emprunte son embouchure à la forme 55 et sa panse à la forme 23 .

Les trouvailles démontrent que les bouteilles 55 appartiennent au Romain II (5).

(I) J. PILloy, Études sur d'anciens lieux de sépultures dans l'Aisne, t. II, p. I38; et TH. Eck, loc. cit. pl. $\mathrm{V}, \mathrm{n}^{\circ} 5$.

(2) Bonn. Provinzialmuseum, no I.74I.

(3) Voy. Catalogue du Musée archéologique de Reims, p. 78, nº 2.424.

(4) A Us'M'WEerTh, dans les Bonner Jahrbïcher de I88I, fasc. 7 I, pl. V, collection Disch, nº I.386.

(5) I,es spécimens de la vallée du Rhin [Cologne. Incinérations tardives. Voy. Bonner Jah̆rbücher, r9o6, fasc. II 4-II5, P. 405, pl. XXIII, tombe $1^{\circ} 34$ ], et de la Picardie [Mnsée de Picardie, fouilles à Amiens, rue des Trois-Cailloux, en I897] sont des Ire $^{\mathrm{e}}$, rve siècles. 
Fornus 56. - Enochoé à col renversé. - La forme 56 existe déjà

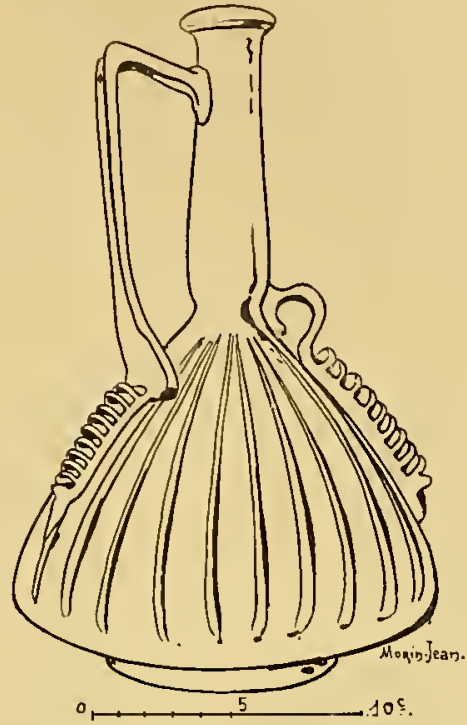

Fig. i 4. - Boutenle en verre jaUnatre. - Fabrication tardive. - Musée de Majence, $\mathrm{n}^{\circ} 460 \mathrm{I}$. en argile, à une époque très reculée, dans le bassin de la mer Égée (I).

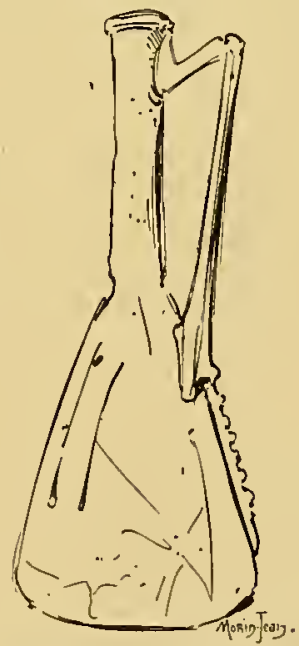

FIG. I42. - CARAFE APODE. - Cimetière romain d'A vennes (Belgique). - Mrisée de Liége.

Dans la verrerie impériale romaine, elle est très rare. Elle n'y est

(I) Poteries à décor géométrique de Chypre, de Crète, de Milo [voy, CoLLIGxor' et Couve, Calalogue des Vases peints du mesée d'Atheines, pl. $\mathrm{rV}, \mathrm{n}^{\circ}{ }^{30}$ ]. 
représentée, à notre connaissance, que par un beau spécimen du musée de Bonn (fig. I39). Par la composition de sa pâte vitreuse qui est incolore et par ses ornements, cette cruche se classe au Romain II.

FORME 57. - Les œnochoés 57 à 6 I se reconnaissent à la forme de leur panse dont la silhouette est un triangle plus ou moins curvi-

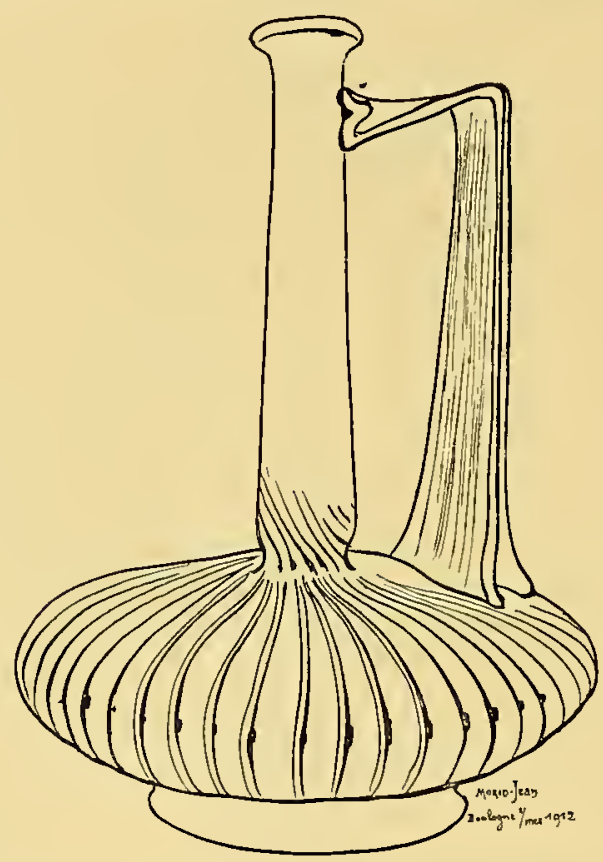

Fig. 143. - CARAfE a paNSE COTELÉE. - Vieil-Atre. Fouilles de I87o. - Musée de Boulogne-sur-Mler, $\mathrm{nt}^{\circ} 2664$.

ligne. Un des côtés du triangle forme la base de la bouteille ; les deux autres côtés se fondent dans le goulot.

Les flacons forme 57 sont des types de la haute époque impériale. Ils sont communs danș la basse vallée du Rhône (fig. I40). L'un d'eux, touvé à Piolène, en I883, et conservé au musée Calvet à Avignon (no $236^{1}$ ), a plus de 30 centimètres de hauteur.

FORME 58 . - Les bouteilles 58 sont caractérisées par: une panse peu élevée, ordinairement décorée de côtes en relief, un goulot très 
long étranglé à la base, une anse terminée par un appendice orné de saillies nombreuses (I) (fig. $\mathrm{I}_{4} \mathrm{I}$ ).

Le type $.5^{8}$ donne naissance à diverses variétés tantôt apodes (fig. I42), tantôt pourvues d'un pied (fig. I43) et dont la panse, par

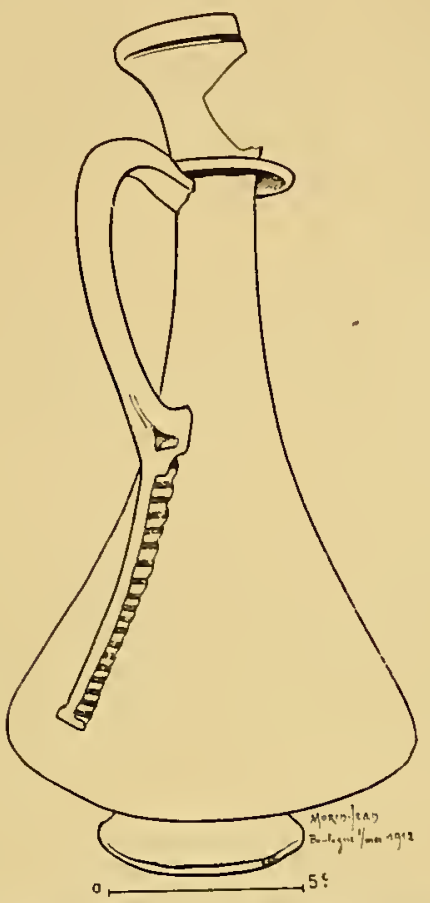

FIG. I44. - BOUTEILE A PAXSE TRONCONIQUE.

- Fouilles du Boulonnais. Romain II tardif.

- Musée de Boulogne-sur-Mer, n' $25 \mathrm{I} 6$.

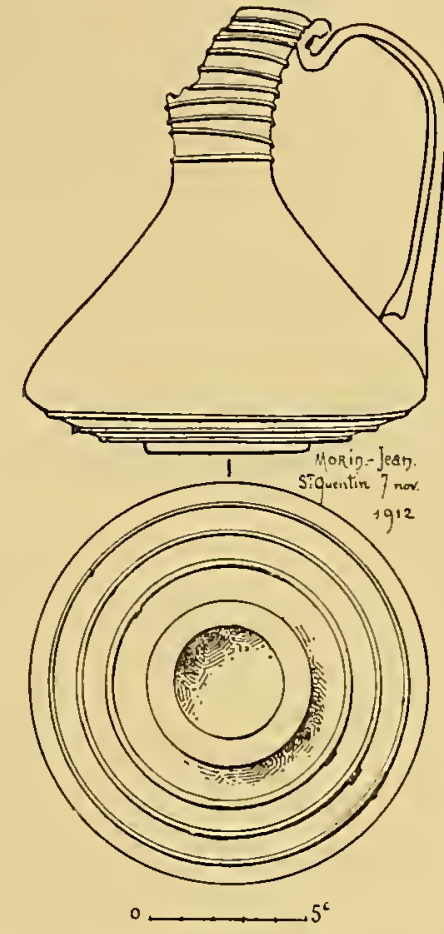

FIG. 145. - FLACON A PANSE TRONCONIQUE. Vermand. Romain II tardif. - Collection Théophile $E c k$, à Saint-Quentin.

des déformations successives, arrive à prendre l'aspect d'un bulbe très aplati (fig. I43).

Il semble que la fabrication des bouteilles 58 ait duré longtemps. Des exemplaires en verre bleu-verdâtre de bonne qualité ont été trouvés dans des tombes à incinération remontant à la fin du $\mathrm{II}^{\mathrm{e}}$ siècle ou aux premières années du $\operatorname{III}^{\mathrm{e}}(2)$. Des spécimens en verre sale etrempli

(I) Quelques archéologues donnent à ces bouteilles le nom de Flasca [mot de basse latinité] (voy. W. Frcemner, La Verrevie antique, p. 78).

(2) Bouteille 58 dont l'attache inféricure de l'anse est masquée par un médaillon figurant une tête de Méduse, trouvée à Cologne avec une coupe 68 en verre bleu et un moyen brouze d'Antonin le Pieux [voy. Bonner Jahrbuicher, I906, fasc. I I4-I I5. Tombe à incineration no 3 I (fouilles de I903), p. 402 et pl. XXIII]. 
de bouillons paraissent dater, at contraire, d'une époquetrès basse (I).

FORME: 59. - Bouteille à pansetronconique dont l'anse est fixée à une

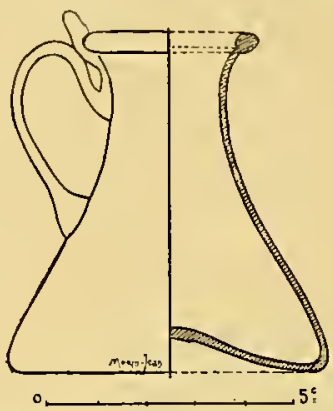

Fig. I 46. - Fiole tronconioue a LARGE ORTFICE. - L,illebonne. Fouilles de i 853. - Musée du Louvre, $\mathrm{n}^{\circ} 97$. bague qui entoure le goulot un peu au-dessous de l'embouchure. Les bouteilles 59, assez répandues dans la Gaule belgique, sont toutes

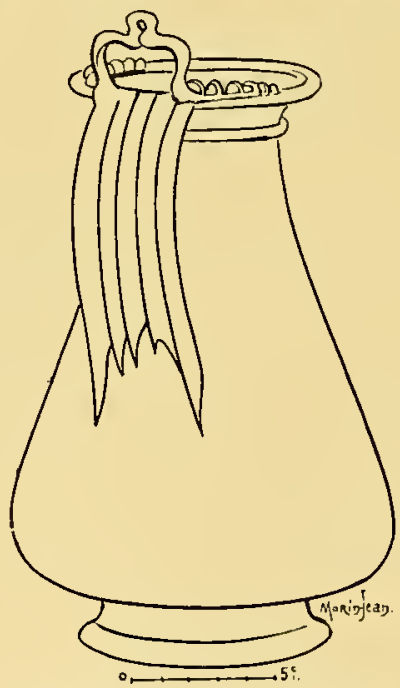

FIG. I47. - CARAfe a laRge embovchure. - Verre incolore. Romain II. - Musée provincial de Bonn. Salle $V, n^{0}$ I6 42 .

du Romain II (fig. I44). Très nombreuses à Vermand (2), elles ne sont pas rares non plus dans le Rheinland (3).

(I) Par exemple, ceux du musée de IIayence (fig. I4 $\mathrm{I}$ ).

(2) Voy. TH. Eck, Les denx cimetières gallo-romains de Vermand et de Saint-Quentin, pl. IV, n ${ }^{0 s} 2,3,5,9$ et p1. $\mathrm{V}, \mathrm{n}^{\circ} 6$.

(3) Bouteille 59 à panse côtelée, recueillie dans la tombe à incinération $n^{\circ} 43$ du cimetière de la rue de Luxembourg, à Cologne, avec le verre ichthyomorphe forme I29 et un grand bronze d'Alexandrc Sévère [voy. Bonner Jahrbiicher, I906, fasc. II4-II5, p1. IIIT]. 
FORME 60. - Variante à panse tronconique des flacons fig. 134 à 137. - Les bouteilles de ce modèle se rencontrent en France, surtout dans le Nord et dans 1'Est (fig. I 45). Ellles ont été recueillies dans les nécropoles de l'Aisne (I) dont les sépultures se classent pour la plupart au IVe siècle. Il y en a plusieurs au musée de Reims (2).

FORIIE 6I. - Carafe à large embouchure. Ansep1 (p1.3, p. 37). - Les récipients de ce type, qu'Anton Kisa appelle prochous, ne font leur apparition en Gaule qu'à partir du $\mathrm{III}^{\mathrm{e}}$ siècle (fig. I47). Les uns datent de l'époque des empereurs syriens (3), les autres du rve siècle (4).

\section{9.- BOUTEILLES APPARENTÉES AU LÉCYTHE ITALIOTE DE TERRE CUITE}

(Formes 62 à 65.)

Les types 62 et 64 ont pour point de départ le lécythe d'argile, à panse en forme de poire, si répandu en Apulie, en Campanie et en I ucanie du $\mathrm{IV}^{\mathrm{e}}$ au $\mathrm{II}^{\mathrm{e}} \mathrm{s}$. avant J.-C. (5).

Ils ne furent connus, en Gaule, qu'après le règne de Commode $(+\mathrm{Ig})$.

De forme gracieuse, montés parfois sur un pied délicat, ces flacons ont été en vogue au temps d'Héliogabale et d'Alexandre Sévère (6). Ils ont été façonnés dans une pâte vitreuse, incolore, d'une grande pureté. Ils sont presque toujours ornés d'applications vermiculaires

(I) Fouilles F. MIOREAU au cimetière de la Villa d'Ancy [roy. Album Caranda, pl. 79, nouvelle série, $\left.\mathrm{n}^{\circ} \mathrm{I}\right]$. I 887 , tombe I07, $\mathrm{u}^{0} 4 \mathrm{I}$.I 40 , hauteur : Io centimètres I/2.

(2) Voy. Catalogue du musée archéologique de Reims, $\mathrm{n}^{0 \mathrm{0}} 2 . \mathrm{I} 3 \mathrm{I}, 4.663,4.875$ et 4.876 .

(3) Nous citerons le $n^{\circ}$ I6.I $\uparrow_{2}$ du musée de Bonn [verre incolore; hanteur: 20 centimètres] et

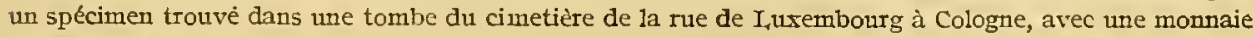
d'Alexandre Sévère.

(4) Des exemplaires très tarđifs ont été r encontrés à Andernach [tombe à inhumation, $\mathrm{n}^{\circ} \mathrm{I9}$, du cimetière d'Andernach. Voy. Kaenes, dans les Bonner Jahrbücher, I888, fasc. 86, p. I85, et pl. X, $n^{0}$ I7] et à Cologne [avec une coupe 76 à dépressions, un barillet frontinien forme 132 et un ballon forme 40 dans une séputture à inhumation du IV'siecle].

(5) Sur les différentes formes du licylhi grec, cousulter Dictionnaire des Antiquittis de MI. Saglio, t. III, deuxième partie, p. I023.

(6) Les plus beaux ont été trouvés dans la vallée du Rhin [voy. Bonner Jahrbücher, I906, fasc. II 4 -II 5 . p. 406 et 409 et pl. XIIII et XIIIV, tombes nos 35 et 38 du cimetière de Cologne]. 
en verre opaque ou transparent, dont les colorations douces créent une harmonie distinguée (fig. 277 à 280).

FORME 63. - Variante à trois compartiments du type 62. - L'anse, comme dans le type 59 , est fixée à une bague de verre qui souligne la jonction de la panse et du goulot (fig. I48).

La forme 63 est connue par des exemplaires appartenant aux musées de Trèves (I), de Bonn (2), de Cologne (3).

FORnE 65. - Variante à panse aplatie du type 64. - Les bou-

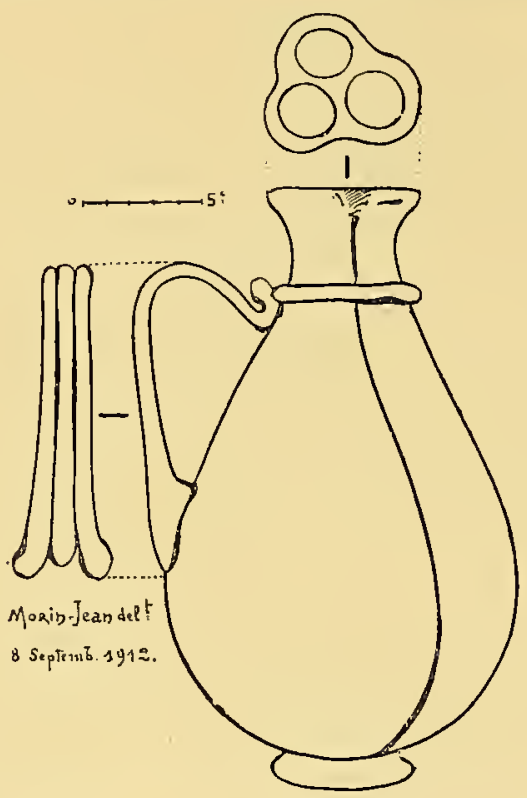

Fig. I48. - Bouteinle a trois compartments. - Vetre verdâtre. Romain II. - Musée de Trìves, Salle XX. Vitrine VIII (G. 706).

teilles 65 font partie du même groupe de récipients que les bouteilles 43 . Ce sont des gourdes plates, en verre incolore et ornées d'applicacations vermiculaires, dont les plus beaux modèles sont sortis des tombes tardives à incinération de la Gaule rhénane (fig. 282).

(I) Salle 20 , vitrine VIII, $\mathrm{u}^{\circ}$ G.706 [voy. Fïhrer durch das Provinzialmuseum in Trier, p. II I]. Fouilles de 1908 à Pallien.

(2) Bonn. Provinzialmuseum, $\mathrm{n}^{\circ}$ I.729.

(3) Cologne. Ansée Wallraf-Richartz, $n^{\circ} 252$, hauteur : 32 centimètres. 

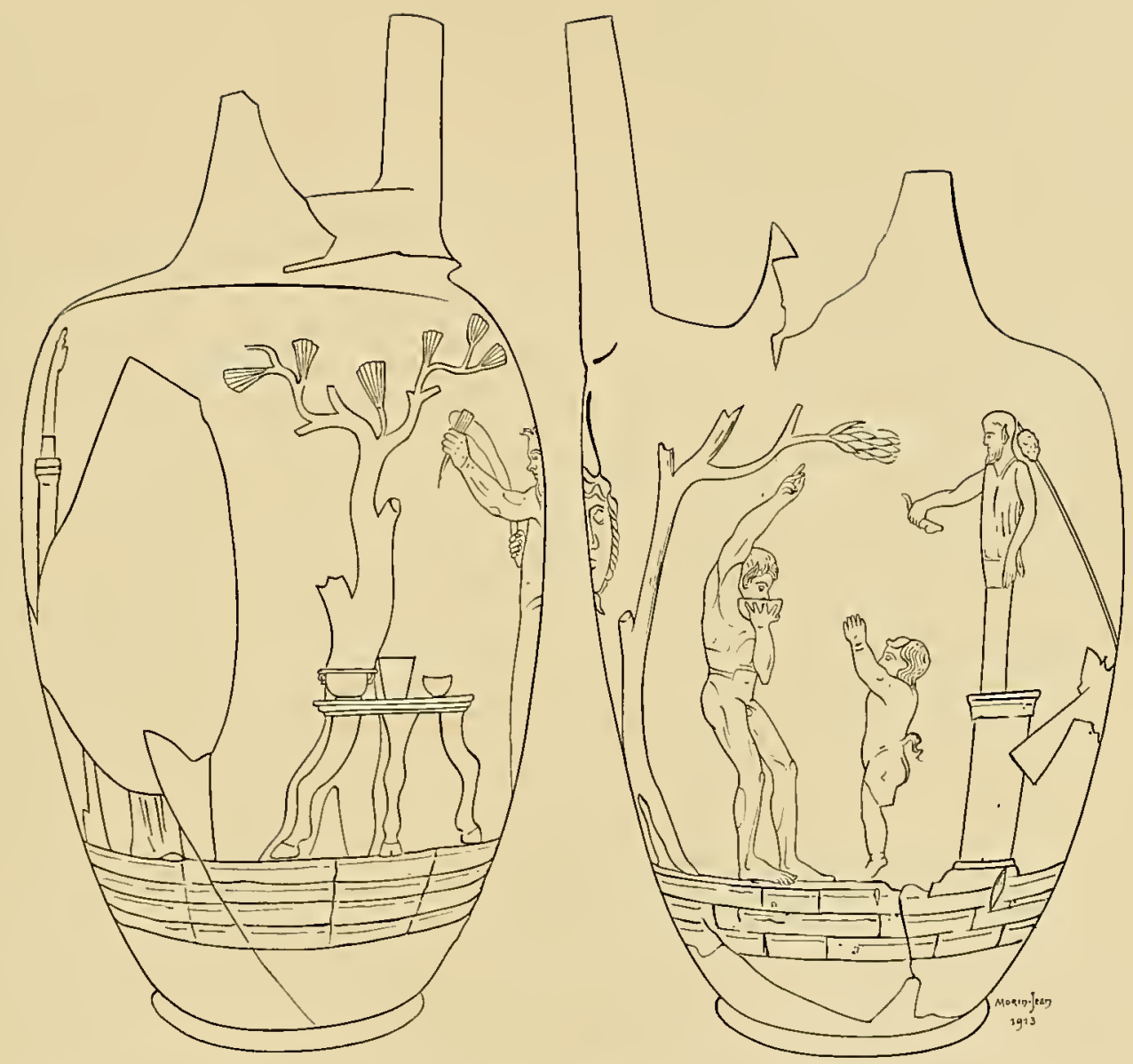

1'L. 6. - VERRE A DEUX CoUches (FAUX CAMEE). - Ginochoé priapique trouvée à Besançon. - Ier siècle ap. J.-C. - Musée archéologique de Besançon (Doubs.) 



\section{IO. - BOUTEILLES A FOND BULBEUX.}

(Formes 66-67.)

FORME 66. - Bouteille cylindrique à fond plat plus ou moins élargi. - Les récipients de ce type ont un galbe mon, disgracieux (I) (fig. I49). Ils sont en verre de très mauvaise qualité. Ils apparaissent au IV siècle

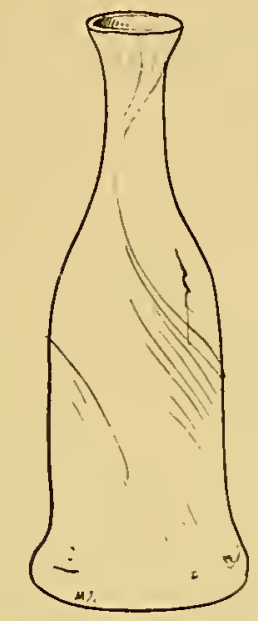

FIG. I 49. - BOUTEILE A FOND BULAEUX. - Cimetière de Sablonnière (Aisne). Fin du $\mathrm{IV}^{\mathrm{e}} \mathrm{s}$. Musce de Saint-Germain. Salle F. Moreau. Tombe $\mathrm{n}^{\circ}$ IOI2.

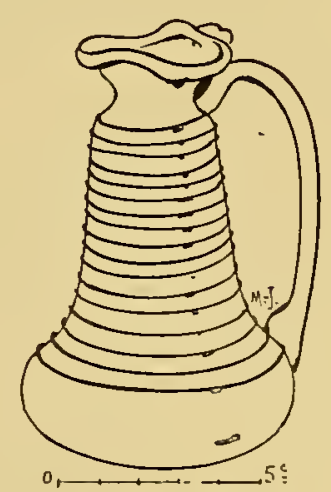

FIG. I5O. - GNOCHOÉ A FOND BULBEUX, - Verre filandreux. Basse époque impériale. - Musée provincial de Bonn. Salle $T$.

et se rencontrent encore fréquemment au ve. M. Cl. Boulanger en a trouvé un bel exemplaire au cimetière franc d'Achery-Mayot (2).

Si la forme des fioles 66 est peu séduisante, le décor dont quelques-unes d'entre elles sont agrémentées est, par contre, d'une réelle élégance. Il est composé de larges ondes d'émail blanchâtre dont les extrémités effilées se poursuivent en filets verticaux jusqu'au sommet du goulot (fig. 270).

(I) On en a recueilli plusieurs à Reims (Marne), au cimetière d'Armentières (Aisue) [arusée de SaintGermain. Salle XI. Tombe 534. Vitrine 44. Fouilles F. Joreau en I882. Voy. Album Caranda, pl.28, nouvelle série $n^{0} 4$ ], à Trèves [n ${ }^{0}$ 04.I00 ${ }^{a}$. Salle 2 I. Tombe $n^{\circ} 227$ ] et dans la nécropole la plus récente d'Andernach [Spécimen d'environ 18 centimètres de hauteur, conservé au musée germanique, à Niuremberg].

(2) Voir CL. BOULATGer, Le Wobilier funêraire, pl. 3I, no I. 
FORME 67.- Bouteille à fond bulbeux. Embouchure trilobée. Anse décrivant une belle courbe. Fil de verre enroulé autour de la panse. Ce modèle de petit vase n'est représenté que par un spécimen en verre filandreux du musée Provincial de Bonn (fig. I5o).

\section{II. - PHIALES, BOLS ET PLATS.}

(Formes 68 à 92.)

FORME 68. - Les phiales forme 68 reproduisent des coupes en métal repoussé. Elles sont tantôt plates (fig. I5I), tantôt profondes (fig. I52). Elles ont des parois très épaisses et sont ornées de grosses

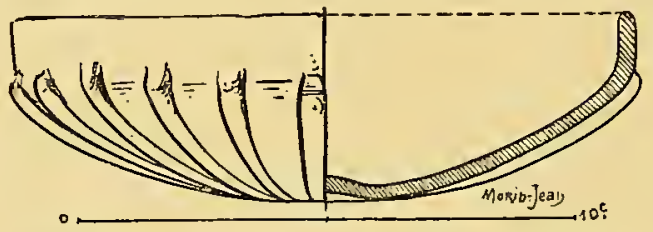

Fig. I5I. - PhLALe CotelÉE. - Romain I. - Collection Morin-Jean, $\mathrm{n}^{\circ} 985$.

côtes. Les unes sont en verre bleu-verdâtre, naturellement teinté par les oxydes métalliques. Les autres sont en verre uniformément coloré, en bleu vif ou en jaune d'or. Des exemplaires de luxe, faits à l'imitation des vases de calcédoine, de marbre et d'agate rubanée, sont couverts de taches, de veines et de bandes irrégulières de toutes nuances (I).

Les coupes 68 sont des produits de la haute époque impériale. On en a découvert dans tout le monde romain. Nombreuses dans la verrerie pompéienne, elles se sont répandues de bonne heure au nord des Alpes. En Gaule, elles font partie des mobiliers funéraires du I ${ }^{\text {er }}$ et du $\mathrm{II}^{\mathrm{e}}$ siècles (2).

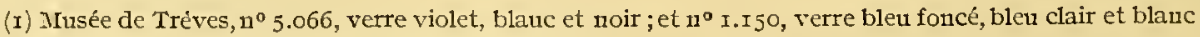
[Fiihrer durch das Provinzialmuseum in Trier, p. 107].

(2) La forme 68 est fréquente dans la verrerie d'Alésia ; elle est représentée au musće đèpartemental de Rouen par plusieurs spécimens en verre bleu verdâtre, jaune ou violet; au musée de Boulogne-sur-Mrer par quatre exemplaires ( 2479 à 2481 et 2483 ) dont l'un est en verre d'un bleu criard; au musée de Nîmes [spécimen de 25 centimètres de diamètre à la Maison Carrée, $\pi^{\circ}{ }_{13}$ ] ; au musée Calvet à Avignon.

A Cologne, dans une incinération déconverte, rue de Boun, en 1903 , une phiale 68 était associée à un moyen bronze d'Antonin-le-Pieux. A Majence, une coupe à peu près semblable faisait partie d'un mobilier funéraire qui contenait, entre autres objets du début de l'Émpire, une fibule à disque et à couvre-ressort du type dit Provincial Militaire. 
Forme 69. - Ce modèle de phiale côtelée est voisin du type 68. I1 en diffère par diverses particularités : il est en verre très mince et, au lieu d'être largement ouvert, il se resserre plus ou moins vers

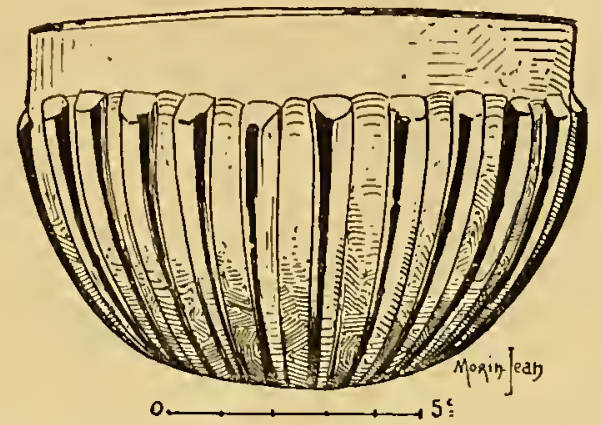

Fig. I52. - Coupe cotelíe, verre verdatre. - Arles. - Cabinet des Médailles, à Paris, $\mathrm{n}^{\circ} 790$.

l'embouchure (fig. I53). Son ornementation consiste en festons blancs opaques, se détachant sur un fond de verre incolore, verdâtre ou jaunâtre (I).

Nous n'avons, pas, en ce qui concerne les bols de la forme 69 ,

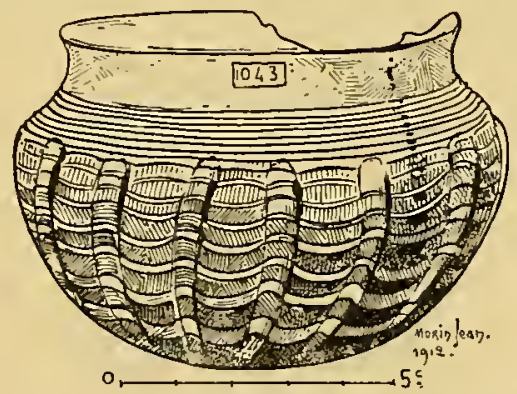

FIG. I53. - COUPE COtelíe du Roulari Ir. - Grand Verger, près Aigle (Suisse). - Musée de Lausanne.

un critérium chronologique absolu ; mais il est probable que certạins d'entre eux sont d'une époque assez basse.

Formes 70 à So. L Le bol de verre soufflé, qui, dans sa forme la plus simple, la plus parfaite, offre l'aspect d'une calotte hémisphérique à orifice coupé aux ciseaux et non ourlé, comporte de très nom-

(I) On conserve à Saint-Germain (Salle $\mathrm{XV}, \mathrm{n}^{\circ} 24.637$ ), de très belles coupes 69 trouvées à Saintes. - Ces coupes sont ornées de festons en verre blauc. 
breuses variantes, issues de déformations morphologiques intéressantes à étudier. Le type 70 est un segment sphérique inférieur à l'hémisphère (I). Le type 7 I est aussi un segment sphérique, mais supérieur à la demi-sphère. Le modèle 78 se compose d'une

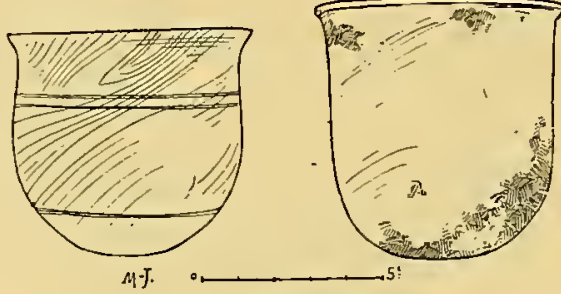

FIG. I54. - BoLs DU ROMAIN Atre, à Boulogne-sur-Mer. - B, n ${ }^{\circ}$ 2 2I5. Cimetière de Bcaumont-sur-Oise (ancienne Collection Bernay.)

calotte hémisphérique et d'un tube cylindrique plus ou moins haut (2). La courbe des tulipes 79 se rapproche beaucoup d'une hyperbole (3). L_es modèles galbés et carénés ( 72 à 77 et 80 ) dénotent une certaine recherche dans la structure du profil.

I a forme 7 I est si simple qu'elle devait être connue dès le début de l'époque romaine; à Nîmes, on a découvert des bols $7 \mathrm{I}$

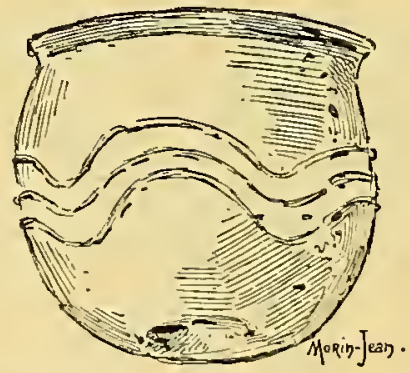

IIG. I 55. - BOL ORNÉ DE TROIS FILETS D'ÉMAII VERT. - Versigny. Musée de LaOn (Aisne .

dans des incinérations des premiers temps de 1'Empire (4); mais il est

(I) C'est la forme donnće à presque toutes les coupes chrétiennes gravées du Ive siécle (fig. 326 et 327 ).

(2) Un grand verre de cette forme, orné de scènes à personnages gravées, a été trouvéà Tréves, en compagnie d'une monnaie de bronze de l'empereur Septime Sévère [MIusée provincial de Trèves, $\mathbf{n}^{0}$ 3.609. Voy. Catalogue, p. IOI].

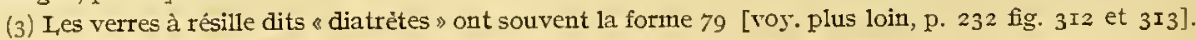

(4) Musẻe archéologique de Nîmes. Tombe du Romain I, trouvée au quartier de Grézan (Urne en plomb). 
intéressant de constater que le bol et ses dérivés constituent une classe de récipient si répandus aux $\mathrm{III}^{\mathrm{e}}-\mathrm{IV}^{\mathrm{e}}$ siècles qu'on peut presque les considérer comme des verreries caractéristiques du Romain II.

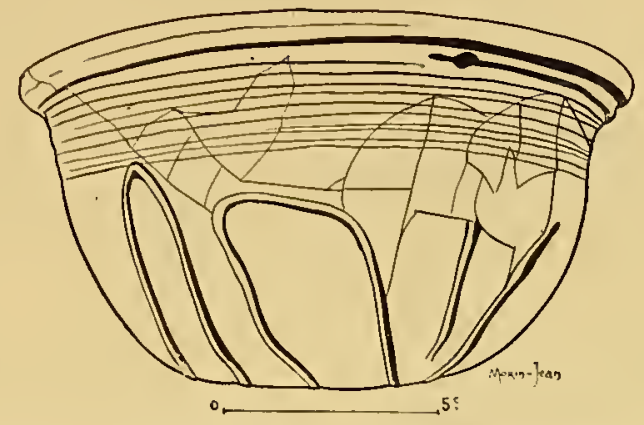

FIG. 156. - Bol a APplications ver3mcUlaIRes. - Boulogne. Fouilles de I891. Époque franque. Musée de Boulogne-sur-Mer, no 721 .

Les bols 7 I et leurs variantes sont en verre incolore presque toujours filandreux, et abondent dans les nécropoles à inhumations de Beanvais, d'Abbeville, de Vermand, du Boulonnais et de l'Aisne (I). Un grand nombre d'entre eux sont gravés (fig. 324) ou ornés, soit de cabochons (fig. 296), soit de fils de verre (fig. I55 et I56), soit de pin-

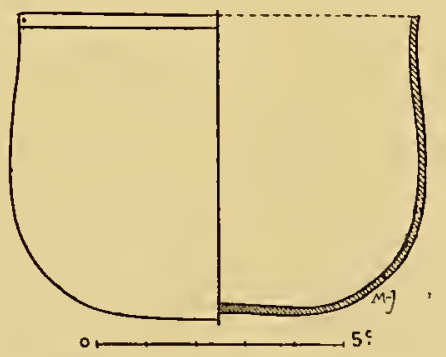

FIG. 157. - BOL EN VERRE VERT-ÉMreradde, dit : Bol des Pygmées et des Grues. - Nîmes. Musée du Lowvre. (I rofil et coupe.)

çures faites à l'outil (fig. 307). Quelques-uns sont en verre de couleur (fig. $I_{57}$ et $I_{58} 8$ ).

L,e type 73 a été trouvé à Cologne avec des monnaies de Volu-. sien, Postume, Clande le Gothique, Carus et Galère-Maximien (2).

(r) Nombreux spécimens au musée de Saint-Germain. Salle XI. Fouilles de F. Moreau.

(2) Bonner Jahrbücher, fasc. II4-II5, p. 425 et pl, XXV. 
Il n'a pas disparu à l'époque des invasions; il est resté en faveur sous les Mérovingiens ( $\mathrm{I}$ ).

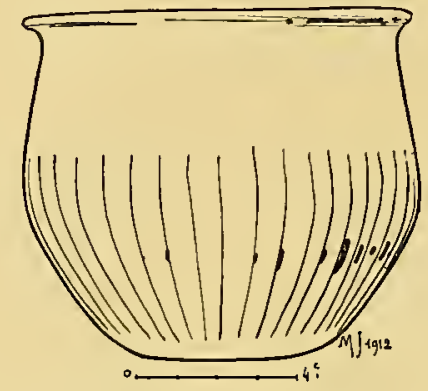

Fig. 158. - BOL DE VERRE BLEU PALE, Décor côtelé très flou. - Vermand, rve siècle. Musée Lécuyer, à Saint-Quentin, $n^{0} 263^{2}$.

Le type 75 a été recueilli au cimetière d'Homblières avec une monnaie de Gratien ( 375 à 383 ) (2).

Le type 76 est toujours orné de dépressions (fig. 255). Il a été rencontré à Andernach dans des inhumations contenant des fibules cruciales, bijoux caractéristiques du IV siècle (3); à Cologne avec

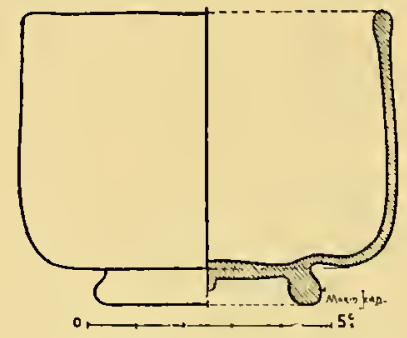

FIG. I59. - BOL DE vERRE INCOLORE. - Grainville, près de Fécamp (Seine-Inférieure). Fouilles de 1756. Romain II. - Musée du Louvre. E. D. I59r.

des monnaies de Constantin, des bouteilles forme 40 et des barillets frontiniens forme I32 (4); à Vermand (5), ̀̀ Ven-

(I) Musée de Saint-Germain. Salle XI. Fouilles F. IIorean (Tombe no 2.3 I 8 . Arcy-Sainte-Restitue. Bol de verre 73 découvert avec une fibule digitée du ve on du vi ${ }^{\mathrm{e}} \mathrm{s}$.).

(2) Voy. J. Prlloy, Études sur d'anciens lieux de sćpultures dans l'A isne, t. I, p. rgr, tombe no 65, pl. III, no 16.

(3) Bonner Jahrbiicher, I888, fasc. 86. p. I97, pI. XI.

(4) Bonner Jahrbiucher, Igo6, fasc. IIf-II5, p. 430 et suiv,, et pl. XIVI, nos 66 et 68 .

(5) Nombreux spécimens au musée Lécuyer et dans la collection TH. Eck à Saint-Quentin. 
dôme (I), à Homblières (2), dans les tombes romaines tardives. Il se maintient dans les sépultures de l'époque barbare.

FORnes SI à 9I. - Verreries faites à l'imitation des bols romains en terre rouge, à décor moulé, de fabrication italique ou gauloise, auxquels M. Dragendorff a attribué une désignation numérique (3).

La forme 8I est représentée par de nombreux exemplaires (fig. I59). Nous citerons ceux du musée de Rouen, trouvés par l'abbé Cochet à Cany en I 849 , à Orival près Fécamp en I864, à Thiétreville en I842.

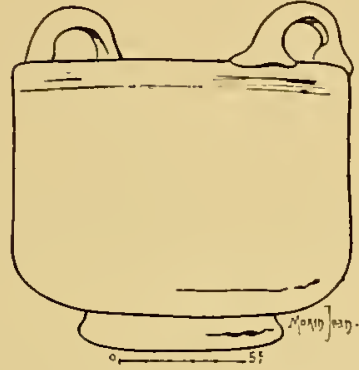

FIG. I60. - BOL EN VERRE VERDATRE FILANDREUX. Basse époque impériale. - Musée provincial $d \dot{c}$ Bonn. Salle $\mathrm{V}, \mathrm{n}^{\circ} 5566$.

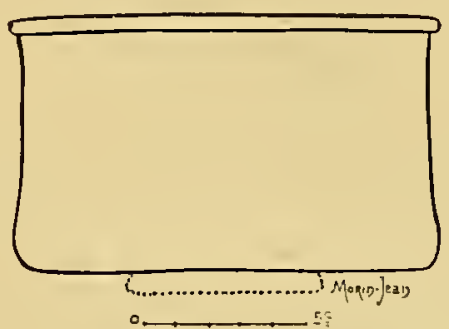

FiG. I6r. - RÉCIPIENT DE VERRE SOUFFLE A L'TMITATION DES CHAUDRONS DE BRONZE. Vermand. IV ${ }^{\mathrm{e}} \mathrm{s}$. - Collection $T h$. Eck, à SaintQuentin.

La plupart d'entre eux sont en verre incolore du Romain II. Quelques variantes sont intéressantes à signaler, notamment celle qui comporte 2 petites anses rondes (fig. I60).

I es bols $8 \mathrm{I}$, faits à l'imitation des poteries, ne doivent pas être confondus avec les récipients vitreux à fond plat légèrement élargi, qui sont des copies, assez fidèles, des chaudrons de bronze du IVe siècle (fig. I6I).

Le type 82 est une variante, à pied très haut, du bol $\delta$ I. Il est particulièrement abondant au cimetière des Dunes, à Poitiers (fig. I62).

Ia forme 83 (forme 30 de M. Dragendorff) est celle qu'affectent les bols moulés ornés de courses de chars et de gladiateurs combat-

(I) MIusée de vendôme (fig. 255).

(2) Toy. J. PIllox, loc. cit., t. I, p. 204 , et pl. III, $11^{\circ} 3$.

(3) Toy. Dragendorff, Terra Sigillata. Dans les Bonner Jahrbiicher, I895, fasc, 96-97, pl. I-III. 
tant (voy. plus loin p. I88 et suiv.). Une variante à fond légèrement élargi est en verre incolore du $\mathrm{III}^{\mathrm{e}}$ siècle (fig. I63).

Le type 84 (forme 37 de M. Dragendorff) est une imitation des

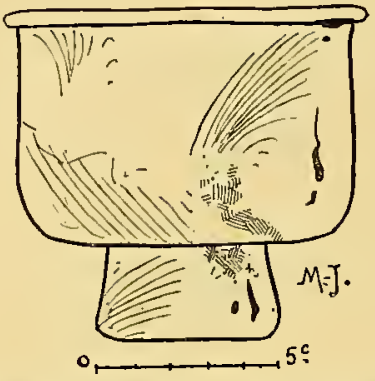

FIG. I62. - BOI A GRAND PIED. - Poitiers. Cimetière des Dunes. - Musée de la Société des $A n$ 'iquaires de l'Ouest, à Poitiers (no 88 [I84]).

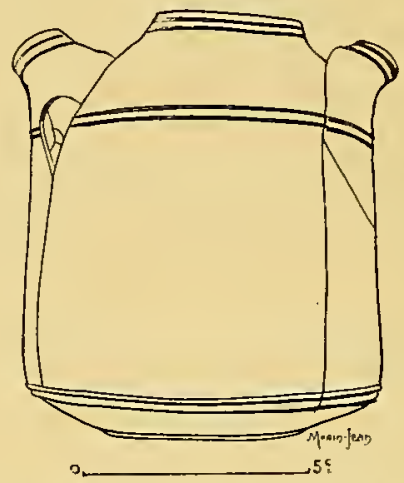

FIG. I63. - BOL DE VERRE TRÈS MINCE. - Paris. Cimetière romain du faubourg Saint-Jacques. Romaiu IX. - Musée Carnavalet.

bols rouges qui sortaient en masse, au $\mathrm{II}^{\mathrm{e}}$ et au $\mathrm{Im}^{\mathrm{e}}$ siècles, des ateliers de Lezoux (fig. I64).

Le type 85 (forme 38 de M. Dragendorff) est caractérisé par une collerette qui entoure 1a panse (fig. I65). Les spécimens en terre cuite de cette forme étaient connus dès le I ${ }^{\text {er }}$ siècle de l'ère chré-

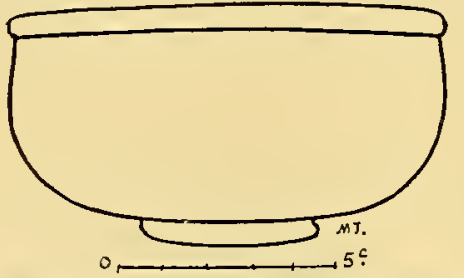

FIG. I64. - BOL trouvé a ORANGe. Muske Borély, à Marseille.

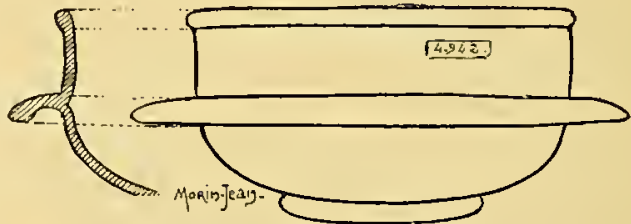

FIG. I65. - Bol DE VERRE A COLlerette. - Musée de Reins, n०4942.

tienne (I). Il est difficile de dire à quelle époque sont apparus les exemplaires de verre soufflé. On peut seulement affirmer qu'ils se rencontrent encore à une époque assez avancée du Iv siècle (2) (fig. I66).

(I) A Xanten, le bol d'argile à collerette a été trouvé avec des monnaies de Vitellius (Bonner Jahrbïicher, I895, fasc. 96-97, p. I I , pl. III). A Andernach, il était associéà des monnaies de Claude (Bonner Jahrbücher, I 888, fasc. 86, p. I72, tombe à ustion $n^{\circ} 3 I$ ).

(2) Voy. TH. Eck, Les derıx cimetières gallo-romains, pl. V, $\mathrm{n}^{0} 7$. 
Le type $S 6$ (fig. I67) existait en Europe occidentale avant +79 , comme le prouvent les exemplaires découverts à Pompéi. Il est souvent en verre violet (Musée Borély, à Marseille, $\mathrm{n}^{\circ} 560$, et musée de Nîmes).

Le type 87 (Forme 43 de M.. Dragendorff) est rare. Nous n'en

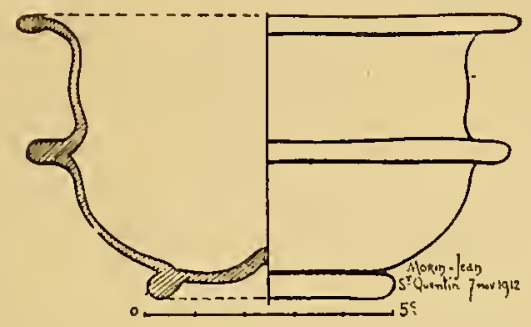

Fig. I66. - Bol A COLlerette. verre verDATRE. - Termand. IV s. - Musée Lécuyctr, à Saint-Quentin, $12^{0} 2618$.

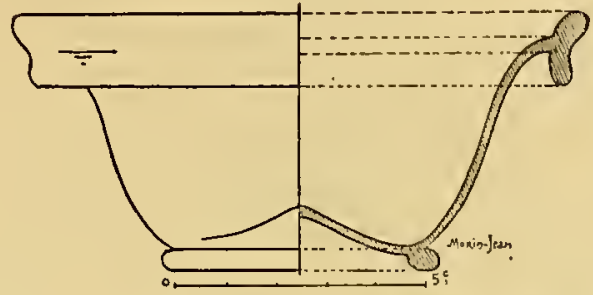

FIG. I67. - Bol TROUVÉ DANS LE DÉPARTEMENT DE LA MARNE. - Collection Morin-Jean, $\mathrm{n}^{\circ} 566$.

connaissons qu'un seul spécimen exposé au musée de Mayence (fig. I68). Par la nature de sa pâte vitreuse incolore et filandreuse et de son décor (grossières applications vermiculaires), ce bol peut être daté de la seconde moitié du $\mathrm{III}^{\mathrm{e}}$ siècle.

Le type $S S$ (forme 7 de $M$. Dragendorff) se voit au $I^{\text {er }}$ siècle dans la verrerie pompéienne. Il est passé de bonne heure en Gaule (fig. I69).

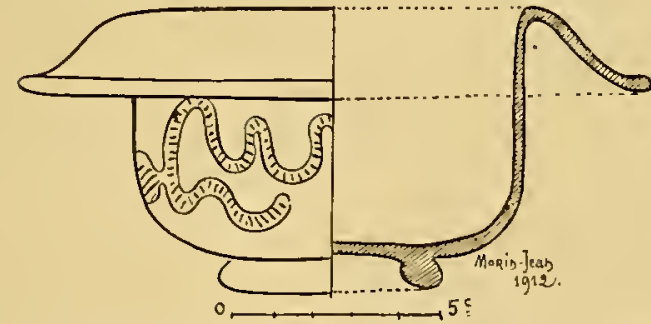

FIG. I68. - BOL ORNÉ D'APPLICATIONS VERUUCULAIRES. - Romain II. - Musée de Mayence.

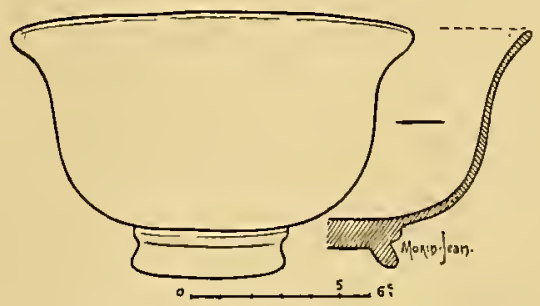

Fig. I69. - BOL DE VERRE BLEU, trouvé à Arles. - Cabinet des Médailles, à Paris, nº 791 .

[Les exemplaires du musée d'Arles et du musée Calvet, à Avignon, sont du Romain I.]

A la forme 89 appartiennent les coupes de verre incolore (ornées d'applications vermiculaires) qui, dans les incinérations de Cologne, 


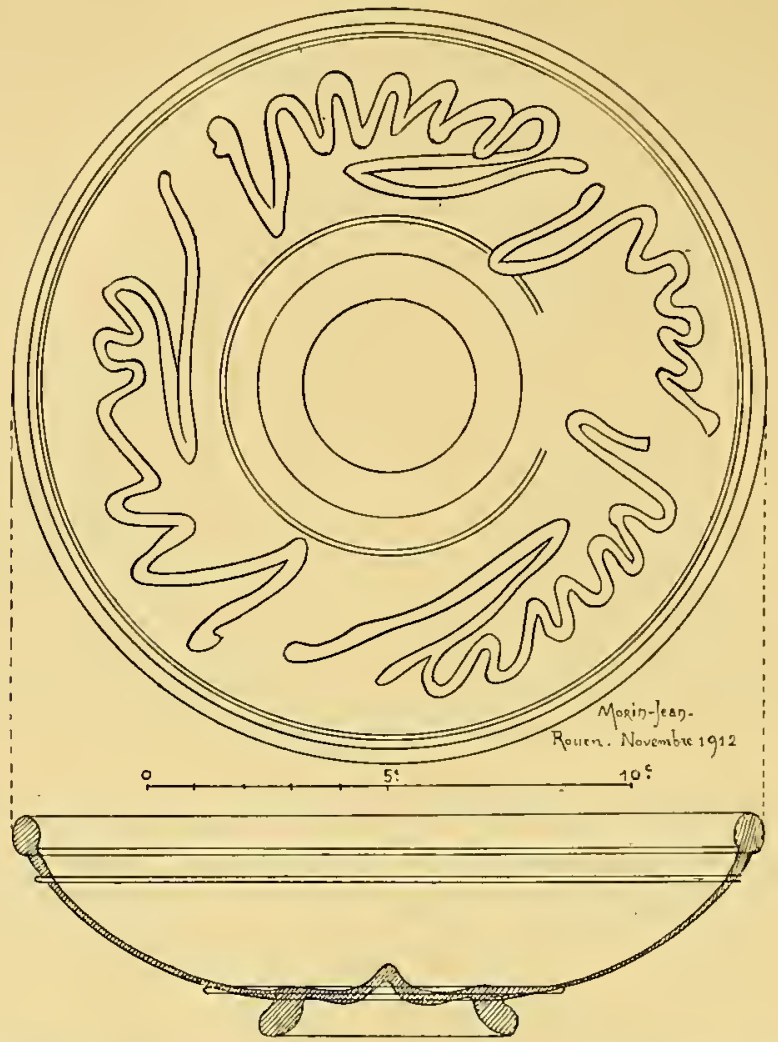

Fig. 170. - CoUPE DE verRe INCOLORE ORNÉE D'APPLICATIONS VERMTCULATRES EN VERRE ALTERNATIVEMIENT BLEU ET BLANC. - $\mathrm{I \Pi}^{\mathrm{e}} \mathrm{s}$. - Musée départemental d'antiquités, à Rouen.

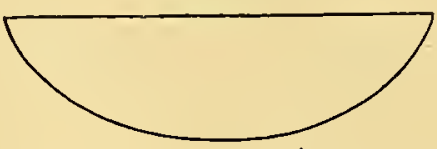

A.

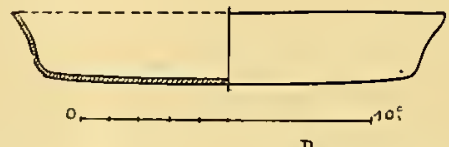

B.

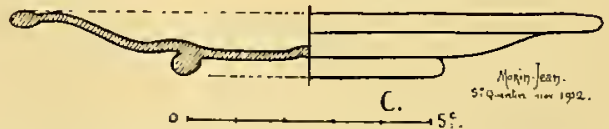

FIG. I7I. - COUPE ET PLATS DE VERRE FIN III ${ }^{\mathrm{e}}$ IV $^{\mathrm{e}} \mathrm{S}$. - Cimetière de Vermand. - Collection Théophile Eck, à Saint-Quentitı. 
ont servi de soucoupe aux cenochoés forme 54, et une coupe du musée de Rouen, reproduite fig. I70. Ces récipients sont de la première moitié du $\mathrm{III}^{\mathrm{e}}$ siècle.

Les types go et $9 \mathrm{I}$ sont des plats de différents modèles connus à

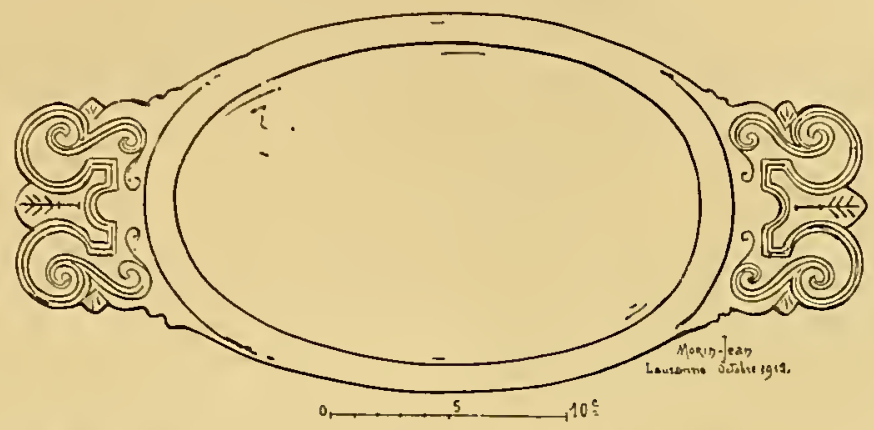

FIG. I72. - Plat Ex BRoxze ĖTaMé, trouvé à Saint-Saphorin-sur-MIorges (Suisse). - Musíz de Lausanne, ño $20 \mathrm{r}$.

Pompéi, et dont les Romains se servaient encore à l'époque constantinienne (fig. I7I). Quelques-uns de ces plats atteignent de très grandes dimensions.

FORME 92. - I,e plat ovale à anses plates est l'imitation d'un

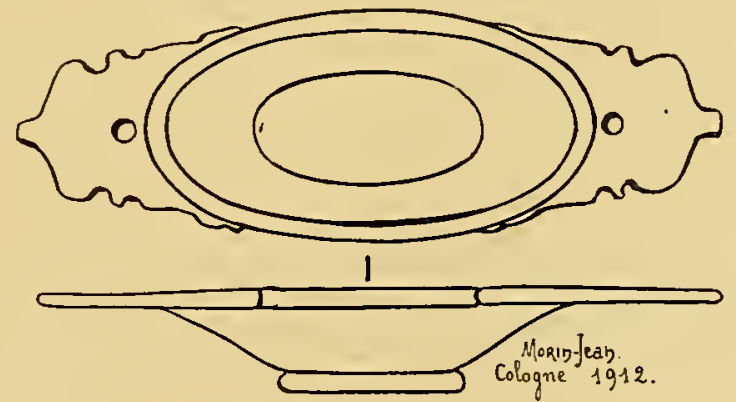

FIG. I73. - Plat losg Ex Verre LyColore DÉcosposé. - Romain II. - Musée Wallraf-Richartz, à Cologne, $n^{0} 760$.

type métallique représenté par de beaux spécimens dans la toreutique de l'époque romaine (I) (fig. I72).

La figure 73 reproduit un plat ovale, en verre, bien conservé, pro-

(I) Un plat d’argent forme 92, publié par l"abbé Cocher (La Seine-Inférieure historique ct archéologique, p. 4I3), a été trouvé en octobre I $\$ 64$, au cimetière de I,illebonne, dans une sépulture à ustion de la fin du $\boldsymbol{I}^{\mathrm{e}}$ siècle ou du $\boldsymbol{I I}^{\mathrm{e}}$ siècle. L,es céramistes ont fait, eux aussi, des plats de cette forme (British MItseum. Plat en terre rouge de Lezoux II. Io8. Toy. WALters, Catalogue of the Roman Pottery, p. 67, pl. XIY. 
venant du Rheinland. D'autres plats, à peu près semblables, mais dépourvus d'anses, sont aux musées de Bonn ( $\mathrm{I}$ ) et de Mayence. Tous sont en verre incolore du Romain II.

I2. - TASSES ET RÉCIPIENTS A LARGE OUVERTURE ÉMANANT DES TYPES GREQS: CANTHARE, SKYPHOS, CARCHESIUM ET CIBORIUM

(Formes 93 à I03.)

FORME 93. - Copie assez exacte d'un type métallique qui figure parmi les vases d'argent du trésor de Boscoreale.

La forme 93 existe dans la verrerie pompéienne. D'Italie, elle a

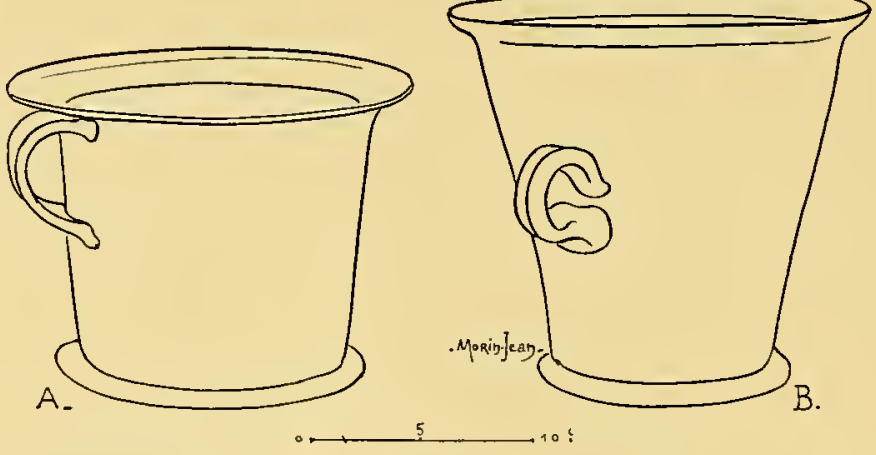

Fig. I74. - Verreries de la Vallée du Rhône: A. Musée de Nîmes. - B. Musée de Lyon.

passé en Gaule (fig. I74). Un spécimen en verre jaune, et à panse côtelée, appartient au musée de Reims (2). Son profil curviligne lui donne de l'élégance.

FORIF, 94. - La forme 94 reproduit un modèle de canthare métallique connu par les belles coupes de Boscoreale et de Berthouville (3). Elle comporte deux anses du type $\lambda$ (p1. 2, p. 36).

Des canthares 94 en verre bleu-verdâtre, façonnés par les industriels du Romain I, ont été trouvés en Italie (notamment à Pompéi)

(I) Bonn, Provinzialmuseum, salle V, vittine $4, \mathrm{n}^{0} 7.68 \mathrm{I}$.

(2) Catalogue du Musée archéologique de Reins [n ${ }^{\circ} 2.548$, hauteur : I2 centimétres].

(3) Les coupes du trésor de Berthouville (Eure) sont au Cabinet des Mrédailles, à Paris [roy. E: BABELoN, Guide illustré au Cabinet des Médailles et antiques de la Bibliothèque Nationale, p. 352, fig. I67]. 
et dans la vallée du Rhône (I) (fig. I75). Dans le courant du III siècle, la forme 94 est remplacée par la forme I03.

FORME: 95. - Coupe profonde dont la forme dérive du skyphos

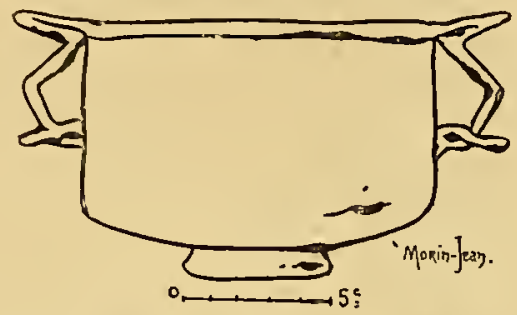

IIG. I75. - CANTILARE DE vERRE. - Musée de la Maison Carrée, à Nîmes.

grec (2). Mêmes anses qu'au type 94. Les skyphoi 95 se classent au Romain I (fig. I76).

FORnie 96. - Canthare (3) dont les anses surélevées décrivent une très belle courbe (fig. I77).

FORMIEs 97-98. - Canthares à parois concaves, presque toujours sans anses et pourvus d'un pied anmulaire ou d'un pied en forme de plateau séparé du vase par une boule ou un cylindre de verre.

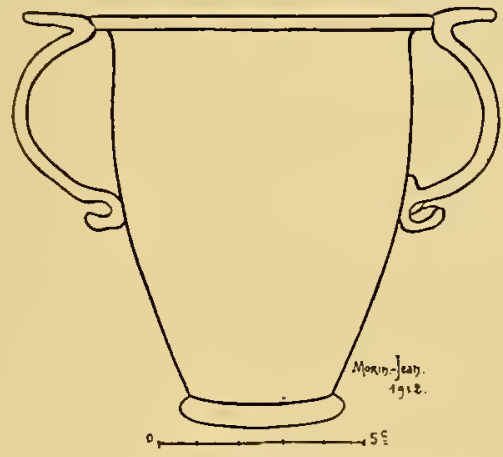

FIG. 1;6. - SKiphos DE verre. - Romaiu I. - Musée de Mayence.

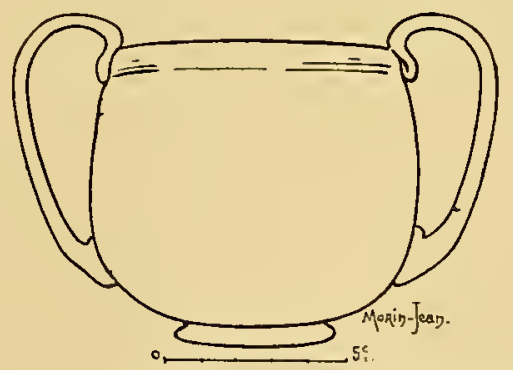

FIG. I77. - CANTHARE DE VERRE BLEU-VERDATRE, trouvé à Saintes. - Musce de Saint-Germain. Salle $\mathrm{XV}, \mathrm{n}^{0} 24634$.

Ces verreries ont pour ancêtre morphologique le carchesium hellénistique (4).

(I) Canthares du unusée de la Maison Carrce à Nîmes [ $\pi^{0} 37$, hauteur : 8 centimètres] et du musée Calvet, à Aviguon [Fouilles de Piolène].

(2) Sur le skyphos grec, consulter le Dictionnaire des Antiquitćs de Mr. SAGLIO, $43^{\mathrm{e}}$ fasc., p. Ir 59 et suiv.

(3) Diclionnaire cité, t. I, deuxième partie, p. 893 et suiv.

(4) Dictionnaire cité, t. I, deuxic̀ne partie, p. grg. 
La forme 97 est plus ancienne que la forme 98. Elle n'est pas in- . connue à Pompéi. En Gaule, elle est assez répandue dans la basse

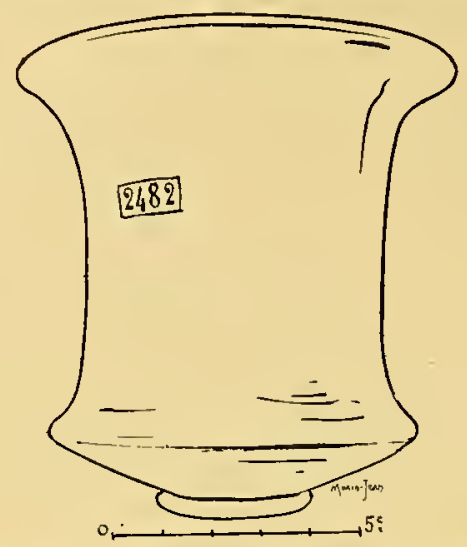

Fig. I78. - CARChesrum SAvS Anses. - Verre jaune-verdâtre foncé. Fouilles du Boulonnais. $\mathbf{l I}^{\mathrm{e}} \mathrm{s}$. Musée de Bonlogne-sur-Mer, $\mathrm{n}^{0} 2482$.

vallée du Rhône. La forme $9^{8}$ ne semble pas être apparue avant le $\mathrm{III}^{\mathrm{e}}$ siècle (I). Les vases de cette dernière forme sont souvent colorés soit en jaune (2), soit en verre émeraude (fig. 284), soit en violet (3),

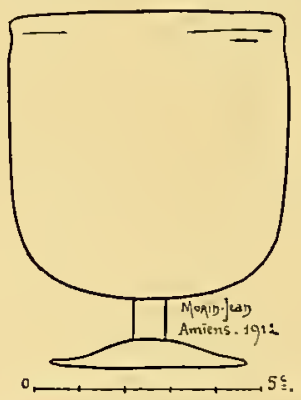

FIG. I79. - VERRE A PIED DU III ${ }^{\circ}$ S. Verte incolore très pur. - Picquigny (Somme). - Musée de Picardie, à Amieus.

soit en noir (imitation de l'obsidienne). Ils sont parfois ornés d'applications vermiculaires (fig. 284).

(I) Un carchesium de la même forme que celui que nous reproduisons figure 284 a été trouvé à Cologne, dans une tombe à inhumation, avec des monnaies des empereurs Volusianus, Postumus et Gallienus [Voy. Bonner Jahrbiicher, I906, fasc. II4-II5, pl. XXV, tombe 59].

(2) Un carchesium d'un très beau jaune a été découvert à Saintes [Musée de Saiut-Germain, salle XV, n० 24.635$]$.

(3) Un carchesium en verre améthiste a été publié en couleur par W. Freaner [Collection J. Gréan, no I.3I5, pl. 248 (Provient de Cologne)]. 
Au $\mathrm{V}_{\mathrm{L}}^{\mathrm{e}}$ siècle, la forme $9 \mathrm{~S}$ évolue ; elle perd son pied et devient la clochette à bouton caractéristique de l'époque, mérovingienne.

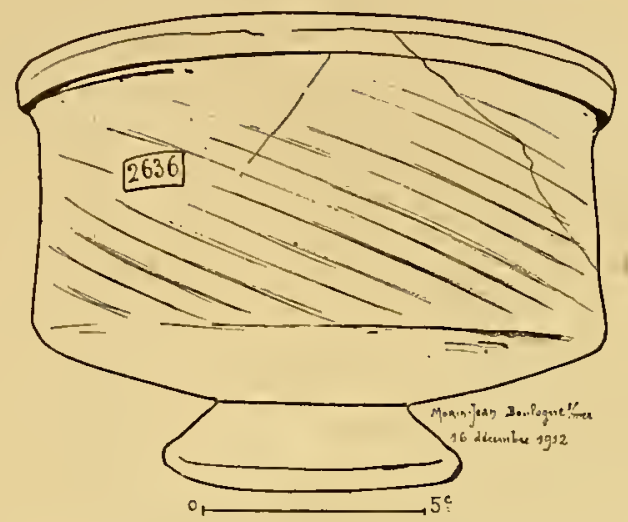

FIG. ISo. - Bor A PIED. - Verre verdâtre. Vieil-Atre (fouilles de I870). - Musèe de Bonlogne-sur-Mer, $\mathrm{n}^{0} 2636$.

Un carchesium de verre, muni de deux anses, a été découvert à Cologne (I). On peut le rapprocher à la fois des verreries de notre

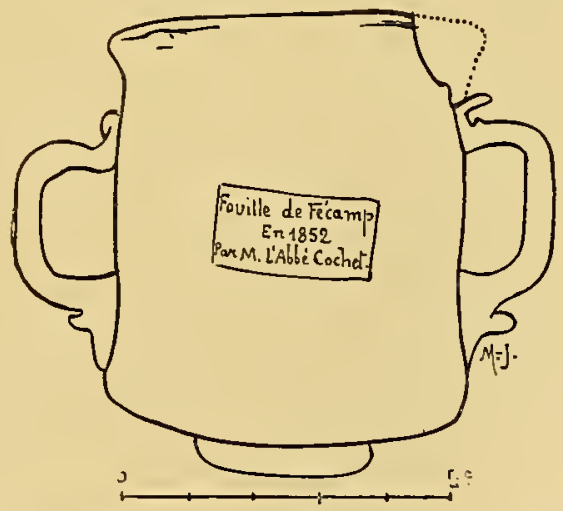

Fig. I8I. - Cixthare trouvé a FÉcamp. - Fouilles de l'abbé Cochet en I852. - Musée dé Roren.

type I02, des poteries forme 53 de M. Dragendorff (2), du canthare en sardoine dit Coupe de Ptolémée ou de Mithridate conservé à Paris,

(I) AEs'y'TEeRtH, dans les Bonner Jahrbiucher, I $\$ 7 \delta$, fasc. $64, \mathrm{pl} . \mathrm{I}$.

(2) Dragendokfr, Terra Sigillata, dans les Bonner Jahrbiicher, I895, fasc. 96-97, p. I39, pl. III. 
au Cabinet des Médailles (I), et du calice d'or massif du trésor du Gourdon (2).

FORMES 99-IO0. - Verreries à pied. Types du Romain II (fig. I79, I80). - I a forme 99, qui semble avoir été usitée surtout au $\mathrm{III}^{\mathrm{e}}$ siècle, est un bol 7 I auquel on a ajouté un pied délicat. Une verrerie de ce modèle, provenant d'une incinération du cimetière de Cologne (3), est ornée d'applications vermiculaires.

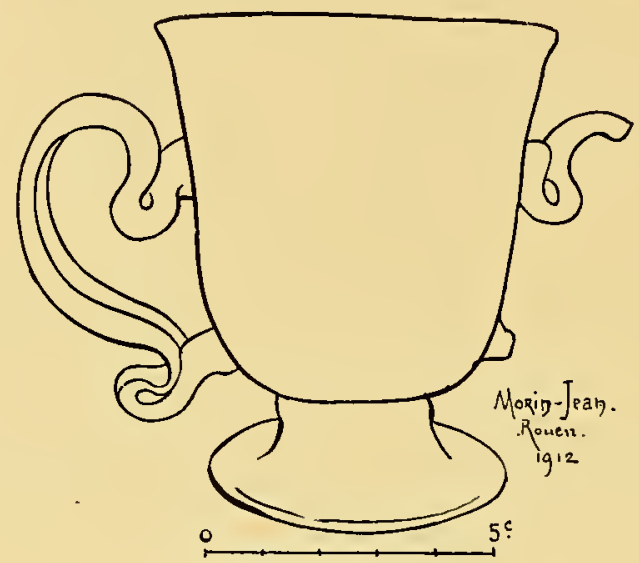

Fig. I82. - CANThARE EN VERRE INCOLORE. - Romain II. - Musée de Rouen.

FORME IOI. - Petit canthare à pied bas. - Forme peu commune en Gaule. III ${ }^{\mathrm{e}}$ siècle après J.-C. ? (fig. I8I).

FORME I02. - Canthare de style hellénistique dont les anses appartiennent au type - (p1. 3, p. 37).

On connaît deux spécimens de ce genre de verrerie. L'un est au musée de Rouen (fig. I82). L'autre, trouvé aux environs d'Amiens, est conservé au British Museum. Le canthare d'Amiens (4) est plus

(I) La coupe de Mithridate est un carchesium de l'ćpoque ptolémaïque. Au Moyen-âge, ce précieux vase faisait partie du trésor de Saint-Denis [voy. E. BABELon, Guide illustré au Cabinet des Miédailles, Paris, I900, p. I57 à I6z, fig. 65 et 66 I.

(2) Le calice trouvé à Gourdon (Côte-d’Or), en 1845 , est de l'époque mérovingienne. Il fait partie des riches collections du Cabinet des Médailles [voy. E. BABELON, loc. cit., p. I68, et AUs'M' WVERTH, dans les Bonner Jahrbiicher, 1878 , fasc. $64, \mathrm{pl} . \mathrm{X}]$.

(3) Fouilles de la rue de L,uxembourg en I 897 [voy. Bonner Jahrbiicher, I906, fasc. IIf-II5, p. 408 et pl. XXIII, tombe $n^{\circ} 37$.

(4) Le canthare d'Amiens a été publié par AUs'Mr'WEERTH dans les Bonner Jahrbiicher de I878, fasc. 64 , pl. X. Ou en trouvera une assez bonne reproduction dain Robert Schmmt, Das Glas, Berlin, rgr2, p. 33 , fig. I7. 
élégant que celui de Rouen. Ses anses, bien proportionnées, s'élèvent plus haut que l'orifice de la vasque; sa panse en forme de bulbe

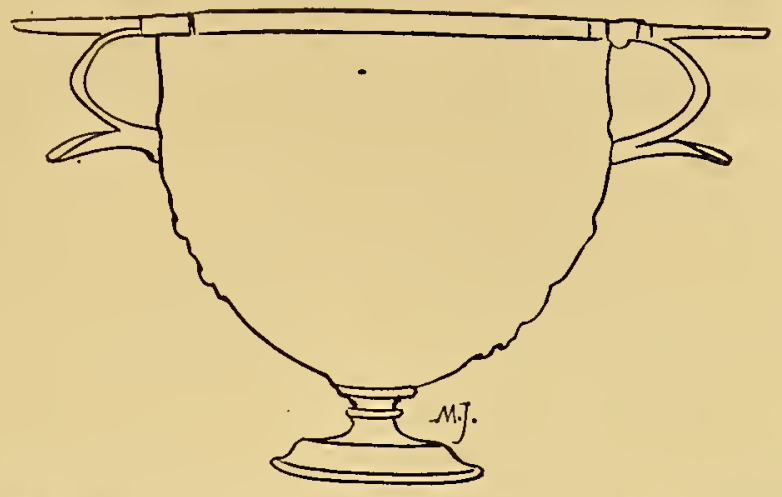

FIG. I 83 . - IE VASE D'ARGENT D'ALESL (eroquis schématique). - Musée de Saint-Germain.

côtelé est surmontée d'un col largement évasé. Seul, son pied est un peu lourd, un peu trop grand par rapport aux autres organes du vase. Cette pièce remarquable, qui semble dater du rve siècle, est un

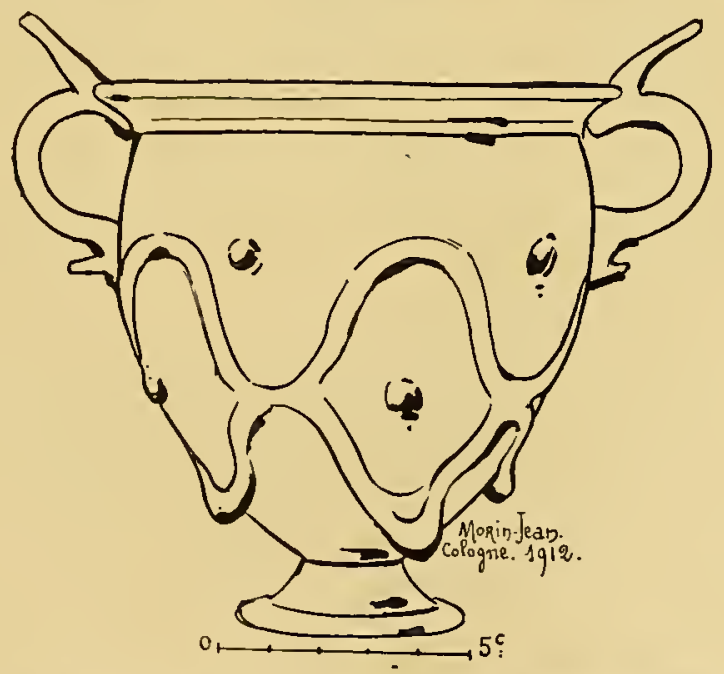

FIC. I34. - VASE EN VERRE LYCOLORE DÉCOMIPOSE. Romain II. - Nusée Wallvaf-Richartz, à Cologne.

carchesium qui, à bien des égards, se rattache à nos formes 97-98, et que M. Aus'm'Weerth a rapproché du calice d'or de Gourdon.

FORIE I03. - Ciborium. - Imitation plus ou moins exacte d'un 
modèle métallique représenté parmi les coupes d'argent de Boscoreale (I), d'Hildesheim (2) et d'Alesia (3) (fig. I83). Le ciborium de verre, que certains archéologues appellent calix pterotus, est une élégante vasque munie de deux anses dont la boucle s'ouvre dans un plan vertical et qui s'amorcent, dans le haut, sous deux oreilles horizontales. Chacune de ces oreilles est, dans la majorité des cas, cons-

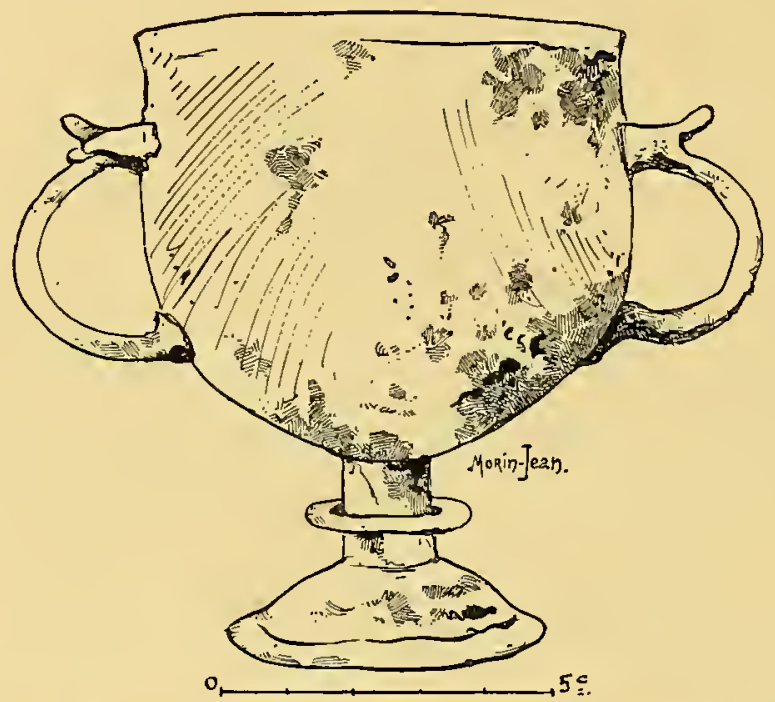

FIG. I85. - CIBORIum DE verre INCOLORE DÉCOMPOSÉ. - Trouvé à Amiens etl I 883 . Romain II. MItuée de Péronne (Somme).

tituée par une petite plaque de verre terminée par trois pointes. Le pied du ciborium, assez variable dans sa structure, est parfois orné d'une bague (fig. I85) dont les exemplaires de métal ne sont pas non plus dépourvus.

Les ciboria de verre ont été rencontrés surtout dans le nord des Gaules. Ils apparaissent au $\mathrm{III}^{\mathrm{e}}$ siècle (4); mais beaucoup d'entré

(I) Héron de VILlefosse, Le Trésor de Boscoreale, dans les Monunents Piot, t. T, r\$99, pl. I.I et I.

(2) Erich PERnice et Franz WnTer, Der Hildesheimer Silberfund. Berlin, rgor, p. 32 et pl. X.

(3) Voy. Revue Pro Alesia, r906-I907, pl. XXX, et S. Rervacr, Guide illustré du musée de Saint-Germain, p. 55, fig. 49 .

(4) Notamment au cimetière de Cologne. Tombe $n^{\circ}$ 34. Fouilles de Igo+ [Bonner Jahrbücher, I906, fasc. II4-II5, p. 405, pl. XXIII]. 
eux sont de la fin de la période gallo-romaine (I), ou même du ve siècle.

Maints exemplaires sont décorés de cabochons de verre (fig. 304) D'autres ont été gravés (2).

\section{I3. - VERRES A BOIRE.}

(Formes ro4 à II2.)

FORMES IO4-I05. - Gobelets tronconiques. - La forme ro4 a été

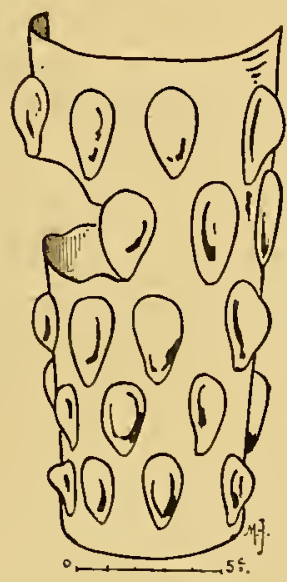

FIG. IS6. - TERRE A NoDosités. - Musée d'Avignon, no rooo.

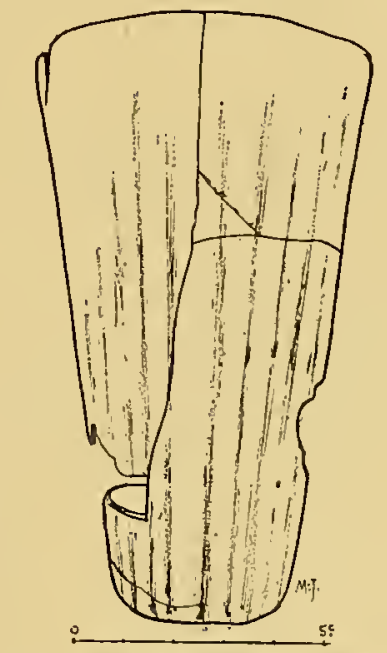

FIG. I87. - VERRE A BOIRE. - Fouilles de Paris Cimetière du faubourg Saint-Jacques. rve s. Musée Camavalet.

donnée à certains verres moulés du Romain I dont la panse est couverte de volumineuses nodosités disposées en quinconce. Ces verres à nodosités ont été recueillis les uns en Italie (beaux exemplaires de Pompéi au musée de Naples), les autres dans la vallée du Rhône (fig. I86).

(I) Par exemple le ciborium à cabochons trouvé dans la tombe no 53 du cimetière d'IIomblières à Abbeville, avec une monnaie de Valentinien I ${ }^{\mathrm{cr}}(364$ à 375$)$, le ciborium découvert eu I 820 à Heiligenstein (Palatinat) dans un sarcophage de pierre, et celui du musée de Boulogne-sur-Mer, volé en I 844 et dont il ne reste qu'un mauvais dessin dans RoAcH Surn, Collectanea Antiqua, I $843, n^{\circ} \mathrm{I}$.

(2) Des ciborix ornés de gravures ont été trouvés à Strasbourg [fouille d'un sarcophage du Ive sidcle. Voy. STRAUB, Le eimelière gallo romain de Strasbourg, p. 37, tombe 29, pl. IV], à Trèves, près l'église SaintIraxinuin [fouille d'une sépulture chrétienne. Voy. Bonner Jahrbïcher, I878, fasc. I, XIV, p. I26], à Bonn Bonn. Provinzialmuseum, $11^{\circ}$ I0.49 I]. 
La forme I04 a été également donnée à des verreries tardives

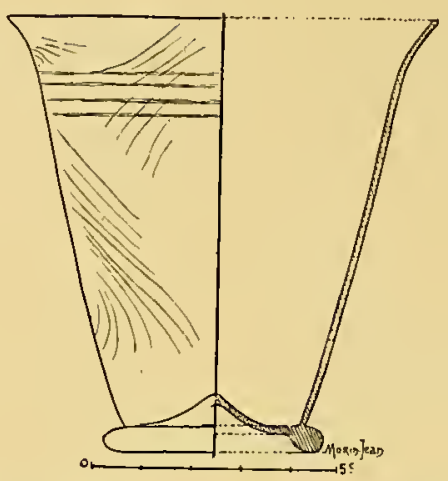

FIG. 188, - GoBELET DE VERRE A PIED. - Fouilles du Vieil-Atre à Boulogne-sur-Mer. Romain II. - Collection Morin-Jean, $\mathrm{n}^{\mathrm{O}} 2227$ (ancienne Collection Bernay).

façonnées à l'aide d'une pâte incolore ou verdâtre et à décor variable (fig. I87).

Les verres du type I05 sont de basse époque. Parfois, ils sont munis d'un pied annulaire (fig. I88).

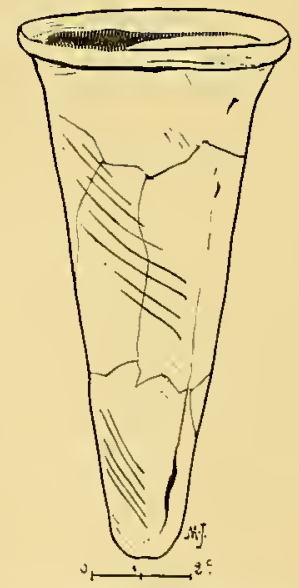

FIG. I89. - CORNET DE VERRE DU IV ${ }^{e}$ s. - Cimetière de Sablonnière (Aisne). - Musée de Saint-Germain. Salle F. Moreau. Tombe $n^{\circ} 274$.

FORME I06. - Grand gobelet tronconique à très petit pied anmulaire. $\mathrm{IV}^{\mathrm{e}}$ siècle et début du ve. Les verres 106 sont nus ou ornés, soit 
d'une résille en fil de verre (fig. 262), soit de cercles gravés (I). FORIE I07. - Cornet apode. Verre impur. Embouchure tantôt ourlée, tantôt non ourlée (fig. I89).

I.es verres coniques, très répandus dans tout le nord des Gaules, se rencontrent dans les tombes de la fin de l'Empire (fig. 344) et dans les sépultures franques $d u v^{e}$ et du vi ${ }^{e}$ siècles (2).

FORMES IOS à III. - Formes diverses de verres à pied du Ro-

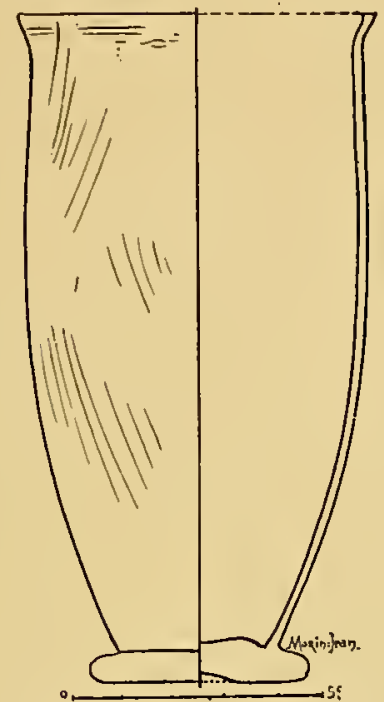

FIG. I90. - IEERRE A PIED, trouvé à Reims (Marne). Fin $\mathrm{III}^{\mathrm{C}}$ ou $\mathrm{IV}^{\mathrm{e}} \mathrm{s}$. - Collection Morin-Jean, $n^{\circ} 2880$.

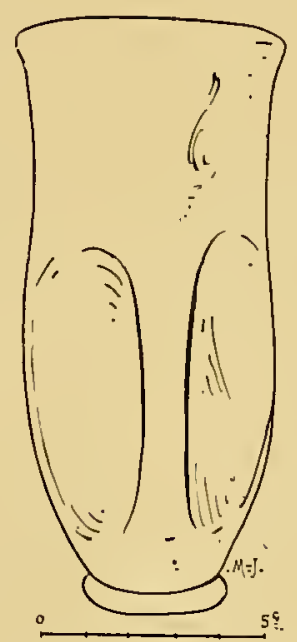

FIG. I9I. - VERRE A PIED ORNE DE QUATRE DEPRESSrons. - Romain II. - Musée de Rouen (ancienne Collection de Girancourt).

main II. - Le type I08, un des plus délicats de la série, est muni d'un pied séparé de la panse par une petite boule de verre. Il est fréquemment orné d'applications vermiculaires en forme de feuilles (3), ou de serpents (4).

(I) Un bel exemplaire à cercles gravés a été trouvé, à Cologne, đans une inhumation tardive [voy. Bonner Jahrbücher, xgo6, fasc. x I 4-II5, p. 433, pl. XXVI, tombe 72].

(2) Le type de verrerie 107 était associé, dans la tombe 2.786 du cimetière d'Arcy-Sainte-Restitue, à une boucle de guerrier franc [gros anneau (de potin) à ardillon]. [voy. MIusée de Saint-Germain. Salle $X I$. Vitrine 45].

(3) Spécimeu du $\mathrm{m}^{\mathrm{e}}$ siècle, publié par Aus $x^{\prime}$ WeERTh dans les Bonner Jahrbücher de I88r, fasc. 7r, pl. VI, n० I.388.

(4) IIusée archéologique de Reims, nos 4.705 et 4.706 . Voy. plus loin, p. 216 et fig. 292. 
I.e type Iog (fig. Igo) dont le pied est moins élégant, est parfois

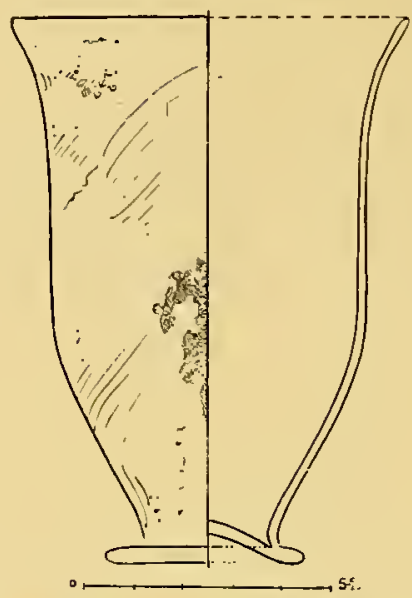

FIG. I92. - VERRE CARÉNÉ. - Tombes à inhumation de la Marne. - Collection Morin-Jean, nº 1025.

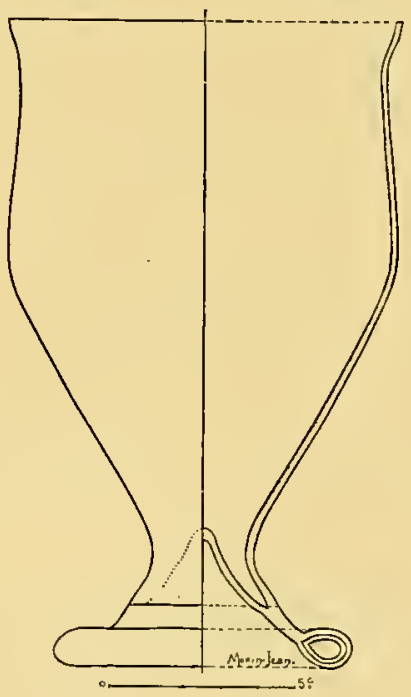

Fig. I93. - GRand Verre A_PIED, trouvé à Vermand (Aisne). IVe s. - Collection MIorin-Jean, nº 22 I 9 (ancienne Collection Bernay).

décoré de dépressions (fig. IgI) de fils de verre enroulés autour de la panse (I), d'un texte gravé (2).

(I) Certains verres rog sont simultanément ornés de fils et de dépressions [Verre trouvé dans une tombe, à inhumation du cimetière d'Andernach. Foy. KcENEN, dans jes Bonner Jahrbücher, I888, fasc. $\$ 6$, p. I 85 , pl. $X, 29]$.

(2) Deux exemplaires à légende gravée sont au musće de Irayence (voy. plus loin, p. 247). 
Il est abondant en Picardie (I). Il fait partie des mobiliers funéraires du IVe siècle (2).

I,es verres carénés IIO-III, à profil plus ou moins anguleux, ont l'orifice coupé aux ciseaux et non ourlé. Ils ont un pied refoulé du type Io, fig. 9, dont le gros bourrelet creux est souvent rempli d'un émail blanchâtre, rosé ou brun (fig. I93). Ils sont en verre

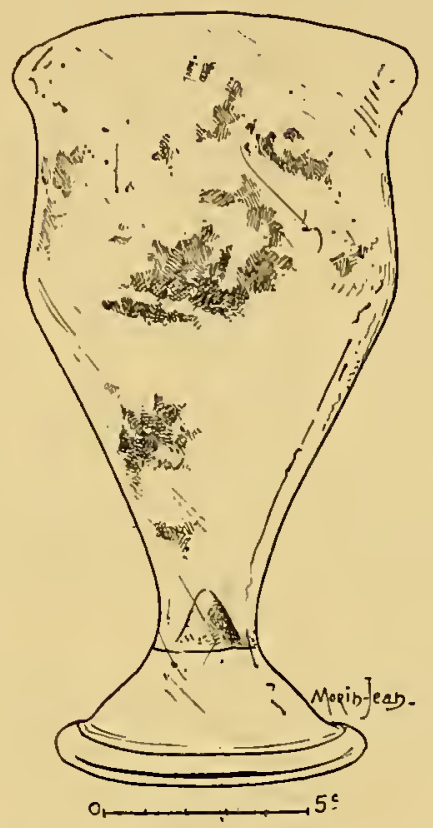

FIG. I94. - VERRE A PIED, trouvé à Vermand (Aisne). IVe s. - Collection Morin-Jean, no Io22.

incolore et filandreux. Ils ont ordinairement I2 à 20 centimètres de hauteur, mais atteignent quelquefois 30 centimètres. Ils sont tantôt nus (fig. I93 et I94), tantôt décorés d'un réseau en fils de verre (fig.263) ou de serpents (fig. 290 et 29I).

Ils sont spéciaux à la Gaule Belgique (3) et ne se rencontrent que sporadiquement dans d'autres régions.

(x) Nombreux exemplaires du cimetière de Vermand [voy. Tн. Eck, Les acux cimetières gallo-romains, p1. VII, no 7 .

(2) Bonner Jahrbuicher, I906, fasc. II4-II5, pl. XIV, tombe 62 du cimetière de Cologne. Dans cette sépulture, un verre tog a été recueilli avec une plaque de ceinture et une fibule cruciale.

(3) On en a trouvé beaucoup à Vermand [TH. Eck, loc. cit., pl. VII, nos 8 et 9], à Boulogne-sur-2Ier, à Amiens [Musée de Picardie, nos 856 et 978 ], à Abbeville, daus la forêt de Compiègne [fouilles de Roucy. Iusée de Saint-Gernain], et dans les nécropoles de la Marne. 
Ils sont synchroniques avec les types Io6 à Iog (I).

FORME II2. - Verre tronconique à fond plat, plus large que l'embouchure (forme de la boîte au lait moderne). - Les verreries de ce type peu gracieux ne sont pas communes. Deux spécimens, con-

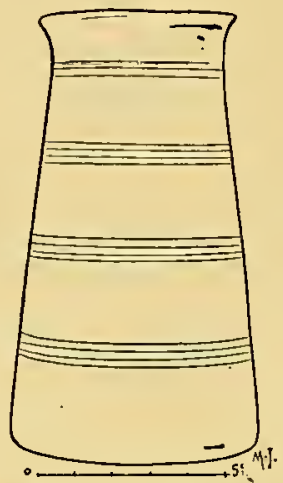

FIG. I95. - Gobelet EN VERRE INColore, orné de cercles gravés. - Romain Il. - Musée de Trèves. Salle $\mathrm{XX}$. Vitrine $\mathrm{X}$.

servés au musée provincial à Trèves (2), sont en verre incolore et se classent au Romain II (fig. I95).

I4. - VERRERIES NON ANSÉES, A PANSE OVOIDE. FORMES EMPRUNTÉES A DES POTERTES ROMAINES DE IAA BASSE ÉPOQUE IMPÉRIALE. ?

(Formes II3 à II6.)

FORME II3. - Vase ovoïde muni d'un pied annulaire et dépourvu de goulot. - Ce type de récipient vitreux, auquel certains auteurs réservent le nom d'obba, présente une grande analogie avec la forme 52 des vases d'argile classés par M. Dragendorff (3). Il est d'une époque tardive. Il ne nous est connu que par quelques exemplaires en verre incolore ou impur de la Gaule nordique (4).

(I) Au cimetière d'Homblières, on a trouvé un verre caréné du type I I I, daus une sépulture à inhumation qui contenait une fibule cruciale et uu petit bronze de MIagnence (350 à 353) [Voy. J. Prllor, Eiudes sur d'anciens lieux de sépultures dans l'A isne, t. I, p. I $8 \mathrm{I}]$.

(2) L'un d'eux [salle $2 \mathrm{I}$, vitrine VIr, tombe $I 85, n^{\circ} 04.92 \mathrm{r} c$ ] était accompagné d'un flacon de verre identique à celui que nous reproduisons figure 29 et de plusieurs vases de terre noire décorés à la barbotine blanche.

(3) DragendorfF, Terra Sigillaza, dans les Bonner Jahrbiicher, I895, fasc. 96-97, pl. III, p. I39.

(4) Musée de Reins ( $\mathrm{n}^{0} 4.787$, hauteur : I centimètres) et musée de Saint-Germain, salle II [Spécimen de 16 centimètres de hauteur, trouvé par F. MOREAU au cimetière de la Villa d'Ancy (Aisne)]. 


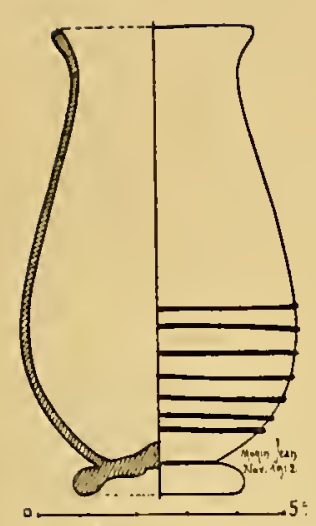

FIG. 196. - RÉCIPIENT DE IERRE TRATSPARENT, OTné d'un fil de verre opaque bleu pâle. - Vermand, fin Ir $^{\mathrm{e}}$ ou rve s. - Musce Léculer, à Saint-Quentiu, $n^{\circ} 2673$.

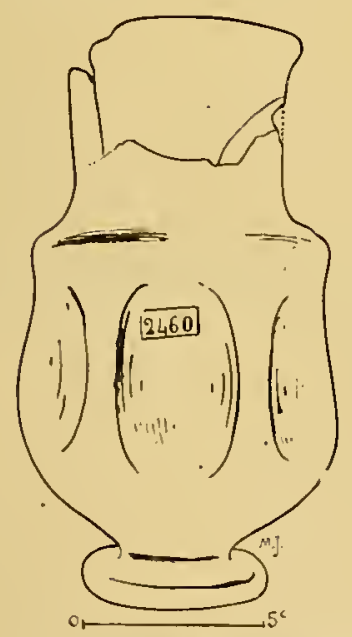

FIG. 199. - VASE EN VERRE MPUR. - Neufchâtel (Pas-de-Calais). IV s. - Music de Boulogne-surIfer $\mathrm{n}^{0} 2460$.

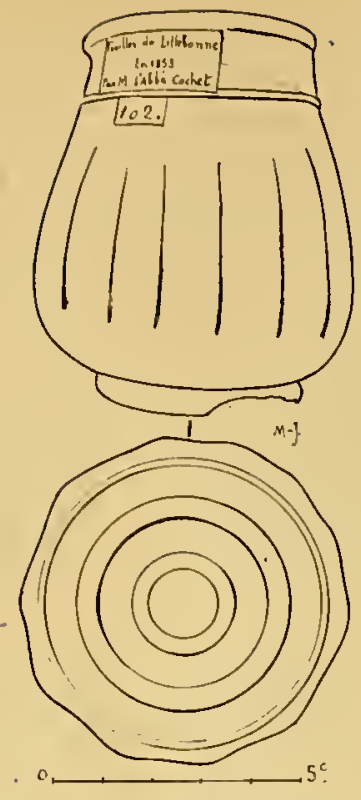

Fig. I97. - Petit VASE EN VERRE INCOLORE DÉCONIPosÉ, - Fonilles de I,illebonne, en 1853. - Missie du Louvre, $11^{\circ}$ IO2.

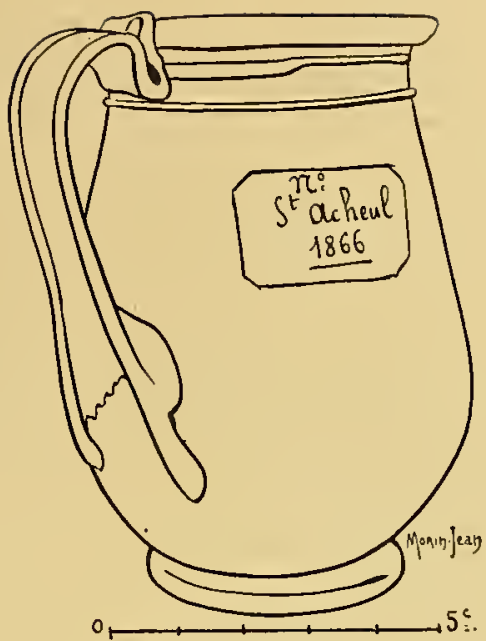

FIG. I98. - VASE DE VERRE A UNE ANSE. - Saint-Acheul (Sorume). Fouilles de I866. - Musie de Rowen.

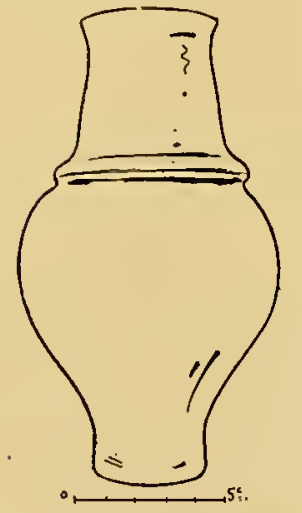

FIG. 200. - VERRE RHÉNAN d'époque tardive. - Musce de Cologne, $1^{0}$ ir 43 .

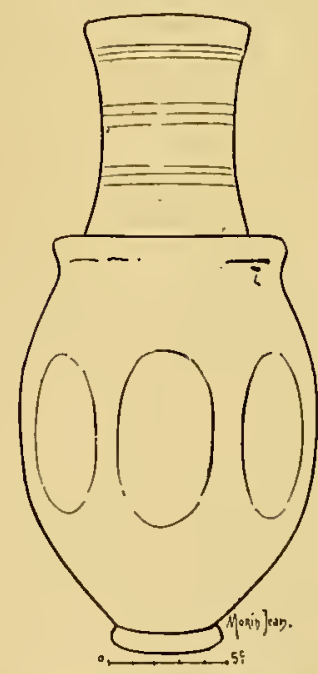

Fig. 20I. - VASE DE VERRE NCOLORE FILANDREUX. Panse ornée descpt dépressions. Col décoré de cercles gravés. - Misse de Trives. Salle XX $\left(\mathrm{a}^{\circ}\right.$ 0554 $\left.\mathrm{I}^{2}\right)$. 
FORME II4. - Type de verrerie analogue au II3, mais pourvu d'une embouchure évasée formant un bourrelet plus ou moins prononcé. - Les spécimens dont la capacité est le plus élevée mesurent 26 centimètres de hauteur (I). Mais cette dimension est un peu supérieure à la moyenne. On connaît quelques-unes de ces verreries qui n'atteignent pas ro centimètres.

Les verres II4 sont tantôt nus, tantôt décorés de fils de verre (fig. I96), ou de dépressions peu marquées (fig. I97). Ils sont exceptionnellement ansés (fig. I98). Ils ne sont pas rares à Vermand (2) et dans le Boulonnais, en Picardie et en Champagne. Ils datent du IV siècle (3).

FORMES II5-II6. - Panse ovoïde. Pied annulaire ou simplement formé d'un renflement de la partie inférieure de la panse. Col large et élevé, séparé de la panse par un bourrelet très saillant. - Les vases II5-II6 sont souvent ornés, comme les poteries qui leur ont servi de modèles, de dépressions plus ou moins allongées (fig. I99). Ils sont en verre incolore de mauvaise qualité. Ils ont été rencontrés dans les inhumations tardives du nord de la France et des vallées de la Moselle et du Rhin (4).

\section{I5. - INFUNDIBULA (5).}

(Formes II7 et II8.)

FORME II7. - L'entonnoir romain, qu'il soit en verre, en métal ou en argile, se présente sous la forme d'une tasse plus ou moins pro-

(1) Deux verres de cette taille ont été recueillis, l'un à Vermand (Collection de M. TH. Eick, à SaintQuentin), l'antre dans le Boulonnais (Miusée archéologique de Boulogne-sur-Mrer).

(2) Voy. TH. Ëck, loc. cit., pl. T'II, $\mathrm{n}^{03} 3,6$ et $\mathbf{1} 4$.

(3) Tne verrerie de la forme I I4 a été découverte à Cologne dans une tombe à inhumation avec des monnaies de Constance II (337 à 36 I). [voy. Bonner Jahrbuicher, r9j6, fasc. II4-II5, p. 433 et pl. XXVI, tombe $n^{\circ} 73$ ].

(4) Musée Wallraf-Richartz, à Cologne, $n^{0} 2 .{ }_{43}$ (forme I I5). Musée de Bonn, $\mathbf{n}^{0}$ 17.279 (forme II6). Musée archéologique de Boulogne-sur-Mrer (forme rI6). Fouilles du Dr Sauvage à la Porte Gayole [voy Dr SAUvage, Notes sur les fouilles faites rue de la Porte Gayole dans le Bullet in de la Société académique de Bowlogne-sur-Mer]. - Une verrerie, forme II6, a été publiée par AUs's'WeErTh, dans les Bonner Jahrbücher de $\mathbf{I} 88 \mathrm{r}$, fasc. 79, pl. V, $\mathrm{n}^{\circ} \mathbf{I} .556$ (Collection Disch à Cologne).

(5) Consulter l'article Infundibulum, dans le Dictionnaire des Antiquités grecques el romaines de Daremberg et Saglio, t. III, première partie, p. 5 I6. 
fonde on évasée, an fond de laquelle s'adapte un tuyau plus on moins long (fig. 202 à gauche).

Les entonnoirs de verre, forme II7, dépassent rarement 20 centimètres de longueur. Ils ne sont rares ni à Pompéi (I), ni dans la basse vallée du Rhône.

Dans la Gaule du Nord, ils sont moins fréquents.

Un spécimen de petite taille est conservé au musée de Reims ; il a été trouvé dans les environs de cette ville.

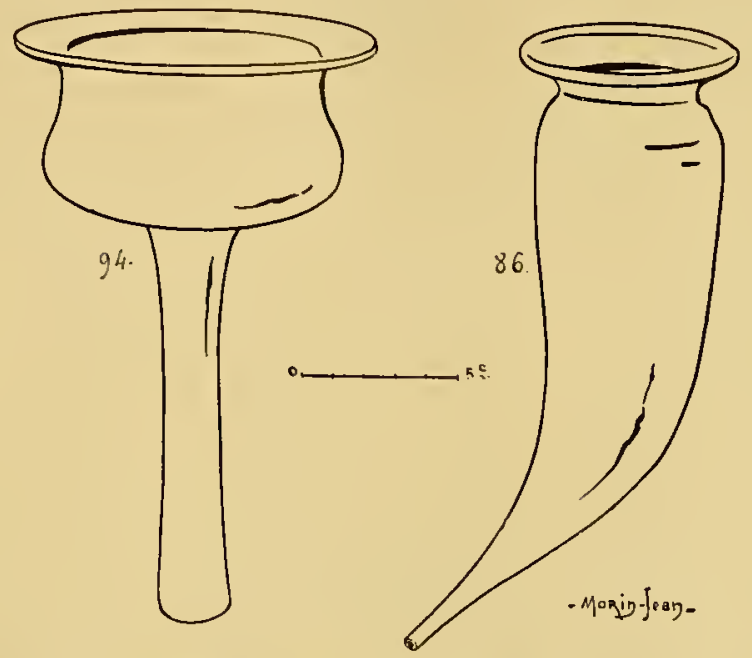

Fig. 202. - Infundibula de verre, - Musie de la Maison Carté, à Nìmes.

Un exemplaire en verre bleu-verdâtre est exposé à Cologne, au musée Wallraf-Richartz.

La plupart des entonnoirs, forme II7, se classent a11 Romain I.

FORME IIS. - Infundibulum à tuyau oblique. - Les entonnoirs à tuyau oblique ont été utilisés, soit pour transvaser des liquides, soit en qualité de rhytons pour boire, comme 1'on dit, «à la régalade». Ils paraissent devoir se placer en synchronisme avec les infundibula II 7 . Ils sont, comme ceux-ci, très nombreux à Pompéi. D'Italie, ils se sont répandus en Gaule. On en a recueilli à Nîmes (fig. 202 à droite),

(I) Musée de Naples (no I2.124). 
à Aramon (x), à Arles (2), à Cologne (3), à Mayence (4). Quelques-uns sont en verre de couleur.

\section{I6. - VERRERIE PLASTIQUE.}

(Formes II9 à I39.)

a. Verres anthropomorphes (formes II9 à I22). - Les verreries à l'étude desquelles nous allons passer sont en forme de tête humaine. En faisant de tels récipients, les verriers n'ont rien inventé. Ils ont tout simplement copié des poteries très répandues dans le bassin de la Méditerranée à l'époque hellénistique. Retracer l'histoire de ces vases d'argile, ce serait se livrer à une digression considérable. Mais, s'il convient, pour ne pas trop nous éloigner de notre sujet, de ne pas étudier ici d'une façon approfondie la genèse de la céramique plastique des Grecs, il est indispensable de l'envisager quelque peu pour saisir comment s'est constituée la forme des verres céphalomorphes exhumés du vieux sol de la Gaule.

L.es vases céphalomorphes en terre cuite remontent à la plus haute antiquité. Dans le bassin oriental de la Méditerranée, entre 2.000 et $3.000^{\circ}$ av. J.-C., des potiers faisaient maladroitement des vases ayant l'apparence de têtes de femmes. Ce n'était pas l'émotion que pouvait leur procurer la beanté féminine qui les poussait à concevoir et à modeler de pareils récipients. Ils n'avaient pas de préoccupations esthétiques. Superstitieux comme tous les membres des sociétés primitives, très enclins à faire intervenir la magie dans toutes les manifestations de leur activité, et à la laisser s'infiltrer dans toutes les traductions de leurs idées, dans toutes les modalités de leurs jouissances physiques comme de leur jouissances morales, ils s'imaginaient que leurs produits devaient constituer des prophylactiques, servir de symboles.

Ne voyant ou ne voulant voir en la femme que son aptitude à per-

(I) Avignon. Musée Calvel. Spécimen de zo centimètres de longueur.

(2) Marseille. Musée Borély, $\mathrm{n}^{\circ} 458$

(3) Cologne. MIusée Wallraf-Richartz. Spécimen en verre verdâtre.

(4) Mayence. IIusée central romano-germanique. Spécimen en verre jaune-verdâtre publié par Lindenschmitt dans Mainzer Zeitschrift, I906, pl. V, no 8 . 
pétuer la race humaine, ils s’ingéniaient à la représenter en toute occasion, tant bien que mal, afin de donner corps à de naïves conceptions de leur esprit, touchant l'accroissement de leur prospérité, la multiplication de leurs sources de richesse et de puissance et afin de constituer pour eux et pour leurs contemporains des sortes de talismans.

Si frustes qu'elles soient, leurs œuvres forment incontestablement

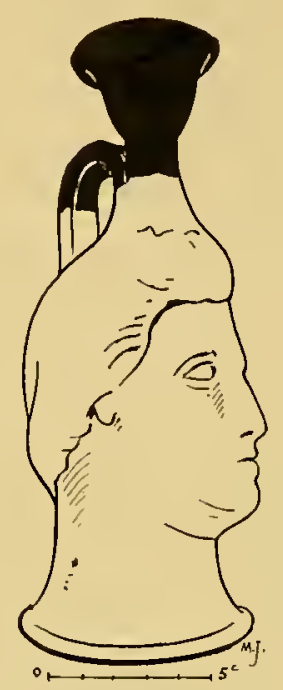

FIG. 203. - LECYTHE GREC DE TERRE CUITE, ell forme de lête humaiue. - Collection Morin-Jian, $\mathrm{n}^{\circ}$ 1523.

le point de départ de la fabrication des vases en forme de tête humaine.

L,es Chypriotes de l'âge du bronze (I), les potiers rhodiens (2) et corinthiens $d u v I^{e}$ et $d u v^{e}$ siècles av. J.-C. eurent out façonnèrent des céramiques analogues à ces poteries grossières. Puis le vase céphalomorphe se transmet à travers les âges sans subir de grands changements. Jusqu'à l'époque romaine, à l'aurore de notre ère comme au moment de sa création, il est fait de deux parties dont la coordination ne s'établit pas très bien: une panse céphalomorphe et un goulot emprunté aux formes de la poterie courante (goulots d'aryballe, d'amphorisque, de lécythe, d'œnochoé, de canthare, etc.).

(I) ED. POTTIER, Catalogue des vases du Louvre, p. 86.

(2) ED. PotTIER, loc, cit., p. I5I-I52. 
Une fois constitué, il prend une vitalité surprenante. On façonnait dans les ateliers attiques de la belle époque (vI ${ }^{\mathrm{e}}$ et $\mathrm{v}^{\mathrm{e}}$ siècles av. J.-C.) des récipients auxquels une grande exactitude dans la reproduction des traits de la figure humaine donne un surprenant caractère artistique (I) et, dans l'Italie méridionale, au $\mathrm{IV}^{\mathrm{e}}$ et au $\mathrm{II}^{\mathrm{e}}$ siècles av. J.-C., une grande quantité de rhytons. Ces rhytons sont les véritables ancêtres des verreries céphalomorphes (fig. 203).

Comme les rhytons hellénistiques, les verres romains en forme de tête humaine forment deux catégories bien distinctes. Les uns ont une large ouverture constituée par une sorte de calathos: ce sont des verres à boire. Les autres sont pourvus d'un goulot étroit emprunté aux verreries courantes [goulots d'aryballes forme 33 (fig. 206), d'œnochoés forme 54, de lagènes forme 50 (fig. 210), de fioles forme 40 (fig. 208) ] : ce sont des vases destinés à la conservation de liquides et de parfums.

Les verres céphalomorphes sont généralement apodes (fig. 206), plus rarement munis d'un pied (fig. 208). Leur panse est parfois formée d'une tête unique (fig. 209,2I0), mais souvent aussi d'une double tête (fig. 206, 208). Accouplés ou non, les masques qui les caractérisent sont assez différents les uns des autres. Parmi eux, il est un facies féminin qui est moins celui d'une déesse déterminée que la survivance de l'ancien fétiche féminin. Des masques masculins (fig. 210), des physionomies de nègres (2) ornent aussi des verreries plastiques du temps de 1'Empire. Les céramistes grecs avaient d'ailleurs déjà pour modèles des têtes de nègres (3).

(I) Les plus beaux vases grees en forme de tête humaine ont été signés parles artistes qui les outcrẻs. CLÉoménés est l'auteur d'un adnirable rhyton constitué par une tête d'homme et une tête de fennue. On peut se faire, en examinant cesfaeies, une idée assez exaete ulu type gree de l'époque de Pisistrate. I $\mathrm{e}$ vase de cléoménés, conservẻ an I,ouvre, a été publié par M. MLAx. Col.uignon dans les Monuments grecs publies par l'Association pour l'encouragement des itudes grecques en France, deuxième volume I882-I897,

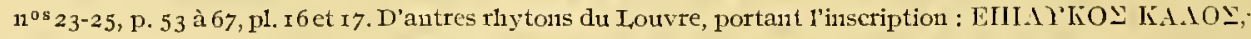
sont de vrais petits ehefs-d'œuvre de techuique [Snt les vases grecs en forme de tête humaine portant des inscriptions, voy. KLEIN, Meistersignatuen, p. 2x4; et ED. POTTIER, dans les Mémoires des Monuments Piot, t. IX, t9o3, p. r 35, pl. XI à XV.]

(2) Sur la représentation du nègre dans l'antiquité, eonsulter ED. POTTIER et SALOMON REINACH, La Nicropole de Myrina, p. 473 et suiv.

(3) I,es aneiens appréciaient beaucoup les nègres. I,e nègre était pour eux un porte-bonheur, une sorte de prophylactique [voy. l'article Servi dans le Dictionnaire des Antiquités de M. SAGLIo, t. IV, deuxième partie, p. x.260 et suiv.]. 
Enfin les verreries constituant des caricatures ne sont pas les moins curieuses de 1a série (fig. 209). Elles rappellent beaucoup les terres cuites grotesques découvertes à Smyrne et dont le Louvre possède une très belle collection (I). L,es unes et les autres sont dues

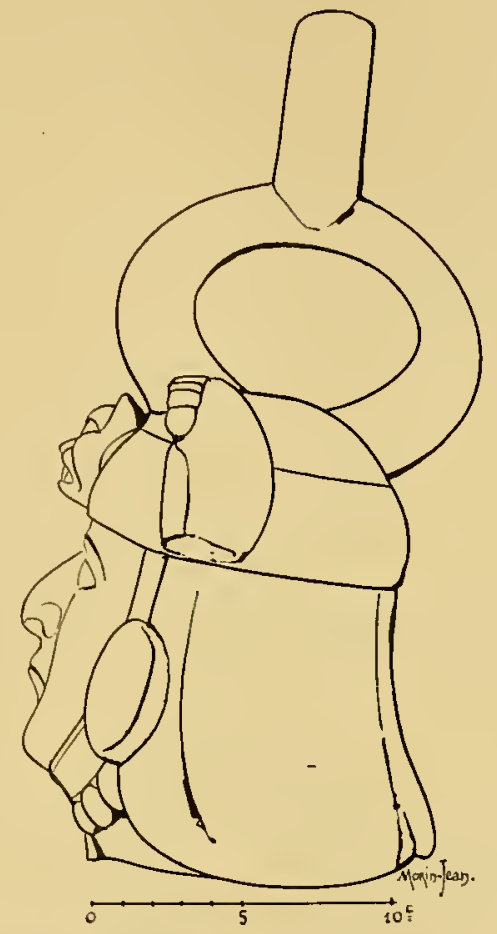

Fig. 204. - Poterte céphalonorphe De TrujtLlo (Pérou). - Collection Morin-Jean.

à la même préoccupation esthétique, à la même recherche de l'exactitude dans les traits comiques d'un visage.

Il est à peu près certain que le bassin oriental de la Méditerranée est le lieu d'origine de ces verreries.

Pourtant, il est possible que des objets semblables aient été fabriqués par des Gaulois, soit que ceux-ci aient copié fidèlement des modèles venus d'Orient, soit qu'ils se soient astreints à reproduireles traits plus ou moins caractéristiques de quelques individualités de

(I) Eid. PotrIER, Diphilos et les modeleurs de terres cuites grecques, Paris, I,aurens, p. 96 et $\mathrm{n}^{03} 435,43^{6}$, 437,438 . 
leur temps et de leur pays (I). La ressemblance qui existe entre certains verres anthropomorphes et certaines terres cuites blanches de l'Allier induit à croire que les Gaulois ne se sont pas toujours laissés hypnotiser par les traits d'une physionomie nettement ou vaguement asiatique (2).

La chronologie des verreries céphalomorphes n'est pas facile à établir.

Il est bien probable qu'on fit de telles verreries pendant toute la période romaine. Il est tout naturel de penser que les verriers alexandrins, mûs par le désir de reproduire en verre une forme intéressante inventée par les céramistes, les marbriers, les orfèvres de l'époque grecque, en fabriquèrent dès que leur industrie eut progressé assez pour le leur permettre. Il en existait au $\mathrm{I}^{\mathrm{er}}$ siècle; on en a des exemplaires pompéiens. Mais, en Gaule, c'est surtout à partir du III $^{\mathrm{e}}$ siècle que se développa la verrerie céphalomorphe.

Des verres en forme de tête humaine ont été trouvés dans les régions les plus diverses. Il est inutile d'en dresser la liste complète. Il suffit d'en mentionner quelques-uns pour savoir à quoi s'en tenir à leur égard.

I. - Forme II9. - Petits flacons prismatiques sans anse, ornés, sưr les côtés, de masques de Méduse en haut-relief (fig. 205). - Ces petites fioles, que nous signalons ici à cause de leur décor anthropomorphe, font en réalité partie des verres à bas-reliefs moulés (voy. plusloin, p. I88 et suiv.). Elles sont en verre très mince, généralement coloré en bleu-cobalt, vert-émeraude, rouge de vin, rouge violacé, jaune ou blanc opaque. Elles proviennent, pour la plupart, des officines orientales. Elles sont.abondantes en Syrie, à Chypre, dans 1'Italie du centre et dans la France méridionale. Elles sont plus rares dans la vallée du Rhin. On en a cependant trouvé une au cimetière d'Andernach (3). Cet exemplaire, conservé au musée de Bonn, a été recueilli avec une monnaie de Claude (4I à 54).

(I) L,es céramistes primitifs de l'Amérique ont, eux aussi, créé des vases céphalomorphes, et ces vases, qui n'ont aucun lien de parenté avec ceux qui nous occupent, sont souvent de véritables portraits (fig. 204).

(2) Sur les vases-statuettes en argile du centre de la Gaule, consulter J. DÉchELETTE, Les vases céramiques ornés de la Gaule romaine, t. II, p. 322 à $325, \mathrm{pl}$. I.

(3) Constantin Koenen, Die vorrömischen, römischen und fränkischen Gräber in Andernach, dans les Bonner Jahrbücher, I888, fasc. 86, pl. VII, nº 
Les flacons à 1nasques de Méduse en relief sont de la liaute époque impériale.

2. - Forme I20. - Petites fioles formées de deux masques accolés. Verre épais bleu-verdâtre. Goulot d'aryballe forme 33. - Une de ces verreries, exposée au nutsée de Picardie, à Amiens, a été découverte en ISS + , à Amiens, dans le laut quartier Saint-Louis, avec les ustensiles et le cachet de l'oculiste AchrLEVS (I). Une autre, du musée de Rouen, n'a pas plus de 8 centimètres de hauteur (fig. 206).

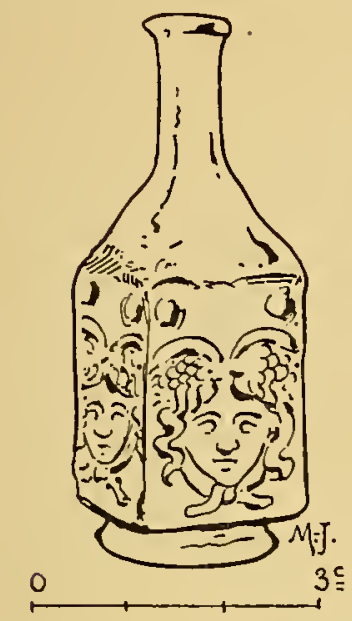

FIG. 205. - FLACON DE VERRE BLET, omé de quatre inasques de Méduse en relief (Saintes). - Rouain I. Musie de Saint. Germain. Salle XV, $n^{\circ} 2464$ I.

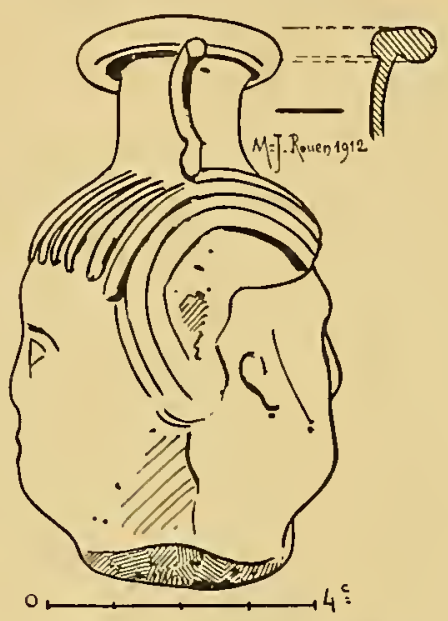

FIG. 206. - VERRERIE MIOULÉE EN FORUIE DE DOUBLE TETE. - Musie dipartemental d'antiquitis, à Rouen.

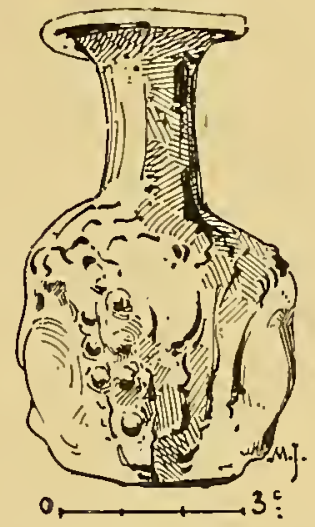

FIG. 207. - FLACON DE VERRE EN FORIIE DE DOUBLE TÊTE (Syrie). - Rouluain II. - Collection Morin-Jean, $\mathrm{n}^{0} 3047$.

Des flacons analogues, mais en verre très mince, et grossièrement façonnés, datent d'une époque plus basse (fig. 207). Très abondants en Syrie, ils ne sont pas rares non plus dans la vallée du Rhin (2).

3. - Forme I2I. - Boutcilles de grande taille. Deux masques juvéniles accolés. Goulot évasé analogue à celui des ballons forme 40. Verre incolore plus ou moins filandreux, Ive siècle ap. J.-C. - Le plus beau spécimen de cette série est conservé au musée de Boulogne-sur-

(I) I'ublice par ALFRED Danicour'T, Elude sur quelques antiquilés tronvécs in Picardic. Paris, ISS6, p. I9, fig. Io.

(2) Axtox Kisa, Das Glas im Alierlume, fig. 292 à 295. 
Mer (fig. 208). Il a été trouvé dans une tombe à inhumation du cimetière du Vieil-Atre [terrain Arnoul] en I888. Il a été publié par V.-J. Vaillant 1'année suivante (I).

Deux exemplaires, à peu près semblables, ont été découverts, l’un

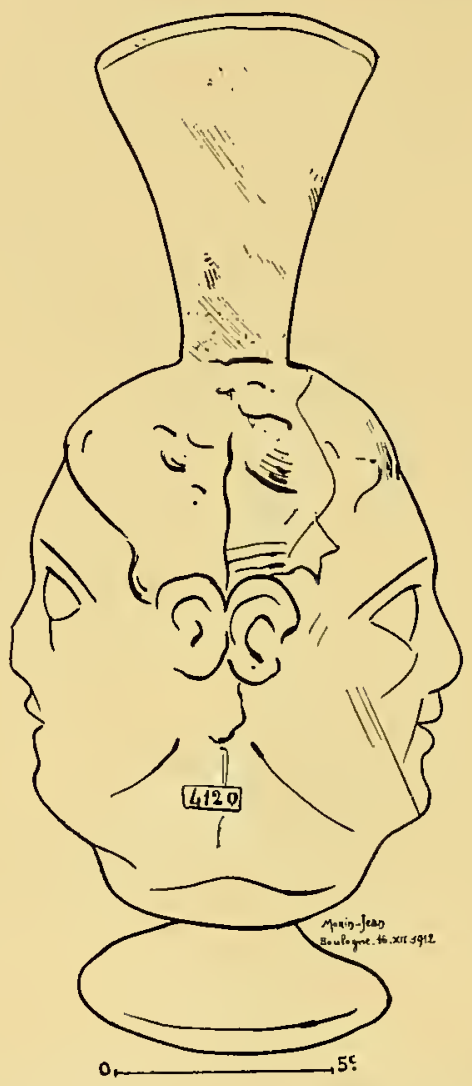

FIG. 208. - GRANDE BOUTEILIE EN FORME DE DOUBLE TÊTE. — Cimetière du Vieil-Atre à Boulogne (fouilles de 1888$)$. $\mathrm{IV}^{\mathrm{e}} \mathrm{s} .-$ Musée de Boulogne sur-Mer, nº $4 \mathrm{I} 2 \mathrm{o}$.

à Boulogne, cimetière du Vieil-Atre, le 28 octobre I888 (2), l'autre dans la vallée du Rhin [musée Wallraf-Richartz à Cologne] (3). Les

(I) V. J. Vamlant, Notes boulonnaises [Epigraplie de la Morinie]. Boulogne, I89o, p. 28 et Revue archéologique, I889, pl. XV.

(2) Cet exemplaire, saus pied, a été vendu à M. Bellon, de Sajut-Nicolas-les-Arras [YAILANT, Quelques verreries romaines de Boulogne-sur-Mer, daus la Revue archéologique, I 889].

(3) Ie verre céphalomorphe de Cologne a 2 centimètres $I / 2$ de hauteur. Il est apode. Il est décrit dans ANTON KrSA, loc. cit., p. 754 et fig. 299. 
figures qui constituent la panse de ces bouteilles céphalomorphes sont grasses. I,es yeux sont à fleur de tête, les prunelles sont soigneusement modelées: c'est un type caractéristique de l'époque constantinienne (I).

4. - Forme I22. - Bouteille en forme de tête unique. Type

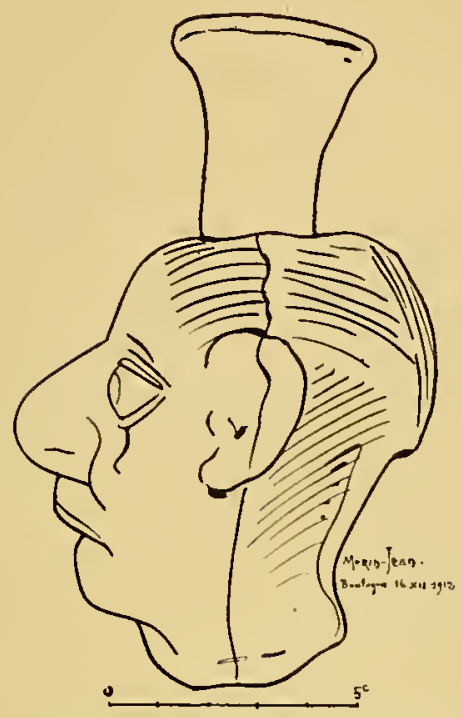

Fig. 209. - FLACON EN FORME DE TETE GROTESQUE. - Cimetière du Vieil-Atre (fouilles de I888). - Musée de Boulagne-sur-Mer, no 4045.

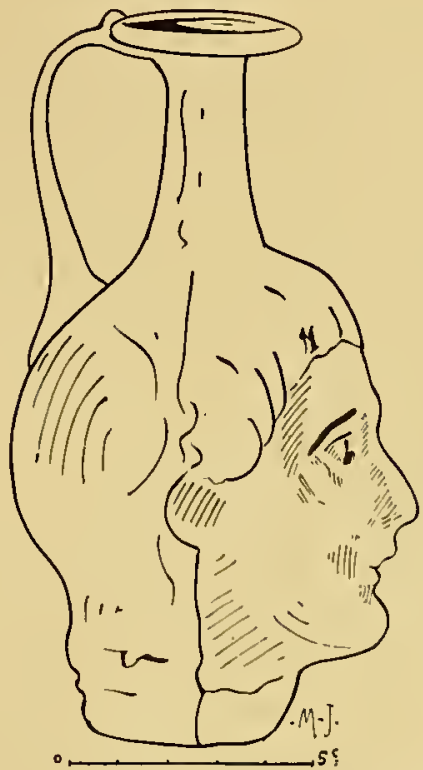

Fig. 2 Io. - Flacon CéphaLOMoRPHE. - Cimeticre du Grand Hôle de Chassemy (Aisne). Iv s. Musée de Saint-Germain. Salle XI.

caricatural. $\mathrm{II}^{\mathrm{e}}$ et $\mathrm{rV}^{\mathrm{e}}$ siècles. - On a trouvé dans le nord des Gaules un certain nombre de verreries en forme de tête plus ou moins ricanante avec les lèvres boursouflées, le nez énorme, les yeux exorbités, le front fuyant et le derrière du crâne très développé. Une grosse verrue se trouve quelquefois sur la joue. Ces caricatures, ces grotesques, ont été recueillis en assez grande quantité dans la vallée du Rhin (2).

(r) A ce type appartient la figure humaine formant la panse d'une bouteille à une anse, découverte à Saint-Mansuy, près Toul. Ce flacon, conservé autrefois dans la collection Charvet, est actuellement au Métropolitan-MIuseum de New-York [Frofrer, La Verrerie antique, pl. XV, to 83 ; et ANT. KISA, loc. cit., fig. 298$]$.

(2) Les céramistes et les bronziers romains ont fait, eux aussi, des vases plastiques en forme de tête grotesque. Ils ont créé, dans cette série, des récipients qui ne diffèrent des verreries qui nous occupent que 
Il en existe, au musée de Boulogne-sur-Mer, un très intéressant spécimen (r). Il a été découvert en I 888 au cimetière du Vieil-Atre [fouilles Lelaurain au terrain Capet] (fig. 209). On connait des verres romains en forme de tête unique dont le facies n'appartient pas à la série des grotesques. Témoin l'exemplaire recueilli le 5 décembre I888 par Frédéric Moreau, au cimetière du Grand Hôle de Chassemy (Aisne), dans une inhumation de l'époque de Constantin, de Valentinien ou d'Honorius (2) (fig. 2IO).

b. Verres zoomorphes (formes I23 à I3O). - En donnant à un récipient la forme d'un animal, les primitifs obéissaient à un sentiment religieux qui se rattache au très vieux culte de la zoolâtrie. Dès l'époque la plus reculée, l'homme a représenté, soit à plat, en dessin ou en peinture, soit en ronde bosse, sous forme de vase ou de statuette, les animaux dont il tirait sa subsistance. Son but, en agissant ainsi, était d'attirer ces animaux autour de lui, par une sorte de syinpathie magique. Plus tard, ces conceptions fétichistes se sont affaiblies; mais, jusqu'à la fin de l'antiquité, les vases en forme d'animaux ont été des prophylactiques, des porte-bonheur.

Les anciens ont connu deux sortes de rhytons zoomorphiques:

a. Des vases représentant un animal entier;

$b$. Des vases en forme de tête d'animal.

Les Grecs ont créé, dans les deux genres, de véritables chefsd'œuvre. Ils ont fait des récipients de terre cuite en forme de fauves, de singes, d'oiseaux, de chevaux, de bœufs, de cerfs, de sangliers (3).

I.es verreries zoomorphes de l'époque romaine sont des copies de ces vases d'argile. Nous nous limiterons à la description des plus curieuses d'entre elles.

par la matière mise en œuvre. Un flacon de bronze en forme de tête humaine à facies caricatural a étẻ trouvé en 1899 dans une incinération du $\mathrm{II}^{\mathrm{e}}$ siècle, au cinetière de la rue de Luxembourg, à Cologne [Bonner Jahrbïcher, I906, fasc. II4-II5]. Des masques grotesques en argile, présentant un facies analogue à celui qu'adoptaient les verriers romains, servaient à orner les vases à reliefs d'applique du Ime siècle [roy: J. Decheletre, Les vases céramiques ornés de la Gaule romaine, t. II, p. 227 et suiv., fig. I2 I-I27].

(I) Publié pat Vanlant, Notes boulonnaises, p. 24 ; et Revue archéol. de 1889 , pl. XIV.

(2) Frédéric MIoreau, Album Caranda, pl. 96. Nouvelle série. Un flacon semblable, sorti du même moule, a été trouvé, en I 849 , à Steinfort. Il est conservé au musée de I uxembourg. Il a été publié dans le Bulletin de la Socièté pour la recherche et la conservation des snonuments histosiques du Grand-Duché de Luxembourg, $\mathrm{n}^{\circ} 5$, année I849, pl. II, $11^{\circ}$ II.

(3) I,e Louvre (Salle H, vitrine centrale) possède une très riche série de rhỵtons zoomorphes corinthiens, attiques et italiotes. 
I. - Forme, I23. - Singc-musicicn. - L'animal est assis dans 111 de ces fautenils d'osier à dossier semi-circulaire, qui furent très en vogue en Gaule sous l'Eupire (r). Il est vêtu d'un cucullus orné de stries, qui figurent les bandes ou calicules de couleurs voyantes dont on décorait les vêtements au $\mathrm{Im}^{\mathrm{e}}$ et au $\mathrm{IV}^{\mathrm{e}}$ siècles. De ses deux mains, il presse sur sa poitrine une syrinx ou flûte de Pan à sept tuyaux.

L'origine alexandrine du sujet traité n'est pas douteuse. L'animal représenté est le cynocéphale sacré des temples de l'Égypte, le cynocéphale que les riverains du Nil ont modelé dans toutes les matières : granit, porphyre, calcaire, albâtre, terre émaillée, argent et bronze.

L'image du singe est un prophylactique très ancien. M. de Morgan a trouvé à Surse des petits singes qui remontent à 2.500 ans av. J.-C.

Sous Hadrien, le singe était consacré à Pan: c'est pourquoi les artistes de l'époque romaine lui ont mis une syrinx dans les mains (2).

De quelles officines les lécythes en forme de singe-musicien sont-ils sortis? Les terres cuites gallo-romaines peuvent fournir, à cet égard, une indication précieuse. On a fait, au temps des Césars, dans la vallée de l'Allier, des figurines d'argile blanche qui ont, avec les verres qui nous occupent, de nombreux points de contact. Plusieurs de ces figurines représentent des personnages assis dans un fautenil d'osier et tenant des deux mains une syrinx (3). Il est bien probable que, comme elles, les singes de verre ont été fabriqués dans les officines de la Gaule, soit par des ouvriers orientaux, soit par des indigènes en relation directe avec l'Orient. Les pays où ils ont été trouvés confirment, d'ailleurs, leur origine gallo-romaine :

I. Vermand (A isne). - Fouille du 27 février I 885. Tombe d'enfant $\mathrm{n}^{0}$ I55. Verre verdâtre. Hauteur : 2I centimètres. Saint-Quentin. Musée Lécuyer, nº 2.668 (4).

(I) Des sièges de ce type sont sculptés en relief sur les stèles funéraires des vétérans romains [voy. ANron KISA, loc, ciz., fig. I4. Stèle du musée Wallraf-Richartz à Cologne].

(2) Très populaire au Romain II dans les ateliers des verriers et des céramistes, le type du cynocéphale jonant de la sytinx figure sur une gourde de terre cuite du musée de Saint-Gernain, connue sous ie nom de Vase Sallier et appartenant à la céraniqute du nIr siccle [roy. DÉcheletTe, Les vases ornés, t. II, pl. IV] Sur la Syrinx antique, consulter un intéressant article de h̊. Théodore Reinach daus Pro Alesia, maijuin rgo7, p. I6r et p. I80.

(3) Voy. TUdor, Figurines gauloises, pl. 67, et J. Déchelexte, lcc. cit., t. II, p. 323 et pl. د, $11^{\circ}$ I.

(4) TH. Eck, Les deux cimcticres gallo-romains de Vermand el de Saint-Quontin, p. I13 et $\mathrm{r} 49$, pl. III, $\mathrm{n}^{0} 2 ; \mathrm{J}$. PILloy, Études sur d'anciens lientx de sípullures dans l' A isne, $\mathrm{t}$. II, p. I23, et pl. $2, \mathrm{u}^{0} 3$. 
II. Amiens (Somme). - Verre verdâtre filandreux. Hauteur I4 centimètres. Amiens. Musée de Picardie (I) (fig. 2II).

III. Cologne (Magnusstrasse). - Fouilles de I865. Inhumation. Verre incolore décomposé (Ancienne collection Disch). Cologne. Musée Wallraf-Richartz, $\mathrm{n}^{0} 292$ (2).

IV. Martinsberge, près Andernach. - Verre jaunâtre. Hauteur:

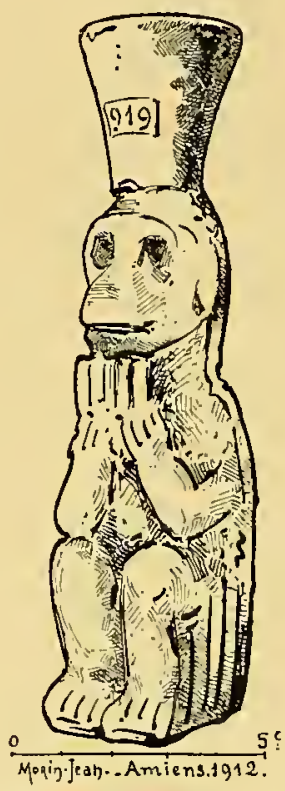

Fig. 2 II. - Flacon ex forme DE singe-musicien. - Picardie. - Musée d'A miens, no grg.

20 centimètres. Basse époque impériale. Bonn. Provinzialmuseum, $\mathrm{n}^{0} 3.0 \mathrm{II}(3)$.

V. Trèves. - Fouilles de Igo4. Verre rempli de bulles d'air (la tête de l'animal a été cassée). Trèves. Provinzialmuseum. Salle 20. Vitrine VII. No 05.475 (4).

On remarquera que tous les exemplaires connus, jusqu'à présent, de la forme I23 ont été trouvés dans le nord des Gaules, et que tous

(r) Atfred Dantcovrt, Etude sur quel ques antiquités trouvées en Picardie, Paris, I886, p. 19.

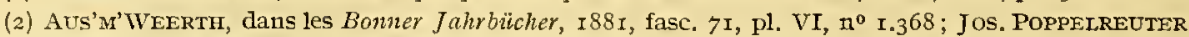
dans les Bonner Jahrbïcher, I906, fase. II4-II5, p. 359, fig. 5 ; A. KIS., loc. cit., fig. 307.

(3) Fïhrer durch das Bonner Provinzialmuseum, p. Io3.

(4) Anton Kisa, loc. cit., p. 760. 
appartienuent à la basse époque impériale et sont contemporains ou à peu près des verres à résille dits diatrètes (Voy. p. 23I).

2. - FORME I24. - Imitation en verre d'une come de taureau ou d'aurochs. - Les cornes à boire forme I 24 sont ordinairement ornées de fils de verre appliqués à chaud et disposés en spirales (fig. 2I2), en festons ou en filet. Elles sont quelquefois aussi décorées de cannelures en long. Elles ont été rencontrées pour la plupart dans les provinces rhénanes. Quelques-unes d'entre elles sont percées d'un trou à leur

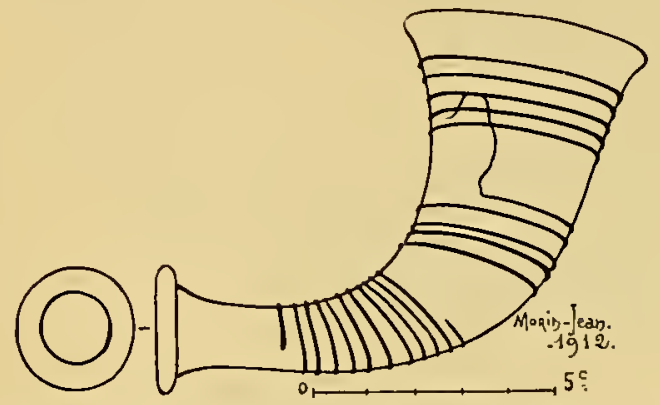

Fig. 2I2. - CORIE DE verRe verdatre ornée de fils en émail blanc. - Basse époque romaine. Musée Wallraf-Richartz, à Cologne.

extrémité, afin que le liquide puisse s'écouler en un mince filet comme dans les rhytons grecs.

Deux cornes à boire, dont l'une est munie de deux petites anses de suspension, ont été publiées par Aus'm' Weerth dans les Bonner Jahrbiicher de I88I (I). Une autre a été découverte à Cologne, dans une tombe à inhumation qui contenait des monnaies de: Claude le Gothique (268 à 270), Carus (282 à 283) et Galère (305 à 3II) (2).

De très beaux spécimens de la forme I24 sont conservés aux musées de Trèves, Cologne, Bonn, Mayence, Wiesbaden, Worms et Strasbourg; d'autres sont dans les collections privées des provinces rhénanes.

I.es cornes à boire sont d'époque tardive. Elles n'apparaissent pas avant la fin du III siècle et sont très en vogue sous les Mérovingiens.

(I) Bonner Jahrbücher, I88I, fasc. 7I, pl. VI, no $\mathrm{r} .369$ et I.370.

(2) Bonner Jahrbiicher, I go6, fasc. II 4-II5, pl. XXV, nº 61. 
3. - Forme I25. - Porc (I). - Les verteries en forme de porc ne sont pas très nombreuses. Une des plus intéressantes a été trouvée, en I893, rue de Luxembourg, à Cologne, dans la même tombe que la bouteille à deux anses (fig. 274) décrite plus loin, p. 204. Le corps de l'animal est en verre bleu intense. Les pattes, la queue et les oreilles sont en verre opaque blanc-jaunâtre. Sur le dos, les poils de la bête sont exprimés par une bande de verre de même couleur, plissée à

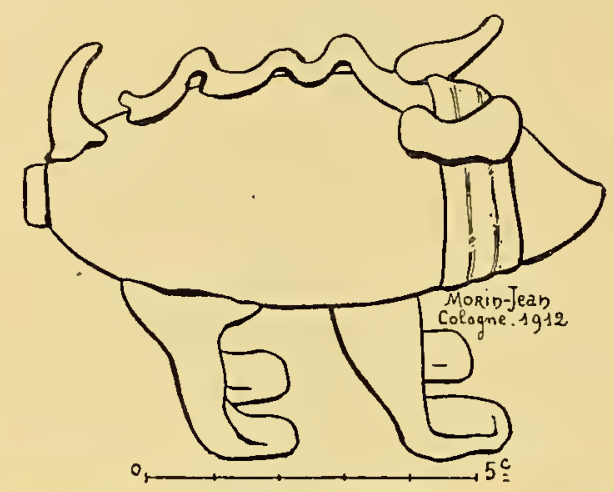

Fig. 2I3. - FLACON EN FORME DE PORC. — Cologne. Cimetière de la rue de Iuxembourg (fouilles de I893). Romain II. -- Musée de Cologne, nº 549.

intervalles plus ou moins réguliers (fig. 2I3). Ce petit balsamaire est au musée Wallraf-Richartz à Cologne (2).

Une autre verrerie en forme de porc a été découverte à Cologne, dans la tombe à inhumation $n^{0} 49$ des fouilles de 1904 (3).

Un grand flacon en verre incolore du Paulusmuseum de Worms appartient à la même série de récipients (4).

4. - Formes I26-I27-I28. - Oiseau. - La verrerie I26 représente un oiseau à cou assez court dont la tête est légèrement tournée sur le côté. Elle constitue un type de la haute époque impériale. On peut en voir un exemplaire au musée de Trèves [nº St. 469o], dans unè cuve de pierre. Cette cuve contient en outre des ossements calcinés,

(I) Le porc ou plutôt le sanglier semble avoir été un ancien totem celtique [roy. SaLòion REñach, Cultes, Mythes et Religions, t. I, p. 7I].

(2) Il a été publié par ANToN KISA, dans les Bonner Jahrbiicher, I 896 , fasc, , n 99, p. 50-53 et pl. II, n 6 .

(3) Bonner Jaltrbücher, I906, fasc. II4-II5, pl. XXIV, p. 4I6-4I7.

(4) AnTon Kisa, Das Glas im Altertume, p. 764 . 

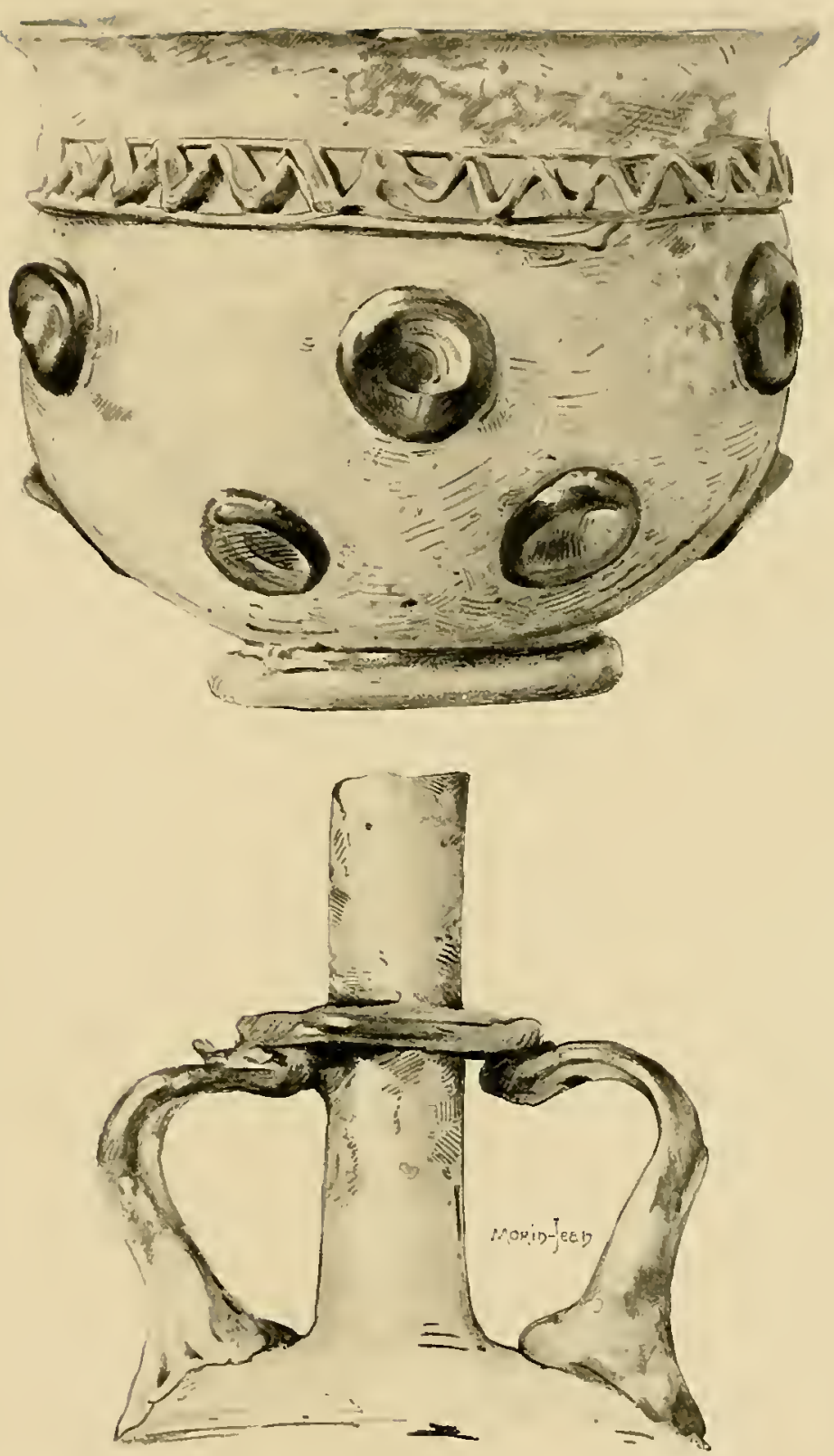

Pl. 7. - Verreries du re stècle. - Musée de Saint-Germain. - A, $\mathrm{n}^{\circ} 628_{4}$ : Bol omé de cabochons. Clû̃lons (Mame) ; B, no 27.230: Diota. Reims (Marne) [Détail des anses]. 

un flacon forme 27 et trois petites ampoules de verre mince. C'est une incinération typique des $\mathrm{I}^{\mathrm{er}}$, $\mathrm{n}^{\mathrm{e}}$ siècles de notre ère.

Une fiole I26, originaire de Provence, est conservée au musée Borély, à Marseille (fig. 2r 4 , B.). Une autre, en verre d'un beau bleu, se trouve au musée de Bonn [ $\mathrm{n}^{\circ} \mathrm{A}$. r.oIo].

Les oiseaux à très long cou, forme 127, appartiennent à un type tardif (Romain II) de la Gaule nordique. Ceux que nous reproduisons (fig. 2I4, A et C) proviennent, 1'un du cimetière de Strasbourg (I), l'autre de la nécropole belgo-romaine de Strée (2). Un bel exemplaire en verre

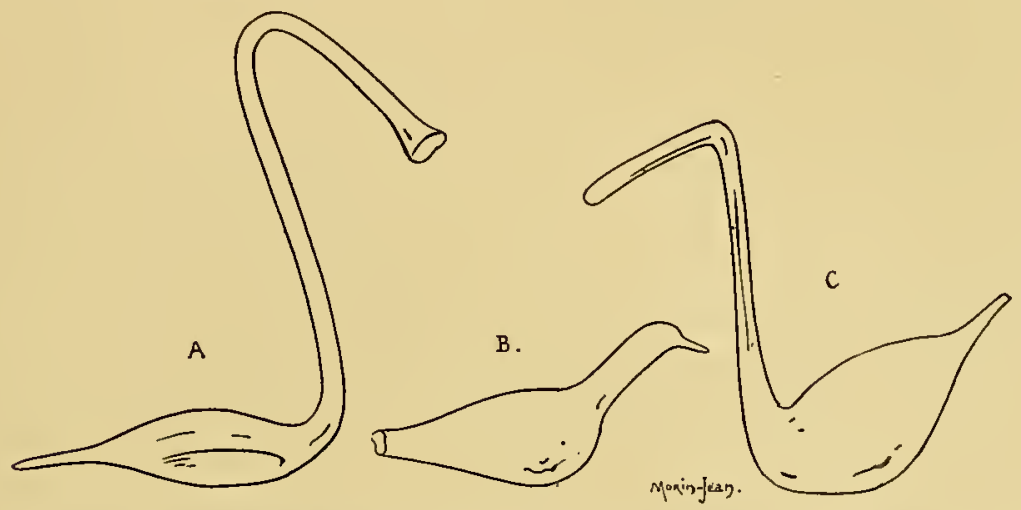

Fig. 2I4. - Verres orntrhomorpires: A. Musée de Slrasbourg. - B. Musée Borély, à Marseille. [n $\left.\mathrm{n}^{\circ} 429\right]$ - C. Musée de Charleroi (Belgique).

incolore, de la fin du mie ou de la première moitié du IV siècle, fait partie des riches collections du musée de Mayence. D’autres spécimens sont exposés aux musées de 'Trèves et de Cologne.

La verrerie ornithomorphe I28 appartient au musée archéologique de Boulogne-sur-Mer. Elle a été trouvée en I828, dans une tombe explorée par M. A1. Marmin, au faubourg de Bréquerecque (3).

Elle est en verre verdâtre impur, ce qui permet de la dater d'une époque tardive. L'oiseau représenté est sans doute un coq.

(I) Tombe à iuhumation $\mathrm{n}^{0} \mathrm{12}$, IV ${ }^{e}$ siècle [STRAUB, Le eimetière gallo-romain de Strasbourg, p. 24 et fig.].

(2) Musée de Charleroi (Belgique). Hector MLAnceaux, Le cimetière belgo-romain ei franc de Strée, Mons, I 877 .

(3) Ira verrerie ornithomorphe de Boulogne-sur-Mer a été publiẻe par RoAcH Smrt, dans Collectanea Antiqua, 1843, $\mathrm{n}^{\circ} \mathrm{I}, \mathrm{pl}$. I, et par V.-J. VALLANT, dans la Revue archíologique de $\mathrm{I} 889$ [Quelques verreries romaines de Boulogne-sur-Mer]. 
Son ventre ballonné repose sur trois petits pieds; sa tête minuscule est surmontée d'une crête dentelée ; ses ailes sont courtes; sa queue

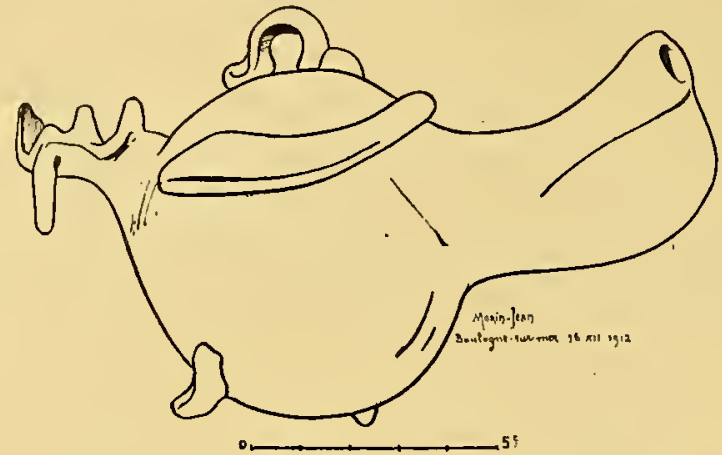

FIG. 2r5. - Fíacon EN Forme d'oIsEAd. - Fouilles du Boulonnais. Romain II tarơif، Musée de Boulogne-sur-Mer, $\mathrm{n}^{\circ} 2525$.

s'étale largement et se raccorde gauchement au goulot mal dissimulé du récipient; son dos est muni d'une petite anse de verre formant anneau de suspension (fig. 2I5).

Un oiseau de forme analogue, ayant autrefois fait partie de la collection Disch, a été publié par M. Aus'm' Weerth, dans les Bonner Jahrbücher de I88I (I).

5. - Forve I29. - Poisson. - Les flacons en forme de poisson

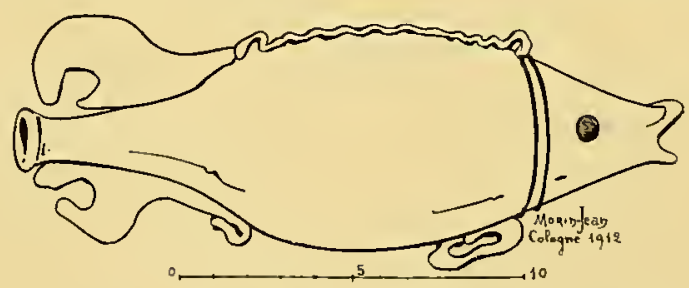

FIG. 2 I6. - FLACON ICHTHYoMorPHE. $\mathrm{m}^{0} \mathrm{~s} .-$ M usée de Cologne, $\mathrm{n}^{0} 9^{8} 3$.

ne sont pas très répandus. Nous reproduisons (fig. 2I6) un bel exemplaire de fiole ichthyomorphe duIIre siècle, appartenant au musée Wallraf-Richartz, à Cologne. Le corps de l'animal est en verre incolore décomposé. L,es yeux, très saillants, sont en pâte de verre bleu. La tête est séparée du corps par un double filet de verre

(I) Bonncr Jahrbücher, I88I, fasc. $\mathrm{n}^{0} 7 \mathrm{I}, \mathrm{pl}$. VI, $\mathrm{n}^{\circ} \mathrm{I} .372$. 
également bleu; elle forme le fond du récipient, tandis que la queue en constitue l'orifice.

Ce balsamaire, bien conservé, a été trouvé à Cologne lors des fouilles opérées en $\mathrm{I} \delta 9 \delta$ dans la rue de Luxembourg (I). Il faisait partie du mobilier funéraire de la tombe $n^{\circ} 43$ qui contenait, outre cette curieuse bouteille, des poteries caractéristiques du $\mathrm{III}^{\mathrm{e}}$ siècle, une verrerie forme 59, une carafe de verre ornée de petits cabochons et un grand bronze d'Alexandre Sévère.

Une verrerie ichthyomorphe est exposée au musée de Wiesbaden (2). Une autre a été trouvée dans le Châlonnais, au lieu dit la Croix-Saint-Germain, dans un sarcophage en pierre du Romain II (3). Cette dernière est entièrement entourée d'un gros fil de verre spiralé, système de décor très en vogue à la fin du $\mathrm{II}^{\mathrm{e}}$ et au $\mathrm{IV}^{\mathrm{e}}$ siècles. Dans le catalogue de la collection Gréau, Froehner reproduit plusieurs flacons en forme de poisson ; l'un de ces flacons, découvert à Chypre, rappelle, dans son galbe général, l'exemplaire de Cologne (4).

Au groupe des verreries ichthyomorphes, on peut rattacher de beaux verres à boire, dont le décor original consiste en poissons soufflés à part dans un moule et soudés ensuite sur la surface externe du vase.

On a trouvé en Italie des poissons isolés qui portent sur le dos des traces de soudure prouvant qu'ils ont appartenu à la décoration de récipients vitreux. Èn $I 857$, Visconti a recueilli à Ostie un fragment de vase de verre sur lequel des poissons étaient encore adhérents. Ce fragment portait une inscription chrétienne: Bibe. Zeses, qui a permis de le dater de la basse époque impériale.

En I873, on a découvert à Rome un verre complet, orné de poissons et de mollusques admirablement modelés. Ce précieux monument, dont la stabilité est assurée par la disposition ingénieuse de

(x) Voy. les Bonner Jahrbücher de I906, fasc. I I4-II5, pl.XIIV, et p. 4I5. - La Nécropole de la rue de I,uxembourg, à Cologne, a fourni au musée Wallraf-Richartz un autre flacon ichthyomorphe en excellent état de conservation [voy. Axton Kusa, Das Glas im Altertume, p. 767].

(2) Nassauer Annalen, VII, I 864, t. 43.

(3) Publié par M. de Fontenay, dans le Bulletin Monumental de i 855, à la page 88.

(4) Froenver, Collection Julien Gréau. Verrevieantique appartenant à M. John Pierpont-Morgan. Paris, 1903, $\mathrm{n}^{\circ}$ I.I26, pl. CCIII, n². 
trois coquillages de verre qui font office de pieds, est conservé au Vatican ( $\mathrm{I}$ ).

Deux verreries du même type proviennent de la Gaule du Nord. L'une d'elles, au Provinzialmuseum de Trèves, est l'exemplaire

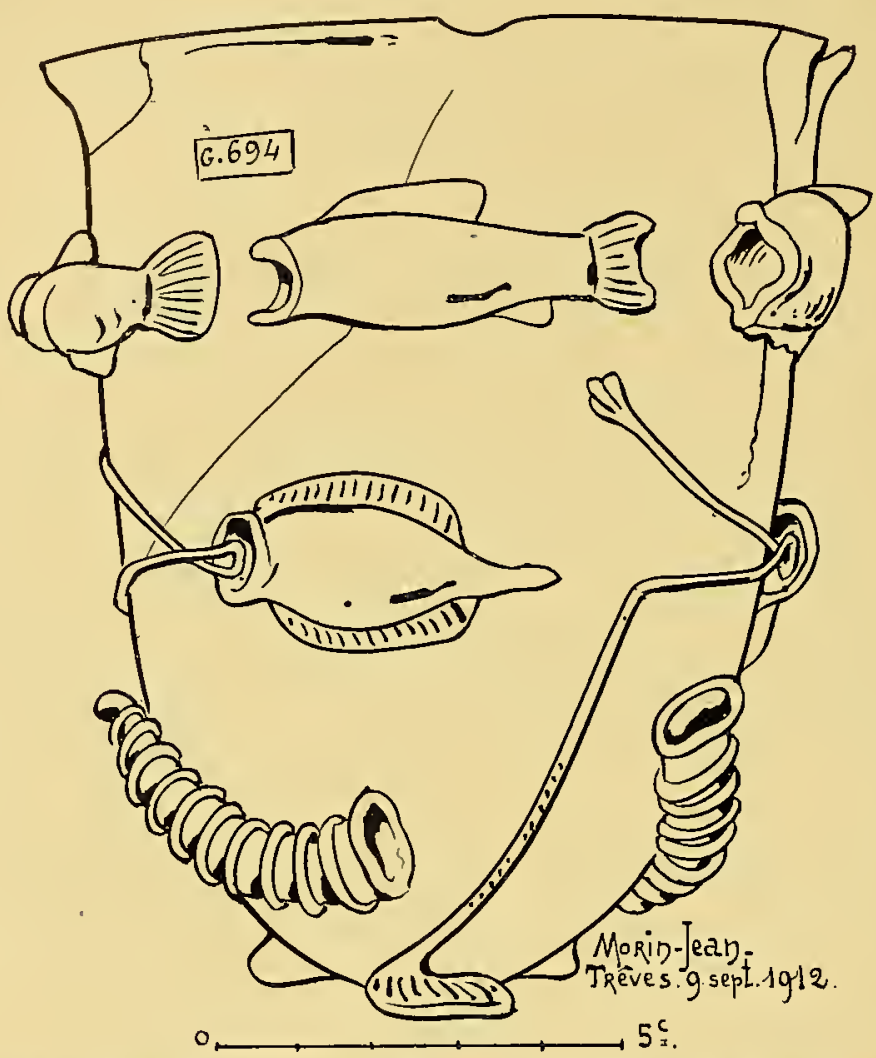

FIG. 2I7. - VERre INCOLORE, orné de coquilles, d'algues et de poissous en ronde bosse. - Fouilles de Pallien. Fin $\Pi^{\mathrm{e}}$ on IVe s. - Musée de Trèves. Salle XX. Vitrine VII, no 694,

le plus beau et le mieux conservé de toute la série (fig. 2I7). Elle a été trouvée à Pallien dans un sarcophage; elle était placée sur. un pinax de verre blanc laiteux lui servant de soucoupe (2).

La forme du récipient ( $\mathrm{n}^{\circ} 79$ du tableau de morphologie générale) est caractéristique de la fin $d \mathbf{u} \operatorname{III}^{\mathrm{e}} \mathrm{s}$. ou de la première moitié

(I) On trouvera un bon dessin de celte verrerie dans ANTox KISA, loc. cit., p. $78 \mathrm{I}$, fig. 3 I 5.

(2) Voy. von Wurowser, Archäologische Funde in Triey und Ungegend, Trèves, rS73. Voỵ. aussi Fither durch das Provinzialmuseum in Trier, p. III, no 694. 
du Ive. La pâte vitreuse, jadis incolore, s'est décomposée et a pris l'aspect dı verre dépoli; elle est remplie de br1les d'air. I,e décor comporte trois rangs superposés d'animaux marins. Dans la rangée inférieure sont disposés trois coquillages tubulaires, entourés chacun d'un fil de verre en spirale. Au milieu du vase, on reconnaît trois soles, poissons plats qui affectionnent les courants moyens. De la bouche de ces pleuronectes partent trois algues dont les bases élargies constituent les pieds du récipient. Dans la rangée du haut, cinq poissons préférant les régions supérieures de l'élément liquide, nagent en file indienne. Tous ces animaux ont été minutieusement faits d'après nature; ils ont été modelés avec beaucoup de goût par des artisans maîtres de leur technique. Si des couleurs vives venaient rehausser cette œuvre charmante, on pourrait, sans exagération, la mettre en parallèle avec les produits les plus soignés de Bernard Palissy.

Le second exemplaire gaulois, appartenant à la série des verres à boire ornés de poissons en ronde bosse, est une pièce beaucoup moins belle que celle de Pallien. C'est un récipient vitreux analogue à cette dernière par sa forme, mais auquel on a adjoint deux petites anses arrondies et $11 n$ pied tronconique.

Il a été trouvé à Cologne, en I904; il fait partie des collections du musée Wallraf-Richartz ( $\mathrm{r}$ ). Comme son congénère de Trèves, il est en pâte vitreuse incolore, fortement décomposée. Les poissons qu'on y a soudés, sont disposés en trois rangées superposées; ils sont tous de la même espèce; ce sont des malacoptérygiens appartenant peutêtre au genre brochet. Dans la rangée médiane, l'un d'eux a été placé, par erreur sans doute, dans la position verticale.

I,e verre de Cologne provient d'une tombe à inhumation du début du IV siècle dans laquelle on a recueilli, en outre, une bouteille forme 40, un flacon forme Io à anses delphiniformes et un moyenbronze de Constance Chlore (mort en 306) (2).

On ne sait pas exactement où les verres à poissons de Rome, de Trèves, et de Cologne, ont été fabriqués.

(I) Une photographie de ce verre a ėté publiće par ANToN KisA, Das Glas in Allertume, p. 783, fig. ${ }_{3} 6$.

(2) Bonner Jahrbiicher, Igo6, fasc. II4-II5, p. 424 et pl. XXV, tombe 60. 
G. B. Rossi écarte l'hypothèse de l'origine classique et opte pour 1'origine gauloise. Selon lui, le fragment découvert à Ostie aurait été apporté à l'embouchure du Tibre avec de nombreuses marchandises gauloises expédiées de Marseille à destination de Rome.

En admettant, avec quelques archéologues, 1'hypothèse d'ouvriers travaillant sur les rives de la Moselle ou du Rhin, on est obligé de convenir que ces ouvriers devaient y être venus d'une région maritime, d'un port où ils avaient pu étudier à loisir la faune marine.

Ce port était-il Marseille où florissait une industrie verrière très développée? Était-i1 Boulogneoù 1'on a trouvé de très belles verreries plastiques? Nous ne le savons pas et nous ne le saurons peut-être jamais.

Rien, d'ailleurs, ne confirme l'hypothèse monogéniste touchant la fabrication des verreries qui nous occupent. I e verre de Cologne, d'un travail négligé, est peut-être une œuvre provinciale, sortie d'une officine où l'on imitait des produits plus artistiques dont le vase de Pallien aurait fait partie.

6. - Forme I30. - Coquille. - Les verriers romains, à 1'imitation des céramistes et des orfèvres, ont fait des flacons en forme de coquille.

La panse de ces flacons est constituée par un mollusque bivalve se rattachant à la classe des Pecten (fig. 2I8). Le pied, le goulot, l'embouchure, les anses ne présentent pas de particularités anormales. Ils appartiennent aux types courants du Romain II. I.es bouteilles conchiformes ont uneoriginetrès ancienne. Elles étaient connues des Grecs chez qui le Pecten était consacré à Aphrodite (I). Elles semblent avoir été surtout destinées à des usages de toilette.

En Gaule, on ne rencontre guère de verreries conchiformes avant le $\mathrm{III}^{\mathrm{e}}$ siècle. L,es exemplaires qui sont parvenus jusqu'à nous sont tantôt en verre incolore, tantôt en pâte de verre blanc opaque ou bleu-azur. Ils proviennent du nord de la France et de la vallée du Rhin.

(I) Consulter Salonon Rervach, Répertoire des Vases peints grecs et étrusques, Paris, I S99, t. I, p. 34,35 et 509. - L,es vases grecs conchiformes ne sont pas rares au musée du Louvre. Un lécythe, dont la panse est formẻe de 3 pectens accolés, est exposé au musće académique de Bonn. Un vase grec en forne de

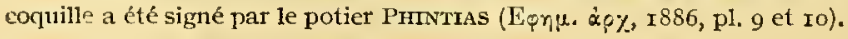


c. Terres phytomorphes (FORME I3I). - Parmi les vases de verre dont la forme appartient au monde végétal, le type en forme de grappe de raisin est le seul dont nous trouvions en Gaule des représentants.

Les flacons forme I3I imitent tantôt une grappe dont les grains sont

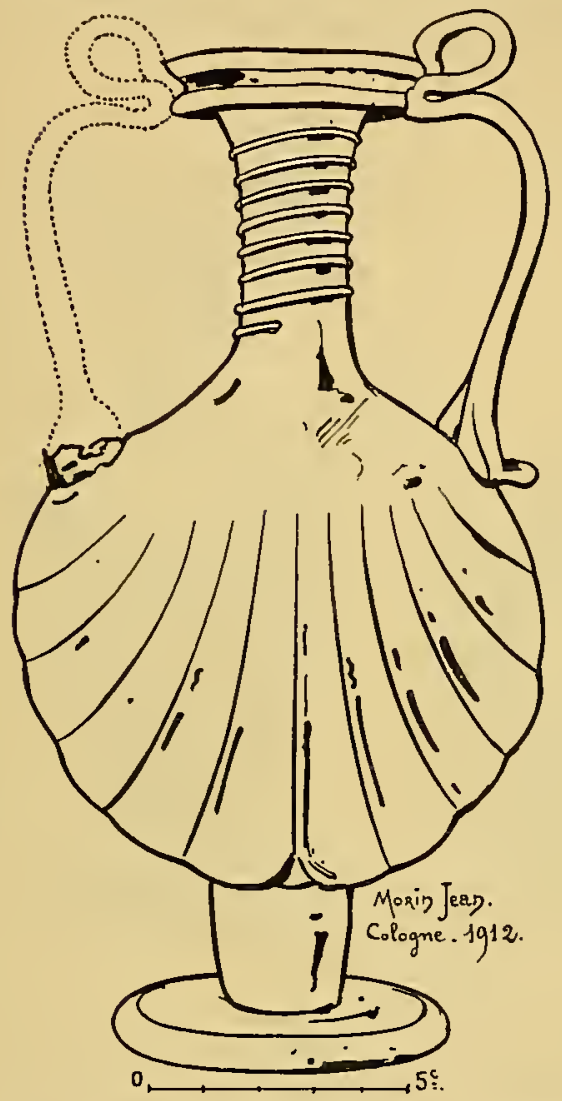

I'Ig. 2I8. - BOUTEIrLE CONCHEORME. - Cologne. Cimeticre de la rue de Luxembourg (fouilles de I893). Romaitr II. - Musée de Cologne, no 529.

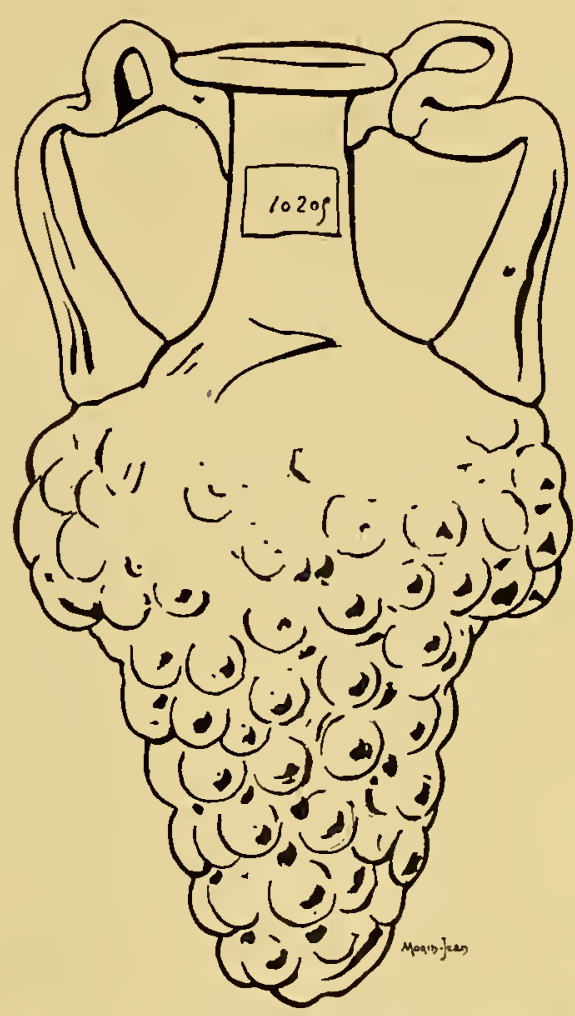

Fig. 2 I9. - BOUTEILle EN FORME DE GRAPpe DE RAISIN. - Cimetière des Dunes, à Poitiers (Vienne). - Musée de Saint-Germain, nº 30309.

groupés en une seule masse (fig. 22I et 222), tantôt une triple grappe (I) (fig. 2 I9, 220). Ils sont apodes (fig. 2 Igà 22 I), ou munis d'un pied consistant en un plateau séparé du vase par un sphéroïde ou un cylindre bas

(x) Ces deux types de grappe se remarquent dans la numismatique, dès une époque très reculée. Ia grappe unilobie est gravée sur les monnaies primitives de Julis (Ile de Céos). La grappé trilobíc orte les monnaies archaïques de l'île de Ténos. 
(fig. 222). Quelques-uns d'entre eux (fig. 22I) ontle goulot et les anses de notre type 33. D'autres (fig. 220) ont le goulot et les anses du type 43. Des spécimens, en verre de deux tons (fig. 222) sont de la même famille que les flacons 50 (série B) décrits plus haut (p. Io8); et ne diffèrent de ces derniers que par la structure de leur panse.

Les verreries en forme de grappe de raisin, trouvées en Gaule, sont

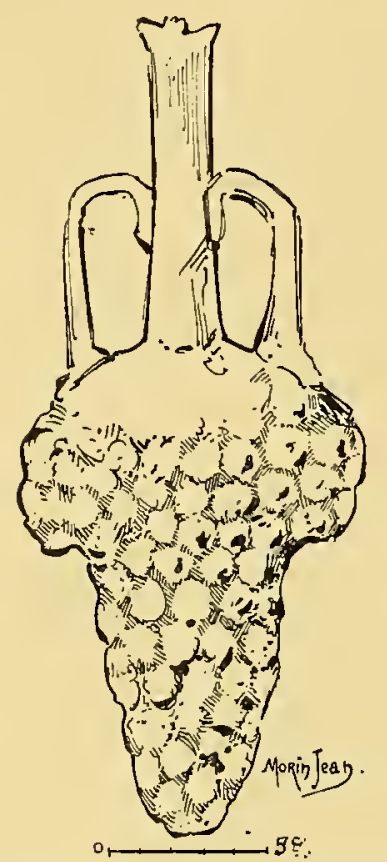

FIG. 220. - BOUTEILLE EN FORME DE GRAPPE TRLOBEE. Musée d'Arles, no $233^{8}$.

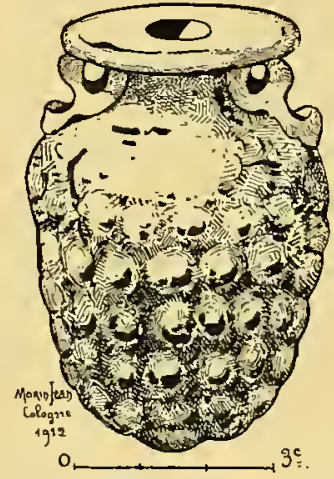

FIG. 22I. - ARYBALle A PANSE MOULÉE EN FORMIE DE GRAPPE. - Verre noir. Cologne. Musée Wallraj-Richartz, $\mathrm{n}^{\circ}$ 5 I 8 .

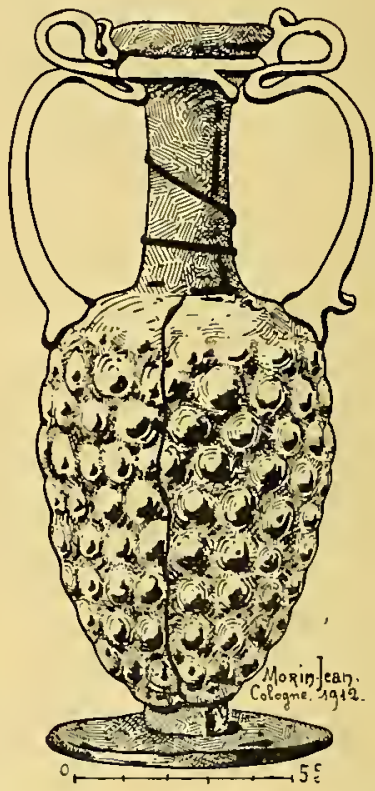

FIG. 222. - FLACON EN FORMI DE GRAPPE. - Verre bleu (anses et bourrelet inférieur de l'embouchure en émail jaune). Romain II. - Musée Wallraf-Richartz, à Cologne.

assez nombreuses. Elles se classent au Romain II. Nous signalons ci-après les plus intéressantes d'entre elles :

Io Six beaux exemplaires tronvés au cimetière des Dunes, à Poitiers (fig. 2I9). - Quatre d'entre eux sont au musée de Saint-Germain (salle XV). Les deux autres sont au musée des Antiquaires de l'Ouest, à Poitiers (Dunes U, XXII. Nos 73 et 74 . Verre bleu-verdâtre). 
$2^{0}$ Grande grappe trilobée. - Hauteur: 25 centimètres. Musée d'Arles, (fig. 220).

$3^{\circ}$ Spécimen apode recueilli à Frésin (province de Limbourg) (Belgique). Musée du Cinquantenaire, à Bruxelles (I).

$4^{0}$ Spécimen découvert à Verrines (Deux-Sèvres), publié dans la Revue archéologique de $\mathrm{I} 858$, p. 538.

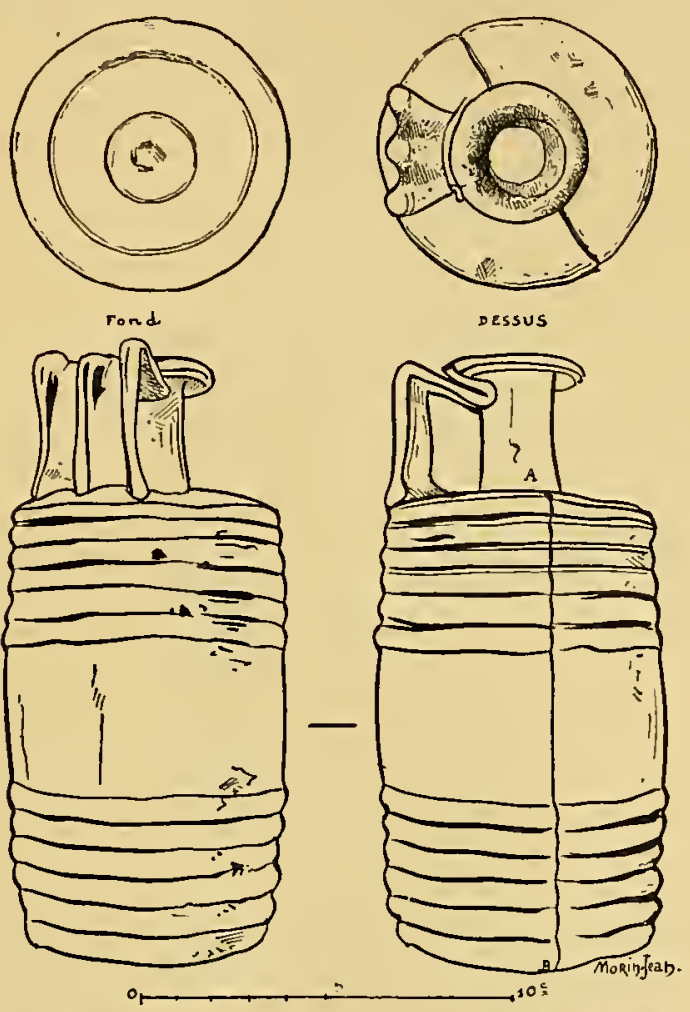

Fig. 223. - Barulet frontinien. - Collection Morin-Jean, $\mathrm{n}^{\circ}$ I5o6.

$5^{\circ}$ Spécimen trouvé en France (sans indication de provenance précise), publié par Froehner. Collection Charvet. P1. IV, I7.

$6^{\circ}$ Grappe de 1'ancienne collection Heydenreich à Spire.

$7^{\circ}$ Grappes découvertes à Trèves (2). (Musée de Trèves. Vitrine VII. Salle 20. Voir Catalogue, p. Iog).

(I) Scheulruans. Dans Bull. comm. Belges, I 863,1 . 27.

(2) Bonner Jahrbücher, I886, fasc. 81, p. 49, pl. I, no 24 ; I 896, fasc. 99, p. 52, pl. II, no I. FroELnER, Eollection J. Gréau, u० I.I57, pl. 209, n० I [Grappe unilobée à pied; hauteur: I7 centimètres]. 
$8^{\circ}$ Plusieurs exemplaires de la vallée du Rhin conservés à Cologne, au Musée Wallraf-Richartz (fig. 22I et 222) et dans des collections particulières.

$9^{\circ}$ Fragments de grappes aux musées de Saintes et de Mayence.

d. Verres skeiomorphes (Formes I32 à I39).

FORME I32. - Barillet frontinien. - Le barillet I32 (Fasskanne des archéologues allemands) est une bouteille en verre moulée de la

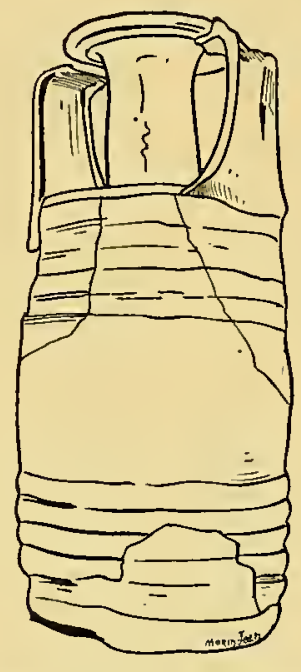

Fig. 224. - BarLlet a DeUtx ANSEs. - Cimetière de Beaumont-sut-Oise. - Collection MIorin-Jean, $n^{0} 2217$.

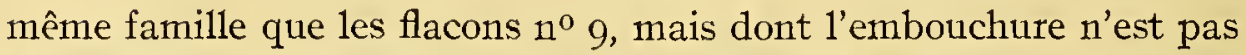
à bourrelet double et dont la panse est garnie, à ses deux extrémités, de cercles en relief (I) (fig. 223). Le nombre de ces cercles est variable. On en compte généralement cinq ou six à chaque extrémité.

I.es barillets ont tantôt une anse, tantôt deux anses appartenant à notre type $\gamma^{1}$.(pl. 3, p. 37) (2). Un modèle à trois anses du musée de Boulogne-sur-Mer fait exception. Nous devons ranger également parmi les raretés le tonnelet sans anses et sans goulot que nous reproduisons fig. 227 , et les barils ornés

(I) La forme $\mathrm{I}_{32}$ a été donnée aussi à des rẻcipients d'argile (M usće d'Amiens, Barillet de terre cuite, hauteur : 27 centimètres; et Collection TH. E,ck, à Saint-Quentin; Barillet à une anse trouvé à Vermand; terre jaunâtre, hauteur : I7 centimetres).

(2) I'anse à section circulaire du barillet fig. 226 est une exception. 
soit d'un semis de cabochons (voy.plusloin, p. 224, nos 7 et 8 et fig. 305). soit d'une seule guttule de verre simulant la bonde du tonneau (fig.342).

Le type normal du barillet est une bouteille de 14 à 18 centimètres de hauteur (I), à parois minces, soufflée dans un moule à deux parties. Le fond et le goulot sont rapportés. La bavure du moule s'arrête

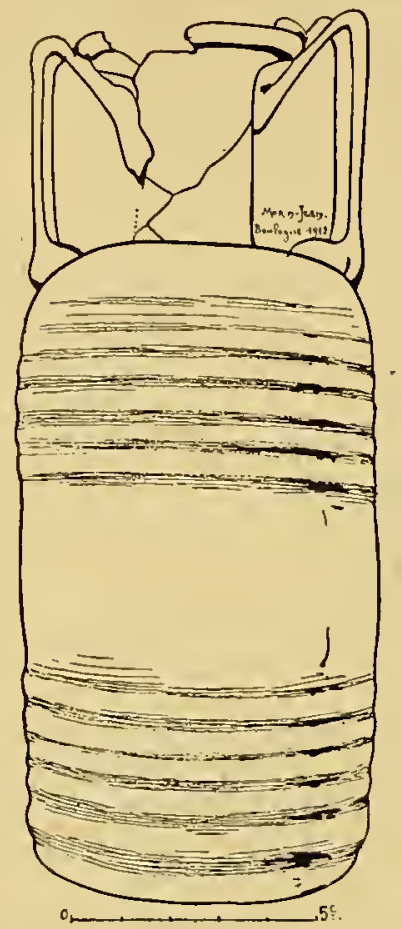

Fig. 225. - BARILLET EN VERRE VERDATRE FILANDREUX. - Fouilles du Boulonnais (I896). IV ${ }^{0} \mathrm{~s}$. - Musée de Boulogne-sur-Mer, $n^{\circ} 5154$.

en $\mathrm{A}$ (fig. 223) à l'amorce du goulot, et en $\mathrm{B}$ au point de jonction de la panse et du fond.

Le fond est divisé en plusieurs zones par des cercles en relief et porte une signature, celle de l'industriel Frontimus dont le nom est inscrit en toutes lettres ou en abrégé (2).

(I) Fxceptionnellement, certains barillets ne dépassent guère 7 à 8 centimètres (fig. 229). D'autres ont pres de 30 centimetres de hauteur.

(2) Quelques barillets portent l'estampille Frontiniana [Fabrica] ou Comior. Fron. D'autres sont signés Frontinus, Front. ou Fro. (Consulter A. Deville, Histoire de l'art de la verrerie dans l'antiquité, p. 48; W. Fromner, La Verrerie antique; J. PuLoy, Etudes sur d'ancicns lieux de sépuliures dans l'A iste, t. II, p. III-II7: ANION KISA, Das Glas im Altertume, p. 943-947. 
Si nous examinon's les rapports de proportions des diverses parties du barillet frontinien, nous constatons que toutes les dimensions indiquées en $\mathrm{A}, \mathrm{B}, \mathrm{C}, \mathrm{D}, \mathrm{E}$ et $\mathrm{F}$ de la fig. 228 sont égales entre elles. La partie unie de la panse a la même hauteur que chacune des deux zones cerclées. La largeur de la panse est égale aux deux tiers

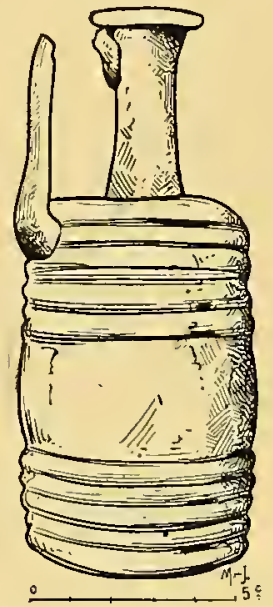

FIG. 226. - BariLlet MarquÉ F. R. O. - Villeneuve-Saint-Georges (S.-et-O.). - Musée de Saint-Germain. Salle XV; ${ }^{\circ}{ }_{2} 6040$.
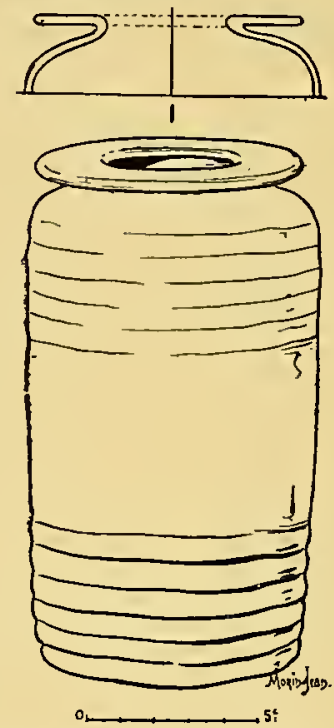

FIG. 227. - BARTLET A OUVERTURE LARGE, SANS ANSE ET SANS col. - Trouvé à Reims. - Mrsée archéologique de Reims, $\mathrm{n}^{\circ} 4748$.

de sa hauteur totale. Ira hauteur du goulot est égale au tiers de la hauteur de la panse.

Nous sommes donc en présence d'un canon de proportions très simple observé dans la fabrication de presque tous les barillets.

Le barillet frontinien s'est rencontré en abondance dans la région du nord des Gaules comprise entre le Rhin et la Bretagne, c'est-à-dire en Normandie, dans 1'Ile-de-France, en Champagne, en Picardie, dans le Boulonnais, en Flandre et dans les vallées de la Moselle et du Rhin (x).

Il est particulièrement fréquent dans les nécropoles de Cany (2),

(I) Une carte des lieux de trouvailles des barillets a été dressée en 1906 par le Dr I,EBLGND (Marque de verrier sur un barillet gallo-romain trouvé à Beauvais, I907).

(2) Abbé Cochet, La Normandie souterraine, p. 6I et suiv. 
du Bois-des-Loges près Étretat (I), du Mesnil-sous-I,illebonne (2), de Neuville-le-Pollet (3), de Beauvais et de la forêt de Compiègne (4), de Reims et de la Marne (5), d'Amiens (6), du Vieil-Atre à Boulognesur-Mer (7), de Vermand, de Tournay et du Limbourg Belge (8), de

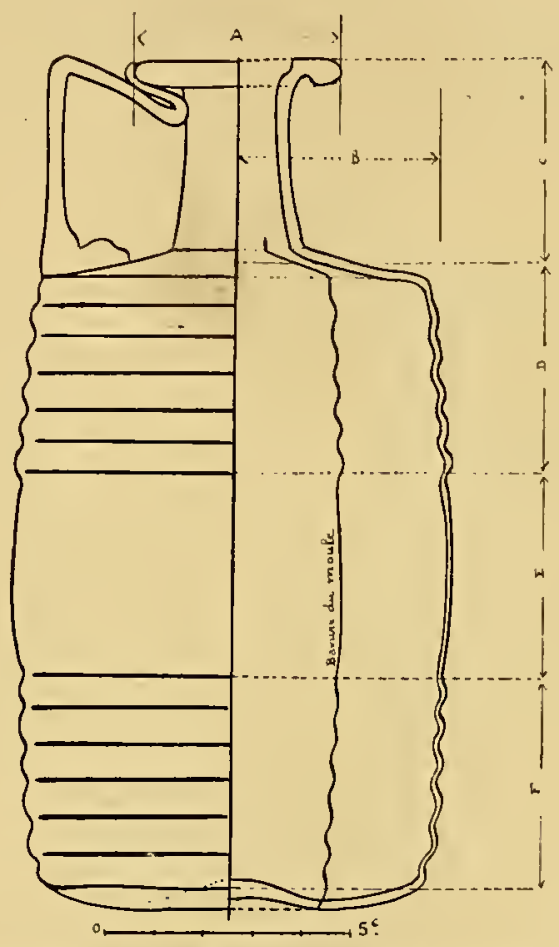

Fig. 228. - BARILLET FrontINIEN, - Collection Morin-Jean, $\mathrm{n}^{0}$ I506.

Trèves (9), de Cologne (Io), d'Andernach (II), de Strasbourg (I2), de Metz, de Worms et de Remagen (I3).

(I) Abbé Cocher, loc. cit., p. 87 et suiv.

(2) Abbé Cochet, loc. cit., p. I I I et suiv.

(3) Abbé Cochet, Fouilles de Neuville-le-Pollet, r845, pl. XIX.

(4) Fouilles de Roucy. MIusée de Saint-Germain.

(5) Catalogue du musée archéologique de Reims, $\mathrm{n}^{\mathrm{0s}} 4.653,5.276,7.063$, etc.

(6) Nombreux exemplaires au musée de Picardie, à Amiens.

(7) Riche série au musée archéologique de Boulogne-sur-Mer. [Voy. Dr SAuvage, dans le Bullelin de la Société académique de Boulogne, t. VII, et J. VaIllant, Epigraphie de la Morinie, I8go.

(8) J. PILLOY, loc. cit., t. II, p. III.

(9) Riche série au musée Provincial de Trèves. Nombreux spécimens à deux anses.

(ro) Voy. Bonner Jahrbiicher, I906, fasc. II4-II5, p. 430, pl. XIVI, tombe 68.

(II) KCENEN, dans Bonner Jahrbücher, I 888 , fasc. 86 , p. I86, pl. X, no ${ }^{0} 9$.

(I 2) Voy. Stratr, Le cimetiere gallo-romain de Strasbourg, I88I, p. 20-2 I et pl. VI, no 2.

(I3) DRAGENDORFF, dans les Bonner Jahrbilcher, I895, fasc. 96-97, p. I23. 
Par suite de relations commerciales, il s'est répandu sporadiquement en dehors de ces régions, notamment au cimetière des Dunes, près de Poitiers (I).

On ne 1'a pas trouvé en dehors des pays gaulois, des régions où le vin se transportait dans des tonneaux formés de douves de bois cintrées et maintenues par des cerceaux. En Orient et dans les pays grecs et latins, le vin était renfermé dans des amphores de terre cuite

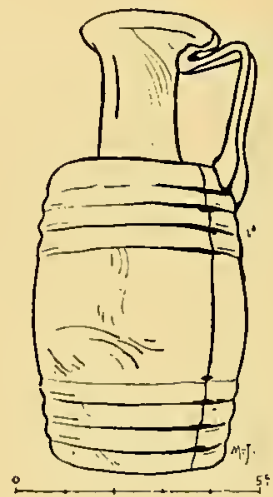

FIG. 229. - BARILLET EN VERRE VERDATRE. Paris. Cimetière du faubourg Saint-Jacques. $\mathbf{r v}^{\mathrm{e}} \mathbf{s}$. - Musée Carnavalet.

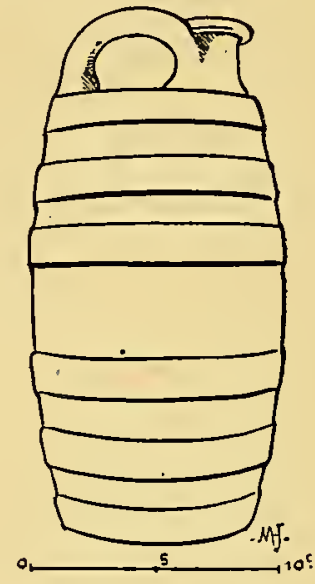

Fig. 230. - BARILLET DE TERRE CUITE A GOULOT ET ANSE D'ASKOS. - Mrusée de Saint-Germain, $\mathrm{n}^{0} 20749$.

ou dans des outres de cuir (2). Le tonneau, cupa (3), n'y était pas absolument inconnu; mais Pline nous dit que ce récipient n'était d'un usage journalier que dans la région des Alpes et dans les contrées du Nord (4).

Les barils de verre sont de fidèles copies des tonneaux gaulois en

(I) P. DE CESSAC, Découverte d'un cimetière des premiers siècles de notre ire à Poitiers, dans la Revie Archéologique, 1879 , vol. $3^{8}$, p. $4^{6}$.

(2) L'outre de cuir des pays méditerranéens a servi de modèle aux céramistes grecs qui, en s'inspirant de sa forme, ont créé le vase dit : askos. L'askos d'argile a été imité par les verriers pompéiens (Musée de Naples, nos I I3.248 et II8. I42). Il ne s'est pas répandu au nord des Alpes. On peut considérer comme une exception le tonnelet de terre cuite du musée de Saiut-Germain (fig. 230), dont le col et l'anse sont einpruntés à l'askos grec. Ce tonnelet est un curieux type hybride où l'imitation du tonnean gaulois se joint à celle de l'outre à vin méditerranéenne.

(3) Voy. article Cupa dans le Dictionnaire des Antiquités de M. SAGLIO, t. I, deuxième partie, p. I594.

(4) PLINE, Hist. nat., XIV, I32. 
bois. Ils sont d'autant plus précieux pour nous que presque tous les tonneaux de bois ont péri (I).

Ia fabrication des barillets frontiniens a dû commencer au $\mathrm{III}^{\mathrm{e}}$ siècle. Les exemplaires les plus anciens, ceux de la Normandie, ont été rencontrés dans des tombes à incinération. Ils sont en verre bleu-verdâtre d'assez bonne qualité. A la fin du $\mathrm{Im}^{\mathrm{e}}$ et pendant le

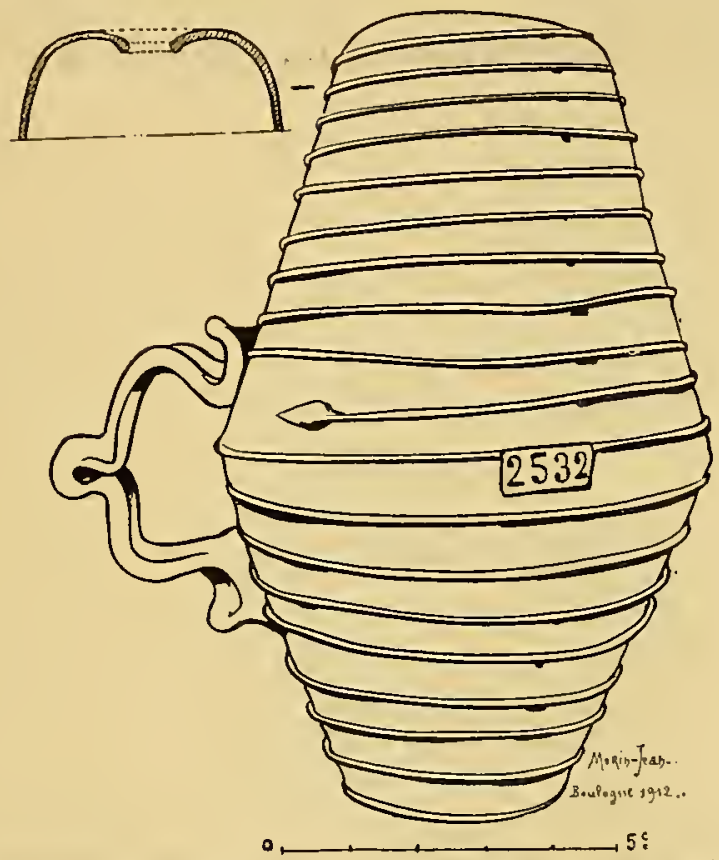

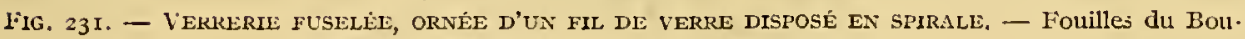
lonnais. - Music de Boulogne-sur-Mer, $\mathrm{n}^{0} 2532$.

IV $v^{\mathrm{e}}$ s, la fabrication frontinienne s'est poursuivie intensivement jusque vers 385 ou 390 ap. J.-C. Les spécimens les plus tardifs, ceux trouvés à Vermand avec des monnaies de Constantin (306 à 337) (2), de Valens (364 à 378) (3), de Gratien (375 à 383) (4)

(I) Un tonneau romain en bois, d'environ $\mathrm{I}^{\mathrm{m}}, 75$ de hauteur et $\mathrm{I}^{\mathrm{m}}, 20$ de diamètre, est conservé au musée de Mayence. Un autre a été découvert en Angleterre, dans le Comté de Buckinghann. Ce sont des raretés. Les barillets de verre ne sont pas les seuls objets qui nous fassent connaître la forme des barriques de bois de l'époque romaine. On peut voir, à Trèves, au musće provincial, d'intéressants monuments en pierre qui représentent des galères chargẻes de tomneaux (Voy. Fravz CRAMre, Das rōmische Tricr, p 20 et $2 \mathrm{I}$ ].

(2) Cimetiere de Vermand. Tombe 339. Fouilles TH. TCқ, en 1885.

(3) Cimetière de Vermand. Tombe 22. Fouilles I,ELAURAIN, en I 885.

(4) Cimetière de Vermand. Tombe 183 , Fouilles IrLaubaIN. 
et dans les cimetières à inhumations du Boulonnais, de la Picardie et de la vallée du Rhin, sont en pâte vitreuse incolore ou verdâtre, pleine de bulles d'air et de filandres.

FORMES I33-I34. - Verres en forme de tomnelets fuselés. - Les cercles du bariI sont exprimés par un fil de verre qui s'enroule du haut en bas du récipient (fig. 23I) ou autour de ses deux extrémités seulement (fig. 232).

Les verres I33-I34, ansés ou non ansés, appartiennent aux pro-

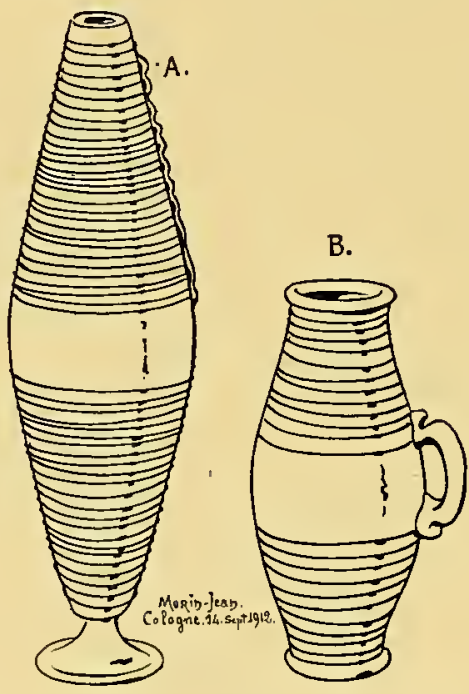

FIG. 232. - VERres fUSELES : A. Musée provincial de Bonn. Salle V, no 15 II2. - B. Musée de Cologne $\mathrm{n}^{0} 642$.

ductions de la Gaule nordique et rhénane du $\mathrm{Ir}^{\mathrm{e}}$ et du Iv siècles. Le type I34 est moins rare que le type I33. Il est représenté par des spécimens découverts à Boulogne (fig. 23I), à 'Trèves (I), à Cologne (2) (fig. 232), à Andernach (3), et par un exemplaire de la collection Pierpont-Morgan (ancienne collection Julien Gréau) publié par M. Froehner (4).

FORME I35. - Le barillet I35 diffère des précédents en ce qu'il

(I) Trèves. Musée Provincial. Salle 20. Vitrine IX (P. Mt. 602).

(2) Voy. Bonner Jahrbiichcr, I88I, fasc. 7I, pl. VI, $\mathrm{n}^{0} \mathrm{I} .382$.

(3) Voy. Bonner Jahrbücher, I888, fasc. 86, pl. I et p. 185.

(4) W. Froeiner, Collection J. Gréau, no $\mathrm{n}^{\circ}$ 1.242, pl. 233 (no 4). 
est couché (fig. 233) (I). Il repose sur quatre petits pieds de verre. Sur le dessus, à l'emplacement de la bonde, est placé un goulot court,

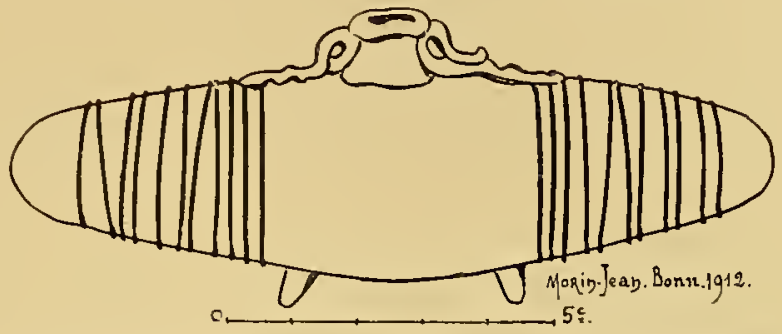

FIG. 233. - BARrlet polypode. - $\mathrm{II}^{e}$ s. - Musce provincial de Bomu. Salle V, A. IOIz.

surmonté d'une embouchure en bourrelet et flanqué de deux anses appartenant au type $\%(\mathrm{pl}, 2, \mathrm{p} .36)$. Les verreries de ce modèle sont d'ordinaire en assez beau verre incolore; les filets représentant les

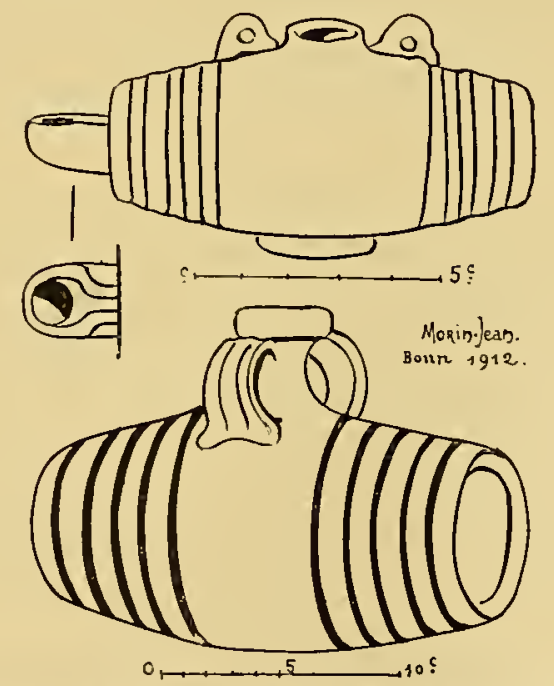

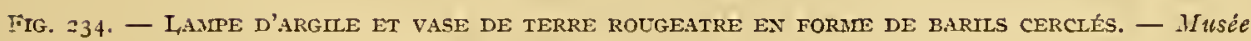
provincial de Bontu. Salle III (n ${ }^{\text {os }} 73$ I et 5829 ).

cercles du tonneau, les anses et l'embouchure sont en verre bleu. Les tonnelets forme I35 ne sont pas communs. Ils ont été trouvés dans la

(I) A l'époque romaine, les barillets du type 135 ne sont pas tous en verre. Quelques-uns sont en terre cuite (fig. 234: l'exemplaire du laut cst une lampe). D'autres sont en bronze. [Petit barillet de bronze de 8 centimètres de longueur. M[usée de Bonn, $n^{\circ} 3.673$, Patine varte]. 
vallée du Rhin (I). Ils datent du $\mathrm{III}^{\mathrm{e}}$ siècle et font partie du même groupe de produits que les verres à applications vermiculaires de la première série (voy. plus loin, p. 200).

FORMES I36 ET I37. - Patères à manche. - La forme de ces récipients vitreux reproduit exactement celle des patères de bronze et d'argent que l'on conserve dans un assez grand nombre de musées et collections.

Le type I36 paraît être le plus ancien des deux. Il existe, dès le $\mathrm{I}^{\text {er }}$ siècle, dans la verrerie pompéienne (exemplaires dı musée de Naples). Il n'était pas tombé en désuétude au Romain II, puisqu'on en connait des spécimens ornés d'applications vermiculaires (2) (fig. 287).

Frœhner a publié une patère forme I36 trouvée à Amiens (3).

Le type I37 (Trulla des archéologues allemands) est une coupe peu profonde à pied annulaire, et munie d'un manche. Les patères de cette forme sont en verre incolore et décorées d'applications vermiculaires (fig. 286). Elles n'ont guère été recueillies en dehors de la vallée du Rhin.

Au cimetière de Cologne, elles étaient dans les sépultures à incinération de l'époque des empereurs syriens, en compagnie des plus belles verreries à applications vermiculaires (4). Quelques-unes ont servi de soucoupes aux cenochoés forme 52 et fig. 275 .

Forme I38. - Verreries en forme de panier. - Les verriers de l'époque romaine ont copié les objets les plus variés. On a recueilli à Pompéi un flacon de verre en forme de marteau (5). On a découvert en Gaule des récipients vitreux en forme de paniers munis d'une ou de deux anses.

Le panier que nous reproduisons fig. 235 est décoré de filets en

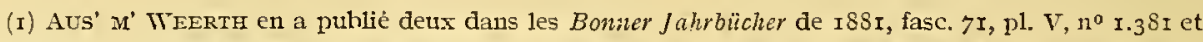
pl. VII, no I.3So. FrRGHNER en a publié un de 2 I centimètres de longueur dans son grand catalogue de la Collection Gréau (n० 1.244, p]. 233, $\mathrm{n}^{\circ} 6$ ).

(z) Une patère en verre ornée d'applications vermiculaires, provenant d'une tombe du III ${ }^{\mathrm{e}}$ siècle déconverte à Hauret, est conservée au musẻe de Namur (roy. ANToN Krs., Das Glas im Alterthme, p. 460 et fig. I 28 b).

(3) W. Froehner, La Verrerie antique, pl. XX, na 89.

(4) Voy. Bonner Jahrbilcher, r9o6, fasc. II4-II5, p1. IXIV.

(5) Ausée national de Naples, $\mathbf{n}^{0}$ x 2.087 . 
émail blanc. Il est difficile de lui assigner une date précise. En tout cas, il ne semble pas antérieur au $\mathrm{III}^{\mathrm{C}}$ siècle. Un spécimen thénan, d'un modèle un peu différent, a été publié par Anton Kisa (I).

FORne I39. - Flacons en forme de casque de gladiateur fermé (2). Les bouteilles du type I39 sont des vases à huile parfumée dout se sont, sans doute, servis les gladiateurs. Quand le casque est, comme dans notre figure, placé à l'endroit, le flacon se trouve à l'envers, car c'est le gorgerin qui constitue le col du vase. La panse est ornée de fils de verre qui simulent les détails de la visière. Elle a été soufflée à part. Elle présente une petite ouverture à l'endroit du raccord avec

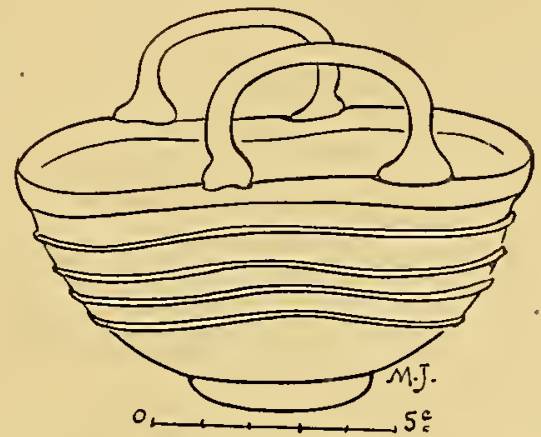

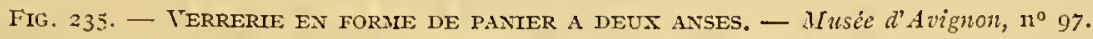

le goulot. Par cet étroit orifice, l'huile, contenue à l'intérieur de la bouteille, ne pouvait couler que goutte à goutte.

On ne connaît jusqu'ici que deux exemplaires de ce genre de verrerie (3).

Le premier, conservé au musée Wallraf-Richartz à Cologne, est en verre incolore d'une grande pureté. Il est décoré d'applications vermiculaires, reprises au petit fer, qui représentent des feuilles cordiformes dans le style caractéristique de l'époque des empereurs syriens (fig. 236). Il a été trouvé à Cologne, rue de Luxembourg, en

(r) Anron Krsa, Das Glas im Altertume, fig. 7r. Cologne, Collection Niessen.

(2) Sur les différentes formes des casques de gladiateurs, consulter le Dictionnaire des Antiquités de Daremberg et Saglio, t. II, deuxième partie, p. I 4.t9.

(3) $I_{1}$ a forme de casque de gladiateur a élé donnée à une lampe d'argile à converte émaillée, trouvée dans un sarcophage à Alteburg près de Cologne et conservée an British Museum [K. 49]. (Voy. WraLrers, Catalogue of the Roman Pottery, p. 8, et pl. II.) 
I897, dans une tombe à incinération qui fait partie du groupe de sépultures que nous avons datées en bloc de l'époque des Sévères (I).

Le second, découvert, lui aussi, à Cologne, faisait autrefois partie de la collection Disch (2). A la vente de cette collection, il a été acheté par M. Hoffmann, de Paris. Il n'est pas une reproduction exacte de celui du musée Wallraf-Richartz. Il est polychrome. La bouteille est en verre incolore; les arcades sourcilières et le nasal sont en verre

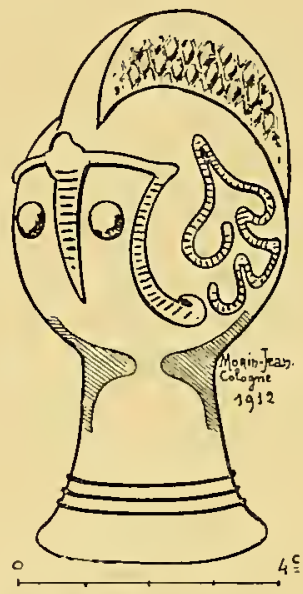

Fig. 236. - Flacon EN Forne DE CASQue DE GLAdiateur. - Musée Wallraf-Richartz, à Cologie.

bleu. Sur les joues, des fils de verre ingénieusement disposés dessinent des pigeons becquetant des baies (voy. plus loin, p. I99).

Le casque de la collection Disch se classe, comme son congénère du musée de Cologne, au IIr ${ }^{\mathrm{e}}$ siècle.

\section{I7. - Formes ABERRANTES.}

Nous avons groupé dans un dernier paragraphe les verreries qui se distinguent par la singularité de leur structure et n'appartiennent à aucun des types figurant au tableau de morphologie générale.

(I) Consnlter Bonner Jahrbiücher, Igo6, fasc. II4-II5, p. 4I2, et pl. IXIV, tombe no 4 I.

(2) I,e casqne de la collection Disch a été publié par M. AUS' M' WeERTh, dans les Bonner Jahrbïcher en

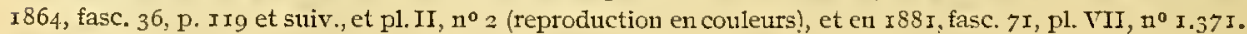
On en trouvera un bon dessin dans Axton KisA, Das Glas im Altertume, p. 250-25I, fig. I25. 
Nous mentionnerons les plus curieuses d'entre elles.

I. Vase à étroite ouverture munic de trois anses. Verre épais, bleu-verdâtre. - Nous ne connaissons que deux spécimens de cette

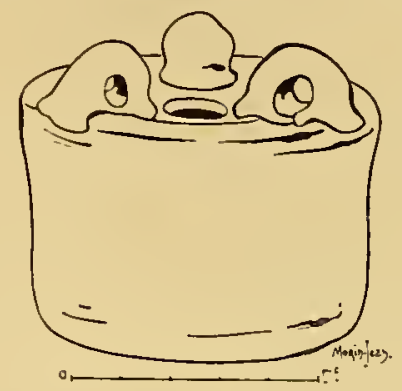

Fig. $23 \%$ - RécipIeñ en verre épaIs. - Musée de Trives. Salle $\mathrm{XX}, \mathrm{n}^{0} \mathrm{I} \mathrm{z} 26$.

sorte de récipient. L'un est au musée de Trèves (fig. 237). L'autre fait partie de la collection Ch. Magne, à Paris (fig. 238). Tous deux paraissent dater du II $\mathrm{e}$ siècle.

2. Verreries de forme étrange découvertes aux Aliscamps, ì

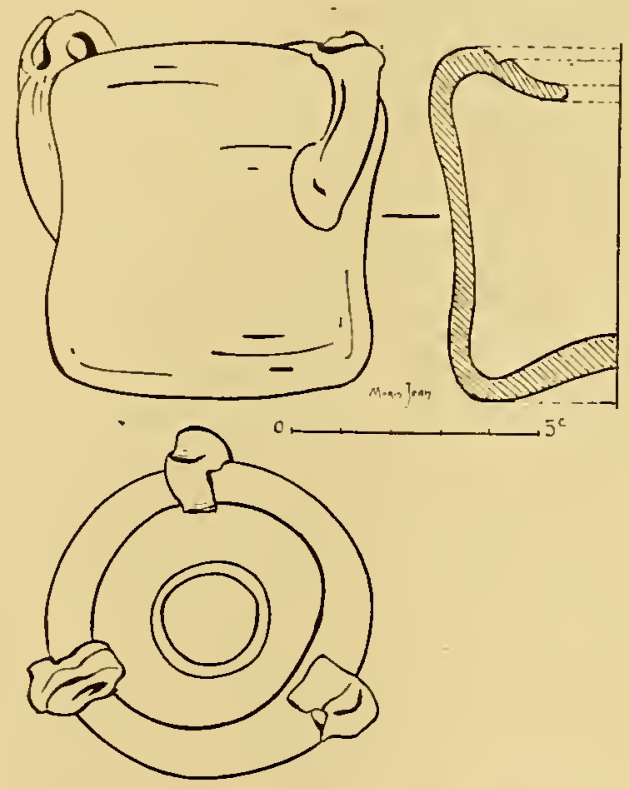

FIG. $23^{8}$. - Récipient trouvé le 6 avril ıgoo, au cimetière romaiu du boulevard de Port-Royal, à Paris. -Collection Ch. Magne.

Arles, et conservées au musée Borély, à Marseille (fig. 239). - Ces 
deux pièces, sur la destination desquelles on n'est pas fixé, se trouvaient en I870, dans la collection Augier. Elles ont été décrites par Quicherat (I).

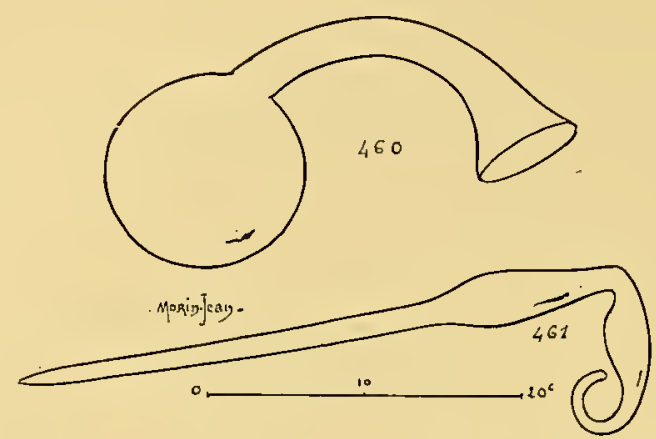

Fig. 239. - FIOLEs DE verRe, trouvẻes aux Aliscamps (Arles). - Musée Borély, à Marseille.

3. Ballon à tubulure courbe, trouvé à Saintes, dans les ruines de Saint-Saloine (musée de Saintes) (fig. 240).

4. Petit flacon ansé du musée d'Arles (fig. 24I). - Sur le fond, l'inscription Patrimoni.

5. Fiole à deux anses et à panse tronconique du musée de Dijon (fig. 242).

6. Fiole cylindrique en verre verdâtre épais. - Embouchure de

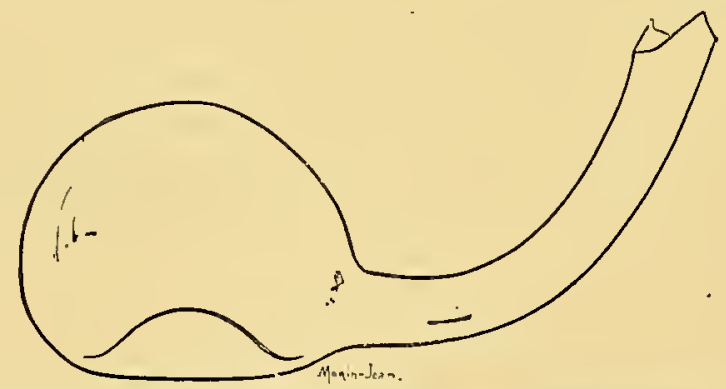

Fig. 240. - Ballon a tubulure courbe. - Saintes. Ruines de Saint-Saloine. - Musée de Saintes.

forme étrange (fig. 243). Fouilles du Soissonnais (Collection Th. Eck, à Saint-Quentin).

7. Bouteille à deux compartiments superposés et reliés entre enx par

(I) QUICHERAT, De quelques pièces curieuses de verrcrie antique. Dans la Revue archéologique, I874, t. II, p. 80 et pl. XIII, nos 3 et 5 . 
cinq tubulures (fig. 244, A). - Un seul vase, conservé au musée de SaintGermain, correspond à cette forme. Il est en verre de couleur jaunâtre et de manvaise qualité. Il a été découvert, le 8 mai I875, dans une tombe à inhumation du cimetière de Caranda (Aisne), avec deux fibules d'argent (fig. 244, B) et une monnaie d'or de Valens (364 à 378 ) (I). C'est donc tune verrerie de la fin de l'époque romaine.

8. Bouteille ajouréc (fig. 245). - Deux vases répondent à cette forme. I,e premier, recueilli à Trèves, est au musée provincial de cette ville (2) (fig. 245). Il est en très mauvais état de conservation.

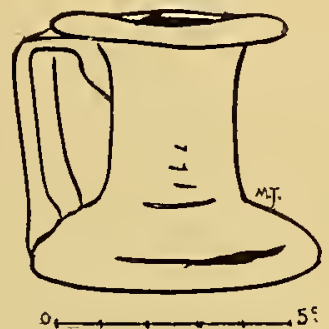

FIg. 24r. - PETIT fLACON ANSÉ. - Nusée d'Arles.

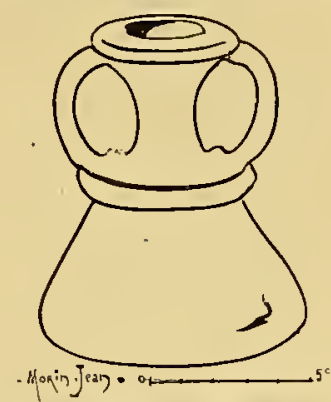

Fig. 242. - Ftole a DeUx ANSES. - Misie de Dijon.

C'est une bouteille prismatique dont la section est un carré à angles arrondis. Elle est en verre incolore. Elle est portée sur un pied tronconique séparé du fond du récipient par un sphéroïde. Ia panse est ornée, aux quatre coins supérieurs, de coquilles Saint-Jacques moulées d'où pendent des rubans de verre qui sont alternativement bleus et jaunes et présentent de nombreuses saillies faites à la pince. Le goulot, assez long, est décoré de fils de verre incolore. Le bord de l'embouchure est en verre bleu. Au centre de la bouteille, on a réservé un espace vide au milieu duquel est placée une petite amphore de verre dont les anses sont bleues.

Le second vase, qui diffère très pelı du premier, a été trouvé à Cologne et fait partie d'une collection particulière de cette ville (3).

(r) Frédóric Moread, Album Caranda, pl. ILV, no r, et pl. XXIT, no $2 \mathrm{r}$ (tombe 2.Ir4).

(2) Voy. Avton KIs., Das Glas im Altertume, p. 350 et fig. 79.

(3) Collection Yom Rath. 
Il est très bien conservé. Il mesure 22 centimètres de hauteur. Les ornements dont il est chargé sont en verre bleu et jaune. I,e bord de l'embouchure est entouré d'un fil bleu. Dansle vide réservé au milieu de la bouteille était autrefois une petite cruche aujourd'hui perdue (I).

Les bouteilles ajourées de Trèves et de Cologne sont des créa-

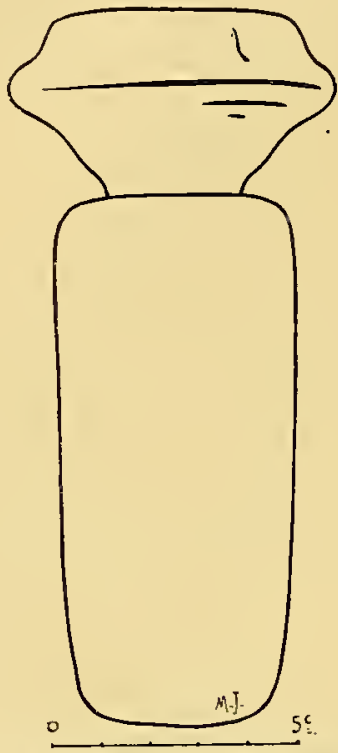

FIG. 243. - BOUTEILLE EN VERRE VERDATRE. Fouilles du Soissonnais. - Collection Théophile Eck, à Saint-Quentin.

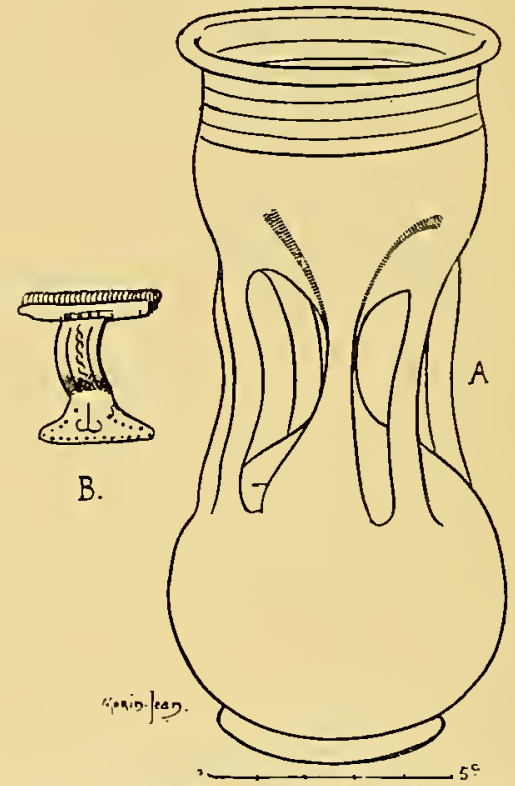

FIG. 244. - MOBICIER FUNERAIRE D'UNE TOMRE DU CTIETIËR DE CARANDA (Aisne). rve s. : A. Bouteille de verre à deux compartiments;- B. Fibule d'argent. Type à grand ressort. - Musée de SaintGermain. Salle XI. Collection F. Horeau, nº 2 I 4 .

tions de l'école rhénane du III $^{\mathrm{e}}$ siècle. Elles sont sorties des mains d'ouvriers fort habiles, mais dont le goût n'était pas toujours très sûr.

9. A cette série d'œuvres compliquées, chargées d'ornements qui les alourdissent sans raison, portant en elles un germe inquiétant de caducité, nous devons rattacher la gourde plate que nous reproduisons (fig. 246) (2). Cette bouteille de verre incolore filandreux ressem-

(I) Voy. Axton Krss, Das Glas im Altertume, p. 349 et fig. 78.

(2) Voy. Anton Kisa, loc. cit., p. 350 et fig. 80. 
ble à la grande gourde (fig. 274). Elle a dû sortir du même atelier que cette dernière. Sa panse est percée de quatre ouvertures arrondies.

Dans l'iutérieur de chacune de ces ouvertures, se trouve un

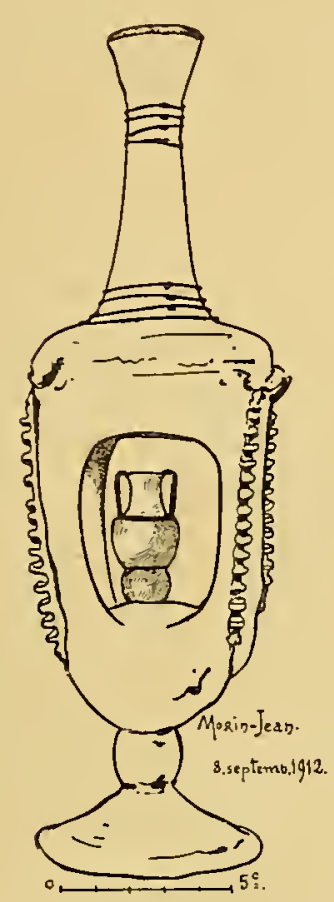

FIG. 245. - BotteILLE AJOURÉE. - III ${ }^{e}$ S.

- Musée de Trèves. Salle $\mathrm{XI}, \mathrm{n}^{\circ} 05429^{\mathrm{b}}$.

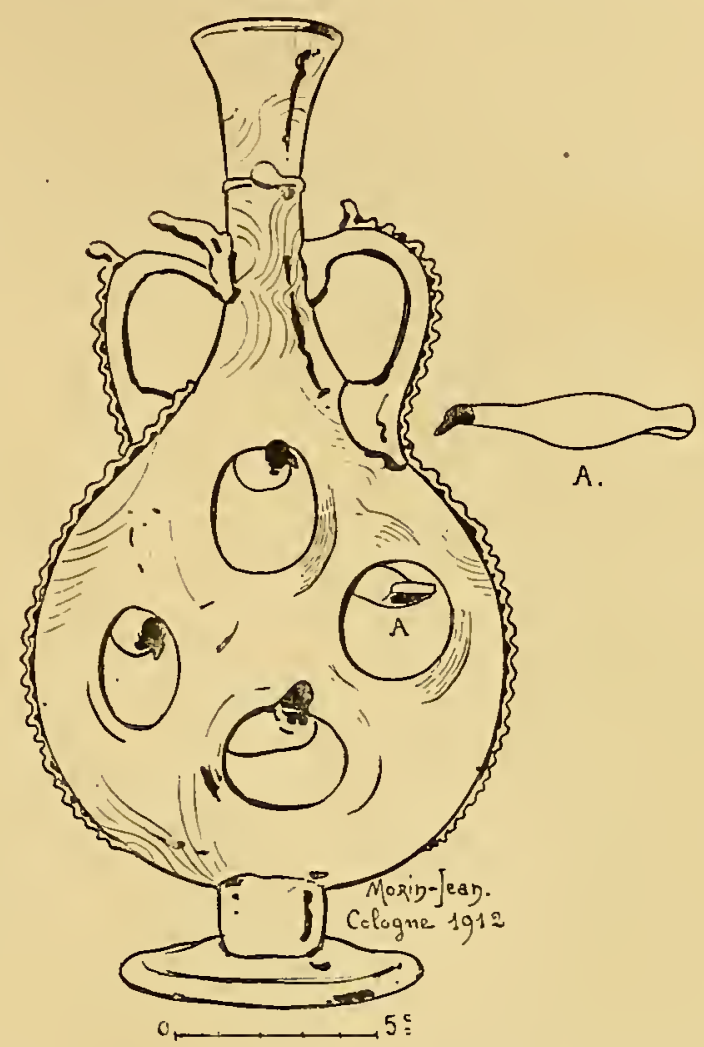

Fig. 246. - Bouteille a PANSE PLATE, percée de quatre ouvertures. - Romain II. Cologne. - Musée Wallraf-Richartz, no 674 .

petit pigeon dont le corps est en émail blanc et dont la tête est en verre blet1.

Trois de ces oiseaux se dirigent du même côté. Le quatrième prend la direction opposée. Peut-être cette particularité est-elle le résultat d'une erreur. Peut-être aussi le verrier a-t-il voulu illustrer ainsi quelque conte populaire inconnu de nous.

IO. L.es verriers du $\mathrm{II}^{\mathrm{e}}$ et du $\mathrm{IV}^{\mathrm{e}}$ siècles étaient arrivés à une habileté d'exécution si prestigieuse qu'ils perdirent souvent de vue le côté 
pratique et utilitaire des choses et créèrent d'étranges fantaisies dont le moindre détail vise à être une surprise. On remarque parmi ces fantaisies de curieuses bouteilles à goulot étroit, affectant la forme de nos types 50 ou 59 et contenant à l'intérieur une autre bouteille fixée sur le fond.

A Vermand ( $\mathrm{I}$ ), à Trèves, à Bonn, à Worms, à Cologne (2), on a recueilli quelques-uns de ces produits bizarres qui attestent d'une grande virtuosité, mais témoignent d'un goût assez médiocre.

(I) Voy. J. Prlloy, Eudes sur d'anciens lieux de sépultures dans l'A isne, t. II, pl. IV , n ${ }^{0} 7$.

(2) Voy. AvTon KISA, Das Glas im Altertume, p. 349. 


\section{Les procédés d'ornementation.}

\section{I. - MOULAGE.}

Le soufflage du verre dans des moules plus ou moins ornés est

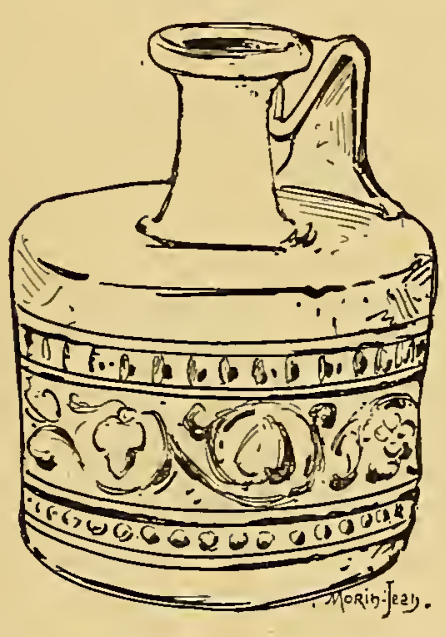

FIG. 247. - BOUTEILLE SOUFFLÉE DANS UN MOULE ORVE. - Musée de Reims, $\mathbf{n}^{\circ} 49+8$.

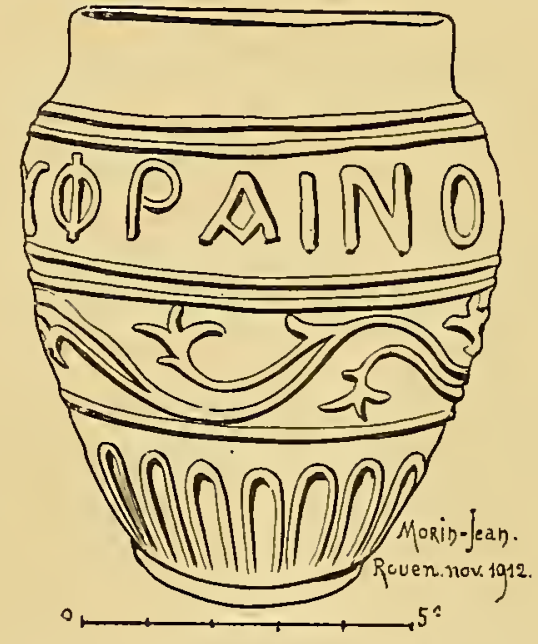

FIG. 248. - GOBELET SOUFFLÉ D.ANS UX MOULE ORxĖ. - Musée départemental d'antiquités, à Rouen.

un procédé auquel les verriers romains ont eu recours depuis le début de l'Empire jusqu'aux invasions du ve siècle.

Au Romain I, les verreries moulées sont exécutées avec soin. Au III e siècle, elles trahissent déjà une technique négligée. Aux $I V^{e}$, ve siècles, l'ouvrier ne se donne plus la peine 
d'imprimer fortement sa pâte dans les moules. Bâclé sans soin, son travail révèle une décadence profonde.

Le procédé du moulage permettait aux verriers antiques 'd'obtenir deux sortes de produits: des verres ornés de bas-reliefs; des verres moulés en ronde-bosse. Il ne sera question ici que des premiers, les seconds ayant fait précédemment l'objet d'un paragraphe spécial sous le titre de verrerie plastique (Voy. p. I48 et suiv.).

Les verres moulés à bas-reliefs sont faits à l'imitation des réci-

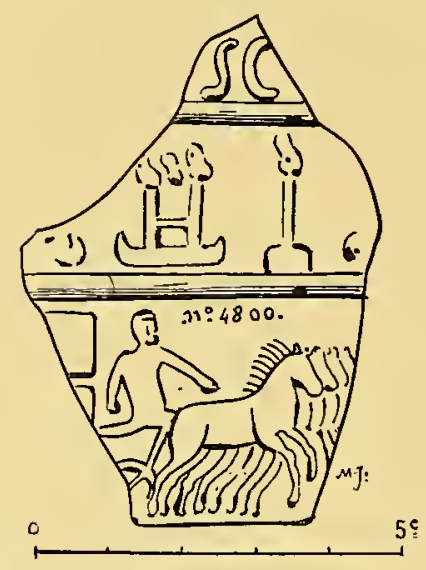

FIG. 249. - FragMent D'UN BOL DE verRe MoulÉ. - Courses de chats. Autun, I855. - Musée de Sèvres, $\mathrm{n}^{\circ} 4800$.

pients de métal ciselé gréco-alexandrins, des bols d'argile dits de Mégare, des poteries sigillées en terre rouge.

Sur les vases d'or et d'argent, sur les récipients de terre cuite et de verre, les mêmes motifs sont figurés. Ces motifs sont de plusieurs sortes. Les uns ont un caractère ornemental (fig. I86, 247 et 248). I,es autres reproduisent des scènes du cirque (fig. 249 et 250) et de 1'amphithéâtre (fig. 25I).

Les verres à courses de chars et à combats de gladiateurs ont presque tous la forme 83. Ils ont été recueillis en France, en Belgique, dans la vallée du Rhin, en Suisse et en Angleterre. Des noms de personnages célèbres de l'arène sont ordinairement disposés dans une zone étroite ménagée à la partie supérieure de ces récipients. 
Ces vases, dont le 110mbre est linité, forment deux séries que j'examinerai successivement. Je laisse de côté les spécimens anglais qui sortent du cadre topograplique de mes recherches.

a. Verres ornés de courses de chars.

I. Autun (Saône-et-I_oire). - Fouille de I855. Fragment d'un bol forme 83 . Quadrige. Inscription dont il ne reste que deuxlettres SC qui paraissent avoir appartenu au nom CRESCES quel'on a pu lire en entier sur d'autres récipients vitreux du même type. Verre bleuverdâtre clair (fig. 249). Musée de Sèvres, $n^{0} 4.800$ (I).

2. Trouvillc-cn-Caux (Seine-Inférieure). - Fouille de ${ }^{8} 5_{5}^{6}$, dans le jardin du château. Bol forme 83. Quatre quadriges. Inscription Bvfycheva-Oinbviva. Au bas de la panse, frise ornée du sujet gréco-oriental de la chasse au lièvre. Sur le fond du récipient, cercles concentriques en relief. Verre verdâtre clair (2). En IS70, ce verre était dans la collection de M. Fleury fils, architecte à Rouen.

3. Charnay (Saône-et-I Ioire). - Fouille de I860. Bol forme 83 . Quatre quadriges au galop. Verre verdâtre clair (3).

En I870, ce verre était dans la collection H. Baudot, à Dijon.

4. Couvin (Belgique). - Fouille de I892. Bol forme 83. Quatre quadriges. Inscription : Pyrame va. Ev CE (VA.) IERAX. VA. Ol yMPE. va. Musée archéologique de Namur (4).

5. Schonecken. - Bol forme 83 (type analogue au bol de Trouvilleen-Caux). Quadriges. Inscription. Firise inférieure ornée de la chasse au lièvre. Cercles concentriques en relief sur le fond. Verre bleuté rempli de bulles d'air (fig. 250). Musée provincial de 'Trèves $\mathrm{n}^{0} 2 \mathrm{I} .008(5)$.

6. Baden (Suisse). - Fouille de I893 (Fragment d'un bol forme 83 ).

(I) Fracrner, La Verrerie antique, p. 67.

(2) Cochet, dans le Bulletin de la Société des Antiquaircs de Normandie, I, I860-I86z, p. I48 et suiv.; I, e même, La Scine-Inférieure historique et archéologique, Paris, I886, p. 227, 228, 395 ; A. DEvILLE, Histoire de l'art de la rerrerie dans l'antiquité, Paris, I\$73, pl. I,I.

(3) D.AUdot, dans les. Mémoires de la Comm. dela Cóte d'Or, VII, p. 204 et fig. ; Le même, dans le Bulletin Monumental de 1870, p. 187 ; FraEnTR, La Verrerie antique, p. 67.

(4) Scmedermans, Verre de course de chars de Convin, dans les Annales de la Socićti archóologique de Namu;, 20, I893, p. I45; AvTov KISA, Das Glas in Altcrume, fig. 279.

(5) Fiihrcr durch das Provinaialmesenin in Tricr, 1903, p. I00; ANTox Krs., Das Glas im Altertume, p. 730 , fig. 282 . 
Quadrige et inscription : CLOSÆ. Verre vert clair très transparent (I). Musée national suisse, à Zurich, $n^{\circ}$ I0.935. (2)

b. Verres ornés de combats de gladiateurs.

I. Le Cormier (commune de Chavagnes-en-Paillers), Vendée.Fouille de I848. Bol forme 83. Inscription: Spicvluvs. Colvmibvs. Cal,amvs. Holes. Petraites. Prvdes. Procvl,vs. Cocvmbvs.

Sous chacun de ces noms est figuré un gladiateur. Verre jaune clair. Bon état de conservation (hauteur: 0,070 m. ; diam. : 0,075 m. ;

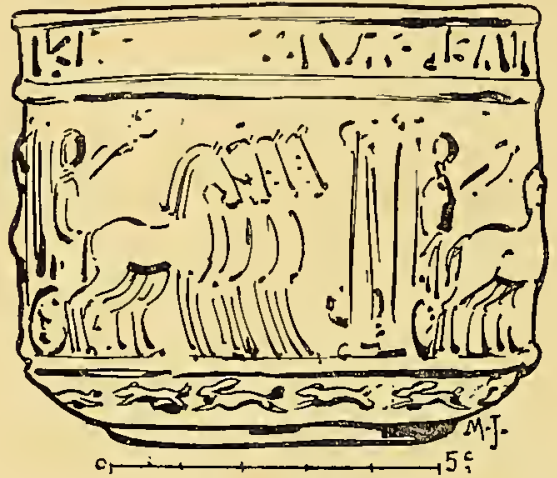

FIG. 250. - BOL DE VERRE MOULÉ. - Courses de chars. Schonecken. - Musée de Trèves. Salle XY, no 21008.

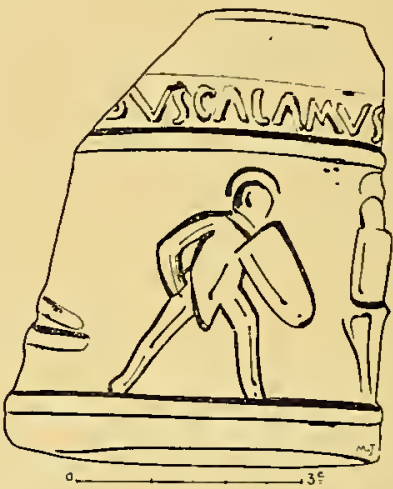

FIG. 25I. 一 FRAGHENT D'UN BOL DE VERRE BLEU.

- Combats de gladiateurs. - Masée de Trèves.

épaisseur moyenne du verre : 0,002 m.) (3). Ce verre a figuré à 1'Exposition de Nantes en I872 (gravé sur une des planches du catalogue). Il faisait alors partie de la collection Gourand à Chavagnes, où il se trouvait encore en 1885 .

2. Montagnole, près Chambéry (Savoie). - Fouille de I 855 . Bol forme 83. Inscription en deux lignes superposées. En haut, noms des vainqueurs: Tetraites. Spicvi,vs. Gamvs. Calamvs. Au-dessous, noms des vaincus : Prvdes. Colvmbvs. Merops. Hermes. Quatre

(1) Dr O. BoHx, Zwei Fragmente römisch Glasbecher, dans 1'Anzeiger für Schweizeriche Altertumskunde (Indicateur d'Antiquités suisses), I903-I904, p. 272-278.

(2) Onpeut rattacher aux verres moulés ornés de scènes du cirque un très petit fragment de vase en verre transparent d'une belle teinte verte, trouvé à Alésia le 4 juillet I90\%. Sur ce fragment, conservé au musée de la Société des sciences de Semur, à AliseSainte-Reine, ou voit uu cheval au galop auprès d'une des bornes (Meta) du cirque.

(3) De la Vildeginde, Bulletin du. Comité de la langue de l'histoire et des arts de la France, 4, 1857, p. 919, pl. II et III; Benj.AmLn Fillon, L'a de terre chez les Poitevins, 186.4, p. r92-I95; Deville, Histoire de l'art de la verrerie, $\mathrm{x} \$ 73, \mathrm{p} .42, \mathrm{pl}$. XIII, A. 
couples de gladiateurs. Verre jaune transparent (hauteur: o,o80; diamètre : o,09o) (I) Metropolitan Museum de New-York (ancienne collection Charvet à Paris).

3. Lillcbonne (Seine-Inférieure).- Fouille de I867. Forme 74 sans bourrelet au pied. Inscription: PeTrahes. Prvdes. Au-dessous, gladiateurs au combat. Terre vert. Très mauvais état de conservation (hauteur: o,oSo $\mathrm{m}$ ). Musée départemental de Rouen (don de M. Montier-Huet) (2).

4. Environs de Berne (Egiswalde). - Fouille de I879. Fragment d'un bol de verre vert orné de deux paires de gladiateurs. Musée historique de Berne, $n^{\circ}$ I $_{3} . S_{32}(3)$.

5. Trèves. - Fouille de I902. Petit fragment d'un bol forme 83 . Inscription IBVs CALAmvs. Au-dessous, gladiateurs au combat. Verre bleu intense (fig. 25I). Musée provincial de Trèves, $\mathrm{n}^{0} 3.436^{\mathrm{b}}$ (4).

6. Heimersheim. - Bol de verre vert clair. Musée de Wiesbaden (5).

Les bols de verre moulé ornés de chars et de gladiateurs reproduisent des sujets empruntés aux ciseleurs, mais que les ciseleurs, eux-mêmes, auraient traités d'après des tableaux ou des bas-reliefs monumentaux.

Les pièces d'orfèvrerie ont été, dans la circonstance, le trait d'union entre le grand art et l'industrie verrière.

L'époque des verres décorés de scènes du cirque et de l'amphithéâtre est difficile à préciser.

Trois des gladiateurs, dont les noms sont rapportés plus haut, Procvuvs, Spicvi,vs et Colvmbvs, sont cités par Suétone (6). L'historien latin $\mathrm{du} \mathrm{II}^{\mathrm{e}}$ siècle les met en scène au temps de Caligula et de

(I) FRuxçOIS LEXORuANT, Vase antique dc verre représentant des combats de gladialenrs, dans la Revue

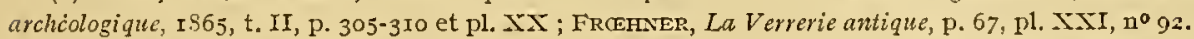

(2) Courricr du Hâve, + juillet I867; Revue archeol., I867, p. I51 ; CochET, Bulletin de la Scine-Inférieurc, I868, p. 40; Le même, Rípertoire archéol. de ta Seine-Inférieure, p. 572 ; A. DEVILIE, loc. cit., I873, pl. II,IX, no 6.

(3) $\mathrm{D}^{\mathrm{r}} \mathrm{O}$. BOHN, Zwei Fragntentc rōmisch Glasbecher, dans l'Anzeiger für Schweizerische Altertumskundi, I903, I904, p. 272-278; A.TTON KISA, loc. cit. p. 739.

(4) Fïltrer durch das Provinzialmuseum in Trier, I903, p. II3 ; ANTOx KISA, loc. cit., p. 737-738.

(5) $\mathrm{D}^{\mathrm{r}} \mathrm{O}$. BoHN, loc. cit. Un fragment de bol de la même série, découvert ell Allemagne, en verre vertclair, orné de gladiateurs combattant et pourvu de l'inscription. Artes. Prvdes. CaL.usvs, est exposé au Cabinet des Antiques, ̀̀ Vienne. Il a été publié par ARxerH, Dic antiken Kancen des $K$. K. Münz und Antiken Kabinettes, pl. XX, 5.

(6) Suétone, Gaius, 60; Nero, 30. 
Néron. Mais les bols portaut les noms de ces personnages peuvent avoir été fabriqués après leur mort, à une époque où le souvenir de leurs exploits était encore très vivace. C'est du moins ce qui semble résulter de l'examen de la pâte vitreuse et du style de ceux qui nous sont passés par les mains.

Le verre de ces récipients, lorsqu'il n'est pas teinté volontairement, est transparent, verdâtre, et contient, comme il arrive souvent au Romain II, de très nombreuses bulles d'air. Les reliefs sont traités

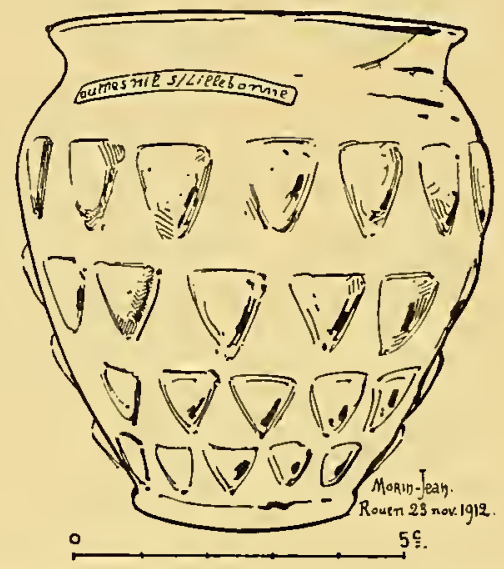

Fig, 252. - GOBELET DE verRe verdatre, souffé dans un monle orné. - Lillebonne Musée de Rouren.

avec négligence. Les chevaux et les personnages offrent des proportions disgracieuses et lourdes. Le moulage est flou.

D'autre part, on est porté à placer ces bols avant le Ive siècle, car ceux de Trouville-en-Caux, de Couvin et de Montagnole ont été recueillis dans des tombes à incinération. Le fragment de Baden était dans un milieu romain dont les monnaies vont jusqu'à Antoninle-Pieux ( $\mathrm{I}_{3} 8$ à I6I). Celui de Berne se trouvait dans des ruines oụ l'on a recueilli des monnaies allant jusqu'à Dèce (249 à 25r).

Les sujets moulés, qu'ils appartiennent aux jeux du cirque ou aux combats qui se livraient dans l'amphithéâtre, se retrouvent et sont traités dans le même style, sur les vases à reliefs d'applique que M. Déchelette est parvenu à dater du $\mathrm{III}^{\mathrm{e}}$ siècle (I).

(I) J. DÉchelETTE, Les vases céramiques omis de la Gaule romaine, t. II, p. 300, fig. I22. 
L'ensemble de ces considérations permet de dire que les bols à scènes du cirque et de l'amphithéâtre, ne sont pas antérieurs au II siècle de notre ère, et ne sont pas postérieurs à la période constantinienne.

Nous croyons que, dans l'état actuel de nos connaissances, il ne serait pas prudent de chercher à resserrer ces dates extrêmes. Peutêtre quelque heureuse trouvaille apportera-t-elle un jour plus de précision dans la solution de ce problème chronologique.

Les verres moulés du Ive siècle et du début du $v^{e}$ diffèrent com-

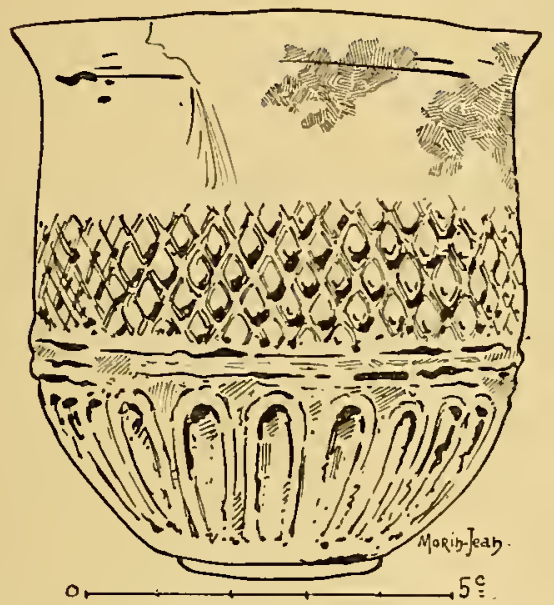

FIG. 253. - VERRE Moulí. - Décor géométrique flou. Ive s. - Musée de Coblence. Vitrine $\mathbf{I V}$, $\mathrm{n}^{\circ} \mathrm{I} 273$.

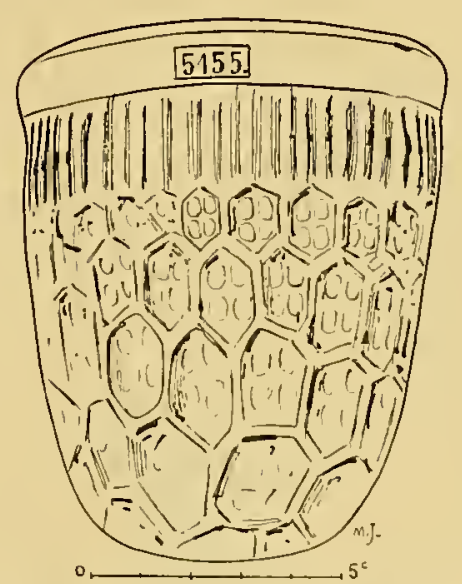

Fí 254. - VERRE MIOULÉ DE LA SECONDE MOITIÉ De Ive s. - Boulogne. Fouilles de I896. - Musée de Boulogne-sur-Mer, $\mathfrak{1}^{\circ} 5155$.

plètement de ceux des époques antérieures. Ils se reconnaissent à la négligence du travail. Leur décor, toujours très flou, consiste le plus souvent, en combinaisons géométriques (fig. 253 et 254).

On connaît de la fin du IV siècle ou des premières années du ve des verres moulés ornés du monogramme du Christ.

\section{2. - DÉCOR PAR DÉPRESSIONS.}

Le décor par dépressions ne constitue pas l'ornementation caractéristique d'une époque déterminée. On le trouve appliqué à toutes sortes de formes depuis le commencement jusqu'à la fin de la période 
romaine. Il n'était pas obtenu par moulage.Les dépressions étaient faites à l'aide d'un outil de métal pendant que le verre était malléable.

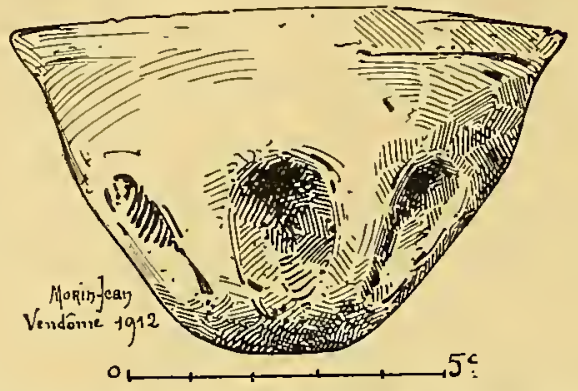

Fig. 255. - Bol EN verre verdatre orné DE DÉpRessions. - Pezou (Loir-et-Cher). Ive s. - Musée de Vendôme.

Elles sont plus ou moins profondes, tantôt rondes (fig. 255), tantôt allongées verticalement (fig. 257 et 258 ).

Une ornementation analogue, dont les verriers se sont sans doute inspirés, se voit souvent sur les poteries et sur les récipients métal-

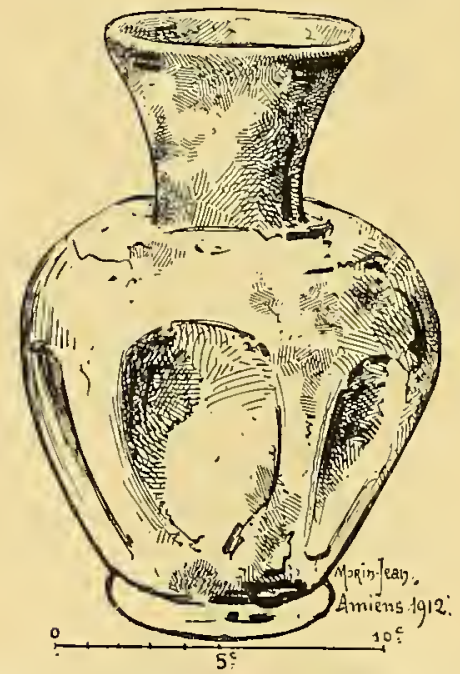

FIG. 256. - BOUTEILlE A DÉPRESSIONS, VERRE VERDATRE. - Romain II lardif. - Musée de Picardie, à Amiens.

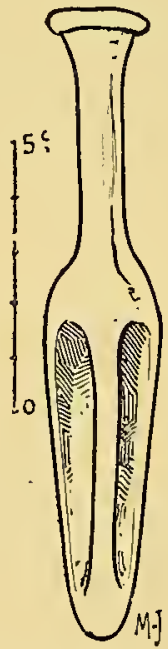

Fig. 257. - FIOLE ORNÉE DE DÉPRESSIONS. Masée de Picardie, à Amiens.

liques. Les céramistes 1'obtenaient en travaillant 1'argile au pouce avant la cuisson et les orfèvres en martelant le métal. 


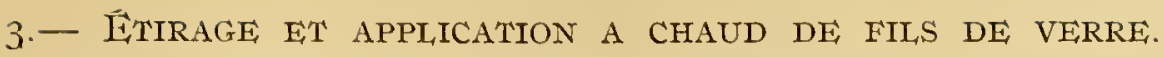

Le procédé de décoration qui consiste à étirer et à appliquer à chatud, sur la surface des verreries, des fils de verre plus ou moins gros, incolores ou diversement teintés, est d'origine orientale. Il apparait

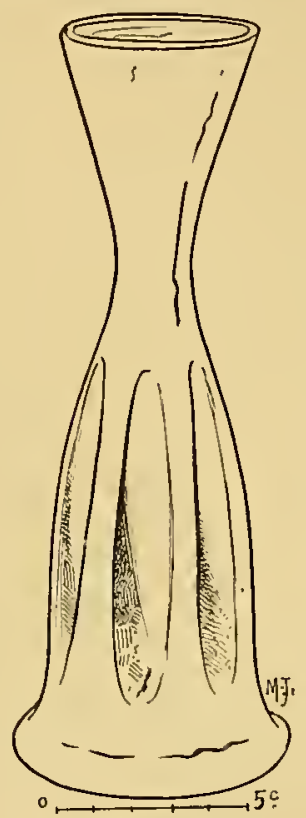

Fig. 258. - Itole a dépressions allosgées. - Cimetière de Mayence. Ive s. - Musée de Mayence.

peut-être, en Gaule, dès la fin du $\mathrm{II}^{\mathrm{e}}$ siècle, mais ne s'y développe vraiment que pendant le $\mathrm{II}^{\mathrm{e}}$ et le $\mathrm{IV}^{\mathrm{e}} \mathrm{S}$. (I).

L'époque oì les verriers passèrent maîtres en cet art est celle des empereurs syriens. Les plus beaux verres à fils en relief ont été découverts en Gaule Belgo-rhénane dans des tombes à ustion datant du règne d'Alexandre Sévère $(222$ à 235$)$ ou à peu près. Tous

(I) L.es Romains ont employé le procídé d'étirage à chaud de fils de verre, pour orner de côtes cu relief certains récipients. Il importe en ce cas de ne pas confonüre ce procédé avec celui du souffiage au moule. Les côtes de eertaines urnes forme 5 du tableau de morphologie gẻnẻrale, sont faites à l'aide de fils te verre qui, en s'incorporant à la pâte du récipient, ont refonlé celle-ci à l'intéricur rlu vase. C'est pourquoi ces côtes fout saillie à la fois en dedans et en delors (rọ̃. fig. 5, $\mathbf{u}^{\circ} 5$ ), ce qui ne se présente pas daus la technique du moulage. 
offrent des particularités d'ornementation très originales qui attestent la grande habileté technique des verriers qui les ont créés. Au IV $V^{e}$ siècle, les ouvriers ont la main plus lourde que leurs prédécesseurs,

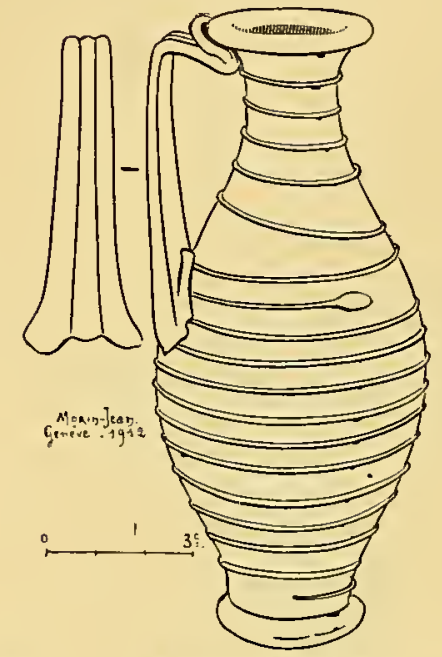

FIG. 259. - BOUTEILlE ORTÉE D'UN FIL DE VERRE DISPOSÉ EN SPIRALE. - Crêts de Pressy. - Musée de Genève (Suisse).

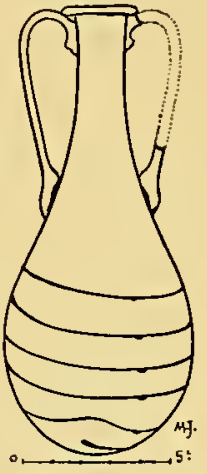

Fíg. 260. - Bouteille DE VERRE BLEU. - Anses en verTe vert-clair. - Musée de Trèves. Salle XX. Vitrine IX, $\mathbf{n}^{0} \mathrm{I}_{455}$.

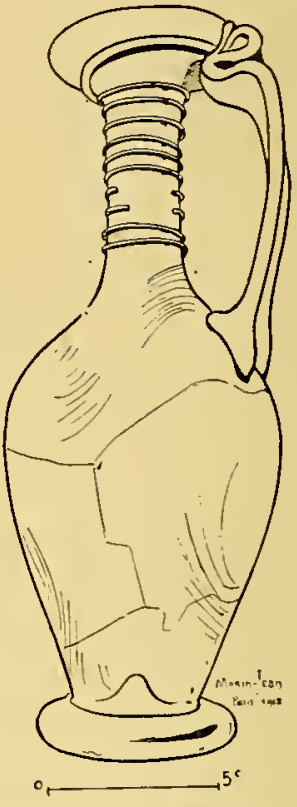

FIG. 26I. - BOUTEILLE EN VERRE VERDATRE. - Paris. Cimetière du faubourg SaintJacques. IV ${ }^{\mathrm{e}}$ s. - Musée Carnavalet.

mais nous verrons qu'ils s'exerçaient encore à couvrir de fils de verre la panse de maints récipients.

Je propose de répartir toute la série de ces curieux produits en cinq variétés principales.

A. Verres à spirales. - Un grand nombre de verteries du Romain II sont ornées de fils de verre qui s'enroulent en spirales autour. de leur panse ou de leur col (fig. 259 à 26r). Ces fils, quelquefois assez gros, souvent aussi d'une finesse, d'une ténuité remarquables (fig.26o), s'étendent sur le vase tout entier (fig. 259), ou n'en couvrent que certaines parties (fig. 260, 26I). Lorsqu'ils n'ont été appliqués que sur le goulot, ils apparaissent comme l'imitation, comme la survivance décorative des liens qui retenaient le bonchon du récipient. 
B. Verres ornés de résilles. - I.orsque les fils de verre se croisent, le décor prend l'aspect d'une résille. Il semble avoir été inspiré par ces filets de matière textile dont on enveloppait certains vases pour les garantir ou les porter.

Sur un grand gobelet tronconique en verre verdâtre découvert

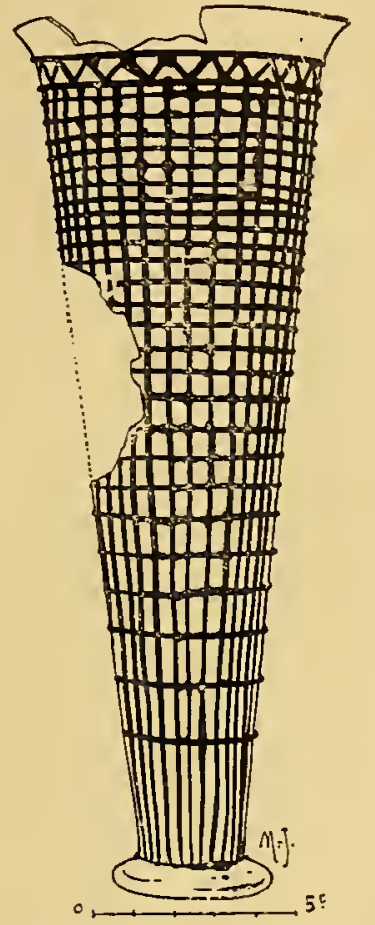

Fig. $262 .-$ Gobelet en verRe JaUNe-verdatre, orné d'une résille de verre brun. - Fouilles de Mayen, - Ives. - Musée de Nuremberg.

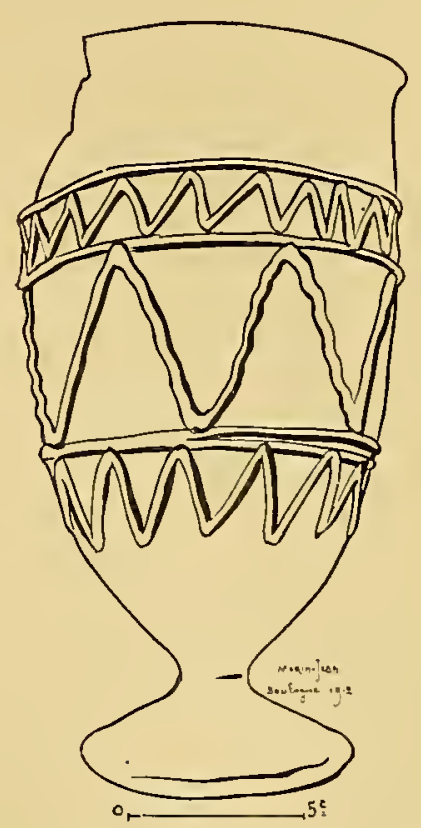

FIG, 263. - VERRE A PIED DU IV ${ }^{\circ}$ s. - Neufchâtel (Pas-de-Calais). Fouilles de 1848 . - Musée de Bonlogne-sur-Mer, $\mathrm{nt}^{\circ} 2506$.

à Mayen et conservé au Musée germanique de Nuremberg, des filets verticaux et horizontaux de teinte or brun forment un treillis régulier (fig. 262). Sur un verre à pied du musée de Boulogne-surMer, le dessin est plus compliqué, mais reste toujours anguleux (fig. 263).

Fréquemment, le treillis est constitué par un réseau de mailles arrondies qui ne résulte pas du croisement des fils, mais d'une ingé- 
nieuse disposition de lignes qui se touchent alternativement aux partis convexes et concaves (fig. 264).

En élargissant inégalement le fil qui forme les mailles, en l'aplatissant sur certains points de manière à le fondre dans la pâte du récipient, en lui donnant ici et là un très haut relief, les verriers du III et $d u I V$ siècles ont créé une décoration savante et rationnelle qui

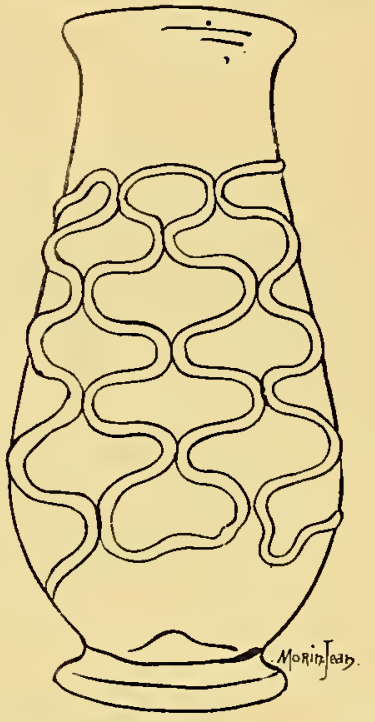

FIG. 264. - VERRE ORNÉ D'UNE RÉSILLE. - La Fortelle (Oise). - Musèe de Saint-Germain.

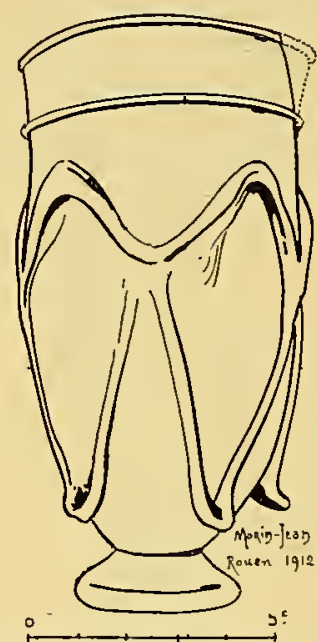

FIG. 265. - VERRE A PIEd, trouvé à Thiétreviile, en 1842 . - Romain II. - Musée de Rouen.

leur permettait de répartir habilement les accents lumineux à la surface du vase (fig. 265 et 266).

C. Verres à décor ondé. - Ici, les fils de verre ne se croisent plus; ils jaillissent de parties saillantes, de gouttes plus ou moins volumineuses (fig. 267) ; ils décrivent des courbes d'une rare élégance, forment des guirlandes et des festons (fig. 268, 269). A la fin de la période romaine, ces festons dégénèrent en imbrications dites plumes d'oiseau (I) (fig. 270). A l'époque des Invasions, le décor en plumes d'oiseau n'est plus établi avec des fils étirés et appliqués à chaud. Il est peint en blanc opaque sur un verre verdâtre ou jaunâtre. Les ver-

(I) L es ormements en plumes d'oiseau sont fréquents sur les verres francs du ve et du vi siècles [roy. Boulanger, Le Mobilier funéraire,"pl. 3 I, no I et 4 ]. 
riers reviennent insensiblement, par des procédés différents, aux ornements des balsamaires en verre opaque des temps archaïques.

D. Verres à applications vermiculaires (Fils serpentants) (I). Les applications vermiculaires trahissent une origine gréco-orientale. Elles ont beaucoup d'analogie avec les ornements blancs crémeux des vases peints de la série apulienne, dite de Gnathia. Elles reprennent avec plus ou moins de fidélité les rinceaux, les feuilles, les vrilles ciselés sur les pièces d'orfèvrerie alexandrine ou reproduits par le procédé du moulage sur les bols d'Arezzo, de la Graufesenque et de Lezoux. Quelques-unes d'entre elles sont des survivances de motifs extrême-

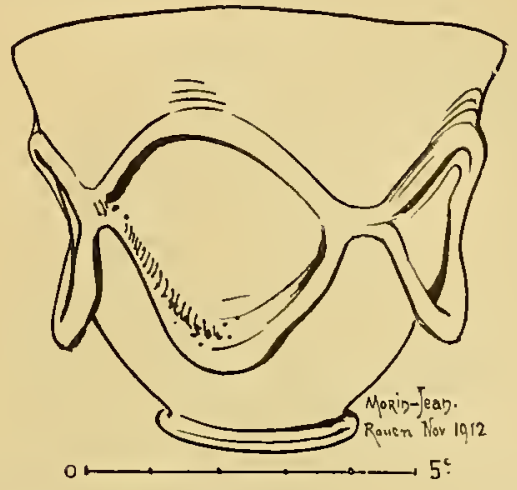

FIG. 266. - BOL A PIED trouvé dans le département de l'Eure. - Verre incolore. Romain II. - Mrusée de Rowen.

ment anciens comme le swastika (2) (fig. $27 \mathrm{I}, \mathrm{n}^{0}$ 6) et la double volute (fig. $27 \mathrm{I}, \mathrm{n}^{0} 7$ ).

D'autres figurent des animaux (oiseaux, serpents). Sur un flacon représentant un casque de gladiateur [forme I39] ayant fait autrefois partie de la collection Disch à Cologne, le fil décrit les contours de deux pigeons becquetant des baies (3). Ces volatiles sont fort bien faits. L'ouvrier qui les a tracés devait avoir une sûreté de main absolue, car il était obligé de se hâter dans son travail, et toute reprise lui était interdite.

(I) Schlangenfaden des archéologues allemands.

(2) Sur le swastika aux temps préhistoriques, consulter Joseph DÉcheLETTE, Hantel d'Areliéologic réhistorique, celtique et gallo-romaine, t. II, chap. IIII, § TI, p. 453-464.

(3) Axton KIss, Das Glas im Altertume, fig. 125 et p. $+5 \mathrm{I}$. 
Les verres à applications vermiculaires découverts en Gaule proviennent pour la plupart des nécropoles nordiques. Ils se divisent en deux séries qui se suivent chronologiquement.

a. Ceux de la première série, plus abondants dans les vallées du Rhin et de la Moselle que sur les autres points du territoire gaulois, étaient en vogue à une période comprise entre l'époque de Septime Sévère (I93 à 2II) et celle d'Aurélien (270 à 275). A Cologne, on en a recueilli plusieurs dans des cuves de pierre à com-

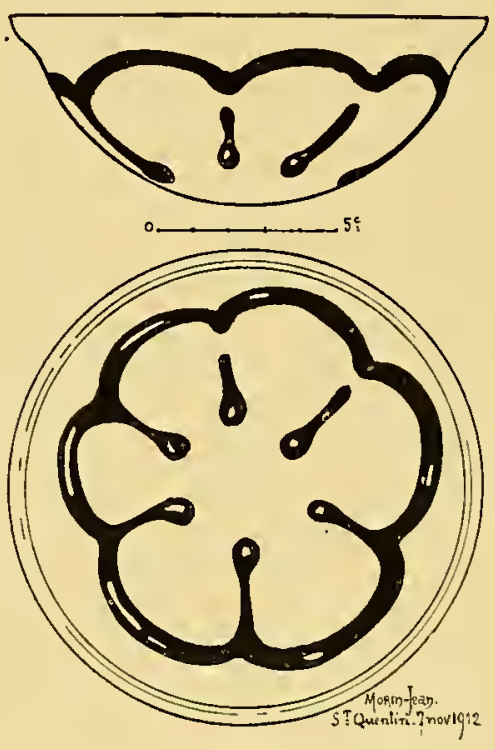

FIG. 267. - COUPE DE vERRE INCOLORE. - Décor vert foncé. Vermand. IV s. - Musée Lécuyer, à SaintQuentin, $n^{\circ} 2628$.

partiments qui renferment des incinérations tardives et constituent, comme le dit Kisa (I), une transition des tombes à urnes aux tombes à sarcophages. Par contre, les grands cimetières à inhumations du nord de la France, qui ne furent créés que dans les dernières années du Irre siècle, n'en contiennent pas.

Les verres à fils serpentants du $\mathrm{mI}^{\mathrm{e}}$ siècle ont un caractère très particulier qui permet de les reconnaître à première vue. Ils sont en pâte incolore, débarrassée des teintes données par les oxydes de fer 


$$
\text { do }
$$



contenus dans les sables; ils sont décomposés pour la plupart et ont pris l'aspect du verre dépoli. I,es applications vermiculaires dont ils sont décorés sont striées transversalement au petit fer. Elles sont - tantôt incolores, tantôt teintées en blanc opaque, en bleu pâle, en

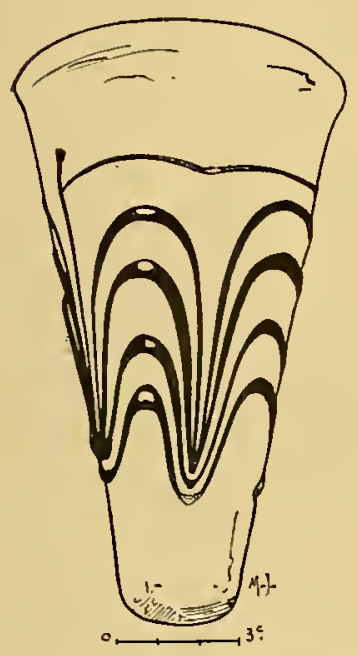

FIG. 268. - GOBELET DE VERRE VERT-JALAATRE.-DéCor jaunebrun. $\mathrm{IV}^{\mathrm{re}}$ ou $\mathrm{v}^{\mathrm{e}} \mathrm{s} .-$ Cabinet des Médailles, à Paris, $\mathrm{n}^{0} 5+59$.

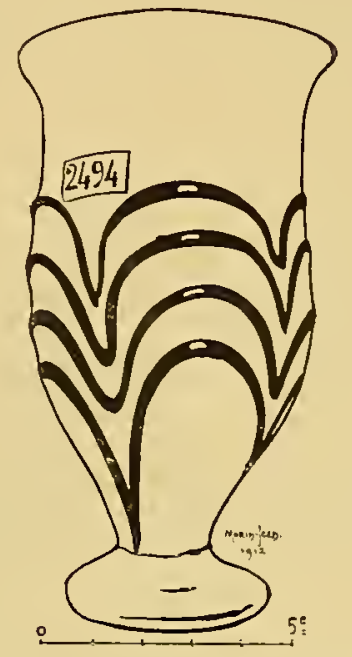

FIG. 269. - TERRE A PIED, ornẻ de festons bleu-verdâtre. Fouilles du Boulonnais. Ives. - Musie de Bonlogne-surHer, $\mathrm{nI}^{\circ} 2494$.

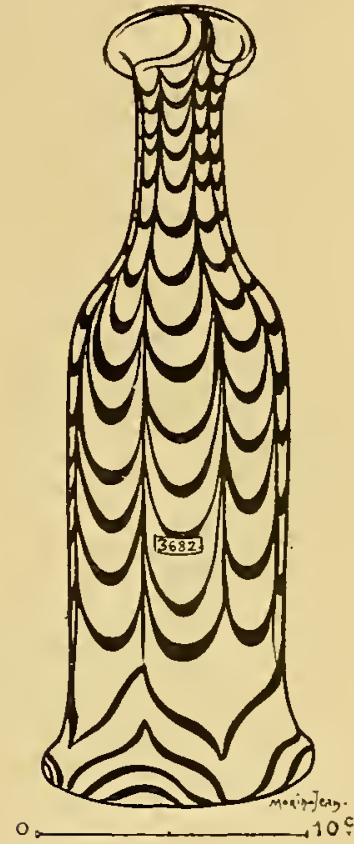

FIG. 270. - Bouteille A FOND BULBEUx. - Décor en plumes d'oisear. Fouilles à Sainte-Geneviève, en I823. $\mathrm{V}^{\mathrm{e}} \mathrm{s}$. - Musie de Sivres, $\mathrm{n}^{\circ} 3682$.

jaune clair, ou bien elles sont dorées. Elles affectent des formes diverses dont la fig. 27I montre les principales variétés. Ce sont des pampres, des motifs capricieux d'un style caractéristique (fig. 27I, $\mathrm{n}^{\text {os }} 4$ et 5 ), des feuilles cordiformes ( $\left.\mathrm{n}^{\circ} 8\right)$, de longues palmes ou feuilles à nombreuses échancrures $\left(n^{0} 9\right)$, des swastikas $\left(n^{\circ} 6\right)$, des doubles volutes $\left(n^{\circ} 7\right)$.

I.es récipients ornés d'applications vermiculaires appartiennent pour la plupart aux formes $9,43,5 I, 54,62,64,65,89,98$, I36, I37, I39 de notre tableau de morphologie générale. Le nombre de ceux 
qui ont été découverts en Gaule est trop élevé pour songer à en dresser une liste complète. Je me bornerai à signaler les plus intéressants d'entre eux :

I. - Ginochoé trouvée dans une tombe à incinération à CortilNoirmont (Brabart) et conservée au musée du Cinquantenaire, à Bruxelles (I) (fig. 272).

Ce verre est en pâte incolore de bonne qualité, devenue légèrement laiteuse sous l'action du temps. Son anse est pourvue d'une petite plaquette destinée à recevoir le pouce lorsqu'on incline le vase pour en verser le contenu. Son embouchure est bordée d'un

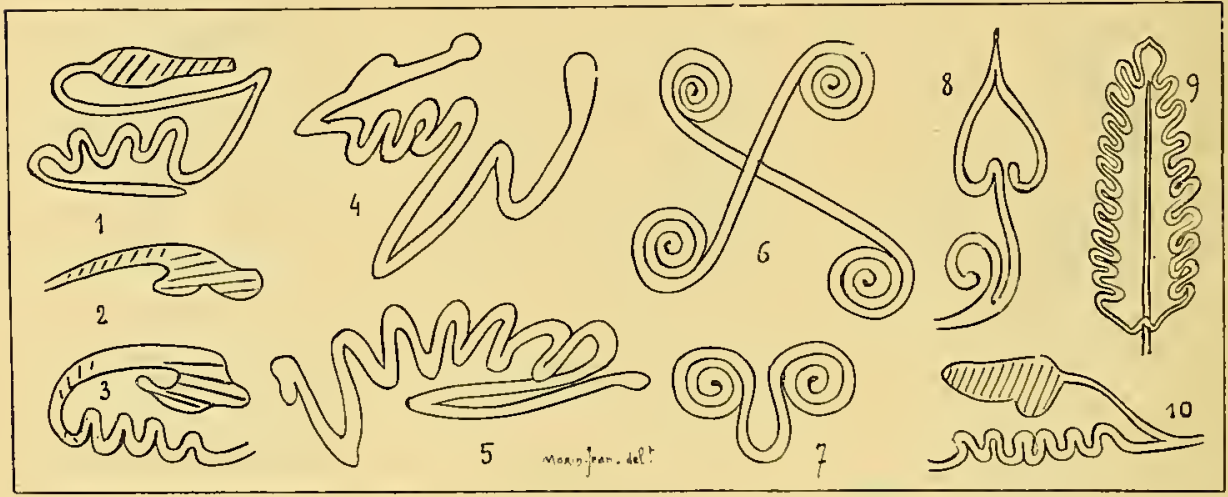

Fíg. 27I. - Applications vermicularres (fils serpentants). - Motifs divers du mie s. - 1, 2, 3, 4, 6, 8, 9, ro, Cologne; 5, Rounen; 7 , Bonn.

fil blanc opaque. Son col est entouré d'une fine spirale de même couleur. Sa panse est ornée d'un motif qui se répète quatre fois. On y remarque des palmes ( $n^{\circ} 9$, fig. $27 \mathrm{I}$ ) dont les contours échancrés sont indiqués par des fils incolores et dont la nervure est formée d'un fil blanc opaque. Ces palmes sont insérées sur une tige ondulée en verre opaque bleu ciel. Un filet assez gros entoure le bas de la panse, un peu au-dessus du pied du récipient.

L'auteur de cette charmante œenochoé a signé son œuvre. Il a tracé sur le fond, à l'aide du fil qui constitue le procédé technique

(r) Publiée par R. Petrdcci, Sur deux vases de verre antique, dans le Bulletin des Musćes royaur. des Ants décoratifs et industriels, troisième année, $\mathrm{n}^{0} 4$, janvier $\mathrm{I} 904, \mathrm{p} .27$ ). 
de toute sa décoration, une spirale entourée de lignes rayonnantes (I). Les archéologues belges voient dans ce sigle une image solaire et une marque de fabrique essentiellement orientale. Anton Kisa croit y reconnaitre, a11 contraire, $11 n$ monogramme employé dans les ateliers rhénans (2). Quoi qu'il en soit de son origine, l'œnochoé de CortilNoirmont est sortie d'une officine où les ouvriers avaient acquis une habileté technique tout à fait remarquable. La sépulture où on

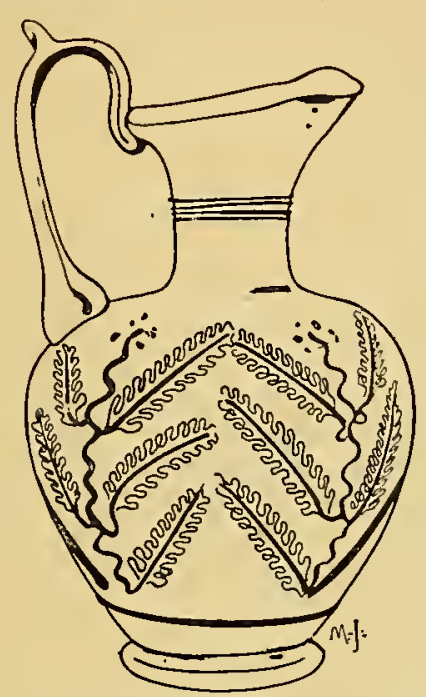

FIG. 272. - CEXOCHOÉ DE CORTIL-NOIRMONT. Musée du Cinquantenaire, à Bruxelles (Belgique).

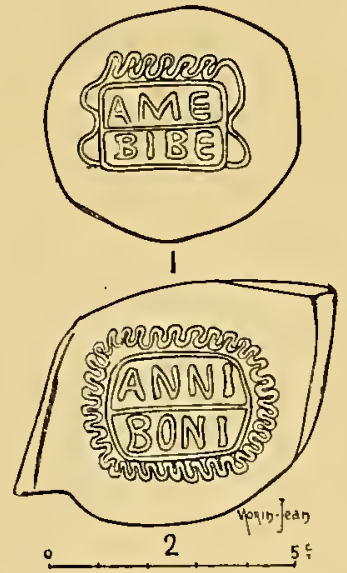

FIG. 273. - INSCRIPTIONS EN FIL DE VERRE DORE. - Palais des Beaux-Arts de la Ville de Paris, $\mathrm{n}^{\circ} 233$ et 234 .

l'avait déposée renfermait des monnaies de Marc-Aurèle et d'Antoninle-Pieux.

Kisa, en la datant de la seconde moitié du $\mathrm{II}^{\mathrm{e}}$ siècle, a été entraîné, croyons-nous, à une conclusion chronologique erronée. La tombe de Cortil-Noirmont appartient au groupe d'incinérations tardives qui,

(r) On connaît aussi des inscriptions completes tracées en fils de verre sur le fond ou sur la panse dequelques récipients du Romain II. Ce sont le pius souvent des souhaits adressés au buveur, disposés daus un cartonche entouré d'un fil décrivant des sinuosités. Ces inscriptions, pour la plupart dorées, sont, presque toujours, recouvertes d'une ćpaisse couche de verre transparent. Citons quelques-imes d'entre elles: SALvo. IA. Tvraso, sur un fragment de bouteille du muséc de Cologne (Bors, Corpus inscriplionum latinarum,

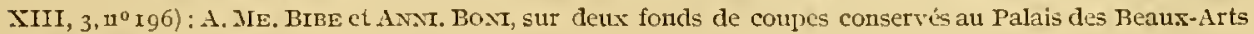
de la Ville de Patis ( $1^{08} 233$ et 234 ) (fig. 273) [Corpus inscriptionum latinxum. XV, 7055].

(2) A.vTox KIsA, loc. cit., p. 452. 
bien que contenant des monnaies ne dépassant pas le règne de Commode, sont du III siècle de notre ère. Il y a eu en Gaule, après Commode, une période d'une cinquantaine d'années environ pendant laquelle les monnaies alors en cours n'ont été que très rarement déposées dans les sépultures. Nous ne pensons pas qu'il soit possible de séparer l'œnochoé de Cortil-Noirmont d'un groupe homo-

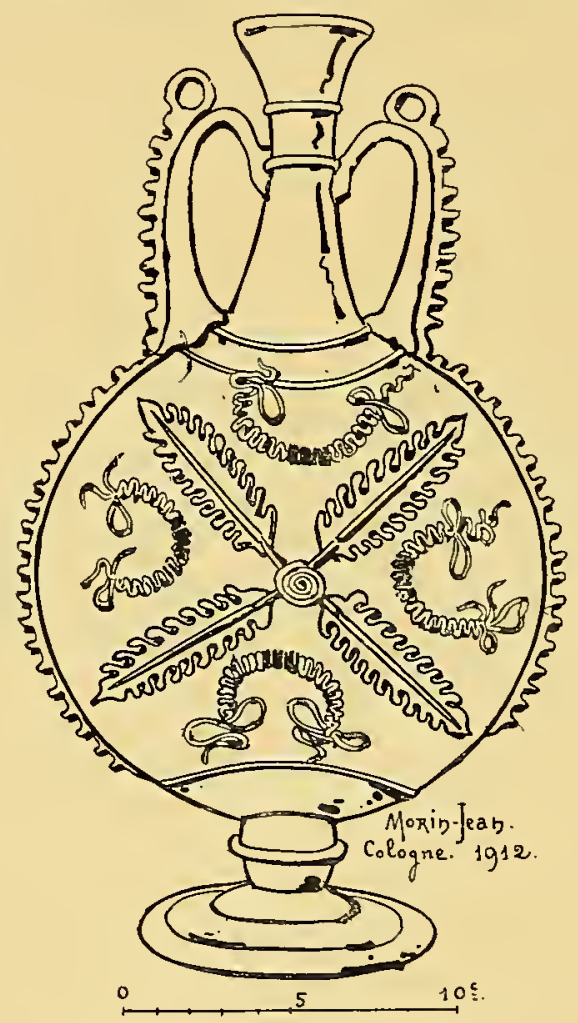

Fig. 274. - Bouteille a P.ANSe aplatie. - Cologne. Cimetière de la rue de_Luxembourg. - Musée Wallraf-Richartz, à Cologne, $\mathrm{n}^{0} 54 \mathrm{x}$.

gène de verreries dont les plus anciens représentants n'apparaissent pas avant la fin du règne de Septime Sévère.

2. - Bouteille à deux anses et à panse aplatie, découverte dans une tombe de la rue de Luxembourg à Cologne et conservée au musée Wallraf-Richartz (I) (fig. 274).

(r) Publiée dans les Bonner Jahrbücher, fasc. no 99, I 896, p. 50-53 et pl. II, no 5 . 
Ce vase, cassé en plusieurs morceaux, mais habilement remonté, est de style oriental dans sa forme et dans son décor. Il est en verre incolore impur, filandreux. Ses anses, curieusement appendiculées appartiennent au type $\delta^{3}$ de la pl. 3, p. 37, type qui n'est pas antérieur au IIr siècle. Son pied a une forme caractéristique du Romain II (type 2I, fig. 9).

Sa panse est ornée, des deux côtés, du même motif. Ce motif, consiste en une spirale d'où partent quatre feuilles à échancrures

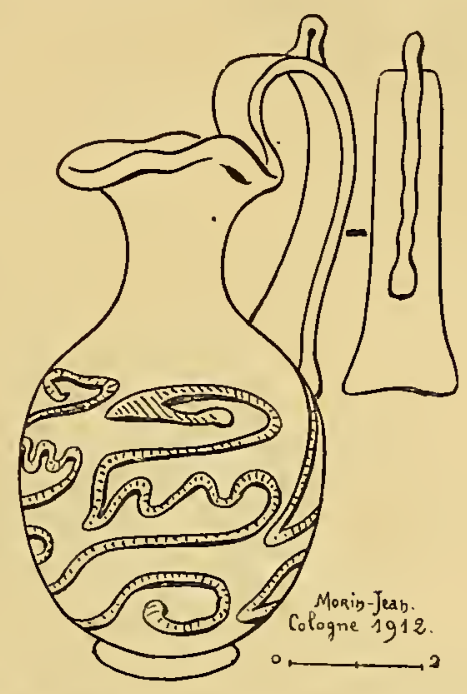

Fig. 275. - Génochó a applications verniculatres. Première mo:tié du III ${ }^{\mathrm{s}}$ s. - Cologne. Mirsée Wallraf-Richartz, $\mathrm{n}^{\circ} 668$.

semblables à celles de l'œnochoé de Cortil-Noirmont. La spirale et la dentelure des feuilles sont dorées.

Dans les espaces restés libres entre les palmes se trouvent des guirlandes semi-circulaires, en fil polychromé, terminées par des nœuds de fil blanc gracieusement contourné.

L,e vase de Cologne faisait partie d'un riche mobilier funéraire qui contenait un vase de verre du même type réduit en miettes, des plaquettes de bronze ayant fait partie de la garniture d'un coffret, une verrerie plastique en forme de porc décrite plus haut (p. I60, fig. 2I3) et figurée au tableau de morphologie générale $\left(n^{0}\right.$ I25). 
Ce mobilier indique une époque peu éloignée du règne d'Alexandre Sévère.

D'après Kisa, des bouteilles semblables à celle de Cologne et pourvues de la même ornementation, ont été découvertes à Krefeld (pièce du South-Kensington-Museum) et à Strasbourg (spécimen fragmenté) (I).

3.-CEnochoé forme 54. Musée Wallraf-Richartz, à Cologne (fig. 275).

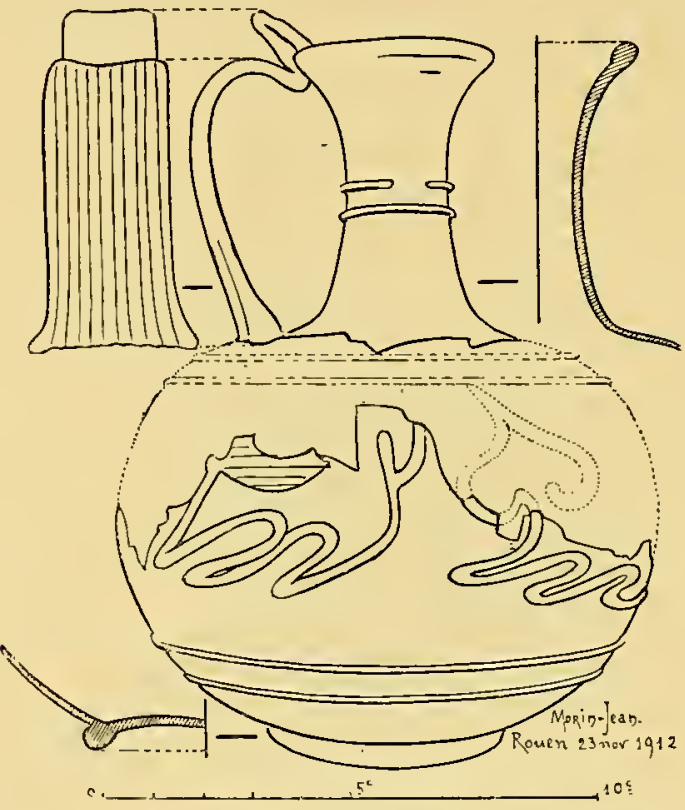

Fig. 276. - Bouteille a applications veruiculatres. - Cimetiète de Cany (Seine-Inférieure). Fouilles

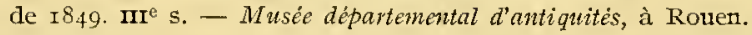

Les œnochoés de ce type sont ornées d'applications vermiculaires alternativement bleues et blanches. Elles ont une anse plate agrémentée d'un filet bleu formant poucier à la partie supérieure. Trois de ces élégantes verreries ont été recueillies à Cologne [Cimetière de la rue de Luxembourg. Sépultures à ustion $n^{0 s} 38$, 40 et 42] (2). Elles étaient placées dans une soucoupe. Cette soucoupe, décorée, elle aussi, d'applications vermiculaires, affecte tantôt la forme 89 , tantôt la forme I37 (patère à manche).

(I) ANTTON KISA, loc. cit, D. 454.

(2) Voy. plus haut, P. II 3 , note $I$. 
4. - Carafe forme 5I, cécouverte en I849 par l'abbé Cochet, au cimetière de Cany (Seine-Inférieure) et conservée au musée départemental d'Antiquités à Rouen (I) (fig. 276). Pièce brisée et recollée. Verre incolore décomposé. Embouchure évasée. L'anse, en forme de ruban plat à cannelures verticales, est repliée deux fois sur ellemêne à la partie supérieure où elle forme poucier. Les applications vermiculaires de la panse sont en émail alternativement blanc et jaune.

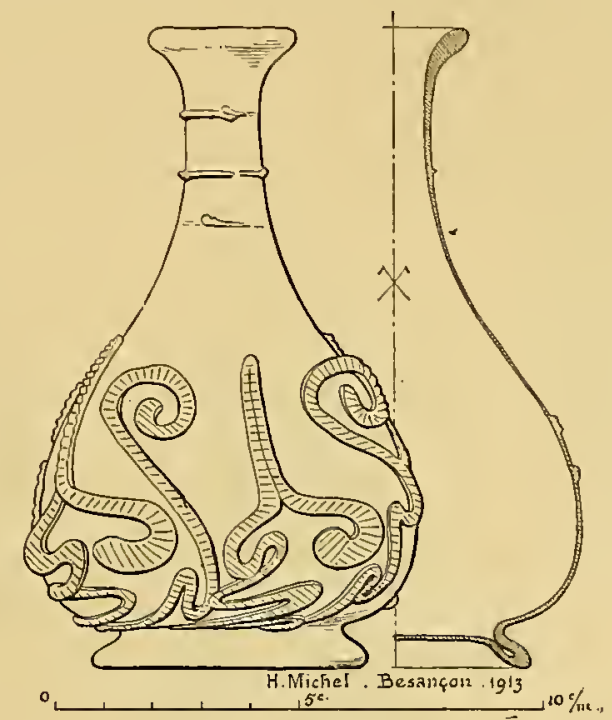

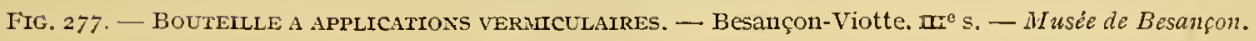

Au-dessous du vase, on voit très nettement la cassure du scellement vitreux qui fixait la bouteille au pontil du tourneur.

Cette intéressante carafe est du $\mathrm{III}^{\mathrm{e}}$ siècle. C'est l'époque à laquelle remontent la plupart des tombes à incinération du cimetière de Cany. Plusieurs de ces tombes contenaient des monnaies de Philippe l'Arabe (mort en 249) et de Valérien (253 à 260).

A Cany comme à Gels.dorf (près Meckenheim) (2), les verres à applications vermiculaires sont associés aux flacons prismatiques à long col forme Ig.

(I) Publiée par l'Abbé Cochet, dans La Seine-Intérieure historique et arehéologique, Paris, r866, 1) 448 et suiv.

(2) Anton Kisa, Das Glas in .Allertume, p. $45^{8}$. 
5. - Bouteille forme 62, recueillie à Besançon, au cimetière de la Viotte (I). Musée de Besançon (fig. 277) (2).

Cette pièce, malheureusement détériorée sur 1'une de ses faces, est en verre incolore et présente quelques légères irisations. On remarquera combien ses parois sont minces (8/10 de millimètre vers
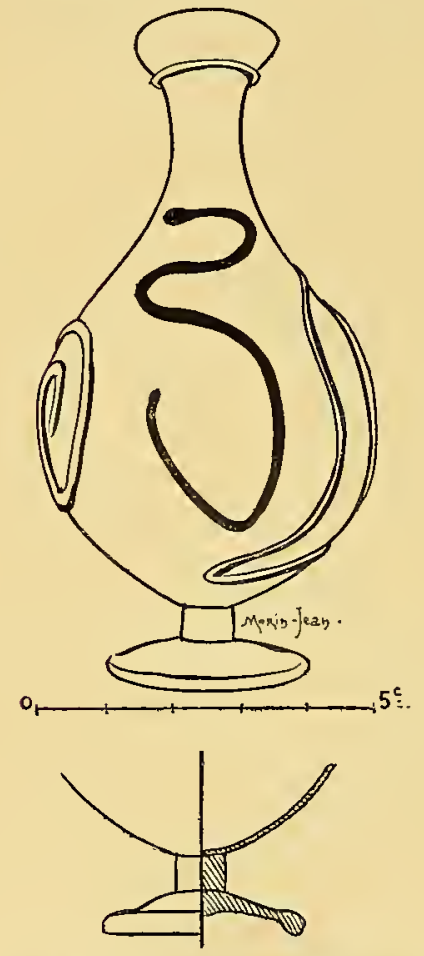

FIG. 278. - FLACON A APPLICATIONS VERMTCULATRES. - Vieil-Atre (I893). $\mathrm{uI}^{\mathrm{e}} \mathrm{s} .-$ Musée de Boulogne-sur-Mer, $\mathrm{n}^{0} 4556$.

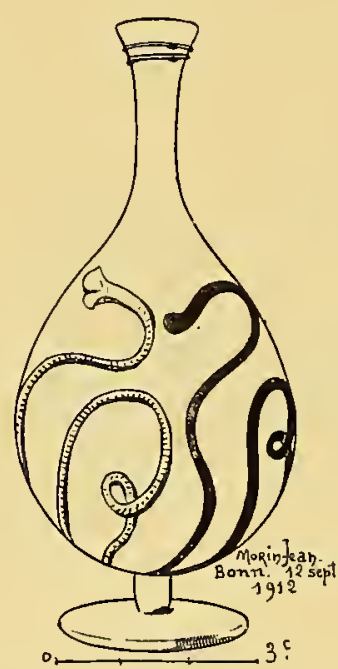

FIG. 279. - FLACON A APPLICATIONS VERMICULAIRES EN ENILIL BLANC ET BLEU PALE. $\mathrm{III}^{\mathrm{e}}$ s. - Musée provincial de Bonn. Salle V.

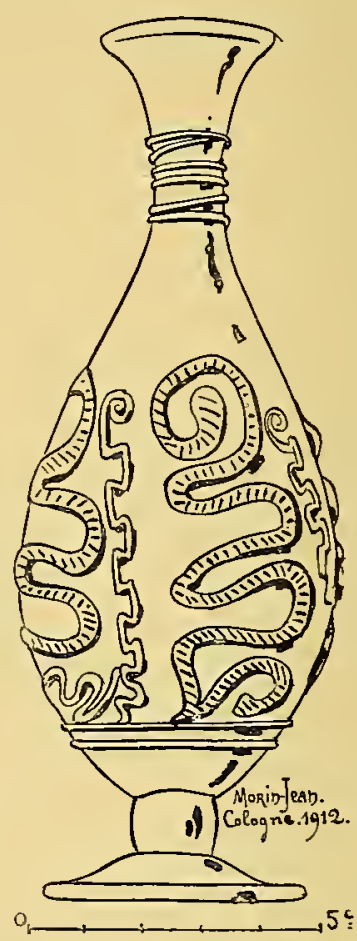

FIG. 280 . - LECYTHE ORIÉ D'APPLICATIONS VERMIICULAIRES BLEOES, BLANCHES ET JAUNES. - Romain II. - Musee WallrafRichartz, à Cologne.

le milieu de la panse). Les applications vermiculaires, striées au fer, reproduisent alternativement des crosses et des feuilles cordi-

(I) Publiće par VaIssier, Le Cimetière gallo-romain de la Viotte, à Besançon. Dans les Mćmoires de la Société d'Emulation du Doubs, I885, p. 405-4I3. Avec planche. (C'est par erreur que Vaissier donne à cet objet une couleur verdâtre.)

(2) Les figures 277 et $28 \mathrm{r}$ sout dues à M. MIcheL, conservateur du Musée archéologique de Besançon, qui a bien voulu les exécuter pour moi d'après les originaux de son musée. C'est avec plaisir que je publie ces relevés d'une exactitude rigoureuse et que je renouvelle à leur auteur l'expression de ma sincère gratitude. 
formes (I). Ces feuilles sont établies dans des proportions observées surtout à partir du $\mathrm{III}^{\mathrm{e}}$ siècle : leur pointe s'allonge démesurément et leurs lobes s'aplatissent.

Les vases d'argile à reliefs d'applique et les poteries noires à ornements blancs du Romain II sont souvent décorés de feuilles présentant ces caractères. Je daterais volontiers cette élégante verrerie de la même époque que ses congénères de la vallée du Rhin (2), c'est-à-dire du temps d'Héliogobale et d'Alexandre Sévère. L,e cimetière à incinérations d'où elle provient contenait d'ailleurs une monnaie du dernier de ces empereurs.

6. - Fiole sans anse, forme 64 , découverte en 1893 , dans un éboule-

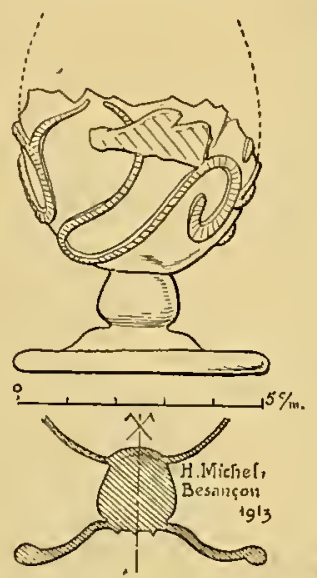

Fig. 281. - Fragient de verrerte a Applications vermiculatres. - Cimetière à incinérations de la Viotte (Besançon). - Musée de Besançon.

ment au cimetière du Vieil-Atre, à Boulogne-sur-Mer (Fouilles de M. Inamy). Musée archéologique de Boulogne, $n^{0} 4.556$ (fig. 278). Verre incolore. I es fils appliqués sont en émail alternativement blanc et bleu pâle. Une bouteille semblable, dont le verre, admirablement conservé, a gardé sa pureté et sa transparence, fait partie des riches collections du Musée Provincial de Bonn (fig. 279). Des fioles du même genre, mais dont le pied est un peu différent, ont été recueillies

(1) Des feuilles cordiformes entrent dans l'orncmentation d'une verreric forme 5 I trouvće à cléré (Maine-et-Iroire) dans une sépulture assez tardive [roy. B. FILION, L'art de terre chez les Poitevins, p. I92, $\mathrm{u}^{\circ} 9 \mathrm{j}$.

(2) Bonner Jahrbïchcr, I906, fase, II4-II5, 1. 344-378 et pl. XXIV. 
à Cologne (fig. 280) et à Besançon (Cimetière de la Viotte) (fig. 28I).

7. - Bouteille à panse plate forme 65 . Cologne, Musée WallrafRichartz, $\mathrm{n}^{0} 232$ Verre incolore très décomposé. Applications vermiculaires incolores (fig. 282).

8. - Bouteille cylindrique (forme 9 à une seule anse). Cologne. Musée Wallraf-Richartz, no 504 (fouilles de I893 au cimetière de la

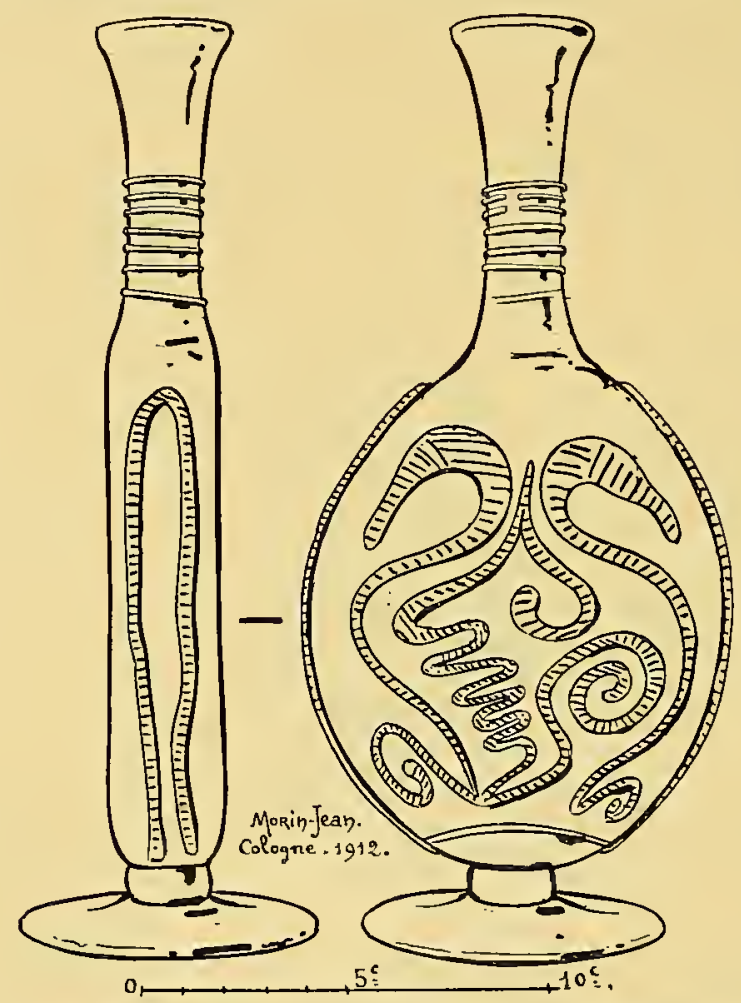

Fig. 282. - Lícythe a panse APtatie, oRNé d'APplicatrons verniculatres. - Romain II. Cologne.Musée Wallraf-Richart $z, n^{\circ} 232$.

rue de Luxembourg) Verre incolore décomposé. Applications vermiculaires incolores (I) (fig. 283).

9. - Carchésium (forme 98). Cologne. Musée Wallraf-Richartz, $n^{0} 670$. Ce gracieux récipient est en verre vert émeraude de bonne qualité. Parmi les applications vermiculaires dont il est orné, on

(I) Consulter ANTON KISA, dans les Bonner Jahrbïcher, fase. 99, p. 50-53, pl. II. 
voit un swastika en fil de verre doré dont les extrémités s'enroulent en spirale (I) (fig. 284).

Io. - Coupe (forme \$9). Rouen. Musée départemental d'antiquités (Provenance indéterminée). Verre incolore filandreux légèrement

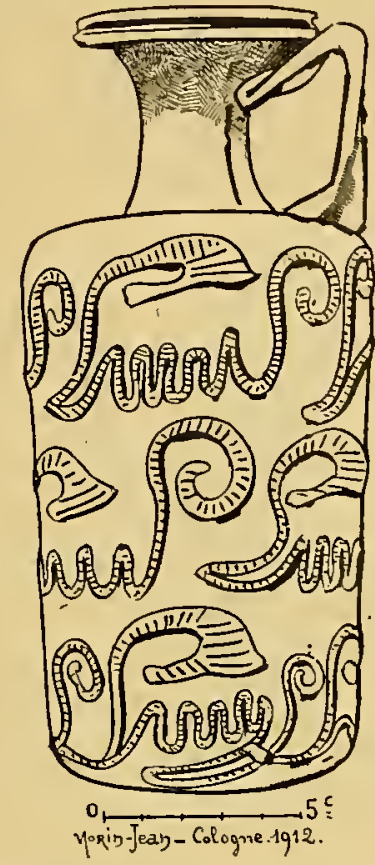

Fig. 283. - FlaCoN CYLINDRIQUE A APPLICATIONS VERMCUlaIres. - Cologne. Fouilles de 1893. - Nusée de Cologne, $11^{\circ} 504$.

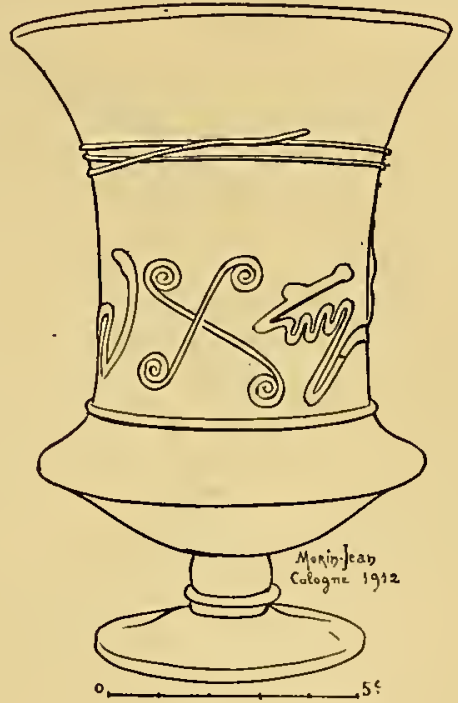

FLG. 284. - CARChESIUM DE VERRE VERT. - Otnements blanes et dorés. - Musée de Cologne, n० 670 .

décomposé. Applications vermiculaires en verre alternativement incolore et bleuâtre (fig. 285).

Ir. - Patère à manche (forme I37). Bonn. Provinzialmuseum. Salle $V, n^{0} 2$ I 5 . Verre incolore très peu décomposé. Applications vermiculaires en verre alternativement bleu et blanc (doubles spirales en émail blanc) (fig. 2S6).

I2. - Patère à manche (forme I36). Cologne. Musée Wallraf-Richartz, $n^{\circ}$ 9r9. Verre verdâtre rempli de bulles d'air. Les applications vermiculaires sont de la même couleur que le récipient (fig. 287).

(I) Ce carchésium a été publié par KIsA, en noir (Das Glas im Alteriume, fig. IIg) et en couleur (luc. cit., pl. V, no I). 
I3. - Fioles représentant des casques de gladiateurs (forme I39), décrites plus haut (p. I79 et I8o, fig. 236) (feuilles cordiformes, enroulements et oiseaux).

$b$. Les verres à applications vermiculaires de la seconde série remontent à la période comprise entre Aurélien et Honorius. Ils sont abondants dans les nécropoles du nord de la France, dans les tombes à inhumation du IVe siècle, découvertes dans la Marne, l'Aisne,

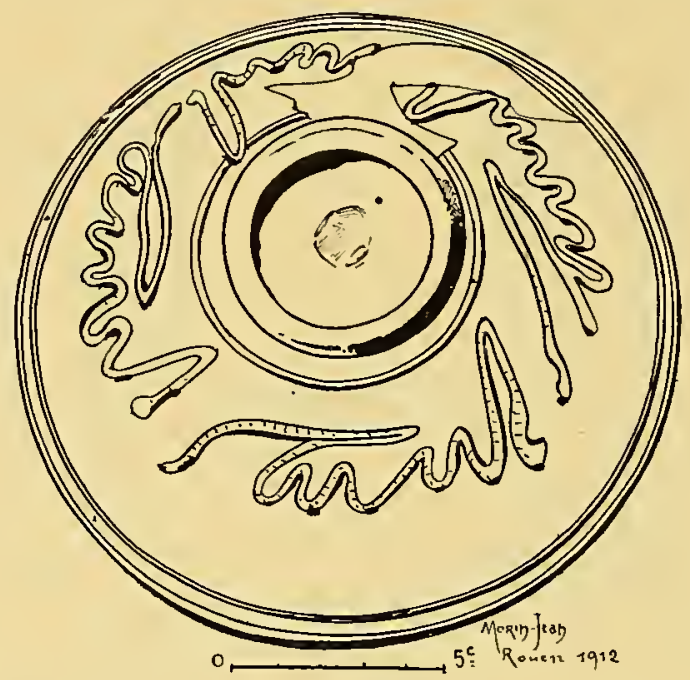

Fig. 285. - Coupr a Applications verniculatres. - Romain II. - Musée de Rouen (1).

1'Oise, la Somme, le Pas-de-Calais. Ils sont rares dans la vallée du Rhin. Ils sont en pâte très impure, verdâtre ou jaunâtre, remplie de filandres et de bulles d'air. Les applications vermiculaires dont ils sont décorés représentent des serpents. Ces serpents sont plus ou moins stylisés (fig. 288). Le $n^{0} \mathrm{I}$ appartient à la série du $\mathrm{II}^{\mathrm{e}}$ siècle (Série $a$ ), mais trahit déjà les intentions ophiomorphiques du décorateur. Le $n^{\circ} 2$ est une image plus naturaliste ; les écailles de l'animal y ont été reproduites avec soin; elles sont constituées par des empreintes rhombiques qu'on retrouvera dans le décor des poteries franques. Le $n^{0} 5$, d'un style large, fait songer à certains uraeus égyptiens.

Les serpents appliqués sur les verres de la fin du III et $d \mathbf{u} \mathrm{IV}^{\mathrm{e}} \mathbf{s}$.

(r) Voy. un autre dessin de cette coupe, p, r 30 , fig. I7o. 
sont des ornements, rien de plus; mais il est important de ne
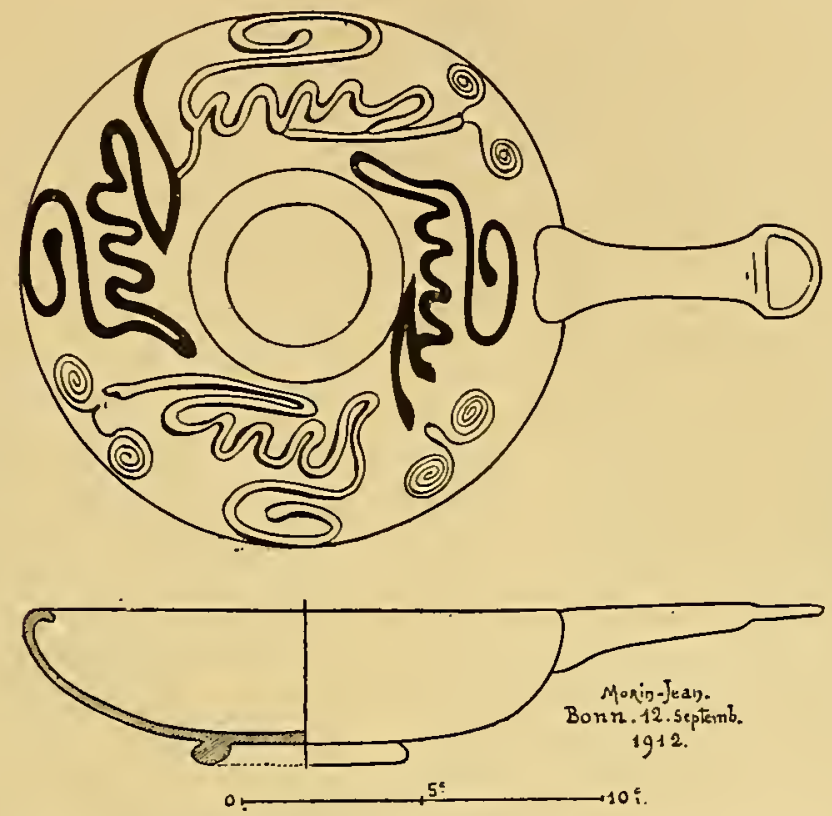

FIG, 286. - Patère a ILANChE, ornée d'applications vermiculaires. - Musée provincial de Bonn, $\mathrm{n}^{\circ} 215$.

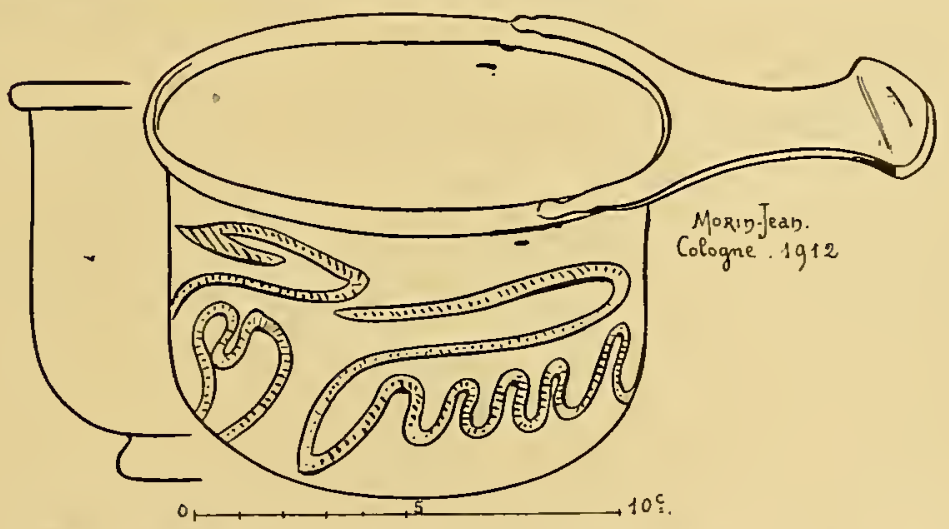

FIG. 287. - PATĖRE a MLATCHE, ornée d'applications vermiculaires. - Romain II. - Musée de Cologne, nº gI 9.

pas oublier qu'à une époque plus ancienne, de telles représentations avaient un sens religieux $(I)$.

(r) Y,es serpents figurés sur les monuments romains sont les arrière-neveux d'animaux sacrés qui ont perdu peu à peu leur sens prophylactique. Ils sont la survivance d'anciens totems orientaux [SALOMON RELVACH, Orpheus. Histoire génerale des Religions, Paris, x909, p. 268]. 
Les verres à décor ophiomorphique sont, pour la plupart, des récipients à large ouverture.

C'est exceptionnellement que des serpents ornent une bouteille forme 42, découverte au cimetière de Vermand et publiée par Pilloy (I), et une carafe 59, trouvée à Mayen (Rheinland) et conservée au Musée germanique à Nuremberg (fig. 289). Les verres à serpents énumérés ci-dessous sont tous des verres à pied formes I08 à III.

I.Boulogne-sur-Mer (Pas-de-Calais) (Neufchâtel). - Travaux du

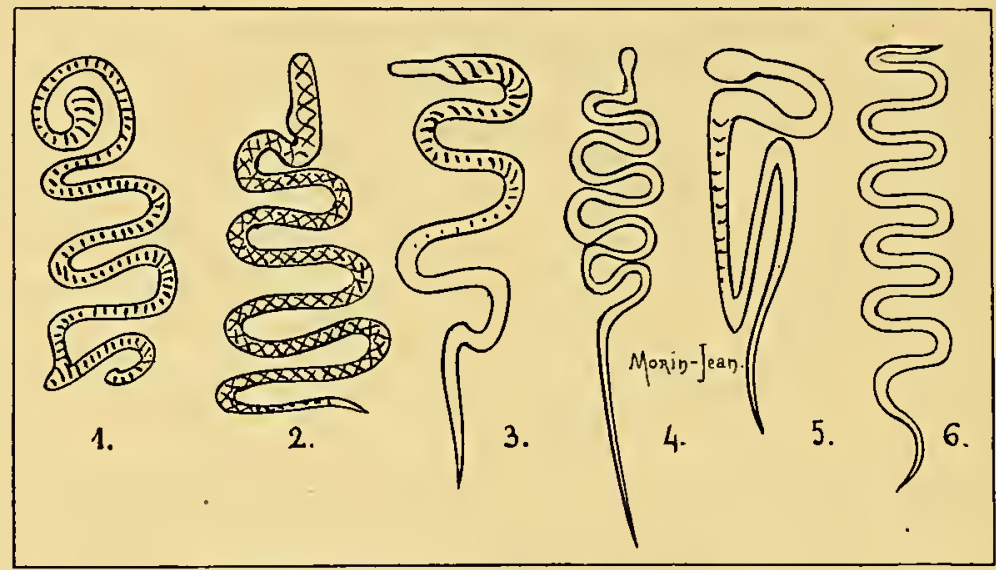

Fig. 288. - Applications vermicutatres (fils serpentants). - Motifs fin III $^{\mathrm{c}}$ s. et ive s. Décor ophiomorphique. - I. Cologne, 2. Mayen, 3. Jonchery-sur-Suippes (Marne), 4. Cómpiègne (Oise), 5. Villa d'Ancy (Aisne), 6. Reims (MIarne).

chemin de fer en 1848 (Fouille de M. Bazaine, ingénieur). Musée de Boulogne-sur-Mer, $\mathrm{n}^{0} 2.505$ (fig. 290).

2. Seuil, près Rethel (Ardennes) [Quatre serpents] (2).

3. Vermand (Aisne) (3).

4. Villa d'Ancy (territoire de Limé) (Aisne) [Trois serpents]. Fouilles Frédéric Moreau, 20 novembre I886. Tombe $n^{\circ} 94$ (4). Cette sépulture contenait des monnaies de Gratien (375 à 383 ) et de Valentinien II (375 à 392). Musée de Saint-Germain (Salle XI, Vitrine IO, A) (fig. 29I).

(I) Voy. plus haut, p. 96 , note 3 .

(2) Publié par I,IEBBE, Le Cimetière gallo-romain de Seuil près Rethel (Ardennes) ; Paris, r899.

(3) Publié par PrLloy, loc. cit., t. II, p. I 45 et pl. 7 bis, $1^{\circ} 8$.

(4) Publié par Frédéric Moreau, Album Caranda, pl. 68, nonvelle série. 


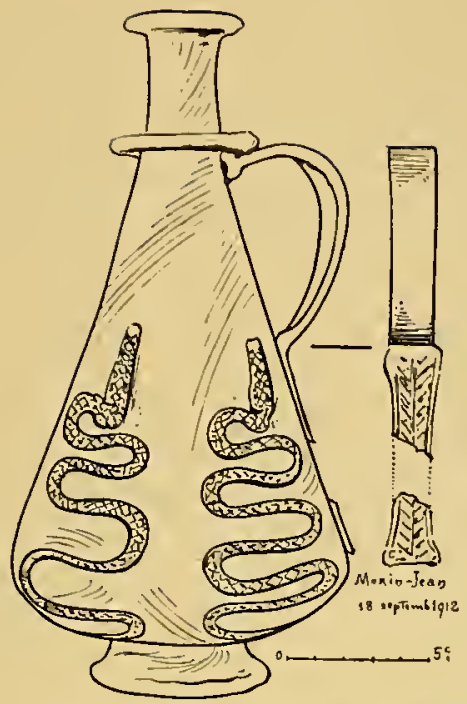

FIG. 289. - BOUTEILLE ORNÉE DE SERPENTS. Mayen. Ives. - Musée de Nurenberg.

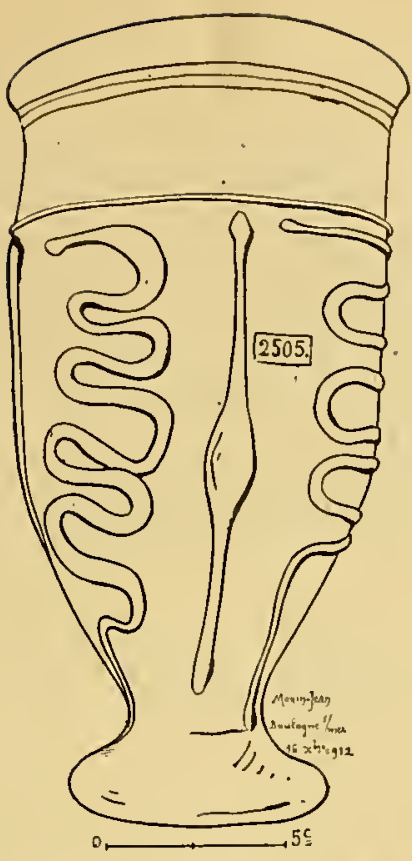

FIG. 290. - VERre A SERPENTS. - Boulonnais, IV0 s. - Musée de Boulogne- sur-Mer, no 2505.

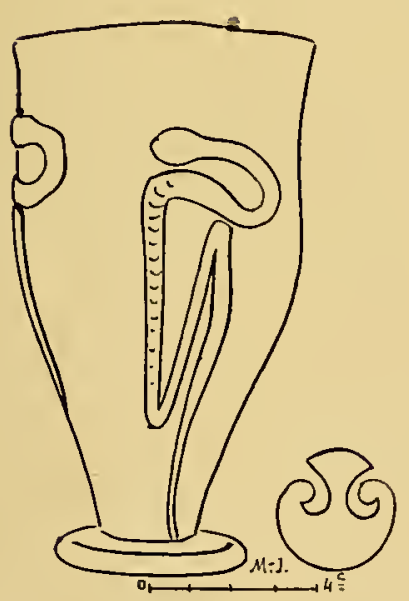

FIG. 29I. - VERRE CARENTE, ORNÉ DE TROIS SERPENTS. - Cimetière de la Villa d'Ancy (Aisne). Fin du IV ${ }^{e}$ s. - Musée de Saint-Germain. Salle $\mathrm{XI}$.

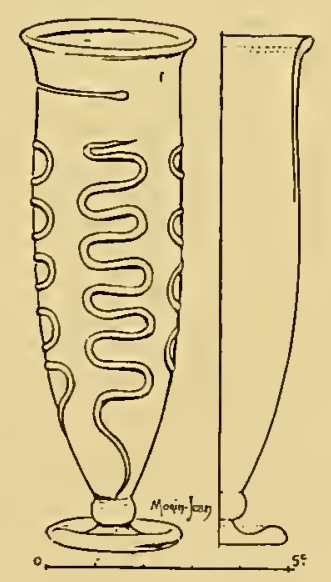

IIG. 292. - VERRE A SERPENIS.

- Reims (lieu dit La Maladrerie). - IIusèe de Reims, $n^{0} 4706$.

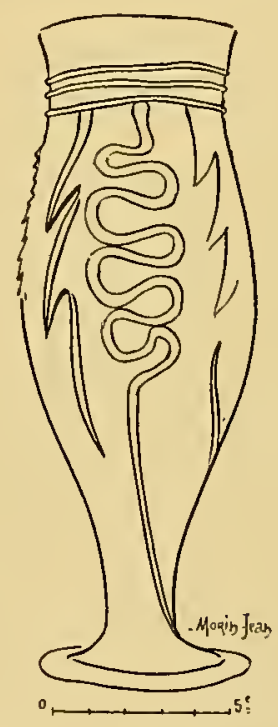

FIG. 293. - VERIE A SERPENTS. - Ives. - Musíe de Compiègne (Oise). 
5. Sissy (Aisne) [Huit serpents alternativement blancs et bruns] (I). Collection C1. Boulanger, à Péronne (Somme).

6-7. Reims (Marne) (lien dit «La Maladrerie») [Quatre serpents : deux en verre blanc et deux en verre bleu]. Musée archéologique de Reims, nos 4.705 et 4.706 (Iregs Léon Foucher) (2) (fig. 292).

8. Jonchery-sur-Suippes (Marne). Fouilles Lelaurain [Trois serpents] (P1. 9). Musée de Saint-Germain. Salle XV. Vitrine r6, $\mathrm{n}^{0} \mathrm{I} 3.345$.

9. Compiègne (Oise). Musée Vivenel (fig. 293).

4. - BARBotine DE VERRE.

La barbotine de verre ne doit pas être confondue avec le fil étiré

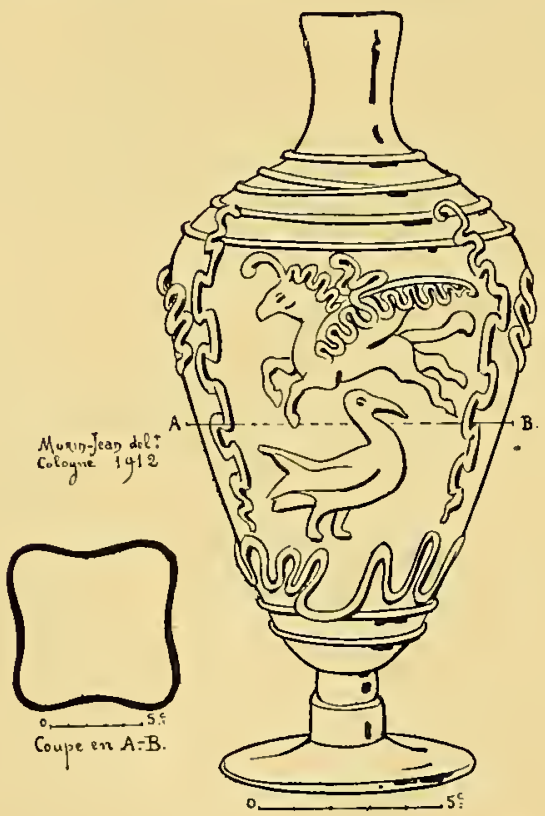

FIG. 294. - BoUTEILlE DU $\mathrm{II}^{*}$ s. - Décor barbotiné et applications vermiculaires. - Musée de Cologne, $\mathrm{n}^{0} 449$.

à chaud. Elle s'obtient par la chute d'un filet de verre liquide. Elle

(I) Publié par Cl. Boulanger, Le Mobilier funeraire, pl. I3, no I.

(2) Catalogue du Musèe archéologique de Reims, p. I69. Ces deux verres paraissent un peu plus anciens que les autres. La colòration de la pâte vitreuse et la forme du pied (pied à balustre) nous déterminent à les placer vers le milieu du $\mathrm{m}^{\mathrm{e}}$ siecle. 
permet de représenter en relief le corps même des objets, tandis que le fil de verre n'en décrit que les contours (I).

Les deux procédés, barbotine et fil de verre, ont été employés dans la décoration d'une bouteille conservée au musée Wallraf-Richartz à Cologne (2) (fig. 294). Cette pièce, de verre incolore décomposé, est en très mauvais état de conservation. Son pied appartient à un des modèles caractéristiques du $\mathrm{Im}^{\mathrm{e}}$ siècle; sa panse est ornée d'un quadrupède ailé (3), galopant vers la gauche au-dessus d'un oiseau tourné vers la droite. Le volatile est en barbotine de verre bleu; ses pattes et son bec sont en émail blanc. Les deux ani-

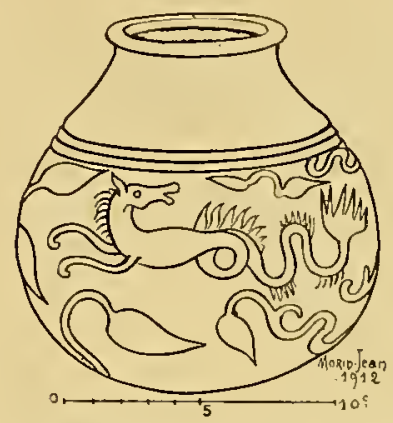

Fig. 295. - Poterie rovge. - II ${ }^{\mathrm{e}} \mathrm{s} .-$ Musée de Cologne.

maux sont encadrés de fils serpentants. Un fil mince s'enroule en spirale sur l'épaule du vase. Par le style de ses ornements et par la technique de sa fabrication, une verrerie comme celle-ci est au moins du second quart ou du milieu du Ime siècle. Je suis disposé à la mettre en synchronisme avec les poteries rouges et noires sur lesquelles on a peint en blanc, avec de la barbotine, des inscriptions bachiques, des animaux, des ornements divers. Ces poteries, dont on peut voir de très beaux spécimens au musée de Boulogne-sur-Mer et dans les diverses collections de la vallée du Rhin, proviennent des officines de la Gaule du nord. Elles sont communes dans les cimetières

(1) Sur les verres ornés à la barbotine, cousult. ANTON KISA, Das Glas im Altertume, p. 472-479.

(2) Publiée par Krs., loc. cit., p. 477 et fig. I3I.

(3) On peut rapprocher le décor de cette verrerie de celui d'une poterie rouge du $\mathrm{Ir}^{\circ}$ siecle, conservécau musće de Cologne (fig. 295). 
$d u \mathrm{III}^{\mathrm{e}}$ et $\mathrm{du} \mathrm{IV}^{\mathrm{e}}$ siècles. On les a surtout rencontrées dans les tombes qui vont de 250 à la mort de Constantin (I).

\section{5. - CABOCHONS DE VERRE (2).}

Aux $I \mathrm{II}^{\mathrm{e}}$, IV $\mathrm{V}^{\mathrm{e}}$ siècles, les verriers de la Gaule du nord ont orné de cabochons en verre un grand nombre de leurs produits. Appliqués à chaud avec plus ou moins de symétrie sur la panse des verreries,

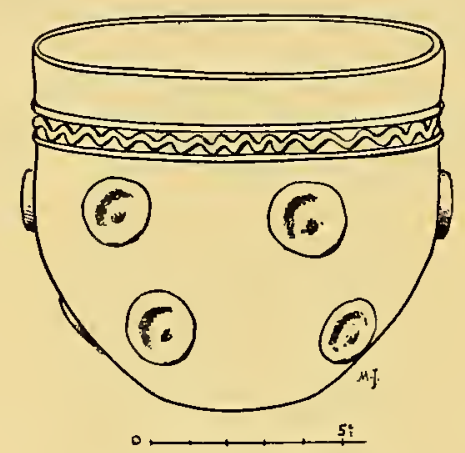

FIG. 296. - BOL orNé DE CABOChons A OMBILIC. - Cimetière de Brény (Aisne), Fouilles de I880. Iusée de Saint-Germain.

groupés en triangles, en bandes ou en losanges, ces guttules sont parfois incolores, mais plus souvent teintées en bleu-saphir, en brun, ell violet, en vert-émeraude, ent noir, en jaune-topaze, en blanc laiteux, en rouge purpurin.

Il semble bien que l'intention des verriers, en les colorant ainsi, était d'imiter les pierres précieuses.

Au IVe siècle, les cabochons étaient si estimés du public qu'on allait jusqu'à enrichir de cinquante gemmes artificielles des bols ne dépassant pas I4 centimètres de hauteur. Leurs couleurs, ingénieusèment alternées, se mariaient dans un accord harmonieux et donnaient aux verreries une fraîcheur de ton tout à fait remarquable.

(I) Sur ces vases, consulter KöNEN, Gefässkunde, p. I09, pl. XVIII et les Bonner Jahrbücher de I889, cahier LXXXVII, p. 60.

(2) Nuppen des archéologues allemands. Ces cabochons rapportés ne doivent pas être confondus arec les saillies obtenues au moule dont on trouve des exemples dès la haute époque impériale. 
Deux variétés de cabochons étaient connues des Romains:

I.es cabochons lisses, simples pastilles lenticulaires (fig. 299 à 302).

Les cabochons à ombilic, anneaux saillants pourvus au centre d'un point en relief (fig. 296, 297 et p1. 7).

La forme classique du verre à cabochons est le bol (formes 70, $7 \mathrm{I}$, et variantes, 72,73 , So, etc.).

Les bols à cabochons sont du IVe siècle et du début du ve. Ils sont
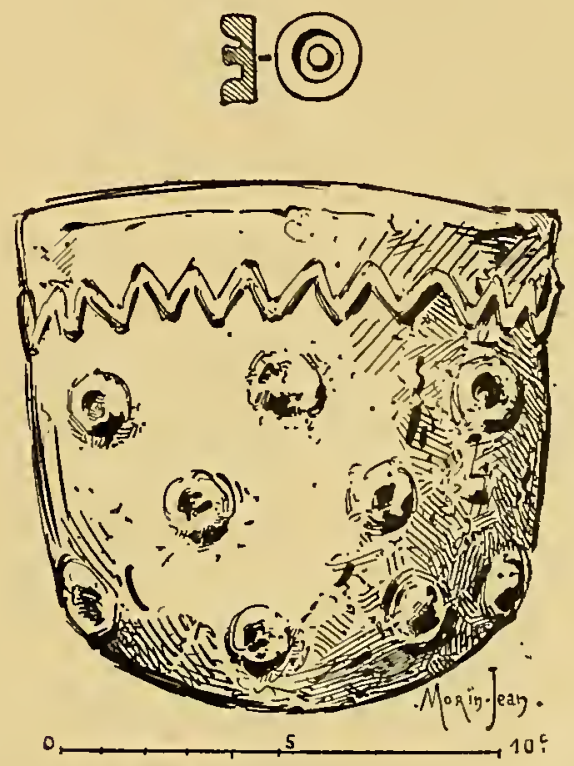

FIG. 297. - BOL ORNÉ DE CABochoNs A OMBruIC. - IV s. - Musée de Beauvais, nº 47 I.

très nombreux. Je me borne à signaler les plus curieux et les plus complets d'entre eux :

I. Monceau-le-Neuf (Aisne). - Bol forme 73. Cabochons à ombilic bruns et incolores. Inhumation d'un chef gallo-romain dans un cercueil de bois. Dans la bouche du défunt, denier d'argent de Constantin II (337 à 340) (I). Collection Cl. Boulanger, à Péronne.

2. Vermand (Aisne). - Bol de même forme. Cinquante cabochons à ombilic en verre alternativement incolore et brun-orangé, placés en quinconce (2). Musée Lécuyer, à Saint-Quentin.

(I) Publé par CL. Boularger, Le Mobiluer funeraire, pl. I2, $11^{0} \mathrm{I}$, et pl. 20.

(2) Tr. F, Les deux cimelièes gallo-romains de Vermand el de Saint-Quentin, p. I44 et p!. V, nº 3 . 
3. Vermand (Aisne). - Bol de même forme. Trente-six cabochons à ombilic en verre alternativement noir et verdâtre. Un peu audessous de l'orifice, court circulairement une inscription chrétienne gravée : Vivas. Cvm. Tvis. P. Z. Entre cette inscription et les cabochons, le verrier a appliqué un feston de verre noir entre deux filet's de verre blanc (I). Musée Lécuyer, à Saint-Quentin.

4. Brény (Aisne). - Bol de forme analogue. Douze cabochons à ombilic en verre alternativement bleu et brun-jaunâtre. Au-dessous de 1'orifice, feston de verre brun entre deux filets; 1e filet du haut en verre brun ; celui du bas en verre bleu (fig. 296). Tombe à inhumation $n^{0}$ I.620, explorée par Frédéric Moreau, le 2 I octobre I88o (2). Musée de Saint-Germain, salle XI.

5. Homblières (Abbeville) (Somme). - Bol de forme analogue. Cabochons à ombilic en verre alternativement bleu et jaune. Audessous de l'orifice, feston de verre bleu entre deux filets de verre jaune. Tombe à inhumation $\mathrm{n}^{\circ} \mathrm{I}$ (femme). Mobilier funéraire caractéristique des dernières années du $\mathrm{IV}^{\mathrm{e}}$ siècle (3).

6. Châlons (Mame). - Bol à cabochons à ombilic. Même type ; même époque (p1. 7). Musée de Saint-Germain, no 6.284 .

7. Reims. - Bol forme 73 à cabochons à ombilic en verre incolore. Musée archéologique de Reims, $\mathrm{n}^{\circ} 4.667$ (4).

8. Bury (Oise). - Bol à cabochons à ombilic découvert par l'abbé Hamard en I897. Inhumations dans des cercueils de bois. Monnaies de l'époque constantinienne (5).

9. Boulogne-sur-Mer. - Bol ornée de quatre cabochons à ombilic (deux en verre jaune et deux en verre vert), alternant avec quatre petites saillies lenticulaires. Filet de verre jaune près de l'orifice (fig. 298). Fouilles de l'abbé Haigneré au cimetière du Vieil-Atre en I870. Musée de Boulogne-sur-Mer, ñ 2.672.

Io. Sissy (Aisne). - Bol forme 72, orné de cabochons lisses

(I) Tн. Eck, loc. cit., p. x 70 et pl. III, no 3.

(2) Frédéric Moreau, Album Caranda, pl. 3. Nouvelle série, $n^{\circ}$ r.

(3) Pilloy, Études sur d'ancicns lieux de sćpultures dans l'Aisne, t. I, p. I79 et 205, pl. III, nº 9.

(4) Cataloguc du Musće archéologique de Reims, p. I67.

(5) Abbé IIAMard, Déconverte d"une nécropole romaine à Bury (Oisc), dans le Bulletin archéologique du Comité des travaux historiques et scicnlifiques, 1900, p. 23-25, pl. I, fig. 6. 
alternativenent jaunes et verdâtres et d'une collerette où des zigzags

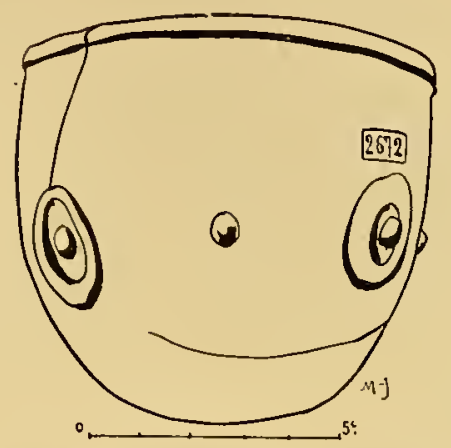

FIG. 298. - Boz a carochons, - Vieil-Atre. louilles de r87o. - Musée de Boulogne-sur-Mer, nº 2672.

courent entre deux filets circulaires. Collection Cl. Boulanger, à Péronne (I).

II. Vermand (Aisne). - Coupe forme 70, très irisée, garnie sur toute sa surface, de dix-neuf cabochons lisses bleu-saphir (2).

I2. Sablonnière (Fère-en-Tardenois) (Aisne). — Bol forme 73
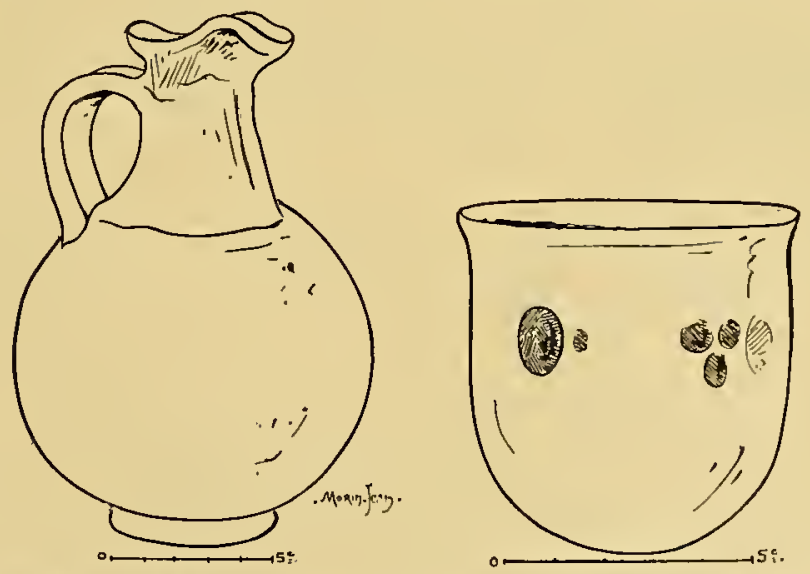

IHIG. 299. - MoBLLER FUNÉRAIRE d'une tombe à inhunation du cimeticre de Sablonnière, à Fère-enTardenois (Aisne). rv c s. - A. Crnche de terre rougeâtre. - B. Bol de verre à cabochons lisses. - Mrusie de Saint-Germain. Salle XI.

en verre jaune décoré de cabochons lisses en verre brun-verdâtre (deux groupes de trois petits cabochons posés 2 et I alternant avec

(1) Cl. Boulanger, Le Mobilier funeraire, pl. $\mathrm{I}_{2}, \mathrm{n}^{0} 3$.

(2) Тн. Еск, loc. cit., p. I $\{3$, et pl. V, nº 9 . 
deux gros cabochons (I) (fig. 299). Fouilles Frédéric Moreau. Inhumation $\mathrm{n}^{0}$ I.068. Musée de Saint-Germain, salle XI, vitrine 48 .

I3. Strasbourg (Alsace). - Bol forme 7 I. Gros cabochons lisses alternativement violets (fig. 300, A) etbleus (fig. 300, B), séparéspar des groupes de six guttules disposées en triangle la pointe en bas. Cés groupes de guttules sont alternativement bleus et violets. Fouilles du chanoine Straub au cimetière de Strasbourg. Inhumation du IV ${ }^{\mathrm{e}}$ siècle (2). Musée archéologique de Strasbourg. [Notre figure 300
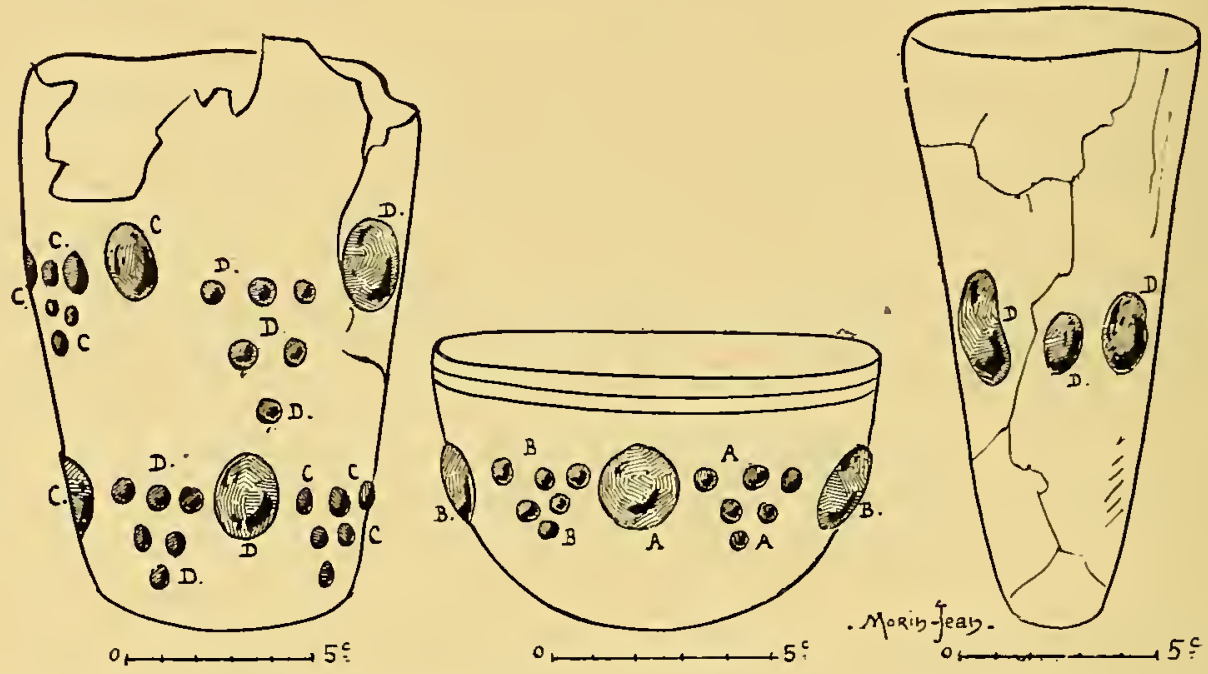

FIG. 300.-VERRES a Cabochons LISSES (A. violet, B. bleu, C. vert, D. jaune).-IVes. - M uséede Strasbourg.

reproduit deux autres spécimens de verreries à cabochons du même cimetière. Leurs pastillages sont verts et jaunes].

I4. Homblières (Abbeville) (Somme). - Bol forme 73. Même thème ornemental que sur les verres de Strasbourg. Cabochons bleus. Inhumation $n^{0} 4$ (homme). Fibule cruciale à charnière (type de la fin de l'Empire (fig. 340, B). Monnaie de Constance (337 à 36r) ou de Magnence (mort en 353) (3).

(I) Ces pastillages ne constituent pas une décoration particulière à la Gaule. On les retrouve sur un grand nombre de bols et de comets coniques découverts à Sayda (Phénicie). Frehner, Collertion Gréa1l.

(2) StraUB, Le cimetiere gallo-romain de Strasbourg, p. $2 \mathrm{I}$, pl. V.

(3) J. PILloy, loc cit., t. I, p. I79, pl، III, no 8. 
I5. Reims (lieu dit les Trois Piliers) (Marnc). - Gobelet forme So, orné de quatre cercles gravés et de quatre guttules lisses en verre bleu (fig. 30I). Trouvé en janvier I\$96 par M. G. Logeart dans une sépulture, avec une statuette de terre blanchâtre figurant une femme assise dans un fauteuil d'osier et allaitant deux enfants. Musée de Reims (I).

On connait un certain nombre de verreries à cabochons diffé-

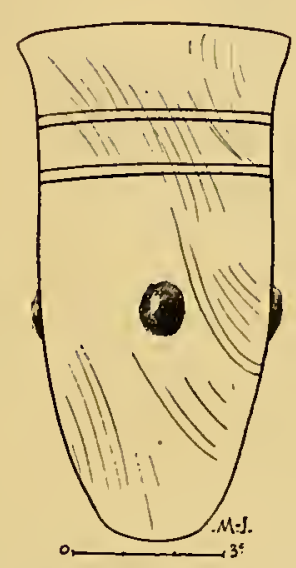

I'IG. 30I. - GOBELET ORVÉ DE CABOCHONS LISSES ET DE FILETS GRAvÉs. - Reims. Fouilles de $\mathbf{1} 896$. - Musée de Reims, ñ ${ }^{\circ}$ SSI.

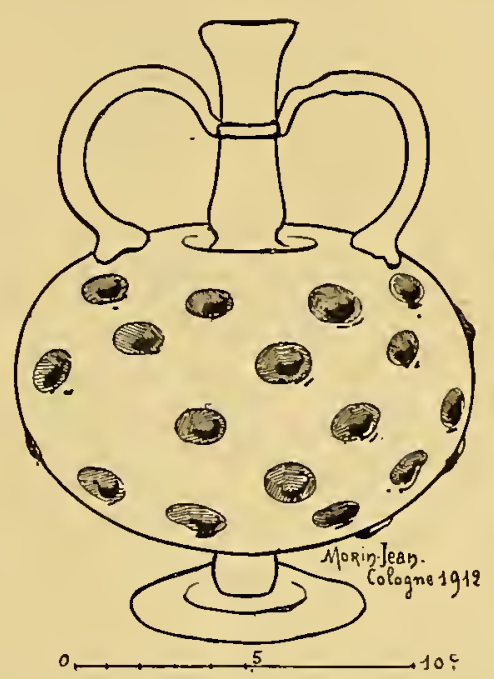

Fig. 302. - BoutetLle ornée de guttules eN VERRE BLEU. - Romain II. - Musée de Cologne.

rentes, au point de vue des formes, de celles auxquelles appartiennent les spécimens que nous venons de signaler.

r. Cologne. - Fouilles de la rue d'Aix-la-Chapelle. Bouteille forme 40 en verre incolore décomposé. Guttules de verre bleu irrégulièrement semées sur la panse (fig. I04, C.). Musée Wallraf-Richartz, $\mathrm{n}^{\circ} 602$.

2. Cologne. - Bouteille en verre incolore décomposé. Nombreuses guttules de verre bleu (fig. 302). Musée Wallraf-Richartz.

3. Vermand. - Bouteille forme 42 à quatre anses en verre inco-

(r) Catalogue du Mrsèe archéologique de Reims, p. 65 et $\mathrm{r} 86, \mathrm{n}^{08} 2.13^{8}$ et $4.88 \mathrm{I}$. 
lore, ornée de trois couronnes de cabochons à ombilic en émail blanc laiteux. Musée de Saint-Quentin, $n^{0} 2.666$ (I).

4. Homblières (Somme). - Ciborium forme I03 à cabochons à ombilic, trouvé dans la tombe $\mathrm{n}^{0} 53$, aux pieds d'un squelette

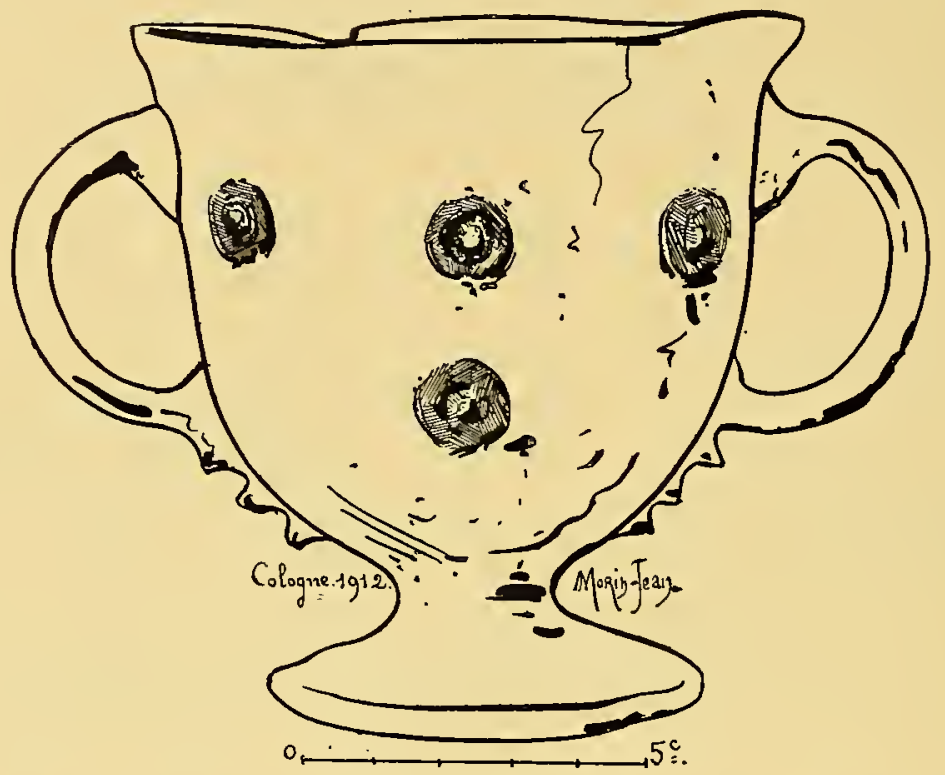

FIG. 303. - CIBORTOM DE vERRE INCOLORE, orné de cabochons polychromes. - Cologne. Fouilles de I892. IV s. - Musée de Cologne.

d'homme de vingt à vingt-cinq ans, avec une lagène de verre forme 49 et une monnaie de Valentinien I ${ }^{\text {er }}$ (364 à 375) (2).

5. Cologne. - Ciborium forme ro3 à cabochons bruns et bleus, trouvé en 1892 , Löwenstrasse, avec une monnaie de Maximien (286 à 3Io) (fig. 303). Cologne. Musée Wallraf-Richartz.

6. Kreuznach. - Ciborium forme I03, en verre verdâtre et impur de très basse époque. Guttules brunes et vertes. Près de l'orifice, feston de verre vert entre deux filets de verre brun (fig. 304). Bonn. Provinzialmuseum, salle V.

7. Boulogne-sur-Mer (Pas-de-Calais). - Barillet forme I32

(2) Pilloy, loc. cit., t. I, pl. III, no ${ }^{0} 3$. 
(fig. 305). Verre incolore très pur. Musée de Boulogne-sur-Mer, $\mathrm{n}^{0} 2496$ (I).

8. Trèves. - Barillet forme I32. Verrre bleuâtre rempli de bulles

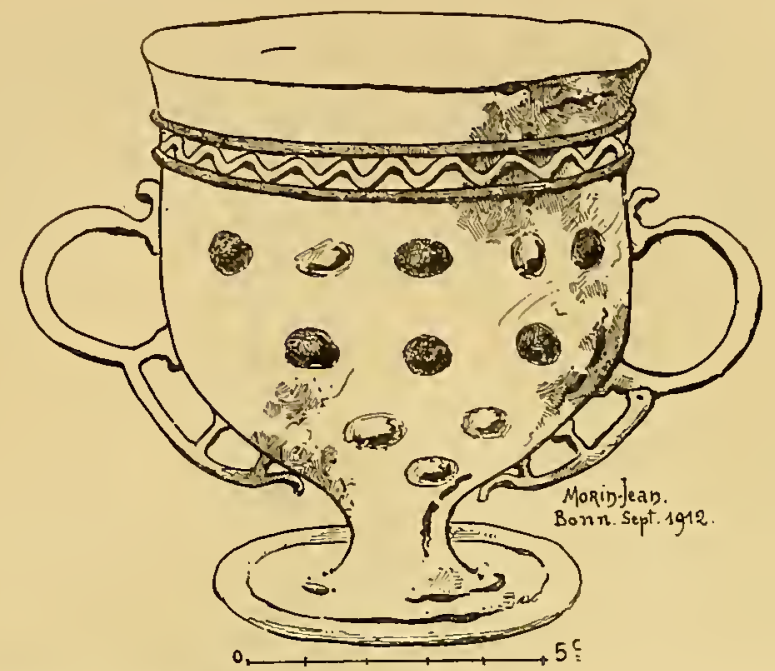

IIG. 30.1. - CiboriUm a cabochons. - Kreuznach. Fin du IV s. - Musée provincial de Bonn.

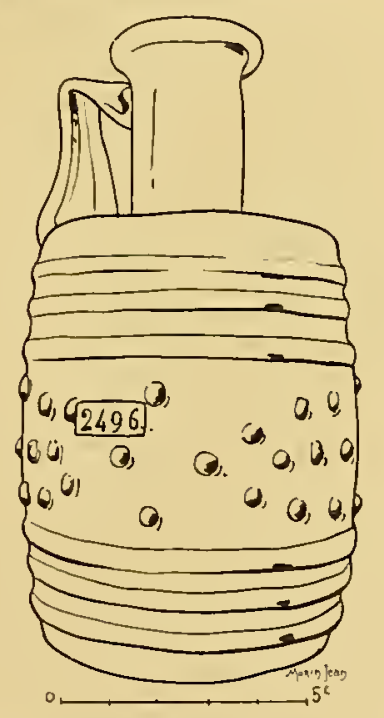

VIG. 305. - BARLLET A CABOchoNs. - Fouilles dn Boulonnais. - Romain II. - Musée de Boulogne-suy Mer, $11^{\circ} 2496$.

d'air. Trèves. Provinzialmuseum, salle 20 , vitrine VII, $\mathrm{n}^{0} 99.34 \mathrm{I}$.

(r) RoAch Sirte, Collectanca Antiqua, I843, pl. I. 


\section{6. - GutTuLLES APPENDicUl,ÉES.}

Quelques verreries du IV siècle sont rehaussées d'ornements constitués par une masse de verre dont on a étiré la partie inférieure à l'aide d'une pince (fig. 306). L'intention des décorateurs, en créant de tels motifs, était de conserver à la pâte vitreuse une fois refroidie, l'apparence d'un matière visqueuse qui coule tout autour

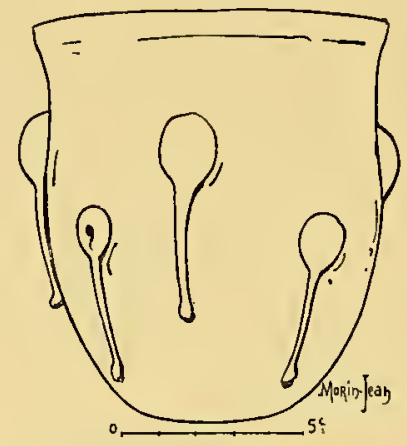

Fig. 306. - Bol orné de guttules Appendiculśes. - Fouilles des cimetiètes de la Marne. Ive s. Musée de Saint-Germain, $\mathrm{n}^{\circ} \mathrm{I} 3357$.

du vase. C'est une décoration rationnelle en parfaite conformité avec la nature du matériau employé.

Les guttules appendiculées sont les précurseurs de ces énormes trompes dont les Mérovingiens ont chargé si souvent leurs gobelets tronconiques.

\section{7. - PinçuREs Faites a l'outil.}

Les bols, les verres à boire des $\mathrm{III}^{\mathrm{e}}-\mathrm{IV}^{\mathrm{e}} \mathrm{s}$. sont fréquemment ornés de petites saillies que les ouvriers obtenaient en pinçant la pâte vitreuse pendant qu'elle était encore malléable. Nos figures 307 à 3 Io reproduisent quelques spécimens de verreries à pinçures qui suffisent à donner une idée précise de ce genre de décoration. On remarquera la forme particulière des ornements du bol trouvé par l'abbé Cochet à Neuville-le-Pollet, en I845 (fig. 3Io). 
Le bol de Neuville n'est pas seul de son espèce. Des verreries sem-

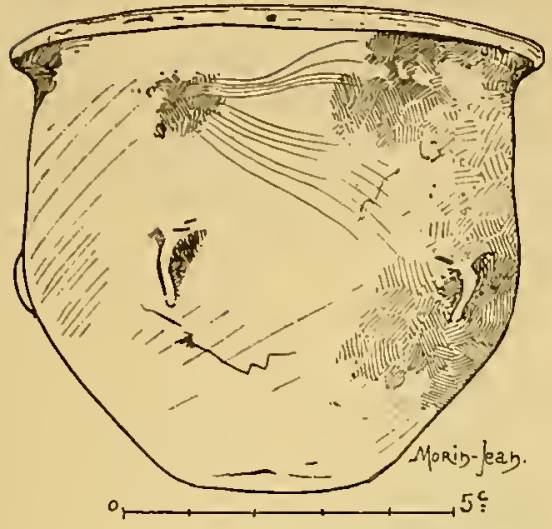

FIG. 307. - BOL ORNÉ DE PLÇURES FAITES A L'ovTrt, verre verdâtre. - Cimetière de Vermand. $\mathrm{IV}^{\mathrm{r}} \mathrm{S}$. Collection Morin-Jean, $\mathrm{n}^{\circ} 2220$.

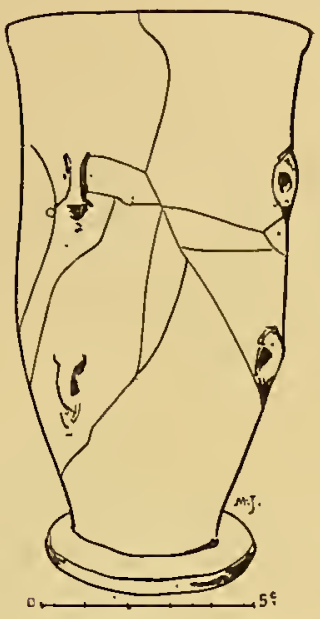

FIG. 308. - VERRE ORNÉ DE PINÇURES. - VieilAtre. Fouilles de I87I. Romain II tardif. Musée de Bonlogne-sur-1Yer, $\mathrm{n}^{0} \geq 660$. c.

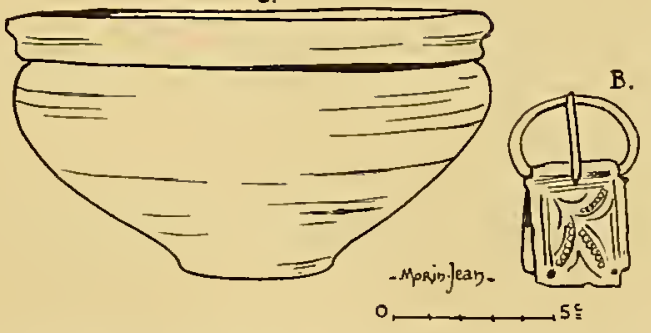

A

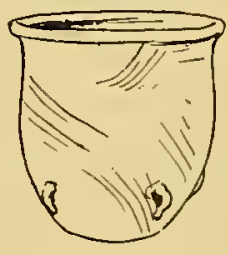

FIG. 309. - MOBILIER FUNÉRAIRE D'UNE TOMBE A INHUMIATION DU CIMETTÈRE DE VIERVILLE (EuTe-etIoir). - Fouilles de $\mathrm{x} 890 . \mathrm{r}^{\mathrm{e}} \mathrm{s} .: \mathrm{A}$. Bol deverte orne de quatre saillies faites à la pince. - B. Boncle de ceinture en bronze. - C. Bol de terre grise contenant des ossements de poule. - Collection Morin-Jean, à Paris.

blables sont conservées dans diverses collections, notamment au musée de Cologne (I).

\section{8. - CISELURE EN RELIEF.}

Nous avons examiné les principaux procédés de décoration à chaud

(1) AnTox Fis., Das Glas im Altertume, P. 476, fig. I52. 
connus à l'époque impériale (I). Il nous reste à étudier la décoration à froid qui laissait aux artistes beaucoup plus de temps et de liberté, qui leur permettait de créer des œuvres d'une belle qualité, des objets de grand luxe dont quelques remarquables spécimens sont parvenus jusqu'à nous.

VERRES A DEUX COUCHES [FAUX CAMÉES] (2). - Au premier rang de ces précieuses reliques, il faut placer les verres à couches superposées travaillées à la façon des camées. L’ouvrier appliquait l'une sur

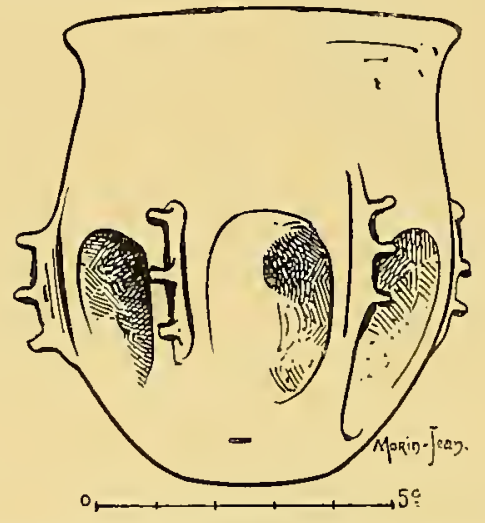

FIG. 3 10.- BOL DE VERRE INCOLORE, orné de dépressions et de saillies à trois pointes. - Neuville-le-Pollet. Fouilles de 1845 . - Musie de Rouen.

l'autre deux couches de verre de couleurs différentes ; puis il sculptait et affouillait la couche superficielle jusqu'à la rencontre de la couche sous-jacente (3).

(I) L,es coupes dans la pâte desquelles sont incorporêes à chaud des baguettes polychromes, les verres imitant les agates rubanées, tous les produits que les Allemands désignent par le terme général de $M o s a i ̈ k-$ gläser [A. KIsA, Das Glas im Alterime, p. 501 et suiv.], n'entrent pas dans le cadre que je me suis tracé: $I^{0}$ parce qu'ils se rattachent par leur techuique aux verreries péromaines. Iis pourraient constituer le dernier chapitre d'un livre consacré à celles-ci ; $2^{\circ}$ parce que les plus beaux d'entre eux n'ont pas été découverts en Gaule. Je rappellerai toutefois que nos ciuetières de la haute époque impériale ont livré un assez grand nombre de tessons ayant appartenu à des verreries de cette catégorie. Je signalerai comme exemples les débris de deux coupes apodes trouvés à Besançon sous les ruines des monuments ronains entourant le champ de Mars. $L_{1}$ 'une de ces coupes pouvait avoir un diamétre de $o^{m}$, Io environ. Elle est en verre richement coloré imitant les veines de l'agate [pâtes vitreuses jaune, rouge, blanc-crème et bleu foncé]. L'autre a été obtenue par soufflage d'un verre transparent légèrement verdâtre dans lequel l'ouvrier a encastré des baguettes de verre rouge et bleu. Les fragments de ces verreries sont conservés au musée de Besançon (Doubs). Ils font partie d'une série d'objets provenant d'un cimetière à incinérations qui a dû servir depuis la conquête jusque vers le temps de Néron. Les monnaies trouvẻes dans les urnes ne ront que jusqu'au re̊gne de Claude. Il y avait aussi quelques monnaies gauloises.

(2) Ueberfanggläser des archéologues allemands.

(3) On peut rapprocher des verres doublés du I ier siècle, les verres d'époque plus basse, recouverts d'ornements découpés à jour dans ume plaque d'or, d'argent ou de brouze. Ces vases sout des créations d'ouvriers 
Ce travail délicat est appelé sculptura vitri par Quintilien (I) et toreuma vitri par Martial (2).

I,e Vase Portland (Vase Barberini) du British Museum (3) et le Vetro blu (Vase de la Vendange), recueilli en I837 à Pompéi et conservé au Musée de Naples (4), en sont les plus fameux exemples. Ils n'ont pas été découverts en Gaule. Il n'y a pas lien de leur consacrer ici une étude spéciale.

Une autre verrerie, tout aussi remarquable quoique moins célèbre, faite, comme eux, à l'imitation des camées, a été trouvée en France.

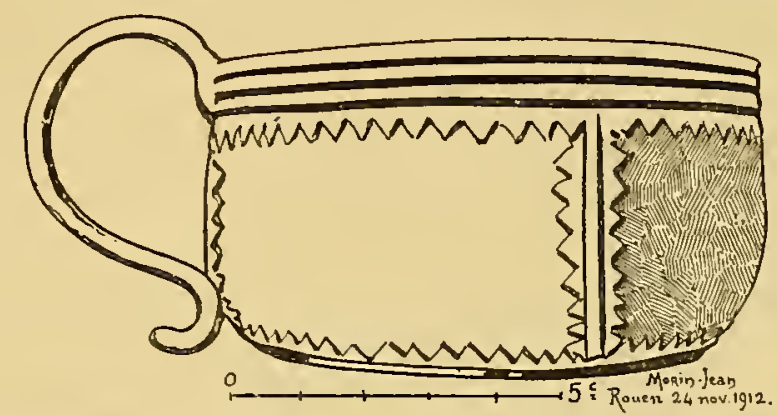

FIG. 3II. - MSSE DE VERRE A MIONTURE MUÉTALLIQUE. - Mont-Afrique, près Dijon (Côte-d'Or). - Musée de Roucn.

C'est une onochoé d'un galbe très pur, malheureusement fracturée, recueillie en septembre I 886 par des terrassiers dans un terrain dépendant de l'ancien couvent des Annonciades, dans le quartier de

alexandrins de la fin de l'époque impériale. On a euployé, pour les omer, le procédé que les anciens désigraient sous le $n 0 m$ d'Opus interrasile. Nous signalons trois de ces produits : $x^{\circ}$ Un carchésium forme 98 (anses et pied en métal), en verre rouge foncẻ sur lequel se détachent des rinceaux et des scẻnes de chasses en argent découpé, trouvé en $\mathrm{r} \$ \mathrm{Y}$ près Tillis et conservé au Iusée de l'Ermitage à Saint-Pétersbourg (STEPHAN, C. rendus de la Comm. arch. de Saint-Pëtersbourg, I\$72, p. I 43, pl. II, I-2) ; $2^{\circ}$ Un bol à décor végétal et inscription : EYTYXWC, en argent découpé. Trouvé dans le Seeland avec des monnaies de Probus, (276 à 282) et conservé au musée de Copenhagne (Aarboger for nordisk oldkindighed, IS77, p. 354, avec pl. en couleur) ; $3^{\circ}$ Une tasse de verre vert à monture d'argent trouvẻe au Mont-Afrique près Dijou (Côte-d'or) et conservẻe au inuscé départemeutal d'antiquités à Rouen (fig. 3Ir). Au point de vue artistique, cette pièce est trés inférieure aux précédentes [Publiée par A. Deville, Histoire de l'art de la verrerie dans l'antiquite, pl. XIIII, H.].

(I) QULTILIEX, lib. II, XII, 9.

(2) MLARtiul, $\mathrm{X}, 87$.

(3) Gersp.ich, L'art de la verrerie, p. 50-53, fig. I9, 20, 21 ; - A. Fis., loc. cit., p1. VII.

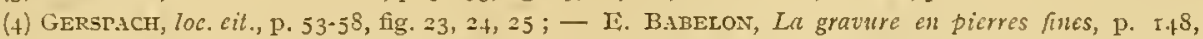
fig. Iog ; - A. KrsA, loc. cit., pl. VIII et IX ; - Guide des Antiqucs du musée national de Naples, tgo8, p. $126, n^{\circ}+3.52 \pi$. 
Besançon où se trouvaient les plus riches villas gallo-romaines (autour du Palatium).

Mais on a pensé que ce vase avait pu être apporté là avec des déblais provenant d'un autre point de la ville, probablement dụ quartier de Chamars (ancien Champ de Mars), où l'on a rencontré un riche cimetière du $\mathrm{I}^{\mathrm{er}}$ siècle de notre ère.

L'œnochoé de Besançon est en verre violet foncé sur lequel apparaît, en faible relief, un décor en verre opaque blanc sculpté à la manière des camées (I) (p1.6).

Les personnages, qui se détachent en clair sur le fond sombre de cette belle verrerie, accomplissent une cérémonie en l'honneur de Priape. Un mascaron, figurant une tête de face, une sorte de gorgoneion, est placé au-dessous de l'attache de l'anse.

Les faunes, la statue ithyphallique de Priape, la divinité féminine dressée sur une colonne, les arbres (laurier et conifère), la table à trois pieds de bouc sur laquelle on a déposé un canthare de type hellénistique, et deux autres vases, tous les motifs de cette élégante composition sont d'un modelé admirable. Le style des figures est presque aussi beau que dans les camées les plus remarquables de l'époque d'Auguste.

Le vase priapique de Besançon est une œuvre d'art d'un ordre élevé. Il a certainement été exécuté par des artistes grecs, à la même époque que le Vetro blu de Pompéi, c'est-à-dire avant le dernier tiers du I $^{\text {er }}$ siècle.

On ne sait pas de quelle officine il est sorti, mais il est probable qu'il a été fait à Alexandrie.

VERRES A RELIEFS TAILIÉS DE BASSE ÉPOQUE. - A partir de l'époque des empereurs syriens, le travail des sculpteurs sur verre devient dur et sec. Les verres à reliefs taillés du Romain II ne sont intéressants que par l'effort qu'ils ont coûté. Ce sont des œuvres qui procèdent de l'industrie et du métier.

La pièce la plus remarquable dans cet ordre de production est

(I) X'œnochoé de Besançon a été minutieusement décrite par MM. VAIssier et Castaĩ dans les Mémoires de la Société d'Emulation du Doubs, 6e séric, vol. I, année I887, p. 249-254: Vase priapique en verre du musée de Besancon. Une planche lithographique en couleurs représente le développement de la panse, et un petit dessin donne l'aspect du vase à une échelle très réduite. 
111 récipient du $\mathrm{II}^{\mathrm{e}}$ siècle, découvert à Trèves en I905 et exposé au musée de cette ville (I).

Ce vase, plus curieux que beau, est en forme de tronc de pyramide. Il est en verre incolore complètement décomposé. Il est muni d'une anse placée verticalement sur le côté. Malgré son très mauvais état de conservation, il laisse voir en maints endroits sa décoration qui consiste en rameaux sinueux chargés de feuilles triangulaires sculptées en méplat.

Cette nouvelle technique, dont le vase de Trèves nous offre un des plus anciens exemples, fait perdre au bas-relief son caractère plastique.

I,es ornements maintenus à une faible distance d'un fond uniformément plat, ont l'air d'avoir été découpés à la scie dans une plaque présentant partout la même épaisseur. Quel contraste entre leurs contours heurtés et le modelé savant et délicat de l'œnochoé de Besançon.

VERRES A RÉSILLE TAILLÉE A JOUR ET MAINTENUE A DISTANCE DU RÉCIPIENT (Diatrètes). - Si l'art des sculpteurs sur verre est en décadence à l'approche du IV e siècle, il n'en est pas de même de leur habileté technique. Les verres à résille maintenue à distance du récipient en font foi. Ces vases remarquables, qu'on appelle ordinairement diatrètes (2), sont de vrais chefs-d'œuvre de métier. Leur forme est celle d'un bol apode plus ou moins évasé (forme 79 et variantes). Leur ornementation consiste en une résille de verre découpé. Cette précieuse dentelle n'adhère pas au récipient; elle y est rattachée par de fines barrettes de verre.

L,es diatrètes étaient des pièces de grand luxe d'une extrême fragilité. Les rares exemplaires qui sont parvenus jusqu'à nous datent tous du dernier quart du $\mathrm{II}^{\mathrm{e}}$ siècle ou de la première moitié du $\mathrm{IV}^{\mathrm{e}}$.

Nous signalerons les suivants comme particulièrement dignes d'attention :

I. Strasbourg (A1sace). - Fouille de I825. Diatrète recueillie dans un sarcophage en pierre avec une monnaie d'or de Constance Ier (mort

(I) Trères, Provinzialmuseun, salle 20 , vitrine VIII, $n^{\circ} 05.429^{\circ}$ [voy. Avrox Kis., Das Glas ill Altertume, p. 639, et fig. 243].

(2) Netzbecher des archéologues allemande. 
en 306) (I). La résille, comme il est de règle dans les récipients de ce genre, ne montait pas jusqu'à l'orifice du vase. Une bande, réservée dans la partie supérieure, portait une inscription en relief. De cette inscription, il ne restait que les lettres : .... XIm.... NE. Avgv....

On a pensé que cette coupe faisait partie du service de tablé de l'empereur Maximien Hercule qui passa le Rhin en 297.

La diatrète de Strasbourg, conservée au musée de cette ville, fut détruite lors du bombardement de 1870 .

2 et 3. Cologne. - Fouille de 1844 . Deux diatrètes de verre inco-

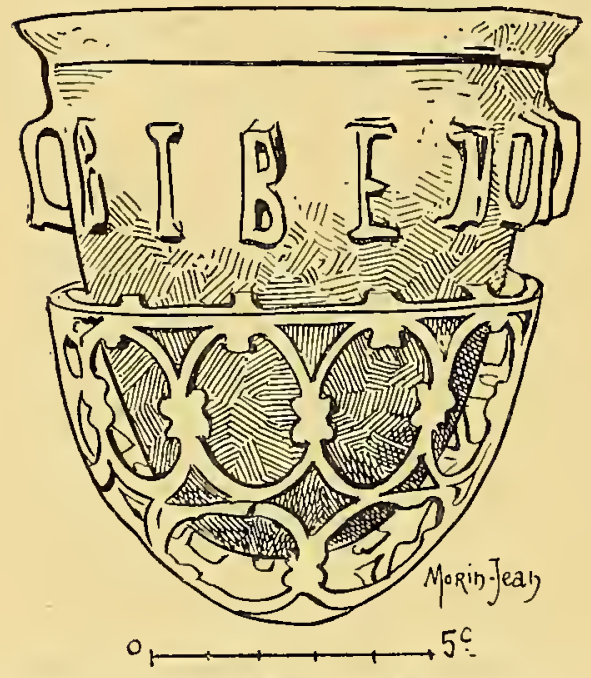

FIG. 3I2. - DIATRÈTE, trouvée à Cologne. - IV se. - Antiquarium de Munich.

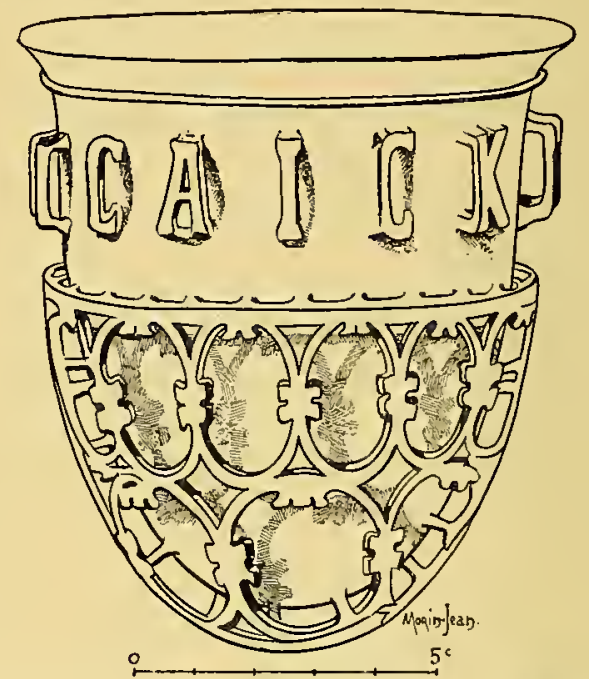

Frg. 3ry. - Diatrète découverte à Cologne. - IVe s. - Musée de Berlin.

lore, découvertes, rue Benesis, dans deux sarcophages voisins dont l'un contenait une monnaie de Trajan, l'autre une monnaie de Constantin II (337 à 340) (2).

La plus grande de ces diatrètes, conservée à l'Antiquarium de Munich, est pourvue d'une inscription latine : BIBE. Mvitis. ANNIS. (fig. 3I2).

La plus petite est au musée de Berlin. Sa résille est surmontée d'un texte grec : [nife zнсагс камwid (fig. 3I3).

(I) SchweIGHAUSER, dans Kunstblatt, I826, p. 358; dans Bonner Jalirbücher, V-VI, 380 et dans Mémoires de la Société des Antiquaires de France, t. VI, 1842 .

(2) URLichs, Vasa diatreła in Ko óln, dans Bonmer Jahrbïcher, I 844 , fasc. 5.et 6, p.377-382, pl. XI et XII. 
4. Hohcnsulzen. - Fouille de I869. Diatrète trouvée dans un sarcophage avec une bouteille forme 9 en verre incolore gravé. Cette diatrète, une des pièces les plus remarquables de toute la verrerie antique, est de taille exceptionnelle (2I centimètres de diamètre). Elle est en verre incolore décomposé. Elle est dépourvue d'inscription (I) (fig. 3I4).

Dans le sarcophage où elle a été découverte, elle gisait, cassée en

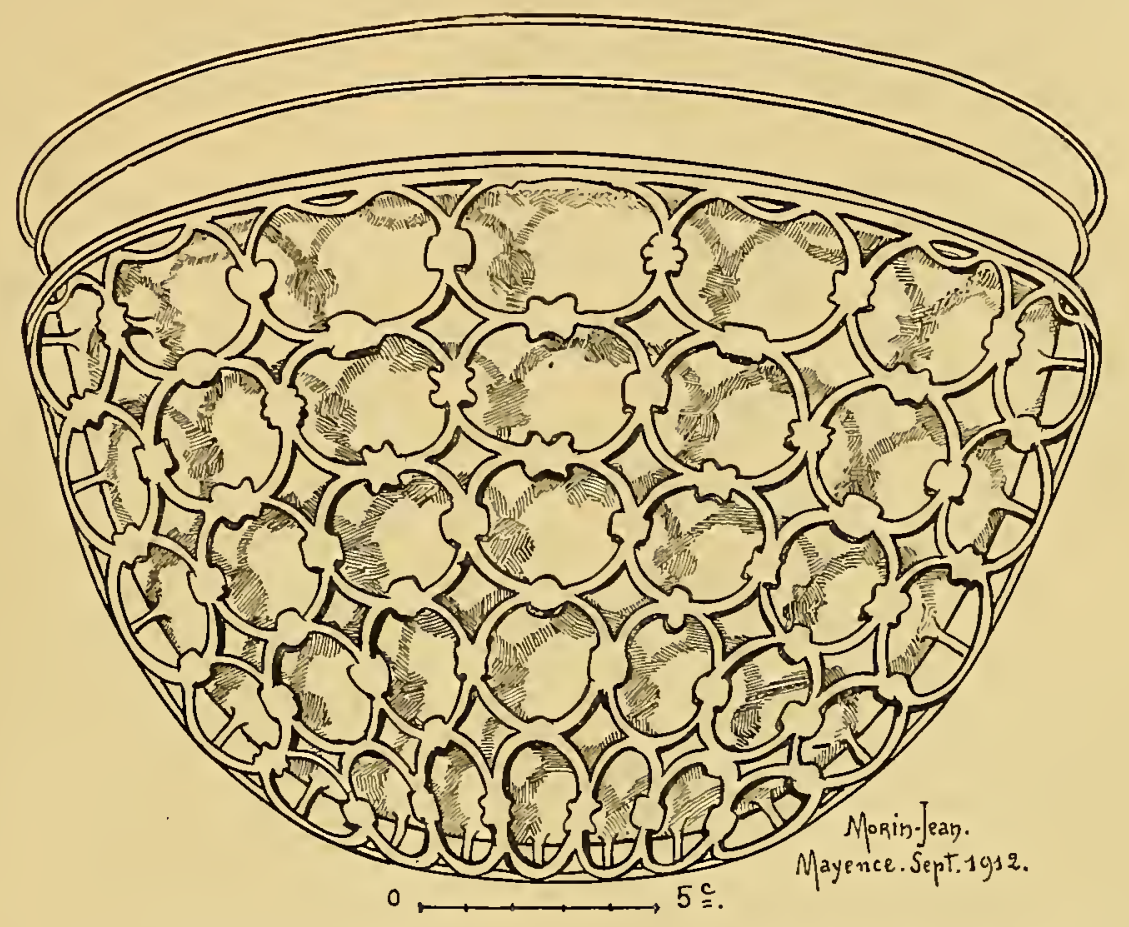

Iig. 3I4. - DIATRÈTE, trouvée à Hohensulzen. - Musée de Mayence et Musée provincial de Bonn.

deux morceaux, aux pieds du squelette. A la suite de quelles péripéties ces deux morceaux, au lieu d'avoir été rejoints, sont-ils arrivés dans des musées différents? On ne sait. Toujours est-il que le plus grand fragment est actuellement exposé au musée de Mayence, et le plus petit au Provinzialmuseum de Bonn (2).

(I) Bonner Jahrbïcher, I,IX, 69, pl. II, 2.

(2) To A. 864. 


\section{9. - Gravure ein creux (I).}

Clément d'Alexandrie (I60 à 220) parle de la prétentieuse, inutile et vaine gloire des GRAVEURS sur verre (2).

Ce texte ne renseigne guère les archéologues, car nous ignorons de quel genre de gravure 1'auteur chrétien a voulu parler. Son blâme était peut-être dirigé contre les diatretarii qui sculptaient le verre à la façon des camées.

Il est certain qu'on a dû de bonne heure faire des essais de gra-
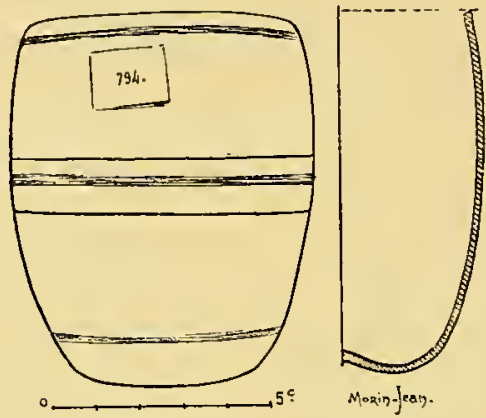

FIG. 3r5. - Verre a cercles gravés. - Arles. Romain II. - Cabinet des Médailles, à Paris, no 794.

vure sur verre, puisque l'on connaissait la gravure en pierre fine depuis les temps les plus reculés.

Toutefois, les verres gravés en creux ne se rencontrent guère dans les sépultures de Gaule avant le $\mathrm{mm}^{\mathrm{e}}$ siècle. A Cologne, ils sont rares dans les incinérations qui contiennent les plus beaux verres à applications vermiculaires; ils sont nombreux dans les inhumations qui vont de 250 au début du ve siècle (3).

Ceux de la seconde moitié du $\mathrm{III}^{\mathrm{e}}$ siècle sont d'un assez bon style ; ceux du rve trahissent une main lourde et maladroite; ceux du ve. accusent une profonde décadence.

Il est très intéressant de constater que les verres gravés ont pour

(I) La gravure en creux se faisait, dans l'antiquité, soit à la pointe de pierre dure (quartz, émeraude, corindon) guidée à la main, soit à la molette montée sur un tour.

(2) Clement d'Alexandrie, Pcedagogus, liv. II, ch. $\mathrm{II}$.

(3) Anton Fisa, Das Glas in Altertame, p. 247. 
la plupart été trouvés dans la Belgica et sur les bords du Rhin, mais il n'est pas prudent d'en déduire que le Rheinland était, au Ro-

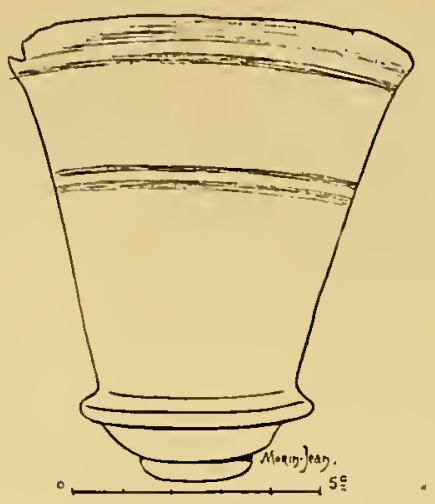

FIG. 316. - GOBELET DE VERRE INCOLORE, omé de cercles gravés légèrement. - Cimetière du Vieil-Atre, à Boulogne-sur-IIer. - Collection Morin-Jean, no 2228 .

main II, le seul pourvoyeur des verreries à sujets gravés. Ces sujets appartiennent presque tous au répertoire hellénistique et oriental. On peut les répartir en plusieurs grandes séries.

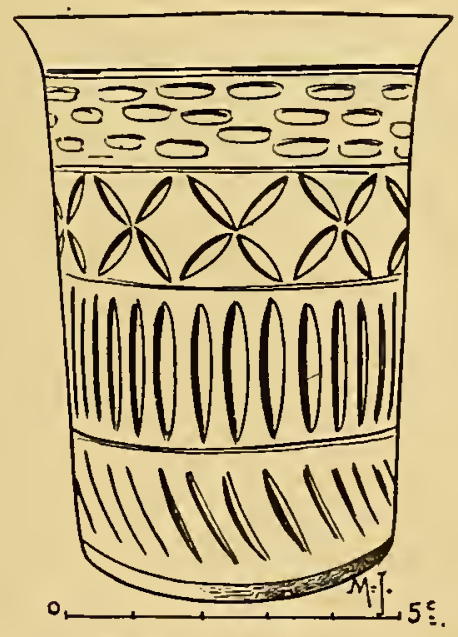

FIG. 3I7. - VERRE GRAVÉ EN CREUX. - ROMain II. - Musée d'A miens, no 988 .

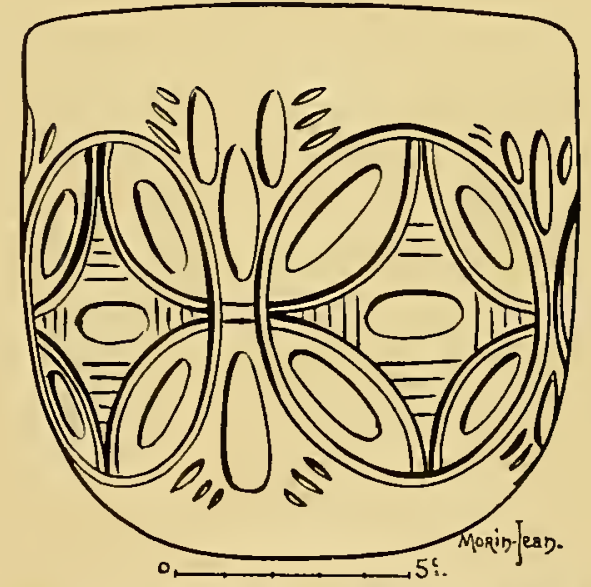

FIG. 3I8. - BOL DE VERRE GRAVÉ. - Étampes (S.-et-O.). Romain II. - Musie de Saint-Germain, $n^{0} 29665$.

a. Combinaisons géométriques. - Le décor le plus simple et le plus répandu consiste en de fines lignes gravées à la meule, disposées 
en cercle autour du récipient (fig. 3I5, 3I6). Des combinaisons plus savantes : rosaces, étoiles, cannelures, etc., varient à l'infini

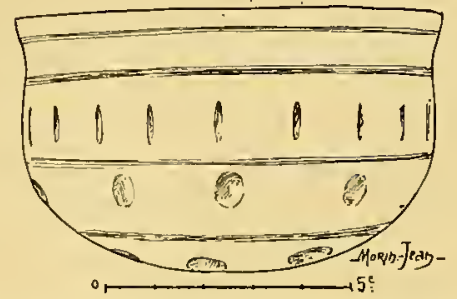

FIG. 3I9. - BOL GRAVÉ. — Verre incolore. Fouilles de Reims (Marne). - Collection Morin-Jean, $\mathrm{n}^{0} 2039$.

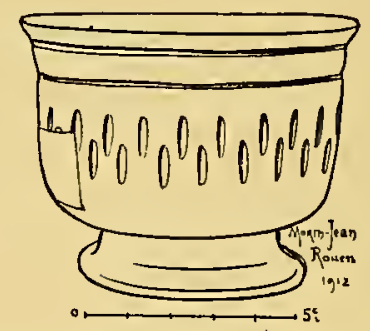

FIG. 320.-BoL A PIED. - Verre incolore. CollevilleOrival, I864. - Romain II. - Musée de Rouen (ancienne Collection de Girancourt.)

(fig. 3I7, 322). Elles sont quelquefois formées d'un assemblage régulier de cupules assez profondes qui miroitent à la lumière (fig. 320). Dans un fragment de verre incolore, très filandreux, découvert en I87I à Boulogne-sur-Mer et qui semble appartenir à une époque

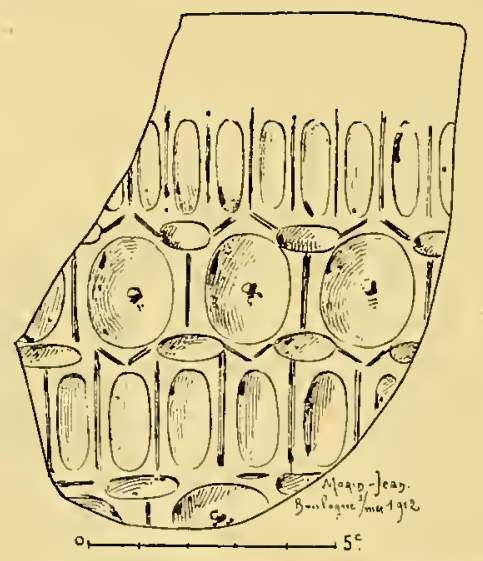

Fig. 32I. - Fragment D'UN BOL DE vERRE INCOLORE, orné de cupules et de traits gravés. - Cimetière du Vieil-Atre à Boulogne. Fouilles de I87r. Romain II. - Musée de Boulogne-5ur-Mer, $\mathfrak{n}^{\circ} 2724$.

assez tardive, les cupules sont pourvues au centre d'un point en relief (fig. 32I).

b. Scènes du cirque et de l'amphithéâtre. - Les graveurs ont quelquefois repris, sans apporter de changement dans la composition, les scènes de courses et de combats des verres moulées. C'est ce 
que nous apprennent un beau fragnent de verrerie et un bol forme $8 \mathrm{I}$ du musée de Trèves :

Le fragment appartenait à un récipient de fabrication soignée. On y voit des cliars d'un excellent style (I).

Le bol est noins bien gravé. Il est orné d'un bige courant vers la droite d'une panthère et d'un bestiaire armé d'un poignard et d'un trident (2). Au-dessus de cette décoration court une inscription latine : Brbavvs, qui n'a aucun rapport avec les sujets figurés plus bas ; c'est un souhait adressé au buveur.

c. Scènes de chasse. - Le graveur à qui nous devons une coupe,

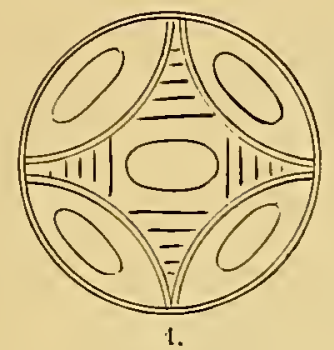

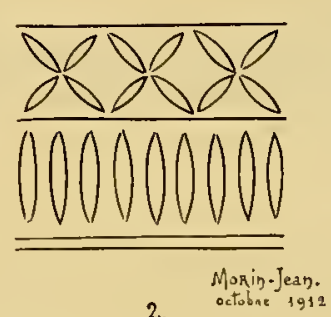

2.

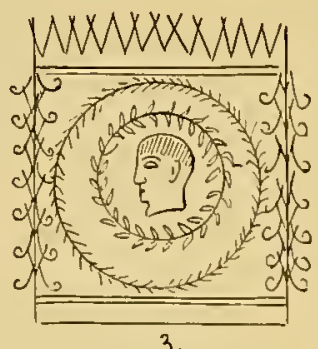

3.

Fig. 322. - Gravure et taille DU verre aU Romain II. - r. Citampes, 2. Amiens, 3. Cologne.

décorée d'une chasse au cerf (3), reproduite par Kisa (4), n'a pas une personnalité bien marquée. Si ce n'est pas un oriental, c'est un orientalisant. Il appartient à cette lignée d'artistes et d'artisans qui furent, à l'époque de la civilisation grecque, les peintres de vases ioniens ; à l'époque impériale romaine, les céramistes, les verriers et les orfèvres d'Alexandrie; au Moyen-âge, les enlumineurs persans, les ivoiriers byzantins, les faienciers de Rhodes et de Damas. I1 ne desine pas bien, mais il sait composer. Il devait travailler au IVe $\mathrm{s}$. ou vers le début du ve.

(I) Avton KIsA, Das Glas im Altertume, p. 650, fig. 250.

(2) ANTON KisA, lor. cit., p. 648, fig. 257.

(3) Une chasse au cerf est gravée sur une grande coupe de la collection Pierpont-גIorgan (ancienne collection Gréau), publiée par W. Froerner [Coll. Julien Gréau, Paris, 1903, nº 1.103, pl. CIXXXX]. Prés du bord de cette conpe, on lit la formule de souhait : MIvtros. axios. - Un sujet, qui semble se rattacher à la chasse au cerf, est gravé sur un fragment de verterie du musée de Saint-Germain (nº z9.5 rr, Clermont-Ferrand, Puy-de-Dôme). I,es animaux représentés sur ce fragment n'ont pas étẻ gravés en creux, mais traités en relief, suivant une curieuse technique dont nous ne connaissons pas d'antre exemple.

(4) Avtox Kiss, loc. cit., p. 653 , fig. 263 [Collection Vom Ratis, à Cologne]. 
L'auteur d'un bol découvert à Strasbourg, en I878, dans une inhumation assez tardive (I), n'avait aucune finesse de touche. De plus, il était assez pauvre d'imagination. N'ayant pas une manière originale de penser, il ne pouvait se créer une manière originale de dire. Aussi n'a-t-i1 pas eu recours à de nouvelles formules pour orner les produits dont il avait la commande. Il a repris un de ces thèmes extrêmement anciens employé à satiété par les décorateurs depuis l'antiquité la plus haute : la chasse au lièvre.

Les monuments décorés de la chasse au lièvre sont innombrables.

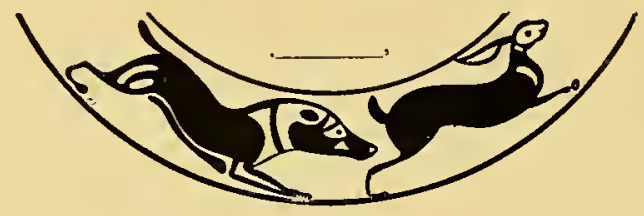

A

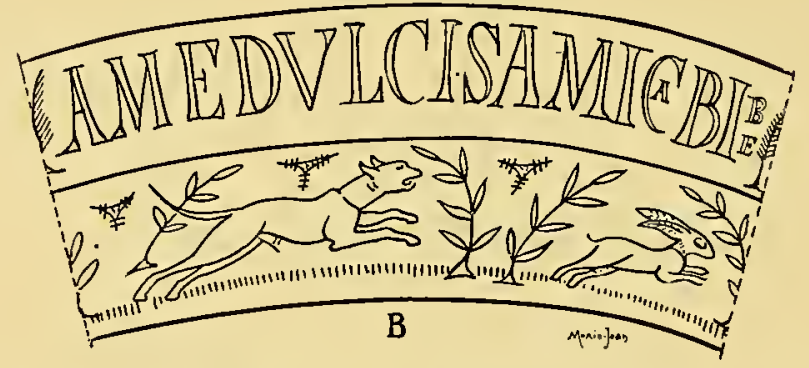

FIG. 323. - MOTIF DE LA CHASSE AU LIÈVRE: A. Sur une amphore thodienne en terre cuite du vin $\mathrm{s}$. av. J.-C. (MIusée du Louvre, A. 329). - B. Sur un verre du rve s. apr. J.-C., dècouvert à Reims en I884 (Musée de Reims, $\mathrm{n}^{\circ} 4720$ ).

Ce sont des gobelets préhistoriques découverts à Suse et qui, d'après les évaluations les plus modérées, remontent à 3.000 av. J.-C. (2), des vases mycéniens, des poteries doriennes du virI $\mathrm{fiècle}^{\mathrm{e}}$ des vases rhodiens (fig. $323 \mathrm{~A}$ ), et corinthiens (3), des amphores attiques, des bucchéros étrusques, des pièces d'orfèvrerie alexandrine, des bols

(I) Straub, Le cimetière gallo-romain de Strasbourg, p. 28 , avec pl. lithog.

(2) E.D. Pottrer, J. DE Morgan et R. DE Mecouenen, Mémoires de la Délégation en Perse, t. XIII, Paris, I $9 \mathrm{I}_{2}, \mathrm{p} .73, \mathrm{pl}$. I, $\mathrm{n}^{\circ} 4$, pl. III, n० 7 et pl. II I, no 4 .

(3) MORIN-JEAN, Le dessin des animanx en Grice d'apris les vases peints, p. 6I-62-I 72-I 85, fig. III, IV 60 , I30 et 213 . 
d'Arezzo et de la Gaule romaine (I), des étoffes d'Antinoë (2), des plats de Rliodes, des tapis de Dan1as.

C'est encore la chasse an lièvre que nous trouvons sur un verre à boire du musée de Reims (3) (fig. 323 B). Ce gobelet est orné de deux zones de gravure superposées. Dans la zone supérieure est une inscription latine: A. ME. Dvrcis, Amica. BibE; dans la zone inférieure, un chien poursuit un lièvre au milieu d'un paysage exprimé par des plantes à feuilles lancéolées.

Sur un bol trouvé à Bonı et conservé au musée de cette ville, le

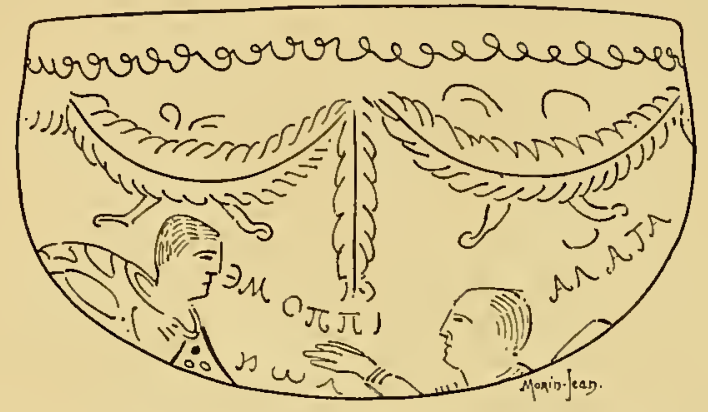

FIG. 324 - Bol Grave. Atalante et Hipponìne, - Reims. Fouilles de r896. - M usée de Reims, nu 22 I.

lièvre est poursuivi par un chasseur monté sur un cheval et par deux chiens.

I,e thème de la chasse au sanglier a été choisi par le graveur d'une coupe du musée de Mayence publiée par Aus'm' 'Weerth (4). Un chasseur, à pied, aidé de ses deux chiens, attaque un sanglier. La scène est accompagnée d'une légende circulaire: VALERI. VIVAS.

Une coupe 70 en verre vert pâle de la collection Pierpont-Morgan est ornée d'une représentation analogue (5).

d. Sujets mythologiques. - Les verres gravés à sujets mythologiques ont pour la plupart été découverts dans la vallée du Rhin.

(r) J. Décheletre, Les vases céramiques ornés de la Gaule romaine, t. II, p. I38-I 42.

(2) Necropole de Deïr-el-Dyk. Founlles de M. AL. GAyet, r898-1899.

(3) Verre découvert à Reins (lieu dit la Fosse Plantine. Clairmarais), le Ig juillet I 88 +. Voy. Catalogue du Musée de Reims, I9or, P. $170,11^{\circ} 4.720$.

(4) Bonner Jahrbicher, isSo, p. 49, p. I.

(5) Ancienne collection Gréau, publiẻe par WV. FRathvir, Collection J. Griau, no r.092, pl. CLXXXVII. 
Classiques dans leur style, mais alexandrins dans leur facture, ils ne peuvent être séparés du groupe des productions de l'Orient grec. Quelques-uns de ces monuments méritent une description détaillée :

I. Reims (lieu dit Fosse-Pierre-I,a-Longe) (Marne). - Fouilles J. Orblin (I6 mars I896). Bol 7 I en verre incolore. Le sujet représente le combat d'Atalante et d'Hippomène, au moment où Atalante se reconnaît vaincue, et étend le bras vers son adversaire pour mettre fin à la lutte. Les combattants, tête nue, sont vêtus d'amples manteaux. Leurs noms sont inscrits auprès d'eux : atananta et mnomedWN (I). Style fin $\mathrm{III}^{\mathrm{e}}$ ou $\mathrm{IV}^{\mathrm{e}}$ siècle (fig. 324). Musée archéologique de Reims (2).

2. Cologne. - Bol 73. Le sujet gravé figure la création de l'homme, 1' anepunoronı. Assis sur un tertre, Prométhée est occupé à modeler une figurine humaine. Epiméthée lui tend 1'argile. Atlas contemple cette opération. Dans un autre compartiment, un enfant joue près d'une femme personnifiant la terre. Du côté opposé, Menoitos foudroyé par Zeus. Les noms des personnages sont gravés

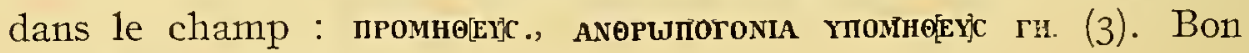
style. Musée de Berlin.

3. Cobern-sur-Moselle. - Fouille de $\mathrm{I} 878$. Coupe. Poseidon, armé du Trident, tient son pied gauche levé au-dessus d'un édifice. Il est entouré de poissons et de fauves à queue de dauphin. Sur le pourtour du récipient, inscription : Propino. Amantibvs (fig. 325). Style lourd et barbare (4). Musée de Berlin. M. Aus'm' Weerth a établi un ingénieux rapprochement entre le Poseidon de cette coupe et le Poseidon Domatites de Pausanias [III, I4].

4. Cologne. - Bol 7I. Mythe de Lyncée, un des cinquante fils

(I) M. DÉchelette signale sous le no 80 de son recueil général des types figurés sur les vases à relief d'applique [Les vases céramiques ornès de la Gaule romaine, t. II, p. 279 et suiv.], un médaillon de terre cuite qui représente le tnême sujet et sur lequel le nom du vainqueur est reproduit avec la même orthographe ( $\triangle$ au lieu de N) que sur le verre de Reims. Ce médaillon n'est pas antérieur au troisième siècle de notre ère.

(2) Catalogue du Musée archéologique de Reims, $\mathrm{n}^{\circ} 2.28 \mathrm{I}, \mathrm{p} .72$ et pl. II. I,es dessins de ce joli bol sont tracés sur l'extérieur du vase et les noms des personnages sont écrits de droite à gauche, de façon à ce qu'ils soient lisibles de l'intérieur.

(3) La coupe de l'Anthropogonie a été publiée par F. G. Welcker, dans les Bonner Jahrbïcher de I860, fasc. 28, p. $54^{-62}$ et pl. XVIII. On en trouvera un dessin dans le Dictionnaire de MI. S.1GLIo, t. IV, première partie, p. $68_{3}$, fig. 5.805 .

(4) Bonuer Jahrbücher, I880, p. 52, pl. V; et Roвert Schumt, Das Glas, Berlin, I912, p. 23, fig. Io. 


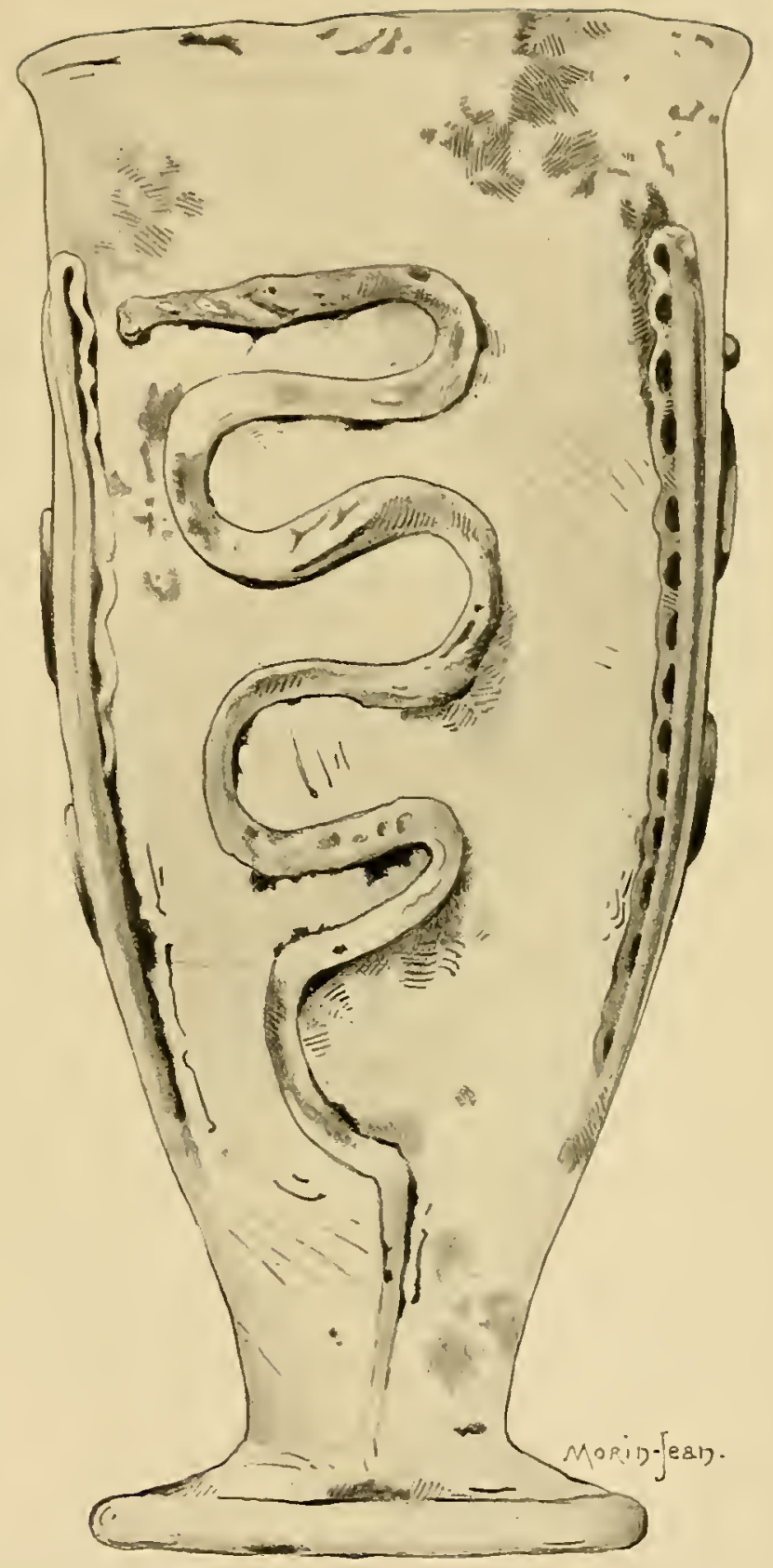

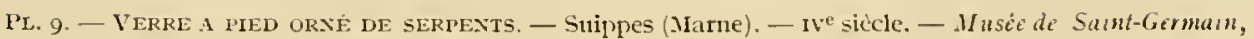
$11^{\circ}$ I 3.345 . 

d'Aegyptus, à qui son épouse Hypermnestre sauva la vie, tandis que tous ses frères furent tués par les filles de Danaüs (I). La scène représente Hypermnestre couronnée, tendant la main à son mari qu'elle refuse de mettre à mort. Au-dessous, Pothos ailé. Dans le champ sont gravés les noms : үпернистра arnrexc поөоc. Cologne. MIusée Wallraf-Richartz.

5. Cologne. - Verre à boire tronconique. Eros ailé. Style barbare du $\mathrm{Iv}^{\mathrm{e}}$ ou du ve s. (2). Musée Wallraf-Richartz.

6. Hohensulzen, près Worms. - Verregravé orné d'une scène appar-

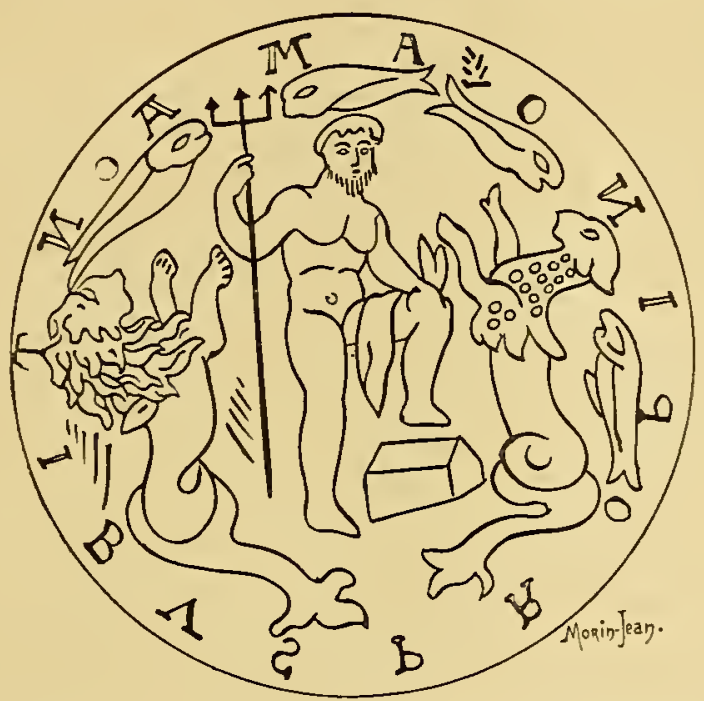

Frg. 325. - COUPE GRAvÉE, découverte en I878, à Cobern-sur-AIoselle. - Musée de Bcrlin.

tenant au Cycle dionysiaque. Les personnages sont Dionysos tenant un ihyrse et une coupe, Héraklès ivre et étendu à terre, Attvs, Pan, des Silènes et des Ménades. On interprète ordinairement cette scène comme le triomphe du vin sur la force (3).

(1) Le bol de Iyncée a été publié par Kasrp, Die epigraphischen Anticaglicn in Köln, IS6́g, p. I6. Il est reproduit dans KIsA, Das Glas in Altertume, fig. 246 et 247 .

(2) Avtox Kiss, loc cit., p. 665 , fig. $2+9$.

(3) Bonner Jahrbücher, I870, p. T4, pl. III. Un sujet analogue est représenté sur le vase Sallicr, du

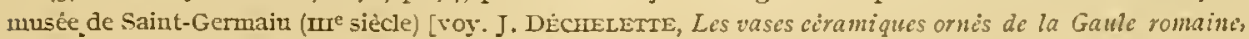
t. II, P. 3 ro et pl. IV]. 
7. Gobelet tronconique du Provinzialmuseum de Bonn. - Aphrodite et Eros (I).

8. Rheindorf près Opladen. - Bol $7 x$. Éros au milieu de pampres. Texte latin : Merveifa. Vivas. Tvis (2). Bonn. Provinzialmuseum.

9. Fragment de coupe de la collection Pierpont-Morgan [Ancienne collection Gréau]. - Verre verdâtre épais. Combat d'Héraklès et de 1'Hydre de Lerne. Style barbare (3).

e. Têtes de personnages disposées en médaillons. - Quelques verres gravés de la basse époque impériale sont ornés de têtes de personnages. Chacune de ces têtes se présente, comme sur les monnaies, au centre d'un encadrement circulaire. Nous signalerons deux spécimens de ce genre de verreries, tous deux trouvés à Cologne.

Le premier est un bol conservé au musée de Bonn ( $\left.\mathrm{n}^{\circ} 5.566\right)$ (fig. I6o). La tête, gravée de profil dans une double couronne de feuilles,

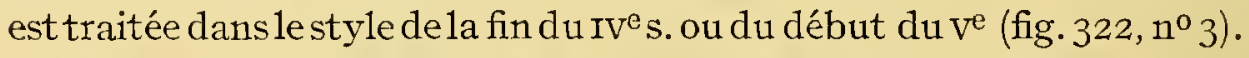

Le second appartient à M. Pierpont-Morgan [ancienne collection Julien Gréau]. C'est une coupe en verre verdâtre, de Io centimètres de diamètre et de 5 centimètres et demi de hauteur. Elle porte quatre médaillons. Au centre de chacun d'eux est un buste imberbe, drapé, tourné vers la gauche. Près du bord du récipient, sont gravés deux étoiles et deux petits temples distyles (4).

f. Sujets chrétiens. - De bonne heure, 1'Église manifesta un goût pour le luxe qui n'était guère en harmonie avec ses humbles origines. Dès que le culte chrétien fut ouvertement autorisé par l'Empire (3I3), ses prêtres adoptèrent les plus riches matières pour le mobilier liturgique: métaux précieux, ivoire et verre.

Alexandrie, par sa situation géographique, par sa position sur la route des pèlerins et des marchands, semble avoir été le centre le plus actif de la fabrication des verres chrétiens.

Les verres chrétiens sont des œuvres de petits artisans, des œuvres populaires remplies de tous les défauts de basse époque : lourdeir,

(1) ANToN KisA, loc. cit., p. 663 , fig. 248 .

(2) AUs'm'WeERTh, Römische Gläser, dans las Bonner Jahrbücher, I882, fasc. 74, p. 63 ; - ANTOx KISA, loc. cit., p. 665, fig. 252.

(3) Froenner, Collection Julien Gréau, no 1.094 , pl. I88, no 2.

(4) Froehner, loc. cit., $\mathrm{n}^{0} \mathrm{I} .084$, pl. $\mathrm{I}_{4}, \mathrm{n}^{\circ} 4$. 
incorrection du dessin, impuissance à donner aux physionomies des personnages une expression en accord avec le nouvel idéal religieux. Ce sont pourtant des œuvres d'art. Sous ces formes naïves qui trahissent une inexpérience à peu près complète, apparaît quelque chose que l'antiquité ignorait. Il a passé sur ces productions comme un souffle d'universelle espérance. Comme les plafonds peints des catacombes, les verres chrétiens sont le germe vivant d'une fleur nouvelle qui s'épanouira dans les mosaïques byzantines, sur les custodes et les reliquaires du Moyen âge, sur les façades de nos églises romanes.

En puisant leurs expressions plastiques dans le vieil arsenal du paganisme, les peintres, les graveurs, les ciseleurs chrétiens, établirent une transition imprécise, flottante, mais réelle, entre l'esprit antique et l'esprit médiéval.

Essayant d'arracher une nouvelle doctrine à l'amas confus des vieux mythes, incapables de renouveler les formules mais sachant leur donnet une âme nouvelle, ils racontent avec une simplicité touchante, ils psalmodient, sur un rythme lourd mais empreint d'un grand caractère, les épisodes les plus populaires de l'Ancien et du Nouveau Testament.

Les graveurs des coupes que nous allons examiner ne savaient pas dessiner. Ils ont pourtant été des artistes, car ils ont su équilibrer les masses, disposer harmonieusement les lignes, lier intimement le décor d'un objet à sa forme, ne jamais sacrifier les ensembles au profit des détails.

On peut étudier à Paris même un des plus précieux monumentsde 1'art chrétien primitif. C'est une coupe, forme 70 , découverte en $I 884$, au cimetière d'Homblières, à Abbeville, et achetée en I 887 par le musée du Louvre. Elle faisait partie du mobilier funéraire d'une femme de cinquante à soixante ans, inhumée vers la fin du IV $\mathrm{s}$. ou le début $\mathrm{du} \mathrm{v}^{\mathrm{e}}$. Elle est en verre verdâtre et filandreux. Elle a été gravée sur sa face externe (fig. 326) (I).

(I) Ia coupe d'Homblietres a été publié dans la Gazctte archéologique de I88, pl. IXII, et daus les Mémoires de la Sociétć Académique de Saint-Quentin, I886, $4^{\circ}$ série, t. VI. On la trouvera aussi décrite dans J. PILroy, Eludes sur d'anciens lieux dc sépultures dans l'Aisue, Saint-Quentin, I886, t. I, p. I79 et suiv. (Description du cimetière d'Homblicres. Tombe no 52). 
La gravure représente plusieurs motifs dont le sens s'établit aisément. On voit au centre un grand monogramme du Christ auprès
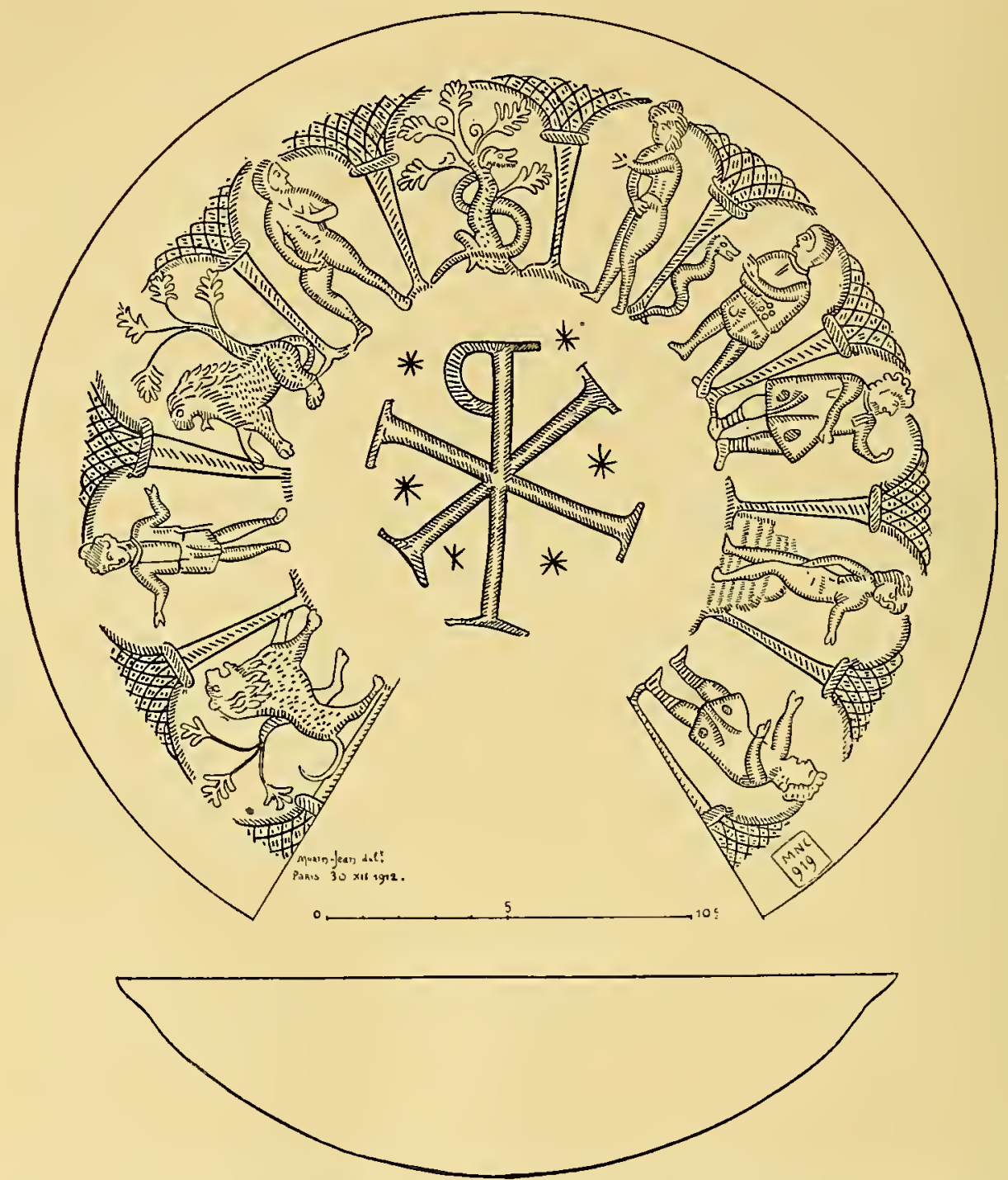

FIG. 326. - Coupe chrétrienNe GRAvÉE, - Cimetière d'Homblières, à Abbeville (Somme). Fouilles de I884. Fin du $\mathbf{I V}^{\mathrm{e}}$ ou début du ve s. - Musée du Louvre. MI.N.C. 9 Ig.

duquel brillent six étoiles à huit rayons; et, sur le pourtour, Daniel entre deux lions, Adam et Evve auprès de l'arbre du bien et du mal 
et du serpent, Daniel et le dragon de Bel, la chaste Suzanne entre les deux vieillards.

Les personnages et les animanx sont séparés par des palmiers stylisés formant dix arcades d'égale grandeur. Le modelé des figures est obtenu au moyen de hachures d'un travail barbare. L'imperfection du dessin ue retire rien du caractère des sentiments qui ont inspiré le graveur.

La coupe d'Homblièreș est d'une belle tenue décorative. Peutêtre est-elle la copie de quelque œuvre plus importante, d'une coupe en métal précieux, ou d'une de ces riches tapisseries dans la confection desquelles excellaient les industriels orientaux.

On a découvert en Gaule un certain nombre de verreries gravées qui se rattachent directement à elle par le style et la nature des sujets qui les ornent. Voici les plus connues d'entre elles:

I. Vermand (Aisne). - Fouilles Théophile Eck pour la Société Académique de Saint-Quentin. Coupe trouvée le 3 février I886, à So centimètres de profondeur dans la tombe à inhumation $n^{\circ} 330$. Diamètre : I9 centimètres. Hauteur : 5 centimètres. Le sujet gravé au burin sur la face externe représente la résurrection de Lazare. Cette scène, qui figure dans l'Évangile de Jean, mais n'est rapportée ni dans Mathieu, ni dans Marc, ni dans Luc, fut néanmoins une des plus familières de 1'iconographie chrétienne. On la trouve reproduite à satiété sur les sarcophages, dans les peintures et dans les mosaïques. Autour de la coupe, on lit un souhait de vie et de bonheur: VIVAs. IN. DEO. P.Z. Dans le champ, au-dessous du $Z$, sont gravés le monogramme du Christ et une étoile à huit branches. Fin du rve siècle. Musée Lécuyer, à Saint-Quentin (I).

2. Vermand (Aisne). - Fragment d'une coupe gravée représentant Daniel dans la fosse aux lions et portant une inscription dont il ne reste que les mots : VIVAS. IN... Cette pièce faisait partie, en I886, de la collection de M. Hoffmann, antiquaire à Paris (2).

3. Boulogne-sur-Mer (Pas-de-Calais). - Fouilles au cimetière du

(1) Bulletin de la Sociêté des Antiquaires de France, I886, p. 238 , avec figure au trait; - TH. Eck, Les deux cimeticres gallo-romains de Vermand et de Saint-Quentin, IS9r, p. 94 et I73, pl. III, ñ ${ }^{\circ}$.

(2) TH. ECE, loc. cit., p. I72-I73. 
Vieil-Atre, le $2 \mathrm{I}$ octobre I888. Coupe en verre incolore un peu verdâtre, de 3 à 4 millimètres d'épaisseur. Grand diamètre : 0,192 millimètres. Profondeur : 0,053 millimètres. L,e sujet gravé représente le sacrifice d'Isaac. Dans le milieu, un autel allumé. A droite, Isaac,

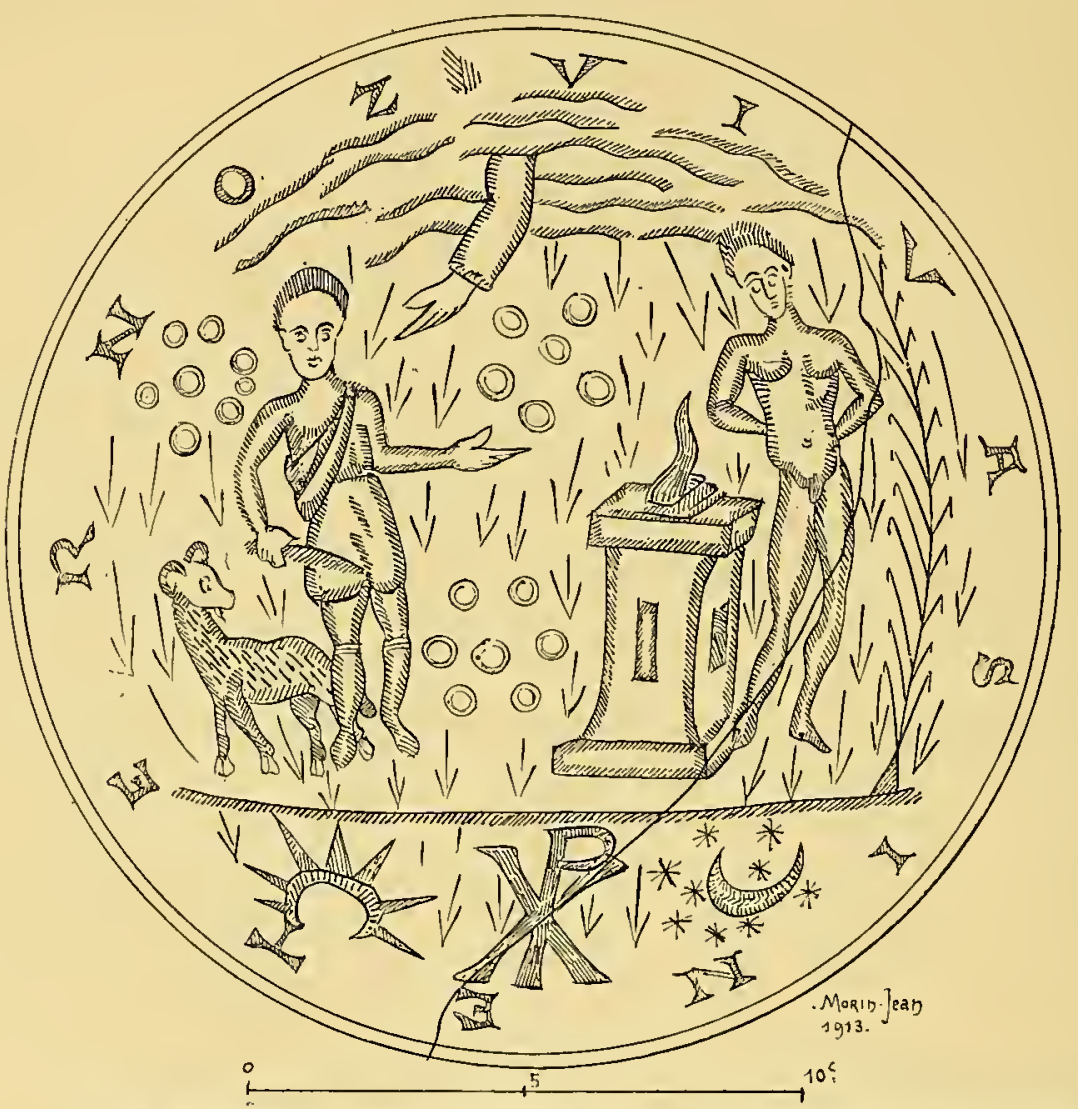

FIG. 327. - COUPE ChrÉtIENNe GRAvÉE. LE SACrifice D'IsAaC. - Cimetière du Vieil-Atre, à Boulogne-

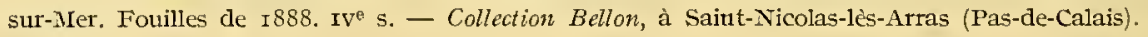

nu, debout, les mains liées derrière le dos. A gauche, Abraham tenant le couteau du sacrifice; près de lui, un bélier. Dans le haut, le bras de Dieu sortant d'une nuée. Dans le bas, le monogramme du Christ, un croissant radié, un croissant non radié et des étoiles. Dans le fond de la coupe, des anneaux et des traits gravés. Sur le côté, près d'Isaac, un arbre. En pourtour, l'inscription VIVAs. IN. ETERNO. Z. (fig. 327). Travail en hachures obliques taillées à la meule. Collection Bellon 
à Saint-Nicolas-lez-Arras (I). Dans la sépulture, qui contenait cette coupe, on a trouvé quatre monnaies de bronze de Tacite (mort en $276)$.

4. Trèves. - Fouilles du chanoine von Wilmowski au cimetière de Pallien en 1873 . Coupe de 0,235 millimètres de diamètre. Le sacrifice d'Isaac. En pourtour, VIVAS. IN. DEO. Z. Provinzialmuseun de Trèves (2).

5. Strasbourg. - Fouille du I4 mai i88o. Tombe en maçonnerie ${ }^{11^{\circ}}$ I57. Gobelet en forme de cône tronqué. Hauteur: I2 centimètres. I.es sujets gravés représentent la résurrection de Lazare, le sacrifice d'Isaac, Moïse frappant le rocher (3).

6. Bonn. - Fouilles de I877.Coupe gravée représentant la résurrection de Lazare (4).

7. Coupe du Paulus-Museum de Worms. - Suzanne (5).

D'autres verres gravés à sujets chrétiens sont signalés par Froehner (6) et par Kisa ( 7$)$.

g. Inscriptions. - Les verres gravés ne portant qu'une simple inscription sont nombreux. Nous nous contenterons de mettre quelques exemples sous les yeur du lecteur :

Tol,ITE. VI. sur une coupe faisant partie du mobilier de la tombe du chef de Monceau-le-Neuf. Collection Cl. Boulanger, à Péronne (8).

Vivas. Cvm. Tvis. P.Z. sur un bol forme 73 découvert à Vermand et conservé au musée de Saint-Quentin (décrit plus haut, p. 220, $\mathrm{n}^{0} 3$ ).

Cvrre Pverva. sur une bouteille forme 40. Musée de Mayence, $n^{0}$ II25 (fig. I04, B.).

SIMPLICI. ZESES. sur un verre à pied forme Iog. Musée de Mayence.

(I) V. J. Vartlaist, Notes boulonnaises. Epigraphie de la Morinie, Boulogue, I89o, p. 210 , et planche; - LE BLANT, dans le Bulletin A rchéologique, 1890, p. 78 ; - PAUL ALLARD, dans La Science catholique, $3^{e}$ année, $\mathrm{n}^{\circ} \mathrm{I}$.

(2) Von Wrinow'ski, Archaeologische Fundein Trier und Umgegend, 1873, p. 42 ; et pl. IV. - Aus's'WEERTH, dans les Bonner Jahrbücher, I88o, p. 53, pl. VI.

(3) Straub, Le cimetière gallo-romain de Strasbourg, p. 9I et suiv., et pl. II et III.

(4) Bonner Jahrbiicher, L, IIII, pl. 5, 4 a, LגIIV, x28.

(5) ANToN Kissa, loc. cit., p. 674 .

(6) W. Fremerer, Collection Julien Gréan, Paris, I903, u I ogr, pl. I86. Fragment de coupe en verre verdâtre. Hoïse frappant le rocher et les trois jeutes Hébreux dans la Fournaise.

(7) A.vton Kiss, loc. cit., p. 67o, fig. 259 (la résurrection de I.azare) et p. 674, fig. 265 (Suzaune).

(8) CL. Boulanger, Le Mabilicr funéraire, pl. I4 et pl. 20. 
Felix. Vivas. sur une bouteille forme 4I. Musée de Mayence. (Fouille de Kastel) (I) (fig. III, B).

Pver. Miscetve. D (otabo) sur une bouteille forme 4o. Musée de Mayence.

On remarquera que les verreries, sur lesquelles ces inscriptions' sont gravées, sont toutes du Romain II tardif.

\section{IO. - PEINTURE.}

L'antiquité nous a laissé quelques monuments qu'on peut considérer comme les précurseurs des verres peints du Moyen-âge et des Temps modernes (2). Ces produits sont rares. Les sujets qui les ornent ont été d'abord gravés légèrement à la pointe.

Le plus remarquable des verres peints qui nous soient parvenus est un bol forme $7 \mathrm{I}$, trouvé à Nîmes en I 858 et conservé au musée du Louvre (3) (p1. I et fig. I57). Il est en verre vert émeraude, sur lequel se déroule une scène polychromée appartenant au répertoire gréco-oriental : le Combat des Pygmées et des Grues (4). L'artiste a représenté trois grues et deux Pygmées armés d'une lance et d'un bouclier ; sur le fond du vase, il a peint une fleur à huit pétales.

En examinant de près ce précieux document, on aperçoit la trace d'une première ébauche à laquelle le peintre ne s'est pas arrêté ; c'est ce qui explique la présence de deux têtes de grues qui n'ont pas servi et qui doublent les têtes définitives.

Il est probable que le bol de Nîmes a été fabriqué dans quelque officine des régions méditerranéennes. Deux bols peints, présentant avec lui de frappantes analogies, ont été recueillis en Algérie.

(I) BECKER, Römisch. Inschrift, VII, H. I.

(2) N'ayant pu faire analyser l'enduit des verres peints qui nous passerent par les mains, nous n'avons pas voulu aborder les questions ayant trait à la technique de la peinture sur verre dans l'antiquitè.

(3) Le verre peint de Nîmes a été publié par M. HÉRON DE VILLEFosse duns la Revue archéologique de 1874 , t. I, p. $28 \mathrm{I}$ à 289 avec planche.

(4) Le Combat des Pygmées et des Grues est d’origine égyptienne. Il est souvent représenté sur les vases antiques du vi et du ve siècles av. J.-C. Il est peint notamment sur le pied du célébre vase François conserré au musée de Florence et sur le vase F. 44 du Louvre. [Voy. Eo. PotTrer, Catalogue des vases antiques du musée du Lowvre, p. 733, et le Dictionnaire des Antiquités de MI. SAGLIo, t. IV, p. 783, fig. 5.90r.] L,es Pygmées sont assez communs dans le décor des vases arvernes à reliefs moulés fabriqués à I,ezoux. [Voy. J. DÉchELETTE, Les Vases ornés, I, p. 224, et II, p. I46, no 99 I.] 
Le premier, en verre blanc laiteux, provient d'Alger (fouille de I852). Il est orné de deux sujets représentant des combats de gladiateurs d'abord gravés à la pointe, puis peints (I).

Le second, en verre bleu, a été découvert à Khamissa. Il est décoré de deux oiseaux voltigeant dans des feuillages. Une fleur à pétales rayounants, rappelant celle du bol de Nîmes, est peinte sur le fond (2).

La peinture sur verre a laissé dans la vallée du Rhin quelques œuvres importantes du Romain II. C'est une bouteille forme $4 \mathrm{I}$, originaire de Dürffenthal près Zïlpich, décorée d'un quadrige (Bonn. Provinzialmuseum $n^{0}$ I7.303) (3). C'est encore une carafe forme 40 , découverte à Cologne, ornée de poissons et de scorpions (Musée Wallraf-Richartz) (4).

Peut-être faut-il, avec les Allemands, rattacher aux productions rhénanes du IVe siècle, des bols forme $8 \mathrm{I}$ trouvés en I87o, dans une sablière à Thorslunde, en Seeland (5). Les sujets peints sur ces bols appartiennent au répertoire gréco-oriental : chiens courants, oiseaux, fauves poursuivant des cervidés.

\section{II. - DORURE.}

Au commencement du $\mathrm{III}^{\mathrm{e}}$ siècle, la dorure sur verre était connue. A l'époque des empereurs syriens, on dorait quelquefois les applications vermiculaires rapportées à chaud (voy. plus haut, p. 204, $\mathrm{n}^{0} 2$, et p. 2I0, $\left.\mathrm{n}^{0} 9\right)$.

(I) HÉRON DE VILLFosse, Verres antiques trouvés en Algérie, dans la Revue archéologique, I874, t. I, P. $2 S I-2 S g$.

(2) Héron DE VHLEFosse, loc. cit. Les bols de Nìmes et d'Algérie sont difficiles à dater. On serait tenté de les placer au m$^{\ominus}$ siècle de notre ère. Mais, des verres peints par le même procédé, découverts en Russie méridionale, seraient d'une époque bien plus haute. Ils faisaient partie, paraît-il, de mobiliers funéraires non remaniés, caractéristiques du $\mathrm{I}^{\mathrm{er}}$ siecle av. J.-C. Nous ne pensons pas qu'il faille faire remonter si liaut le bol de Nìmes; mais il est prudent, dans l'état actuel de nos connaissances, de différer la solution de ce problème chronologique. Quoi qu'il en soit, la peinture sur verre, ou plutôt sur quartz, se rencontre déjà à Pompéi [roy. Revue des études grecques, I9I $2, \mathrm{p} .400]$.

(3) Avtow KISA, Das Glas im Attertume, p. 818, fig. 345.

(4) Aston Kisa, loc. cit., p. 8 I9-820, fig. 343 .

(5) Ces bols font partie des collections du musée de Copenhague. Ils ont été publiés par C. ĖvGELHARDT dans les Mémoires de la Société royale des Anliquaires du Nord, nouvelle série, I872, p. 57 et suiv., pl. X, XI et III. 
Ce n'est cependant qu'aux $I v^{\mathrm{e}}-\mathrm{v}^{\mathrm{e}}$ siècles que la dorure devint d'un usage fréquent. Les verres chrétiens de cette période tardive sont souvent à la fois gravés, dorés et peints.

La coupe dite de Sainte Ursule et la coupe de Saint Séverin en sont les exemples les plus célèbres.

La coupe de Sainte Ursule a été trouvée en I866, à Cologne (I). En I867, elle était dans la collection de M. E. Herstatt, à Cologne. Elle a ensuite été achetée par le Musée Britannique. Elle est ornée de huit scènes de 1'Ancien et du Nouveau Testament, disposées en cercle : I et 2. Jonas ; 3. Daniel entre quatre lions ; 4. Les trois jeunes Hébreux dans la fournaise; 5 . Guérison d'un aveugle; 6 . Suzanne dans la position de 1'Orante ; 7. Guérison du paralytique; 8 . Ézéchiel ressuscitant des débris humains. Les personnages sont dorés. Les feuillages qui remplissent les vides sont peints en vert. I,e centre de la coupe manque : il n'en reste que quelques débris portant les fragments d'une inscription : Ec.... DVLCI...

Ia coupe de Saint Séverin, trouvée, elle aussi, à Cologne, faisait partie en I864 de 1a collection Disch. Comme sa parèdre, elle a été acquise par le British Museum (2). C'est un fond de patène sur lequel on a appliqué, à chaud, une série de rondelles de verre à feuilles d'or historiées (3). Les sujets traités appartiennent au répertoire chrétien ordinaire: Adam et Ève, le sacrifice d'Isaac, Moïse frappant le rocher, les trois jeunes Hébreux dans la fournaise, Jonas, Suzanne, Daniel, etc...

Deux de ces rondelles dorées sont plus spécialement dignes d'attention. Sur l'une d'elles, le sujet d'Adam et Ėve est déjà composé, comme il le sera beaucoup plus tard dans les mosaïques, les fresques, les lampes, les enluminures, les ivoires, les plats de cuivre du Moyenâge et de la Renaissance (fig. 328).

Sur l'autre est représenté un lion [fragment du motif de Daniel]. dont la tête est tournée de face. Le motif constitué par un animal

(I) Ia coupe de Sainte Ursule a été publiée par H. DüNTzER, dans les Bonner Jahrbiicher de I867, fasc. 42, p. I69-1 82 et pl. V (bonne reproduction en couleurs).

(2) Ia coupe de Saint Séverin a été publiée par AUS'y'WEERTH dans les Bonner Jahrbücher de I\$64, fasc. 36 , p. I Ig et suiv. et pl. III (en couleurs).

(3) I,es Catacombes de Rome ont fourni un grand nombre de ces rondelles isolées. 
posé de profil avec la tête placée de face est oriental. Il a eu une vitalité surprenante. De l'Orient, il a pénétré de bonne heure dans la zoographie grecque pour se répandre ensuite en Europe où il s'est

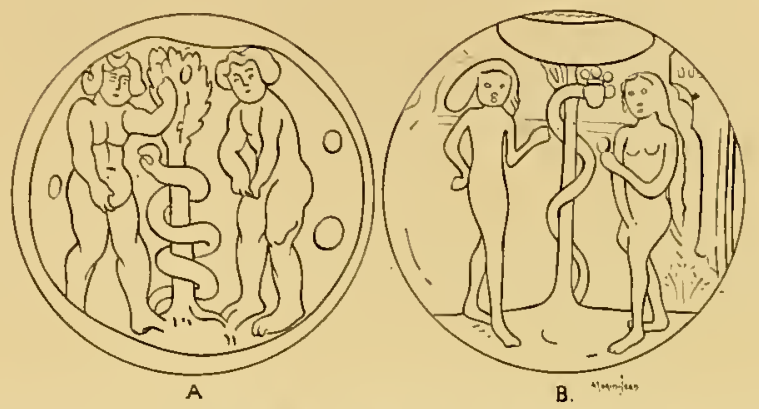

FIG. 328. - ADAM Et ÈvE: A. D’après un des médaillons de verre doré de la coupe de Saint-Séverin.

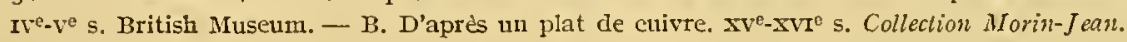

maintenu jusque dans l'ornementation des chapiteaux et des tympans des églises romanes ( $\mathrm{I}$ ).

(I) Consnlter à ce sujet: ED. POTrIER, L'histoire d'une bête, dans la Revue de l'Art ancien et moderne,

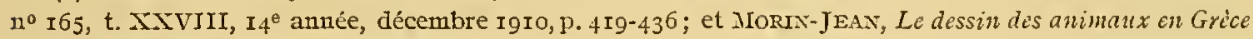
d'après les vases peints, p. 23 et note p. 24 . 


\section{La verrerie en Gaule dans le mobilier funéraire. Principaux lieux de trouvailles.}

Nous avons tenu à mettre à la fin de cet ouvrage un certain nombre de croquis où les verreries romaines ne sont pas reproduites

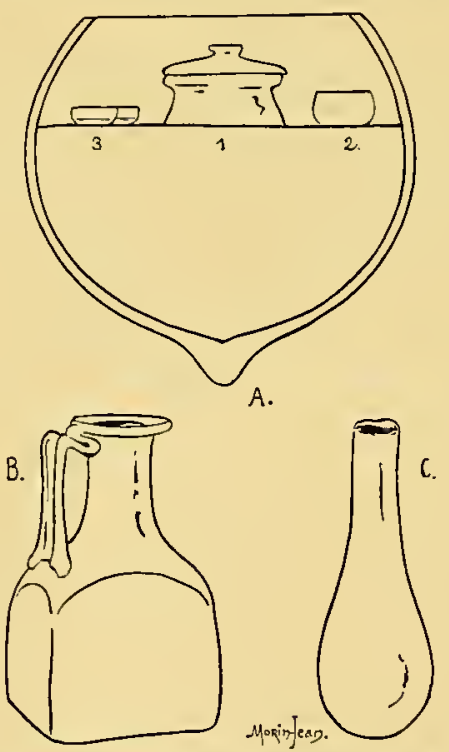

Fig. 329. - SÉpuziture A ustron, découverte à Nîmes (chemin de Montpellier, Pont-Biais). - Musée archéologique de Nimes. - A. Ampliore de terre cuite contenant le mobilier funéraire (r. Olla de terre renfermant un bronze de Caligula; 2 . deux bols d'argile; 3 . lampe de terre cuite). - B. Bouteille de verre à panse prismatique. - C. Ampoule de verre.

isolément et pour elles-mêmes, mais figurées avec les objets composant l'ensemble du mobilier funéraire où elles ont été trouvées. 
Ces croquis, au nombre de IS, ont été disposés dans l'ordre chronologique, de façon à ce que le lecteur puisse se rendre facilement compte des modifications qui ont été successivement amenées dans
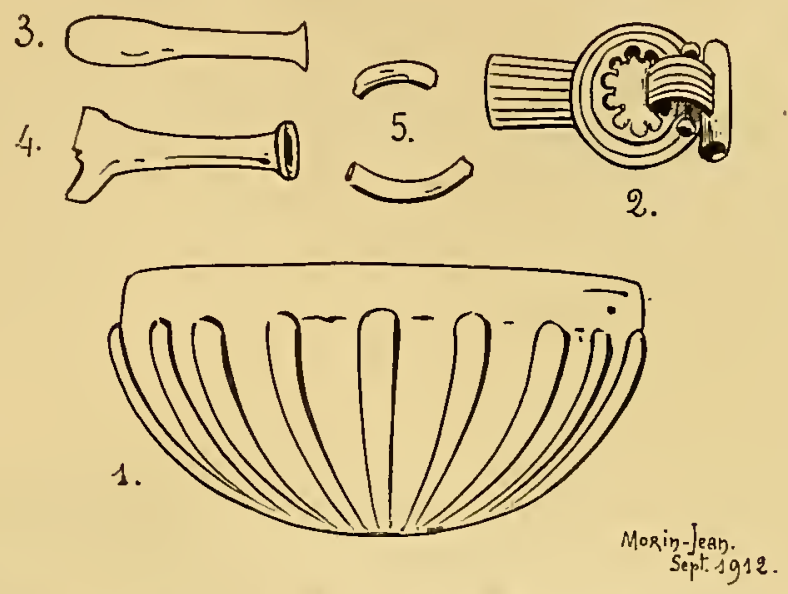

FIG. 330. - MIOBILIER D'UNE TOMIBE A INCLVERATION DU CMIETTÈRE DE KREUZXACH. - Musée de Mayence. I. Phiale côtelée, - 2. Fibule de bronze du type à couvre-ressort et à disque, dite Provinciale militaire. - 3. Ampoule de verre mince. -4 . Goulot d'une fiole en verre noir. -5 . Fragment d'un anneau de verte noir.

Ja composition du mobillier des tombes depuis la haute époque impériale jusqu'au temps des invasions.

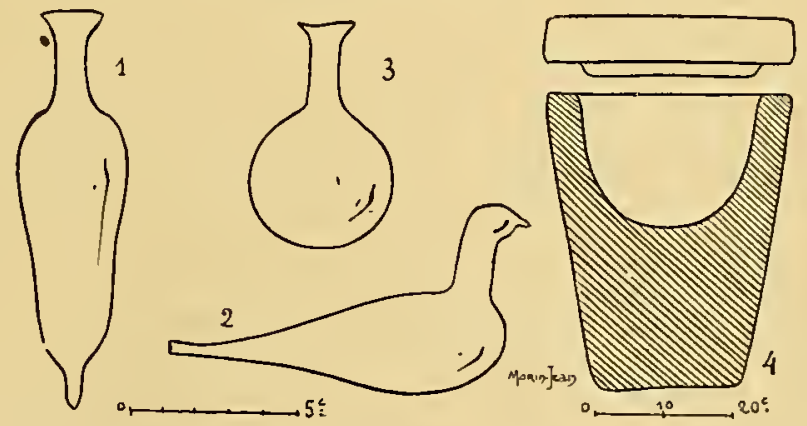

FIG. 33I. - MIOBIIIER D'UNE SĖPULTURE A USTION, conservée au Musée provincial de Tríves (S. T. 469o). - I. Amplzorisque de verre souffé. - 2. Verrerie en forme d'oiseau. - 3. Trois ampoules de verre mince dont une colorée en bleu. - 4. Cuve de pierre à operculum, contenant le ruobilier fuuéraire et des os calcinés.

I.es tombes de l'époque romaine se rencontrent par groupes formant des cimetières dont quelques-uns ont été fouillés avec mé- 
thode, mais dont beaucoup, ou bien n'ont pas encore été explorés, ou, ce qui est plus grave, ont été saccagés par des chercheurs de trésors qui y ont tout bouleversé sans se soucier qu'ils arrachaient et perdaient pour toujours les feuillets les plus précieux de nos annales archéologiques.

Les grande nécropoles de la Gaule contiennent, pour la plupart, des tombes d'époques très variées depuis le second âge du fer jusqu'aux temps mérovingiens.

On distingue facilement, par l'examen des mobiliers funéraires,

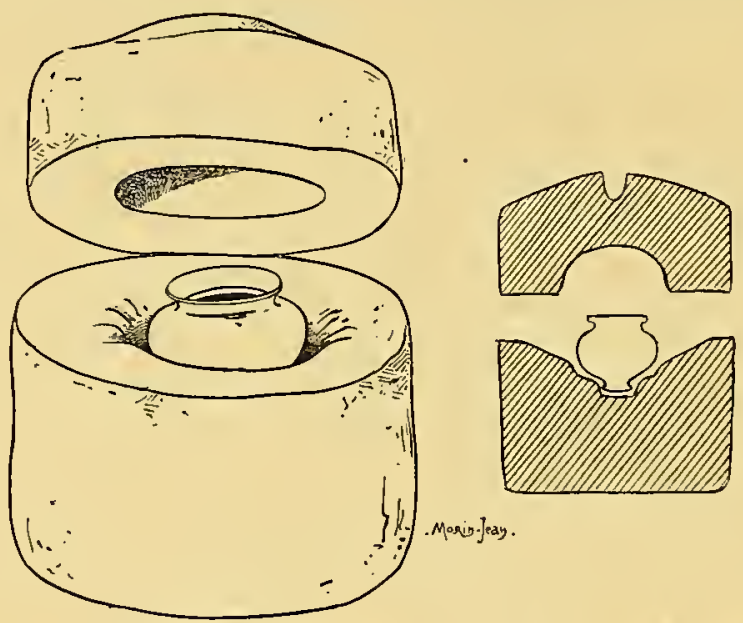

Fig. 332. - OLLA CINERARIA DE VERRE, encore en place dans une cnve de pierreà operculum. - Incinération de Fomperron (Deux-Sèvres). - Musée de Niort.

les sépultures gauloises des tombes romaines, ou franques; mais des difficultés surgissent quand il s'agit d'établir des coupures chronologiques dans l'ensemble des sépultures romaines.

On connaît plusieurs sortes de cimetières romains :

Io Les cimetières de longue occupation, qui ont été utilisés depuis le premier siècle jusqu'aux grandes invasions. Ces nécropoles contiennent à la fois des incinérations et des inhumations. Citons comme exemple le cimerière du Vieil-Atre à Boulogne-sur-Mer, qui a servi depuis Claude jusqu'à la fin du rve siècle.

$2^{\circ}$ Les cimetières qui ne contiennent que des incinérations. - Ces cimetières n'offrent, en général, pas plus d'homogénéité que les pré- 
cédents, car ils sont le plus souvent à cheval sur le Romain I et le Romain II. C'est le cas de la plupart des cimetières que l'abbé Cochet a fouillés en Normandie et où il a recueilli des verreries des deux périodes.

$3^{\circ}$ Les cimetières qui ne contiennent que des inhumations. - Tels le cimetière d'Homblières à Abbeville, qui n'a été utilisé qu'entre Magnence (350 à 353) et Honorius (395 à 423), et celui de Vermand qui a servi de Gallien (260 à 268) au début du ve. Ces nécropoles ne contiennent en général que des verres dela seconde phase du Romain II.

\section{Répartition géographique des verres romains découverts en Gaule.}

NARBONNAISE.

Prédominance de la verrerie du Romain I. Verres importés

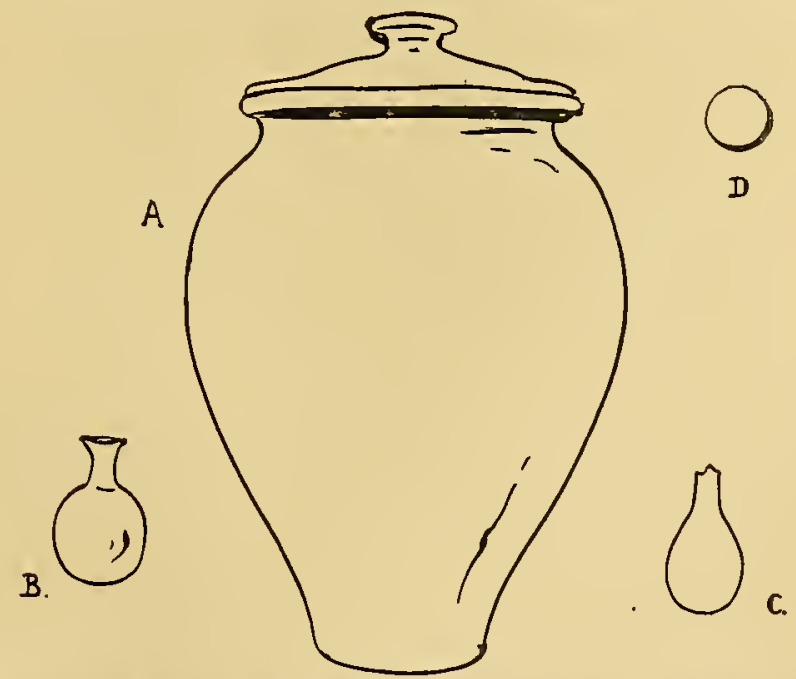

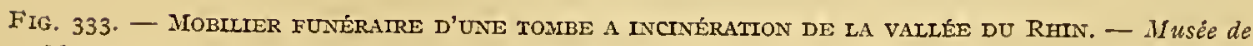
Mayence-A. Urne cinéraire en terre blanchâtre. - B. Ampoule de verre jaune. - $\mathrm{C}$. Ampoule de verre bleu. - D. Monnaie d'Hadrien (I I y à I38).

d'Italie et d'Orient. Verrerie locale. Grande abondance d'urnes cinéraires.

PrincipaUX liEUX DE TROUVAILILS. - Tolosa ('Toulouse), Nemausus (Nîmes); Massilia (Marseille), Aqua Sextice (Aix), Arelate 
(Arles), Avenio (Avignon), Arausio (Orange), Apta Julia (Apt), Vasio (Vaison), Saint-Gabriel (Vaucluse), Le Pouzin (Ardèche), Montagnole (Savoie).

\section{Aquitaine.}

Découvertes importantes dans le Poitou, la Vendée, la Saintonge. Restes d'un établissement d'industrie verrière, trouvés en I863

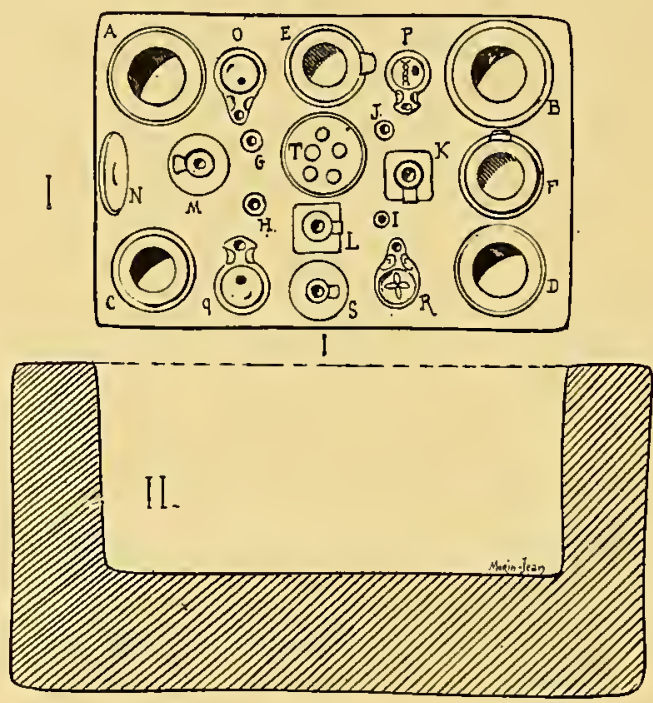

Fig. 334. - Incinération collective dans UnE cuve de pierre a Cavité rectangulatre. - Fouilles de Vaison, en 1838 . - Musée d'Avignon. - A. B. C. D. Quatre olle de verre type sans anses. E. F. Deux œuochoés de verre, forme 44 (I). - G.H. I. J. Quatre ampoules de verre mince. - K. I. Deux flacons de verre à panse prismatique. - M. Bouteillè de verre, forme 45. - N. Mitoir. - O. P. Q. R. Irampes d'argile. - S. Cruche d'argile. - T. Plat de terre rouge contenant 5 monnaies (Agrippa, Domitien, Trajan et Antonin).

dans la forêt de Mervent (Vendée). Fouilles du R. P. Camille de la Croix au cimetière des Dunes, près de Poitiers.

PRINCIPAUX IIEUX DE TROUvallies. - Burdigala (Bordeaux), Santones (Saintes), Grues, Saint-Médard-des-Prés, Chavagnes-enPaillers (Vendée), Amuré, Verrines (Deux-Sèvres), Pictavi (Poitiers), Iciodorum (Issoire), A qua calida (Vichy), A qua-nere (Néris), Moulins, Varennes (Allier).

(I) Voir au tableau de morphologie générale. 


\section{LYYONNAISE.}

Riches découvertes. Très anciens ateliers de verrerie établis à Lugdunum (Lyon). Fouilles de l'abbé Cochet dans le pays des Vélio-

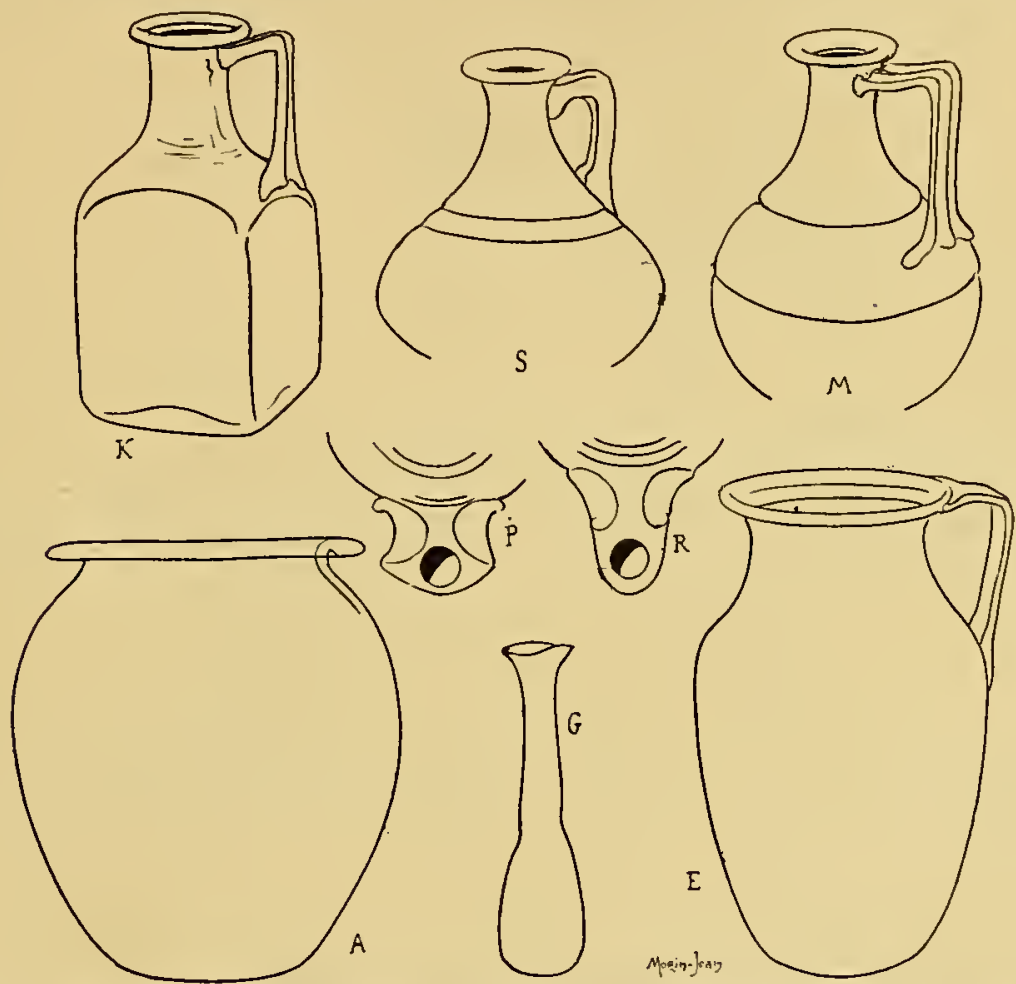

FIG. 335. - Ixchíratioxi collective dans une cuve de pierre rectangulaire.-Fouilles de Vaison en 1838 . - Musée d'Avignon. (F'orme des objets de la fig. 334.)

casses, et des Calètes (Barillets frontiniens et verres de toutes sortes).

D'intéressantes verreries, remontant à la période comprise entre le $\mathrm{II}^{\mathrm{e}}$ siècle et les invasions, ont été trouvées à Paris. Ces verres sont loin de former des séries aussi riches que celles de la vallée du Rhin. Ils mériteraient pourtant une étude particulière. Ils ont été trouvés sur la rive gauche de la Seine, surtout dans deux nécro- 
poles sur lesquelles aucun travail d'ensemble n'a été fait (I).

La plus ancienne de ces nécropoles s'étendait, du sud au nord, entre 1'Observatoire et la rue actuelle du Val-de-Grâce; de 1'est à l'ouest, entre la voie romaine de Lutèce àvGenabum (Orléans) et . un chemin vicinal qui se dirigeait sur Montrouge.

Ce cimetière, dit de la Rue Nicole, contenait des tombes païennes $\mathrm{du} \mathrm{II}^{\mathrm{e}}$ et $\mathrm{du} \mathrm{III}^{\mathrm{e}}$ siècles, les unes à incinération, les autres à inhuma-
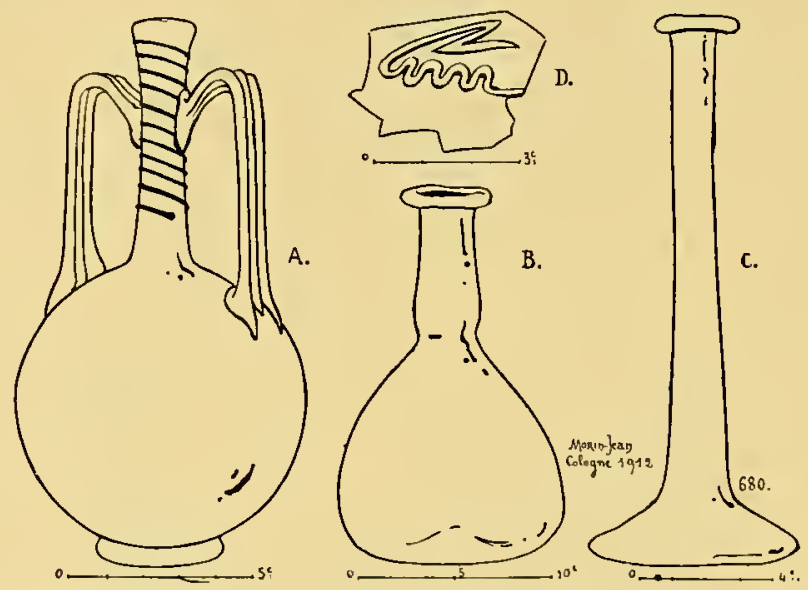

FIG. 336. - MoBILIER D'UNE TOMBE DU $\Pi^{e}$ s., découverte à Cologite, tue de Luxemboutg. - Musée de Cologne. - A. Diota de verre, forme 42. - B. Bouteille de verre sans anse. - C. Fiole de verre, forme 24. -D. Fragment d'une verrerie à applications vermiculaires. - Cette sépulture contenait. en outre, une monnaie de l'Impératrice Crispina Augusta (morte en I83).

tion. On y a trouvé d'intéressantes pierres funéraires, notamment la stèle du Forgeron conservée au musée Carnavalet.

L'autre nécropole parisienne, dite Cimetière Saint-Marcel, était comprise, du sud au nord, entre les environs de la rue Le Brun et la Bièvre ; de l'est à l'ouest, entre la rue des Fossés-Saint-Marcel et la ruelle des Gobelins. Elle bordait la voie romaine de Lutèce à Lug.

(I) Sur les fouilles exécutées à Paris, on pourra consulter :

DE LASTEYRIE, Un cimetière romain déconverté a Paris, rue Nicole (Extrait de la Revne archéologique, juin $\mathbf{1} 878$ ).

Ch. Magne, Les voies romaines de l'A ntique Lulece, Paris (Champion, éditeur).

CH. MAGNe. Cimetières gallo-romains et merovingiens de l'avenue des Gobelins et de la rue Descartes, explorés en 1898 . Paris, Champion.

Consulter aussi le plan de Paris à l'époque gallo-romaine, par TH. VAcQter, exposé à la Bibliothèque historique de la Ville de Paris. 
dunum (I yon). Iille a été utilisée très longtemps, depuis le III $^{\mathrm{e}}$ siècle jusqu'à la fin du xve siècle de notre ère.

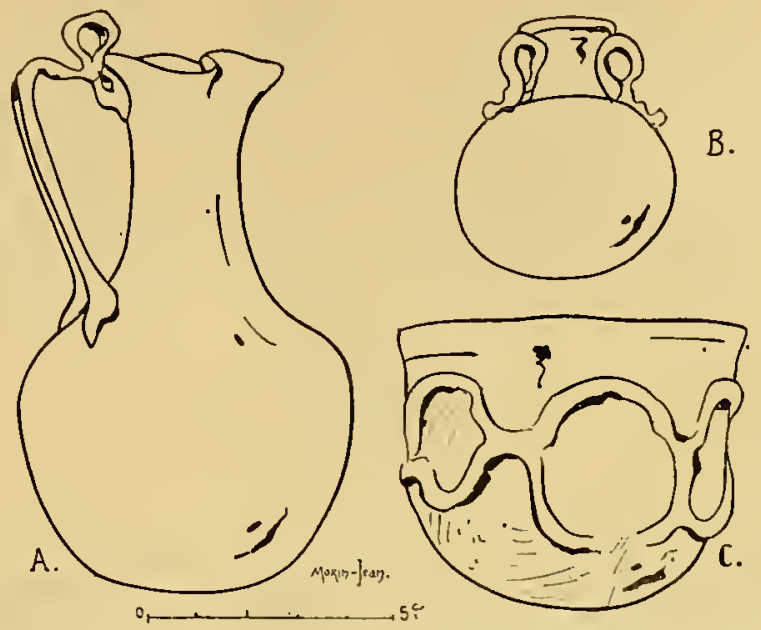

FIg. 337. - Mobilier D'UNE tonibe D'ENFANT, découverte près de Ponś (Charente-Inférieure). - Mísíe de Saintes. - A. Enochoé de verre. - B. Aryballe à anses delphiniformes, forme 33. - C. Bol à décor rapporté à chaud.
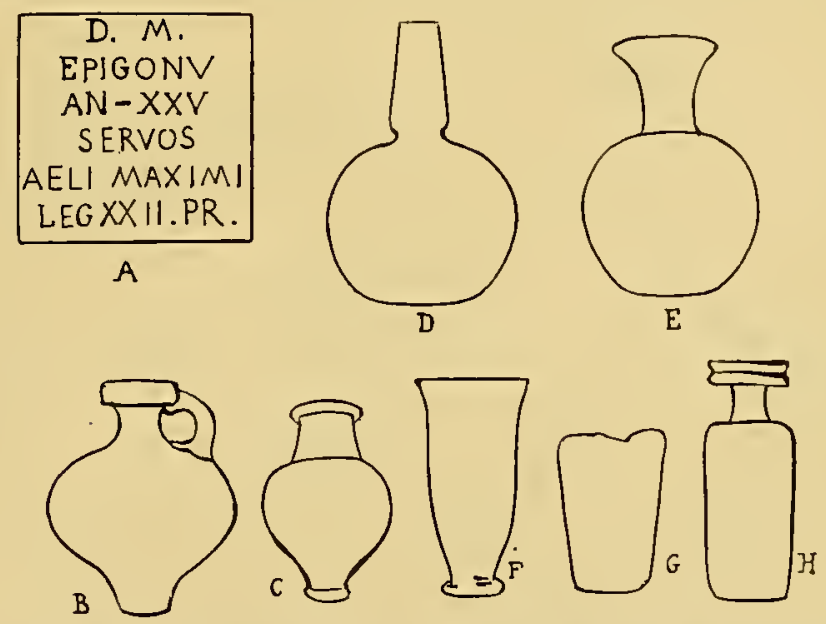

Fig. 338. - Tosibe a ixhmatiox D'Fipigonus, découverte à Mayence, Mombacherstrasse, en I904. Musée de May'ence: - A. Inscription de la stèle de pierre. - B. Cruche de terre blanchâtre. - C. Vase de terre rouge. - D. Ballon de verre, forme 4I. - E. Ballon de verre, forme 40. - F. Verre à pied, forme rog. - G. Gobelet tronconique en verre. - H. Bouteille de verre à parse cylindrique du type décrit p. 55 .

On n'y a pas trouvé d'incinérations. Les tombes, en majorité chrétiennes, y étaient parfois superposées. 
Paris, à l'époque gallo-romaine, était un petit port de commerce,
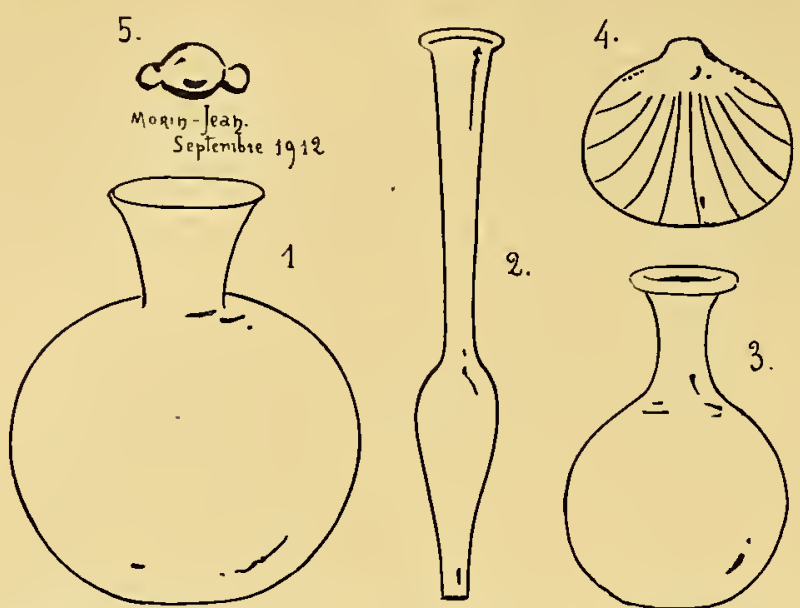

2.

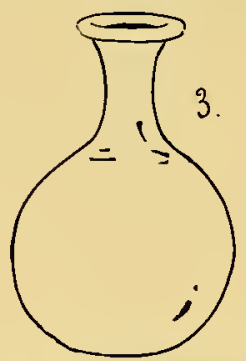

FIG. 339. - MIOBILIER FUNERATRE D'UN SARCOPHAGE A INHUMATION. - Ober Ingelheim (fouilles de Igog). - Musée de Mayence. - I. Ballon, forme 40, en verre verdâtre. - 2. Fiole de verre, forme 31. - 3. Bouteille de verre verdâtre. -4 . Valve de cardiım. -5 . Fibule? - rv s.

une escale du cabotage qui se faisait, sur la Seine, entre Sens et la
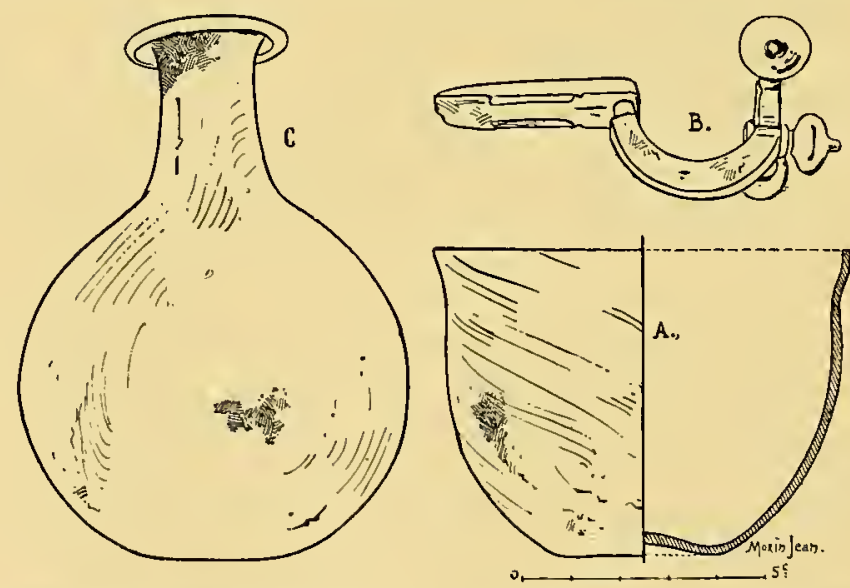

Fig. 340. - Mobilier D'Une tombe A Inhumatron DU IV ${ }^{e}$ s., découverte à Amiens (Somme). - Collection Morin-Jean, à Paris (ancienne Collection Bernay). - A. Bol de verte incolore. - B. Fibule đe bronze du type dit crucial. - C, Bouteille de verre incolore. - Cette sépulture contenait, en outre, une monnaie de bronze de Constantin I ${ }^{e r}$.

mer. Au Ive siècle, la capitale des Parisii se développa grâce aux fréquents séjours qu'y venait faire l'empereur Julien. Aussi les verreries 
du Romain II y ont-elles été trouvées en plus grand nombre que celles du début de l'empire.

PRINCIPAUX LIEUX DE TROUVAm, IES. - Redones (Rennes), Eburovices (Ëvreux), Rotomagus (Rouen), Cany, Neuville-le-Pollet, Etretat (Grand-Val et Bois-des-Loges), Juliobona (Lillebonne) [Cimetière du Mesnil], Fécamp, Trouville-en-Caux, Barentin, Tourvillela-Rivière, Thiétreville (Seine-Inférieure) [Fouilles Cochet]. Pezou près Vendôme, Suèvres (Loir-et-Cher). Vierville (Eure-et-Ioir).

B.
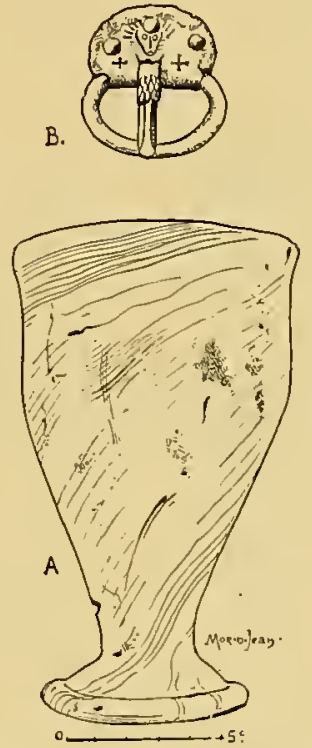

Fíg. 34I. - MOBILIER D'UNE TOMBE DE LA SECONDE MoItIÉ DU IV s. - Amiens, -Collection Morin-Jean, à Paris (ancienne Collection Bernay). - A. Verreà pied, forme I I . - B. Boucle de ceinture, en bronze gravé.

Parisii (Paris). Stampapagus (Étampes). I,e Champdolent, à SaintGermain-lès-Corbeil (Seine-et-Oise). Melodunum (Melun), Héricysur-Seine (Seine-et-Marne). Conflans-sur-Seine (Marne). Tricasses (Troyes), Arcy-sur-Aube (Aube). Augustodunum (Autun), Cabillonum (Chalon-sur-Saône), Charnay (Saône-et-Loire). Alesia (Côted'Or). Montbrison (Loire). Lugdumum (I,yon). 


\section{BELGIQUE.}

Région très riche en verrerie romaine. Prédominance des nécropoles à inhumations et des verres du Romain II. Fouilles de MM. de Roucy dans la forêt de Compiègne; Pilloy, Th. Eck, Cl. Boulanger, Lelaurin, Darly, dans l'Aisne et dans la Somme; l'abbé Hamard

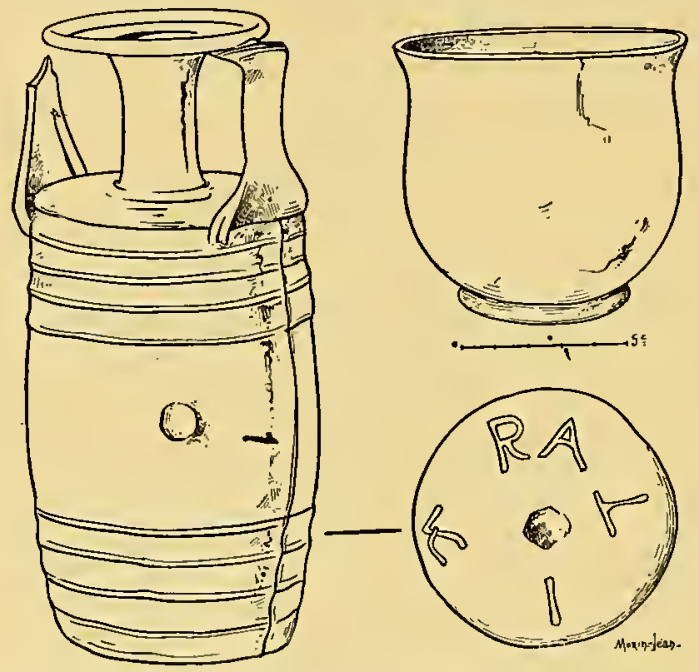

FIG. 342. - MobILIER D'UNE SÉPUltore dU CIMETIÈre dE SABlonntère (Aisne). - Fouilles F. Moreau. Musée de Saint-Germain. Salle XI. Vitrine 49. Tombe n 252. - Barillet Frontinien à deux anses et bol de verre, forme 72. - Basse époque impériale.

dans 1'Oise; l'abbé Haigneré dans le Boulonnais; Frédéric Moreau dans l'Aisne; Th. Habert et J. Orblin à Reims.

PRINCIPAUX LIEUX DE TROUVAILLES. - Bononia (Boulogne-surMer) [cimetière du Veil-Atre], Neufchâtel, Dannes, Étaples, Aubignyen-Artois (Pas-de-Calais). Ambiani (Amiens), Abbeville [cimetière d'Homblières], Misery, Hardécourt-au-Bois, Tincourt-Boucly (Somme). Bellovaci (Beauvais), forêt de Compiègne [La Fortelle, Vieux-Mont, Mont-Chyprès, Mont-Berny, Garenne-du-Roy, etc.]: Hermes, Bury (Oise). Beaumont-sur-Oise (Seine-et-Oise). Laudunum (Laon), Suessionum Civitas (Soissons) [cimetière des Longues-Raies], Faucouzy-Monceau-le-Neuf, Augusta Veromanduorum (Saint- 
RÉPARTITION GÉOGRAPHIQUE DES VERRES ROMAINS. 263 Quentin), Viromandum (Vermand), Renonsart, Caranda, Sablonnière, Brény, Chouy, Ancy, Chassemy, Nampteuil-sous-Muret, Arcy-Sainte-Restitue, Chauny, Sissy (Aisne). Remi (Reims), Lépine, Jonchery-sur-Suippes (Marne). Seuil, près Réthel (Ardennes). Augusta

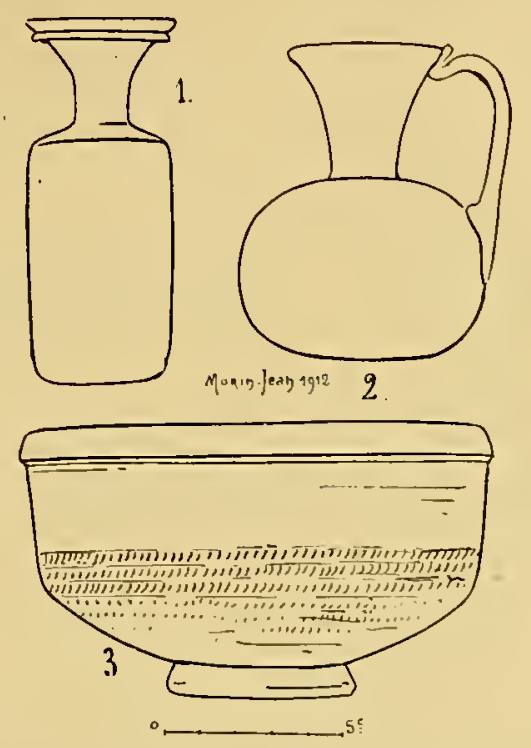

Fig. 343. - Mobilier D'Une tombe a Infumation du cimetière de Nampteuil-sous-MIuret (Aisne). IV ${ }^{e}$ s. - Musée de Saint-Gormain. Salle Moreau. Vitrine Io. - I et 2. Bouteilles en verre inpur. 3. Bol de terre rouge à zones striées.

Trevirorum (Trèves) et Pallien (Allemagne). Steinfort (Grand-Duché de Luxembourg).

\section{GERMANIE.}

Très importantes découvertes, surtout à Cologne (cimetières de la rue de Luxembourg et de Saint-Séverin) et à Mayence (tombes à incinération et à inhumation). Prédominance de verreries du Romain II. Nombreux verres de l'époque des empereurs syriens (III ${ }^{\mathrm{e}}$ siècle). Abondance des spécimens ornés d'applications vermiculaires. Fouilles du chanoine Straub au cimetière de Strasbourg.

- Principaux lieux de TrouvaILLES. - Io Dansl' Allemagne actuelle. 
Vetera Castra (Xanten), Novesium (Neuss), Colonia Agrippina (Cologne), Bonna (Bonn), Gelsdorf près Meckenheim, Remagen, Antunnacum (Andernach), Confluentes (Coblence), Cobern, Mayen, Kreuz-

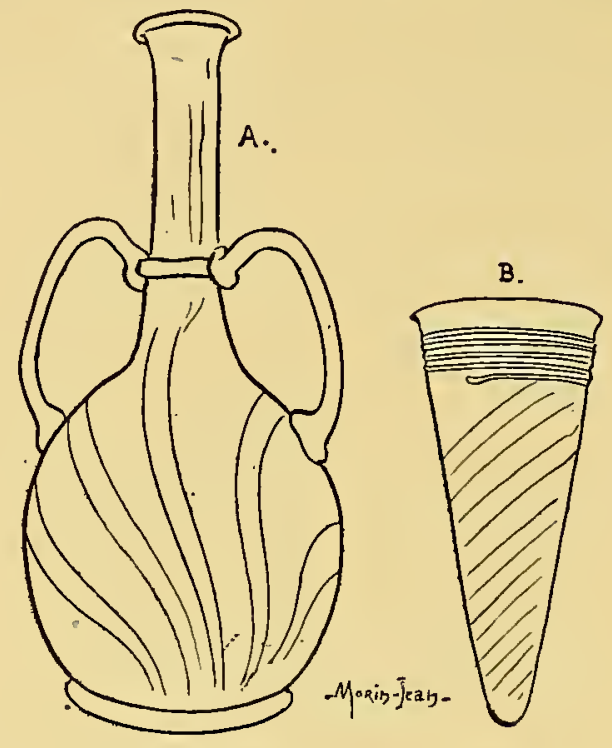

FIG. 344. - MORILIER D'UNE SÉPULtURE A INHUMATION du cimetiète d'Arcy-Sainte-Restitue (Aisne). - Fin du Ive s. - Musée de Saint-Gennain. Salle Moreau. Vitrine 45. Tombe $2560 .-A$. Diota de verre, forme 42. - B. Cornet de verre, forme ro7, orné d'un fil d'émail blanc.

nach, Mogontiacum (Mayence), Vangiones (Worms), Hohensulzen, Argentoratum (Strasbourg).

$2^{\circ}$ Dans la Belgique actuelle : Namur, Avennes, Furfooz, Couvin, Samson, Spontin, Strée, Flavion [cimetière des Iliats].

\section{GRANDE SÉquaNAISE.}

Riche série de verres provenant de trois nécropoles découvertes à Besançon (Doubs) et dans les environs de cette ville :

$I^{\text {o }}$ Sous les ruines des monuments romains entourant le champ de Mars, dans une couche correspondant au I ${ }^{\text {er }}$ siècle de notre ère, on a trouvé, en établissant les fondations de l'arsenal actuel, les vestiges. d'un cimetière gaulois et gallo-romain, d'une nécropole à incinéra- 
tious qui a dî servir depuis la conquête des Gaules jusque vers l'époque de Néron (monnaies gauloises et monnaies romaines allant jusqu'à Claude).

$2^{\circ}$ On a déconvert un vaste cimetière à incinérations des $\mathrm{II}^{\mathrm{e}}$ et $\mathrm{III}^{\mathrm{e}}$ siècles (monnaies allant jusqu'à Alexandre Sévère), de part et d'autre de la voie romaine allant de Besançon à Langres, à l'endroit où s'élève aujourd'hui la gare de Viotte. Les vases en verre soufflé y ont été rencontrés en grand nombre. Quelques-uns, de formes très
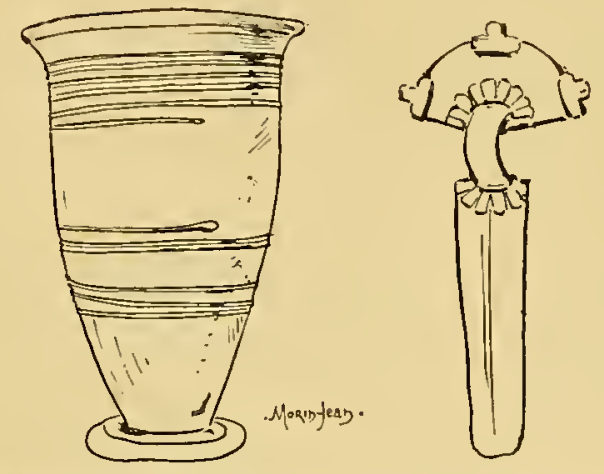

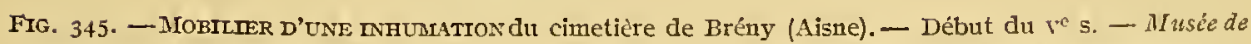
Saint-Germain. Salle Morcau. Vitrine 44. Tombe $\mathrm{n}^{\circ}$ I67. (Verre à pied orné de filets d'émail blanc et fibules.)

variées, ont servi d'olla cinerarice, et les fioles à parfums s'y sont montrées de dimensions, formes et décoration très différentes.

$3^{\circ}$ Un important cimetière à inhumations a été exploré à Thoraise (Doubs) (I), à I5 kilomètres au sud-ouest de Besançon.

On y a recueilli de belles verreries, notamment des bols formes 72 et 73 , ornés de cabochons colorés ou de pinçures faites à l'outil, des verres carénés forme III, des bouteilles à col évasé forme 40, des cornets forme Io7, et une très jolie œnochoé dont la panse est décorée de gaufrures en forme de protubérances mamelonnées, disposéesrégulièrement en spirales et grossissant progressivement avec le diamètre du vase (voy. fig. $4, n^{0} 3$ ). Les sépultures du cimetière de Thoraise datent toutes de la fin du III $^{\mathrm{e}}$ siècle et de la première moitié du Ive. On ne rencontre pas, dans cette nécropole, de tombes posté-

(r) Jules Gautmer, Le Cimeticre gallo-romain de Thoraise (Doubs). Besançon, I88I. 
rieures à 355, date de la terrible invasion de Germains qui anéantit la Séquanaise.

PRINCIPAUX liEUX DE TROUVAILLES : Vesontio (Besançon), Civitas
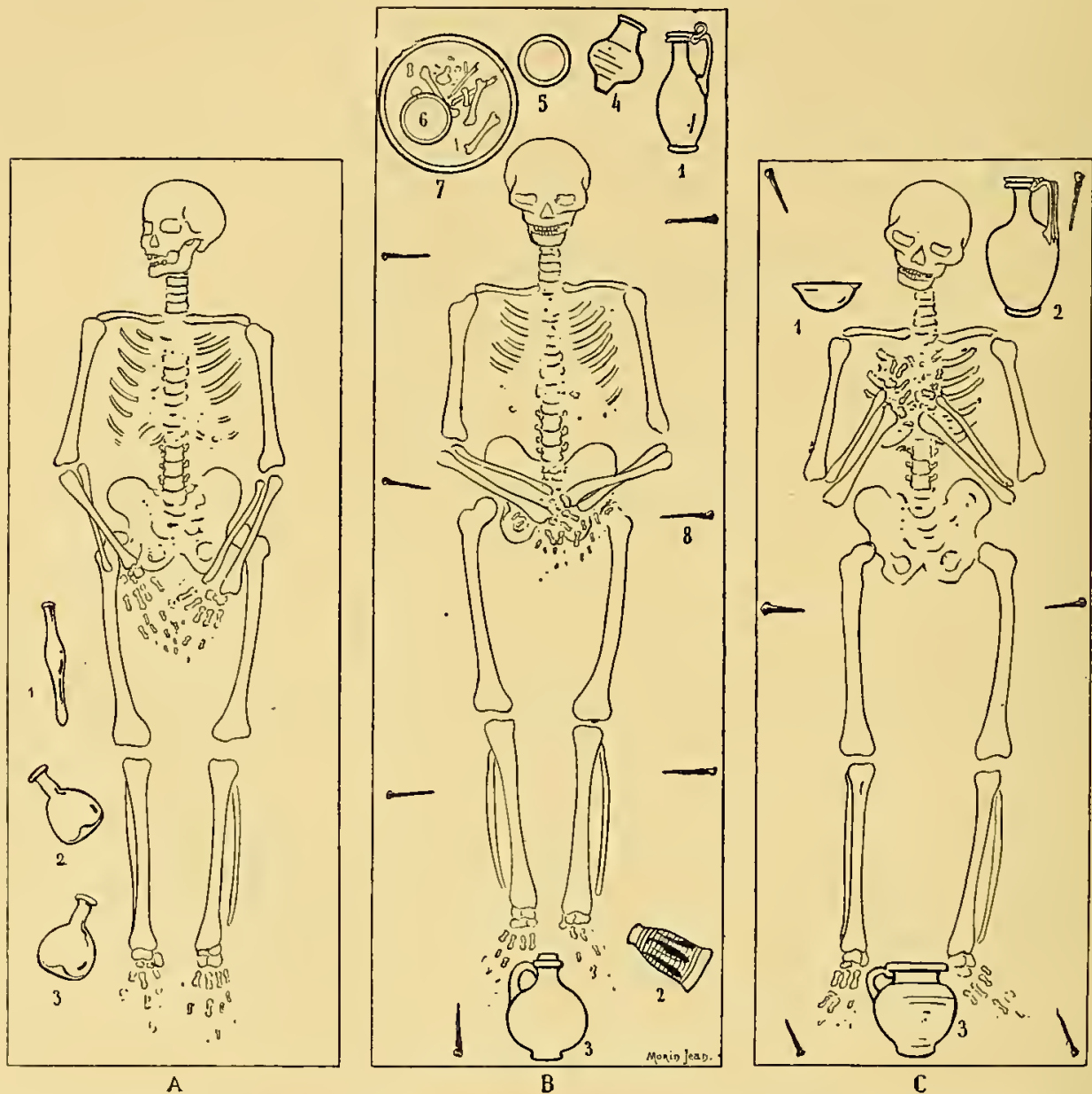

Fig. 346.-Sépultures tardives a inhunation. - A. Musée de Trèves. Salle vI, $\mathbf{n}^{0} 59$ (trois verreries).-

B Musée de Bonn (Inv. I33I-I336). Tombe d'Andernach (I et 2. verreries, 3. cruche de terre blanchâtre, 4. pot d'argile à couverte noire, 5 et 6 . petits bols de terre rouge, 7 . grande patina de terre pâle contenant des ossements de poulet, 8 . clons du cercueil). - C. Mrsée de Cologne. Tombe du cimetière de la rue de $\mathbf{I}$ uxembourg, à Cologne (I et 2. verreries, 3. pot de terre grise).

Epomanduodurum (Mandeure), Thoraise (Doubs). Vaîte, Port-surSaône (Haute-Saône). Audelange (Jura). Baden (Suisse). 


\section{VIII}

\section{Ressemblances que présentent, avec la verrerie impériale romaine, certaines verreries modernes. Fabrication d'un canthare de verre soufflé à Murano.}

I. - On pourrait, sur ce sujet, écrire un livre. Nous n'avons pas la prétention d'avoir écrit même un chapitre. Nous avons seulement groupé ici quelques croquis qui montrent combien certaines formes de verres du Moyen-âge, de la Renaissance et des Temps modernes se rapprochent des formes de la verrerie romaine.

En examinant les figures 347 à $35 \mathrm{I}$, on verra que des verriers italiens et allemands, qui vivaient à une époque relativement peu éloignée de la nôtre, ont créé des récipients vitreux qui, morphologiquement, présentent des analogies frappantes avec les verres du $\mathrm{III}^{\mathrm{e}}$ ou du $\mathrm{IV}^{\mathrm{e}}$ siècle de notre ère.

La gourde B (fig. 347) a plus d'un point de ressemblance avec la bouteille de Cologne reproduite plus haut (fig. 274).

La verrerie C (fig. 347), dont on connaît plusieurs exemplaires conservés dans maints musées d'Europe, semble être une transcription, avec quelques variantes, du curieux vase découvert par F. Moreau au cimetière de Caranda (voy. plus haut, fig. 244).

Il n'y a que des différences de détail entre le flacon D (fig. 347) et la verrerie conchiforme trouvée au cimetière romain de Cologne (fig. 2I8).

I a résille en relief, qui orne la panse de la carafe $E$ (fig.347), est identique à celle qui décore le verre à pied, figure 264. Ici et là, on a 

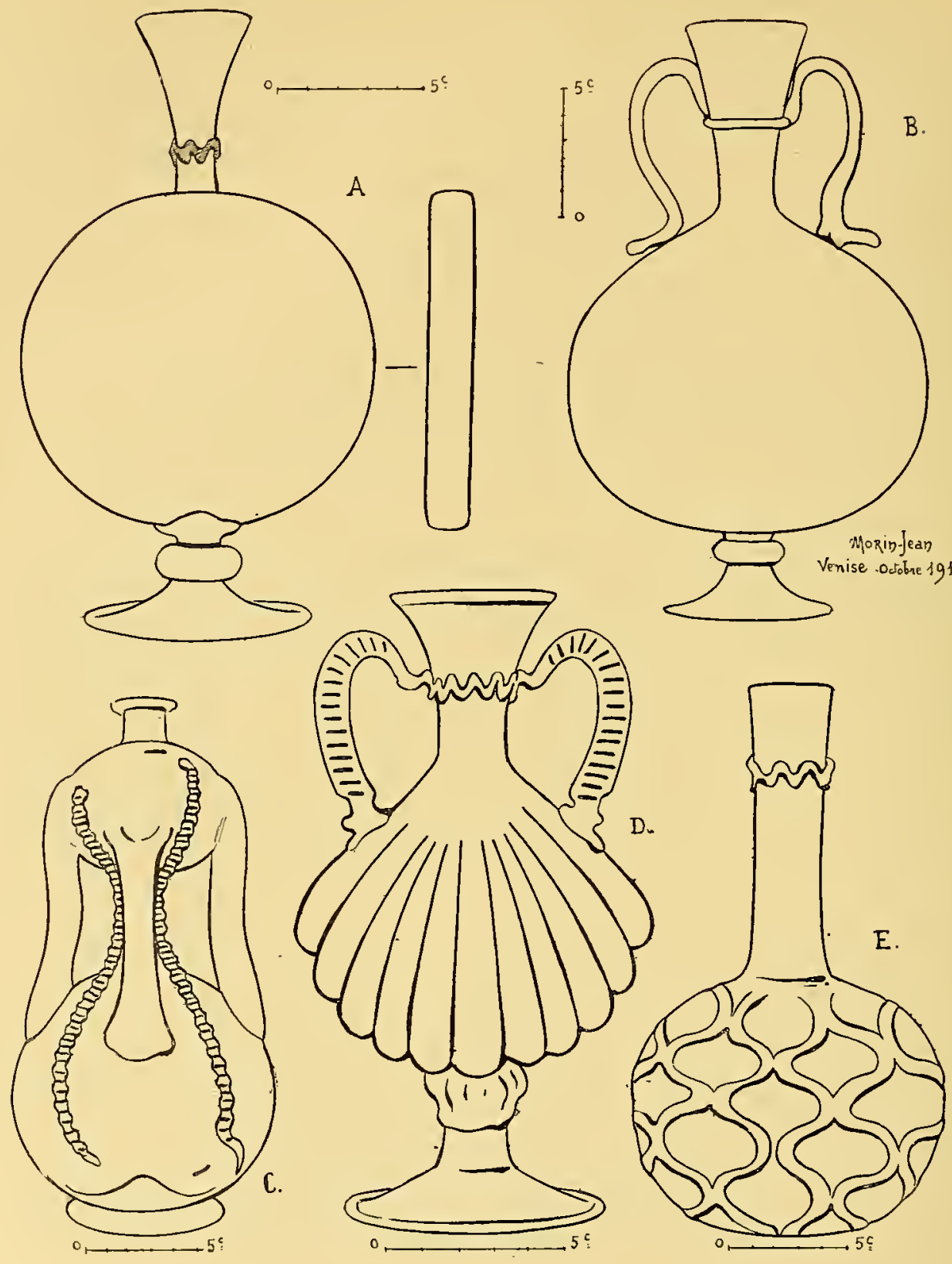

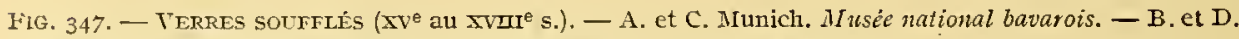
Venise. Musée Correr (Salle XII). — E. Nuremberg. Musée germanique. 
usé, à plus de douze siècles de distance, du même procédé d’ornementation.

La bouteille double (fig. 348) est un dilécythe antique perfectionné.

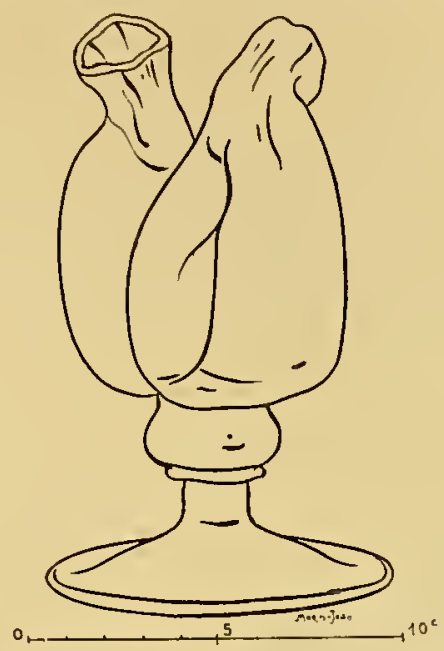

Fic. 34 8. - Bodteille de Verre a Deux Contrartiments, connue sousle nom de Cougoule. — Normandie. xvтr ${ }^{\mathrm{e}}$ s. - Musée de Sèvres, $\mathrm{n}^{0} 668 \mathrm{r}$.

L,es verriers modernes ont, en effet, apporté, à la bouteille à deux compartiments, une modification heureuse, en inclinant en sens inverse les deux goulots. Grâce à cette ingénieuse disposition, on peut

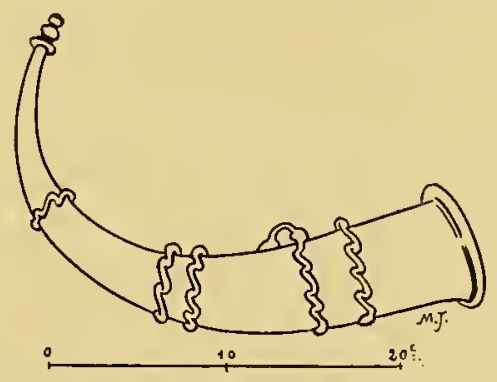

Iig. 349. - HANA' DE VERRE EN FORJIE DE CORNE DE CHASSE. - Venise. Fin du xve s. - Musie de Sévres, $\mathrm{n}^{\circ} 5267$.

aisément verser le liquide contenu dans l'un des compartiments sans avoir à boucher l'autre.

D'élégants hanaps de la Renaissance (fig. 349) sont étroitement 
apparentés aux belles cornes à boire qu'on fabriquait dans le Rheinland vers la fin du IV siècle.

Le baril A (fig. 350) et le tonnelet fig. 233 ont un air de famille surprenant. Un goulot et des anses, analogues à ceux du

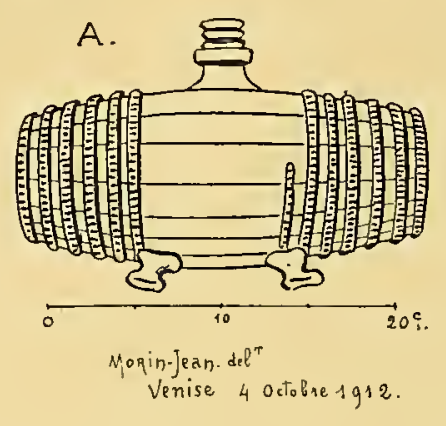

0
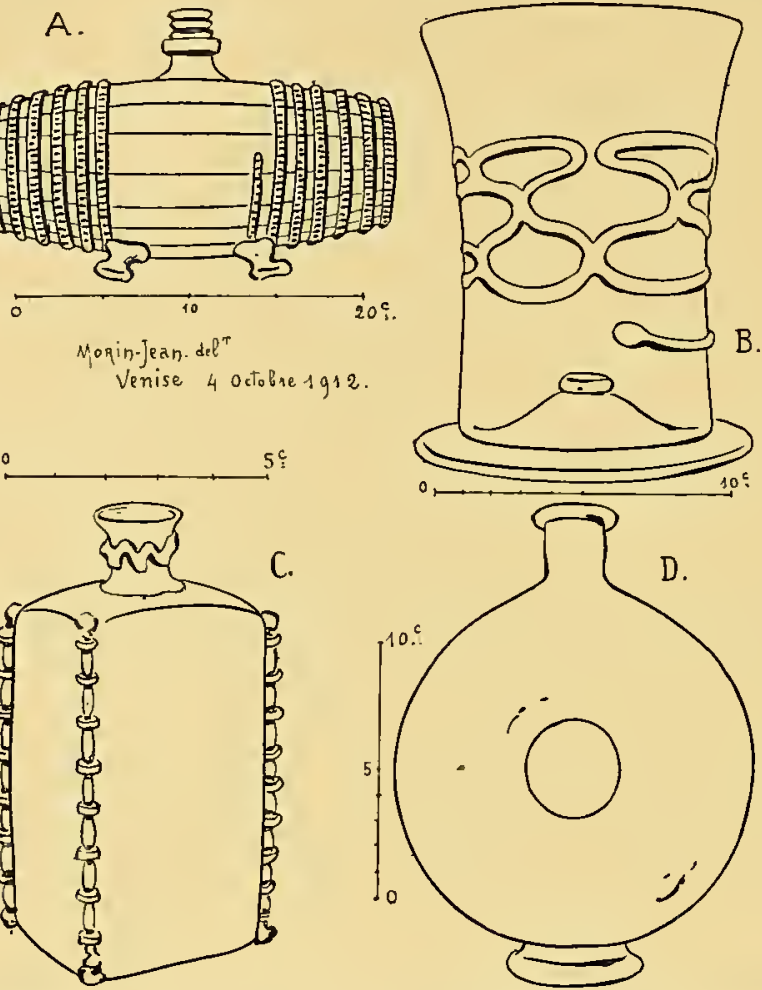

C.

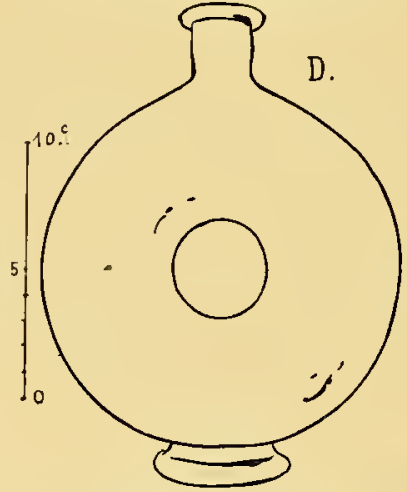

FIG. 350. - VERres SOUfFLÉs ' $\left(\mathrm{xV}^{\mathrm{e}}\right.$ au XVII ${ }^{\mathrm{e}}$ s.). - A. B. D. Nuremberg (Musée germanique). - C. Musée de Murano (Italie) [Fabrique de Murano au $\mathrm{sv}^{\mathrm{e}} \mathrm{s}$. (Famille Scguso)].

barillet romain fig. 233, sont appliqués à des tonnelets de verre et de faïence d'époque très récente ( $\mathrm{XVII}^{\mathrm{e}}$ et $\mathrm{XVIII}{ }^{\mathrm{e}}$ siècles) (fig. 35I et 352 ).

Bien d'autres formes de la verrerie romaine ont été reprises dans des régions très diverses, par les verriers et par les céramistes du Moyen-âge, de la Renaissance et des Temps modernes.

La forme 62 (I), pour prendre un exemple, se rencontre dans les

(I) Voy. forme 62 du tableau de morphologie générale. 
porcelaines de Cline (I) dans les grès coréens, dans les faïences de Rhodes (2), de Perse (3), de Rouen (4), de Nevers (5) et dans les grès allemands (6).

Ia tâche difficile n'est pas de découvrir ces ressemblances, mais de discerner si celles-ci résultent d'une filiation continue, d'un contact médiat entre l'artisan antique et l'ouvrier moderne, ou si elles proviennent simplement d'une recréation, d'une coïncidence, l'ouvrier, en présence de la même matière et des mêmes procédés, étant fatalement enclin à retrouver les mêmes formules.

Prenons, par exemple, les barillets fig. 350 (A) et 35. Ils rappellent

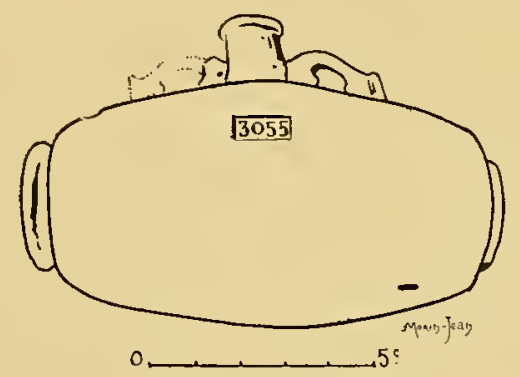

FIG. 35I. - BARILLET DE vERRE vERT, otné de taches blanches et rouges. Fabrication française du xvI ${ }^{\circ}$ s. Procédé de la Margeride (Cantal). - Musée de Sèvres, n⿳ 3055.

à tel point le tonnelet fig. 233 qu'on est tenté d'expliquer par une filiation la similitude de ces trois verreries.

Il n'est pourtant pas impossible que des verriers duxvire siècle, voulant donner à un récipient vitreux la forme d'un tonneau, aient abouti, sans faire d'emprunt à l'antiquité, à une formule presque semblable à celle qu'adoptèrent les Romains quatorze siècles plus tôt.

Il est donc prudent, lorsqu'il s'agit de similitudes entre des objets créés à des époques très différentes et dans des pays fort éloignés les uns des autres, de ne pas s'aventurer dans le domaine des influences

(I) Muscee de Sèvres, no 8.634 .

(2) Musée de Sères, to ${ }^{\circ} .842$ (bouteille ornée de la cliasse au lièvre).

(3) Musée de Sèvres, $n^{\circ} 6.563$ ( $\mathrm{xVI}^{\mathrm{c}}$ siècle).

(4) Musée de Sèvres, $11^{\circ}$ I 3.089 (xvm ${ }^{e}$ siecle).

(5) Mrusée de Sèvres, no 3.129 (xvir sicle).

(6) Musée de Sevres, no 9.4 I9 (Nassau). 
et des survivances, sans avoir des indications historiques permettant d'affirmer que le contact a pu exister.

Il est hors de doute que les recettes des verriers orientaux de l'époque romaine, connues dans toute l'étendue de l'Empire, ont été transmises aux artisans qui vinrent, plus tard, fonder les verreries, de l'Europe médiévale. Il est certain, d'autre part, que les méthodes, les procédés des verriers du Moyen-âge n'ont pas été perdus par la suite. On est donc en droit d'admettre une parenté effective entre

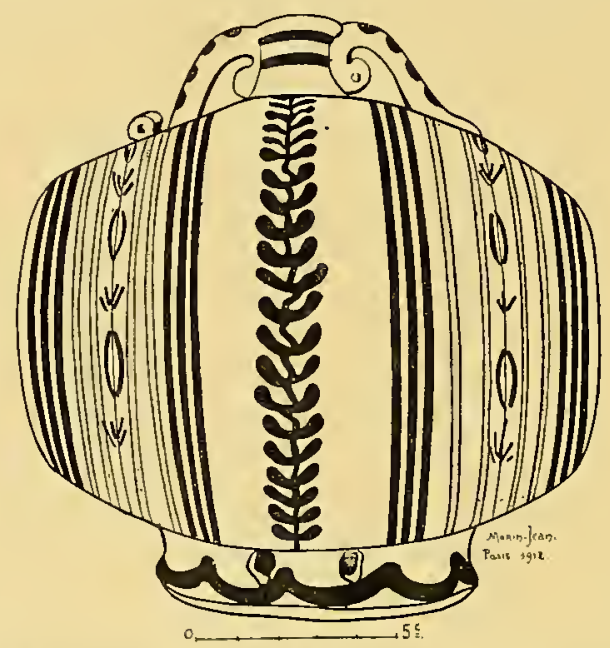

Fig. 352. -Barillet en faience polychronte. - Daté: r791. - Musée Carnavalet, à Paris.

certaines verreries du $\mathrm{XVI}^{\mathrm{e}}$ ou du $\mathrm{XVIr} \mathrm{r}^{\mathrm{e}}$ siècle et certains verres romains.

- Cependant, tout en reconnaissant, dans bien des cas, l'existence de cette parenté, de cette filiation, nous ne devons jamais perdre de vue, que, quelquefois, les ressemblances entre objets, surtout lorsque la forme de ces objets est simple, sont dues à des recréations, qu'elles sont soumises à la loi des coüncidences et des rencontres, et non à la loi des contacts ( $\mathrm{r}$ ).

2. - Les verriers actuels de Murano soufflentet travaillent le verre d'après de très anciennes recettes. Les progrès de l'industrie moderne ne leur ont pas fait abandonner des traditions remontant fort loin

(r) Sur l'application de ces deux lois en archéologie, consulter ED. PotrIER, Catalogue des vases du Lonvre, p. 25I, et tome XIII des Mémoires de la délégation en Perse, p. 67 et suiv. 
dans le passé. Aussi est-ce en étudiant la technique de ces verriers qu'on peut se rendre le mieux compte de la façon dout pouvaient procéder leurs devanciers de l'époque impériale romaine.

Ia figure 353 réunit dix-huit croquis correspondant aux diverses phases de la fabrication d'un canthare de verre soufflé, exécuté sous nos yeux dans l'une des officines de l'île de Murano.

Au bas de la figure, à droite, est dessiné le modèle que nous avions fourni au chef de l'atelier.

La confection d'une pièce de ce genre dure environ trente-cinq minutes.

L'ouvrier chargé d'exécuter le travail plonge dans la masse de verre liquide l'extrémité d'une canne creuse. Une certaine quantité de matière reste attachée à cette extrémité : c'est la paraison (fig. 353, phase I).

En soufflant par l'autre bout de la canne, il se produit, à l'intérieur de la paraison, une concavité qui s'élargit progressivement (phase 2).

I'ouvrier étrangle ensuite la paraison en la faisant tourner rapidement entre les deux branches d'une pince (phase 3 ).

Un aide vient alors fixer une tige de fer ou pontil à l'extrémité de la paraison, sur la face opposée au trou de soufflage.

La canne creuse, désormais inutile, est détachée (phase 4). Puis, pendant que l'on imprime au pontil un mouvement de rotation, on ouvre la paraison (phase 5) et on lui donne la forme désirée (phases 6 et 7).

Pendant toutes ces manipulations, la pièce travaillée doit être très souvent réchauffée dans des ouvertures (ouvreaux) spéciales du four.

On procède ensuite à la fabrication des anses. A cet effet, l'aide apporte au bout d'une tige métallique une petite masse de verre, qu'il dépose à l'endroit où devra se trouver l'attache supérieure de 1'anse (phase 8). Puis, avec des ciseaux, on sectionne cette masse de façon à ne conserver qu'une grosse goutte de pâte vitreuse que l'oulvrier étire et transforme en un boudin (phase 9), auquel il donne la forme voulue et dont il ramène l'extrémité au point où doit se trouver l'attache inférieure de l'anse (phase Io). 


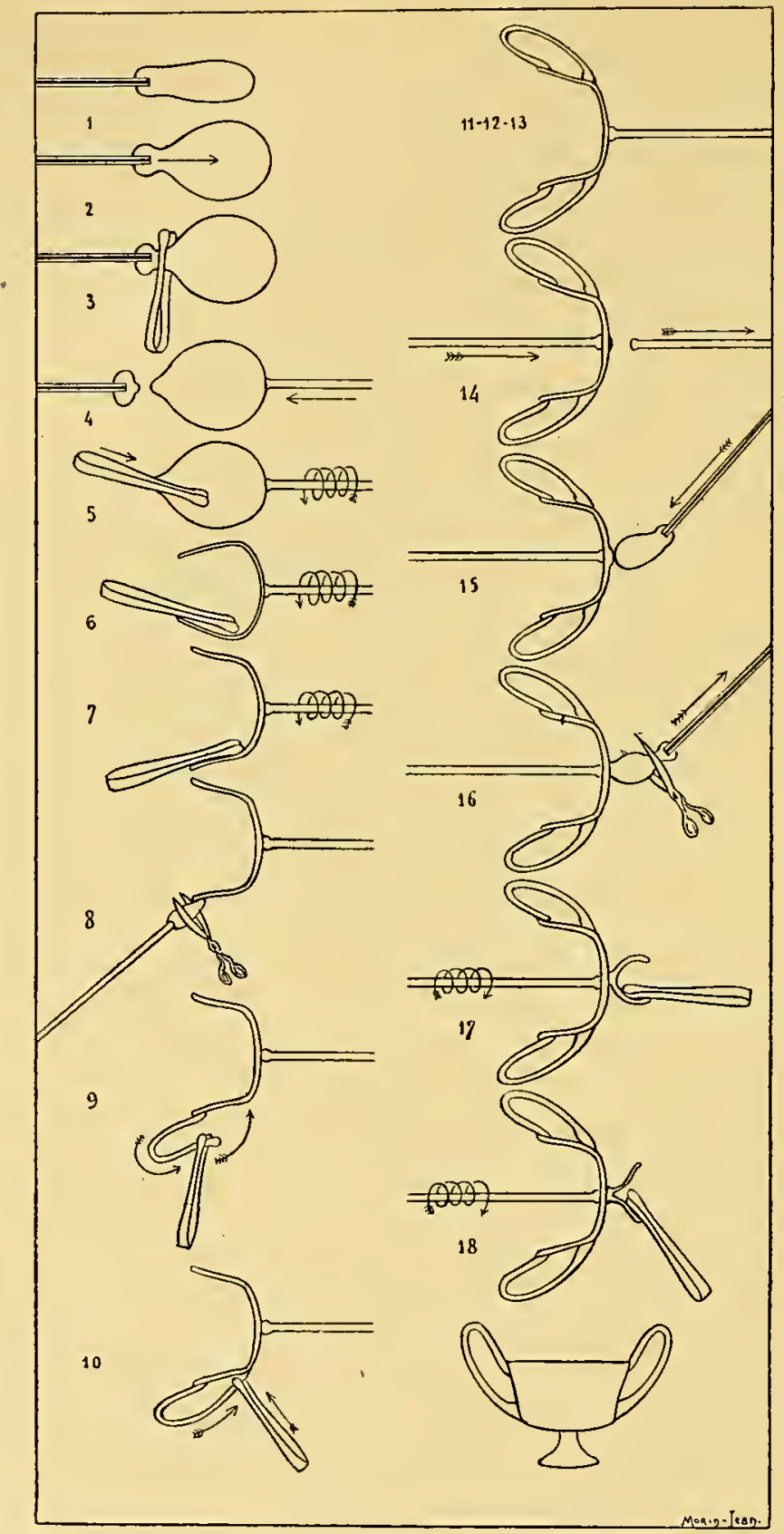

Fig. 353. - Travate du verre a Murano. - Phases diverses de la fabrication d'un canthare. 
On opère de la même façon pour confectionner la seconde anse (phases II, I2 et I3).

Il ne reste plus qu'à faire le pied. Dans cette intention, l'ouvrier commence par changer le mode de prise de l'objet en fixant un nouveau pontil à l'intérieur du vase (phase 14 ) et en détachant celui qui avait servi à tenir la pièce pendant les phases 4 à $I_{3}$ de la fabrication.

Entre temps, un autre ouvrier a fait une petite paraison qu'il fixe sous le récipient (phase I5). La canne creuse à l'aide de laquelle a été soufflée cette paraison est détachée (phase r6). On fait ensuite tourner la pièce (phase $\mathrm{I} 7$ ) ; on ouvre la nouvelle paraison et on l'élargit jusqu'à ce qu'elle prenne la forme que l'on désire donner au pied du canthare (phase I8).

Le canthare terminé est mis dans un four où, grâce à un feu doux, il refroidit lentement. 


\section{CONCLUSIONS}

Beaucoup de problèmes ont été posés dans cet ouvrage. Il en est peu qui aient reçu une solution définitive. La complexité des questions qui y ont été soulevées est telle qu'elle rend difficile l'établissement de règles absolues, l'adoption de principes immuables, de lois rigoureuses.

Toutefois les recherches qui l'ont fait concevoir, les nombreux documents qui y sont présentés et les arguments qui y sont exposés, permettent de formuler quelques conclusions précises.

${ }^{\circ}$ Les produits de l'industrie verrière, à l'époque romaine, présentent, dans toute l'étendue de l'Empire, des caractères communs.

Un verrier avait-il créé, dans quelque grand centre, un nouveau type paraissant supérieur aux modèles courants, l'objet était adopté rapidement dans toutes les provinces. Les modes locales ne pouvaient imposer leurs lois que dans une faible mesure.

Cette uniformité est sans doute due à l'empreinte exercée à cette époque dans tout 1'Fimpire par un pouvoir centralisateur, fortement constitué. Les objets industriels et artisțiques provenant des grands empires ne présentent pas entre eux les différences plus ou moins profondes que l'on constate dans les productions de pays unis par un lien fédératif.

$2^{\circ}$ Sous l'Empire romain, des liens étroits unissent les centres occidentaux d'industrie verrière aux officines orientales.

Les productions orientales se propagent et s'imitent dans tous les pays soumis à la puissance des Césars.

Un grand nombre des ouvriers qui travaillent dans les ateliers établis en Gaule sont originaires d'Orient. 
$3^{\circ}$ Tout en subissant l'infuence de l'Orient, les verriers des officines gauloises ne sont pas uniquement des copistes. Ils créent des objets qui ont un caractère particulicr.

La personnalité des ouvriers de Gaule ne disparait pas entièrenient devant les conceptions des verriers d'Alexandrie, de Tyr et de Sidon. Elle demeure, il est vrai, presque insensible là où, comme dans la Narbon11aise, le joug romain se fait le plus sentir ; mais elle est très accentuée surtout après le second siècle, dans la Lyonnaise, dans la Belgique et dans la vallée du Rhin. Tout en s'inspirant de modèles orientaux, les verriers de ces régions ne les copient pas servilement; ils en modifient assez souvent l'aspect, leur donnent un autre caractère; ils adaptent la forme et le décor de leurs productions au goût peu raffiné, voire même fort médiocre, des bourgeois cossus et des marchands enrichis de Metz, de Trèves et de Cologne.

Ils ne copient pas toutes les formes de verres en usage dans le bassin de la Méditerranée. Ils ne font pas de bouteillles ell forme d'askos, ni de ces flacons géminés à anses compliquées qu'on trouve en Palestine. Par contre, ils sortent parfois des cadres établis par les Orientaux, ils créent quelques types, ils inventent la bouteille en forme de tonneau cerclé appelée barillet. Puis ils recourent, pour orner certains de leurs produits, à des serpents faits de gros fils de verre appliqués à chaud sur la surface des récipients; ce genre de décor, leur devenant peu à peu familier, finit par les caractériser.

D'autre part, ils ne limitent pas leur action à une zone restreinte. Ils trouvent partout des acheteurs, conquièrent l'étranger et arrivent à faire au loin concurrence aux grandes fabriques d'Orient. Enfin, ils jouent un rôle dans la formation des écoles de verrerie de l'Europe médiévale. Il ne faut pas s'exagérer l'importance de ce rôle, mais il est bon de ne pas le méconnaître.

$4^{0}$ Comme l'histoire de la céramique, l'histoire de la verrerie du $\mathrm{I}^{\mathrm{er}}$ au $\mathrm{IV}^{\mathrm{e}}$ siècle de notre ère conduit à conclure qu'en Europe occidentale, les centres de fabrication se sont successivement déplacés du sud au nord.

Au I $^{\text {er }}$ siècle, les officines de 1'Italie sont florissantes et expé- 
dient leurs produits en Gaule. En même temps, les premières verreries gauloises s'installent dans la basse vallée du Rhône.

Dès le $\mathrm{II}^{\mathrm{e}}$ siècle, l'Italie, énervée par des habitudes d'oisiveté, abandonne aux provinces nordiques le monopole du travail industriel.

Aux $\mathrm{III}^{\mathrm{e}}-\mathrm{IV}^{\mathrm{e}}$ siècles, à l'instar de 1'Italie, la Gaule méridionale s'efface complètement au profit de la Belgique et de la Germanie.

Malheureusement la détermination des centres de production est plus malaisée pour la verrerie que pour la céramique. On est cependant en droit d'affirmer que les provinces rhénanes possédaient dans les derniers temps de l'époque impériale d'importantes manufactures de verre (I).

$5^{\circ}$ L'époque impériale romaine est, pour l'industrie du verre, une ère de grandes découvertes.

Dès le début de 1'Empire, peut-être même un peu avant la fin de la République, l'invention du verre soufflé transforme radicalement l'industrie verrière. Cette industrie, dont les différents et peu variés spécimens étaient uniquement des objets de luxe, crée tout à coup des produits utiles et accessibles à tous. Le verre, qui n'était employé jusque-là qu'à faire des perles, des pendeloques, des bibelots de prix, des balsamaires minuscules, sert dès lors à confectionner des récipients usuels, à fabriquer des objets que l'on emploie, grâce à leur transparence, dans maints cas où on ne peut utiliser facilement des poteries.

C'est incontesíablement sous l'Empire que se fit la découverte de certains procédés de soufflage et d'ornementation employés, maintenant encore, dans les officines de Murano.

On a perfectionné ces procédés: on n'en a pas inventé de nouveaux.

La gravure, la peinture, l'émaillage, la dorure sur verre étaient connus des contemporains d'Alexandre Sévère, d'Aurélien, de Probus. Les ouvriers du Moyen-âge et de la Renaissance, pour créer des

(I) Suivant Cramer, certains noms estampillés sur des verreries nordiques (Giamillus entre autres) sont ceux de verriers rhénans. On a découvert, d'autre part, à Avenches une verrerie du Romain II (couservée aujourd'hui au nusée de Nyon) qui porte l'inscription : Carantrvs. Carantonivs. Civis. I.evcrs. C'est un des rares exemples ot̀ le verrier désigne son pays d'origine. (Les Leuci occupaient la Gaule Belgique entre la Marne et la Moselle et avaient Tullum (Toul) pour capitale.) (Voy. Anton Kisa, Das Glas, p. 936 et suiv.) 
chefs-d'œuvre, n'auront guère besoin de perfectionner les moyens techniques de leurs devanciers du temps des Césars.

C'est de même sous l'Empire, peut-être dans le courant ou vers la fin du $\mathrm{rr}^{\mathrm{e}} \mathrm{s}$, qu'on apprit à rendre le verre tout à fait incolore, à le purifier par l'emploi du manganèse, à le débarrasser des colorations naturelles dues aux oxydes de fer qui entrent dans la composition du sable. Cette découverte rendit le verre propre à quantité d'usages et lui donna une valeur inestimable. Seul, le verre incolore pent faire pleinement valoir la coloration des vins. Or, comme, au III siècle, la culture de la vigne commençait à être fort en honneur en Gaule, il devait ne pas tarder à jouir d'une grande vogue auprès des habitants de ce pays.

$6^{\circ}$ Les verreries de l'époque romaine trouvées en Gaule ne penvent pas être facilement réparties dans un cadre systématique de subdivisions chronologiques. La variété des divers facies que présente l'industrie du verre du $\mathrm{I}^{\mathrm{er}}$ au $\mathrm{IV}^{\mathrm{e}}$ siècle, permet tontefois de les partager en denx grands groupes et de diviser en deux séries distinctes le second de ces groupes.

I a chronologie des verres romains soulève des problèmes qui n'ont pas tous reçu une solution définitive.

I, 'étude des mobiliers funéraires de la Gaule montre néanmoins qu'il est possible de distinguer deux périodes d'évolution industrielle qui correspondent à des vagues successives d'influence orientale :

Le Romain I.. Frührömisch ;

Le Romain II. Spätrömisch des archéologues allemands.

Ces deux phases ne sont pas séparées par une cloison étanche. I a seconde est pénétrée profondément des survivances de la première. I e passage de l'une à l'autre se place entre la fin du règne de Commode et le principat d'Héliogabale. Ie Romain II comprend deux périodes. Pendant la première, l'art du verrier atteint son apogée sous les empereurs syriens. Pendant la seconde, une profonde décadence se manifeste dans l'industrie verrière, après Constantin.

Ces diverses phases chronologiques peuvent se grouper de la façon suivante: 


\begin{tabular}{|c|c|c|}
\hline $\begin{array}{l}\text { ROMAIN I } \\
\text { de l'époque d'Auguste } \\
\text { à la fin du règne de } \\
\text { Commode (+ I92) } \\
\text { (I er \& I I siècles). } \\
\text { Incinérations. }\end{array}$ & \multicolumn{2}{|c|}{$\begin{array}{l}\text { Verre blen-verdâtre, naturellement teinté par les oxydes métal- } \\
\text { liques contenus dans les sables. - Verre volontairement } \\
\text { coloré. Tons violents. - Imitation des gemmes. Soufflage du } \\
\text { verte dans des moules de forme géométrique. - Flacons } \\
\text { lourds et trapus à panse prismatique et cylindrique. - Anses } \\
\text { plates coudées à angle droit ou aigu. - Umes cinéraires. - } \\
\text { Ampoules en forme d'alabastres et d'aryballes. } \\
\text { L es officines les plus prospères sont celles de la vallée du Rhône. }\end{array}$} \\
\hline \multirow{2}{*}{$\begin{array}{c}\text { ROMAIN II } \\
\text { du règne de Septime } \\
\text { Sévère }(+ \text { r93 à }+2 \text { I I . }) \\
\text { à la fin du règne } \\
\text { d'Honorius }(+423) . \\
\text { Incinérations et } \\
\text { Inhumations. }\end{array}$} & \begin{tabular}{|c|} 
PHASE A \\
PHÀ à \\
de Septime Sévère à \\
une date imprécise de \\
la seconde moitié \\
du mi siècle. $^{\text {Incinérations }}$ \\
dominantes.
\end{tabular} & \begin{tabular}{|} 
Apogée de l'industrie du verre sous les \\
empereurs syriens. Verre incolore dé- \\
barrassé des teintes naturelles à l'aide \\
du 1nanganèse. Grande variété dans les \\
formes des récipients. Élégantes verre- \\
ries tournées. Anses courbes et curieu- \\
sement appendiculées. Pieds délicats \\
détachés de la panse. Flacons à très \\
long col formes I9, 23, 24, 25. Déve- \\
loppement dela verrerie plastique. Dé- \\
veloppement du décor en fil de verre \\
appliqué à chaud (Fils spiralés, enrou- \\
lements et feuilles cordifornes). - \\
Cabochons. - La gravure, la peinture, \\
et la dorure sur verre se développent \\
surtout à partir du milieu du III \\
siècle. Les offines les plus prospères \\
sont dans la Gallia Belgica et sur les \\
bords du Rhin.
\end{tabular} \\
\hline & $\begin{array}{c}\text { PHASE } \mathrm{B} \\
\mathrm{du} \text { dernier tiers du } \\
\mathrm{III}^{\mathrm{e}} \text { siècle à la fin du } \\
\text { règne d'Honorius } \\
(+423) . \\
\text { Inhumations } \\
\text { dominantes. }\end{array}$ & $\begin{array}{l}\text { Décadence de l'industrie verrière, sur- } \\
\text { tout après Constantin. - Raréfaction } \\
\text { du verre incolore. - Verre impur, } \\
\text { nuageux, verdâtre ou jaunâtre, plein } \\
\text { de bulles d'air et de filandres. Dégé- } \\
\text { nérescence des formes de la phase } \\
\text { A. - Manque de solidité. - Exagéra- } \\
\text { tion des moyens techniques. Virtnosité } \\
\text { excessive dans la fabrication des verres } \\
\text { dits diatretes (dernières années du } \\
\text { nue siècle). Décor lâché. Les feuilles cor- } \\
\text { diformes sont remplacées par de gros } \\
\text { fils figurant des serpents. Cabochons à } \\
\text { ombilic. Extension de la gravure, dela } \\
\text { peinture, de l'émaillage et de la dorure } \\
\text { sur verre. Coupes chrétiennes ornées } \\
\text { de scènes de l'Ancien et du Nouveau } \\
\text { Testament. }\end{array}$ \\
\hline
\end{tabular}




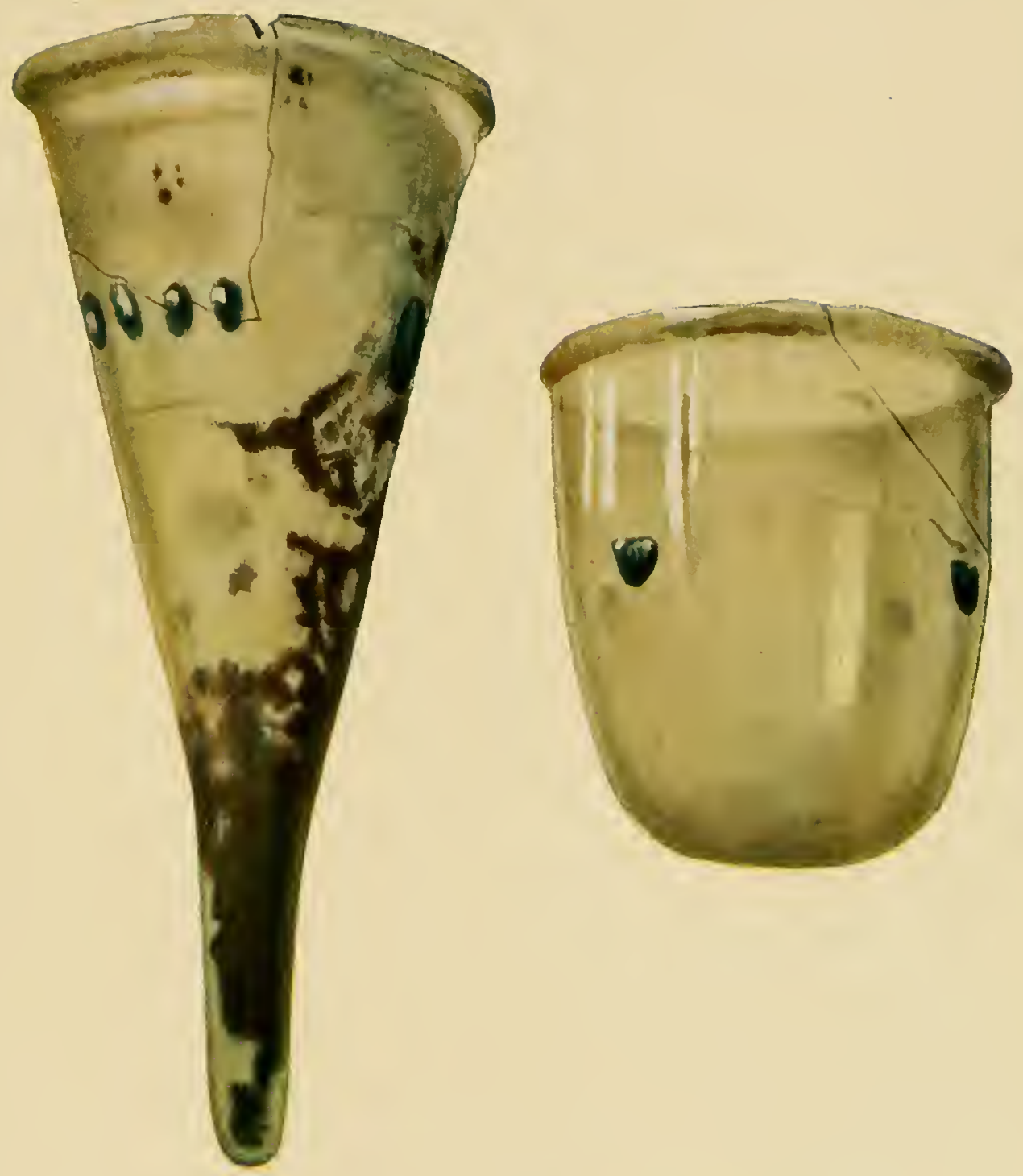

PL. IO, - VerRertes a caBochoxs. - IVe siLccle. - Collection Morin-Jean, Paris.

(D'apres l'aquarelle de l'auteur.) 

$7^{\circ}$ Les formes des verres romains sont presque toutes cmpruntées anx répertoires des céramistes ct des orfèvres.

I a céramique, la métallurgie étaient des industries vieilles de siècles nombreux quand le verre soufflé fit son apparition. Des récipients usuels, des œnochoés, des amphores, des hydries, des canthares, des phiales en argile, en or, en argent, en bronze, précédèrent les objets analogues en verre.

Quand l'emploi du verre soufflé se généralisa, on trouva tout naturel de conserver les formes de récipients usitées depuis longtemps, on n'éprouva pas le besoin d'en créer de nouvelles.

So Les formes des récipients en vorre obéissent anx lois qui régisscut la confection des productions artistiques ct industrielles.

Les formes évoluent selon des lois. Ces lois, surtout en matière de production industrielle, ne sont pour ainsi dire pas modifiées par des individualités, si originales que soient celles-ci dans leurs conceptions.

Le verrier ne peut pas, plus que le céramiste ou l'orfèvre, faire, dans son esprit, table rase du passé, imaginer quelque chose d'entièrement nouveau, chercher dans son propre fonds une création tout à fait personnelle. Sa mentalité est déterminée par un puissant atavisme; elle est, pour une large part, composée de formules héréditaires ; elle ressemble à un canevas où seraient brodés, avec des laines nouvelles, des dessins anciens et peu variés, à une partition musicale où de vieux leitmotivs reviennent à chaque instant. Flle l'oblige à se conformer à la tradition, à prendre place dans la lignée ininterrompue d'artisans condamnée à ne pas procéder par bonds dans sa marche vers le progrès. Dès lors, les formes trouvées par ses aïeux s'imposent à lui inéluctablement. Il les copie.

Peu à peu, sous l'impulsion des mœurs et des usages de son temps, et sous l'influence de son milieu, il y introduit quelques modifications mais la plastique de ses produits s'éloigne si lentement de son point de départ, qu'il se rend à peine compte qu'elle subit une évolution.

Il est des verres de forme étrange, où les réminiscences lointaines, où les conceptions ancestrales paraissent faire défaut: types anormaux, ils ne se sont pas reproduits. 
Par contre, les formes normales constituent un ensemble que des changements graduels partagent, si l'on veut, en séries assez distinctes les unes des autres; mais ces séries forment un bloc tel qu'il est difficile de les isoler.

L'évolution des formes des vases est due, en principe, à ce que l'homme se crée de nouveaux besoins, tâche de varier et de multiplier ses satisfactions matérielles et artistiques : ce sont les facteurs primaires de cette évolution.

Par ailleurs, la religion, la magie, le fétichisme, certaines particularités inhérentes au goût de telle ou telle race humaine ont contribué et contribuent aussi à faire varier les formes: ce sont les facteurs secondaires.

$9^{\circ}$ Le galbe des verreries romaines $n^{\prime} e s t$ jamais parfaitement régulier.

Il n'existe pas de symétrie absolue dans les profils des verres antiques, soit que ces verres, faits à la hâte, constituent des produits communs, soit que, faits avec soin et habilement travaillés, ils doivent être considérés comme des objets de luxe. Une constatation analogue peut se faire dans le domaine de la céramique. L,e travail mécanique, qui, de nos jours, rend les objets industriels tout à fait semblables les uns aux autres, était inconnu des anciens.

I0 ${ }^{\circ}$ Les formes les plus belles sont celles qui proviennent de l'adaptation du galbe des objets à des besoins déterminés.

Pour être essentiellement et strictement belle, la forme d'un objet usuel en verre, en terre cuite ou en métal, doit être en corrélation absolue avec la destination de cet objet. Si un objet usuel a une belle forme, c'est parce qu'il est adéquat à l'emploi auquel il est destiné. Quelque peu important que soit un objet, il est intéressant s'il répond bien aux fins, fussent-elles très humbles, qui l'ont fait concevoir.

Platon a dit que tout ce que nous trouvons beau nous paraît d'autant plus beau que nous en constatons davantage l'utilité.

Les hommes ayant besoin de meubles, d'ustensiles de ménage, de vêtements et de véhicules, d'armes et d'outils, non seulement apprécient beaucoup ces objets parce qu'ils sont de première nécessité, 
mais encore les trouvent beatx du moment qu'ils correspondent bien aux exigences de leur existence et qu'ils peuvent être utilisés selon leurs désirs.

I,es verriers de l'antiquité ne se sont quelquefois pas souciés d'établir une étroite corrélation entre l'objet créé par eux et l'usage auquel il était destiné ; mais cela vient de ce qu'ils avaient, ou plus exactement que ceux dont ils copiaient les créations, avaient eu d'autres soucis que de simples préoccupations utilitaires.

Pris en eux-mêmes, les verres plastiques, les flacons en forme de tête humaine, d'animaux, de plantes, ne répondent à aucun besoin. Sauf quelques exceptions, ils sont des erreurs de goût et de bon sens; ils sont mal en main, difficiles à nettoyer, fragiles à l'excès; ils ne valent guère plus, au point de vue artistique, que les verreries modernes qui reproduisent une botte de gendarme, le buste de M. Thiers, la colonne Vendôme ou le campanile de Venise. Mais nous prenons goût à les étudier quand nous savons qu'ils sont les tenaces survivances de récipients plus anciens créés par une humanité primitive, dont la mentalité était plis fétichiste qu'artistique, pour qui l'art avait bien moins d'importance que la religion. 


\section{INDEX MUSÉOGRAPHIQUE}

Alesia. Muséf, DF LA SOCIF́té DES SCIENCES DE SEMUR et MUSÉ MUNICIPAI. - Quelques verreries entières. Très nombreux fragments. Prédominance de la forme 68 ( $\mathrm{x}$ ).

Amiens. MUSEE DE PICARdIE. - Riche série. Verrerie locale. Nombreux barillets forne I32. Un flacon $123\left[\mathrm{n}^{\circ} 919\right]$ (2). Une fiole 120 [no 943$]$. Un aryballe forme 36 sans pieds [ $\left.\mathrm{n}^{\circ} 936\right]$.

Arles. MUSÉE LAPIDAIRE ET ARCútologIOUE. - Verrerie locale. Prédominance des types du Romain I : ollce cinerarice, ampoules formes $20,2 \mathrm{I}, 22$, fioles à long col $23,24,25$, bouteilles à panse prismatique. Bean flacon forme $1_{3} \mathrm{I}$ (grappe de raisin à trois lobes) $\left[n^{\circ} 23387\right.$.

Avignon. MUSÉE CALVET. - Riche série. Verrerie de la basse vallée du Rhône. Prédominance des types du Romain I. Types pompéiens. Olla cinerarice, formes $I, 2,3,4$. Nombreuses bouteilles à panse prismatique. Ampotules et fioles formes 20, 2I, 22, 23, 24, 25. Bouteille à deux compartinents forme 46 , tronvée à Orange en 1840 [ $\mathrm{n}^{\circ}$ II 3$]$. Flacon en forme de tête humaine. Verre en forme de corbeille à denx anses forme 138 [ $\left.\mathrm{n}^{\circ} 97\right]$.

Beauvais. MUsEe D'ARChÉlogiE. - Verretie locale. Prédominance des types du Romain II. Verre à pied forme I Io, orné de fils de verre formant résille [série B, $n^{0}$ 266]. Beau bol orné de cabochons à ombilic [série $B, n^{\circ} 47 \mathbf{I}$ ].

Berlin. ANTiguariun. - Trois verreries célèbres tronvées dans la Gaule du nord : Io Coupe gravée dite de Poseidon [Cobern] (voy. p. 240, fig. 325); $2^{\circ}$ Coupe gravée dite de l'Anthropogonie [Cologne] (voy. p. 240); $3^{\circ}$ Vase à résille, dit diatrète, portant une inscription grecque [Colognel (voy. p. 232, fig. 313).

Berne. MUŚ́E HISTORIoUE. - Fragment d'un bol moulé, orné de combats de gladiateurs (voy. p. I 91 ).

Besançon. MUSÉE ARChÉLOGIQUE. - Importante série de verres de la région : Ververies du cimetière du champ de Mars ( $\mathrm{I}^{\mathrm{er}}$ siècle). Débris de coupes imitant l'agate rubanée (voy. p. 228). Verrevies du cimetière de la Viotte (II et $\mathrm{III}^{\mathrm{e}}$ siècles). Bouteilles forme 64 (fragmentée) et forme 62 (ornée d'applications vermiculaires) (voy. p. 207). Verreries du cimetière de Thoraise (inhumations fin $\mathbf{I I}^{\mathrm{e}}$ et $\mathrm{IV}^{\mathrm{e}}$ siècle). Formes 40,72, II $x$, etc.... - Pièce remarquable : œulochoé à décor priapique, verre travaillé en deux couches (voy, p. 229 et pl. 6).

(I) Ces numéros renvoient au tableau de morphologie générale placé en tête du volume.

(2) Les numéros entre crochets sont ceux des musées où les objets sont conservés. 
Bonn. Provinziamusi:um. - 'Très inportantes séries de verreric locale. Belle collection de rerres à applications verniculaires de l'époque des emperents syriens. Verres gravés. Verres peints. Mobiliers funéraires classés par tombes. Aryballes fonne 35 à deux compartiments [11 os 8953 et 15 313]. Bouteille à 3 compartinuents forme 63 [110 864]. Fragnnent de la diatrète de Hohensülzen (voy. p. 233). Bouteille oncée de gravures et d'mı quadrige en peinture polychronle. I'iole en forme de tête

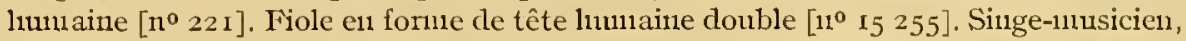

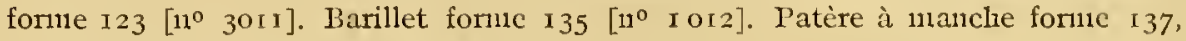
ornée d'applications verniticulaires $\left[\begin{array}{lll}11^{\circ} & 2 & 1\end{array}\right]$.

Bordeaux. MIUSÉE D'ANTIQUTYAS et MIUSÉE CARREIRE. - Verreries provenant du cimetière gallo-ronnain de Terre-Nègre, à Bordeaux, nécropole explorée de iso, à 1830 .

Boulogne-sur-Mer. MUSÉ ARCHologroue. - Très iniportante série de verres de la région. Prédoninance des types du Romain II. Les plus nombreux viennent du cimetière du Vieil-Atre (enplacenent du cimetière actuel); les autres ont été trourés au Val-Saint-Martin, à Châtillon et à Brequerecque. Belle urne cméraire à convercle (panse hexagonale) $\left[\mathrm{n}^{\circ}{ }^{2} 5^{\mathrm{I}} 2\right]$. Belles coupes forme $68\left[\mathrm{I1}^{\mathrm{os}} 2479\right.$, $\left.24^{80}, 2481,2483\right]$. Très grandle bouteille forne 9 , à décor gravé $\left[\mathrm{n}^{\circ} 25^{13}\right.$, hauteur : $\left.\mathrm{o}^{\mathrm{m}}, 33\right]$. Nombreux verres à boire fornle I Io. Carafe fonne $53\left[\mathrm{n}^{\circ} 2673\right]$. Très grand

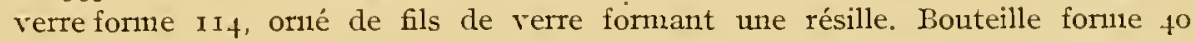
et $f^{1}$. Verres forme 98 . Très belle bonteille en forme de tête liumaine double, forme I2I ' $\left[\mathrm{n}^{\circ}+\right.$ I20] (voy. p. I53, fig. 208). Bouteille en forme de tête grotesque forme $122\left[\mathrm{n}^{\circ}+\mathrm{O}_{45}\right.$ ] (voy. p. 156, fig. 209). Flacon en forme d'oiseau [ $\left.\mathrm{n}^{\mathrm{0}} 25^{25}\right]$ (voy. p. I61, fig. 215). Nombreux barillets forme 132 , dont un à 3 anses [ $11^{\circ} 2501$ ]. Verre forne 134 (voy. p. I76, fig. 231).

Bourges. MUUSÉ DU BERRI (Hôtel Cujas). - Série de verres provenant du cimetière romain du Fin Renard à Bourges et du cimetière dit de Séraucourt (ancien champ de foire). Grosse bouteille prisulatique en verre verdâtre, trouvée à la Maladrerie (commune de Châteuneilland-sur-Cher) (hauteur: ${ }^{\mathrm{m}}, 35$ ).

Bruxelles. MuseE DU CinguantenaIRE. - Verrerie belgo-romaine. Belle cenochoé découverte à Cortil-Noirmont (Brabant) (voy. p. 202, fig. 272). Fiole à deux anses en forne de grappe de raisin trouvée à Frésin (voy. p. 169).

Charleroi. Musét ARCHÉologiQuL. - Verrerie belgo-romaine. Spécimens du cimetière de Strée. Verre ornithomorphe forme 127.

Cologne. IIUSÉE WALiRAF-Richartz. - Très riches séries. Prédominance des types nordiques du Romain II. Nombreux verres à applications vermiculaires du IIr siècle. Au rez-de-chaussée du Cloître, Mobilier funéraire du cimetière de la rue de Luxembourg à Cologne. Disposition méthodique des objets. Reconstitutions de sépultures. Classement chronologique du $\mathrm{I}^{\mathrm{er}}$ au IVe siècle. Dans le cloître du haut (aile nord), belle collection de verres antiques. Pièces tout à fait remarquables. Gourde plate à deux anses décrite page 20.4. Nombreuses bouteilles (Kännchen) forne 50. Belles œnochoés à applications vermiculaires forme 5 . Bouteille à trois compartinents forme $63\left[n^{\circ} 252\right]$. Plat ovale $\left[1^{\circ} 760\right]$. Carchesium forme 98 , à applications vermiculaires [no 670$]$. Verrerie plastique (belle série). Verres en forme de tête humaine (Tête double, tête simple, grotesques). Flacon en forme de singe-1musicien $\left[\right.$ [1 $\left.^{\circ} 292\right]$. Flacon en forme de porc forme $125\left[\mathrm{n}^{\circ} 549\right]$. Flacon en fonne de poisson forne 129 $\left[\begin{array}{ll}n^{\circ} & 983\end{array}\right]$. Verre orné de poissons en ronde bosse décrit page ${ }_{6} 6_{5}$. Bouteille en forme de coquille [n $\mathrm{n}^{\circ}$ 29]. Flacons en forme de grappes de raisin. Barillet forme 135 . Patìres 
à manches. Flacon en forme de casque de gladiateur. Verreries de formes aberrantes. Gourde plate à quatre ouvertures ornées de pigeons en émail blanc (voy. p. 185 ). Linportante série de verres gravés (Bol dit de Lyncée. Voy. p. 240). Verres peints.

Compiègne. MUSEE VIVENEL. - Verreries de la région. Beau verre à pied, orné de serpents en relief.

Laon. MUSÉ ARChÉ,OLOGIQUE COMmUNaL. - Verreries de la région.

Le Hâvre. Musẹ́ Cocmær. - Verreries découvertes en Normandie par l'abbé Cochet. Urnes cinéraires. Grande bouteille à panse prismatique, trouvée à Bréauté, en I 856 . Sépulture à incénération provenant des fouilles de MM. Delacour et Cochet, à Lillebonne, en $x_{5} 6$ (Olla de verre sans anses renfermée dans un gros dolium de terre rougeâtre).

Liége. Muste ARCHÉlogroue. MaIson CuRIrus (Petit Guide sommaire, Imprimerie liégeoise. S. A., rue des Clarisses, 52, à Liège). - SALLE I. Vitrine I. Antiquités belgoromaines classées par mobiliers funéraires. Verreries des tombes d'Avennes (territoire de Braives), de Blehen, de Heron, de Noville (incénérations), de Celles (Waremme) (tombe féminine à inhumation de basse époque). Vitrine 3. Belles verreries provenant de Tongres. - SALLE II. Mobilier funéraire des sépultures fouillées dans le Condroz, par M. Firmin Hénaux (verres particulièrement remarquables dans les tombes $n^{08}$ I et 2 de Vervoz (incinérations).

Londres. Musée britannioue. - Coupes chrétiennes dorées, dites de Sainte-Ursule et de Saint-Séverin, découvertes à Cologne (voy. p. 250).

Luxembourg. MUSÉE ARChéologrouf. - Belle série de verres de la région. Prédominance des types du Romain II.

Lyon. Musé DES ANTigues. - Verres trouvés dans la région. Spécimens du midi de la France. Urnes cinéraires à anses et sans anses [Lyon, Belleville (Rhône), Andance (Ardèche), Montélimar (Drôme), Montmerle (Ain), Reventin, Ruffieux (Isère)]. Nombreuses fioles à long col formes $23,24,25$. Belle série d'ampoules 37 en verre mince jaune et bleu.

Marseille. MUSÉE BORÉLY. - Importante collection de verreries de la basse vallée du Rhône (beaucoup d'entre elles proviennent d'Arles). Urnes ossuaires. Nombrenses fioles formes 20 à 25 . Bouteille carrée forme I $_{5}$ à deux compartiments [no 494]. Curieuses verreries de forme aberrante [nos 460 et $46 \mathrm{I}$ ] (voy. p. I82).

Mayence. MUSÉ DES ANTIQUITÉs ROMANO-GERMANIQUES, fondé en I852. - Très importantes séries de verres du Rheinland. Classement par mobiliers funéraires. Reconstitutions de sépultures (tombe de femme à perruque, cercueil de plomb, Basse époque). Tombe d'Epigonus (nombreux verres). CEnochoés à anse en chaîne (voy. p. 40, fig. 128). Verres à légendes gravées (souhaits adressés au buveur). Belle diatrète (voy. p. 233) et grande bouteille forme 9 ornée de scènes bachiques gravées, trouvées dans un sarcophage à Hohensiilzen.

Munich. ANTTQUARIUm. - Diatrète à inscription latine, trouvée dans un sarcophage, tute Benesis, à Cologne (voy. p. 232, fig. 312).

Namur. MUSÉE DES ANTiouités PROVINCrales. - Objets classés par époques et lieux de provenances. Riche série de verres trouvés dans la région. Verres des cimetières de Flavion, Corennes. Bol moulé à courses de chars, trouvé à Couvin (voy. p. 189).

Nancy. MUSÉE LORRAIN. - Verreries déconvertes en Lorraine. Urnes cinéraires de grande taille. Unne à anses, en verre bleuâtre, enfermée dans une cuve cubique en pierre, découverte à Longwy (Meurthe-et-Moselle). 
New-York. MI:TRopolitan MUSEUM. - Verres autrefois conservés dans la collection Clarret. Série de Vaison (types de la basse vallée du Rlône). Verrerie plastirune. (Bouteille en forme de tête lnunaine publiée par $W^{T}$. Froelmer dans La verrevie antiquc, pl. $\mathrm{XV}^{\top}, n^{\circ} \mathrm{8}_{3}$ ). Bol moulé, on de combats de gladiateurs, trouvé à Montagnole (Saroie) (roy. p. 190).

Nimes. Io MUSÁE ARCHÉLOGIQUE. - Mobiliers funéraires avee verreries déposés dans des cuves de pierre. Verreries du midi de la France. Prédoninance des types du Romain I.

$2^{\circ}$ MUSEE DE LA MAISON CARREE. - Ricle série de verres provenant de la basse vallée du Rhône. Urnes cinéraires de Saint-Baudile. Bouteille à panse prismatique portant me marque grecque $(Z 1 I(-)) C$ et un éléphant). Nombreuses fioles, à long col, formes 23 à 25 .

Niort. IIUSÉ DE IA SOCIËTÉ HISTORIQUE E'T SCIEATIFIQUE DES DEUX-SÈVRES. Verreries découvertes sur la commune de Verrines, près Niort. Unes cinéraires sans anses. Bouteilles à panse prismatique. [No 33 , 'Tombe à incinération de Fomperron] (voy. fig. 332).

Nuremberg. MUSGE GERIANIQUE. - SALLE IV. Vitrine III. Quelques belles verreries. Bouteille forne 4o, trourée à Zahlbach, près de Mayence. Bouteille forme 59, ornée de serpents (roy. fig. 289). Grand verre à pied forme Io6, onné d'une résille (voy. fig. 262). Flacon en forme de tête humaine double (Mayen). Verres provenant d'Andernach. Belle coupe gravée du Romain II tardif.

Paris. Io MUShe Historigue DE IA VILIE (HOTEL CARNAvaleti). - Belle série de verres provenant des nécropoles Saint-Narcel et de la rue Nicole. Mobiliers funéraires méthodiquement classés.

$2^{\circ}$ IIUSEE NATIONAL, DU LOUVRE. - Riche série deverres pour la plupart de provenance indéterminée (fonds Durand et Campana). Quelques verres desfouilles de l'abbé Cochet en Norn andie. Très belle coupe chrétienne gravée, trouvée à Homblières (Abbeville, Sonune), ell 1884 (voy. 1. 243 , fig. 326). [Achat en I 887 . Inventaire M. N. C., 919 ].

$3^{\circ}$ CABINET DES MIEDAILLES A LA BIBLIOTHÈ QUE NATIONALE. - Quelques verres provenant d'Arles (fonds de Luynes).

Péronne. MIUSEE DE L'HOTEL-DE-VILIE. - Prédominance de la verrerie du Romain II. Beau ciborium forme 103, trouvé à Amiens en I $88_{3}$. Flacon en forme de tête hunıaine, décourert à Amiens en 1884.

Poitiers. MUSEE DE LA SOciété DES ANTtQUATREs DE L'OUEST. - Fouilles du R. P. Camille de la Croix au cimetière des Dunes. Reconstitution de plusieurs sépultures à incinération. Olle de verre dans des coffres de pierre. Flacon en forme de tête humaine double [Dunes U, XXII, no 72 ]. Bonteilles en forme de grappe de raisin [Dunes U, XYII, nos 73 et 74 ]. Barillets frontiniens forme I32.

Reims. IIUSEE ARCHEOLOGIQUE, fondé, en I893, par Théophile Habert (bon catalogue illustré, publié par la ville de Reims et imprimé à Troyes, en 190r). - Riche série de verres prorenant des fouilles Th. Habert et $\mathrm{J}$. Orblin. Verres gravés : Coupe dite : d'Atalante et Hippomène [ $\left.\mathrm{n}^{\circ} 228 \mathrm{x}\right]$ (voy. p. 240, fig. 324): Gobelet orné de la chasse lièvre [no 4720 ] (voy. p. 239, fig. 323).

Rouen. IIUSEE DÉPARTEXIENTAL D'ANTIQUités. - Très riche série de verres dans la salle Derille. Dans une salle voisine est installée l'ancienue collection de Girancourt, donnée au musée de Rouen, en 1912. La majorité des pièces du musée de Routen proviennent des fouilles opérées en Normandie par l'abbé Cochet. Récipient de verre à monture métallique trouvé au Mont-Afrique ${ }_{4}$ près de Dijou (roy. p. 229, fig. 311). Verre à combat de gladiateurs trouvé à Lillebonne (voy. p. I9I). 
Saint-Germain-en-Laye. MUSEE DES ANTIQUITES NATIONALES (Catalogue sommaire, troisième édition, et Guide illustré, par Salomon Reinach). - Les verreries du musée de Saint-Germain sont réunies: ${ }^{\circ}$ Dans la salle $X V$. Belle série de verres de provenances diverses, surtout de Compiègne, Poitiers, Vaison, Suèvres, Verrines, Varennes, Noulins, Néris. Précieux verres colorés, découverts dans une sépulture à Saintes. en 1871 (belles coupes côtelées forme 69 , ornées de filets blancs qui leur donnent l'aspect de l'onyx); $2^{\circ}$ Dans la salle $X I$. Verreries du Romain II recueillies par Frédéric MIoreau dans les cimetières du département de l'Aisne (description et reproduction des types principaux dans 1'Album Caranda). Verre à deux compartiments communiquant par cinq tubulures (voy. fig. 244). Flacon en forme de tête humaine (voy. fig. 210).

Saint-Quentin. MIUSÉLA EUYER. - Importantesérie deverres du Roniain II tardif, provenant du cimetière de Vermand. Coupe gravée (La résurrection de Lazare) (voy. p. 245). Grand bol à cabochons à ombilic et à inscription gravée: vIVAS. CVM. TVIS. P. Z. (voy. p. 220). Flacon en forne de singe-musicien (voy. p. I57).

Sèvres. Musét, DE la Manufacture nationale. - Fragment d'un bol inoulé, orné de courses de chars, découvert à Autun (voy. p. I 89 et fig. 249).

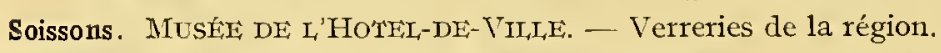

Strasbourg. MUSAE DFS ANTIOUTTÉS ALSACIENNES. - Riche série de verres romains recueillis en Alsace. Présentation méthodique.

Trèves. Provinzialanuseun (Petit guide publié par la direction du Musée, en 19I1). Riches séries de verres de l'époque impériale. Grande variété de types. Bouteille à trois compartiments forme 63 , trouvée à Pallien [no 706] (voy. fig. 148). Bol 83 orné de courses de chars trouvé à Schönecken $\left[\begin{array}{ll}n^{\circ} & 21008\end{array}\right]$ (voy. p. I 89 et fig. 250). Fragment d'un bol orné de combats de gladiateurs $\left[n^{\circ} 346^{b}\right]$ (voy. p. 19I). Flacon en forme de tête humaine double [no $64^{16}$ ]. Flacon ell forme de singe-musicien $\left[\mathrm{n}^{\circ} 05475\right.$ ] (voy. p. ${ }_{5}{ }^{8}$ ). Verre orné de poissons et de coquilles en ronde bosse [10 69.4 (voy. p. I64 et fig. 2 I 7). Bonteille en forme de grappe de raisin [no 340$]$. Barillet 132 orné de cabochons $\left[n^{\circ} 9934\right.$ I] (voy. p. 225). Coupe chrétienne gravée (Le Sacrifice d'Isaac) (voy. p. 247). Bouteille ajourée (voy. p. I83, 110 8).

Vienne (Isère). - Verres trouvés dans la région. Formes I, 12, 22, 26, 40, 68, 76, 86, 9I.

Wiesbaden. COLLECTION D'AxTiouites. - Verrerie gallo-rhénane. Petit flacon moulé à panse prismatique ornée de masques de Méduse.

Worms. Paunushuseur (installé dans l'église Saint-Paul). - Très riche collection de rerres gallo-rhénans.

Zurich. Muste Natroxal, SuIsse (petit Guide officiel par le Dr H. Lehman11;Zurich, I 903). - Verrerie impériale courante. Fragment d'un bol 83 orné de courses de chars, trouvé à Baden [n ${ }^{\circ}$ ro 935] (voy. p. 189).

\section{COMPARAISON}

Copenhague. - Bols de verre peints, ornés de bestiaires, d'animaux et de gladiateurs (voy. p. 249).

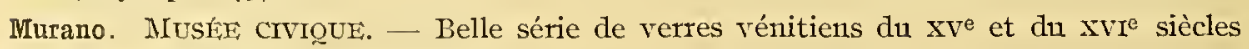
(très peu de verres antiques).

Naples. MIUSHE NATIONAL. - Séries très nombreuses de verres du Romain I, provenant pour la plupart des fonilles de Pompéi. 


\section{INDEX BIBLIOGRAPHIQUE}

BARTHÉLEMY (A. de). Une verrevie romaine près de Sainte-henehould (Marne). Bulletin archéologique (I) (Organe du Comité des Travaux historiques et archéologiqnes), I904, p. 82-85. BAUDot. Mémoire sur les verres antiques. Bulletiñ monumental publié sous les auspices de la Société Française d'Archéologie, IS70, p. I87 à 195. - Mémoires de la Commission des Antiquaires de la Côte-d'Or, VII, 205, pl. I et II.

BERTHEIOT. Analyse d'un vin antique consevvé ảans un vase de verre. Revne archéologique, 1877 , tome I, p. 392. - Nouvelle note sur un liquide renferné dans un vase de verre très ancien. Revue archéologique, I 877 , tome II, p. 394 .

BoHn (Prof. Dr O.). Zwei fragmente römisch. Glasbecher. Anzeiger für Schweizerische Altertumskunde (Indicateur d'antiquités suisses). Zurich, I903-1904, p. 272-278. - Fabrikantennamen auf römisch. Gläsem. rheiu. Museen. Westdeutsche Zeitschrift für Geschichte nnd Kunst. Trèves, I904, p. I-IO.

BONE (Karl.). Römische Gläser der Sammlung des Herrn Franz Merkens in Köln. Bonner Jahrbücher (J alırbuch des Vereins von Alterthumsfreunden im Rheinlande). Bonn, r886, p. 49-77.

BOUdAnger (Cl.). Le mobilier funéraire gallo-romain et franc en Picardie et en Artois. Paris, Leroux, 1902-I905.

CARAVEN-CAChIN (A.). Sépultures gauloises, romaines et franques du Tarn. Castres, i873.

Castan. Vase antique en verre à deux couches trouvé à Besançon. Bulletin de la Société Nationale des Antiquaires de France, i 886, p. 292-295.

CEssAC (de). Découverte d'un cimetière des premiers siècles de notre ère à Poitiers. Revue archéologique, is79, vol. 38, p. 46 .

CHARDN (Ferdinand). Vases de verre du musée de Sirasbourg. Revue archéologique, i 867 , tome II, p. 148 .

Cocher (Abbé). Fonilles de Newville-le-Pollet, 1845. - La Normandie sonterraine, I855. - Bulletin de la Société des Antiquaires de Normandie, I, IS60-I862, p. I 48. - Notice sur des sépultures romaines du IVe et du Ve siècle, trouvées à Tourville-la-Rivière (Rouen, IS63). Revue de la Normandie, mai I 863. - La Seine-Inférieure historique et archéologique, Paris, I866.

COHAUSEN. Führer durch das Altertumsmuseum von Wiesbaden.

Corson. Découverte d'une verrerie gallo-romaine à Sainte-Menehould (Marne). Revue archéologique, I903, toine I, p. 277.

COURTEAUt T (P.). Fiole en fuseau ayant contenu un vin antique trouvée à Bordeaux. Aunales de la Faculté des lettres de Bordeaux, $4^{e}$ série. Revue des Études ancienues, tome XIII, n० 3 , juillet-septembre rgi .

CRAMER (Fr.). Inschriften auf Gläsem des römischen Rheinlandes. Das römische Trier. Gütersloh, I9I1.

Danicourt (A.). Étude sur quelques antiquités trouvées en Picardie, Paris, Leroux, is86.

(I) Le titre en caractères romains plaeé immédiatcment (et sans tiret intermédiaire) apres le titre en italique d'un mémoire d'auteur cst celui du périodique, dans lequel ce mémoire a parı. 
DÉCHELETTE (Josepl1). Les vases céramiques ornés de la Gaule romaine. 2 volumes, Paris, Picard, 1904. - La nécropole gallo-ronaine de Roanne. Montbrison, I904.

DeLAiraix (R...). Les sépultures du Peyrat (Chavente). Angoulême, IgI1.

DETLEFSEN. Revue archéologique, I 863 , tome II, p. 2 I 5 (I).

DEVILLE (A.). Histoire de l'art de la verrerie dans l'antiquité. Paris, I873.

DRAGENDORFF. Torra sigillata. Bonuer Jahrbïcher, I895, fasc. 96-97, p. I 8 à I 55 .

DuCHesNe (Abbé). Plat en verre gravé représentant la résurrection de Lazare. Bulletin de la Société Nationale des Antiquaires de France, I886, p. 283, avec fig. au trait.

DüNtzer (H.). Aus der Antikensammlung des Herm. Ed. Herstatt in $h o ̈ l n$. Bonner Jahrbücher, I 867 , fasc. 42 , p. I 68 à I 82 et pl. V.

Ėck (Théophile). Les deux cimetières gallo-romains de Vermand et de Saint-Quentin. Paris, Leroux, 1891. - Décowverte d'une incinération du IITe siècle à Aubigny-en-Artois (Pas-de-Calais). Bulletin archéologique, I 896, p. 3 I 2-322.

ENGELHARDT. Mémoires de la Société Royale das Antiquaires dı Nord. Nouvelle série, t872, p. 57 et suiv. et pl. X, XI, XII.

B. FiLion. Description de la villa et du tombeau d'une femme artiste gallo-romaine, is49. $-L$ 'Avt de terve chez les Poitevins. Niort, IS64.

FLEURX (Édouard). Antiquités et monuments du département de l'Aisne. Paris, i877, p. 2 I6-2IS.

FLouEST. Trois marques de verviers. Revue des Sociétés savantes, I87.5, tome I, p. I24.

Fontenay (de). Découverte d'un verre en forme de poisson. Bulletin Monumental, I855, p. 88 .

FROEHNER (W.). La verreric antique (description de la collection Charvet). Le Pecq, I879. - Collection Julien Gréau. Verrevie antique appartenant à $M$. John Pierpont-Morgan. I volume de texte et 5 volumes de planches en couleurs, Paris, 1903.

GARNIER (E.). Histoire de la verrevie et de l'émaillerie. Tours, I886.

GaUTHIER (Gaston). Culot de vase romain trouvé à Champvert (Nièvre). Bulletin archéologique I900, p. 7 à 9 .

GAUTHIER (Jules). Le cimetière gallo-romain do Thoraise (Doubs). Besançon, I88 I.

GERSPACH. L' art de la verrerie. Bibliothèque de l'enseignement des Beaux-Arts. Paris, ISS5.

GRIFFith. Beni-Hassan. Londres, rgoo. Part. IV, p. 6, et pl. XX.

Guner (E.). Les Isiaques de la Gaule. Revue atchéologique. tome XXXVI, année Igoo.

Guvencourí (R. de). Vase de verre trowvé à Amiens. Bulletin de la Société des Antiquaires de Picardie, I907, XXII, p. 56, 57, et fig.

HAGEN (J.). Ausgewählte römische Gräber aus Köln. Bonner Jahrbücher, 1906, fasc. I I4-I I5, p. 379-434 et pi. XXI-XXVI.

HAMARD (Abbé). Découverte d'une nécropole romaine à Bury (Oise). Bulletin archéologique, 1900, P. 23.

HÉRON DE VILLEFOSSE. Verres antiques trouvés en Algérie. Rovate archéologique, 1874 , tome I, p. $281-289$.

KAMP. Die epigraphischen Anticaglien in Köln, 1869, p. I6 (2).

Kisa (Anton.). Römische Ausgrabungen an der Luxemburgerstrasse in Köln. Bonner Jahrbïcher, IS96, fasc. 99, p. 2 I-53 et pl. II. - Verzcichnis der römischen Altertïner von Ca. Niessen. Köln, 1896. - Antike Gläser mit Fadenverzievung. Kunst und Kunsthandwerk. Vienne, I899. - Kataloge der Sammlung. M. von Rath in Köln, 1899. - Die rön. Antiken in Aachen. Westdeutsche Zeitschrift für Geschichte und Tinust. Trèves, 1906, p. I-82. - Das Glas in Altertume. Leipzig (Hiersemanns Handbücher), 3 vol., I 908.

KOENEN (Constantin). Die Vorrönischen, rönischen und fränkischen Gräber in Andernach. Bonner J ahrbiicher, I 888 , fasc. 86 , p. I48-230.

LAUREN'T (Marcel). L'art chrétien primitif. Bruxelles, I9I I.

IE BLAN'T. Coupe chrétienne en vervo gravé, trouvée dans les fouilles du Vieil-Atre. Bulletin archéologique, 1890, p. $78-80$.

(r) Descriptiou de 27 vases à panse prismatique, forme I9 du tableau de morphologie générale.

(2) Coupe gravée trouvće à Cologne (I yncée et Hypermnestre). 
LEBI,OND $\left(\mathrm{D}^{\mathrm{r}}\right)$. Marque de verricr sur wh barillet gallo-ronain trouvé a Beauvais. Luauvais, 1907, i11-80, 15 pages et 1 pl.

LECAPLAIN (Dr Jean). Biberons antiques. Revue Assulapc, Paris, $2^{\circ}$ anlice, $11^{\circ}$ xo, octobre 1912.

IEINER. Fïhrer durch das Provinzialmuseum in Bonn.

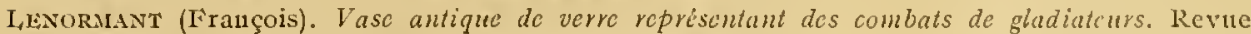
archéologique, 1865 , tome II, p. 305-3 to et pl. XX.

Irix (Léonce). Sepultures gallo-romaines et franques de Bagnoux (Marne). Revue de Chanpague ct de Brie (Arcis-sur-Aube).

LIEBBE. Le Cimatière gallo-romain de Scuil, près Rethel (Ardcnncs). Paris, 1899.

I, rÉGÉrs (Bulletin de l'Iustitut archéologique). XIII. Les Tombes d'Avenchos.

LIMEIEtTe (Auguste). Le cimetiere de Sponlin. Anuales de la Société arcliéologique de Namur, tome VIII, $3^{\text {e }}$ livraison.

I.MES AIIEMANDS (Der Obergermanisch-Raetische Limes des Roencrreiches). Heidelberg.

LINDENSchntr. Dic Altcrtumer unserer Heidnischen Vorzcit (Römisch-Germanischen CintralMuseum in Mainz.). - Mainzer Zeitschrift, Mayence, 1906. - Barillets en vorre de Frontinus. Westdeutsche Zeitschrift. Trèves, 1903, p. 426. - Vasc en vcrre du musée de Mayence. Westdeutsche Zeitschrift. Trèves, 1904, p. 364.

Ioriouer. Marque pharmaceutique inscrite sur une fiole de verre. Revue arcliéologique, I862, tome I, p. $247^{-253}$.

MANCEAUX (Hector). Le cimetiève belgo-romain franc do Strec. Mous, I877.

MARmor, (Fugène del). Fouilles au cimetière des lliats, à Flavion. Aunales de la Société archéologique de Namur, i86r, tome VII.

MOREAU (Frédéric). Albun Caranda. In-folio, I877-IS93.

Mowat (Robert). Exemples de gravure antique en verre à propos de quelques fragments du Monténégro. Revue archéologique, 18S2, tome II, p. 280-300.

Nesbitr. Catalogue of the Collection of Glass formed by Sladc. Londres, 1871.

PETRocci. Sur doux vasos de vorre antiques. Bulletin des musées royaux des arts décoratifs et industriels. Bruxelles, $3^{\mathrm{e}}$ année, $\mathrm{n}^{\circ} 4$, janvier 1904, p. 27 et 28 .

PILLOY (J.). Eludes sur d'ancicns lieux de sépultures dans l'A isne. 2 vol., Saint-Quentin, ISS6. Mémoires de la Société Académique de Saint-Quentin, 4e sétie, I886, tome VI.

POPPELREUTER (Dr Jos.). Die römische Gräber kölns. Bonner Jahrbücher 1906, fasc. I1 4-I I5, p. 344 et suiv.

QUICHERAT. De quelques pièces curieuses de verrevie antique. Revue archéologique, I874, tome II, p. $73-82$.

RABOURDIN. Découverte d'unc sépulture gallo-romainc à Héricy-sur-Seine. Meluu, isg6, I I p. et 2 pl.

Rerms (Ville de) Catalogue du musée archéologique fondée par Th. Habert. Troyes, I901.

REINACH (Salomon). Catalogue sommaire du musée des aniquités nationales au chatcau de SaintGermain-en-Laye. Paris, 1898. - Guide illustré du musée de Saint-Germain. Paris (sans date), - Vase de verve en forme de grappe. Revue archéologique, 1904, IV, p. 287.

SAGLIO, Dictionnaire des antiquités grecques et romaines.

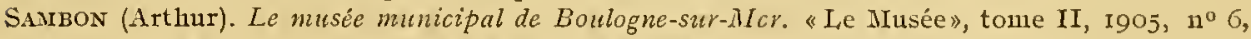
p. 264 et fig. 7. - Les verres antiques «I, Musée», tolle III, 1906, p. 477-524.

SAUVAGE (Dr H. E.). Notes diverses sur la verrerie du Boulonnais, publiées dans le Bulletin de la Société académique de Boulogne-sur-Mer, tome V, p. 236 et 736 et Tome VII. (Notes sur sur les fouilles faites rue de la Porte Gayole. Antiquitès gallo-romaines recueillies dans le Boulonnais. Les vases cn verre gallo-romains avec inscriptions.)

SCHEUERMANs. Vorre en forme de grappe de raisin découvert à Frésin. Bull. comm. belges, $1 \mathrm{S6}_{3}$, p. 127. - Nouvelle notc concernant les marques de fabrique sur la verrerie romaine. Revue archéologique, 1867 , tomé I, p. 436-442. - Verre à courses de chars de Couvin. Anuales de la Société archéologique de Namur, 20, année 1893 , p. 145 et suiv. avec phototypie.

Schumt (Robert). Das Glas. Handbücher der. Kgl. Museen zu Berlin (Berlin. Georg. Reimer, I912).

SchweIGHAtSER. Kunstblatt, I826, p. 358. - Bonner Jahrbücher, V-VI, p: 380. - Mémoires de la Société des Antiq. de France, tome VI, 1842. 
SuIter (Roach.). Collectanea Antiqua. No I. Londres 1843 (Roman Glass Vessels in the Museum at, Boulogno-sur-Mor) avec 2 planches.

SOCIÉTÉ POUR LA RECHERCHE ET LA CONSERVATION DES MONUMENTS HISTORIQUES DU GRANDDUCHÉ, DE LUXEMBOURG (Bulletin de 1a). No 5,1849 , pl. II.

Straub (Chanoine A.). Le cimetiève gallo-romain de Strasbourg. Librairie Trübner. Strasbourg, I88I.

URLıchs. Vasa diatreta in Köln. Bonner Jahrbücher, I844, fasc. 5 et 6, p. 377-382 et pl. XI et XII.

VAILI.ANT (V.-J.). Quelques verreries romaines de Boulogne-sur-Mer. Revue archéologique, $3^{\mathrm{e}}$ série, tome XII, I 889 (avec $2 \mathrm{pl}$. phototypiques représentant les deux verres céphalomorphes du musée de Boulogne). - Notes boulonnaises. Épigraphie de la Morinic. Boulognesur-Mer, 1890 (avec une pl. reproduisant la coupe chrétienne gravée [Sacrifice d'Isaac] 'trouvée au Vieil-Atre, le 21 octobre I888).

VAISSIF́R. Le cimetiève gallo-ronain de la Viotte a Besançon. Mémoires de la Société d'émulation du Doubs, 1885, p. 405-413.

VaIssier et Castan. Vase priapique en verre du musée de Besancon. Mémoires de la Société d'émulation du Doubs, $6^{\mathrm{e}}$ série, tome I, i 887, p. 249 à 254 avec pl. en couleur.

VILLEGILLE (de la). Bulletin du Comité de la langue, de l'histoire et des arts de la France, 1857 , p. 919, et pl. II et III.

WAliRAF-RicharTZ-MUSEum (Führer durch das städtisch...). Cologne, I902.

WeCKERLING. Das Paulusmuseum in Worms.

WEERTH (Aus'm'.). Travaux divers publiés dans les Bouner Jahrbücher : I864, fasc. 36, p. II9, pl. III ; I878, fasc. 63, p. 99-II4, pl. IV, V ; I878, fasc. 64, p. II9-I29, pl. X; 1880, p. 49, pl. I ; I88I, fasc. 7I, p. II9-I 33, pl, V, VI, VII ; I882, fasc. 74, p. 57-68, pl. III ; I 883 , fasc. 76, p. 63 , pl. II.

WELCKER (F.-G.). Prometheus Menschenschopter und die vier Japetiden an einem Glasgefässe. Bonner Jahrbücher, 1860 , fasc. 28 , p. 54-62, pl. XVIII.

Wilnowski (Von). Archäologische Funde in Trier und Umgegend. Trèves, I873, p. 13 (1).

(I) Description d'une coupe chrétienne en verre gravé découverte à Trèves. 


\section{INDEX GÉNÉRAL ALPHABÉTIQUE}

N.-B. - L es chiffres renvoient aux pages du volume.

Les chiffres précédés d'nne $f$ renvoient aux figures.

A

Abbeville, 54, 104, I25, I 39 , I $43,220,222,243$, f. 326 , 255. 262 .

Abraham, 246, t. 327.

Achery-Mayot (Cinetière d'), I $2 \mathrm{I}$.

Achilleus, I 53 .

Adam et Eve, 244. t. 326, $250, t .328$.

Egyptus, $24 \mathrm{I}$.

Agrippa, f. 334.

Aigle (Suisse), $f . \quad 153$.

Aix-en-Provence, 255 .

Alabastre, $20,39,72, f .65$, $73,77,280$.

Alesia, 64, г $22, f$. I $8_{3}$, I 38 , I $57,26 \mathrm{I}$.

Alger, 249.

Algérie, 248.

Alexandre Sévère (roy. Sévère).

Alexandrie, 3, 4, I 3, I 5, 53 , I oo, 230, 237, 242, 277.

Aliscamps, I8 $1, f .239$.

Alise-Sainte-Reine (Musée

d'), f. 50

Allard, 247.

Allier (voy. Figurines).

Amaranthus, I 8 .

Américain, $\mathrm{I}_{5} \mathrm{I}, f .20_{4}$.

Amiens, I4, 56, 57, 65, f. $5 \mathrm{I}, f$. го7, 96, г 36 , f. I $8_{5}$, I 43, I 53, I 58, I 73 , I $78, t$. $340, t .34 \mathrm{I}, 262$.
Amiens (Musée d'), 4o, 56, Arbre du bien et du mal, $65, f .53, f .68,80, f .93, \quad 2+4, f .326$.

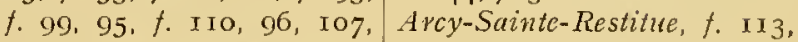

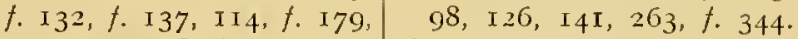
I 43, I 53, I 58, $f .21 \mathrm{I}$, I70, Arcy-sur-Aube, 261.

I 73, t. 256, f. 257, f. 317, Avezzo, 199, 239.

t. 322 .

Amphithéatre, $\mathrm{1} 88,236$.

Amphore, 44, 79, I $74, \mathrm{I} 8_{3}$, t. 333 .

Amphorisque, So, $f$. 8o, I 49 , f. 33 I $\left(\mathrm{n}^{\circ} \mathrm{I}\right)$.

Amuré, 256.

Ancy (Aistre), 263.

Andernach (Cimetière $d^{\prime}$ ), f. $32,57,94$, II9, I2I, I 26, I $28, I_{4}$, I 52, I 58 , I 73, I76, 264, $f .3+6$.

Animaux (roy. Zoomorphes).

Anses, 3t, 35, 36, 37, pl. 2 et pl. $3,3 \mathrm{~S}, 39,40,4 \mathrm{I}$, t. Io.

Anse en chaine, pl. 3, 40, f. I $28, f$. I $34, f$. I 35, I07.

Antinoè, 239.

Anthropogonie, 240.

Anthropomorphes (Verreries), $\mathrm{I}_{4} 8$ à $\mathrm{I} 56$.

Antonin-le-Pienx, II 7, I22, I 92, $203, f .334$.

Aphrodite, $\mathbf{1 6 6 , 2 4 2 .}$

Apt, 256.

A pulie, I I 9 .

Aquitaine, 256.

Aramon, $\mathrm{I}_{4} 8$.

Arbouville, 40.
Arles, $f$. I3, $t .14, f .47$, f. $63, f .66, f .74, f .119$, I $29, f$. I $52, f . \quad{ }_{69}, \mathrm{x}_{4} 8$, I $8 \mathrm{I}, f .239, f .3 \mathrm{I} 5,256$.

Aries (Musée d'), 77, f. 78 , f. 220, I 69, I $82, f .24$ I

Armentières, I2I.

Arneth, I9I.

Aryballes, 3i, 39, 82, 83, f. $8_{4}, f .8_{5}, f .86,8_{4}, f . s_{7}$, f. 88, f. 89, t. 90, t. $9 \mathrm{I}$, f. 92, f. 93, f. 95, f. 97 , t. $98,89, t .99, f$. I00, I 49 , I5o, $5_{53}, \mathrm{f} .22 \mathrm{I}, f .337$, 280.

Askos, IIO, I $74, f .230,277$.

Alalante, $f .324,240$.

Athamas, is.

Athènes, I7.

Athènes (Musée d'), $t$. I6, 48, I I 5 .

Atlas, 240.

Attique, I 5o, I 56, 238 .

Attys, $2+\mathrm{T}$.

Aubigny-en-Artois (Pas-deCalais), 262.

Audelange (Jura), 266.

Auguste, 52, 76, 230, 280 . Aurélien, 23, 200, 212, 278 . Autun, $f$. 249, I89, $26 \mathrm{I}$. 
Avenches (Suisse), 278. Avennes, $f$. I42, 264. Avignon, 256.

Avignon (Musée d'), $f$. I I, f. $22, f .39, f .47$, IоO, I02, $f$. I 22, I 6, I 22, I 29, I33, f. I 86, I $48, f .235$, f. $334, f .335$.

\section{B}

Babclon (Ernest), 9, I8, I32, I36, 229.

Baden (Suisse), I89, I92, 266.

Bain (Bouteilles de). 84 .

Balsamaires, 72, $f .73,77$, 82. I99.

Barberini, 229.

$B$ arbotine de verre, $216, f .294$.

Barentin, $26 \mathrm{I}$.

Barillet frontinien, 30, 70, 86, 94, I I 9, I 26, $f .223$, I 70, I 7I, I72, I 73, I 74, I 75, f. 224, f. 225, f. 226, f. $227, f .228, f .229,225$. f. $305,257, f .342,277$.

Bas-reliefs, $\quad \mathbf{1} 88$.

Bataves, I4.

Baudot, I89.

Beaumont-sur-Oise, $f$. I54, f. 224,262 .

Beauvais, 4I, $f$. I27, I08, I 25, I 73, 262.

Beauvais (Musée de), f. 297.

Becker, 248.

Belgique (Gaule), 262.

Bélier, 246.

Bellon, I 54, 246, f. 327 .

Beni-Hassan, 20.

Berlin (Musée de), 232, f. $3 \mathbf{I} 3$ 240, f. 325 .

Bernay (Ancienne collection), f. $29, f .40, f$. I 54, f. I 88 f. I93, f. 340, f. 34 I.

Berne, I9I, I92.

Berne (Musée de), I9I.

Berthouville, 39, I32.

Besançon, $f .4, t .5, f, 6$, f. 7, f. 277,208, f. $28 \mathrm{I}$ $228,230,264,265,266$.

Besançon (Musée de), 28 , f. $4, f .5, f .6, f .7$ f. $277,208, f .281,228$.

Bestiaive, 237.
Biberon, Iog, I IO.

Bige, 237.

Bissing (von), I3, 2 I.

Bohn (Dr), I90, I9I, 203.

Bois-des-Loges, 86, I73, $26 \mathrm{I}$ $\mathrm{Bol}$, I22 et suiv.

Bombylios, 72, f. 64, 73, 77 .

Bonde, I7I, I77.

Bonn, 8, 57, 84, I39, I 86 , $239,247,264$.

Bonn (Musée académique de), I66.

Bonn (Musée provincial de), 9, f. I, 40, 5I, f. 32, 66, f. $56,70,80,84, f .90$, $88, f .96, f$. Iо0, 95, $f$. I I 5 , I09, $f$. I39, I I4, I $6, f$. I 47, I I9, I 20, f. I 50, I 22, f. I60, I 32, I 39, I 46 , I 52 , I 58 , I 59 , I6I, $f .232, f .233, f .234$, I77. $f .27$ I, f. 279, 209, $2 \mathrm{II}, f .286,224, f .304$, 233, f. 3I 4, 239, 242, 249 , f. 346 .

Bonner Jahrbücher, 8, 43, $52,54,55,56,57,62,63$, $70,76,79,83,86,94,96$, 99, IO5, II 3, I I 4, I I 7, I 8 , I I9, I 25 , I 26, I 28 , I 34, I 35, I 36, I 38, I 39 . I 4 I, I 42, I 43, I 44, I 46 , I 52, I 56, I 58, I 59, I 60, I62, I63, I65, I69, I 73 , I 76 , I 78, I $80,204,209$, 2 IO, 2 I $8,232,233,238$, $239,240,24 \mathrm{I}, 242,247$.

Bordeaux, 82, 256.

Borély (Musée), $f .47, f .63$, f. $74, f .75,77, f . \mathrm{I}_{40} \mathrm{,}$ f. I64, I $29, \quad \mathrm{4} 48, \mathrm{I} 6 \mathrm{I}$, f. $2 I_{4}$, I 8 I, f. 239.

Boscoreale, 6, 39, I32, I38.

Boulanger (Cl.), I $2,54,56$, 98, I08, I 2 I, I 98,2 I6, $2 \mathrm{I} 9,22 \mathrm{I}, 247$.

Boulogne-sur-Mer, I4, 55, f. $29,56,76$, I07, f. I 54 , f. I $56, f$. I $88, I_{43}, I_{46}$, I $54, f .208$, I 6 I, $f .2$ I 5 , I 66, f. 225, I 73, f. $23 \mathbf{I}$, I $76, f .254, f .269,209$, $2 I_{4}, 220, f .298,224$, f. $316,236, f$. $32 \mathrm{I}, 245$, f. $327,254,262$.
Boulogne-sur-Mer (Muséede) $40,53,55,63, f .57, f .58$, f. $72,76, f .79, f .84, f .135$. f. I $43, f$. I $44, \mathrm{I}_{22}, f$. I 56 , f. I $78, f$. I 80, I 39, f. 199 , $\mathrm{I}_{4} 6, \mathrm{I}_{53}, f .208, f .209$, I 56, I $6 \mathrm{I}, f .2 \mathrm{I} 5$. I 70 , f. 225, I73, f. 23 I, f. 254 , I97, $f .263, f .269, f .278$, 209, $2 \mathrm{I} 4, f .290,2 \mathrm{I} 7,220$, f. $298,225, f .305, f .308$, f. $32 \mathrm{I}$.

Bourges, $6 \mathrm{I}$.

Bourges (Musée de), 53, 6I, 8 o.

Brény (Aisne), 42, 65, f. 296 , $220,263, f .345$.

Bréquerecque, 55, f. 57, 107 , I6I.

Breslau (Musée de), Iog.

Bresles, $t$. I 27.

British Museum, 52, 55, I36, $25^{\circ}, f .328$.

Bruxelles (Musée de), 9, I69, 202, f. 272.

Bury (Oise) (Cimetière de), I I I 220, 262 .

\section{C}

Cabinet des Médailles à la Bibliothèque Nationale, à Paris, 9, f. 66, f. 92, $f$. Iо8, I $80, f$. II7, $f$. I I9. f. I 52, f. I69, І 32, I 36 , f. 268, t. 3 I 5 .

Cabirus, 15 .

Cabochons, 6, f. 104, 96 , I 25, I 39, I 7I, 2 I $8, f .296$, $219,: f .297,220,22 \mathrm{I}$ f. $298, f .299 .222$, f. 300 , $223, f .301, f .302,224$ f. $303,225, f .304, f .505$. 265,280 .

Cain (Georges), collservateur du musée Carnavalet, 9 .

Calamus, I 90.

Calathos, I 50.

Calètes, 257.

Calicules, I 57.

Caligula, I9I, $f .333$.

Calix plerolus, I38.

Calvet (Musée) (voy. Avignon). 
Camées (Faux), 228.

Campanie, 6r, II9.

Canne de verrier, 20, 21.

Cannes (Musée de), $t .37$. f. 4 I.

Canthare, 6, 40, 42, 132 et suiv., I 49, 230.

Cany, 70, t. 62, $83,8_{4}$. f. $120,127,172, f .276$, 207,261 .

Caranda, 42, I2I, I56, I 83 , f. $24+, 263,267$.

Carchesium, 132, I33, $\%$. 178 . $134,135,137,210, f .284$. 2 II, 229 .

Cardium, $t .339$.

Caricatures, I5I, f. 209, I55.

Carnavalet (Musée), 9, 40, f. $44, f .48, f .87,89$, $f$ I $03, f . \mathrm{I} 24, \mathrm{I0} 7, f$ 工 $3 \mathrm{I}$, $f . \quad 6_{3}, f . \quad 187, f .229$. f. $26 \mathrm{I}, 258, f .352$.

Caron, 6.

Carthage, I3, I4, 43. I Io.

Carus, 94, I25, I59.

Casque de gladiateur, $\mathbf{1} 79$. I8o, $f .236,199,2$ I 2 .

Castan, 230.

Calacombes, $2+3$.

Céos (lle de), I67.

Céphalomorphes (roy. Tête).

Cêsar, I3.

Cessac (de), I74.

Chaine (Anses en) (voy. Anse).

Chalon-sur-Saône, $26 \mathrm{r}$.

Châlons (Marne), 220.

Champion, 9.

Charnay, I89, 26I.

Charleroi (Musée de), f. 2 I 4 .

Chars (roy. Courses).

Charvet (Ancienue collection), I08, I $55,169,191$.

Chasses, 237.

Chasse au cerf. 237.

Chasse au lièvre, I89, 238, f. $323,239,27$ I.

Chassemy (Aisne), f. 210, I 56,263 .

Chaudron, I27.

Chamny (Aisne). 263.

Chavagnes-en-Paillers, I9o, 256.

Cherbourg, 65.
Chouy (Aisne), 263.

Chrétiens (Terres), I 24,242 . $243,244, \quad$ t. 326,245 . $246, t .327,247,248,25^{\circ}$, $25 \mathrm{I}, t .328,280$.

Chypre, 99, I03. II 5, I52, I 63.

Chypriote, f. II 4, I 49.

Chytre, Iоз.

Ciborium, to, I $32, \mathrm{I} 37 . f$. I 85 , I $38,139,224, f .303, f$. 304.

Cimetières gallo-romains, 254 , 255 .

Cinquantenaire (Ausée du) (voy. Bruxelles).

Cirque (voy. Courses de chars).

Ciselure, 227.

Claude, $128,152,228,254$, 265.

Claude le Gothique, 94, 125, I 59 .

Clément d'Alexandrie, 234.

Cléoménès, 150.

Clerc (Michel), conservateur du musée Borely, à Marseille, 9.

Cléré, 209.

Clermarais, 68, 70 .

Clermont (Oise), I4.

Clermont-Ferrand (Puy-deDôme), 237.

Clochette (Verre en forme de), I35.

Cobern-sur-Moselle, $240, \quad t$. $325,264$.

Coblence, $26+$.

Coblence (Musée de), $t .24$, 62,80, II $0, f .133, t .253$.

Coblenz-Neuendorf (Cinletière de), $6 z$.

Cochet, 8, to, $\% \cdot 45,65,7^{0}$, f. $60, f .62,83,86, f$, 1 20 , $127.131, f .181,172,173$, I89, I9I, 207, 226, 254, $257,26 \mathrm{r}$.

Collevette, $128, f .165, \%$. 166.

Collignon (Mr.), 48 , I I 5, I5o.

Cologne, I $4,1_{5}, 1_{7}, 43,52$, $54,56, f .32,57,62,63$, 65. 70, 76, 79, 8o, f.8I, $84,86, f .104,94,96,105$. I09, II 3 , II4, II 7 , II 8 , I19, I22, I25, I26, I29, ?
134, I36, I $38, I_{4}, I_{43}$,

I 4 6, I +7, I 48 , I 56 , I $5^{8}$,

I59, I60, $f .213, f .216$,

$163,165,166, f .218$, f. $22 \mathrm{I}, \mathrm{I} 70, \mathrm{I} 73$, I 76, I 78 , I 79, I 80, I 83, I $84, f .246$, I86, 200, $f .27 \mathrm{I}, 204$, f. $27+, 205.206, f .283$. f. $28 S, 223,224, f .303$. 232, f. 3I2, f. 3I, 234 , $237, f .322,240,24 \mathrm{I}, 242$ $249,250, \quad f .336,263$, $264, f .346,267,277$. Cologne (Musée de), 9, $f .32$, f. $81,81,87$, f. 104, 95 . f. I I5, 99, I 20, $f$. I73. f. I $84, f .200, I_{46}, I+7$, I 48, I 54, I $57, I_{58}, f .212$, I $59, f .2 \mathrm{I} 3$, I6I, $f .2$ І6, I63, I65, $f .218, f .221$, f. 222, I70, $t .232$, I 79 , I $80, f .236, f .246, f .27 \mathrm{r}$, $203,204, t .274, f .275$, 206, f. $280,2 \mathrm{I0}, f .282$, f. $28_{3}, f .28_{4}, 2$ I I, f. 287 . f. $294,217, f .295,223$. f. 302, 224, t. 303, 227 , $2+\mathrm{I}, 249, f .33^{6}, f .34^{6}$.

Coloration du verre antique, $2 I, 22,23,24,46$.

Columbus, I9o, I9I.

Combats de gladiateurs (voy. Giadiateurs.

Combat des Pygmées et des Grues, 248 , pl. I.

Commode, 70, 79, 96, I I9, $204,279,280$.

Compiègne (Fotêt de), 40, $64, f .49,85, I_{43}, I_{73}$, f. 288,262 .

Compiègne (Musée de), f. 288 , f. $293,216$.

Conchiforme, I66, $t .2$ I8.

Conflans-sur-Seine (Marne), f. $52,26 \mathrm{I}$.

Coningsheim, 42 .

Constance Chlore, 57, I65, $23 \mathbf{I}$.

Constance $I I, I_{4} 6,222$.

Constans, 80, $8 \mathbf{I}$.

Constantin $I^{\mathrm{er}}, \mathrm{I} 5, \mathrm{I} 8,2 \mathrm{I}$, 82, I26, I 56, I 75,2 I 8 , f. $34^{\circ}$.

Constantin II, 54, 104, 219, 232. 
Copenhague (Musée de), 229, Déchelette (J.), conservateur|Égée (Mer), I I 5. 249.

Coq, I6I.

Coquilles, $164, \mathbf{1 6 6 , f .} 2 \mathrm{I} 7$, f. $218, \quad 183,267, \quad$ t. 347 du Musée de Roanne, 9, Ehrang, t. Io4. 70, 99, I52, I56, I57, Émaillage, 6.

192, I99, 239, 240, 24I, Embouchures (voy. Orifices). (D).

Cordiformes (Feuilles), 20I, f. $27 \mathrm{I}\left(\mathrm{n}^{\circ} \mathrm{8}\right), 208,209$, f. $277,212,280$.

Cormier (Le), I 90.

Corne de chasse, $t .349$.

Corporation des verriers en Gaule, I7, I8, 19.

Corpus inscriptionum latinarum, 2.

Correr (Musée), $f .347$.

Cortil-Noirmont, 202, f. 272 , 203, 204, 205.

Cothon, 3I, t. 8, 58, t. 34 .

Cougoule, $7.34^{8}$.

Courajod, I5.

Corne, I $59, \% .212$.

Corintlien, $f .64,73, f .85$, t. 98,89, 1 49, I 56, 238.

Courses de chars, 127 , I 88 , I $89, f .249, f .250,236$, 237.

Conve, 48, II 5 .

Couvin, $189,192,264$.

Cramer, I75, 278.

Cresces, 189 .

Crète, II 5.

Crêts de Pressy, f. 259.

Crispina, 96, f. 336.

Croix (R. P. Camille de la) 256.

Cucullus, 157 .

Cumes, I3.

Cupa, I74.

Cynocéphale, I 57 .

\section{Dèce, 192.}

Décomposition du verve antique, 22.

Découverte du verre soufflé (voy. Verre).

Delphiniformes (Anses), 39. 82.

Dépressions, 126, $f$. 191, I $42, f .197, f .199, f .201$, 146, 193, I94, $t .255$, f. $25^{6}, f .257, f .25^{8}$.

Deville, 8, 87, I71, I89, I90, I9I, 229.

Diatretarii, I8, 234.

Diatrètes, 1 24, I59, 231, 232, f. 3I $2, f .3$ I3 280 .

Dijon (Musée de), I 82, f. 242.

Dilécythe, 64, 269.

Dioclétien, 58, I09.

Dionysos, $24 \mathrm{I}$.

Diota, 90, 95, 96, f. I I 2 , f. II $3,98, f .336, f .344$ (A).

Disch (Ancienne collection). II 4, I58, I62, I 80, I99, 250.

Domitien, 42, 65, \%. 334.

Dorure sur verre, $6,249,250$, $25 \mathrm{I}, f .328$.

Dragendorff, 3, 99, 127, I28, I29, I35, I 44, I73.

Dragon de Bel, 245, f. 326. Dunes (Cimetière des), $f$. I 5 . f. $18,53,6 \mathrm{I}, 65, f .94$, I27, $t .219,168,174,256$. Durffenthal, 249.

\section{D}

Dacius, I8.

Damas, 237. 239.

Danaïs, 24I.

Dangiband, conservateur du Mnsée archéologique de Saintes, 9.

Danicourt, $153, I_{5}^{8 .}$

Daniel, 244, f. 326, 245 , 250.

Dannes (Pas-de-Calais), 63 , 262.
Darly, 262.

\section{E}

Eck (Théophile), conservateur du Musée Lécuyer, à Saint-Quentin, 8, 9, I 2, $22,54,55, f .30, f .3 \mathrm{I}$, $56,57,58, f .34,86,90$, f. 106, 96, 104, 107, 108 , I I $4, f . \quad 145$, I 8, I 26 , f. I6I, I28, f. I7I, I 43 , I 46, I 57, I 7O, I75, I 82, f. $243,219,220,221,224$, $245,262$. 248.

Engelhardt, 249.

Entonnoir (voy. Infundibulum).

Epigonus, $t .338$.

Epilykos, I 50.

Epiméthée, 240.

Epingles, $57,5^{8}$.

Éros, 242.

Étampes, $f .318, f .322,261$.

Etaples, f. I $30,262$.

Etirage de fils de verre, 195.

Étretat, f. 60, I73, 26I.

Evangile, 245.

Ève (voy. Adam).

Evreux, 26I.

Ézéchiel, 250.

F

Faucouzy-Monceau-le-Neuf, 262 (voy. Monceau-leNeuf.)

Faunes, 230.

Fautenil d'osier, 157.

Fécamp, $t$. 45, $f$. I 59, $f$. I8I, 261.

Félix, 18

Fenilles, 179.

Fibules, 94, I22, I26, I43, $144, \quad 183, \quad f .244,222$, f. $330\left(\mathrm{n}^{\circ} 2\right), f .339$ (5), f. $34^{\circ}(\mathrm{B}), f .345(\mathrm{~B})$.

Figurines de l'Allier, I 52, I 57.

Fillon (B.), 190, 209.

Fils serpentants, 6, 199, 200, f. $27 \mathrm{I}, 280$.

Fin Renard (Cimetière du), $53,6 \mathrm{I}, 80$.
Flasca, II7.

Flavion, 264.

Florence (Musée de), 248. Flonest, 63.

Flûte de Pan, I57.

Fomperron (Denx-Sèvres), f. 332.

Fontenay (de), I63.

Forgeron (Stèle du), $25^{8}$.

Fortelle (La), $f .264$.

Franc, 98.

François (Vase), 248. 
Fresin, 169.

Froeher, 8, 4I, 45, 52, 57 , 65,86, I 3 , I I 8 , I 17, I 34 , I55, I63, i69, I 7 , I 76 , I 78, I 89 , I91, 222, 237, $239,242,247$.

Frontinien (voy. Barillet).

Frontinus, I8, I7I.

Furfooz, 264 .

\section{G}

Galère, I 25, I 59.

Gallien, 96, 134, 255.

Gamus, I90.

Garnier, 20.

Gauthier (Jules), 265.

Gayet, 239.

Gelsdorf, 58, 70, 207, 264. Genève (Musée de), f. 259. Germanie, 94, I07, 263.

Gerspach, I4, 20, 229.

Giamillus, 278 .

Gladiateurs, I27, I79, I 80, f. 236 , I 88 , I 90 , I 91 , I 92 , f. $25 \mathrm{I}, 236,249$.

Gorgoneion, 230.

Goulots, 27.

Gouraud, I9o.

Gouvdon, I36, 137.

Gnathia, I99.

Grainville, $f$. I 59.

Grappe de raisin (Verres en forme de), I67, I68, I69, I 70, $f$. 2I9, f. $220, f .22$ I, f. 222.

Gratien, 94, I 26, I75, 214 . Graufesenque (La), I99.

Gravure sur verre, $6, f .32$, f. 80, f. 95, 9I, f. I04, I $00, f$. I I $7,125, f$. I $5 f(A)$, I39, I 4 , I42, f. I95, f. $20 \mathrm{I}, f .30 \mathrm{I}, 234, f .3 \mathrm{I} 5$, 235, f. 3I6, f. $317, f .318$, $236, t .3$ I9, $t$. $320, f .32 \mathrm{I}$, $237, f .322,238, f .323$, 239, f. $324,240,241, f$. $325,242,243,244, f .326$, $245,246, f .327,247,248$.

Gréau (Ancienne collection) $4 \mathbf{I}, \quad 45, \quad 52, \quad 57,65,86$ I03, I 34, I63, I 69, I 76, I78, 222, 237, 239, 242, 247.

Grégoire de Tours, I6.
Griffith, 20.

Grotesque (voy. Caricalure).

Grues, Pl. I. 248.

Grues (Veirdée). 256.

Guimel, 50.

Guttules appendiculées, 226 , f. 306 .

\section{H}

Habert ('lh.), 262.

Hadrien, I 4, 96, I 57, f. 329.

Haignevé (Abbé), 262.

Hamard (Abbé), III, 220, 262.

Hamy, 209.

Hanap, 269, f. 349.

Hardécourt-aut-Bois(Sonme), 262.

Hauret, I78.

Hausweiler, 40.

Hébrenx (Les trois jeunes) $247,25^{\circ}$.

Heiligenslein, $\mathbf{1} 39$.

Heimersheim, I9I.

Héliogabale, I4, I I9, 279.

Héraklès, 24I, 242.

Héricy-sur-Seine (S.-et.M.), $26 \mathrm{I}$.

Hermes (Oise), I go, 262.

Héron de Villefosse, $\mathbf{1} 38,248$, 249.

Heydemann, II.

Heydenreich (Ancienne collection), I69.

Hildesheim, $3^{8}$.

Hippomène, f. 324, 240.

Hoffmann, I8o, 245.

Hohensulaen, $233, f .3 \mathbf{I}$ $24 \mathrm{I}, 264$.

Holes, I 90.

Homblières, 54, $\mathrm{IO}_{4}, \mathrm{I} 26$ I 27, I39, I44, 220, 222 $224,243,244,245$, f. 326 $255,262$.

Honorius, I56, 21 2, 255 280.

Hydre de Lerne, $2+2$.

Hypermuesire, $2,4 \mathrm{I}$.

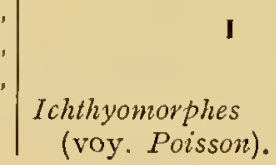

Iliats (Cinetièrc des), 264.

Imperator, I8.

Incitega, 79.

Infundibulum, 146, $147, t$ 202.

Inscriptions, 6, 220, 232, f. 3 I2, f. 3i $3,237, f .323$, 239, f. 324, 240, f. 325, $242,245,246,247,248$ $250, f .338,278$.

Inscriptions en fil de verre, $203, f .273$.

Irisation $d u$ verre antique, 22.

Isaac, $246, f . \quad 327,247$.

Issoive, 256.

\section{$J$}

Jahrbuch des Vereins von Alterims freunden im Rheinlande (voy. Bonner Jahrbiicher).

Jérồne (Saint), I 5 .

Jonas, 250.

Jonchery-sur-Suippes (Marne), $f .288,2$ I 6,263 .

Julia Domna, 5, I4, 70, I 13.

Julia Mcesa, 70.

Julien, 260.

Julis, 167.

Julius Alexander, $\mathbf{I}+$.

\section{K}

Kamp, 241 .

Kastel, 248.

Khamissa, 249.

Kisa (Anton), 2, 7, I 5, 21, $40,84,87,88$, I07, II 9 , I 53, I 54, I 55, I 57, I 58 , I 60, I63, I 64, I 65, I7I, I $78, \quad$ I 79, I $80, \quad$ I $83, \quad$ I $8_{4}$ I 86, I 89, I 9I, I 99, 200, $203,206,207,2 \mathrm{IO}, 2 \mathrm{II}$ $217,227,228,229,23 \mathrm{I}$ $234,237,24 \mathrm{I}, 242,247$, $278,279$.

Klein, I 50 .

Konen, 57, I I 9, I 42, I 52, I 73, 2I 8 .

Frefeld, 206.

Kreatnach, 224, f. $304, f .330$, 264 . 
L.

Lacrymatoire, $73,74,75$.

Lagène, I05, I 50.

Lagona, 89.

Lampes, f. 234, f. 333 , f. $334, f .335$.

Lasteyrie $(d e), 258$.

La Tène, 45, 62.

Laon (Musée de), f. I55, 262. Lausanne (Musée de), $f$. I53, f. 172 .

Lazare, 245, 247.

Le Blant, 247.

Leblond $\left(\mathrm{D}^{\mathrm{r}}\right), \mathbf{1} 72$.

Lecaplain (J.), Iog.

Lécuyer (Musée) (voy. SaintQuentin).

Lécythe, 3I, f. 8, II9, f.203, I 49, I 57, I 66.

Lelaurain, 8, I 75, 262.

Lenormant (Fr.), IgI.

Lépine (Marne), 263.

Leuci, 278.

Lezoux, I28, I99, $24^{8}$.

Liebbe, 214.

Liége (Musée de), 9, f. I 42.

Lièvre (voy. Chasse au lièvre).

Lillebonne, 65, 86, f. Io9, f. I46, I3I, $f$. I97, I73, I $9 \mathrm{I}, f .252,26 \mathrm{I}$.

Limbourg, I 73 .

Limelette, 54 .

Lindenschmitt, I $48 .^{8}$

Liternum, $\mathbf{1} 3$.

Loutrophore, $44, f . \mathbf{1 6}, 47,4^{8}$.

Louvre (Musée du), 9, $f .20$, f. 45, IO2, Iо $4, f . \mathbf{I}_{4} 6$, f. I $57, f . \mathbf{I}_{59,}$ f. I97, I50, I 5 I, I 56, I $66, f .323$ (A.), $243, f .326,248$.

Lucanie, II9.

Lupio, I8.

Lussault (Indre-et-Loire), 64 .

Lutèce (voy. Paris).

Luxembourg (Musée de), I 56.

Lyncée, $240,24 \mathrm{I}$.

Lyon, I4, 6I, 77, 257, 259, $26 \mathrm{I}$.

Lyon (Musée de), f. 19, 77, $90, f . \mathbf{I} 74$.

Lyonnaise, 257.

M

Magie, I48, I56.
Magne (Ch.), I2, $f .43, f .70, \mid$ Metropolitan-Museum (voy. f. 7I, f. 77, f. 82, I8I, New-York).

f. 238,258 .

Magnence, T44, 222, 255 .

Maison Carrée (voy. Nîmes).

Malacoptérygiens, ${ }^{6} 6$.

Manceaux, I6I.

Mandeuve, 266.

Manganèse, 2I, 279, 280.

Marc-Auvèle, 203.

Margeride (La) (Cantal), f. 35 I.

Marques de fabrique, 2, 6 , $63,64, f .45, f .48, f .74$, f. 75,77 .

Metz, I 73, 277.

Michel (H.), conservateur du Musée archéologique de Besançon, 9, 28, $f .4, f .5$. f. $6, f .7,208, f .277, f .28$ I.

Michon, 9.

Milo, II5.

Misery (Somwue), 262.

Mithridate (Coupe de) (voy. Ptolémée).

Mobiliers funéraires, 252 et suiv.

Moüse, 247 .

Marseille, I3, f. 47, f. 63, Mollusques, I63, I64, I65, f. $74, f .75, f .140, f .16_{4}, \quad$ f. 217.

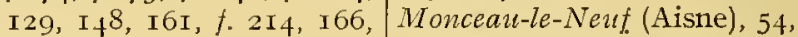
I $8 \mathbf{I}, f .239,255$.

Martean, 178 .

Martial, 229.

Maximien, 224, 232.

Mayen, I97, f. 262, 2 I f, f. 288, f. 289,264 .

Mayence, 56, 58, 94, 96, $f . \quad I_{5}, \mathbf{I}_{22}, \mathbf{I}_{4} 8, f .258$, f. $338,263,264$.

Mayence (Musée de), 9, 40, $55,56,58,70,8 \mathrm{I}, f . \mathrm{IO}_{4}$, $95, f$. I $5,99, f$. I 28 , I 07 , IIf, $f$. I 41 , II8, I29, f. I68, I $32, f$. I $76, I_{42}$, $I_{4} 8$, I $59, I 6 \mathbf{I}, I 70, I_{75}$, $f .258,233, f .3 I_{4}, 239$, $247,248, f .329, f .330$, f. $338, f .339$.

Mazauric, conservateur des Musées archéologiques de Nîmes, 9, 75 .

Mecquenem (R. de), 238.

Médaillons, 242, f. 322 (3). Méduse, 40, II 7, I 52, $f .205$, I 53.

Mégare (Bols de), I 88 .

Melun, $26 \mathrm{I}$.

Ménades, $2+\mathrm{I}$.

Menoitos, 240.

Mercure, 66, 70.

Merkurflasche, 66.

Merops, Igo.

Mérovingiens, I 26, I 35, I 36 , I 59, 226, 254. 98, I 88, 219, 247, 262.

Monnaies (Datation des verreries d'après les), 4, 5, 204 .

Monogramme du Christ, I93, $244, f .326,245,24^{6}$, f. 327 .

Montagnole, I90, 192, 256

Montbrison, $26 \mathrm{I}$.

Mont-Afrique, 229, f. 3 II.

Mont-Chyprès, 40 .

Montfaucon, 42 .

Monture métallique (Verresà), $228,229, f .3 \mathbf{I I}$.

Moreau (Frédéric), 8, 42, f. I I 3, 98, I I9, I 2 I, I 25 , I $26, f . \mathbf{I} 89, \mathbf{I} 44, \mathbf{I} 56, \mathbf{I} 83$, f. 244, 2I $, 220,222$, f. 342,262, f. $343, f .344$, f. $345,267$.

Morgan (de), I57, 238.

Morin-Jean, 238, $25 \mathrm{I}$.

Morin-Jean (Collection), $f$. I2, f. $29, f .40, f .64, f .65$, f. $67, f .69, f .83, f .85$, f. $86, f .88, f .98, f$. IIt, $f . \mathrm{I}_{25}, f . \mathrm{I} 5 \mathrm{I}, f . \mathrm{I}_{54}, f . \mathrm{I}_{67}$, $f$. I 88, $f$. I90, $f$. I92, f. I93, f. I94, f. 203, f. 204, f. 207, f. 223, f. 224, f. 228, f. $307, f .309$, f. 3 I6, f. 3 I9, f. $328, f .340$, f. $34 \mathbf{I}$.

Mosaïkgläser, $22 \mathrm{~S}$.

Moulage, I87 à $\mathbf{I} 93$.

Mervent (Forêt de), $256 . \quad$ Moulins (Allier), 256.

Mesnil-sous-Lillebonne (voy. Munich (Antiquarium de), Lillebonne). 232, t. 3 I2. 
Munich (Muséc national bavarois ii), $45,7.347$.

MItrano, 9, 17, 267, \%. 350 (C.) $272,273, t .353,278$. Mycéniens (Vases), 238.

Myrina, I 5 o.

Mythologiques (Sujets), 239 et suir.

\section{$N$}

Nampteril - sous - Muret (Aisne), 263, $\% \cdot 3+3$.

Namur, 264.

Namur (Musée de), 9, 178, ISg.

Nantes, 190.

Naples (Musée de), $4^{2}, 60$, f. $36,62, f .89,139, I+7$. $174, \quad 178,229$.

Narbonnaise, 255 .

Nègre, I 50 .

Néris (Allier), 64, 256.

Néron, 19, 76, 85, 192, 228, 265.

Netzbecher, 23I.

Neufchatel (Pas-de-Calais). f. I 99, f. 263, 2I 4, f. 290, 262.

Neuss, 264.

Neluville-le-Pollet, to, 86, t. $134, \%$. 138, I 73,226 , 227. $f$. 310, 26I.

New-York (NetropolitanMiseum à), I 55, I9I.

Niessen (Collection), 88, I79.

Nîmes, 102, 124, I47, 248, $249, f .333,255$.

Nimes (Musée archéologique), I $24, f$. I 57, I $29, f . \mathrm{I} 74$, f. 333 .

Nîmes (Musée de la Maison Carrée), $t .46,75, f$. II 8 , f. I $2 \mathrm{I}, \mathrm{IO} 2, \mathrm{I} 22, f$. I 75 , I $33, f .202$.

Niort, 6r, 65 .

Niort (Musée de), $/ .35,65$, t. 332 .

Nocturmus, I 8.

Nodules, 22.

Normandie, 8.

Notitia provincianm et civitatum Gallia, I.

Nuppen, 218.
| Nuremberg (Muséc de), r2r, $19 \%, f .262,2 \mathrm{I} 4, f .-289$, f. 347 (E.), $\% 350$ (. . B. D.). Nyon (Suisse), 278 .

Obba, I 44 .

Ober Ingelheim, f. 339.

Oboles a Caron, 6.

Obsidienne, I34.

Enochoé, 20, 32, \%. 8, 38, เoo, $f$. II 7 , I05, II 2 , I 3 , f. I 39, II6, I3I, I 49, I 50, $178,202, \% .272, \% .275$, 203, 204, 205, 206, 229, $230, f .334, f .335, \% 337$ (A.), 265 .

Oiseau, I60, I6I, f. 214, I62, t. $215,185, f .246$, I99, $2 \mathrm{I} 2, / .294,2 \mathrm{I} 7,249, f .33 \mathrm{I}$ $\left(\begin{array}{lll}11^{\circ} & 2\end{array}\right)$.

Olla cineraria (voy. Umes)

Olla ossuaria, (voy. Urnes).

Ondé (Décor), r 98.

Onyx, 73 .

Operculum, $f$. I I et $\mathrm{I} 2,4+$, $45, f .33 \mathrm{I}, t .332$.

Ophiomorphique (Décor)(voy. Serpent).

Opus interrasile, 229.

Orange, $f .+7,102, f$. I64, 256.

Orante, 250.

Orblin (J.), f. I29, 262.

Orifices, $28, t .4,29, t .5,30$, f. $6,3 \mathrm{I}, f .7, f .8,32$.

Orival, $127, \% .320$.

Ornithomorphe (roy. Oiseau).

Orpheus, 2 I 3.

Ostie, I63, I66.

Oushabti, 50.

Ousirtasen I 2 r, 20.

Outre, 174 .

$\mathbf{P}$

Palais des Beaux-Arts, de la Ville de Paris,203, $\% .273$

Palestine, f. II5, 277.

Palissy (Bernard), $16_{5}$.

Pallien, I 20, I64, I66, $\%$. 217 , $247,263$.

Palmes, 201, f. $27 \mathrm{I}$ no 9 , Pisistrate, 150.
$202, f . \quad 272, f .274,205$.

Palmier, os.

Palmyre, 23.

Pampres, 201.

Pan. 157,24 .

Panier, 178, \%. 235.

Pannonie, I5.

Panse, 25.

Panthère, 237.

Papillon, conservateur du IIusée de Sèvres, 9.

Paralytique, 250.

Paris, to, f. 43, f. 44,65 , f. $48, f .70$, f. 7 I, .7 .77 , f. $82, f .87, f$. гоз, тон, f. I $24,107, f .131, f .163$, f. I $87, f .229$, I $81, f .238$, f. $26 \mathrm{I}, 257,258,260,26 \mathrm{I}$. Patève, I78, 206, 2I I, $f .286$, f. 287.

Patrimonius, I8, IS2.

Pausanias, 240.

Pecten, 166.

Peinture sur verre, 6,248 , 249, pl. $\mathrm{x}$.

Pernice, I38.

Péronne (AIusée de), $t$. I 85.

Pérou, f. 20.4.

Petrucci, 202.

Pezou, f. I02, f. 255, 261.

Phiale, I22, $t$. I5I, $t .330$.

Plilippe l'Arabe, 207.

Phintias, $\mathbf{1 6 6 .}$

Phytomorphes (Verres), I67, 167 à I70, I70, $\%$. 2I9, f. $220, f .22 \mathrm{I}, f .222$.

Picquigny, $f$. I79.

Pieds des ververies romaines découvertes en Gaule, 32, 33. $f .9,34$.

Pierpont-Morgan (Collection), $45,52,86, \quad$ I63, I $76,237,239,242$.

Pigeon, $\mathbf{1 8 0}, \mathbf{1} 85, \quad$. 246 , I 99.

Pilloy, 8, 54, 96, IO4, II4, I26, I 27, I 44, I 57, I 7 I, I73, I 86, 2I $, 220,222$, $224,243,262$.

Pinfures faites a l'outil, $x 25$, 225, 227, t. 307, f. 308, f. 309, f. 310, 265 .

Piolène, II6, I 33 .

Pipette, 8I. 
Plastique (Verrerie), I 48 et suiv., I 88.

Plat, 122, I31, $f$. 171, $f$. I72, f. 173.

Pleuronecte, 165 .

Pline, 4, I3, I9, I74.

Plumes d'oiseau, I98, $f .270$.

Poisson, 42, 57, 162, I63, I64, I65, I66, $f .2 \mathrm{I} 6$, f. $2 \mathrm{I} 7,249$.

Poitiers, $f$. II, $f$. I5, $f$. Is, f. $23, f .27,6 \mathbf{1}, 65, f .94$, I27, f. 162, f. 219,168 , I 74, 256.

Poitiers (Musée de la Société des Antiquaires de l'Ouest, à), $52,53,61,65, f .94$, x68.

Poitiers (Musée de l'hôtel de ville à), $f$. I 5 .

Polypodes (Verreries), 32, f. 9,34 .

Pompéi, 13, 48, 60, 78, 84, 100, I 29, I3I, 132, I34, I 39, I 47, I $78,229,230$, 249.

Pons (Charente-Inférieure). f. 337 .

Poppelventer, I 58 .

Porc, I6o, $f .213,205$.

Port-sur-Saône (Haute-Saône), 266.

Portland (Vase), 229.

Poseidon, 240, f. 325.

Postumus, 4I, 96, I25, I34.

Pottier (E,d.), 89, 99, I49, I 5O, I 5I, 238, 248, 25I, 272.

Pouzin (Le), 256.

Priape, 230.

Priapique (Vase), 230, pl. 6.

Probus, 229, 278.

Proclouss, 105, II 9.

Procultus, I9o, I9I.

Profil, 25, 26, f. 3 .

Prométhée, 240.

Prophylactique, I 48, 150, I56, 157, 213.

Prudes, I9o.

Ptérote, I9.

Ptolémée (Conpe de), I35. I 36.

Pygmées, f. I57, 248, pl. I. Pyxide, 44.

\section{Q}

Quadrige, 189.

Quatremarre, $f$. Iо, $f .28$.

Quicherat, 182.

Quintilien, 229.

\section{R}

Rabs (Nécropole de), rio.

Rath (Collection vom), 183 , 237.

Rechmara, 2 I.

Reims, I4, f. I2, 56, 57 , $5^{8}, f .3^{8}, f .54,70, f .59$, $84, f .108, f$. I29, I I I, I 32 , f. $190,147, f .227,173$, f. $288, f .292,216,220$, $223, f$. 30I, $f .319, f .323$, f. 324, 239, 240, 262, 263. Reims (Musée de), 56, 57, 58, f. $38,68,70,84$, I02, t. I 29, II0, I I 4, I I 9, f. I $65, I_{32}, I_{4} \mathrm{I}, \mathrm{I} 44, \mathrm{I} 47$, f. $227, \mathbf{1} 73, f .247, f .288$, f. 292, 2I6, 220, 223, f. $301, f .323,239, f .324$, 240.

Reinach (Salomon), conservateur du Musée de SaintGermain, 9, 138, 150, 160, I 66,2 I 3 .

Reinach (Théodore), ${ }_{57}$.

Reliefs d'applique, I92, 209.

Reliefs taillés, 230, $23 \mathrm{I}$.

Remagen, $173,264$.

Rennes, 26I.

Renonsart (Aisne), 263.

Répartition géographique des verreries, 255 et suiv.

Résille, I97, f. 262, f. 264.

Résille taillée à joutr, 23I.

Résurrection de Lazare (voy. Lazare).

Rheindorf. $f$. 61, 242.

Rhétie, I 5 .

Rhodes (Faïences de), 237,239.

Rhodiens (Vases), 238, f. 323 (A.).

Rhyton, I47, I50, I56, I59.

Rome, I63, I65, I66.

Rossi, 166.

Roucy (de), 40, 85, I 43, I 73 . 262.

Rouen, 57, $26 x$.
Rouen (Musée départemental de), $f$. 10, $f .28, f .33, f .42$, f. $5 \mathrm{I}, 70, f .60, f .62, f .76$, 8o, $83,84, f .95$, f. 97 , $f$. 105, f. 107, f. 109, $f$. I1 2 , $99, f$. I $6, f$. 工 $20, f . \quad$ I 26 , f. 130, І10, f. I34, f. 136, $f . \quad \mathrm{I} 38, \mathbf{\mathrm { I } 2 2 ,} \mathrm{I} 27, f$. $\mathrm{I} 7 \mathrm{O}$ I3I, $f$. I $81, f$. I 82 , I36, $f$. I9I, $f$. 198, I 53, $f .206$, $f .248$, I9I, $f .252, f .265$, $f .266, f .27 I, f .276,207$, 2 II, f. $285, f$. 3IO $f .3$ II, $229, f .320$.

Ruffieux, $f .19$.

\section{S}

Sablonnière (Aisne) (Cimetière de), $f$. I 49, $f$. I 89 , $22 \mathrm{I}, f .299, f .342,263$.

Sacrifice d'Isaac (voy. Isaac).

Saglio, I8, 31, 32, 42, 72, $79,83,103,105$, II9, I33, I 46, I 5O, I 74, I 79, 240, 248.

Saint-Acheul, f. I98.

Saint-Cassien, f. 4I.

Saint-Denis (Trésor de), 136.

Saint-Gabriel, 256.

Saint-Germain (Musée de), 9, $40, f . \mathrm{II}_{1} f . \mathrm{I}_{3}, f . \mathrm{I}_{4}$, f. I7, $f .18, f .21, f .23$, f. $26, f .27,53,64,65$, f. $49, f .52, f .54, f .55$, f. $59,85, f .9 \mathrm{I}, f$. II 3 , 99 , I03, I2I, $f$. I 49, I 23 , $\mathbf{1} 25, \mathbf{1} 26, f . I_{77}, \mathbf{I}_{34}, f .183$, $f$. I $89, I_{4} I, I 43, I 44, f$. $205, f .210,157, f .219$, $\mathrm{I} 68, f .226, \mathrm{I} 73, \mathrm{I} 74, f .230$, I $83,-f .244, f .264,2 I_{4}$, f. 291, 216, f. 296, 220, $f .299,222, f .306, f .318$, $237,241, f .342, f .343$, $f, 344, f .345$.

Saint-Germain- lès-Corbeil, $26 \mathrm{r}$.

Saint-Jean-lès-Amiens, $f .76$, t.. I05.

Saint-Mansuy, 155.

Saint-Médard des Prés, 256.

Saint-Nicolas-lès-Arras, I54, f. $327,247$.

Saint-Pétersbourg (Musée de l'Ermitage à), 229. 
Saint-Quentin, 263 .
Saint-Quentin (Musée de), f. $2, f$. по1, $96, f$. I23, f. $158, \mathrm{I} 26, f . \mathrm{I} 66, f . \mathrm{Ig6}$, I57, $f .267,219,220,224$, $2+5,2+7$.

Saint-Saloine (Ruines de), f. $94, \mathrm{I} 82, f .240$.

Saint-Saphorin-sur-Morges, f. 172 .

Saint-Séverin (Coupe de), 250, f. 328.

Sainte-Geneviève, $f .270$.

Sainte-Ursule (Coupe de), 250.

Saintes, $f .94,102,123, f .177$, I $34, f .205,182, f .24^{\circ}$, 256 .

Saintes (Musée de), $f .94$, 102, I 70, I $82, f .240$, f. 337 .

Sallier (Vase), 99, I57, $2+1$.

Sanson, 264 .

Sanglier, I60, 239.

Sarzec (de), 102.

Sawvage $\left(\mathrm{D}^{\mathrm{r}}\right)$, conservateur du Musée de Boulognesur-Mer, 8, 9, I 46,173 .

Sauzay, 20.

Savon des verriers, $2 \mathrm{I}$.

Sayda, 222.

Scandinavie, I5.

Scheurmans, I69, I89.

Schlangenfaden, 199.

Schmidt (Robert), 21, I36, 240.

Schonecken, I89, f. 250.

Schweighauser, 232.

Scorpion, 249 .

Sculptura vitri, 229.

Séguret, $f$. II.

Sénèque, 18.

Sens, 260.

Septime Sévère (voy. Sévère).

Sequanaise, 264 .

Serpents, I4I, I43, I99, 2I2, $2 \mathrm{I} 3,2 \mathrm{I}, \mathrm{fI} 6, f .288, f .28 \mathrm{~g}$, $f .290, f .291, f .292, f .293$, 277,280 .

Seuil (Ardennes), 2I $4,263$.

Sévère (Alexandre), I8, II3, II8, II9, I63, I 80, I95. $206,209,265,278$.
Sévère (Septime), 7, 70, I24, $200,204,280$.

Sèvres (Miusée de), $\%$ 6I, Tacite, 247.

f. I27, $f .249$, I $89, f .270$, Tène (voy. La Tène).

f. $34^{8}, \quad \tau .349, \quad$. $35 \mathrm{I}$, Ténos (Ile de), I67. 271.

Sidon, I3, 277.

Silènes, $2+1$.

Singe, 157.

Singe-Musicien, I57, $f .21 \mathbf{I}$.

Sissy (Aisne), 216, 220, 263.

Skeiomorphes (Verres), I70 et suiv.

Skyphos, I32 et suiv., $f$. I 76 .

Smith (Roach), I07, I39, I6I, 225.

Smyrne, I5I.

Soissons, 262.

Sole, 165.

South-Kensington - Museum, 206.

Spiculus, I90, I91.

Spirales, I96, f. 259, f. 260, f. 261 .

Spire, I69.

Spive (Musée de), 40.

Spontin, 54, 264.

Steinfort, I08, I56, 263.

Stéphani, 229.

Strabon, I9.

Strasbourg, I 4, 40, 43, 94, 96, I04, III, I39, I6I, I $73,206,222, f .300,23 \mathrm{I}$, $238,247,263,264$.

Strasbourg (IIusée de), 95, 107, I 59, $f .214,222, f .300$, 232.

Straub, 40, 43, 94, 95, 96, 104, I07, III, I39, I6I, I 73, 222, 238, 247, 263 .

Strée (Nécropole de), I6I, 264.

Suétone, rgI.

Stcères (Cimetière de), f. 26, f. $9 \mathrm{I}, 26 \mathrm{I}$.

Suse, $157,238$.

Sizanne, $245, f .326,247$, 250.

Swastika, I99, 20I, 2II, f. $28_{4}$.

Syrie, 14, 15, 44, f. 65, f. 69, f. 86, I02, I $52, f .207$, I53.

Syriens, I 5, 17, 21.

Syrinx, $\mathrm{I} 57$.
$\mathbf{T}$

Testament, 243, 250, 280.

Tête (Verres en forne de), I 48 à I $56, f .206, f .207$, f. $208, f .209, f .210$.

Tetraites, I9o.

Thèbes, 21.

Thiétreville, I27, $t .265,261$.

Thoraise (Doubs), $f .4,265$, 266.

Thorslunde, 249.

Thyrse, $24 \mathrm{I}$.

Tibère, 76 .

Tibre, 166.

Tiflis, 229.

Tincourt-Boucly (Somme), 262.

Tonnean, I74, 175.

Tonnelets, I76, I77, $f .232$, f. $233, f .234,270, f .350$ (A.), $27 \mathrm{I}, f .35 \mathrm{I}, f .352$.

Toreuma vitri, I8, 229.

Toten, I60, 213.

Toul, 155, $278 .^{2}$

Toulouse, 255.

Tour (de la), conservateur adjoint au cabinet des Médailles, 9.

Tournay, I 73.

Tourville-la-Rivière, $40, f .4^{2}$, f. $126, f .136,26 \mathrm{I}$.

Trajan, 5, 232, $f$. 334 .

Trèves, I 4, I 5, 52, 53, 57, $58,94,96$, I2I, I 24, I 39 , I $58,165, I 69, I 73, I 76$, I 81, I83, I84, I86, I 91 , $225,23 \mathrm{I}, 247,263,277$.

Trèves (Musée de), 9, $f .25$. $52,55,58,77, f .90,86$, f. I00, $f$. 104, 95, 96, 109, III, I $20, f$. I48, I 22, I24, I $44, f .195, f .201, \mathbf{I}_{5}^{8}$, I59, I60, I6I, $f .217,164$, I69, I 73, I75, I76, I8I, f. 237,183, t. 245,189 , f. $250, f .25$ I, I9I, $f .260$, $225,231,237,247, f .33$ I, f. 346 (A.).

Trident, $240, f .325$.

Trilobée (Emboucliure), $f .8$ (C.), 32, II $2, f$. I 50,122 . 
Trouville-en-Caux, I89, I92, $26 \mathrm{I}$.

Troyes, 261.

Trujillo, $f .204$.

Trulla, I 78 .

Tubulure, $f$. I29, f. I30, f. I3I, f. $132, f .133$.

Tudot, I 57 .

Tylosis, 68.

$T y r, I_{3}, I_{4}, 277$.

\section{U}

Ueberfanggläser, 228.

Uraus, $2 \mathrm{I} 2$.

Urlichs, 232.

Urnes cinéraires, 42 à 52 , I95, 200, f. 329, f. 332, $255, f .333, f .334, f .335$, 265,280

Ustion, 5.

\section{V}

Vacquer, 258.

Vaillant, I54, I56, I6I, I73, 247.

Vaison, 45, $f$. I I, 50, f. 39 , t. 55, f. 9I, I O0, $102, f . \mathrm{I}_{4} \mathrm{O}$, $256, f .334, f .335$.

$V$ aissier, 208, 230.

Vaîte, f. 6, 266.

Valens, I04, I 75, I 83 .

Valentinien $I^{\mathrm{er}}, \mathrm{I} 39, \quad \mathrm{5} 6$, 224.

$V$ alentinien II, 2 I4.

Valérien, 207.

Valvéas, $f$. 122.

Varennes, 256.

Vatican (Musée du), $16_{4}$.

Végétal, 167.

Veliocasses, 257.

Vendange, 229.

Vendôme (Musée de), 64, f. I02, I 26, 127, t. 255.

Venise, 24, 39, f. 347, f. 349 .

Vermand (Aisne), I4, I5, 22, f. $2,54,55, f .30, f .3$ I, $56,57,58, f .34, t .83,90$, f. Іог, f. І $66,96, f .123$,
I 04, I07, I08, f. I45, II8, Vienne, I4.

I25. $t . \mathrm{I} 58$, I26, t. I6I, Vievville (Eure-et-Loir), $f .40$, f. I66, f. I 7 I, $t$. I93, I43, $f .309,26 \mathbf{I}$.

f. I94, $t$. I96, I 6, I 57, Villa d'Ancy (Aisne), I I9, I 70, I 75, I $86, f .267,2$ I $4, \quad$ I 44, f. 288, f. 29I, $2 I_{4}$.

2I9, 220, 22I, 223, t. 307, Villegille (de la), I90.

$245,247,255,263$.

Vermiculaires (Applications). 96, I 09, II3, II9, I 20, f. I 56, I $29 . f . \leq 68, f$. I 70 , I 34, I 36, I 4I, I 78, I 79, I $99,200,20 \mathrm{I}, f .27 \mathrm{I}$, f. $275, f .276,206,207$, f. $277,208, f .278, f .279$, f. $280, f .281, f .282, f .283$, f. $285, f .286, f .287, f .288$, 2 IO, 2 II, 2 I $2, f .294,249$, f. 336 (D.), 263 .

Verres a deux couches, 228 et suiv.

Verve au plomb, $2 \mathrm{I}$.

Verre gravé (voy. Gravure).

Verres peints (voy. Peinture sur verve).

Verve souffé (Découverte du), I3, 20, 2I, 278.

Verres soufflés dans un moule (roy. Moulage).

Verres soufflés du $X V^{\mathrm{e}}$ au XVIII e siècle, $f .347$.

Verve soufflé moderne de Murano, 273, 274, f. 353, 275.

Verriers (Condition sociale des), 17 à I9.

Verrines, I69, 256.

Verseuse, I Io.

Versigny, f. I55.

Vesly (de), conservateut du Musée départemental d'Antiquités, à Rouen, 9 .

Vetro blu, 229, 230.

Vichy, 256.

Vieil-Atre (Cimetière du), t. $29, f .79, f .84$, I07, f. $\mathrm{I}_{35}, f$. $\mathrm{I}_{43}, f . \mathrm{I}_{54}, f . \mathrm{I}_{80}$, f. I 88, I 54, I 56, f. $208, f$. I $73,209, t .278,209,220$ f. $208, f .308, f .3 \mathrm{r} 6, f .32 \mathrm{I}$, 246, t. $327,254,262$.
Villenewve-Saint-Georges, $f$. 226.

Villenoisy (de), 9.

Vin, 79, 82, I74, 279.

Viotte, $f .4, f .5, f .6, f .7$, f. $277,208, f .28 I, 2 I 0$, 265.

$V$ isconti, 163 .

Vitellius, 128 .

Vitrearii, 18 .

Vitry-le-François, 45 .

Volusianus, 94, 96, I25, I34.

Tolute, I99, 20I, $f .27 \mathrm{I}$ $\left(n^{\circ} 7\right)$.

\section{W}

Wallraf-Richartz Museum (voy. Cologne [Musée de]).

IVelcker, 240.

IVeerth (Aus'm'), 55, 56, 83, I I $4, I_{35}, I_{36}, I_{37}, I_{4}$, I $46, \quad \mathbf{5} 8, \mathbf{1} 59, \quad \mathbf{6} 62, \mathbf{1} 78$, I 80, 239, 240, 242, 247.

Wiesbaden (Musée de), 40, I 59, I63, I9I.

Wilmowski, I64, 247.

Winter, 138.

Worms, I 73 .

Worms (Musée de), I 59, I60, I 86,264 .

\section{$\mathbf{X}$}

Xanten, 85, 128, 264.

\section{Z}

Zeus, 240.

Zoolátrie, I 56.

Zoomorphes (Verres), I 56 et suiv.

Zurich (Musée national suisse, à), Igo. 


\section{TABLE DES PLANCHES HORS-TEXTE}

PI. I. - VERRE PEINT. - Le combat des Pygmées et des grues... . Frontispice.

PL. 2. - ANSES DES VERRERIES RoMAINES (types du Romain I) . . . . . . . 36

Pl. 3. - ANSES DES VerReries roliaines (types du Romain II)....... 37

PL. 4. - URNe cinéraire EN VerRe. - Fouilles de Clermont-Ferrand (Puy-

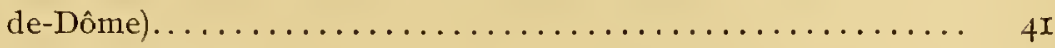

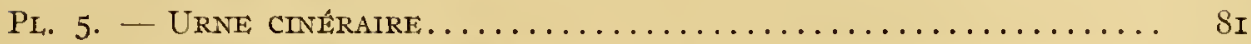

PL. 6. - VERRE A DEUX CoUches (FAUX CAMÉE). - Enochoé priapique trouvée à Besançon. — I ${ }^{\text {er }}$ siècle ap. J.-C............. I2I

PL. 7. - VERRERIES DU IV SIÈCLE. — Bol orné de cabochons. - Diota ... I6I

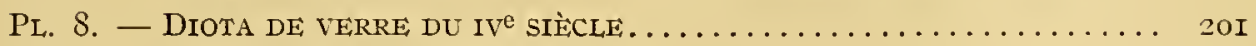

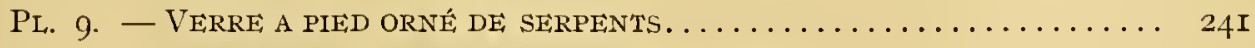

PL. IO. - VERRERIES A CABOCHONS DU IV ${ }^{\mathrm{e}}$ SIÈCLE............. 28 I 



\section{TABLE DES MATIÈRES}

IETTRE-PRÉfACE DE MI. ERNEST BABELON .............. VII

INTRODUCTION.......................... I

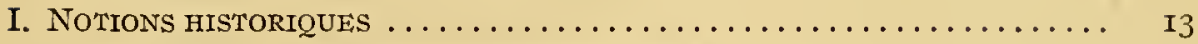

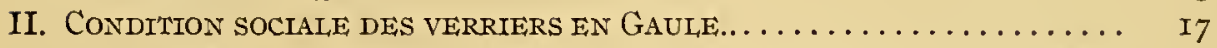

III. DÉCOUVERTE DU VERRE SOUFFLÉ. QUAITTÉ ET COLORATION DU VERRE

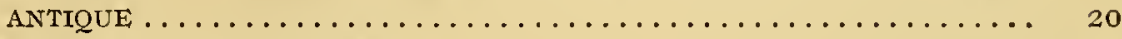

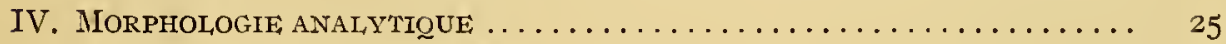

I. Panse (I,es Profils. Le galbe) ...................... 25

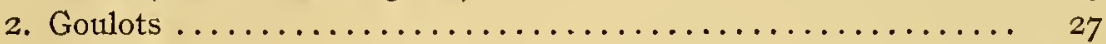

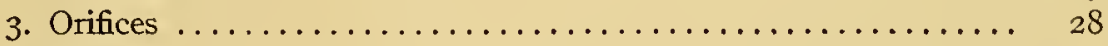

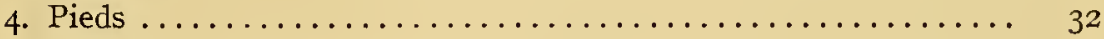

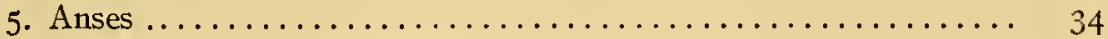

V. DESCRIPTION GÉNÉRALE DES TYPES................... 42

I. Urnes cinéraires ................................ 42

2. Bouteilles à panse cylindrique à fond plat............... $5^{2}$

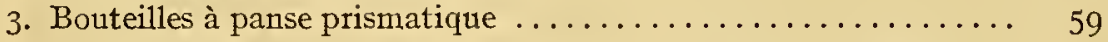

4. Bouteilles apparentées par leur forme au type gréco-oriental de 1'Alabastre et du Bombylios et leurs dérivés........... 72

5. Bouteilles apparentées au type de l'Amphore romaine à base terminée en pointe, et leurs dérivés......................... 79

6. Bouteilles apparentées au type grec de 1'Aryballe......... 82

7. IiAmpoule à panse sphérique et ses variantes. Diotas et Gourdes plates............................................. 90

8. Bouteilles à une anse. (Enochoés et variantes............ I00

9. Bouteilles apparentées au Iécy the italiote de terre cuite...... II9

I0. Bouteilles à fond bulbeux ..................... I2I

II. Phiales, bols et plats.............................. I22

I2. Tasses et récipients à large onverture émanant des types grecs: Canthare, Skyphos, Carchesium et Ciborium.......... 132

I3. Verres à boire ............................ I39

I4. Verreries non ansées, à panse ovoïde. Formes empruntées à des poteries romaines de la basse époque impériale.......... I44 


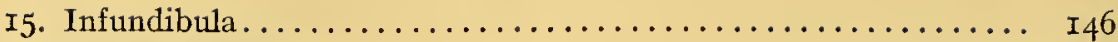

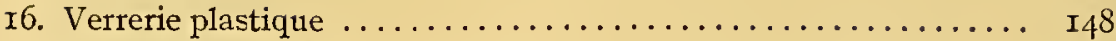

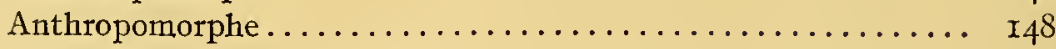

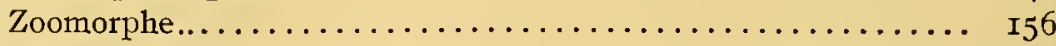

Phytomorphe $\ldots \ldots \ldots \ldots \ldots \ldots \ldots \ldots \ldots \ldots \ldots \ldots \ldots \ldots \ldots$ I 67

Skeiomorphe............................ I70

77. Formes aberrantes ....................... I80

VI. LES PROCÉDÉS D'ORNEMENTATION $\ldots \ldots \ldots \ldots \ldots \ldots \ldots \ldots \ldots \ldots \ldots \ldots$ I 87

I. Moulage............................ I 87

2. Décor par dépressions $\ldots \ldots \ldots \ldots \ldots \ldots \ldots \ldots \ldots \ldots \ldots \ldots$ I93

3. Étirage et application à chaud de fils de verre............ I95

4. Barbotine de verre........................ 216

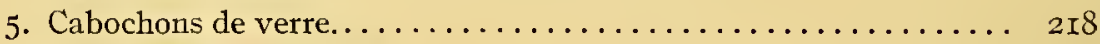

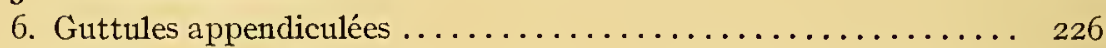

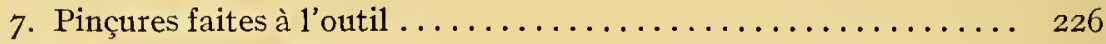

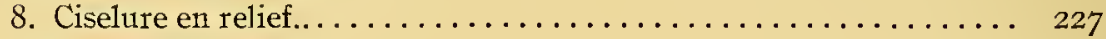

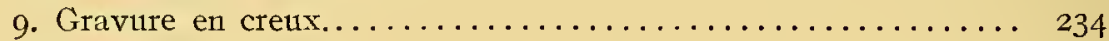

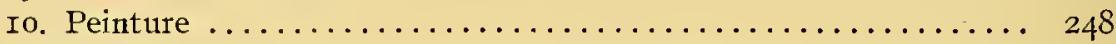

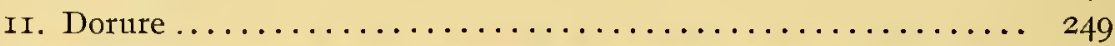

VII. LA VERRERIE, EN GAULE DANS LE MOBILIER FUNÉRAIRE. — PRINCIPAUX

LIEUX DE TROUVAILLES........................ 252

VIII. RESSEMBLANCES QUE PRÉSENTENT, AVEC LA VERRERIE IMPÉRIALE ROMAINE, CERTAINES VERRERIES MODERNES. FABRICATION D'UN CANTHARE DE VERRE SOUFFLÉ A MURANO .............. 267

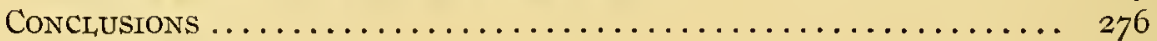

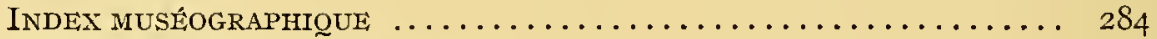

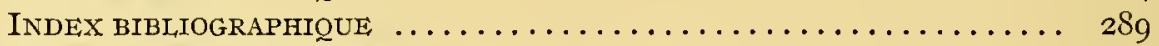

INDEX GÉNÉRAL ALPHABÉTIQUE $\ldots \ldots \ldots \ldots \ldots \ldots \ldots \ldots \ldots \ldots \ldots \ldots \ldots . \ldots \ldots$

TABLE DES PLANCHES HORS TEXTE . ................ 303 


\begin{abstract}
ADDENDA
I O VERRISS IIOULES ORNÁS DE COURSES DE CHARS. - Orange. Fouilles de I859. Fraginent d'un bol en verre verdâtre filandreux du Row1ain II. - Quadriges et inscription. Iusée archéologique de Nîmes (Ancienne Collection Émilien Dumas).

$2^{\circ}$ Muskéogaphie. A. Montpelimier. Musée de la Société Archéologique. - Verrerie à facies industriel du Romain I, provenant de sépultures à incinération découvertes à Murviel en 1872 et en $\mathrm{x} 896$, et à Pignan, en $\mathrm{r} 887$. - Urnes formes 1,2 et 3 et variantes. - Olla de verre violet foncé à anses en émail blanc [S. A. 506. (76)]. Nombrenses ampoules (Iacrymatoires). Gros rhytons (entonnoirs courbes) ornés de cercles gravés. (Les filets concentriques faits an tour semblent bien constitner les plus anciens témoins de la gravure sur verre.)

B. Nines. Musée de la Maison Carrée. - Belle œunochoé en rerre blen-violacé ornée de nombreuses saillies d'émail blanc sur la panse et d'un filet de même émail sur l'anse, trouvée à Nînes (chemin de Montpellier), dans le tombeau d'un prêtre d'Isis. - Urne de verre violet foncé à anses en émail blanc [no I 5 ], (même type qu'au 111usée de Montpellier.) - Petit canthare en verre bleu-violacé à anses en émail blanc $\left[\mathrm{n}^{\mathrm{0}} 3^{6}\right.$ ].

$3^{\circ}$ BIBLIOGRAPHIE. - ÉNILE BONNET. Sur une sépulture gallo-romaine découverte à Pignan (Hêrault). Extrait des Mémoires de la Société Archéologique de Montpellier, 1910.
\end{abstract}

\title{
ERRATA
}

Pages 56 et 66 . Formes Io et 18 , an lieu de: en verre incolore, live : en verre incolore ou légèrement verdâtre.

(Nous entendons par verre incolore celui que les anciens ont cherché à rendre tel. Cè verre n'est pas tonjours d'une pureté absolne. Il a souvent, par places, une teinte plus on moins verdâtre ou jaunâtre.)

Page 74. Fig. 69, au lieu de: Syrie, III ${ }^{\mathrm{e}}$ s., live : Syrie. Romain II. 
6205-I3. - CORBEIL. IMPRIMERIE CRÉTÉ. 






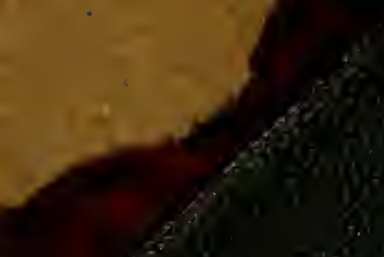

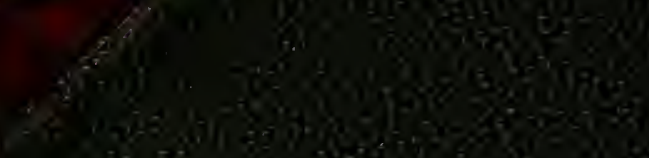

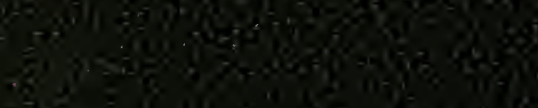

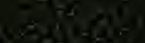

$\left(x^{2}+3\right)$

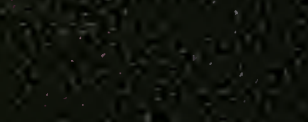

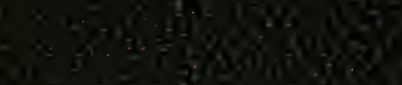

$=2 x$ -

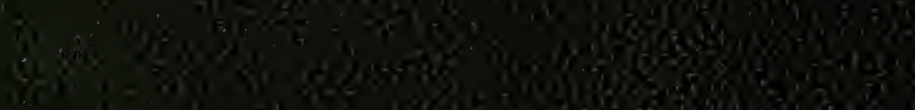

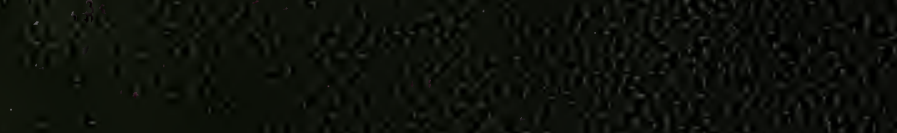

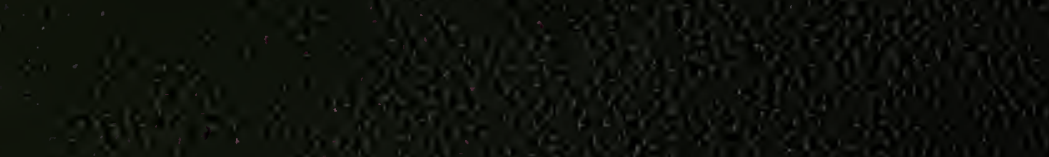

25

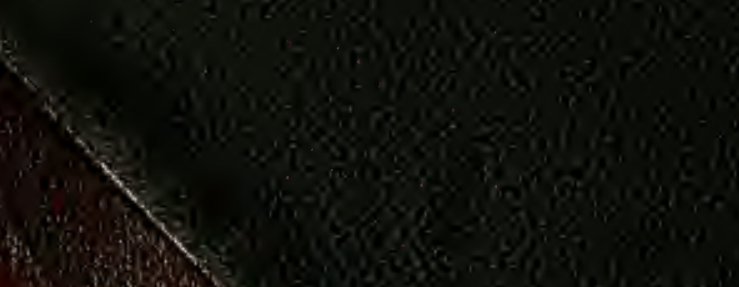

W. 90 in 


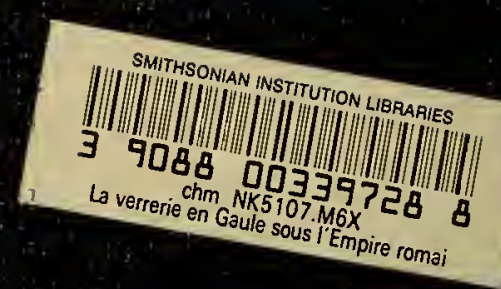

